
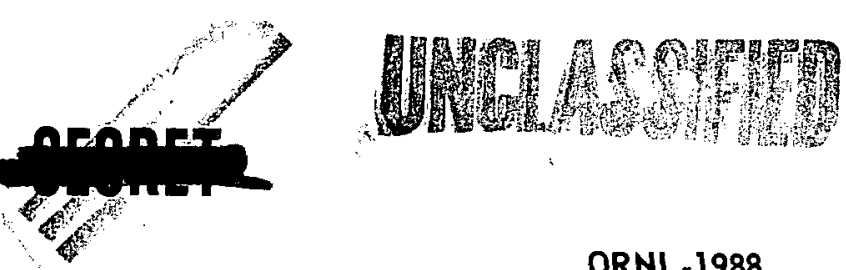

ORNL-1988

C-84 - Reactors-Special Features of Aircraft Reactors

This document consists of 192 pages. Copy/724 281 copies. Series A.

Contract No. W-7405-eng-26

METALLURGY DIVISION

SEMIANNUAL PROGRESS REPORT

for Period Ending October 10, 1955

J. H. Frye, Jr., Director

W. D. Manly, Associate Director

J. E. Cunningham, Assistant Director

DATE ISSUED

CLASSIFICATION CANCELLED

DATE $11-8.62$

For The Atcmic Energy Commission

- the

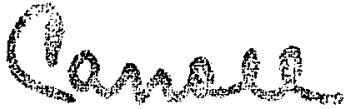

Chief, Deciassification Branch me

\title{
RAY 24-1956
}

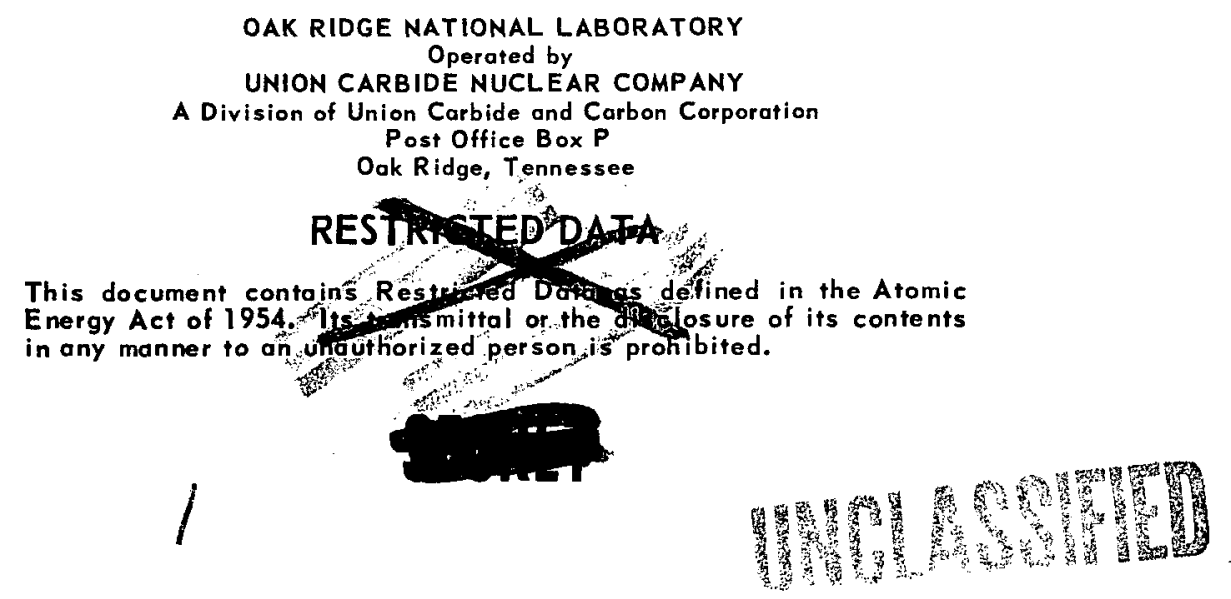




\section{DISCLAIMER}

This report was prepared as an account of work sponsored by an agency of the United States Government. Neither the United States Government nor any agency Thereof, nor any of their employees, makes any warranty, express or implied, or assumes any legal liability or responsibility for the accuracy, completeness, or usefulness of any information, apparatus, product, or process disclosed, or represents that its use would not infringe privately owned rights. Reference herein to any specific commercial product, process, or service by trade name, trademark, manufacturer, or otherwise does not necessarily constitute or imply its endorsement, recommendation, or favoring by the United States Government or any agency thereof. The views and opinions of authors expressed herein do not necessarily state or reflect those of the United States Government or any agency thereof. 


\section{DISCLAIMER}

Portions of this document may be illegible in electronic image products. Images are produced from the best available original document. 
ORNL-1988

C.84 - Reactors-Special Features of Aircraft Reactors

INTERNAL DISTRIBUTION

I. C. E. Center

2. Biology Library

3. Health Physics Library

4. Metallurgy Library

5-7. Central Research Library

8. Reactor Experimental Engineering Library

9-13. Laboratory Records Department

14. Laboratory Records, ORNL RC

15. A. M. Weinberg

16. L. B. Emlet (K-25)

17. J. P. Murray $(Y-12)$

18. J. A. Swartout

19. E. H. Taylor

20. E. J. Murphy

21. E. D. Shipley

22. J. H. Frye, Jr.

23. F. C. VonderLage

24. W. H. Jordan

25. R. A. Charpie

26. S. C. Lind

27. F. L. Culler

28. A. H. Snell

29. A. Hollaender

30. M. T. Kelley

31. K. Z. Morgan

32. T. A. Lincoln

33. A. S. Householder

34. C. S. Harrill

35. C. E. Winters

36. D. S. Billington

37. D. W. Cardwell

38. E. M. King

39. A. J. Miller

40. D. D. Cowen

41. P. M. Reyling

42. W. H. Bridges

43. G. C. Williams

44. S. Cromer

45. L. K. Jetter

46. R. R. Dickison

47. W. D. Manly
48. C. D. Susano

49. W. W. Parkinson

50. R. J. Gray

51. H. L. Yakel

52. P. Patriarca

53. E. E. Stansbury

54. G. P. Smith

55. J. E. Cunningham

56. R. S. Crouse

57. R. E. Adams

58. J. H. Erwin

59. J. O. Betterton, Jr.

60. W. O. Harms (consultant)

61. G. M. Adamson

62. E. S. Bomar

63. R. J. Beaver

64. T. W. Fulton

65. W. J. Fretague

66. R. B. Oliver

67. J. T. Howe

68. T. H. Blewitt

69. C. R. Boston

70. J. H. Crawford, Jr.

71. J. C. Wilson

72. H. W. Savage

73. E. E. Hoffman

74. W. J. Leonard

75. J. A. Milko

76. J. M. Warde

77. H. G. MacPherson (consultant)

78. E. C. Cruetz (consultant)

79. E. P. Wigner (consultant)

80. W. W. Grigorieff (consultant)

81. N. J. Grant (consultant)

82. T. S. Shevlin (consultant)

83. R. W. Johnson

84. J. A. Lane

85. G. E. Boyd

86. R. S. Livingston

87. A. L. Boch

88. ORNL-Y-12Technical Library,

Document Reference Section

\section{EXTERNAL DISTRIBUTION}

89. AF Plant Representative, Baltimore

90. AF Plant Representative, Burbank

91. AF Plant Representative, Marietta

92. AF Plant Representative, Santa Monica 
93. AF Plant Representative, Seattle

94. AF Plant Representative, Wood-Ridge

95. Air Materiel Area

96. Air Research and Development Command (RDGN)

97. Air Research and Development Command (RDZPA)

98. Air Technical Intelligence Center

99. Aircraft Laboratory Design Branch (WADC)

100-102. ANP Project Office, Fort Worth

103. Argonne National Laboratory

104. Armed Forces Special Weapons Project, Sandia

105. Assistant Secretary of the Air Force, R\&D

106-111. Atomic Energy Commission, Washington

112. Battelle Memorial Institute

113. Bettis Plant

114. Bureau of Aeronautics

115. Bureau of Aeronautics (Code 24)

116. Bureau of Aeronautics General Representative

117. Chicago Operations Office

118. Chicago Patent Group

119-120. Chief of Naval Research

121. Convair-General Dynamics Corporation

122. Director of Laboratories (WCL)

123. Director of Requirements (AFDRQ)

124. Director of Research and Development (AFDRD-ANP)

125-127. Directorate of Systems Management (RDZ-1SN)

128-130. Directorate of Systems Management (RDZ-1SS)

131. Equipment Laboratory (WADC)

132-135. General Electric Company (ANPD)

136. Hartford Area Office

137. Headquarters, Air Force Special Weapons Center

138. Idaho Operations Office

139. Knolls Atomic Power Laboratory

140. Lockland Area Office

141. Los Alamos Scientific Laboratory

142. Materials Laboratory Plans Office (WADC)

143. National Advisory Committee for Aeronautics, Cleveland

144. National Advisory Committee for Aeronautics, Washington

145. Naval Air Development Center

146. New York Operations Office

147. North American Aviation, Inc. (Aerophysics Division)

148. Nuclear Development Corporation

149. Patent Branch, Washington

150-152. Powerplant Laboratory (WADC)

153-156. Pratt and Whitney Aircraft Division (Fox Project)

157. San Francisco Operations Office

158. Sandia Corporation

159. School of Aviation Medicine

160. Sylvania Electric Products, Inc.

161. USAF Project RAND

162. University of California Radiation Laboratory, Livermore

163-165. Wright Air Development Center (WCOSI-3)

166-280. Technical Information Extension, Oak Ridge

281. Division of Research and Development, AEC, ORO 


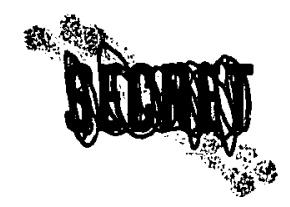

Reports previously issued in this series are as follows:

ORNL-28

ORNL-69

ORNL -407

ORNL.511

ORNL-583

ORNL-754

ORNL-827

ORNL-910

ORNL-987

ORNL-1033

ORNL-1108

ORNL-1161

ORNL-1267

ORNL-1302

ORNL-1366

ORNL-1437

ORNL-1503

ORNL-1551

ORNL-1625

ORNL-1727

ORNL-1875

ORNL-1911
Period Ending March 1, 1948

Period Ending May 31, 1948

Period Ending July 31, 1949

Period Ending October 31, 1949

Period Ending January 31, 1950

Period Ending April 30, 1950

Period Ending July 31, 1950

Period Ending October 31, 1950

Period Ending January 31, 1951

Period Ending April 30, 1951

Period Ending July 31, 1951

Period Ending October 31, 1951

Period Ending January 31, 1952

Period Ending April 30, 1952

Period Ending July 31, 1952

Period Ending October 31, 1952

Period Ending January 31, 1953

Period Ending April 10, 1953

Period Ending October 10, 1953

Period Ending April 10, 1954

Period Ending October 10, 1954

Period Ending April 10, 1955

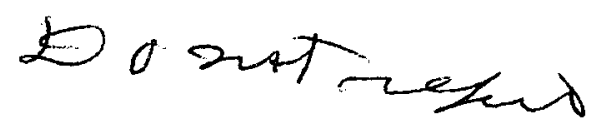


METALLURGY DIVISION

THE OAK RIDGE NATIONAL LABORATORY NOVEMBER 1,1955

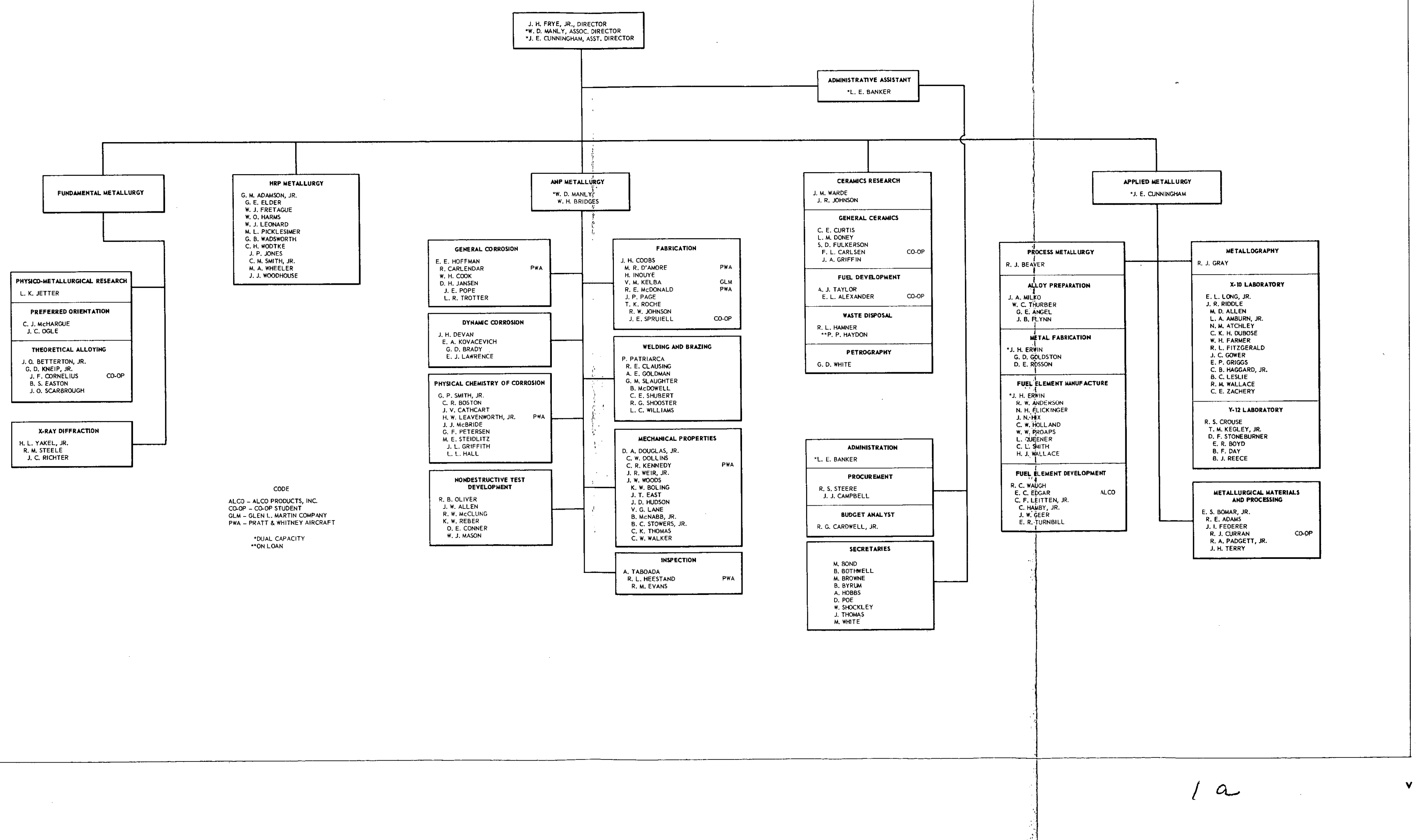




\section{CONTENTS}

\section{ANP METALLURGY}

GENERAL CORROSION

Brazing Alloys on Type 310 Stainless Steel Tested in Sodium and in Fused-Fluoride-Salt

Mixture

Corrosion Tests on Brazed-Inconel and -Nickel T-Joints in Sodium and in Fused-FluorideSalt Mixture

Corrosion Tests on Brazed Hastelloy B T-Joints in Sodium and in Fused-Fluoride-Salt Mixture

Brazing Alloys Static-tested in Lithium.

Hastelloy, B-Inconel Static Tests in a Fused-Fluoride-Salt Mixture.

Inconel Thermal-Convection Loop Tests with Sodium

Inconel Loop Tests with Boiling Sodium

Corrosion Resistance of Inconel to Sodium-Potassium-Lithium .

Type 347 Stainless Steel Thermal-Convection Loop Tests with Lithium

Corrosion Testing of Refractory Metals in Static Lithium.

Screening Tests to Determine the Resistance of Various Materials to Solid-Phase Bonding ............. 14

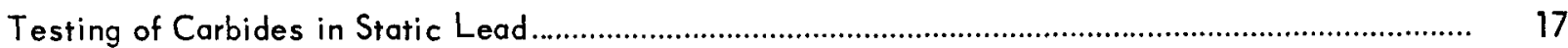

Corrosion Tests of SiC-Si (Durhy) in Sodium, NaF-ZrF $4_{4}^{-U F_{4}}$, Lithium, and Lead ......................... 17

Effect of Ruthenium on the Physical Properties of Inconel ............................................................... 17

Dynamic Loop Tests Involving a Beryllium-Inconel-Versene System ................................................. 20

Corrosion Studies on Types "A" and "L" Nickel Components of Fluorination Equipment ............... 21

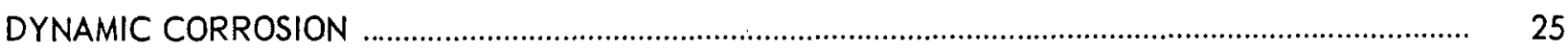

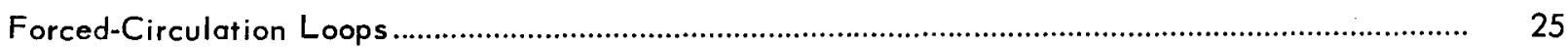

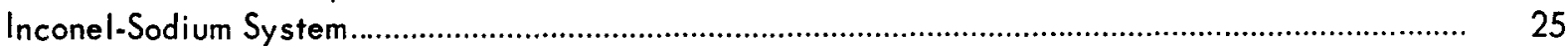

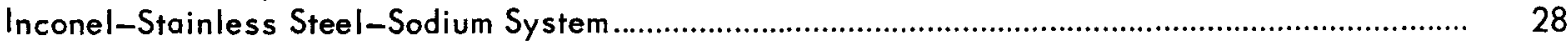

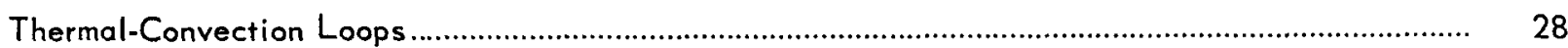

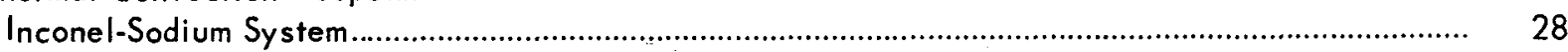

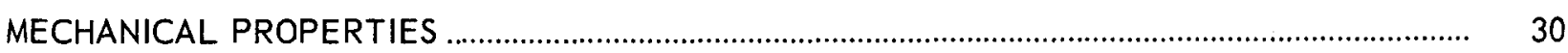

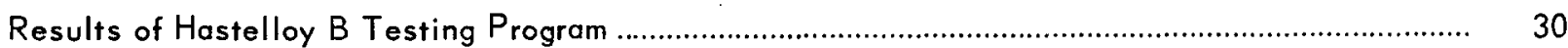

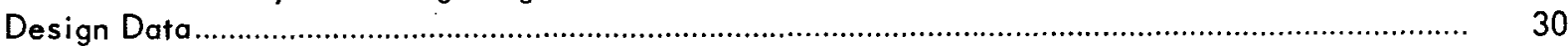

Effect of Fused-Fluoride-Salt Mixture on Stress-Rupture Properties ..............................................

Tests in Air and Hydrogen ............................................................................................................ 30

The Influence of Aging Heat Treatments ................................................................................... 30

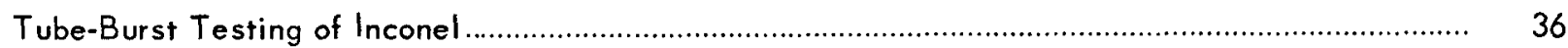

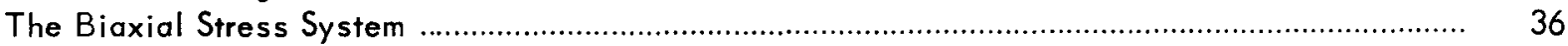

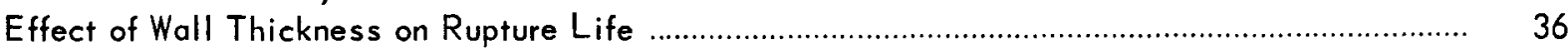

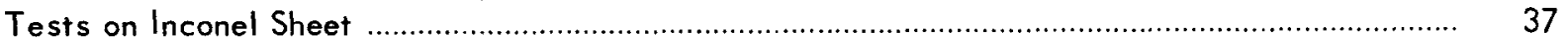

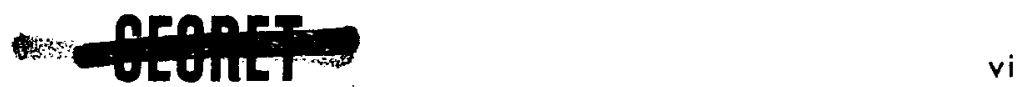




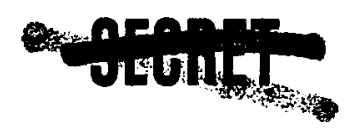

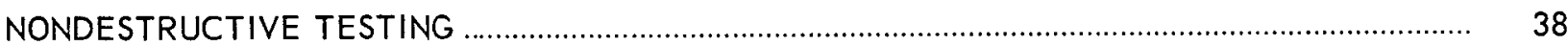

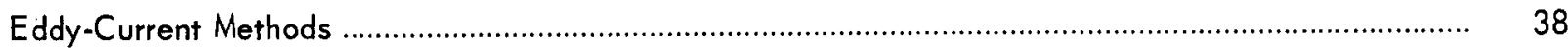

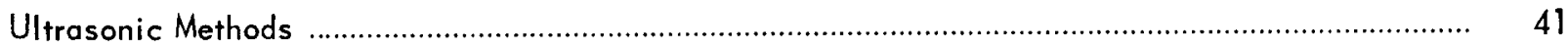

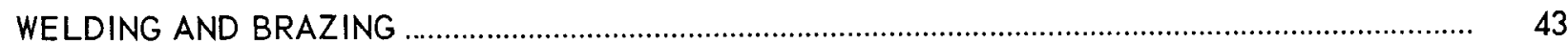

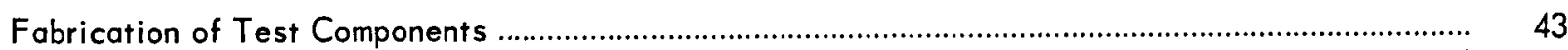

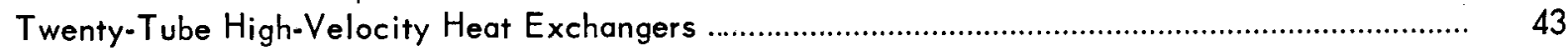

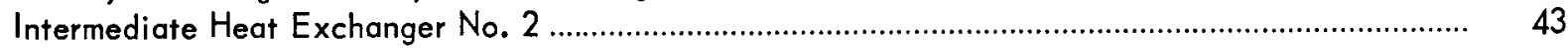

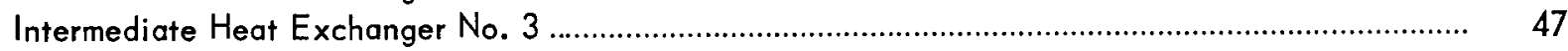

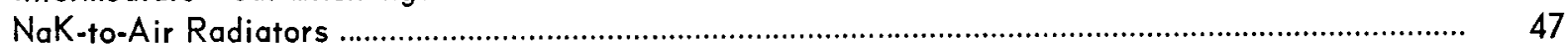

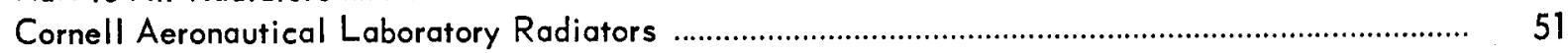

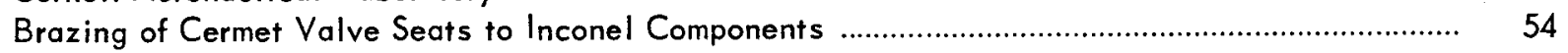

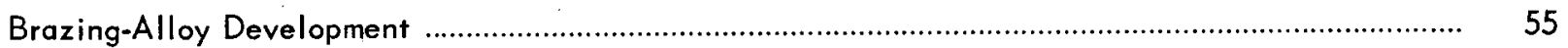

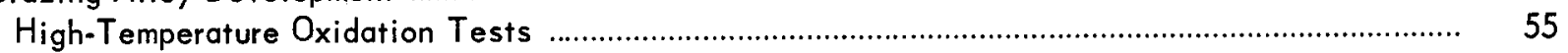

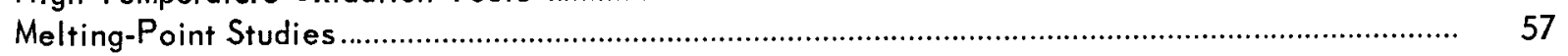

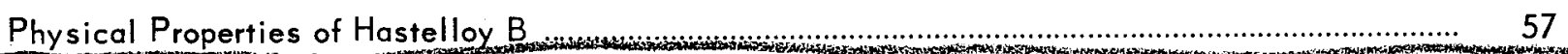

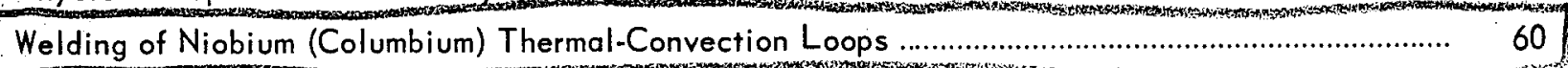

FA

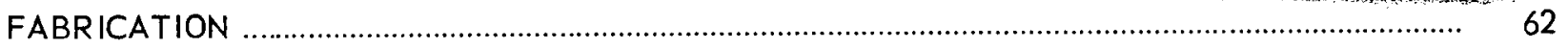

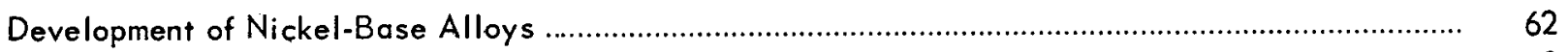

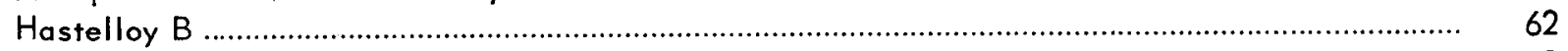

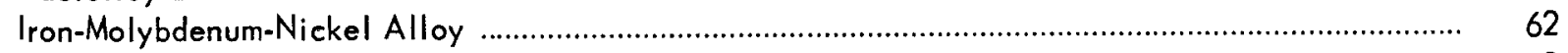

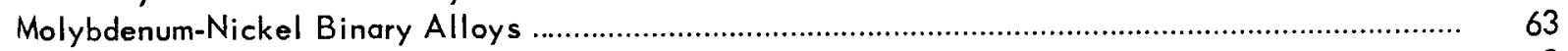

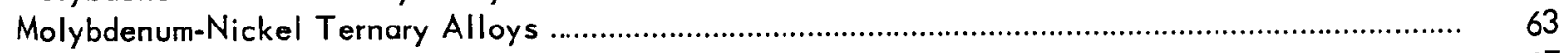

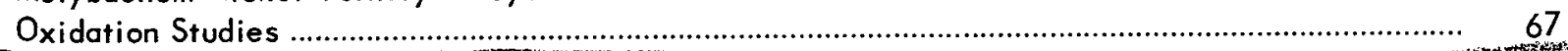

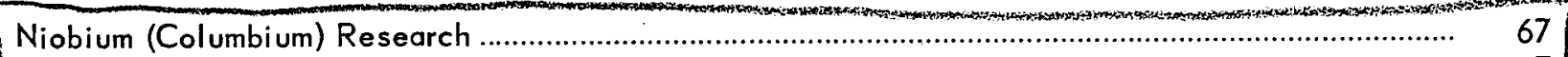

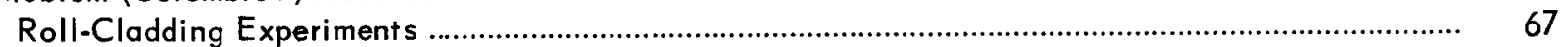

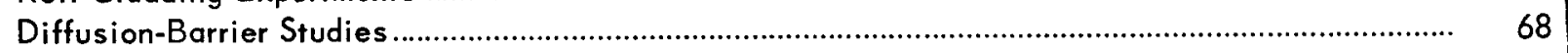

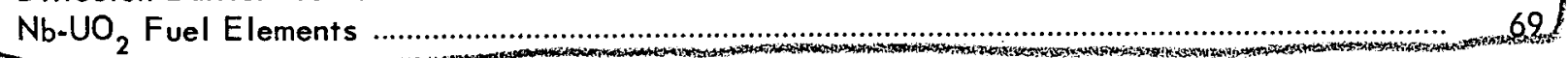

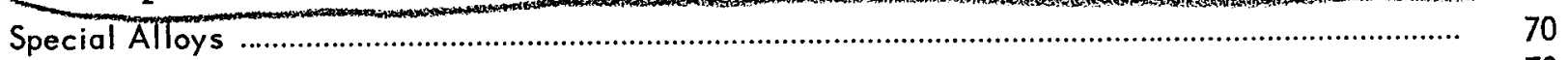

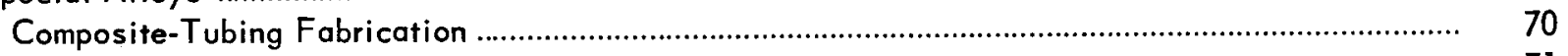

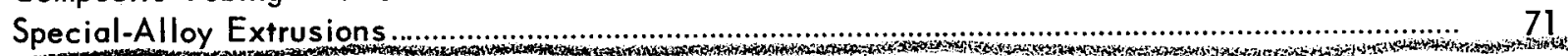

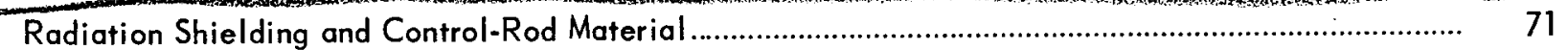

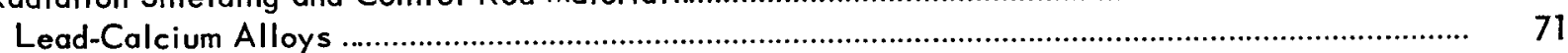

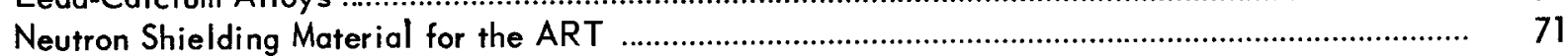

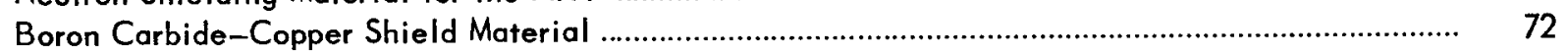

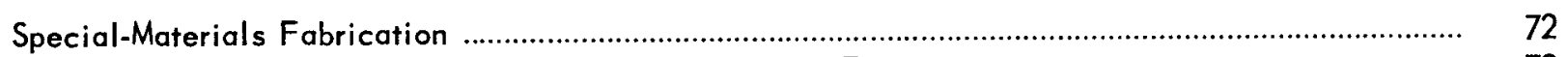

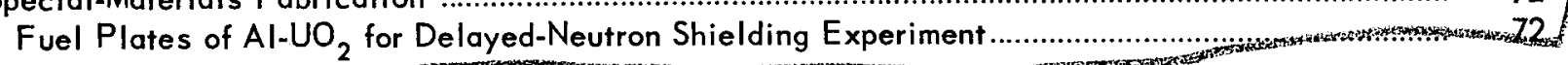

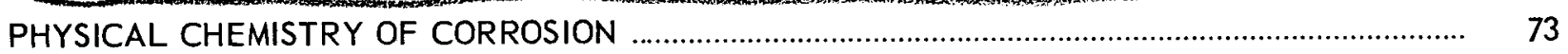

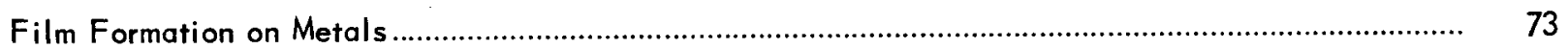

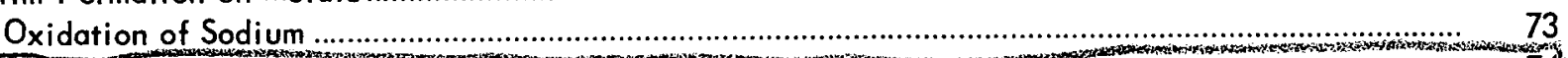

Oxidation of Niobium of

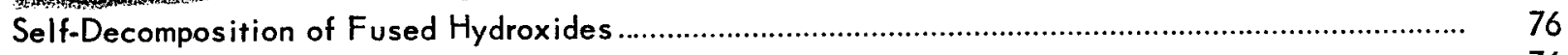

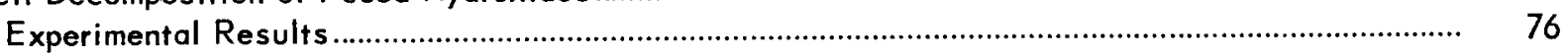

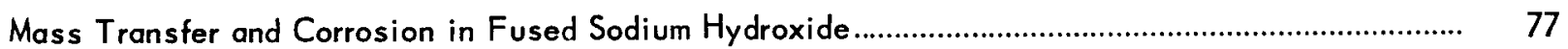

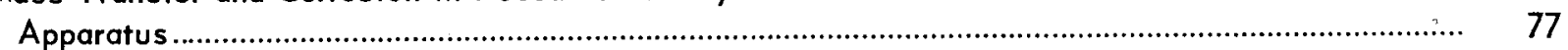

viii 
Experimental Procedure

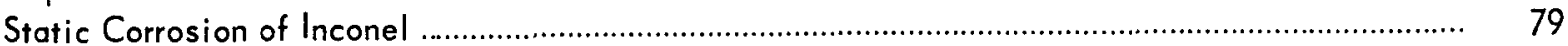

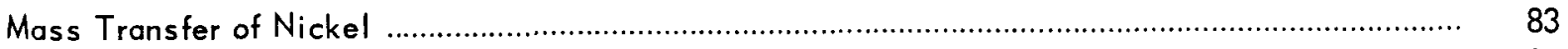

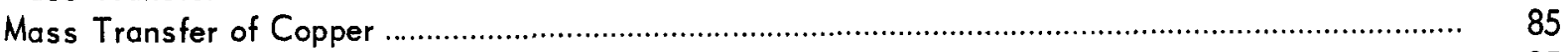

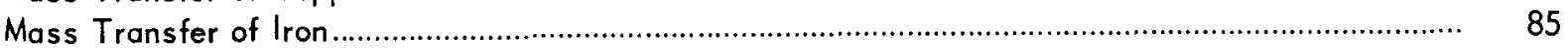

Mass Transfer and Corrosion of Inconel in Dynamic System ..................................................... 85

Mass Transfer and Corrosion of Monel in Dynamic Systems ......................................................... 86

Mass Transfer and Corrosion of Hastelloy in Dynamic Systems .................................................. 87

Mass Transfer and Corrosion of Stainless Steels in Dynamic Systems ........................................ 87

Alloy Development Research ........................................................................................................ 87

HRP METALLURGY

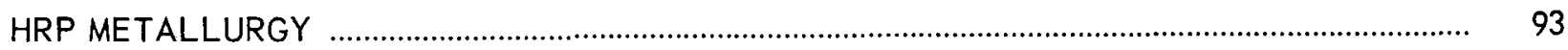

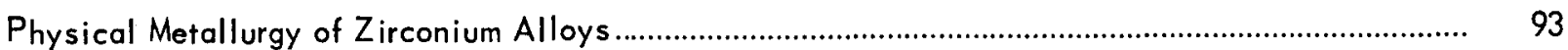

Zircaloy-2 (Zirconium-T in-Iron-Chromium-Nickel-Carbon) .......................................................... 93

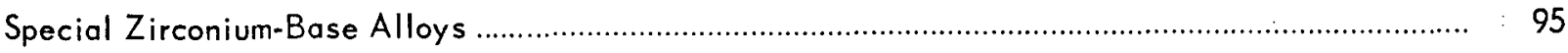

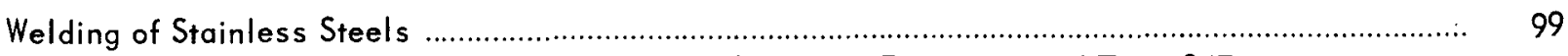

Effect of Heat Treatment on the Ductility and Corrosion Resistance of Type 347

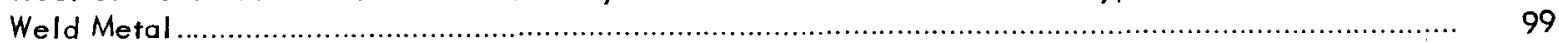

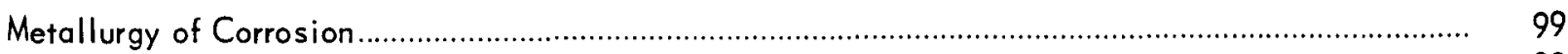

Stress-Corrosion Cracking of Austenitic Stainless Steels .............................................................. 99

Factors Associated with Grain Size and Sigma Phase in Wrought Austenitic Stainless

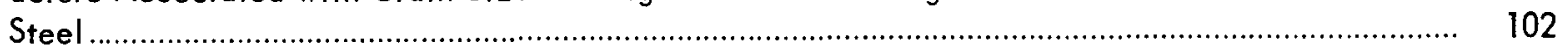

Dynamic Corrosion of Austenitic Stainless Steel Weld Specimens ............................................... 104

Effect of Hydrogen on Properties of Zirconium and Its Alloys ................................................. 107

Role of Oxide Films on Rate of Hydrogen Absorption by Zirconium and Its Alloys .................... 109

\section{APPLIED METALLURGY}

PROCESS METALLURGY

Fabrication of Geneva Conference Fuel Elements ......................................................................... 113

Irradiation Testing of Geneva Conference Reactor Fuel Elements ................................................. 115

Development of Uranium-Aluminum Alloys with Increased Amounts of Uranium for

Application in MTR-Type Aluminum Fuel Elements

Development of Aluminum-Uranium-Boron Alloys for Application in MTR Fuel Elements ................. 116

Manufacture of Reactor Components ........................................................................................ 117

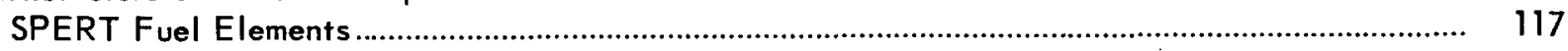

Plutonium-Aluminum Fuel Elements ............................................................................................... 118

Initial Loading for Pennsylvania State College Research Reactor ............................................. 118

Replacement Loading of CP-5 Fuel Elements ................................................................................. 118

Initial Loading for BNL Medical Research Reactor ..................................................................... 118

Control Rods for BSF ............................................................................................................. $\quad 119$

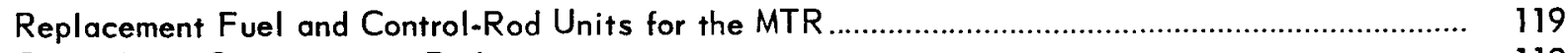

Chalk River Compensating Rods 19

Cast and Extruded "J" Slugs for Phillips Petroleum Company

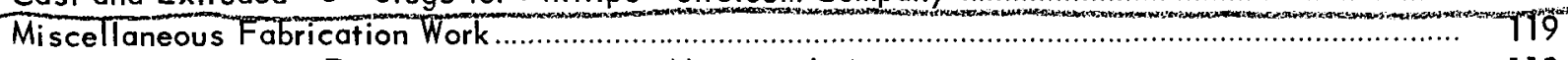

Aluminum-clad Fuel Plates for Brookhaven National Laboratory ................................................... 119

Fuel Tubes and Control Slugs for Hanford Works ..................................................................... $\quad 119$

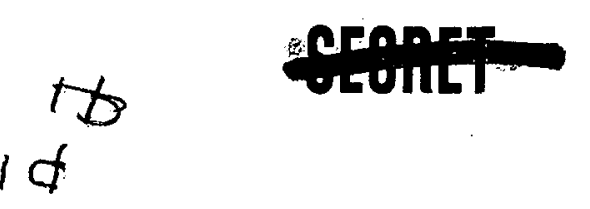


PACKAGE POWER REACTOR PROGRAM

Irradiation of Six-Plate APPR Element in the STR .......................................................................... 120

Irradiation of 18-Plate APPR Element in the MTR ............................................................................... 120

Irradiation Testing of Miniature APPR Plates in the MTR ........................................................... 122

Fabrication of Composite Stainless Steel-Uranium Dioxide Fuel Plates............................................ 122

Component Assembling: Brazing ................................................................................................... 125

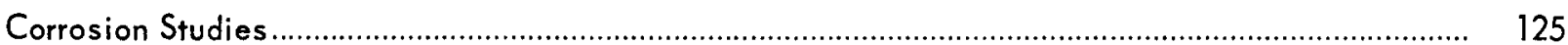

Fabrication of Components for APPR Critical Experiment .................................................................. 126

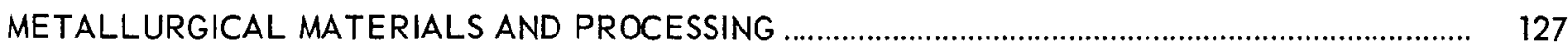

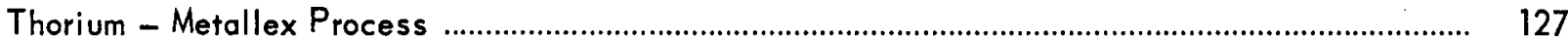

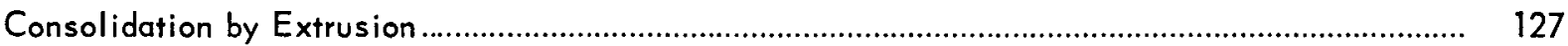

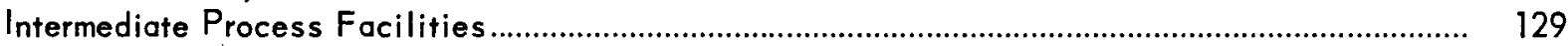

Time-Lapse Photography Study of the Retorting of an Amalgam Compact......................................

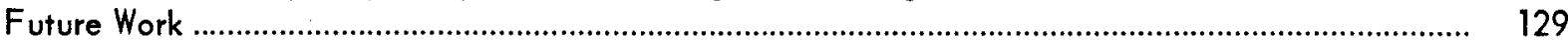

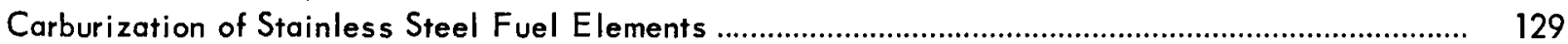

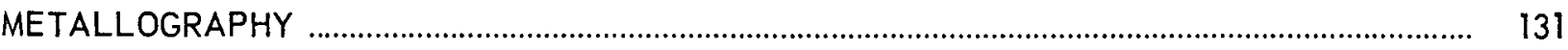

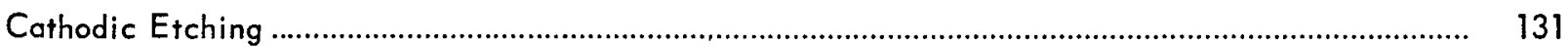

\section{CERAMICS RESEARCH}

CERAMICS RESEARCH

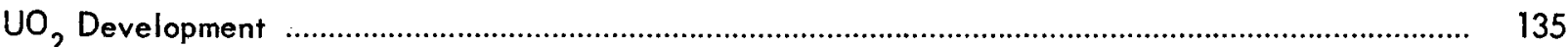

Oxidation of $\mathrm{UO}_{2}$

Production of Large Particles of $\mathrm{UO}_{2}$ from $\mathrm{UO}_{3}$ Hydrates ...................................................... 136

Study of Gas-Ceramic Mixtures in Nuclear Power Generation ..........................................................

Coolant Characteristics ......................................................................................................... 137

Thermodynamic Properties .................................................................................................. 140

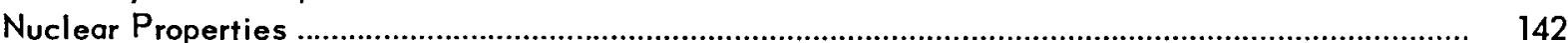

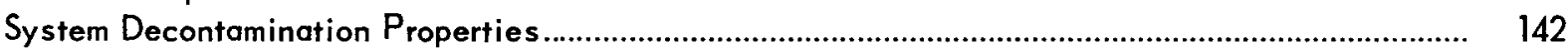

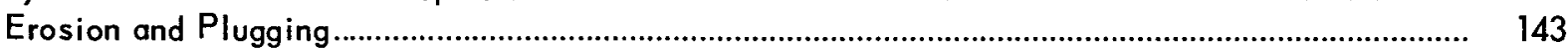

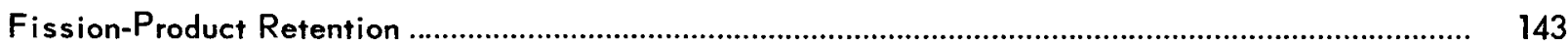

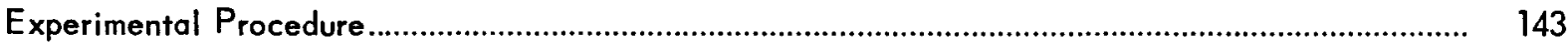

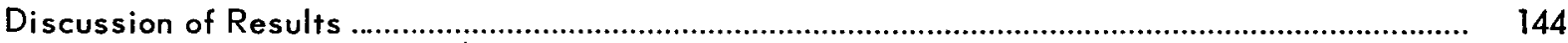

Graphite-Hydrogen Corrosion-Erosion Investigation .................................................................. 144

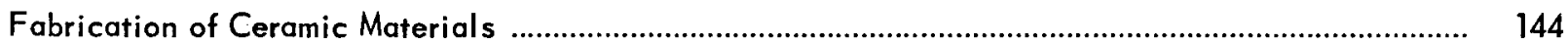

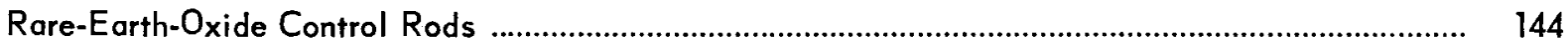

Calcium Fluoride and Alumina Detector Spacers ........................................................................

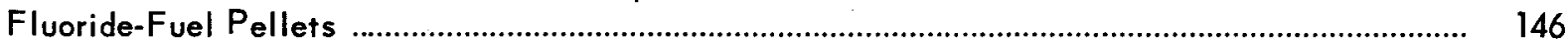

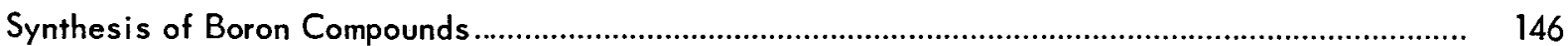

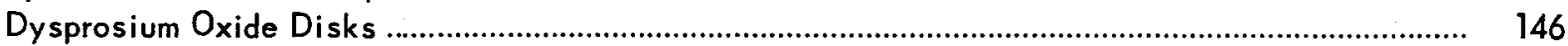

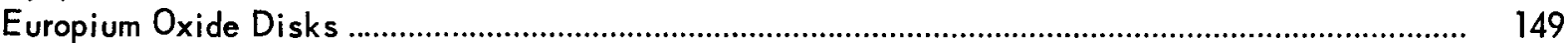

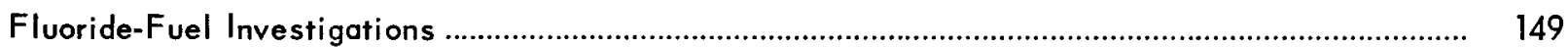

$\mathrm{X}$-raying of Fluorides at High Temperature ….......................................................................... $\quad 149$ 


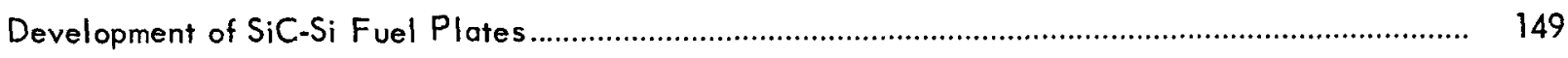

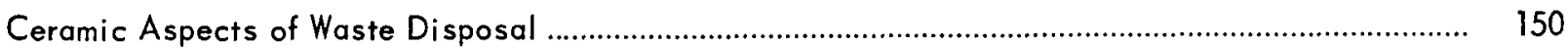

Fixation of Radioi sotopes in Ceramic Bodies ...................................................................... 150

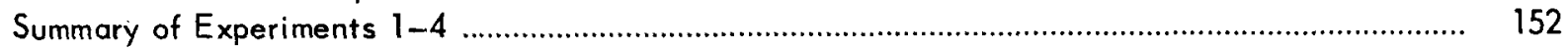

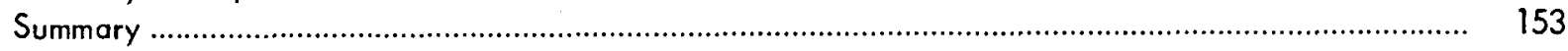

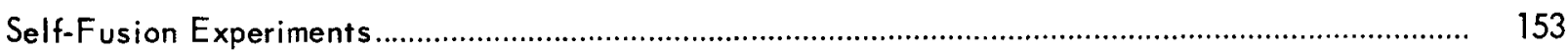

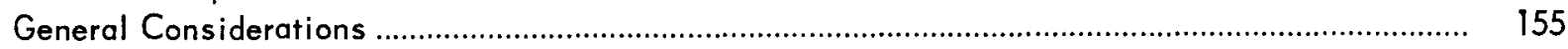

FUNDAMENTAL METALLURGY

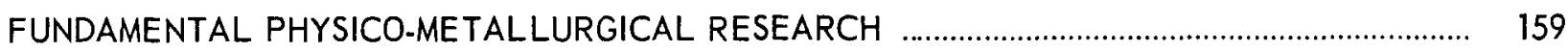

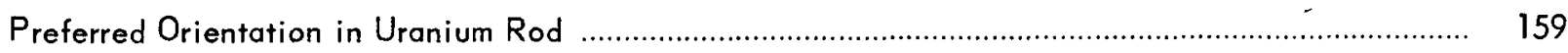

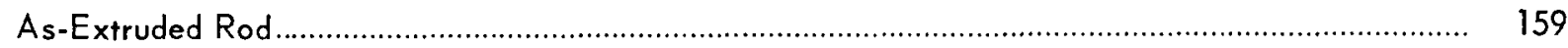

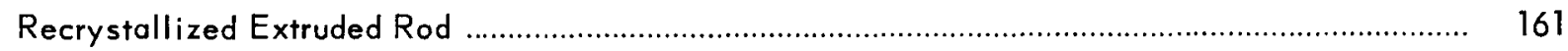

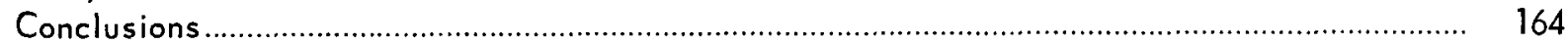

The Antimony-Zirconium Phase Diagram in the Vicinity of the Allotropic Transition

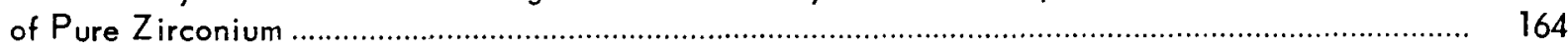

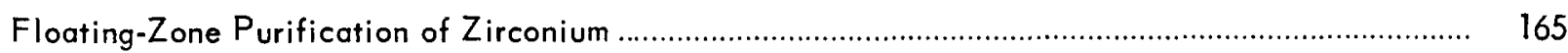

The Silver-Zirconium Alpha Phase Region ......................................................................... 172 


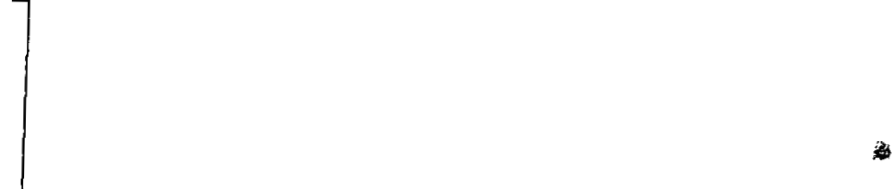

$\bullet$

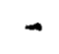

.

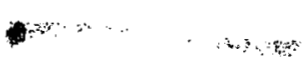




\section{METALLURGY DIVISION}

\section{SEMIANNUAL PROGRESS REPORT}

\section{SUMMARY}

\section{ANP METALLURGY}

General Corrosion. - Static corrosion tests in sodium and in fused-fluoride-salt mixture on type 310 stainless steel $T$-joints brazed with various alloys by the Wall Colmonoy Corporation indicate that the $9 \% \mathrm{Si}-2.5 \% \mathrm{P}-88.5 \% \mathrm{Ni}$ alloy has fair resistance to both media.

Seesaw tests on Inconel T-joints brazed with Coast Metals 50, 52, and 53 and Low Melting Nicrobraz show good-to-fair corrosion resistance to both sodium and the fluoride mixture.

Hastelloy B T-joints brazed with various brazing alloys have been corrosion-tested in the fused-salt mixture and in sodium. Of the alloys tested, the compositions $80 \% \mathrm{Ni}-5 \% \mathrm{Cr}-5 \% \mathrm{Fe}-5 \% \mathrm{Si}-5 \% \mathrm{~B}$ and $69 \% \mathrm{Ni}-15 \% \mathrm{Cr}-5 \% \mathrm{~B}-5 \% \mathrm{Si}-5 \% \mathrm{Fe}-1 \% \mathrm{C}$ had fair or better resistance to both media.

Severai brazing alloys on Tnconel and stainless steel have been static-tested for corrosion in lithium, and all have poor resistance to this medium at $1500^{\circ} \mathrm{F}$.

The compatability of Hastelloy B and Inconel in a system containing the fused-fluoride-salt mixture has been studied. The Inconel in this experiment was found to be more heavily attacked than normally occurs in an all-Inconel test system. The Hastelloy $B$ in the experiment was unattacked.

An Inconel thermal-convection loop containing sodium with an oxygen concentration of $0.03 \%$ showed an appreciable quantity of mass transfer during a 1000-hr high-temperature test. The deposited crystals were 85 wt \% nickel.

An Inconel loop experiment with boiling sodium has been conducted in order to determine the severity of mass transfer in a system where the oxygen content of the sodium is held to a very low level. The system operated for a period of $400 \mathrm{hr}$, and no mass transfer could be detected anywhere in the system. Very heavy intergranular cracking was discovered in the condenser section of the loop, but, as yet, no satisfactory explanation for this cracking has been found.

Inconel has been seesaw-tested in contact with a sodium-potassium bath to which varying amounts (2-30\%) of lithium had been added. The test in which 5\% lithium was added had the heaviest attack -2 to $3 \mathrm{mils}$ of subsurface voids.

Thermal-convection-loop systems consisting of type 347 stainless steel and lithium were tested for $3000 \mathrm{hr}$ with a hot-leg temperature of $1000^{\circ} \mathrm{F}$, and the alloy was attacked to a depth of $5 \mathrm{mils}$ in the weld areas.

Several refractory metals have been static-tested for corrosion in molten lithium and have shown good resistance to attock.

Screening tests of $\mathrm{TiC}$ cermet specimens bonded with 10, 20, or 30 wt \% Ni or with $25 \mathrm{Ni}-5 \mathrm{Mo}$ (wt \%) in NaF- $\mathrm{ZrF}_{4}-\mathrm{UF}_{4}(53.5-40-6.5$ mole \%) at $1500^{\circ} \mathrm{F}$ for $100 \mathrm{hr}$ indicate that these cermets have good resistance to solid-phase bonding if the contact pressures between the test specimens do not exceed 50,000 psi.

The carbides of boron, titanium, zirconium, and chromium were static-tested in lead at $1500^{\circ} \mathrm{F}$ for $100 \mathrm{hr}$ and were ungttacked.

The corrosion resistance of $\mathrm{SiC}-\mathrm{Si}$ (Durhy) has been tested in various media. It has fair resistance in lead but is heavily attacked by sodium, lithium, and the fused-fluoride-salt mixturestan

A ruthenium-plated Inconel specimen has been subjected to a creep-rupture test in order to determine the effect of ruthenium on the physical properties of Inconel. The results of a single test indicate an appreciable increase in creep rate and a decrease in rupture life.

Tests of beryllium metal in contact with Versene (complexing agent) cleaning solution indicate that at $180^{\circ} \mathrm{F}$ the beryllium metal suffers pitting-type attack.

Corrosion tests on two types of nickel used in the fabrication of fuel-mixture fluorination reactors have been conducted. Weld areas in particular were studied, and the attack was found to be slightly heavier on these welded specimens than on unwelded specimens. The heaviest attack was found on a gas inlet tube in the vapor zone of the reactor.

Dynamic Corrosion. - The operation of an Inconel pump loop through which sodium at $1500^{\circ} \mathrm{F}$ was circulated for $1000 \mathrm{hr}$ resulted in considerable 
mass transfer of metal to the economizer and cold leg of the loop. The deposited layers attained a thickness of 26 mils and were analyzed and shown to be predominantly nickel. In subsequent pump loops which were operated with varying temperature differentials, no distinct correlation could be found between the amount of mass transfer and $\Delta T$. The addition of oxides to the sodium in Inconel pump loops and in thermal-convection loops has been shown to increase both the depth of attack and the amount of mass-transferred material. No significant reduction in mass transfer was found in a pump loop which had a cold bypass for the removal of oxides; however, the oxide content did not appear to be reduced by the cold bypass trapping operation.

The use of type 316 stainless steel in cold portions apparently results in some reduction in mass transfer. A loop completely fabricated of type 316 stainless steel showed much less mass transfer than is found in comparable Inconel loops.

Mechanical Properties. - The results of creeprupture tests of Hastelloy $B$ sheet in argon at 1300,1500 , and $1650^{\circ} \mathrm{F}$ and in $\mathrm{NaF}-\mathrm{ZrF}_{4}-\mathrm{UF}_{4}$ (50-46-4 mole \%) at 1500 and $1650^{\circ} \mathrm{F}$ are presented in the form of design curves. A comparison of the creep curves from the tests shows that the rupture properties of the alloy are improved in the fusedfluoride-salt mixture. Creep curves obtained from tests at 12,000 psi in air and in hydrogen indicate that, compared with argon, hydrogen has no effect; whereas, a marked strengthening effect is noted in air. The influence of aging on the creep-rupture properties of Hastelloy B is being studied, and data are presented for creep-rupture tests of aged and solution-annealed material in argon at 1500, 1650 , and $1800^{\circ} \mathrm{F}$.

Stress-rupture testing of $3 / 4$-in. Inconel tubing in argon and in the fused-fluoride-salt mixture is now in progress for the purpose of evaluating the effects of the biaxial stress system set up in pressurized tubing. Results of tube-burst tests compared with tensile creep-rupture tests of 0.060 in. sheet in argon and in the fused-fluoride-salt mixture at $1500^{\circ} \mathrm{F}$ are presented in the form of stress-rupture plots. Data from creep-rupture tests of 0.020-in. Inconel sheet are given in order to show the reduced rupture life for a given stress which occurs as the cross section is reduced.

Nondestructive Testing. - The basic concepts of eddy-current testing as applied to low-conductivity alloy tubing are discussed. The merits of the impedance analysis method are presented along with the problems of flaw detection with both encircling and probe-type coils. There are many technical difficulties to be solved before eddycurrent methods can be applied to the types of problems encountered at ORNL.

Ultrasonic inspection of small-diameter tubing is very promising and is sufficiently sensitive to detect the types of flaws encountered to date. The data presentation for high scanning speeds is very important, and the " $B$ " scan instrument has proved to be a powerful interpretive tool.

Welding and Brazing. - Five Inconel liquidliquid heat exchangers of various designs have been fabricated for a heat-exchanger test program at $\mathrm{Y}-12$. Two NaK-to-air radiators have also been completed for this program, and a third is under construction. Two sodium-to-air integral-fin radiators have been fabricated for the Cornell Aeronautical Laboratory. A technique has also been developed which permits the successful brazing of cermet valve seats to Inconel.

Cyclic oxidation studies at 1500 and $1700^{\circ} \mathrm{F}$ have been conducted on Inconel T-joints brazed with several high-temperature brazing alloys. Short-time tensile data on aged Hastelloy $B$ sheet indicate that for aging times of 500 and $1000 \mathrm{hr}$ the tensile strength reaches a maximum at approximately $1300^{\circ} \mathrm{F}$; whereas, the ductility curve reaches a minimum at this same temperature. This behavior is thought to be the result of the precipitation of beta or beta plus gamma throughout the matrix. Tests also indicate that residual stresses not removed after a cold-working operation are quite detrimental to the ductility of this alloy after aging.

Fabrication. - A study of the factors affecting the fabricability of Hastelloy $B$ has been continued. In the commercial alloy the important variables which affect the production of seamless tubing by extrusion were temperature and lubrication. An extrusion temperature of $2000^{\circ} \mathrm{F}$ was satisfactory in the production of both rod and tubing. It was found that canning the extrusion billets with Inconel reduces the pressure requirements and at the same time clads the alloy tubing with a heat-resistant alloy.

Substitute alloys for Hastelloy B were investigated by means of tensile and stress-rupture tests. The results of these tests indicate that poor ductility was characteristic at elevated temperatures and might be the result of melting practice. 
The binary alloy compositions that were studied ranged in molybdenum content from 15 to $32 \%$. The ternary alloys that were studied contained $20 \%$ Mo, plus 3 to $10 \% \mathrm{Cr}, 2$ to $10 \% \mathrm{Al}, 1$ to $2 \% \mathrm{Zr}$, $1 \% \mathrm{Ti}$, or $2 \% \mathrm{~V}$; and the remainder of the composition was made up of nickel.

The oxidation rates of several experimental alloys were determined.

Tests confirmed that Ni-Mo ternary alloys containing titanium, aluminum, niobium, or chromium can be embrittled by long exposure to hydrogen at elevated temperatures. The properties of the alloy can be restored by a high-temperature anneal in vacuum.

Diffusion barriers between Inconel and niobium were studied. Of the several metals studied, only tantalum and copper show promise as barriers. Mixtures of niobium and $\mathrm{UO}_{2}$ were evaluated for compatability at 1500 and $1832^{\circ} \mathrm{F}$. A solid solution of $\mathrm{Nb}-\mathrm{U}$ and a pinkish phase, as yet unidentified, form at elevated temperature

The deformation pattern obtained in extrusions of two- and three-ply metals was studied. The deformation in a tube wall was found to be complex. The metal ratios and configurations of billets which can be successfully extruded were established.

Three vanadium billets were extruded at $2000^{\circ} \mathrm{F}$ and will be used in corrosion studies.

Six molybdenum extrusions for Battelle Memorial Institute were made at $2600^{\circ} \mathrm{F}$. Pressure requirements were materially reduced by coating the container walls with a salt-type lubricant prior to extrusion.

The creep performance of $\mathrm{Pb}-\mathrm{Ca}$ alloys was found to depend upon the care with which the master alloys were made. Accurate knowledge of the alloyed calcium, rather than of the total calcium, is required. For this reason, chemical analyses were found to be an unreliable index for predicting the properties of the alloy.

The use of boron-containing materials for neutron shields is being studied. Present plans are to attempt the fabrication of boron-containing layers that are thermally bonded to Inconel. The use of $\mathrm{B}_{4} \mathrm{C}$ tiles is also being considered for this application, in which case thermal bonds are not

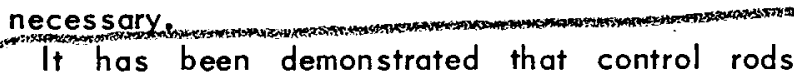
containing rare-earth oxides can be fabricated by extrusion cladding. Uniform and sound cores can be thermally bonded to a heat-resistant alloy.
Alloys containing high-cross-section metals can also be fabricated.

Fuel elements of aluminum and $\mathrm{UO}_{2}$ have been fabricated for use in delayed-neutron experiments. As an aid to the criticality experiments, $C u-B_{4} C$ shapes have also been supplied.

Physical Chemistry of Corrosion. - Results are reported on the oxidation of sodium in the temperature range of -79 to $48^{\circ} \mathrm{C}$. Sodium is found to form protective films over this temperature range, but the rate curves do not fit any of those proposed by existing theory Preliminary work is reported on the oxidation of niobium at temperatures around $400^{\circ} \mathrm{C}$.

Measurements have been made of the selfdecomposition of fused sodium hydroxide into water and sodium oxide. The value of $\Delta H^{0}$ for this reaction, as derived from these measurements, differs from the thermally measured value by $8 \%$. Thi s agreement is considered to be very good.

Experimental results are reported for the corrosion and mass transfer in fused sodium hydroxide of nickel, iron, copper, Inconel, monel, Hastelloy, and two stainless steels.

\section{HRP METALLURGY}

Impact tests have been completed on two sets of Zircaloy-2 specimens from in-pile loop experiments. Specimens from in-pile loop run GG fractured completely when tested; and at the higher testing temperatures, the impact-energy values were appreciably lower than were those obtained with specimens from previous in-pile loop runs. Vacuum-fusion analyses of samples from loop run $G G$ impact specimens showed no increase in hydrogen content over that found in control samples. Metallographic samples showed slightly more second phase in the grain boundaries of the irradiated specimens than was present in the control specimens.

Zircaloy-2 impact specimens irradiated in the MTR to approximately $1 \times 10^{20}$ to $4 \times 10^{20} n v t$ (fast $>1 \mathrm{Mev}$ ) were impact-tested for comparison with the specimens from in-pile loop experiments.

Conversion of small quantities of ferrite in austenitic stainless steel to sigma phase had no detectable influence on the resistance of the steel to corrosion by uranyl sulfate.

The susceptibility of several stainless steels to stress-corrosion cracking in boiling $42 \%$ magnesium chloride solution has been correlated with the ir $M_{d}$ temperatures. Threshold stresses, below 
which no stress-corrosion cracking occurs in a reasonable period of time, have been determined for types $309 \mathrm{SCb}$ and 310 . No value for the threshold stress has, as yet, been found for types 304L and 347, but it is less than 10,000 psi for type 304L. Electropolishing of the type $304 \mathrm{~L}$ specimens has been found to decrease the timeto-failure so that it is one-half that for brightannealed specimens. The other steels have been tested only in the bright-annealed condition.

The effect of grain size on the corrosion resistance of types $304 \mathrm{~L}$ and 347 stainless steel in uranyl sulfate solution is being studied by testing specimens of ASTM grain sizes 2 to 8.

Alloys of $\mathrm{Fe}-\mathrm{Cr}$ and $\mathrm{Fe}-\mathrm{Cr}-\mathrm{Ni}$ in the ferritic and sigma-phase conditions were corrosion-tested in uranyl sulfate. Results to date show that sigma specimens lose more weight than ferritic specimens of the same composition; however, all sigmo specimens broke during testing, and material may have been lost during or after fracture. Both sigmo and ferritic specimens of a similar composition were inferior to wrought type 347 stainless steel.

Dynamic corrosion tests in uranyl sulfate have been completed on coupon and pin type 347 stainless steel specimens that were welded with electrodes depositing different amounts of ferrite and that had several different heat treatments. Base-metal specimens in the same heat-treated conditions were tested for comparison purposes. The lowest weight losses occurred on welded specimens that had a $1000^{\circ} \mathrm{F}$ heat treatment. A very high weight loss occurred on the type 347 base-metal specimen which was heat-treated at $1300^{\circ} \mathrm{F}$. Control specimens were examined metallographically. Heat treatment caused no substantial improvement in corrosion resistance over that which is observed with specimens in the as-welded condition, and a full anneal appears to have a detrimental effect.

Zircaloy-2 specimens have been hydrogenated so as to contain 500,1000,2000, and $3000 \mathrm{ppm}$ and have been submitted for in-pile corrosion testing. Zircaloy-2 and high-purity zirconium impact specimens have been cathodically treated at 30 and $250^{\circ} \mathrm{C}$ by electrolysis in $1 \mathrm{~N}$ sulfuric acid in order to determine their behovior under simulated exposure to radiolytic gas. No hydrogen pickup occurred at $30^{\circ} \mathrm{C}$ after treatment for $100 \mathrm{hr}$. Specimens treated at $250^{\circ} \mathrm{C}$ for $100 \mathrm{hr}$ absorbed hydrogen to a total concentration of 130 to $170 \mathrm{ppm}$, irrespective of whether they were pre- viously outgassed or not. Metallographic examination revealed no hydride needles on the surface or in the bulk material. These specimens are scheduled to be impact-tested.

\section{APPLIED METALLURGY}

Process Metallurgy. - Fifty-six BSR-type fuel elements were constructed for the Geneva Conference Reactor. The fuel plates were prepared from $\mathrm{UO}_{2}$ and aluminum powder and were fabricated in accordance with procedures similar to MTR fuelplate production. The core mixture contained 54 wt $\% \cup_{2}$ and 46 wt \% aluminum; the high concentration was necessary because of the specification that the $U^{235}$ enrichment be limited to $20 \%$. Considerable difficulty was experienced in that a volume increase in the fuel plate occurred during fabrication. This was attributed to a reaction between $\mathrm{UO}_{2}$ and aluminum. The problem was minimized as a result of the development by the Ceramics Section of a $\mathrm{UO}_{2}$ particle which permitted fuel-plate processing to be accomplished without the occurrence of excessive volume changes.

Full-sized irradiation test elements were constructed for tests in the LITR and the MTR. These elements were irradiated to 5 and $23 \%$ burnup of $\mathrm{U}^{235}$ atoms, respectively. Both elements performed satisfactorily, and neither appeared to have been damaged during the test.

An investigation of Al-U alloys was initiated in order to determine at what uranium concentration the alloy is no longer suitable for the manufacture of fuel plates because of segregation and of problems associated with its fabrication. Preliminary experiments have revealed that when the amount of uranium exceeds 30 wt \%, segregation and fabrication difficulties become severe. An alloy containing 45 wt \% uranium was cast and fabricated into clad plate; however, there was evidence of pronounced segregation and nonuniformity in cladding thickness.

An investigation was initiated to determine the feasibility of melting and casting U-Al-B alloys containing 17 wt $\%$ uranium, and $0.08,0.22$, and 0.30 wt \% boron, respectively. The results revealed that inconsistent recovery of boron and segregation of boron in the alloy are the two basic problems which must be overcome.

Forty fuel elements for the Special Excursion Reactor Experiment were fabricated. A modifi- 
cation in the design markedly improved the rigidity of the element.

Arrangements have been made to irradiate six Pu-Al fuel elements in the MTR. Billet parts have been shipped to Los Alamos where the fuel alloy is in the process of being prepared.

Initial loadings of 22 and 25 BSF-type fuel elements were provided for the Pennsylvania State College Reactor and the BNL Medical Reactor, respectively.

Phillips Petroleum Company was provided with 118 replacement fuel elements for the MTR, and Argonne National Laboratory was provided with 17 replacement fuel elements for the CP-5 Reactor.

Thirty-four compensating rods were fabricated for the Canadian Chalk River Reactor.

Other miscellaneous fabrication included the manufacture of "I" slugs for Phillips Eetrolement Company, Boral plates for $\mathrm{Y}$-12, MTR-type fuel plates for Brookhaven National Laboratory, and fuel tubes and control slugs for Hanford. In addition, 60 miniature composite stainless steel fuel plates were fabricated for fission-product activity measurements and for the determination of the effect of fission products in the recovery process.

Army Package Power Reactor. - Development of the Army Package Power Reactor (APPR) fuel element has been progressing steadily. More than ten assemblies containing flat composite stainless steel fuel-bearing plates have been successfully brazed within required tolerances. The construction of the test assembly for irradiation in the active lattice of the MTR and the preparation of a number of miniature APPR plates for similar irradiation testing have been vigorously pursued. Examination of the MTR test assembly after approximately $40 \%$ burnup of $U^{235}$ atoms revealed the unit to be in excellent condition. No visual damage was observed. Examination of the APPR test assembly that was irradiated in the STR indicated that this unit also performed very satisfactorily and experienced no apparent damage. However, at the present time the unit has been limited to approximately $3 \%$ burnup of $U^{235}$ atoms.

Considerable effort has been directed toward the development of composite stainless-steel-clad plates containing either minor concentrations of $\mathrm{B}_{4} \mathrm{C}$ or high concentrations of $\mathrm{B}_{4} \mathrm{C}$. For the APPR critical experiment, 246 of the plates low in boron carbide and 24 of the plates high in boron carbide are required. The results of the development work have shown that the plates low in boron carbide can be fabricated by the substitution of iron for the stainless steel in the matrix of the core. The plates high in boron carbide can be satisfactorily fabricated by substituting copper for stainless steel in the matrix of the core, by nickel-plating the billet mating surfaces, and by limiting the total plate reduction in thickness to $50 \%$.

Experimentation with blending procedures to improve homogeneity in APPR fuel plates has revealed that an increase in the volume of alcohol added, that application of the alcohol with an atomizer, and that the addition of Teflon cubes are effective in improving the blending process for obtaining satisfactory homogeneity in the fabricated powder-fuel core.

An investigation to improve the degree of flatness of APPR fuel plates strongly indicated that flattening by stretcher-straightening was not very promising.

Metallurgical Materials and Processing. - Experimental work on the preparation of thorium by the Metallex process has been continued. Several pounds of metal have been accumulated by repeated retorting operations. Several extrusions have been made in order to evaluate the practicability of this method for the consolidation of small pieces of thorium. A press has been purchased, and retorting equipment with an expected capacity of $10 \mathrm{lb}$ of thorium per day has been designed and built. A record of the events in a retorting cycle has been obtained on film by means of a movingpicture camera and a time-delay exposure device.

Carburization of stainless steel fuel elements is being investigated in the development of a new process for recovery of unburned uranium from spent fuel elements. The gas carburization of full-size Army Package Power Reactor fuel elements so that they will contain the desired amounts of carbon has been established as feasible.

Metallography. - Cathodic-etching equipment has been assembled and put into operation. Cathodic etching has been adopted as a practicable method because it is the only method which permits independent etching of each metal alloy or compound without concentrating the etch on one component and thereby rendering the other components impassive to etch attack. 


\section{CERAMICS RESEARCH}

Differential thermal analyses in air of various types of $\mathrm{UO}_{2}$ indicate exothermic reactions; that is, the $\mathrm{UO}_{2}$ goes first to $\mathrm{U}_{3} \mathrm{O}_{7}$ and then to $\mathrm{U}_{3} \mathrm{O}_{8}$. $\mathrm{X}$-ray examination confirmed the phases present. The finer the grain size, the lower the temperature at which the reactions $\mathrm{UO}_{2} \longrightarrow \mathrm{U}_{3} \mathrm{O}_{7} \longrightarrow \mathrm{U}_{3} \mathrm{O}_{8}$ occur, particularly the first reaction. An improved process has been devised whereby large grain $\mathrm{UO}_{2}$ is produced by reduction with hydrogen of $\mathrm{UO}_{3}$ which has been previously grown from $\mathrm{UO}_{3}$ hydrates by autocloving.

Fission-product-retention studies were made by the use of stainless steel, aluminum, and cermet specimens. Retention data are given over several temperature ranges.

Ceramic additions, namely, graphite, have been found to improve the characteristics of nitrogen as a heat-transfer medium. The average corrosionerosion loss on high-density graphite $(\rho=1.8 \mathrm{~g} / \mathrm{cc})$ was of the order of $0.0001 \mathrm{~g} / \mathrm{in.}^{2} . \mathrm{sec}$ in hydrogen at about $1600^{\circ} \mathrm{C}$ with a velocity of $1900 \mathrm{fps}(\sim 0.18$ Mach number).

Detector spacers of $\mathrm{CaF}_{2}$ and $\mathrm{Al}_{2} \mathrm{O}_{3}$ were prepared for criticality experiments. Ceramic disks containing $\mathrm{Dy}_{2} \mathrm{O}_{3}$ have been prepared for testing as reactor-flux indicators. From $\mathrm{Eu}_{2} \mathrm{O}_{3}$ powder that had been precalcined at $1200^{\circ} \mathrm{C}$, cold-pressed, and sintered at $1500^{\circ} \mathrm{C}$, wafers were prepared and were found to decrepitate in water; on the other hand, uncalcined $\mathrm{Eu}_{2} \mathrm{O}_{3}$ fired at 1200,1300, 1400, and $1500^{\circ} \mathrm{C}$ does not decrepitate in water.

The decomposition temperature of $\mathrm{Li}_{3} \mathrm{ZrF}_{7}$ was found to be $470^{\circ} \mathrm{C}$ by high-temperature $x$-ray examination. This compares with $475^{\circ} \mathrm{C}$ obtained by quench data.

In a study of oxide films on zirconium alloys, it was found that an oxide which exists in several phases may be formed on a metal in one of those phases by selectively alloying the metal; $\mathrm{Nb}_{2} \mathrm{O}_{5}$ shows such promise of "stabilizing" $\mathrm{ZrO}_{2}$ and of forming a suitable alloy. Fuel plates of $\mathrm{SiC}$-Si and containing $1 \frac{1}{2} \mathrm{~g}$ of $\mathrm{UO}_{2}$ have been made.

Heat experiments suggest the possibility that a heat generation of about $0.01 \mathrm{w} / \mathrm{cc}$ will cause a clay fission-product mixture to reach $900^{\circ} \mathrm{C}$ in a moderately well insulated pit $20 \mathrm{ft}$ in diameter where the depth of the mixture when finally dry is $6 \mathrm{ft}$. A considerable number of experiments were conducted to determine the effectiveness of clays and fluxes for fixing various fission products. Some mixtures heated as low as $1050^{\circ} \mathrm{F}$ were found to retain mixed fission products on leaching with water. Most leach waters had little or no activity.

\section{FUNDAMENTAL PHYSICO-METALLURGICAL RESEARCH}

The fiber-axis distributions for $500^{\circ} \mathrm{C}$-extruded and for $550^{\circ} \mathrm{C}$-annealed, $500^{\circ} \mathrm{C}$-extruded uranium rods show that the fiber axes are at locations that do not correspond to poles of planes with low indices. The two as-extruded components are (1) $10 \mathrm{deg}$ from the $\{010\}$ poles and (2) $10 \mathrm{deg}$ from the $\{110\}$ poles. The two components of the annealed and extruded specimen are (1) a position 4 deg from the $\{131\}$ poles and (2) a position $14 \mathrm{deg}$ from the $\{100\}$ and the $\{110\}$ poles.

In the fundamental-research program on zirconium alloys, the purification of zirconium by floatingzone refining has resulted in the preparation of zirconium with less than $2 \mathrm{ppm}$ nickel and with an $\alpha / \beta$ temperature range that is only one-half that for the best iodide zirconium. A new version of the antimony-zirconium phase diagram in the vicinity of the $\alpha / \beta$ transition in pure zirconium has been determined by the use of iodide zirconium of greater purity than formerly reported. In the $\mathrm{Ag}-\mathrm{Zr}$ system, additional experimental results on the solid solubility of the alpha phase show that the maximum value is 1 at. $\% \mathrm{Ag}$. 


\title{
ANP METALLURGY
}

\author{
W. D. Manly
}

W. H. Bridges

Technical Coordinator

TN2 
•

•
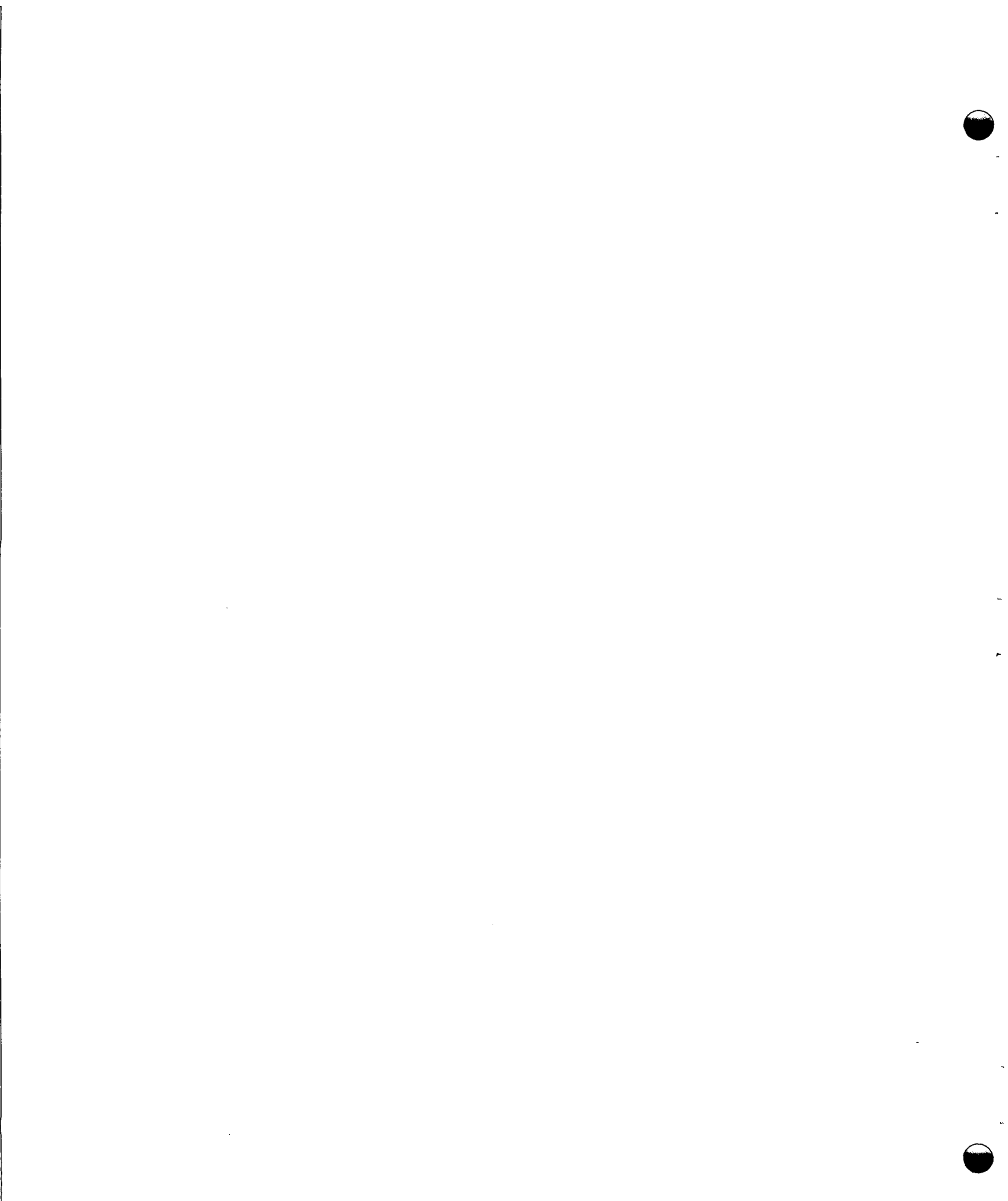


\title{
GENERAL CORROSION
}

\author{
E. E. Hoffman C. F. Leitten, Jr. \\ W. H. Cook D. H. Jansen \\ Metallurgy Division \\ R. Carlander
}

Pratt \& Whitney Aircraft

BRAZING ALLOYS ON TYPE 310 STAINLESS STEEL TESTED IN SODIUM AND IN FUSED-FLUORIDE-SALT MIXTURE
C. F. Leitten, Jr.
D. H. Jansen

Brazing alloys submitted by the Wall Colmonoy Corporation have been static-tested in both sodium and the fused-fluoride-salt mixture $\mathrm{NaF}$.
$\mathrm{ZrF}_{4}-\mathrm{UF}_{4}$ (53.5-40-6.5 mole \%). The tests were conducted in an effort to find a brazing alloy that has good corrosion resistance to both media.

The tests were conducted on type 310 stainless steel brazed with the alloys listed in Table 1 . The table summarizes the results obtained in the static sodium tests. Table 2 indicates the results for static tests in the fused-fluoride-salt mixture.

TABLE 1. BRAZING ALLOYS ON TYPE 310 STAINLESS STEEL TESTED IN STATIC SODIUM AT $1500^{\circ} \mathrm{F}$ FOR $100 \mathrm{hr}$

\begin{tabular}{|c|c|c|c|c|}
\hline \multirow{2}{*}{$\begin{array}{c}\text { Alloy } \\
\text { Designation* }\end{array}$} & \multirow{2}{*}{$\begin{array}{l}\text { Alloy Composition } \\
(w+\%)\end{array}$} & \multicolumn{2}{|c|}{ Weight Change } & \multirow{2}{*}{ Metallographic Notes } \\
\hline & & (g) & $(\%)$ & \\
\hline B.13 & $9 \mathrm{Si}-2.5 \mathrm{P}-88.5 \mathrm{Ni}$ & 0 & 0 & $\begin{array}{l}\text { No attack along surface of fillet; } \\
\text { several cracks in fillet }\end{array}$ \\
\hline$P-11$ & $10.5 \mathrm{Si}-7.5 \mathrm{Mn}-82 \mathrm{Ni}$ & -0.0002 & -0.018 & $\begin{array}{l}\text { No attack along surface of fillet; } \\
\text { several cracks in fillet }\end{array}$ \\
\hline P.12 & $9 \mathrm{Si}-15 \mathrm{Mn}-76 \mathrm{Ni}$ & -0.0003 & -0.033 & $\begin{array}{l}\text { No attack along surface of fillet; } \\
\text { several cracks in fillet }\end{array}$ \\
\hline$P \cdot 10$ & $16.27 \mathrm{Si}-5.9 \mathrm{Mn}-77.83 \mathrm{Ni}$ & +0.0004 & +0.043 & $\begin{array}{l}\text { No evidence of attack; several } \\
\text { large cracks throughout fillet }\end{array}$ \\
\hline$P \cdot 13$ & $7.5 \mathrm{Si}-22.5 \mathrm{Mn}-70 \mathrm{Ni}$ & -0.0008 & -0.085 & $\begin{array}{l}\text { Erratic surface attack to a depth of } \\
0.5 \mathrm{mil} \text {; several cracks in fillet }\end{array}$ \\
\hline B-12 & $10.5 \mathrm{Si}-1.25 \mathrm{P}-88.25 \mathrm{Ni}$ & 0 & 0 & $\begin{array}{l}\text { Erratic surface attack along fillet } \\
\text { to a depth of } 1 \mathrm{mil}\end{array}$ \\
\hline B-14 & $7.5 \mathrm{Si}-3.75 \mathrm{P}-88.75 \mathrm{Ni}$ & -0.0001 & -0.01 & $\begin{array}{l}\text { Uniform surface attack along fillet } \\
\text { to a depth of } 1 \mathrm{mil}\end{array}$ \\
\hline$P \cdot 14$ & $6 \mathrm{Si}-30 \mathrm{Mn}-64 \mathrm{Ni}$ & -0.0002 & -0.022 & $\begin{array}{l}\text { Erratic surface attack to a depth of } \\
1 \text { mil; large cracks throughout } \\
\text { fillet }\end{array}$ \\
\hline G-20 & $9 \mathrm{P}-11.49 \mathrm{~W}-79.51 \mathrm{Ni}$ & -0.0012 & -0.14 & $\begin{array}{l}\text { Maximum attack of } 4 \text { mils along } \\
\text { surface of fillet }\end{array}$ \\
\hline S- 10 & $\begin{array}{l}14.31 \mathrm{Cr}-9.34 \mathrm{Si}-2.66 \\
\mathrm{M}_{0}-19.32 \mathrm{Fe}-54.37 \mathrm{Ni}\end{array}$ & 0 & 0 & $\begin{array}{l}\text { Subsurface voids to a depth of } 3 \\
\text { mils along fillet surface }\end{array}$ \\
\hline B-15 & $6 \mathrm{Si}-5 \mathrm{P}-89 \mathrm{Ni}$ & 0 & 0 & $\begin{array}{l}\text { Maximum attack of } 4 \mathrm{mils} \text { along } \\
\text { surface of fillet }\end{array}$ \\
\hline B-16 & $4.5 \mathrm{Si}-6.25 \mathrm{P}-89.25 \mathrm{Ni}$ & -0.0001 & -0.01 & $\begin{array}{l}\text { Small subsurface voids to a depth } \\
\text { of } 4 \text { mils }\end{array}$ \\
\hline G-21 & $10.98 \mathrm{P}-6.16 \mathrm{~W}-82.86 \mathrm{Ni}$ & -0.0001 & -0.011 & $\begin{array}{l}\text { Uniform surface attack along entire } \\
\text { fillet to a depth of } 4 \text { mils }\end{array}$ \\
\hline$B-17$ & $3 \mathrm{Si}-7.5 \mathrm{P}-89.5 \mathrm{Ni}$ & -0.0012 & -0.14 & $\begin{array}{l}\text { Maximum attack of } 4 \text { mils along } \\
\text { surface of fillet }\end{array}$ \\
\hline$L-20$ & $38 \mathrm{Ni}-5 \mathrm{Cr}-57 \mathrm{Mn}$ & -0.0004 & -0.043 & $\begin{array}{l}\text { Attack in the form of stringers to a } \\
\text { maximum depth of } 5 \text { mils; not } \\
\text { uniform }\end{array}$ \\
\hline
\end{tabular}

\footnotetext{
*Brazing alloys listed in order of decreasing corrosion resistance to sodium.
} 
TABLE 2. BRAZING ALLOYS ON TYPE 310 STAINLESS STEEL TESTED

IN STATIC NaF.Z.ZF $4^{-U F}{ }_{4}\left(53.5-40-6.5\right.$ mole \%) AT $1500^{\circ} \mathrm{F}$ FOR $100 \mathrm{hr}$

\begin{tabular}{|c|c|c|c|c|}
\hline \multirow{2}{*}{$\begin{array}{c}\text { Alloy } \\
\text { Designation* }\end{array}$} & \multirow{2}{*}{$\begin{array}{c}\text { Alloy Composition } \\
\text { (wt \%) }\end{array}$} & \multicolumn{2}{|c|}{ Weight Change } & \multirow{2}{*}{ Metallographic Notes } \\
\hline & & (g) & $(\%)$ & \\
\hline G-20 & $9 \mathrm{P}-11.49 \mathrm{~W}-79.51 \mathrm{Ni}$ & -0.0017 & -0.152 & $\begin{array}{l}\text { No attack on surface of fillet; } \\
\text { several cracks in fillet }\end{array}$ \\
\hline B-15 & $6 \mathrm{Si}-5 \mathrm{P}-89 \mathrm{Ni}$ & -0.0046 & -0.510 & $\begin{array}{l}\text { Uniform surface attack along fillet } \\
\text { to a depth of } 0.5 \mathrm{mil}\end{array}$ \\
\hline B-16 & $4.5 \mathrm{Si}-6.25 \mathrm{P}-89.25 \mathrm{Ni}$ & -0.0057 & -0.562 & $\begin{array}{l}\text { Surface attack along fillet to a } \\
\text { depth of } 0.5 \mathrm{mil}\end{array}$ \\
\hline$G-21$ & $10.98 \mathrm{P}-6.16 \mathrm{~W}-82.86 \mathrm{Ni}$ & -0.0061 & -0.674 & $\begin{array}{l}\text { Erratic surface attack to a depth of } \\
0.5 \mathrm{mil} \text { along fillet }\end{array}$ \\
\hline B-17 & $3 \mathrm{Si}-7.5 \mathrm{P}-89.5 \mathrm{Ni}$ & -0.0053 & -0.516 & $\begin{array}{l}\text { Surface attack along fillet to a } \\
\text { depth of } 0.5 \mathrm{mil} \text {; several cracks } \\
\text { in fillet }\end{array}$ \\
\hline B.13 & $9 \mathrm{Si}-2.5 \mathrm{P}-88.5 \mathrm{Ni}$ & -0.0027 & -0.279 & $\begin{array}{l}\text { Surface attack along entire fillet to } \\
\text { a depth of } 1 \mathrm{mil}\end{array}$ \\
\hline$P \cdot 12$ & $9 \mathrm{Si}-15 \mathrm{Mn}-76 \mathrm{Ni}$ & -0.0034 & -0.331 & $\begin{array}{l}\text { Surface attack in form of small } \\
\text { voids to a depth of } 1 \text { mil; several } \\
\text { cracks in fillet }\end{array}$ \\
\hline B-14 & $7.5 \mathrm{Si}-3.75 \mathrm{P}-88.75 \mathrm{Ni}$ & -0.0052 & -0.479 & $\begin{array}{l}\text { Surface attack along entire fillet to } \\
\text { a depth of } 1 \mathrm{mil}\end{array}$ \\
\hline$P-11$ & $10.5 \mathrm{Si}-7.5 \mathrm{Mn}-82 \mathrm{Ni}$ & -0.0042 & -0.401 & $\begin{array}{l}\text { Surface attack to a depth of } 1.5 \\
\text { mils; several cracks in fillet }\end{array}$ \\
\hline B-12 & $10.5 \mathrm{Si}-1.25 \mathrm{P}-88.25 \mathrm{Ni}$ & -0.0018 & -0.171 & $\begin{array}{l}\text { Surface attack to a depth of } 2 \text { mils; } \\
\text { large cracks throughout fillet }\end{array}$ \\
\hline P.10 & $16.27 \mathrm{Si}-5.9 \mathrm{Mn}-77.83 \mathrm{Ni}$ & -0.0026 & -0.290 & $\begin{array}{l}\text { Uniform surface attack along fillet } \\
\text { to a depth of } 3 \mathrm{mils}\end{array}$ \\
\hline S.10 & $\begin{array}{l}14.31 \mathrm{Cr}-9.34 \mathrm{Si}-2.66 \\
\mathrm{Mo}_{0}-19.32 \mathrm{Fe}-54.37 \mathrm{Ni}\end{array}$ & -0.0030 & -0.344 & $\begin{array}{l}\text { Surface attack to a maximum depth } \\
\text { of } 7.5 \mathrm{mils} \text { along entire fillet }\end{array}$ \\
\hline$P-13$ & $7.5 \mathrm{Si}-22.5 \mathrm{Mn}-70 \mathrm{Ni}$ & -0.0043 & -0.455 & Complete attack of entire fillet \\
\hline$L-20$ & $38 \mathrm{Ni}-5 \mathrm{Cr}-57 \mathrm{Mn}$ & -0.0078 & -0.74 & Complete attack of entire fillet \\
\hline P.14 & $6 \mathrm{Si}-30 \mathrm{Mn}-64 \mathrm{Ni}$ & -0.0099 & -1.06 & Complete attack of entire fillet \\
\hline
\end{tabular}

*Brazing alloys listed in order of decreasing corrosion resistance to the fluoride mixture.

In both tables, the brazing alloys are listed in order of decreasing corrosion resistance.

On consideration of the results of Tables 1 and 2 , brazing alloy $\mathrm{B}-13(9 \% \mathrm{Si}-2.5 \% \mathrm{P}-88.5 \% \mathrm{Ni})$ appears to have the best corrosion resistance to both media. Figure $l a$ is a photomicrograph of alloy B-13 tested in sodium at $1500^{\circ} \mathrm{F}$ for $100 \mathrm{hr}$. No attack can be observed along the surfoce of the brazed fillet. The cracks which are shown in the photomicrograph are not the results of corrosion but, rather, are caused by the brittleness of this alloy. Similar cracking was observed in many of the brazed T-joints listed in Tables 1 and 2. Figure $1 b$ is a photomicrograph of brazing alloy $\mathrm{B}-13$ tested in the fused-fluoride-salt mixture at $1500^{\circ} \mathrm{F}$ for $100 \mathrm{hr}$. A l-mil surface attack can be seen along the entire brazed fillet. In this specimen no cracks were found.
Several conclusions can be derived by studying the metallographic notes in Tables 1 and 2 . Brazing alloys containing relatively high percentages of phosphorus appear to have inferior corrosion resistance in sodium. However, the addition of silicon tends to improve the corrosion resistance of these alloys. On the other hand, brazing alloys having high percentages of silicon and no phosphorus tend to be attacked in the fluoride mixture.

\section{CORROSION TESTS ON BRAZED-INCONEL AND -NICKEL T-JOINTS IN SODIUM AND IN F USED-FLUORIDE-SALT MIXTURE}
C. F. Leitten, Jr.
D. H. Jansen

Seesaw tests have been completed on a series of brazing alloys on Inconel T-joints. The tests were conducted in sodium and in the fused-fluoridesalt mixture NaF- $\mathrm{ZrF}_{4} \cdot \mathrm{UF}_{4}$ (53.5-40-6.5 mole \%) 


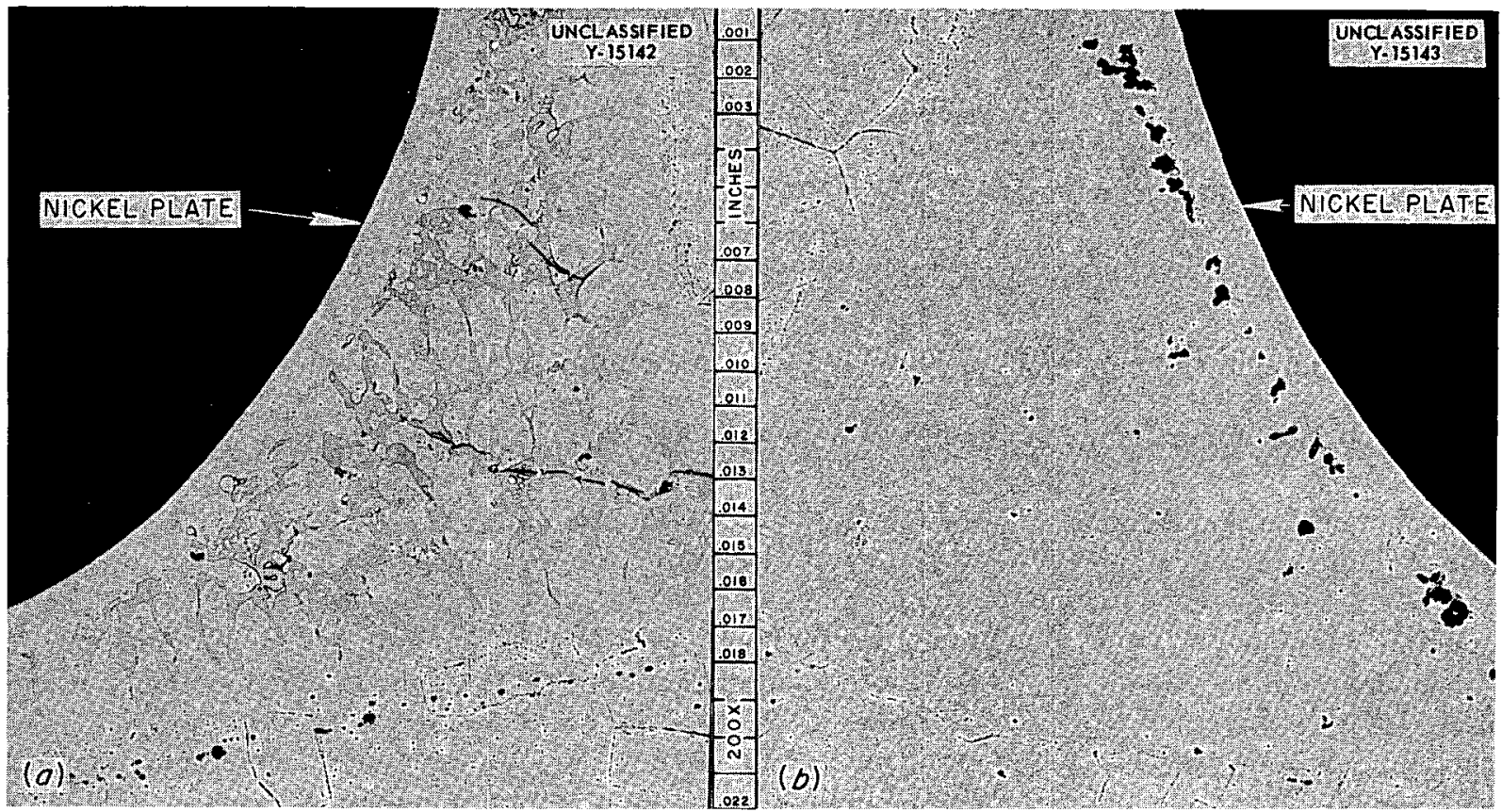

Fig. 1. Wall Colmonoy Corporation Brazing Alloy B-13 Static-tested in (a) Sodium and (b) a Fluoride Fuel. Etchant: aqua regia. 200X. Reduced 22\%. (Secret with caption)

for $100 \mathrm{hr}$ with a hot-zone temperature of $1500^{\circ} \mathrm{F}$. A temperature differential of approximately $400^{\circ} \mathrm{F}$ was maintained between the hot and cold zones of the test containers.

Table 3 gives the data obtained from weight measurements and metallographic examinations of the brazed and tested T-joints. Two of the brazing materials, $82 \% \mathrm{Au}-18 \% \mathrm{Ni}$ and copper, were tested only in the fluoride mixture since previous corrosion data indicated that these alloys had poor corrosion resistance in sodium. The brazing alloy $50 \% \mathrm{Ni}-25 \% \mathrm{Ge}-25 \%$ Mo will be retested in sodium since the results of the first tests were invalidated by a furnace failure.

The brazing alloys which showed good corrosion resistance to both testing media were Coast Metals alloys 50, 52, and 53 and Low-Melting Nicrobraz. Figure $2 a$ is a photomicrograph showing brazing alloy Coast Metals 53 after it had been exposed to the salt mixture for $100 \mathrm{hr}$ in a seesaw test in which the hot-zone temperature was $1500^{\circ} \mathrm{F}$. Only a slight attack can be seen along the surface of the brazed fillet. Figure $2 b$ shows this same brazing alloy after it had been tested in sodium under the same conditions. Again only a slight surface attack occurred along the surface of the brazed fillet.

The brazing alloy Electroless nickel $(90 \%$ $\mathrm{Ni}-10 \% \mathrm{P}$ ) was unattacked by the salt mixture; however, there were several microcracks present in the fillet. These cracks indicate that this alloy is brittle and, thus, that its use for radiator fabrication is limited.

Brazing alloy $75 \% \mathrm{Ni}-25 \%$ Ge on nickel has been statically tested for $100 \mathrm{hr}$ both in sodium and in the fused-fluoride-salt mixture at $1500^{\circ} \mathrm{F}$. There was a 2-mil nonuniform attack on this alloy in sodium and no attack in the fuel mixture. In future experiments Inconel T-joints brazed with this alloy will be seesaw-tested in sodium and in the fluoride-fuel mixture.

\section{CORROSION TESTS ON BRAZED HASTELLOY B T-JOINTS IN SODIUM AND IN FUSED. FLUORIDE-SALT MIXTURE}
C. F. Leitten, Jr.
D. H. Jansen

A series of brazing alloys on Hastelloy B T-joints have been static-tested both in sodium and fused-fluoride salts at $1500^{\circ} \mathrm{F}$ for $100 \mathrm{hr}$. Each brazed T-joint was examined prior to corrosion 
TABLE 3. SEESAW TESTS ON BRAZED INCONEL T-JOINTS IN SODIUM AND IN NaF.Z.ZF ${ }_{4}$ UFF $_{4}$ (53.5.40-6.5 mole \%) FOR $100 \mathrm{hr}$ WITH A HOT-ZONE TEMPERATURE OF $1500^{\circ} \mathrm{F}$

\begin{tabular}{|c|c|c|c|}
\hline $\begin{array}{l}\text { Brazing Alloy Composition } \\
\qquad(w+\%)\end{array}$ & $\begin{array}{l}\text { Weight Change } \\
(\%)\end{array}$ & $\begin{array}{l}\text { Resistance to } \\
\text { Corrosion }\end{array}$ & Metollographic Results \\
\hline \multicolumn{4}{|c|}{ Test Medium: Fluoride } \\
\hline Electroless nickel; $90 \mathrm{Ni}-10 \mathrm{P}$ & -0.041 & Good & No attack \\
\hline $\begin{array}{l}\text { Coost Metals } 52 ; 89 \mathrm{Ni}-5 \mathrm{Si}-4 \\
\mathrm{~B}-2 \mathrm{Fe}\end{array}$ & -0.052 & Good & Nonuniform attock to a depth of $0.5 \mathrm{mil}$ \\
\hline Copper & -0.026 & Good & Attock to a depth of $0.5 \mathrm{mil}$ \\
\hline $\begin{array}{l}\text { Coast Metals } 50 ; 93 \mathrm{Ni}-3.5 \\
\mathrm{Si}-2.5 \mathrm{~B}-1 \mathrm{Fe}\end{array}$ & -0.085 & Good & Uniform attack to a depth of $0.5 \mathrm{mil}$ \\
\hline $\begin{array}{l}\text { Low-Melting Nicrobraz; } 80 \mathrm{Ni}-5 \\
\mathrm{Cr}-6 \mathrm{Fe}-3 \mathrm{~B}-5 \mathrm{Si}-1 \mathrm{C}\end{array}$ & -0.063 & Good & Nonuni form attack to a depth of $0.5 \mathrm{mil}$ \\
\hline $50 \mathrm{Ni}-25 \mathrm{Ge}-25 \mathrm{Mo}$ & 0.0 & Good & Erratic attack to a depth of $1 \mathrm{mil}$ \\
\hline $\begin{array}{l}\text { Nierobraz; } 70 \mathrm{Ni}-14 \mathrm{Cr}-6 \\
\mathrm{Fe}-5 \mathrm{~B}-4 \mathrm{Si}-1 \mathrm{C}\end{array}$ & -0.030 & Foir & Erratic attack to a depth of $1.5 \mathrm{mils}$ \\
\hline $70 \mathrm{Ni}-11 \mathrm{Cr}-6 \mathrm{Si}-13 \mathrm{Ge}$ & -0.067 & Fair & Nonuniform attack to a depth of $1.5 \mathrm{mils}$ \\
\hline $\begin{array}{l}\text { Coast Metals } 53 ; 81 \mathrm{Ni}-4 \mathrm{~B}-4 \\
\mathrm{Si}-8 \mathrm{Cr}-3 \mathrm{Fe}\end{array}$ & -0.092 & Fair & Nonuniform attack to a depth of $1.5 \mathrm{mils}$ \\
\hline $\begin{array}{l}\text { Coast Metals NP; } 50 \mathrm{Ni}-28 \\
\mathrm{Fe}-12 \mathrm{Si}-4.5 \mathrm{P}-4 \mathrm{Mo}-1 \\
\mathrm{Mn}-0.5 \mathrm{Cr}\end{array}$ & -0.092 & Fair & Uniform attock to a depth of $1.5 \mathrm{mils}$ \\
\hline $\begin{array}{l}\text { General Electric } 81 ; 70 \mathrm{Ni}-20 \\
\mathrm{Cr}-10 \mathrm{Si}\end{array}$ & -0.067 & Poor & Attack to a depth of $3.5 \mathrm{mils}$ \\
\hline $65 \mathrm{Ni}-25 \mathrm{Ge}-10 \mathrm{Cr}$ & -0.056 & Poor & $\begin{array}{l}\text { Stringer-type attack to o maximum depth of } \\
4 \text { mils in a few localized areas }\end{array}$ \\
\hline $82 \mathrm{Av}-18 \mathrm{Ni}$ & +0.120 & Poor & Nonuniform attack to a depth of $4 \mathrm{mils}$ \\
\hline \multicolumn{4}{|c|}{ Test Medium: Sodium } \\
\hline $\begin{array}{l}\text { Coast Metals } 52 ; 89 \mathrm{Ni}-5 \mathrm{Si}-4 \\
\mathrm{~B}-2 \mathrm{Fe}\end{array}$ & -0.073 & Good & No attack \\
\hline $\begin{array}{l}\text { Coast Metals } 53 ; 81 \mathrm{Ni}-4 \mathrm{Si}-4 \\
\mathrm{~B}-8 \mathrm{Cr}-3 \mathrm{Fe}\end{array}$ & -0.071 & Good & Erratic attack to a depth of $1 \mathrm{mil}$ \\
\hline $\begin{array}{l}\text { Coa st Metals } 50 ; 93 \mathrm{Ni}-3.5 \\
\mathrm{Si}-2.5 \mathrm{~B}-1 \mathrm{Fe}\end{array}$ & -0.077 & Fair & Very erratic attack to a depth of $1.5 \mathrm{mils}$ \\
\hline Electroless nickel; $90 \mathrm{Ni}-10 \mathrm{P}$ & -0.50 & Fair & Attack to a depth of $1.5 \mathrm{mils}$ \\
\hline $\begin{array}{l}\text { Low-Melting Nicrobraz; } 80 \mathrm{Ni}-5 \\
\mathrm{Cr}-6 \mathrm{Fe}-3 \mathrm{~B}-5 \mathrm{Si}-1 \mathrm{C}\end{array}$ & -0.051 & Fair & $\begin{array}{l}\text { Subsurface voids to a maximum depth of } 1.5 \\
\text { mils }\end{array}$ \\
\hline $70 \mathrm{Ni}-11 \mathrm{Cr}-6 \mathrm{Si}-13 \mathrm{Ge}$ & -0.139 & Fair & Nonuniform attock to a depth of $2.5 \mathrm{mils}$ \\
\hline $\begin{array}{l}\text { Coast Metals NP; } 50 \mathrm{Ni}-28 \\
\text { Ee-12 } \mathrm{Si}-4.5 \mathrm{P}-4 \mathrm{Mo}-1 \\
\mathrm{Mn}-0.5 \mathrm{Cr}\end{array}$ & -0.622 & Fair & Uniform attack to a depth of $2.5 \mathrm{mils}$ \\
\hline $\begin{array}{l}\text { General Electric } 81 ; 70 \mathrm{Ni}-20 \\
\mathrm{Cr}-10 \mathrm{Si}\end{array}$ & -0.016 & Fair & Uniform attack to a depth of $3 \mathrm{mils}$ \\
\hline $65 \mathrm{Ni}-25 \mathrm{Ge}-10 \mathrm{Cr}$ & -0.113 & Poor & $\begin{array}{l}\text { Intermittent surface attack to a maximum } \\
\text { depth of } 4 \text { mils }\end{array}$ \\
\hline $\begin{array}{l}\text { Nicrobraz; } 70 \mathrm{Ni}-14 \mathrm{Cr}-6 \\
\mathrm{Fe}-5 \mathrm{~B}-4 \mathrm{Si}-1 \mathrm{C}\end{array}$ & 0.0 & Poor & $\begin{array}{l}\text { Very erratic stringer attack to a depth of } \\
4 \text { mils }\end{array}$ \\
\hline
\end{tabular}



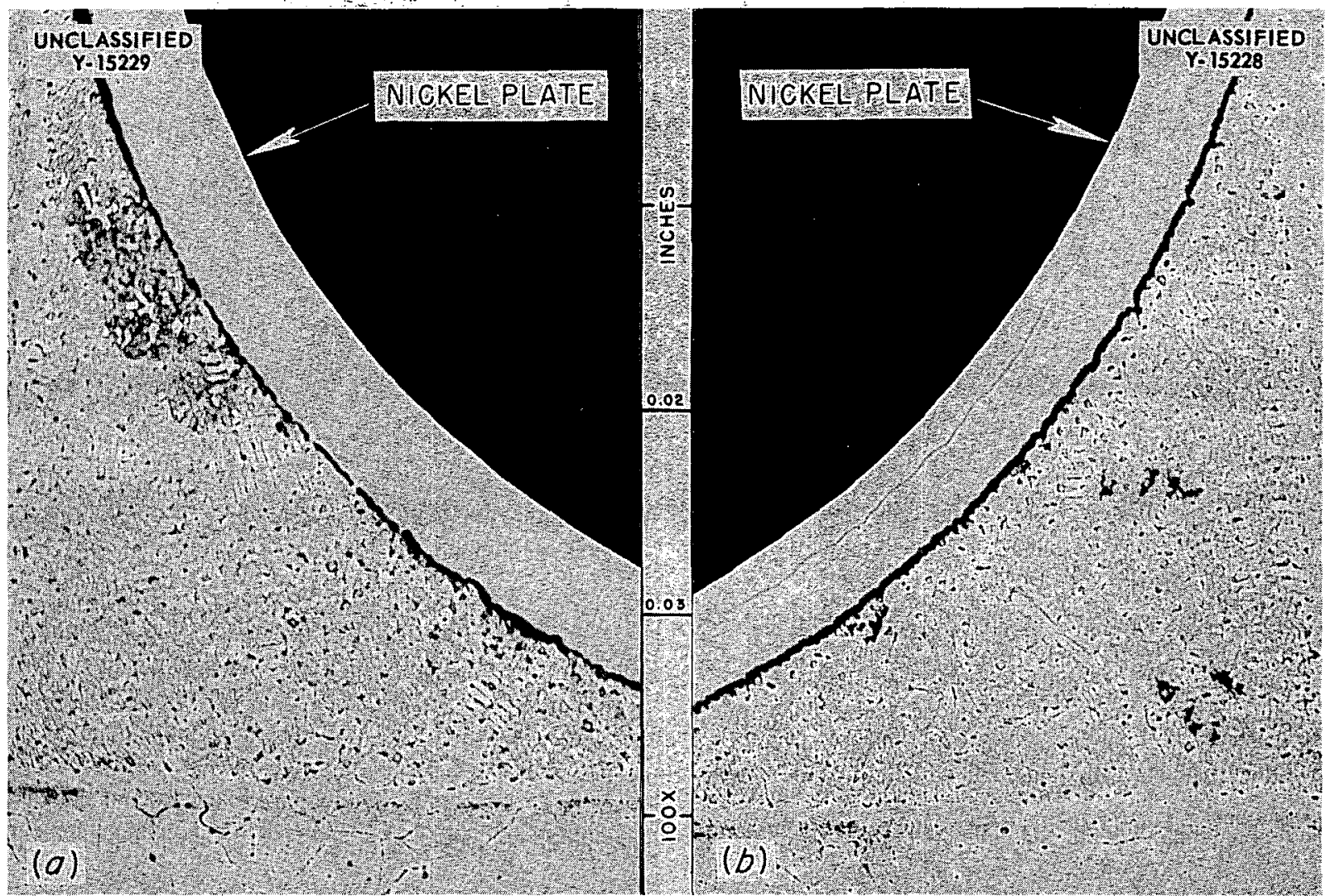

Fig. 2. Coast Metals Brazing Alloy 53 on Inconel T-Joints After Seesaw Testing in (a) a Fluoride Fuel and (b) Sodium. Etchant: aqua regia. 100X. Reduced 1.5\%. (Secret with caption)

testing in order to determine the number of inclusions and the degree of porosity present.

An arbitrary scale, based on depth of attack in mils, was established which evaluated the corrosion resistance of the se brazed joints as follows:

$\begin{array}{cc}\text { Resistance } & \begin{array}{c}\text { Depth of Attack } \\ \text { (mils) }\end{array} \\ \text { Good } & 0-1 \\ \text { Fair } & 1-3 \\ \text { Poor } & 3-6 \\ \text { Bad } & >6\end{array}$

The results of these brazing-alloy corrosion tests are summarized in Table 4 . It can be noted that of all these alloys only the $80 \% \mathrm{Ni}-5 \% \mathrm{Cr}-5 \%$ $\mathrm{Fe}-5 \% \mathrm{Si}-5 \% \mathrm{~B}$ alloy has fair resistance to one medium and good resistance to the other.

\section{BRAZING ALLOYS STATIC.TESTED IN LITHIUM}

\author{
C. F. Leitten, Jr.
}

D. H. Jansen

Static corrosion tests of 100-hr duration in lithium at $1500^{\circ} \mathrm{F}$ have been completed on three brazing alloys: Nicrobraz, $73.5 \% \mathrm{Ni}-10 \% \mathrm{Si}-$ $16.5 \% \mathrm{Cr}$, and $71 \% \mathrm{Ni}-16.5 \% \mathrm{Cr}-10 \% \mathrm{Si}-2.5 \% \mathrm{Mn}$. Type 316 stainless steel and Inconel T-joints brazed with these alloys were used. The purpose of these tests was to verify previous corrosion results.

Table 5 presents the results obtained from weight measurements and from metallographic examinations of the tested specimens. The table shows that all the brazing alloys exhibited poor corrosion resistance to lithium and that the attack was more severe for the brazing alloys on type 316 stainless steel. This is probably due to the difo ference between the amount of nickel in type 316 
TABLE 4. STATIC TESTS ON BRAZED HASTELLOY B T.JOINTS IN SODIUM AND IN NaF.Z.rF ${ }_{4}$-UF $_{4}\left(53.5-40-6.5\right.$ mole \%) FOR $100 \mathrm{hr} \mathrm{AT} 1500^{\circ} \mathrm{F}$

\begin{tabular}{|c|c|c|c|}
\hline $\begin{array}{l}\text { Alloy Composition } \\
\text { (wt \%) }\end{array}$ & $\begin{array}{c}\text { Weight Change } \\
(\%)\end{array}$ & Resistance & Metallographic Results \\
\hline \multicolumn{4}{|c|}{ Test Medium: Fluoride } \\
\hline $80 \mathrm{Ni}-5 \mathrm{Cr}-5 \mathrm{Fe}-5 \mathrm{Si}-5 \mathrm{~B}$ & -0.035 & Good & No attack \\
\hline $69 \mathrm{Ni}-15 \mathrm{Cr}-5 \mathrm{~B}-5 \mathrm{Si}-5 \mathrm{Fe}-1 \mathrm{C}$ & +0.041 & Fair & Several subsurface voids to a depth of $4 \mathrm{mils}$ \\
\hline $69 \mathrm{Ni}-20 \mathrm{Cr}-11 \mathrm{Si}$ & -0.025 & Poor & Uniform surface attack to a depth of $4 \mathrm{mils}$ \\
\hline $90 \mathrm{Ni}-4 \mathrm{~B}-4 \mathrm{Si}-2 \mathrm{Fe}$ & -0.014 & Poor & $\begin{array}{l}\text { Layer of small voids that penetrated } 5 \mathrm{mils} \\
\text { into the body of the material }\end{array}$ \\
\hline \multicolumn{4}{|c|}{ Test Medium: Sodium } \\
\hline $69 \mathrm{Ni}-20 \mathrm{Cr}-11 \mathrm{Si}$ & -0.049 & Good & Attack to a depth of $5 \mathrm{mils}$ \\
\hline $69 \mathrm{Ni}-15 \mathrm{Cr}-5 \mathrm{~B}-5 \mathrm{Si}-5 \mathrm{Fe}-1 \mathrm{C}$ & 0.0 & Fair & Several subsurface voids to a depth of $6 \mathrm{mils}$ \\
\hline $80 \mathrm{Ni}-5 \mathrm{Cr}-5 \mathrm{Fe}-5 \mathrm{Si}-5 \mathrm{~B}$ & -0.041 & Fair & l-mil layer of subsurface voids \\
\hline $90 \mathrm{Ni}-4 \mathrm{~B}-4 \mathrm{Si}-2 \mathrm{Fe}$ & -0.052 & Poor & $\begin{array}{l}\text { Layer of small voids that penetrated } 6 \mathrm{mils} \\
\text { into the body of the material }\end{array}$ \\
\hline
\end{tabular}

\begin{tabular}{|c|c|c|c|c|}
\hline \multicolumn{5}{|c|}{$\begin{array}{r}\text { TABLE 5. BRAZING ALLOYS ON TYPE } 316 \text { STAINLESS STEEL AND } \\
\text { STATIC LITHIUM AT } 1500^{\circ} \mathrm{F} \text { FOR } 100 \mathrm{hr}\end{array}$} \\
\hline \multirow{2}{*}{$\begin{array}{l}\text { Brazing Alloy Composition } \\
\text { (wt \%) }\end{array}$} & \multirow{2}{*}{$\begin{array}{l}\text { Base } \\
\text { Material }\end{array}$} & \multicolumn{2}{|c|}{ Weight Change* } & \multirow{2}{*}{ Metallographic Results } \\
\hline & & (g) & $(\%)$ & \\
\hline $\begin{array}{l}\text { Nicrobraz; } 70 \mathrm{Ni}-14 \mathrm{Cr}-6 \\
\mathrm{Fe}-5 \mathrm{~B}-4 \mathrm{Si}-1 \mathrm{C}\end{array}$ & Type 376 & -0.0087 & -1.17 & Joint failed during testing \\
\hline $\begin{array}{l}\text { Nicrobraz; } 70 \mathrm{Ni}-14 \mathrm{Cr}-6 \\
\mathrm{Fe}-5 \mathrm{~B}-4 \mathrm{Si}-1 \mathrm{C}\end{array}$ & Inconel & -0.0012 & -0.16 & $\begin{array}{l}\text { Joint attacked nonuniformly to a maximum } \\
\text { depth of } 9 \text { mils with a uniform attack of } \\
4 \text { mils over entire fillet }\end{array}$ \\
\hline $73.5 \mathrm{Ni}-10 \mathrm{Si}-16.5 \mathrm{Cr}$ & Type 316 & -0.0035 & -2.97 & Joint failed during testing \\
\hline $73.5 \mathrm{Ni}-10 \mathrm{Si}-16.5 \mathrm{Cr}$ & Inconel & -0.0081 & -1.23 & Braze fillet completely attacked \\
\hline $71 \mathrm{Ni}-10 \mathrm{Si}-16.5 \mathrm{Cr}-2.5 \mathrm{Mn}$ & Type 316 & -0.0949 & -11.3 & Braze fillet completely attocked \\
\hline $71 \mathrm{Ni}-10 \mathrm{Si}-16.5 \mathrm{Cr}-2.5 \mathrm{Mr}$ & Inconel & +0.0312 & +3.66 & $\begin{array}{l}\text { Uniform attock to a depth of } 7 \mathrm{mils} \text { in } \\
\text { form of subsurface voids along fillet }\end{array}$ \\
\hline \multicolumn{3}{|c|}{$\begin{array}{l}\text { stainless steel (10-14\%) and in Inconel ( } 75-80 \%) \text {. } \\
\text { Thus, because nickel is preferentially attacked by } \\
\text { lithium, the attack on the Inconel T-joints is uni- } \\
\text { form and not so severe since the brazing alloys } \\
\text { have approximately the same nickel concentrations } \\
\text { as Inconel; on the other hand, the attack is more } \\
\text { extensive for the brazing alloys on type } 316 \text { stain- } \\
\text { less steel T-joints since most of the nickel has to }\end{array}$} & \multicolumn{2}{|c|}{$\begin{array}{l}\text { be leached from the brazing alloy in order to satu- } \\
\text { rate the lithium with nickel. } \\
\text { The results of these tests corroborate the re- } \\
\text { sults of the previous tests and indicate that } \\
\text { nickel-base brazing alloys have very poor corro- } \\
\text { sion resistance to lithium, especially when used } \\
\text { to braze iron-base alloys. }\end{array}$} \\
\hline
\end{tabular}




\section{HASTELLOY B-INCONEL STATIC TESTS IN A F USED-FLUORIDE.SALT MIXTURE}

\section{R. Carlander}

A Hastelloy $B$ specimen in an Inconel capsule containing $\mathrm{NaF} \cdot \mathrm{ZrF}_{4}-\mathrm{UF}_{4}(50-46.4$ mole \%) was static-tested for $100 \mathrm{hr}$ at a temperature of $1600^{\circ} \mathrm{C}$ so as to determine whether dissimilar-metal mass transfer occurs in such an isothermal system. A helium atmosphere was maintained over the molten salt. A negligible weight loss of $0.0003 \mathrm{~g}$ occurred on the Hastelloy B specimen, but no attack could be detected metallographically. Spectrographic analysis revealed that no molybdenum had transferred to the Inconel capsule wall.

Two 5-mil cuts were machined from the surface of the Hastelloy B specimen and were analyzed spectrographically to determine whether chromium had been picked up from the Inconel tube. There was no detectable difference in the chromium content of the two cuts, which indicated that no appreciable quantity of chromium had transferred. The surfaces of the Hastelloy $B$ specimen and Inconel container are shown in Fig. 3.
The Inconel tube wall was attacked to a depth of 8 mils. Inconel is nomally attacked to a depth of 2 mils in an all-Inconel static test system under similar test conditions.

\section{INCONEL THERMAL-CONVECTION LOOP TESTS WITH SODIUM}

\section{E. E. Hoffman}

A test with sodium in an Inconel thermal-convection loop was recently terminated after $1000 \mathrm{hr}$. Samples of the sodium used in this test were analyzed and found to contain approximately $0.03 \%$ oxygen. The oxygen content is high, but it could be reduced by a factor of 10 by adequate cold trapping. The test shows how serious mass transfer can be even in a thermal-convection loop when the oxygen content is high. The hot leg of the loop was $1500^{\circ} \mathrm{F}$, while the coldest section of the cold leg was $1200^{\circ} \mathrm{F}$. The mass-transferred material was concentrated in that area in the cold leg (Fig. 4) where air had been blown onto the tube wall during the test. Very little mass transfer was detected in other sections of the cold leg. A

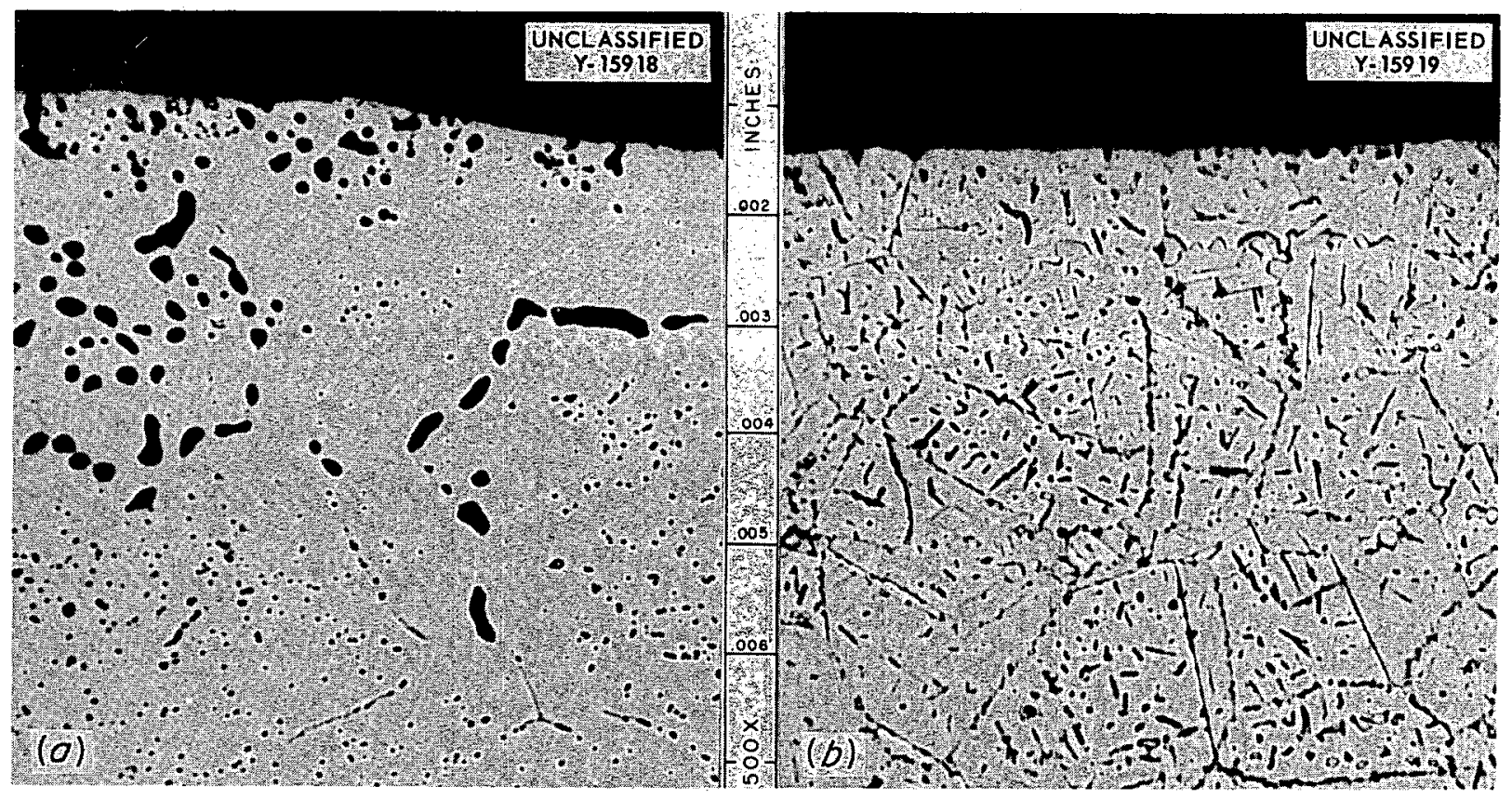

Fig. 3. Surface of (a) Inconel Container and (b) Hastelloy B Specimen After Dissimilar-Metal Test in a Fluoride Fuel. Inconel tube was nickel-plated after the test so as to preserve the edge during metallographic polishing. Inconel etchant: oxalic acid. Hastelloy B etchant: $\mathrm{H}_{2} \mathrm{O}_{2}-\mathrm{H}_{3} \mathrm{PO}_{4}$. 500X. Reduced 5\%. (Secret with caption) 


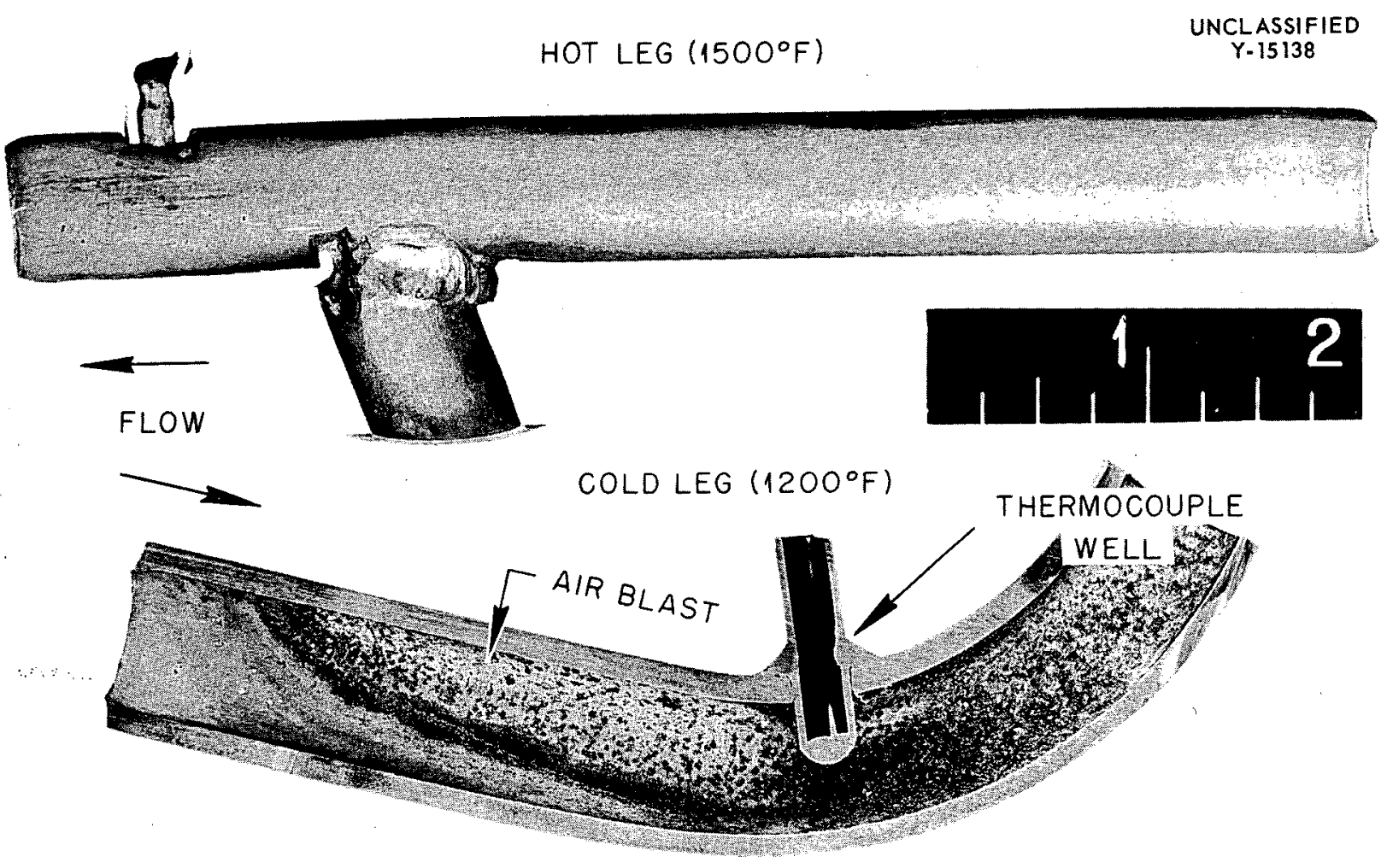

Fig. 4. Mass-transfer Crystals Deposited in Inconel Loop After Circulation of Sodium by Thermal Convection.

similar test will be conducted in which the oxygen content of the sodium will be held below $0.005 \%$ so as to determine how the mass transfer in sodium-lnconel systems is affected by alteration of the oxygen content.

The metal crystals found in the cold leg of the Inconel thermal-convection loop after circulation of sodium have been analyzed and were found to contain $85 \% \mathrm{Ni}, 11.2 \% \mathrm{Cr}, 2.1 \% \mathrm{Fe}$, and $1.4 \% \mathrm{Mn}$, by weight.

\section{INCONEL LOOP TESTS WITH BOILING SODIUM}

\section{E. E. Hoffman}

Tests at ORNL and at other laboratories indicate that the oxygen content of sadium in nickelor iron-base alloy plumbing systems has a considerable effect on the amount of mass transfer occurring in the system. In order that mass trans. fer might be studied in a system where the oxygen content was held to a very low level, a boilingsodium loop test of 400 -hr duration was run. The loop can be seen in Fig. 5. The boiler pot of the loop is located on the right, and the temperatures around the loop during the test are indicated. There are two traps for liquid sodium in the condenser leg of the loop. The first trap is filled with hot, freshly condensed sodium during the test. The second trap catches the overflow from the first trap and operates at a considerably lower temperature. This is an ideal location for metal deposition to occur. Three nickel cooling coils are located on the condenser leg, and an air flow through these coils is regulated to maintain the desired temperatures. The boiler and the small return line to the boiler are the only areas where heat was applied during the test. The test was terminated after $400 \mathrm{hr}$, when a small leak was detected in the coolest section of the bottom return line. X-ray, macroscopic, and microscopic examinations of the traps in the condenser line revealed no mass transfer (see Fig. 6). Heavy intergranular cracking was defected in the condenser tube wall, and, as yet, there is no satis- 


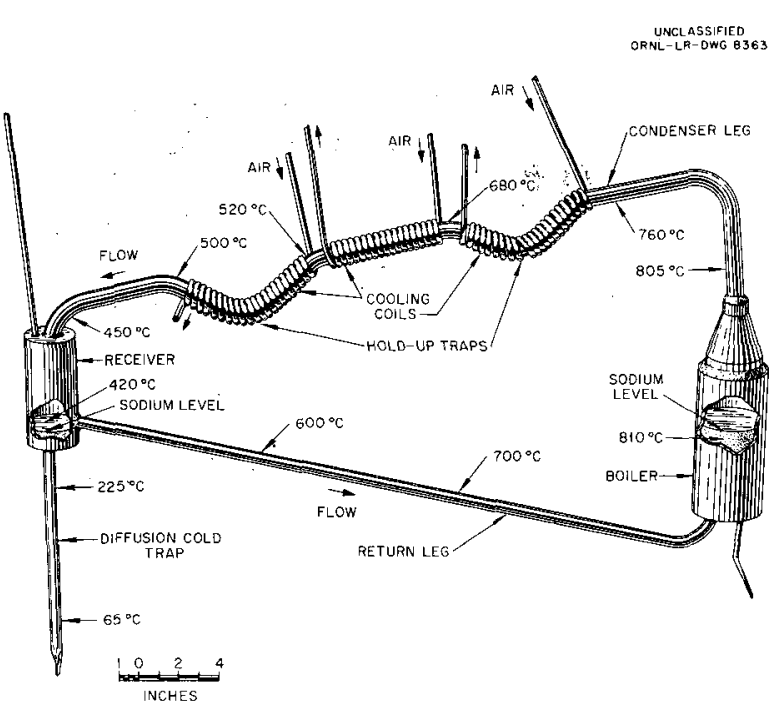

factory explanation for this. This intergranular cracking varied: there was none in the hottest section of the condenser tube, 3 mils in the coolest section, and the heaviest cracking, to a depth of 50 mils, midway between the two traps (see Figs. 5 and 6 ).

As a check on the results of this experiment, a duplicate test is now under way and will be conducted for a period of 1000 hr.

\section{CORROSION RESISTANCE OF INCONEL TO SODIUM-POTASSIUM-L IT HIUM}

\section{E. E. Hoffman}

Five seesaw tests have been conducted to determine the effect of various combinations of sodium-potassium-lithium on the corrosion of Inconel. Inconel tubes were used and were loaded

Fig. 5. Inconel Loop for Corrosion Testing with Boiling Sodium.
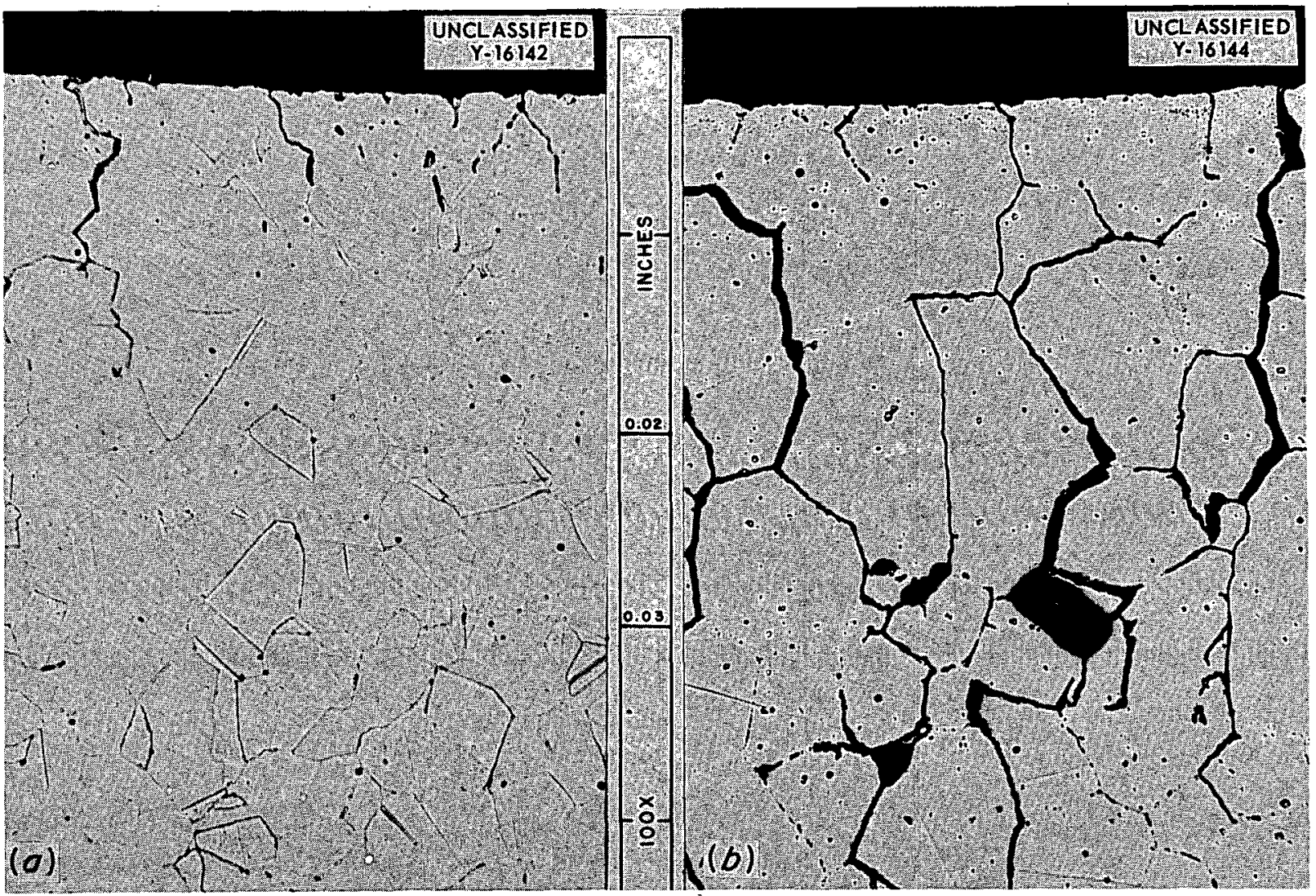

Fig. 6. Condenser Wall of Inconel Loop Subjected to Boiling Sodium: (a) Hot Trap, (b) Cold Trap. Note the pronounced intergranular cracking in both and the absence of mass-transfer crystals on surface of cold-trap wall. Etchant: aqua regia. 100X. Reduced $2 \%$. 
2 to 30 wt \%. The heaviest attack in each test was found in the hot section of the seesaw tube and varied from $\frac{1}{2} \mathrm{mil}$ in the $10 \%$ lithium test to 2 to 3 mils in the $5 \%$ lithium test. It is not understood as yet why the heaviest attack occurred in the $5 \%$ lithium test. Additional specimens cut from the hot zone of this tube confirmed the attack. No mass transfer could be detected in the cold zones of any of the tubes tested. The hot and cold zones of each test container were examined metallographically, and the results are listed in Table 6. Photomicrographs of the hot zones of the 2 and $30 \%$ lithium tests are presented in Fig. 7.

TYPE 347 STAINLESS STEEL THERMAL. CONVECTION LOOP TESTS WITH LITHIUM

\section{E. E. Hoffman}

Two stainless steel loops containing lithium were operated for 1000 and $3000 \mathrm{hr}$, respectively. The hot- and cold-leg temperatures were 1000 and $550^{\circ} \mathrm{F}$, respectively. The loops operated satisfactorily during the test period. Macroscopic examination revealed no mass-transfer crystals in the loops or in the lithium drained from the loops.

The hot zone of the loop that was operated for $1000 \mathrm{hr}$ had subsurface voids and had a ferritic surface layer 0.3 to $1.0 \mathrm{mil}$ thick. Lithium metal had penetrated to this depth also. The weld zone in this area of the loop was attacked to a depth of
3 mils. The cold-zone section of the loop was unattacked; however, there were a few small (0.2mil) crystals attached to the surface. Similar crystals have in the past been identified as carbides.

The attack in the hot leg of the loop used in the 3000 -hr test was similar. However, the spongy ferritic surface layer was 1.0 to $1.5 \mathrm{mils}$ in thickness (Fig. 8). The attack in the weld zone was intergranular in nature, extended 4 to 5 mils in depth, and is due to the preferential dissolution of the grain-boundary carbides by the molten lithium (Fig. 9). A deep groove in the pipe wall may be seen at the weld zone-parent metal interface.

The cold-leg section (Fig. 8) of this loop was very similar in appearance to that from the 1000hr-test loop. Likewise, a few small (0.2-mil) carbide particles were attached to the wall of the tube.

It is believed that the corrosion resistance of type 347 stainless steel to lithium in this temperature range would be improved by reducing the carbon content of the loop piping and by using seam. less instead of welded pipe. The oustentite-toferrite transformation detected in the walls of the hot legs of these loops is attributed to the leaching of nickel by the lithium.

TABLE 6. RESULTS OF TESTS OF INCONEL SEESAW TUBES EXPOSED TO SODIUM-POTASSIUM-LITHIUM MIXTURES FOR $100 \mathrm{hr}$

Hot-zone temperature: $1500^{\circ} \mathrm{F}$

Cold-zone temperature: $1100^{\circ} \mathrm{F}$

$\begin{array}{ccc}\begin{array}{c}\text { Seesaw Test } \\ \text { Number }\end{array} & \begin{array}{c}\text { Bath } \\ (w t \%)\end{array} & \text { Hot-Zone Attack }\end{array}$

265

266

270

271

272
$2 \mathrm{Li}-55 \mathrm{Na}-43 \mathrm{~K}$

$5 L i-53 \mathrm{Na}-42 \mathrm{~K}$

$10 L i-50 \mathrm{Na}-40 \mathrm{~K}$

$20 \mathrm{Li}-45 \mathrm{Na}-35 \mathrm{~K}$

$30 \mathrm{Li}-40 \mathrm{No}-30 \mathrm{~K}$
Intergranular voids in scattered areas to a depth of $1 \mathrm{mil}$

Heavy attack in the form of subsurface voids to a depth of 2 to 3 mils; small, very hard particles of an unidentified phase located in areas where the attack was heaviest

Small sub surface voids to a depth of $0.5 \mathrm{mil}$

Small subsurface voids to a depth of 0.5 to $1 \mathrm{mil}$

Subsurface voids to a depth of 1 to $2 \mathrm{mils}$
No attack

No attack

No attack

Attack in scattered areas to a depth of $0.5 \mathrm{mil}$

Intergranular penetration to a depth of 0.25 to $0.5 \mathrm{mil}$ 


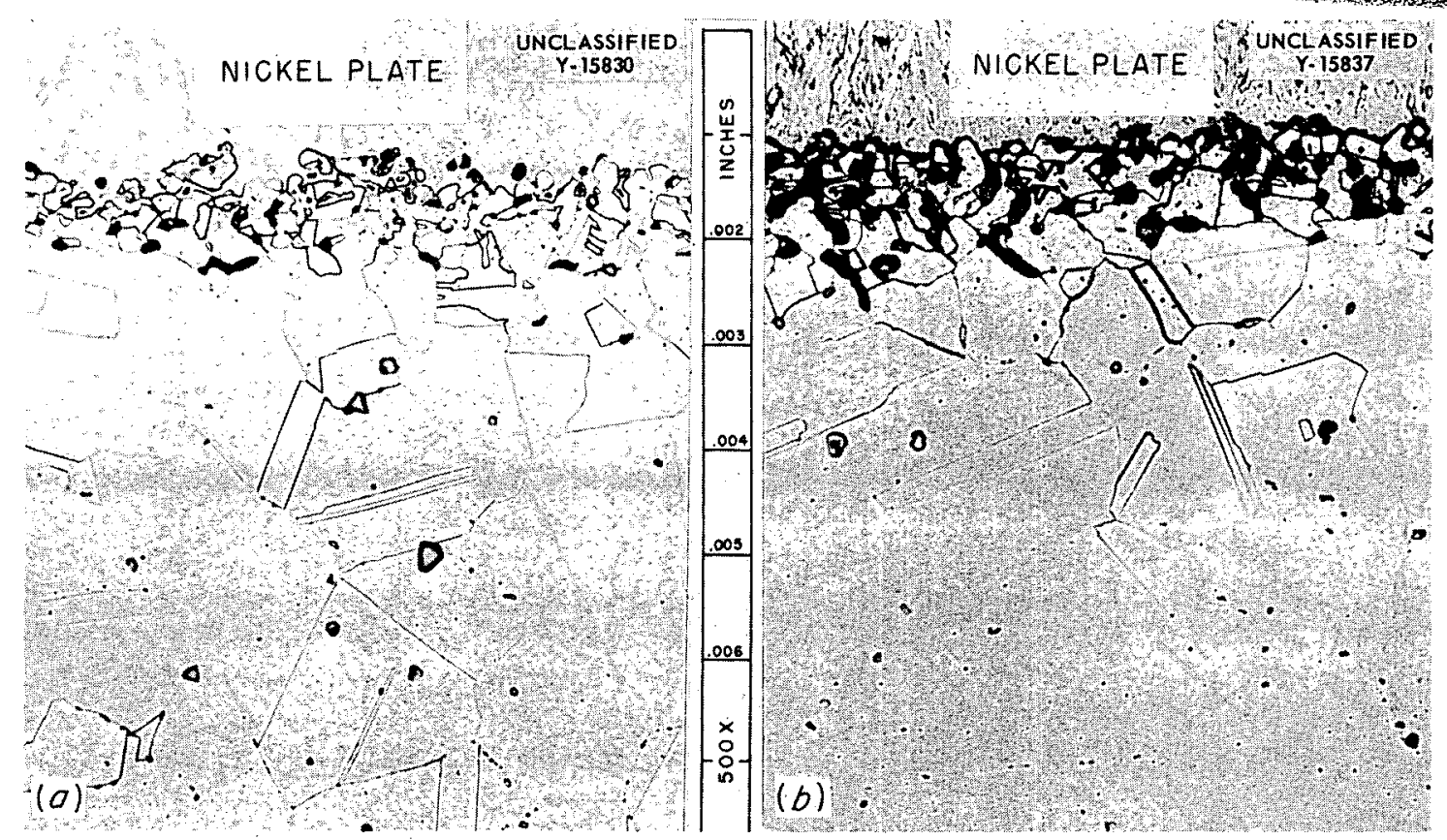

Fig. 7. Surfaces of Hot Zones of Inconel Seesaw Tubes Which Were Exposed to a Bath of Na-K-Li [(a) 55-43-2 wt \% and (b) 40-30-30 wt \%]. Etchant: aqua regia. 500X. Reduced 14\%. (Secret with caption)

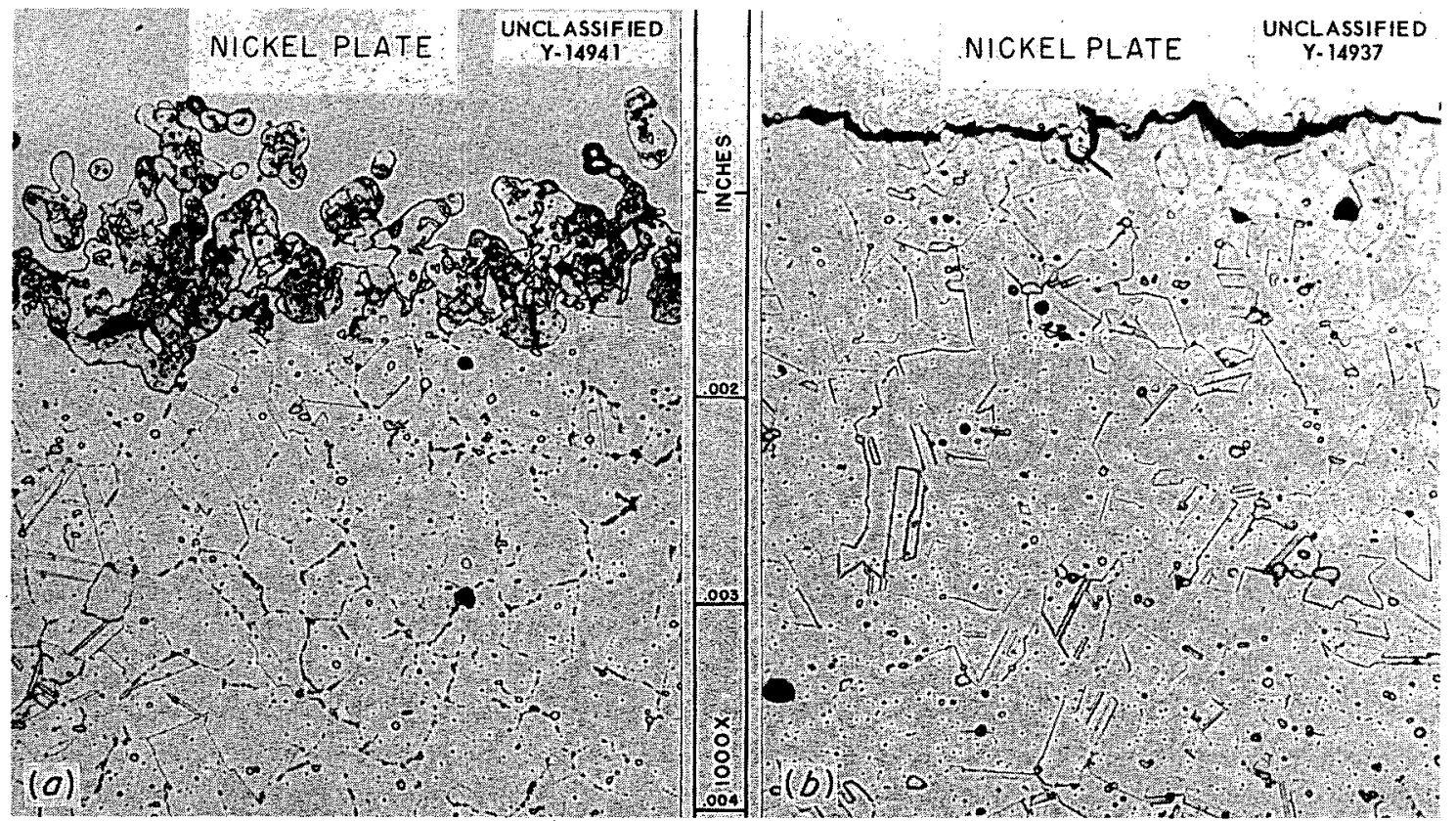

Fig. 8. Surfaces of (a) Hot Leg and (b) Cold Leg of Type 347 Stainless Steel-Lithium ThermalConvection Loop. Note austenite-to-ferrite phase transformation which occurred on hot-leg surface and small crystals which deposited on cold-leg surface. Specimens were nickel-plated after the test. Etchant: aqua regia. 1000X. Reduced 14\%. 


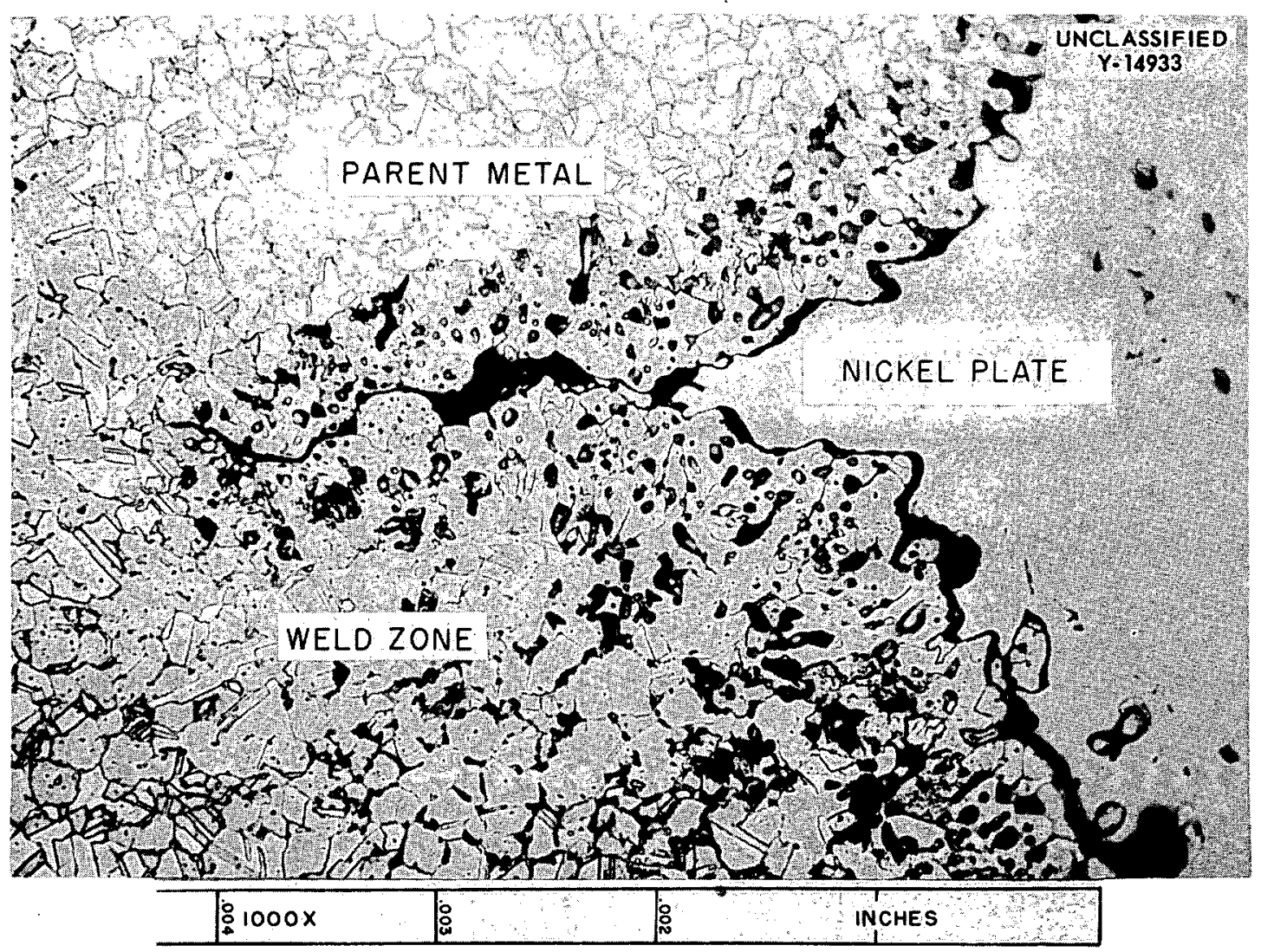

Fig. 9. Inside Wall of Hot Leg of Type 347 Stainless Steel Thermal-Convection Loop in Which Lithium Was Circulated. Note deep ( 4 mils) attack in weld zone as contrasted with attack ( 1 mil) on parent metal. Specimen was nickel-plated after the test. Etchant: aqua regia.

\section{CORROSION TESTING OF REFRACTORY METALS IN STATIC LITHIUM}

\section{E. E. Hoffman}

Static-corrosion tests of 100-hr duration with lithium at $1500^{\circ} \mathrm{F}$ have been conducted on molybdenum, vanadium, and niobium (columbium). In each test the specimens and containers were of the same material. The results of weight-change determinations and metallographic examinations of the specimens from these tests are given in Table 7. The conditions of the exposed surfaces of the niobium and molybdenum are shown in Fig. 10.

\section{SCREENING TESTS TO DETERMINE THE RESISTANCE OF VARIOUS MATERIALS TO SOLID.PHASE BONDING}

$$
\text { W. H. Cook }
$$

The alloys which were proposed for the fuel and coolant lines in the ARE have the undesirable tendency to form a solid-phase bond when they are used as valves, bearings, and seals and are in contact with liquid metals or fused-fluoride salts at elevated temperatures. Therefore, various other alloys, pure metals, ceramics, and cermets are being investigated to determine their resistance to solid-phase bonding. The cermets appear to be the most promising because of their chemical and physical characteristics.

The test apparatus being used is shown in Fig. 11. It is a modification of the equipment used for lever-arm stress-rupture tests. ${ }^{1}$ By use of this apparatus, the test specimens can be brought into mutual compression between the platens in the test medium - a liquid metal or a fused-fluoride salt.

A set of corrosion-resistant cermets and hardfacing alloys has been tested for $100 \mathrm{hr}$ in an ap-

1R. B. Oliver et al., Met. Semiann. Prog. Rep. April
10, 1955, ORNL-1911, P 56. 
TABLE 7. RESULTS FROM 100.hr CORROSION EXPERIMENTS IN STATIC LITHIUM AT $1500^{\circ} \mathrm{F}$

\begin{tabular}{|c|c|c|}
\hline Material & Weight Change $\left(g / i n .^{2}\right)$ & Metallographic Results \\
\hline Molybdenum & 0 & No attack \\
\hline$Z$ irconium & 0 & No attack \\
\hline Niobium & +0.0006 & No attack \\
\hline Vanadium & +0.0084 & $\begin{array}{l}\text { Grain-boundary penetration by unidentified phase to a } \\
\text { depth of } 2 \text { mils }\end{array}$ \\
\hline Tantalum & +0.0076 & $\begin{array}{l}\text { Intergranular attack to a depth of } 4 \text { to } 6 \mathrm{mils} \text { on specimen; } \\
1 \mathrm{mil} \text { of attack on bath zone of tube }\end{array}$ \\
\hline
\end{tabular}
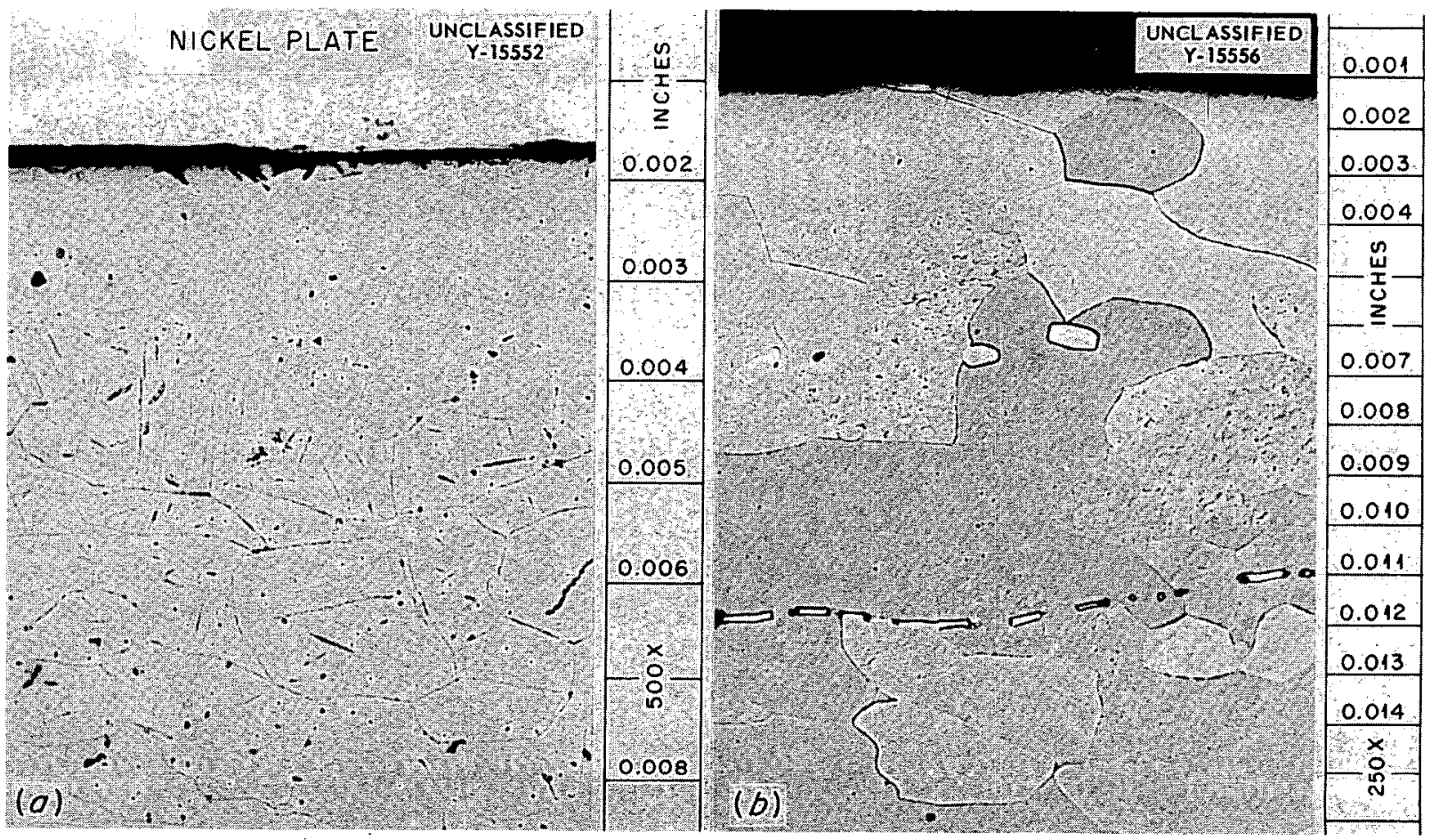

Fig. 10. Surfaces of (a) Niobium and (b) Molybdenum Specimens After Exposure to Static Lithium. The niobium was attacked only very slightly; the molybdenum was unattacked. Niobium etchant: $\mathrm{H}_{2} \mathrm{O}$. $\mathrm{HF}-\mathrm{H}_{2} \mathrm{SO}_{4}-\mathrm{HNO}_{3}$. Molybdenum etchant: $\mathrm{H}_{2} \mathrm{O}_{2}-\mathrm{NH}_{4} \mathrm{OH}$. Reduced $10 \%$.

paratus fabricated from Inconel for the purpose of determining their solid-phase-bonding characteris-

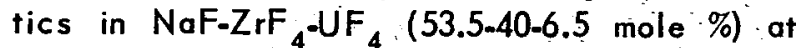
$1500^{\circ} \mathrm{F}$. The test specimens were dimensionally the same $( \pm 0.0002$ in.), and the roughnesses of the contacting surfaces were less than $10 \mu$ in. for those tested at calculated contact pressures of less than $50,000 \mathrm{psi}$ and were 1.5 to $2 \mu \mathrm{in}$. for those tested at calculated contact pressures of 50,000 psi. At the beginning of each test, the contacting surfaces were held apart while the apparatus was flushed with the fused-fluoride salt at $1500^{\circ} \mathrm{F}$. This was done to ensure that any surface films on the specimens would be removed before the compression load was applied. A fresh charge of the NaF- $\mathrm{ZrF}_{4} \cdot \mathrm{UF}_{4}$ mixture at $1500^{\circ} \mathrm{F}$ 


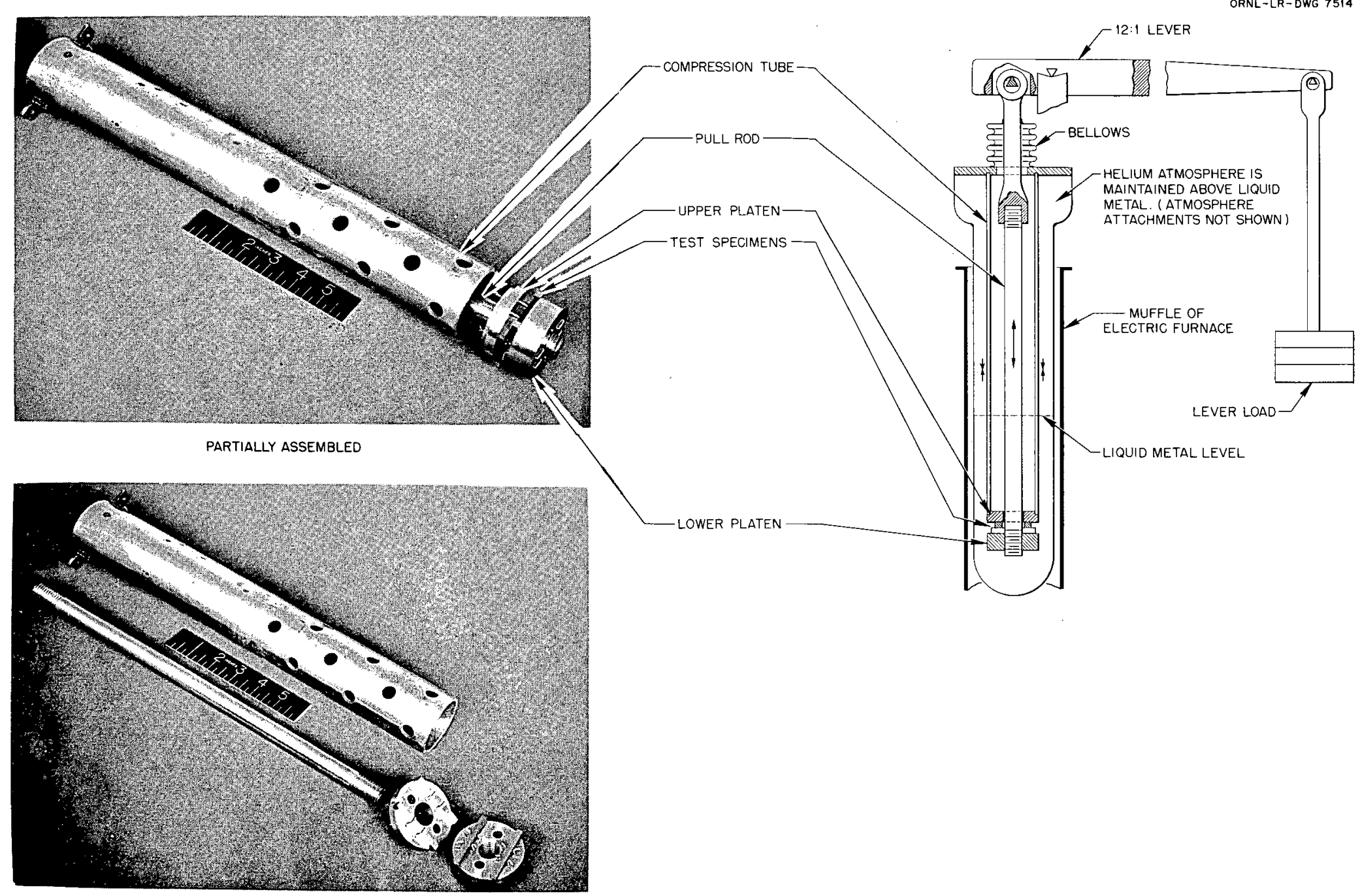

Fig. 11. Apparatus for Solid-Phase-Bonding Screening Tests. 
was then put into the test chamber. The test specimens were then pressed together at the desired contact pressure. At the conclusion of the test, the fused salt was removed, and the system was cooled to room temperature and disassembled.

The contact surfaces of the specimens were examined with a low-power microscope for evidence of solid-phase bonding. There was inconsistent bonding of the test specimens to the supporting Inconel platens. The seating was not perfectly uniform in any of the tests; therefore, the contact pressures in certain areas between the specimens were probably in excess of the calculated values. Table 8 is a summary of the solid-phase-bonding screening tests made at calculated contact pressures of $6,600,10,000$, and $50,000 \mathrm{psi}$. There is no apparent relation ship between solid-phase bonding and the chemical compositions of the cermets tested. In the tests, emphasis was placed on the pair K152B and K162B because these are the strongest cermets that did not solid-phase bond.

\section{TESTING OF CARBIDES IN STATIC LEAD}

$$
\text { W. H. Cook }
$$

Specimens of the carbides of boron, titanium, zirconium, and chromium were tested for $100 \mathrm{hr}$ in order to determine their corrosion resistance to static lead at $1500^{\circ} \mathrm{F}$. The results of these tests together with the measured densities and apparent porosities are given in Table 9.

CORROSION TESTS OF SIC-SI (DURHY ${ }^{2}$ ) IN SODIUM, NaF.Z.F ${ }_{4} \cdot$ UF $_{4}$, LITHIUM, AND LEAD W. H. Cook

SiC.Si (Durhy) specimens have been tested for $100 \mathrm{hr}$ for the purpose of determining their corrosion resistance to static sodium, NaF-ZrF 4 UF $_{4}$ (53.5.40-6.5 mole \%), lithium, and lead at $1500^{\circ} \mathrm{F}$, as requested by the Ceramic Laboratory of the Metallurgy Division. The Ceramic Laboratory supplied the specimens and reported that the average density was $2.76 \mathrm{~g} / \mathrm{cc}$ and that the average porosity was $0.2 \%$. Table 10 is a summary of the test results.

The weight gain of the specimen tested in $\mathrm{NaF}$. $\mathrm{ZrF}_{4}-\mathrm{UF}_{4}$ was probably. caused by droplets of adhering fused salts that were not removed when the specimen was cleaned. Compound formation was ruled out as a possible reason since a powder

\footnotetext{
2"Durhy" is the trade name of the SiC-Si product manufactured by The Carborundum Company.
}

TABLE 8. RESULTS OF SOLID-PHASE-BONDING SCREENING TESTS OF VARIOUS CERMETS AND ALLOYS EXPOSED TO NaF- $\mathrm{ZrF}_{4} \mathrm{UF}_{4}$ $\left(53.5-40-6.5\right.$ mole \%) AT $1500^{\circ} \mathrm{F}$ FOR $100 \mathrm{hr}$

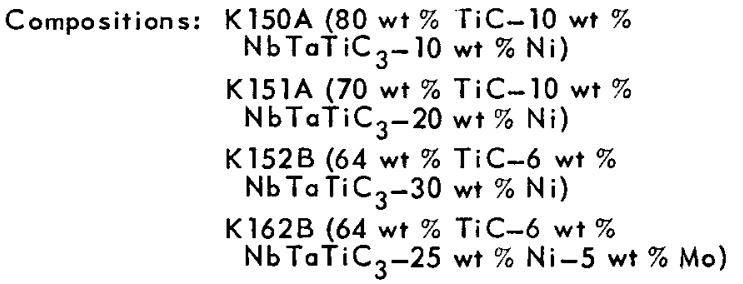

\begin{tabular}{|c|c|c|}
\hline $\begin{array}{l}\text { Contact } \\
\text { Pressure } \\
\text { (psi) }\end{array}$ & Contacting Specimens & Results* \\
\hline \multirow[t]{2}{*}{6,600} & K $150 \mathrm{~A}$ vs Stellite 25 & $S, N$ \\
\hline & K 162B vs Stellite 25 & $S, N$ \\
\hline \multirow[t]{5}{*}{10,000} & K150A vs Stellite 6 & $S, S$ \\
\hline & K 162B vs Stellite 6 & $S, N$ \\
\hline & K 152B vs K 152B & $\mathrm{N}$ \\
\hline & K 152B vs K $162 B$ & $N, N$ \\
\hline & K 162B vs K 162B & N \\
\hline \multirow[t]{10}{*}{50,000} & K 150A vs K150A & $N$ \\
\hline & K $150 \mathrm{~A}$ vs K $151 \mathrm{~A}$ & $N, N$ \\
\hline & K 150A vs K 152B & $S, 5$ \\
\hline & K 150A vs K 162B & $N, N$ \\
\hline & K 151A VS K151A & $N$ \\
\hline & K151A vs K152B & $N, N$ \\
\hline & K151A vs K 162B & $N, N$ \\
\hline & K 152B vs K 152B & $N, S$ \\
\hline & K 152B vs K 162B & $N, N, N, N$ \\
\hline & $\mathrm{K} \mathrm{162B} \mathrm{vs} \mathrm{K} \mathrm{162B}$ & $S, S$ \\
\hline
\end{tabular}

${ }^{*} N=$ no bonding; $S=$ some bonding. Each symbol represents one specimen tested.

$x$-ray analysis of the attacked region showed only $\mathrm{SiC}, \mathrm{Si}$, and the mixed fluorides. Figure 12 shows the structure of untested SiC-Si (Durhy) and its appearance after having been exposed to sodium, lead, and fused fluoride.

\section{EFFECT OF RUTHENIUM ON THE PHYSICAL PROPERTIES OF INCONEL}
C. F. Leitten, Jr.
D. H. Jansen

Since examination of various sections of the $A R E^{3}$ and of the LITR fluoride-fuel loop ${ }^{4}$ revealed

\footnotetext{
${ }^{3}$ M. T. Robinson, S. A. Reynolds, and H. W. Wright, ANP Quar. Prog. Rep. Marcb 10, 1955, ORNL-1864, p 13.

${ }^{4} M$. T. Robinson and T. H. Handley, ANP Quar. Prog. Rep. June 10, 1955, ORNL-1896, p 167.
} 
TABLE 9. SUMMARY OF THE CORROSION DATA FROM VARIOUS CARBIDES TESTED FOR $100 \mathrm{hr}$ IN STATIC LEAD AT $1500^{\circ} \mathrm{F}$

\begin{tabular}{|c|c|c|c|c|c|}
\hline \multicolumn{3}{|c|}{ Specimen * } & \multirow[b]{2}{*}{$\begin{array}{l}\text { Attack } \\
\text { (mils) }\end{array}$} & \multirow{2}{*}{$\begin{array}{l}\text { Weight } \\
\text { Change } \\
(\%)\end{array}$} & \multirow[b]{2}{*}{ Remarks } \\
\hline Formula & $\begin{array}{l}\text { Density } \\
(g / c c)\end{array}$ & $\begin{array}{l}\text { Apparent } \\
\text { Porosity } \\
(\%)\end{array}$ & & & \\
\hline $\mathrm{B}_{4} \mathrm{C}$ & 2.51 & 3.5 & 0 & -1.2 & No attack; black dust-like film on specimen \\
\hline $\mathrm{TiC}$ & 4.81 & 1.3 & 0 & 0 & $\begin{array}{l}\text { No attack; specimen had darkened slightly; } \\
\text { Globiron capsule was expanded as if a } \\
\text { high pressure had occurred during the test }\end{array}$ \\
\hline $\mathrm{ZrC}$ & 6.91 & 0.8 & 0 & +0.1 & No attack; specimen had darkened slightly \\
\hline $\mathrm{Cr}_{3} \mathrm{C}_{2}$ & 6.59 & 2.2 & 0 & $-6.7 * \star$ & No attack; metallic luster had been dulled \\
\hline
\end{tabular}

* The specimens and the data were fumished by the Ceramic Laboratory of the Metallurgy Division.

* The specimen was broken when the lead was stripped from it.

TABLE 10. SUMMARY OF THE CORROSION RESULTS ON SiC-Si (DURHY) TESTED FOR $100 \mathrm{hr}$ IN LIQUID METALS AND A FLUORIDE-SALT BATH AT $1500^{\circ} \mathrm{F}$

\begin{tabular}{|c|c|c|c|}
\hline Test Medium & $\begin{array}{l}\text { Attack } \\
\text { (mils) }\end{array}$ & $\begin{array}{c}\text { Weight } \\
\text { Change (\%) }\end{array}$ & Remarks \\
\hline Sodium & 164 & -19 & $\begin{array}{l}\text { Attacked - completely though the specimen; the } \mathrm{SiC} \\
\text { and carbon phases were apparently not attacked, } \\
\text { but all the silicon was removed from the specimen } \\
\text { except for a small amount trapped inside of a few } \\
\text { SiC particles }\end{array}$ \\
\hline $\begin{array}{l}\mathrm{NaF} \mathrm{ZrF}_{4}-\mathrm{UF}_{4} \\
\quad(53.5-40-6.5 \text { mole } \%)\end{array}$ & 50 & +12 & $\begin{array}{l}\text { Attacked; maximum, minimum, and average depths } \\
\text { of attack were } 56,46 \text {, and } 50 \text { mils, respectively; } \\
\text { as in the sodium test, only the silicon appeared } \\
\text { attacked, as evidenced by its removal from the } \\
\text { specimen }\end{array}$ \\
\hline Lithium & & & Attacked; no visible trace of specimen after the test \\
\hline Lead & 2 to 12 & +0.5 & $\begin{array}{l}\text { Attacked - appeared to be on the Si only; the attack on } \\
\text { a side that was polished prior to testing was } 2 \text { to } 3 \\
\text { mils; on the side of the specimen that appeared to } \\
\text { have been in contact with a fabrication mold, the } \\
\text { attack was } 12 \text { mils }\end{array}$ \\
\hline
\end{tabular}

a slight deposit of ruthenium metal on the walls of the Inconel tubes, the effect of ruthenium on the physical properties of Inconel is being studied.

A thin layer of ruthenium metal was electrodeposited from a solution of ruthenium nitrosochloride on an Inconel creep-test specimen. Up to the present time, three plated specimens and one unplated specimen have been creep-rupture tested by the Mechanical Properties Group. All plated specimens were annealed at $1500^{\circ} \mathrm{F}$ in an evacuated Inconel capsule for $100 \mathrm{hr}$ so as to allow the ruthenium to diffuse into the specimen. The unplated specimen was annealed in the same way and was then creep-rupture tested to serve as a standard. Tests were conducted in a purified argon atmosphere. Table 11 shows the results obtained.

A small area 2 mils deep was milled from the shoulder of the 1100hr specimen after annealing. Spectrographic analysis on the millings showed no ruthenium within the limit of detection, $0.05 \%$. A plated specimen has been under test in purified 

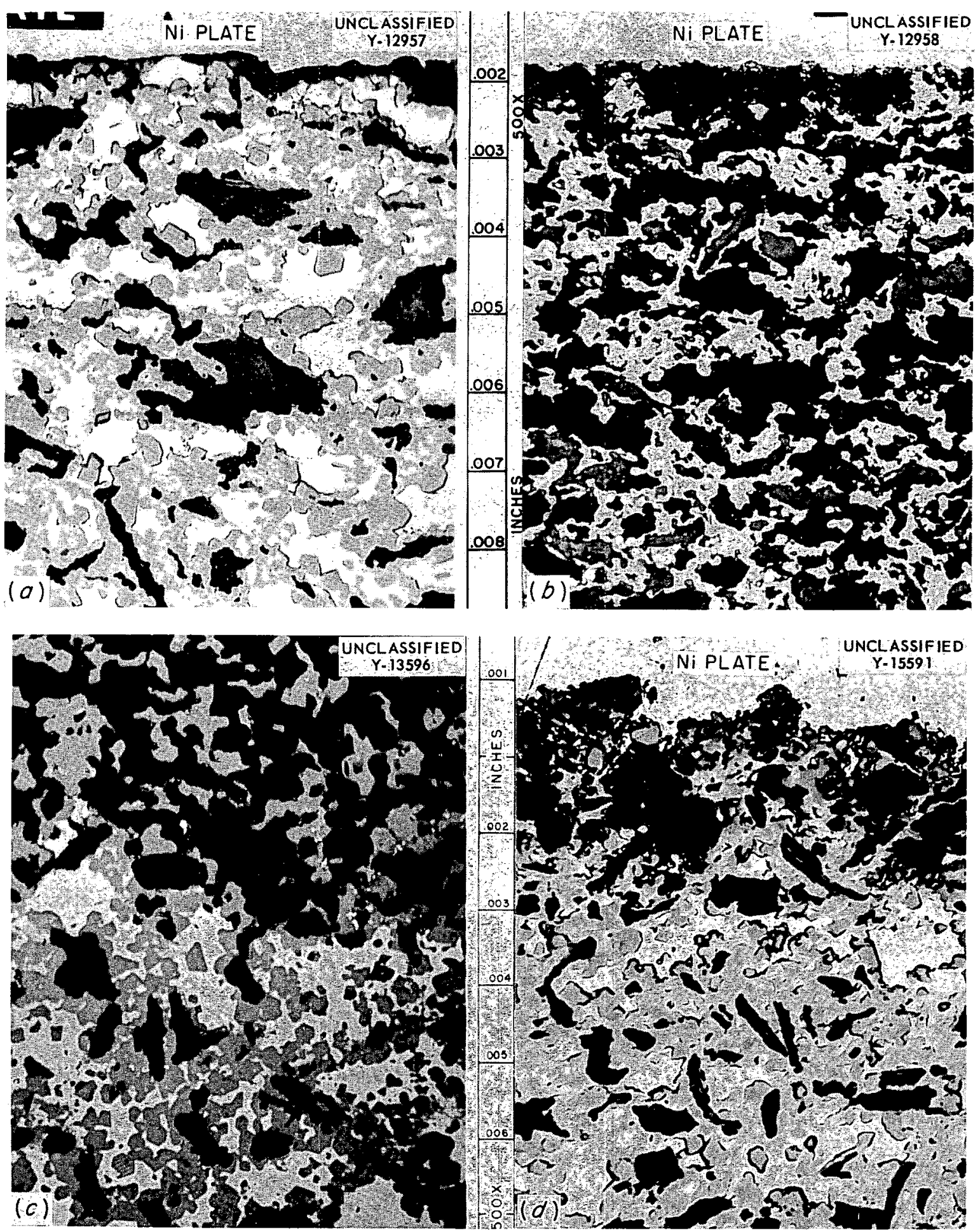

Fig. 12. Static Testing of SiC-Si (Durhy). (a) Typical specimen prior to testing. (b) Tested in sodium. (c) Tested in fluoride fuel. (d) Tested in lead. All specimens were nickel-plated prior to metallographic examination. Unetched. 500X. Reduced 3\%. (Secret with caption) 
argon for $1200 \mathrm{hr}$. Samplesmilled from the shoulder of this specimen to a depth of 2 mils show a ruthenium content of 0.2 to $2.0 \%$. A more accurate analysis has been requested in order to learn whether some correlation between the creep-rupture life and the ruthenium content of Inconel exists.

\section{TABLE 11. CREEP-RUPTURE-TEST DATA ON A \\ STANDARD INCONEL SPECIMEN AND ON RUTHENIUM-PLATED INCONEL SPECIMENS}

Test conditions: Stress, 3500 psi

Temperature, $1500^{\circ} \mathrm{F}$

\begin{tabular}{lcc}
\hline Specimen & Time to Rupture (hr) & Elongation(\%) \\
\hline Unplated & 746 & 14 \\
Plated & 873 & 13.4 \\
Plated & 728 & 13.6 \\
Plated & 1100 & 17.0
\end{tabular}

Two more tensile tests should be conducted before any conclusions can be definitely stated; but at present it appears that ruthenium has no adverse effect on the mechanical properties of Inconel.

A metallographic examination of the strained portions of the ruptured plated specimen showed that the microstructure was the same as in the ruptured unplated specimen (Fig. 13).

\section{DYNAMIC LOOP TESTS INVOLVING A BERYLLIUM-INCONEL.VERSENE SYSTEM}
C. F. Leitten, Jr.
D. H. Jansen

Since Versene has been proposed as the cleaning agent for the ART, the resistance of beryllium to corrosion by dynamic Versene has been investigated. The testing procedure was designed to simulate the cleaning procedure used in the ARE, which was cleaned with a Versene solution. Two such dynamic loop te sts have been completed.

The loops were constructed of Inconel. A tubular beryllium sample was inserted within the loop

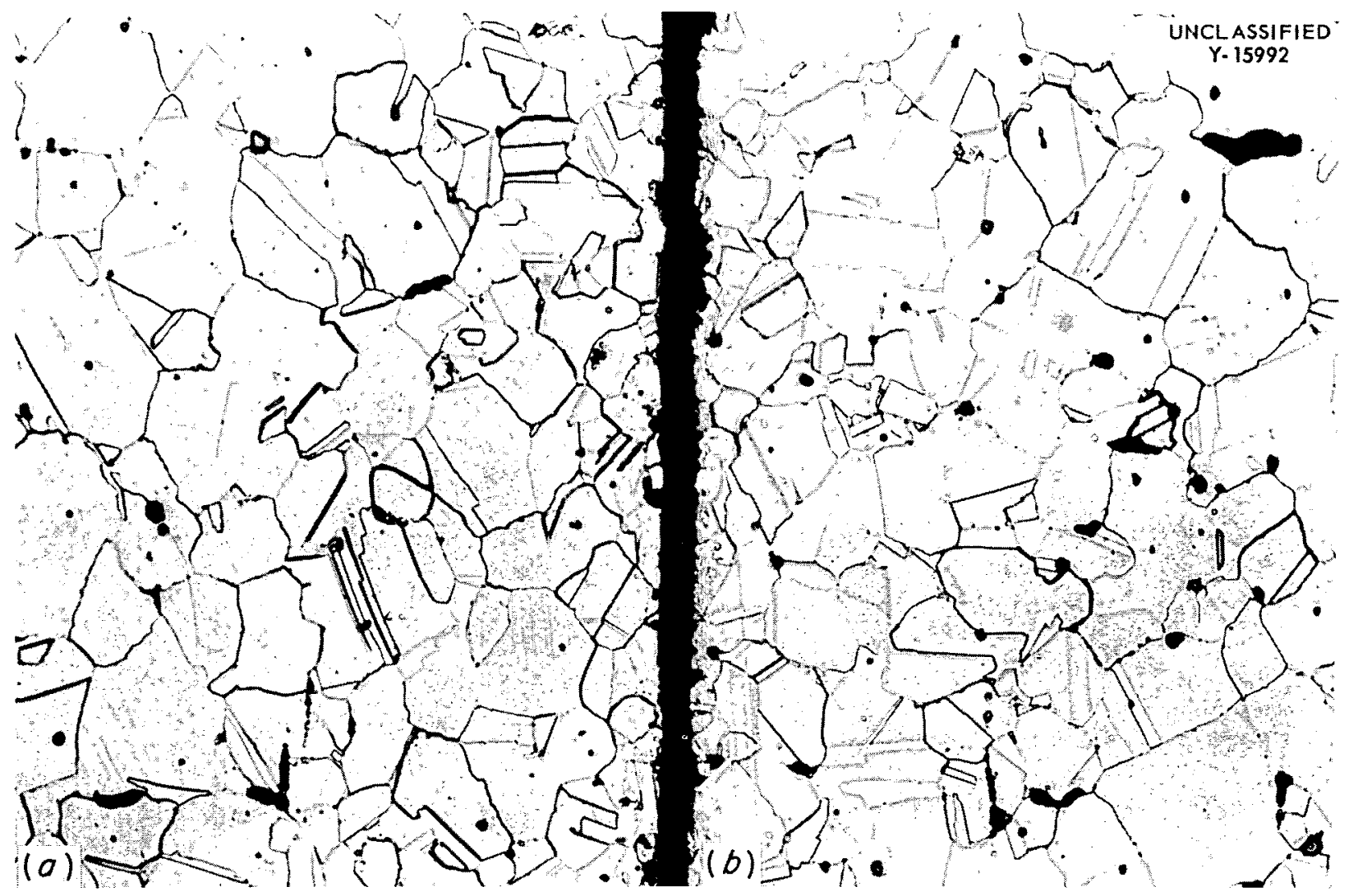

Fig. 13. Strained Portion of (a) Ruthenium-plated and (b) Unplated Inconel Specimens After Rupture in Creep Test. Note similarity. Cathodic etch. 250X. 
between two similar tubular Inconel inserts which were held in place by crimping. The beryllium insert was $3 / 4$ in. OD, $9 / 16$ in. ID, and $3 \mathrm{in}$. in length.

A $1 \%$ Versene solution was pumped through each loop at a rate of $2 \mathrm{gpm}$ (2.6. fps) by a centrifugal pump. Disodium versenate was used, and its concentration was determined on a weight-volume basis. The test temperature of both loops was $180^{\circ} \mathrm{F}$, and each loop was tested for a period of $24 \mathrm{hr}$.

Upon completion of the first test, the Versene was drained from the loop while the loop was still at test temperature. The loop was not flushed with distilled water in this test, but it was in the second loop test. When the first loop was sectioned, it was noticed that a small amount of Versene remained in the static region of the loop. This region is located in the annular gap between the beryllium insert and the Inconel sleeve. In the second test, no trace of retained Versene was noticed in this region.

Macroscopic examination showed that the beryllium inserts from both loops were quite similar after exposure to the Versene solution. Portions of the outer surface were attacked, and metallographic examination revealed erratic pitting to a depth of from 0.5 to 2.5 mils. The unattacked portion, however, retained the original polished appearance. No effect of the Versene solution was visible on the inner surface, and metallographic examination confirmed this.

Figure 14 is a photograph showing the outer surface of the beryllium insert tested in the second loop. This photograph shows the erratic pitting which occurred on the beryllium during the cleaning operation. Figure $15 a$ shows the unattacked inner surface of the beryllium insert used in the first test. The 2.5-mil erratic attack on the outer surface of this same insert is shown in Fig. 15b; this is representative of the attack on the outer surfaces of the beryllium inserts used in both tests. In each test the beryllium inserts lost weight, as is shown in Table 12.

A chemical analysis of a portion of the Versene solution used in the second test revealed a beryl. lium concentration of $0.0024 \mathrm{mg} / \mathrm{ml}$. Since 1.5 liters of $1 \%$ Versene solution was used in this test, the total amount of beryllium in the solution is $3.8 \mathrm{mg}$. This figure agrees fairly well with the $2.9 \mathrm{mg}$ lost by the beryllium in sert in the test.

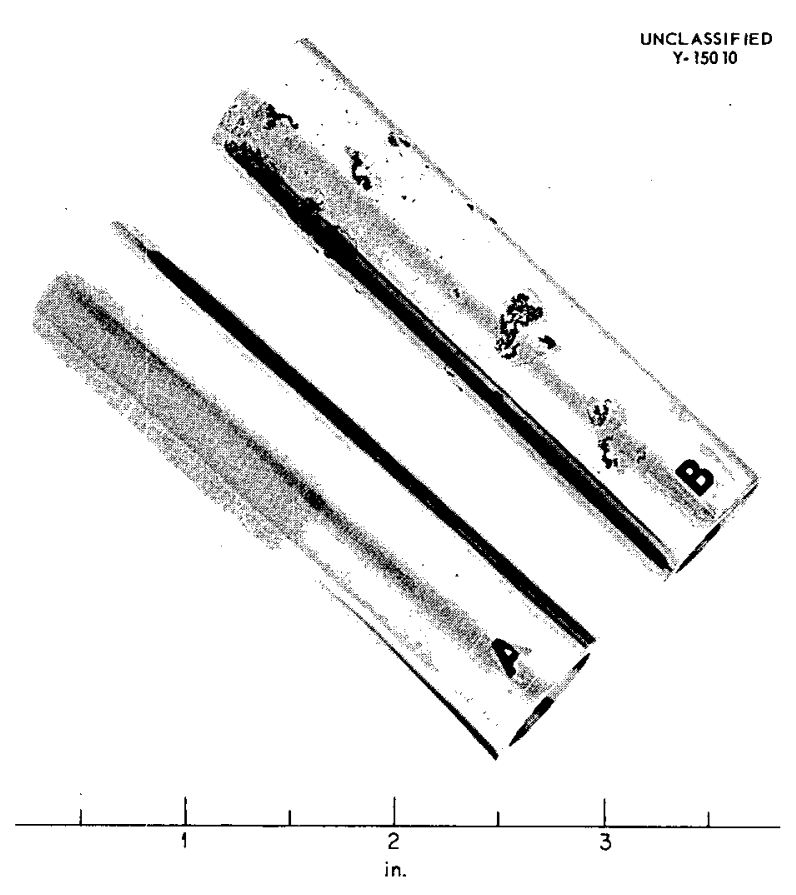

Fig. 14. Effect of Versene on Beryllium Inserts Second Loop Test. (A) As-received specimen. (B) Tested specimen.

\section{CORROSION STUDIES ON TYPES "A" AND "L" NICKEL COMPONENTS OF FLUORINATION EQUIP MENT}
C. F. Leitten, Jr.
D. H. Jansen

The corrosion analysis of two uranium-recovery fluorination vessels has been completed. These vessels were submitted by G. I. Cathers of the Chemical Technology Division. The purpose of these experiments was to determine the resistance of types " $A$ " and " $L$ " nickel-base material and welds to corrosion by a particular fluorination process.

Both reactor vessels were partially filled with the fused-fluoride-salt mixture $\mathrm{NaF} \cdot \mathrm{ZrF}_{4}-\mathrm{UF}_{4}$ (52-44-4 mole \%) into which was passed elementalfluorine gas at a rate of 50 to $300 \mathrm{cc} / \mathrm{min}$. The fluorination in each reactor was performed for about $30 \mathrm{hr}$ over a temperature range from 650 to $680^{\circ} \mathrm{C}$. This fluorination time refers to the total time that the reactor was operated. In the second reactor, 20 runs were made in all; $200 \mathrm{~g}$ of the fused salt was used, and the UF 4 in the molten 




Fig. 15. Effect of Versene on Beryllium Insert - First Loop Test. (a) Inner surface. (b) Outer surface. The outer surface $(b)$ was attacked erratically to a depth of 2.5 mils. Etchant: $10 \%$ oxalic acid. 100X. Reduced $4 \%$.

TABLE 12. WEIGHT LOSSES OF BERYLLIUM SPECIMENS IN VERSENE CLEANING TEST

\begin{tabular}{ccccc}
$\begin{array}{c}\text { Test } \\
\text { No. }\end{array}$ & $\begin{array}{c}\text { Original Weight } \\
(\mathrm{g})\end{array}$ & $\begin{array}{c}\text { Final Weight } \\
(\mathrm{g})\end{array}$ & \multicolumn{2}{c}{ Weight Change } \\
\hline 1 & 16.8715 & 16.8680 & $(\mathrm{~g})$ & 0.021 \\
2 & 16.7970 & 16.7941 & 0.0035 & 0.017 \\
\hline
\end{tabular}

salt was converted to gaseous $\mathrm{UF}_{6}$ by the elemental fluorine.

The reactors were constructed of 2-in.-OD type " $A$ " nickel tubing, in each of which was placed a type " $A$ " nickel gas-inlet tube and bubble screen. In order to more easily determine the effect of the fused salts and the fluorine gas on the corrosion resistance of the type " $A$ ". nickel, the second reactor was fabricated with three test samples mounted in an upright position at the bottom of the reactor. In Fig. 16 is shown the condition of the reactor container and test specimens after having been tested. The specimens were 3 in. long,
$3 / 4$ in. wide, and $1 / 4$ in. thick and were positioned so that 2 in. of each specimen was in the molten salt and the remainder was in the gaseous zone. Two of the specimens were constructed of " $A$ " nickel (nominal composition $99.4 \% \mathrm{Ni}-0.05 \% \mathrm{C}$ ), one of which was cut longitudinally and welded. The third sample was type "L" nickel (nominal composition $99.4 \% \mathrm{Ni}-0.01 \% \mathrm{C}$ ), and it, too, was cut longitudinally and welded.

On examination of both vessels, the most severe attack was observed to have occurred on the bubble screen of the first reactor. This attack was found to range from a depth of 6 to $36 \mathrm{mils}$, the latter 
value being the thickness of the as-received bubble screen. In both reactor vessels, severe attack was also observed on the gas-inlet tubes in a region about 2 in. above the gas-liquid interface. This region is indicated in Fig. 16 by an arrow. An enlarged view of the attacked area may be seen in Fig. 17. The attack is in the form of pits, as can be seen in these figures, and was found to vary from 0 to $19 \mathrm{mils}$. The attack on the remainder of the inlet tubes was more uniform and varied in both tests from 4 to 9 mils in depth.

Measurements on the reactor tubes indicated a nonuniform attack of 5 to $10 \mathrm{mils}$ in both the liquid and gas zones. A metallographic examination of these containers showed that the attack in both cases was of a solution nature.

Metallographic examination of the in serted specimens showed a fairly uniform solution-type attack, and dimensional and weight-change analysis revealed a maximum attack of $3 \mathrm{mils}$ on each side of the test samples. Table 13 summarizes the weight. change data on these specimens. From the table, it can be seen that attack is slightly more severe on the welded specimens than on the unwelded specimen.

Since the testing environment changed continually during the recovery process and since the various components of the reactor vessel were attacked to different degrees, it is not possible to report an over-all rate of corrosion per unit time.

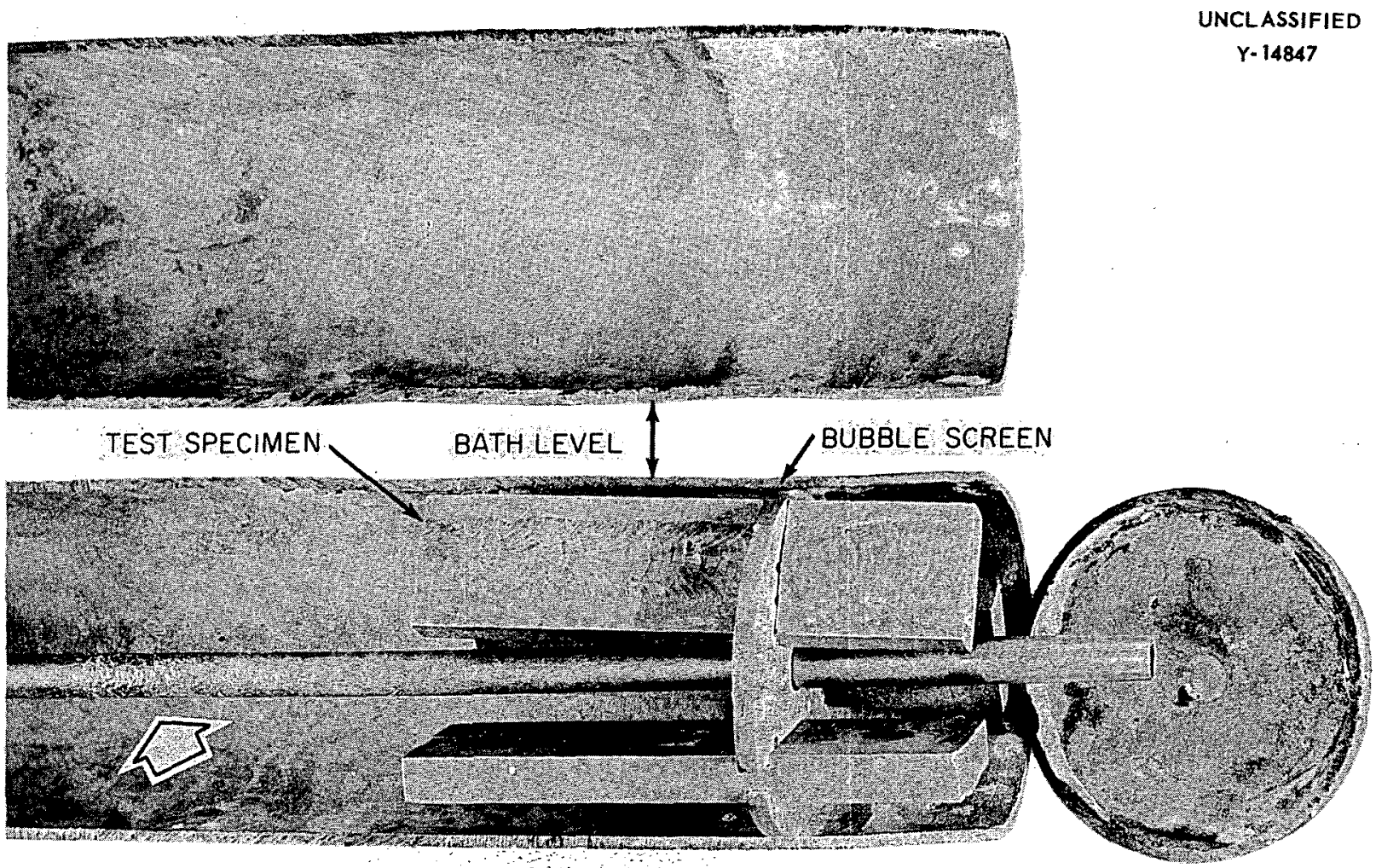

IN

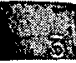

Fig. 16. Nickel Fluorination Vessel After Testing. Note the attack area, which is indicated by the arrow, along the gas-inlet tube. 

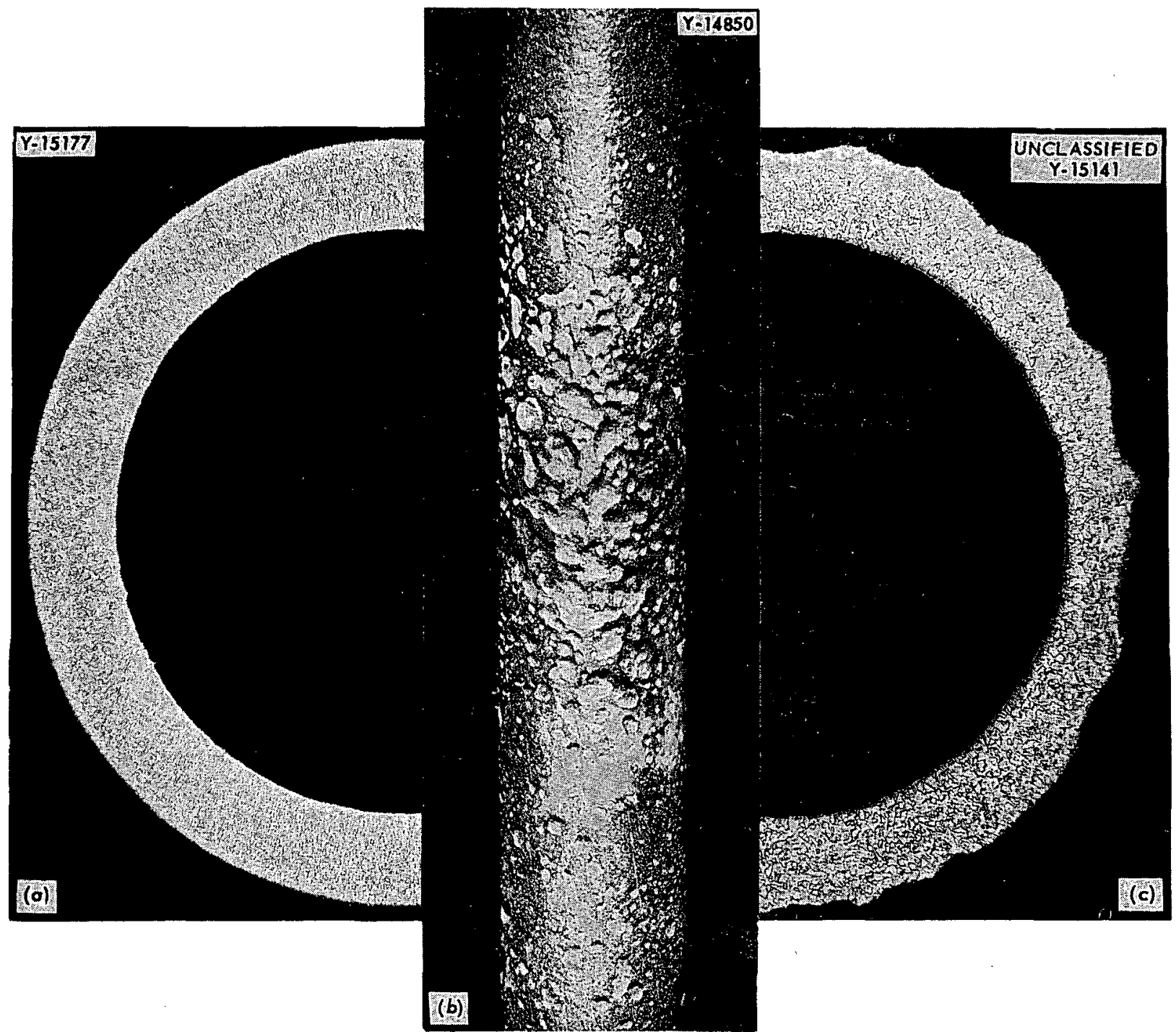

Fig. 17. Gas-Inlet Tube of Nickel Fluorination Vessel: (a) As-received, (b,c) Attacked Section Indicated in Fig. 16. Etchant: aqua regia.

TABLE 13. WEIGHT LOSSES OF NICKEL TEST SPECIMENS EXPOSED TO NaF-ZirF $4_{4}^{\text {-UF }}$ (50.46.4 mole \%) AND ELEMENTAL FLUORINE GAS

Process test conditions: $30 \mathrm{hr}$ at 650 to $680^{\circ} \mathrm{C}$

\begin{tabular}{|c|c|c|c|c|}
\hline \multirow{2}{*}{ Type } & \multirow{2}{*}{$\begin{array}{l}\text { Original Weight } \\
\qquad(\mathrm{g})\end{array}$} & \multirow{2}{*}{$\begin{array}{c}\text { Final Weight } \\
(g)\end{array}$} & \multicolumn{2}{|c|}{ Weight Change } \\
\hline & & & (g) & $(\%)$ \\
\hline "L", welded & 83.9878 & 80.3760 & 3.6118 & 4.3 \\
\hline "A", welded & 86.3445 & 82.7515 & 2.5930 & 4.2 \\
\hline "A", unwelded & 82.6071 & 80.2160 & 2.3911 & 2.9 \\
\hline
\end{tabular}




\section{DYNAMIC CORROSION}
G. M. Adamson
R. S. Crouse
J. H. DeVan
E. A. Kovacevich

A. Taboada

\section{FORCED-CIRCULATION LOOPS}

\section{Inconel-Sodium System}

Pronounced mass transfer of nickel by sodium was observed in Hastelloy B and "A" nickel thermal-convection loops and prompted a further investigation of sodium-Inconel systems. Although results obtained from Inconel convection loops showed little evidence of mass transfer, no information existed for pump loops operating above $1000^{\circ} \mathrm{F}$. An initial evaluation of the corrosion problem in forced-circulation systems was made by means of loop 4689-4, shown in Fig. 18. This loop was operated with sodium for $1000 \mathrm{hr}$ and had a hot-leg temperature of $1500^{\circ} \mathrm{F}$, a temperature drop of $300^{\circ} \mathrm{F}$, and a Reynolds number greater than 50,000 . Upon examination of the loop, a heavy layer of dendritic metal crystals was found in all sections of the economizer, and a lesser amount was found in the cold loop, Fig. 19. Chemical analysis of these crystals showed them to have the composition $89.6 \% \mathrm{Ni}, 8.6 \% \mathrm{Cr}$, and $0.005 \% \mathrm{Fe}$. Metallographic examination revealed a layer 26 mils thick in the cold end of the economizer and an intergranular attack to the extent of $2 \frac{1}{2} \mathrm{mils}$ in the hot leg. On analysis, neither the original nor the drained sodium gave consistent results, although from other work it appeared that the original sodium contained about $50 \mathrm{ppm}$ of oxygen.
A series of experiments were performed in which sodium at $1500^{\circ} \mathrm{F}$ was circulated in pump loops so that such variables as temperature drop and oxide contamination could be evaluated. Three Inconel loops - 4951-1, 4951-2, and 4951-3 - were operated with sodium for $500 \mathrm{hr}$ to form the $\Delta T$ series: 150 , 200 , and $300^{\circ} \mathrm{F}$. Table 14 shows the metallographic and chemical results for these series. There was no consistent correlation between the amount of mass transfer and $\Delta T$. However, it should be noted that different loop designs were used in the three loops and that oxide impurities of differing amounts were found in these loops. The net result is that these differences could be so large as to mask the effect of $\Delta T$ over the range investigated.

Two Inconel loops were operated in order to study the effect of variations in sodium oxide content on mass transfer. Oxide contamination was induced in loop $4951-5$ by adding $\mathrm{Na}_{2} \mathrm{O}_{2}$ to ordinary sodium until the oxygen content was $0.15 \%$. Operation of this loop for $1000 \mathrm{hr}$ with the hot leg at $1500^{\circ} \mathrm{F}$ and a temperature differential of $300^{\circ} \mathrm{F}$ resulted in a mass-transfer deposit 30 mils thick in the economizer and a 2-mil attack in the hot leg. Figure 20 is a photograph of three sections of the economizer and one section of the cold leg and shows the characteristic appearance of this deposit. As seen in Table 14, this loop experienced more mass transfer than did loop 4689-4,

TABLE 14. VARIATIONS IN MASS TRANSFER WITH TEMPERATURE DROP AND WITH OXIDE CONTAMINATION DURING FORCED CIRCULATION OF SODIUM IN INCONEL LOOPS

\begin{tabular}{|c|c|c|c|c|c|c|}
\hline $\begin{array}{l}\text { Loop } \\
\text { No. }\end{array}$ & $\begin{array}{l}\text { Time of } \\
\text { Operation } \\
(\mathrm{hr})\end{array}$ & $\begin{array}{l}\Delta T \\
\left({ }^{\circ} \mathrm{F}\right)\end{array}$ & $\begin{array}{c}\text { Maximum Thickness } \\
\text { of Mass-Transfer } \\
\text { Deposit (mils) }\end{array}$ & $\begin{array}{c}\text { Maximum Hot-Leg } \\
\text { Attack } \\
\text { (mils) }\end{array}$ & $\begin{array}{l}\text { Oxide Analysis } \\
\text { After Test } \\
\text { (ppm) }\end{array}$ & Comments \\
\hline $4689-4$ & 1000 & 300 & 26 & $2 \frac{l}{2}$ & & \multirow{4}{*}{$\begin{array}{l}\text { Loop design differs from } \\
\text { those listed below }\end{array}$} \\
\hline 4951-1 & 480 & 200 & 11 & $1^{2}$ & 450 & \\
\hline $4951-2$ & 500 & 300 & 8 & 1 & 210 & \\
\hline $4951-3$ & 500 & 150 & 8 & $1 / 2$ & 250 & \\
\hline $4951-5$ & 1000 & 300 & 30 & 2 & 270 & $0.15 \%$ oxide addition \\
\hline $4951-6$ & 500 & 300 & 11 & $1 \frac{1}{2}$ & 170 & Cold bypass in system \\
\hline
\end{tabular}




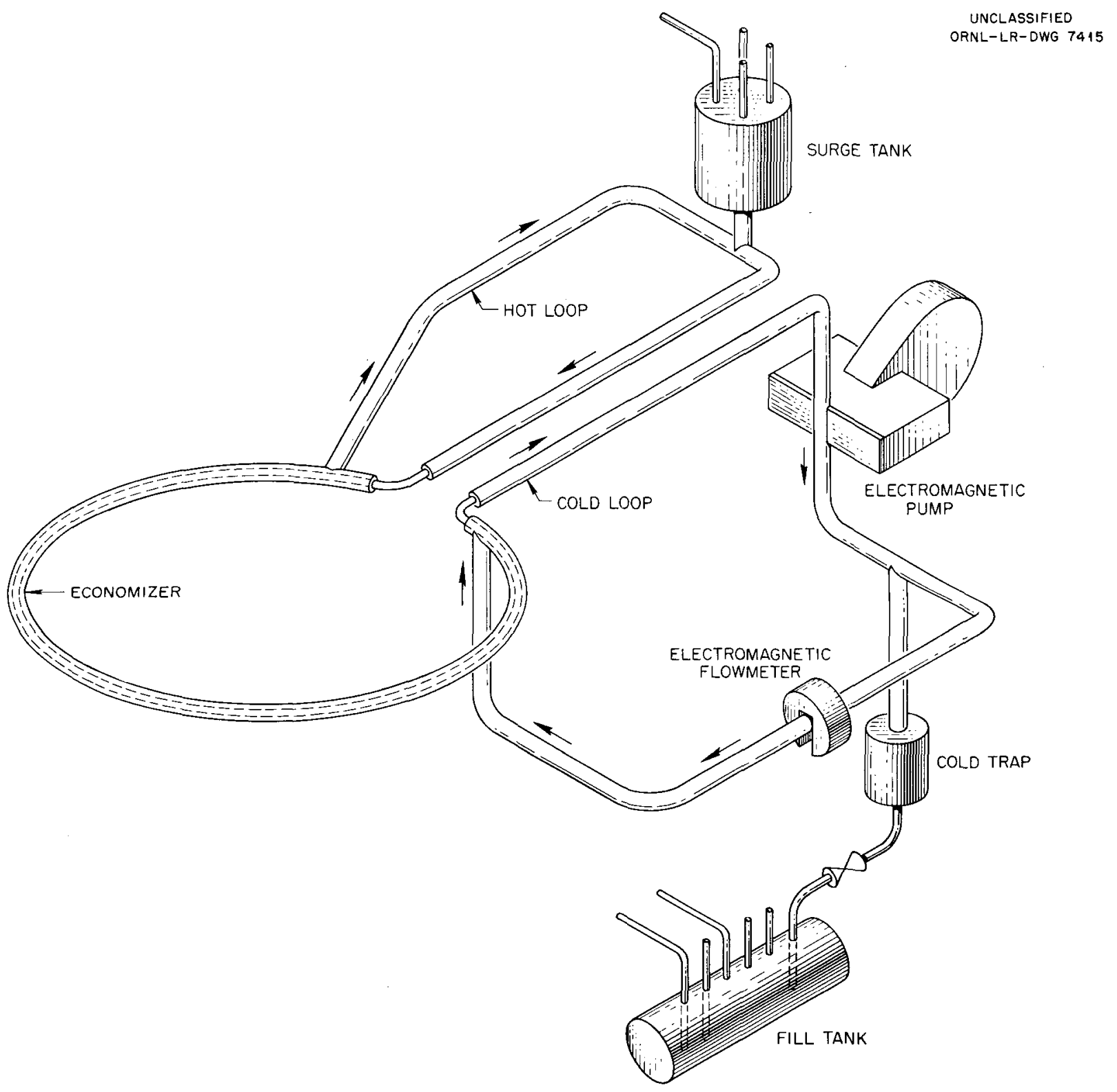

Fig. 18. Inconel Loop for Forced Circulation of Sodium.

which was operated under similar conditions with ordinary sodium, and experienced considerably more attack than loop 4951-2, which was also operated under similar conditions but for only $500 \mathrm{hr}$. However, after operation, an oxide analysis of the sodium failed to indicate that the oxide content was any greater than that found in the sodium from loop 4689-4 or loop 4951-2.

A second loop, 4951-6, was operated for $500 \mathrm{hr}$ with a bypass cold trap included in the system in an effort to remove oxides. The standard $1500^{\circ} \mathrm{F}$ hot leg and standard $300^{\circ} \mathrm{F}$ temperature differential were used. Metallographic results summarized in Table 14 show that mass transfer occurred to a maximum thickness of 11 mils (Figs. 21 and 22), which approximates the mass transfer found in loop 4951-2 that was run without a cold trap. The attack in the hot leg extended to a depth of $1 \frac{1}{2}$ 
pasnpay $X O S Z$-sadnłodadura 146 !H to un!pos fo uo! ןouosu ud u! H!sodog possajsubst-ssoW $Z Z \cdot 6 ! j$

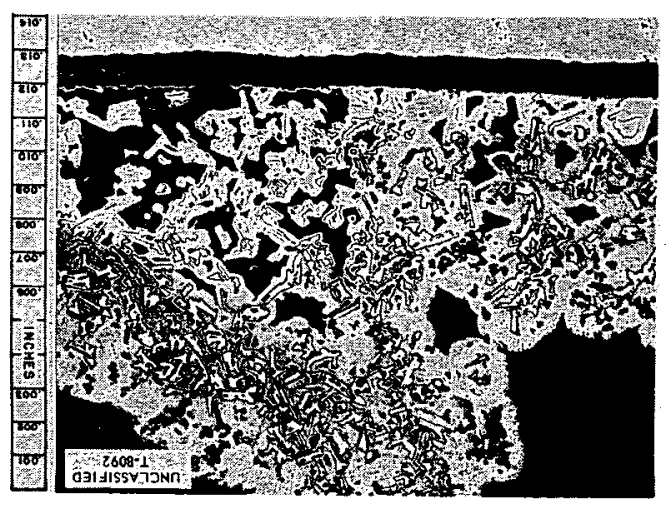

- annfosadur 146 ! 4 to un!pos to

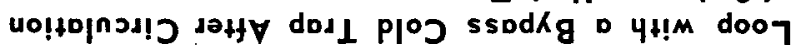
ןouosu uo u! t!sodog pastajsuodt-ssow $\cdot 1 Z \cdot 6 !\rfloor$

$9-196 b$
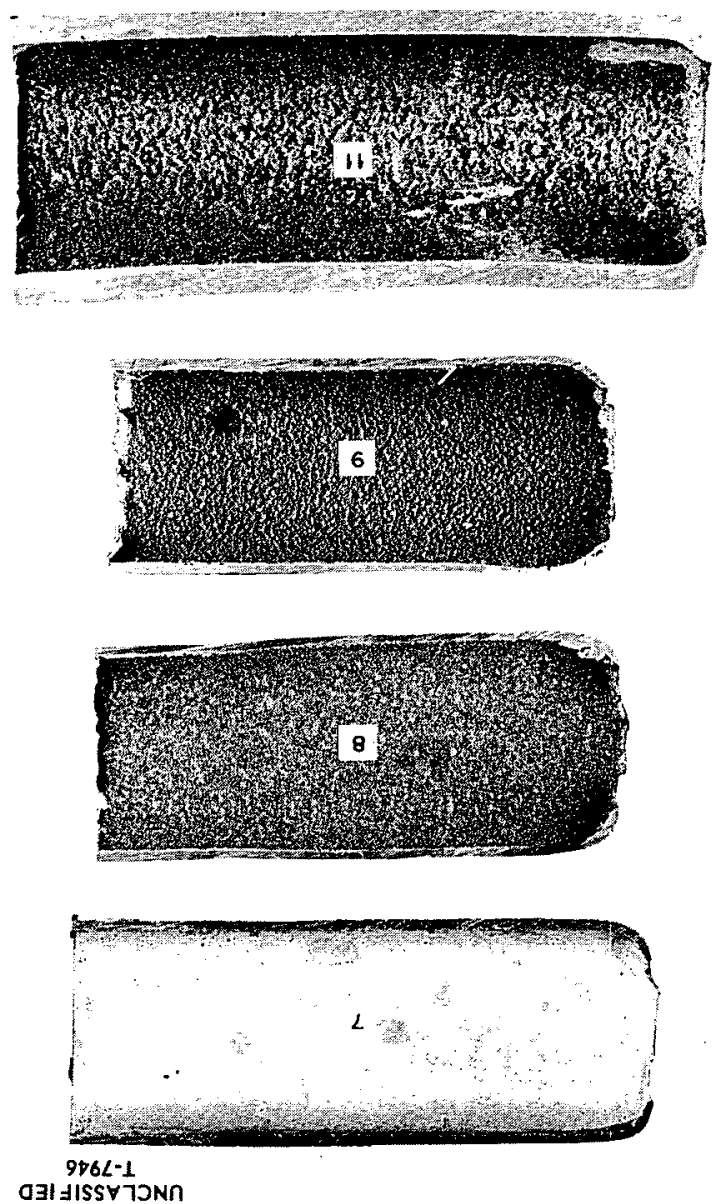

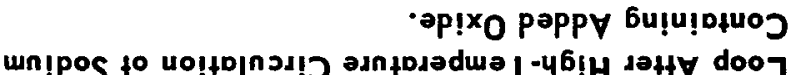
ןauosu u! t!sodag pasejsudt-ssoW $02 \cdot 6 ! y$ $9-1966$
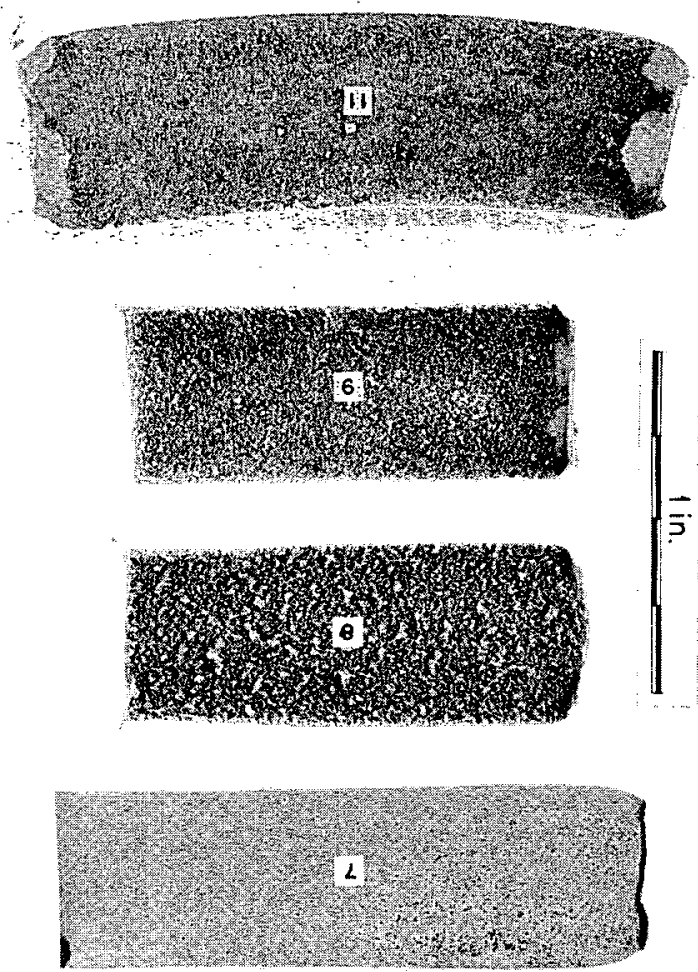

$\angle 608-1$

องIงISS

-adnłojadwa 146 ! th to un!pos fo uo!+ojnsd! lay doo 7 |auosu u! 4 !sodog

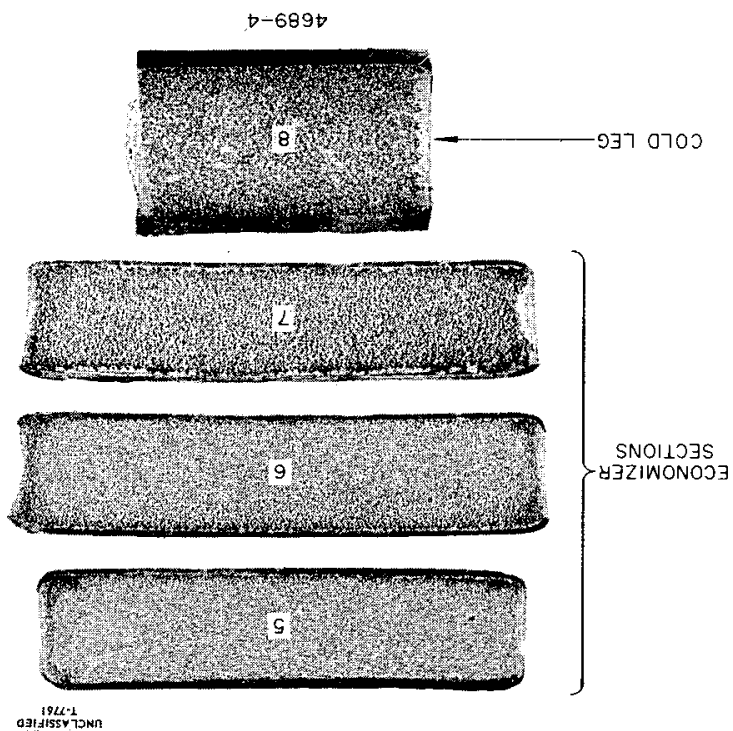


mils (Fig. 23) and was typical of the intergranular type found in sodium-Inconel systems. The oxide content of the sodium after operation varied from 150 to $290 \mathrm{ppm}$, which indicated little oxide removal.

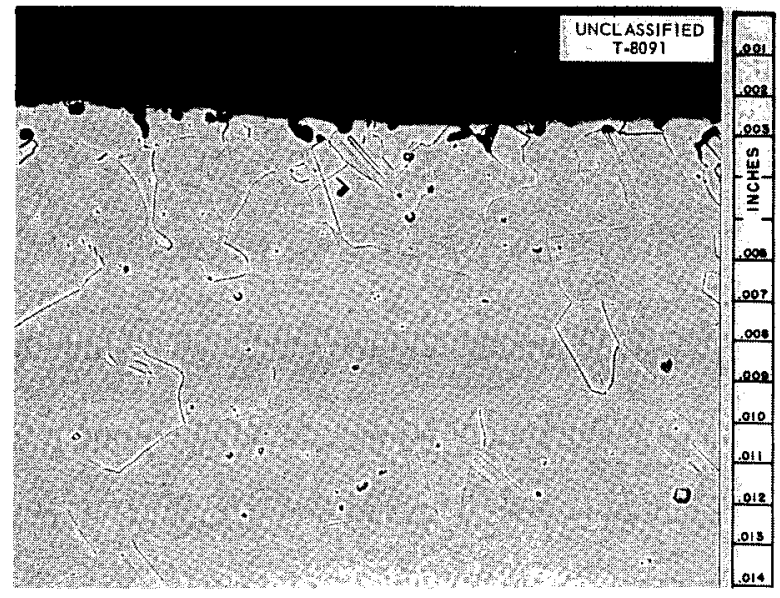

Fig. 23. Typical Attack in Hot Leg of Inconel Loop by High-Temperature Sodium. 250X. Reduced $33 \%$.

\section{Inconel-Stainless Steel-Sodium System}

A series of Inconel-stainless steel loops, in which different portions of the loops were constructed with type 316 stainless steel, was operated with sodium and with a hot-leg temperature of $1500^{\circ} \mathrm{F}$ and a temperature drop of $300^{\circ} \mathrm{F}$. The first loop of the series, 4689-6, had both the economizer and the cold leg constructed of type 316 stainless steel; whereas in the second, 4689-5, only the cold leg consisted of type 316 stainless steel. After $1000 \mathrm{hr}$ of operation, both loops showed evidence of mass transfer, but to a lesser degree than loop 4689-4 described above. The maximum thickness of the deposit was $15 \mathrm{mils}$ in 4689-5 and 12 mils in 4689-6. The hot legs were attacked intergranularly to a depth of $2 \frac{1}{2}$ mils in 4689-5 and $1 \frac{1}{2}$ mils in 4689-6. These data indicate that a type 316 stainless steel cold legresults in a small reduction in mass transfer. The third loop of the series, 4951-7, which was constructed entirely of type 316 stainless steel, was terminated, due to a power failure, after sodium had been circulated for $476 \mathrm{hr}$. This loop had a maximum mass-transfer loyer of 0.8 mil (Fig. 24), which is much less than the 8 mils found in the corresponding
LOOP $4951-7$
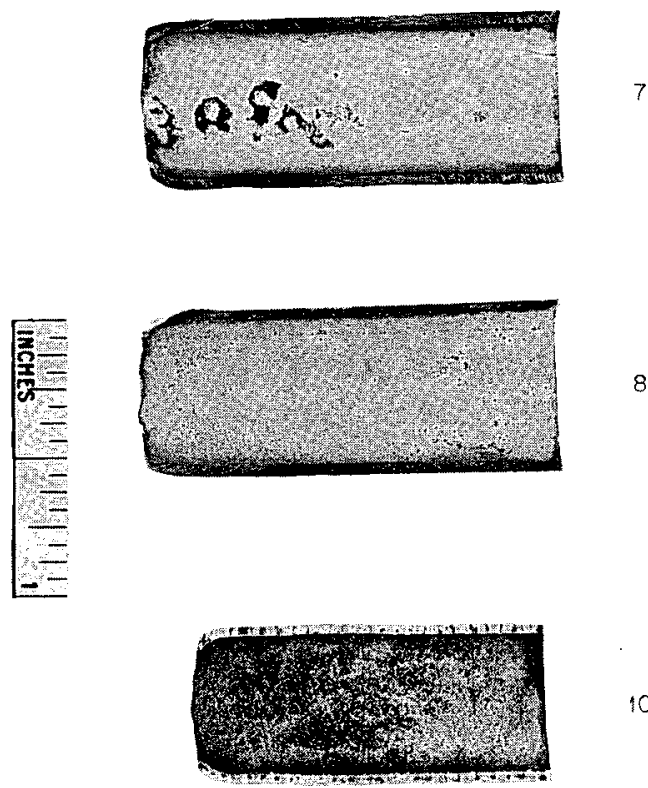

10

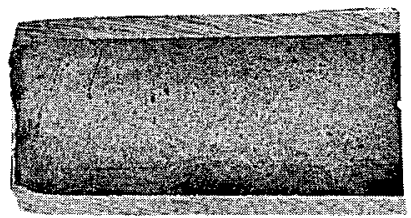

11

Fig. 24. Mass-transferred Deposit in a Type 316 Stainless Steel Loop After Circulation of Sodium at High Temperature.

Inconel loop, 4951-2. Differences were observed in the deposits in the economizer and in the cold leg of the type 316 stainless steel loop. The majority of the deposited material was analyzed as $14.9 \% \mathrm{Ni}, 57.5 \% \mathrm{Cr}$, and $20.0 \% \mathrm{Fe}$. However, a second layer found only in the cold leg in the area of the electromagnetic flowmeter was smooth and adherent and was analyzed as $14.6 \% \mathrm{Ni}$, $19.1 \% \mathrm{C}_{\mathrm{r}}$, and $55.2 \% \mathrm{Fe}$.

\section{THERMAL-CONVECTION LOOPS}

\section{Inconel-Sodium System}

Additional studies of the effect of oxide contamination on mass transfer in molten sodium were 
made by means of thermal-convection loops. Loops were run with ordinary sodium to which $\mathrm{Na}_{2} \mathrm{O}_{2}$ had been added to give a specified $\mathrm{Na}_{2} \mathrm{O}$ content.

These loops revealed that there was a definite increase in mass transfer with increasing oxide additions. Data from this series are tabulated in Table 15. Equivalent lengths were cut from the lower vertical cold leg and from the horizontal hot leg of each loop. The deposit in each section was brushed-out and weighed, and the weights were recorded as "relative moss transfer." These values are not precise, but they do tend to show a consistent increase in deposited metal as the oxide is increased.

The increase in mass transfer is seen to be accompanied by an increasing intergranular attack in the hot leg. The depth varies from $1 \frac{1}{2}$ mils in the control loops to 4 mils in the loops with high oxide content. Unfortunately, several of the loops in this series were terminated on account of leaks encountered at the loop supports, a difficulty which now appears to have been remedied.

TABLE 15. INCREASE IN MASS TRANSFER BY THE ADDITION OF SODIUM PEROXIDE TO SODIUM IN INCONEL THERMAL-CONVECTION LOOPS

\begin{tabular}{ccccc}
\hline Loop No. & $\begin{array}{c}\text { Added } \mathrm{Na}_{2} \mathrm{O}_{2} \\
(\%)\end{array}$ & $\begin{array}{c}\text { Operating Time } \\
(\mathrm{hr})\end{array}$ & $\begin{array}{c}\text { Hot-Leg Attack } \\
(\mathrm{mils})\end{array}$ & $\begin{array}{c}\text { Relative Mass Transfer* } \\
(\mathrm{g} / \mathrm{in.} \text {. })\end{array}$ \\
\hline 729 & 0.0 & 500 & $1 \frac{1}{2}$ & Trace \\
730 & 0.0 & $510^{\star \star}$ & $1 \frac{1}{2}$ & Trace \\
731 & 0.0 & 2000 & 2 & 0.009 \\
666 & 0.1 & $432^{\star \star}$ & 2 & Trace \\
669 & 0.1 & $844^{\star \star}$ & & 0.020 \\
663 & 0.1 & 1000 & 2 & 0.090 \\
670 & 0.2 & $393^{\star \star}$ & 2 & 0.089 \\
664 & 0.2 & $991^{\star \star}$ & 4 & 0.301 \\
667 & 0.2 & 1000 & 3 & 0.130 \\
665 & 0.5 & 500 & 3 & 0.046 \\
668 & 0.5 & 1000 & 3 & 0.388 \\
671 & 0.5 & 2000 & & 0.258 \\
\hline
\end{tabular}

*Obtained by weighing the metal removed from a known length of the horizontal hot leg and by converting this weight to an average weight per inch.

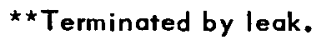




\title{
MECHANICAL PROPERTIES
}

\author{
D. A. Douglas \\ J. H. DeVan \\ J. W. Weir \\ Metallurgy Division \\ C. R. Kennedy \\ Pratt \& Whitney Aircraft
}

\section{RESULTS OF HASTELLOY B TESTING PROGRAM}

\section{R. Kennedy \\ Design Data}

In an effort to furnish design information on alloys with corrosion resistance and high-temperature strength for use in the circulating fuel reactor, a program has been initiated in which the nickelbase molybdenum alloys, beginning with Hastelloy $B$, are being tested. A series of creep-rupture tests on 0.060 -in. Hastelloy $B$ sheet in the solutionannealed $\left(2100^{\circ} \mathrm{F}\right)$ condition has been completed in argon at 1300,1500 , and $1650^{\circ} \mathrm{F}$ and in the fused-fluoride-salt mixture $\mathrm{NaF}-\mathrm{ZrF}_{4}-\mathrm{UF}_{4}$ (50$46-4$ mole \%) at 1500 and $1650^{\circ} \mathrm{F}$. The results are summarized in the design curves presented in Figs. 25-29. A similar series of tests is nearing completion for solution-annealed Hastelloy $B$ in the fused-fluoride-salt mixture at 1300 and $1800^{\circ} \mathrm{F}$ and in argon at $1800^{\circ} \mathrm{F}$.

\section{Effect of Fused-Fluoride-Salt Mixture on Stress-Rupture Properties}

Stress-rupture plots are presented in Fig. 30 for 0.060 -in. Hastelloy $B$ sheet solution-annealed at $2100^{\circ} \mathrm{F}$ which was tested in the two environments, $\mathrm{NaF}-\mathrm{ZrF}_{4}-\mathrm{UF}_{4} \quad(50-46-4$ mole \%) and argon, at 1300,1500 , and $1650^{\circ} \mathrm{F}$. It will be noted that at each temperature, for specified stresses, the timesto-rupture obtained in the fused-salt mixture are actually superior to those obtained in argon. Although no adverse effect on the properties would be expected in the fused-salt mixture, based on the absence of corrosive attack under static conditions, the reason for the increase in rupture life is not entirely clear at present.

\section{Tests in Air and Hydrogen}

Tests in hydrogen and air have also been run in order to determine the effects of these environments on the creep-rupture properties at $1500^{\circ} \mathrm{F}$ of solution-annealed $\left(2100^{\circ} \mathrm{F}\right) 0.060$-in. Hastelloy B sheet. The creep curves for this alloy tested in four different environments at 12,000 psi are shown in Fig. 31. It is obvious that the creep properties of Hastelloy $B$ at 12,000 psi are similar in hydrogen and argon. The results obtained in air closely follow the pattern observed for Inconel and " $A$ " nickel insofar as the creep rate is reduced and the rupture life is longer when contrasted with tests made in argon.

\section{The Influence of Aging Heat Treatments}

The influence of aging heat treatments on the creep-rupture properties of Hastelloy B is being studied at several temperatures that range from 1300 to $1800^{\circ} \mathrm{F}$. In general, aged specimens have shown marked reduction in the initial creep rate and in tensile elongations when compared to specimens in the solution-annealed condition. Results obtained from creep-rupture tests on solutionannealed specimens and aged specimens in argon at 1500,1650 , and $1800^{\circ} \mathrm{F}$ are presented in Table 16.

In the tests at $1500^{\circ} \mathrm{F}$, the appearance of a second phase produces a marked change in the creep-rupture properties of the alloy. It is noticed that at $1500^{\circ} \mathrm{F}$ and at stresses which produce a long rupture life (in excess of $200 \mathrm{hr}$ ) for the solution-annealed material, the difference in creeprupture properties of the solution-annealed specimen and the aged specimens is small. This is understandable; for at this temperature the solutionannealed specimens are actually aging while they are being tested. When tested at higher stresses, the solution-annealed material does not age appreciably before rupture; thus, a large increase in rupture life is observed for specimens in the aged condition.

At $1650^{\circ} \mathrm{F}$ it would be predicted that Hastelloy $B$ should be a single-phase alloy and that there should be little difference in the creep properties of the aged and the solution-annealed specimens. Figure 32 shows the creep curves from tests in argon at $1650^{\circ} \mathrm{F}$ of a solution-annealed specimen and of a specimen aged for $100 \mathrm{hr}$ at $1300^{\circ} \mathrm{F}$. It can be seen that the initial creep rate is lower for the aged specimen but that third-stage creep 
PERIOD ENDING OCTOBER 10, 1955

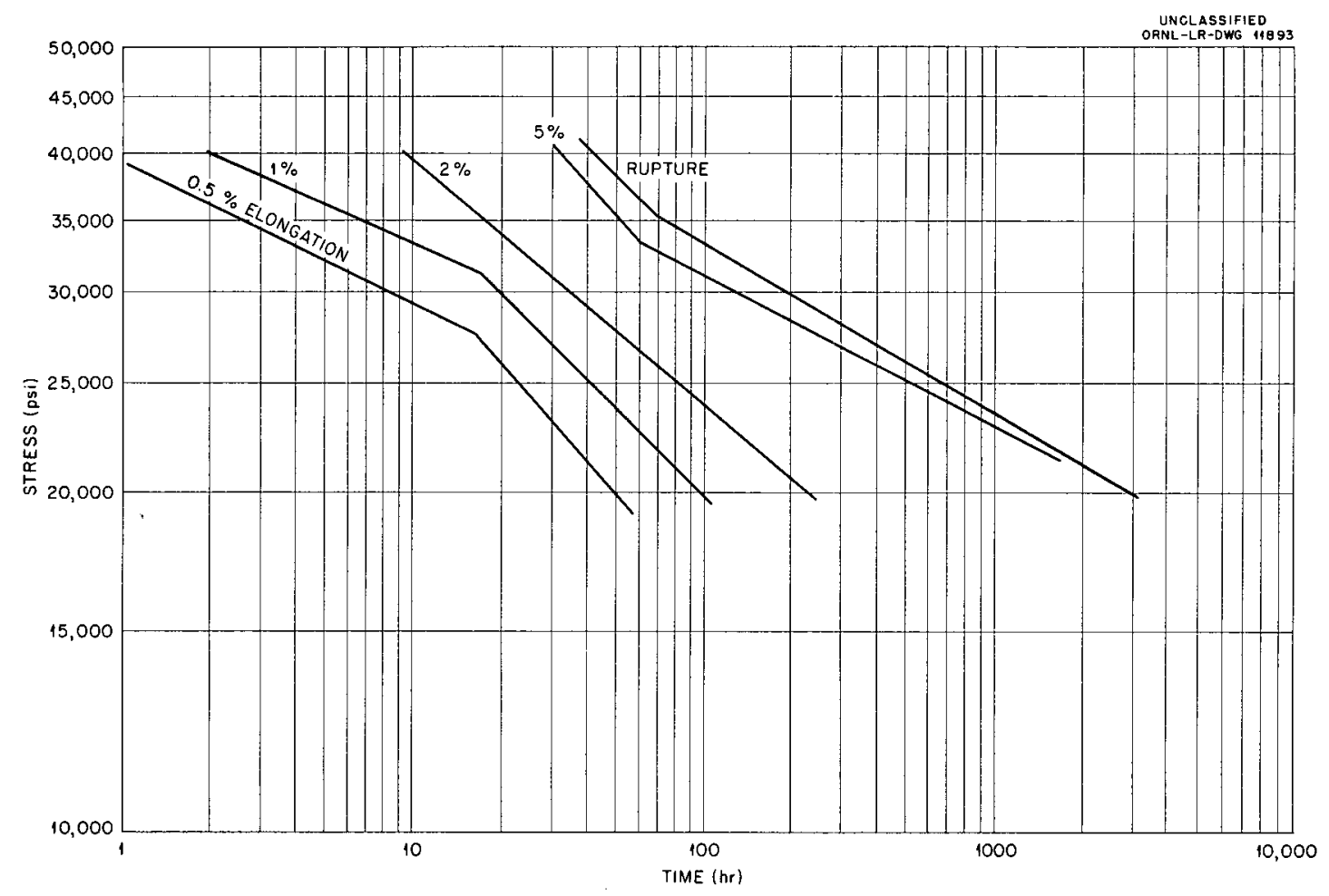

Fig. 25. Design Data for Annealed Hastelloy B Sheet Tested in Argon at $1300^{\circ} \mathrm{F}$.

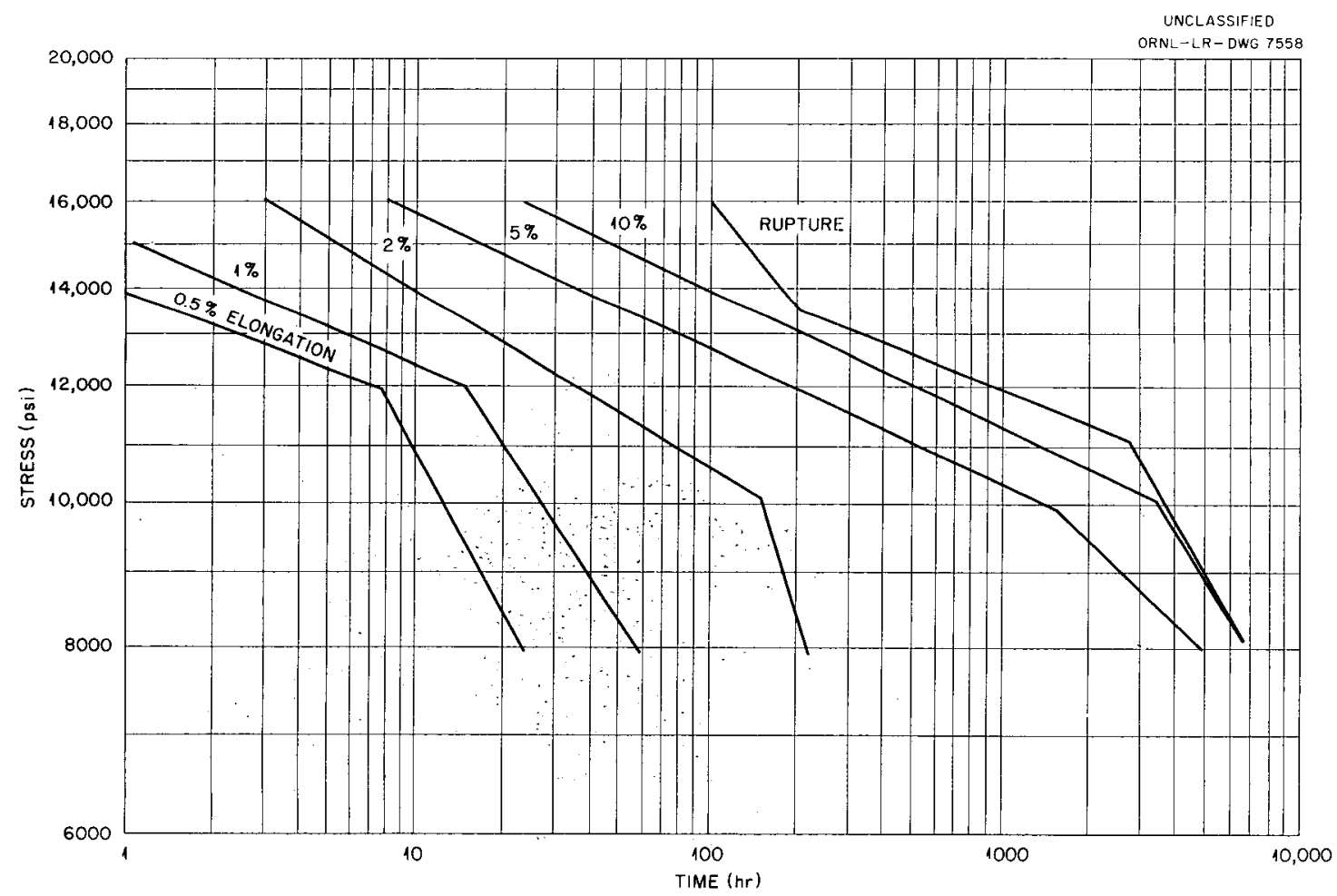

Fig. 26. Design Data for Annealed Hastelloy B Sheet Tested in Argon at $1500^{\circ}$ F. 


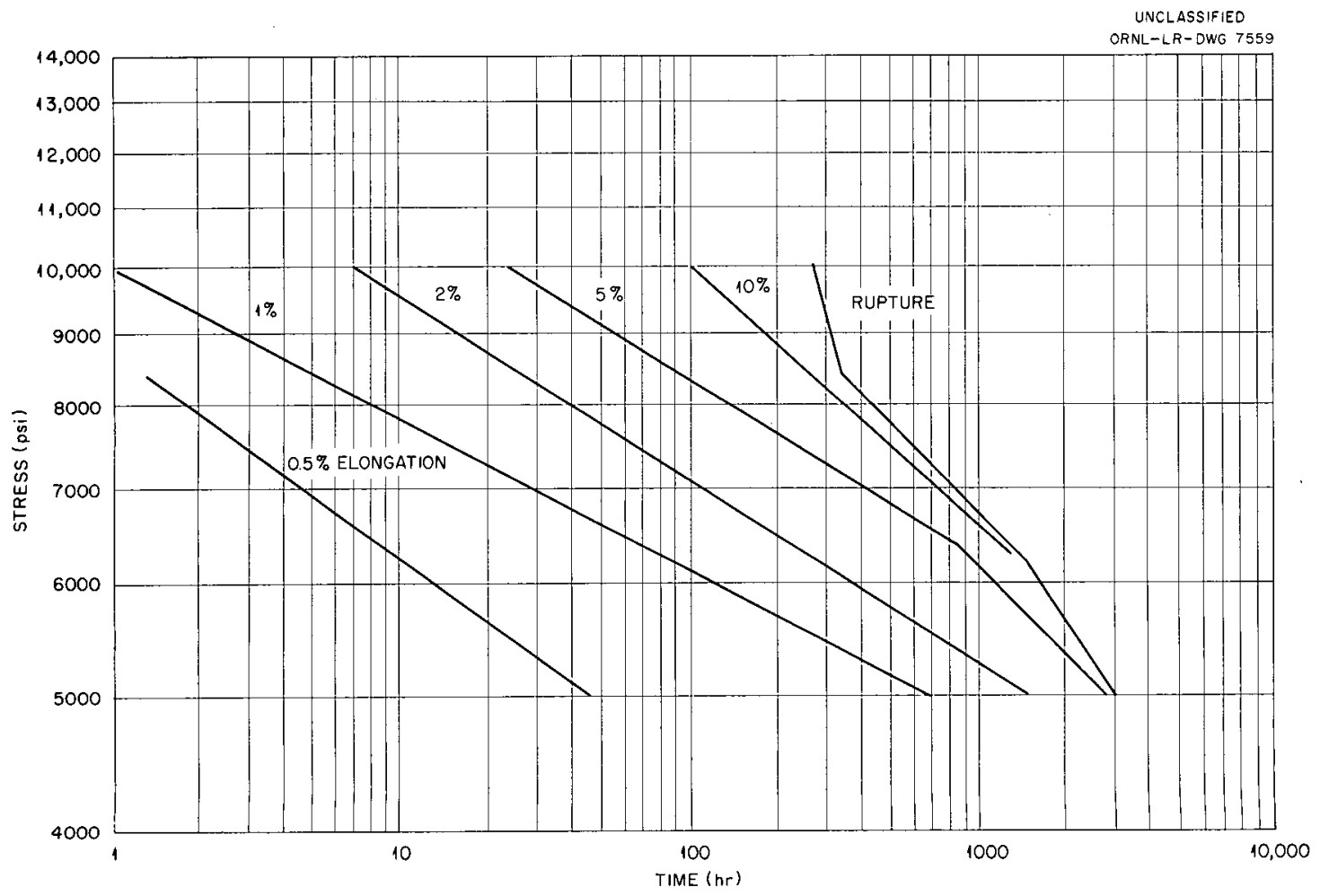

Fig. 27. Design Data for Annealed Hastelloy B Sheet Tested in Argon at $1650^{\circ}$ F.

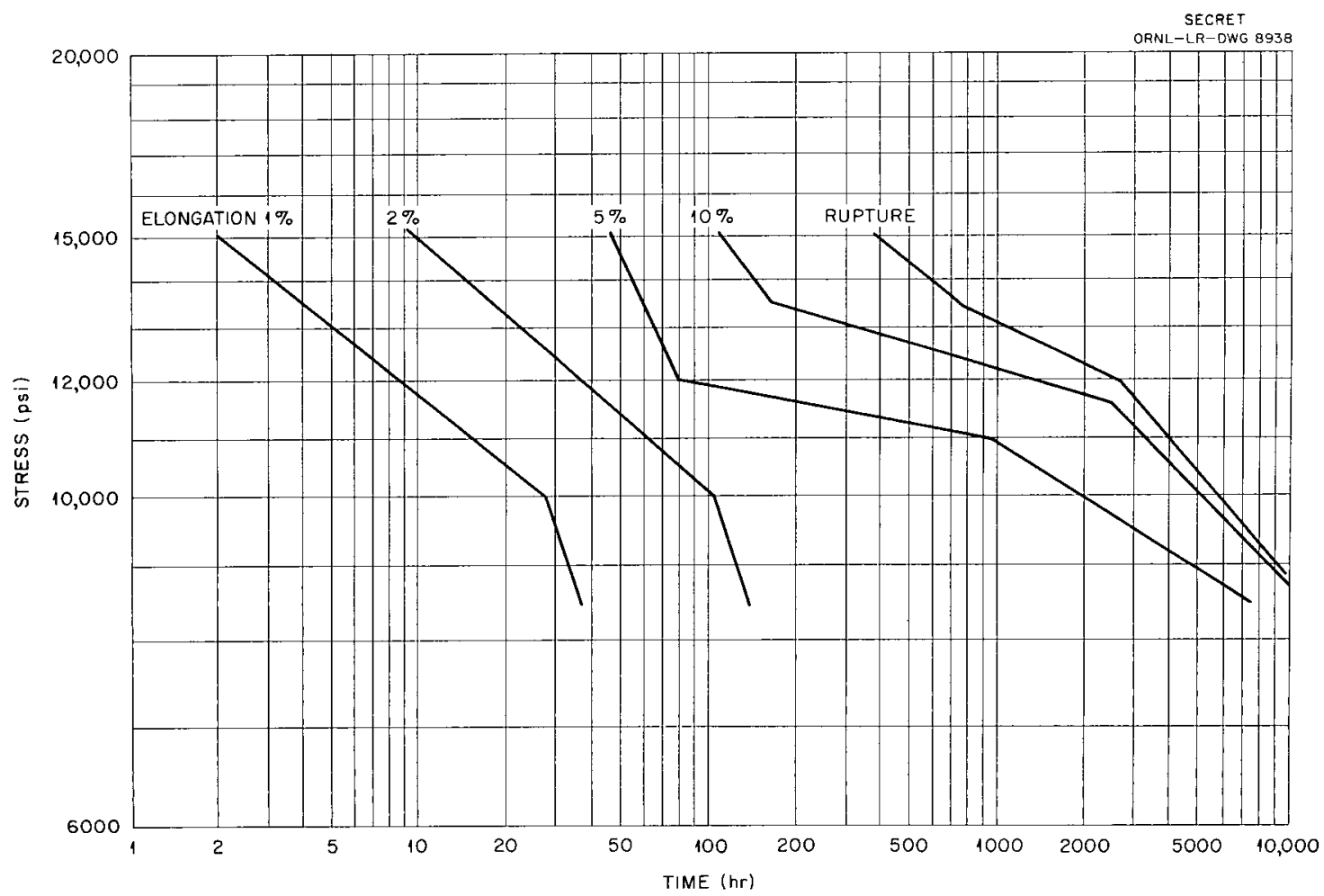

Fig. 28. Design Data for Annealed Hastelloy B Sheet Tested in NaF-ZrF 4 -UF 4 at $1500^{\circ} \mathrm{F}$. 


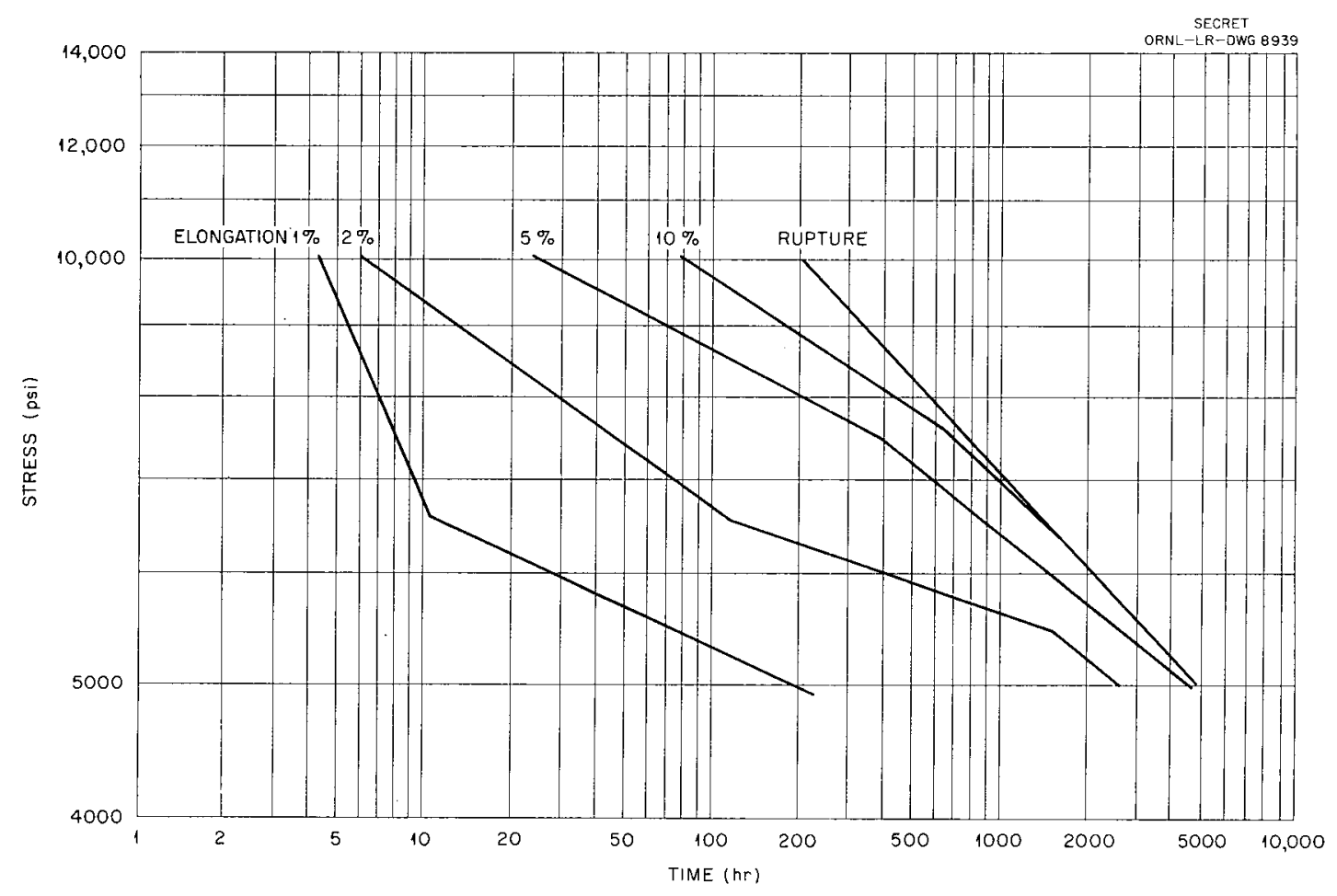

Fig. 29. Design Data for Annealed Hastelloy B Sheet Tested in NaF-ZrF -UF $_{4}$ at $1650^{\circ} \mathrm{F}$.

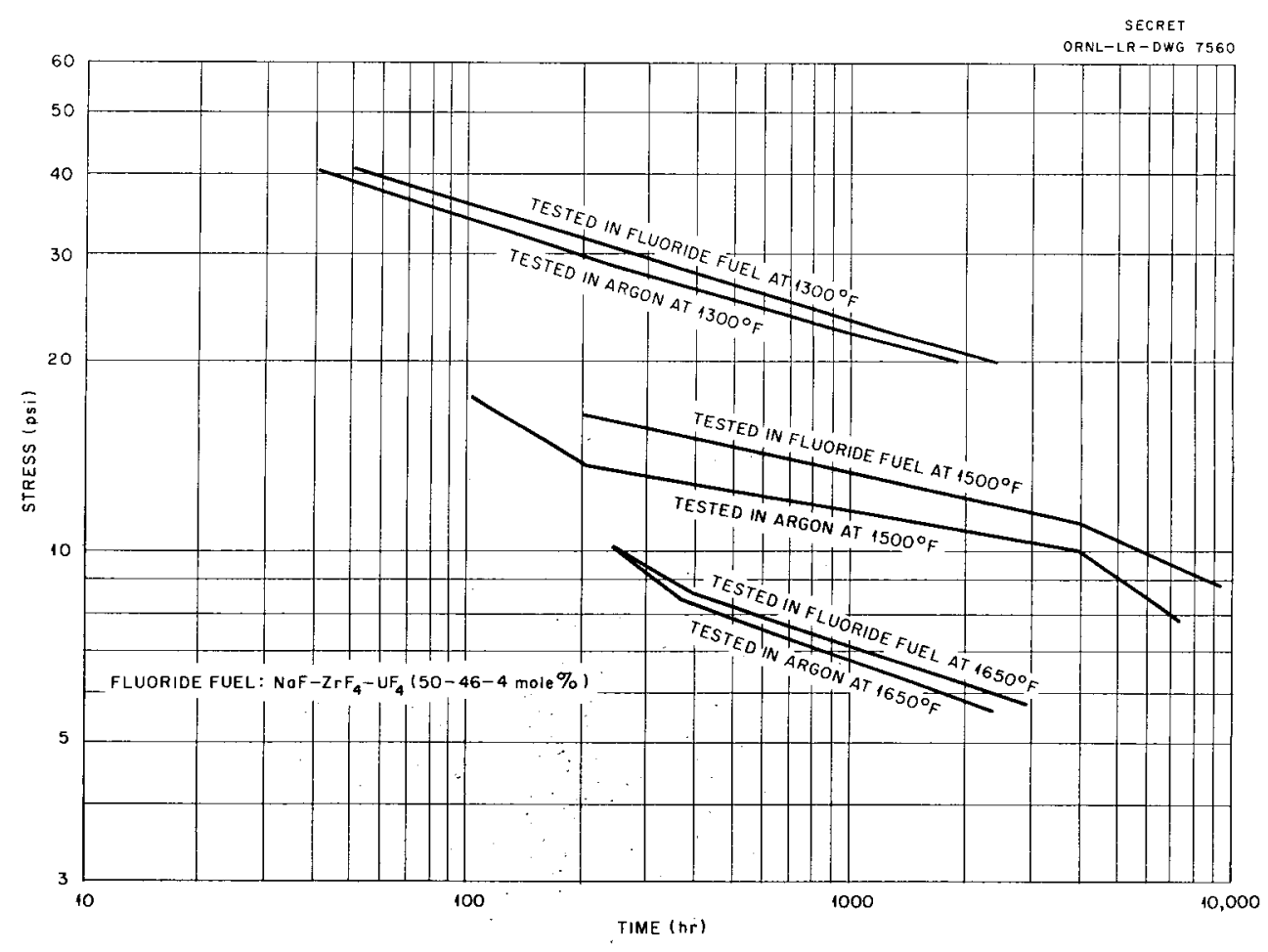

Fig. 30. Effect of Different Environments on the Stress-Rupture Properties of Annealed Hastelloy B Sheet. 


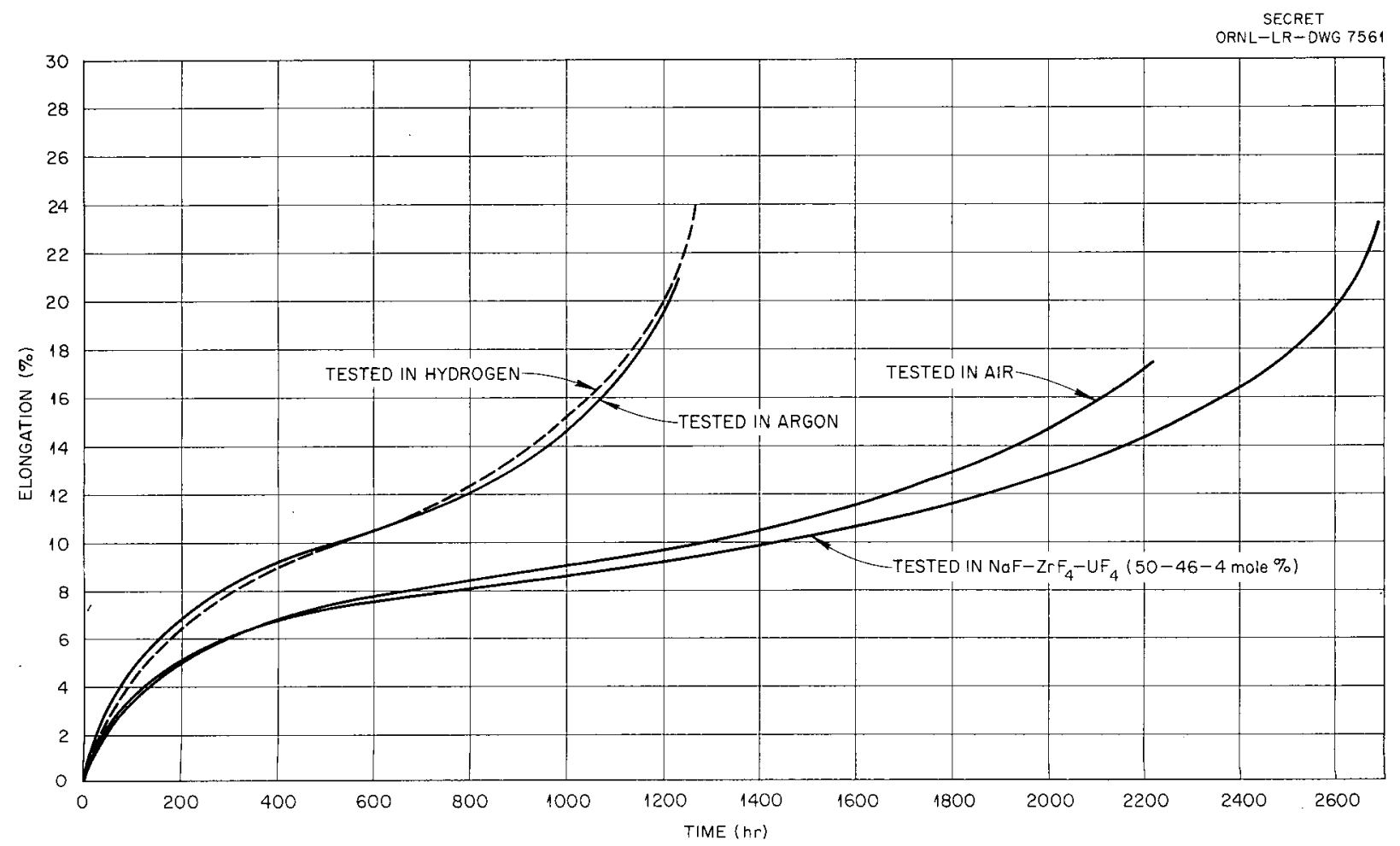

Fig. 31. Creep Curves for Annealed Hastelloy B Sheet Tested at $1500^{\circ} \mathrm{F}$ and 12,000 psi in Various Media.

TABLE 16. CREEP-RUPTURE TESTS ON AGED SPECIMENS AND SOLUTION-ANNEALED SPECIMENS OF HASTELLOY B IN ARGON

\begin{tabular}{lcccc}
\hline \multicolumn{1}{c}{ Condition } & $\begin{array}{r}\text { Test Temperature } \\
\left({ }^{\circ} \mathrm{F}\right)\end{array}$ & $\begin{array}{c}\text { Stress } \\
\text { (psi) }\end{array}$ & $\begin{array}{c}\text { Rupture Time } \\
\text { (hr) }\end{array}$ & $\begin{array}{c}\text { Final Elongation } \\
(\%)\end{array}$ \\
\hline $\begin{array}{l}\text { Solution annealed } \\
\text { Aged } 40 \mathrm{hr} \text { at } 1500^{\circ} \mathrm{F}\end{array}$ & 1500 & 12,000 & 1180 & 20 \\
Aged $70 \mathrm{hr}$ at $1500^{\circ} \mathrm{F}$ & 1500 & 12,000 & 1450 & 16 \\
Solution annealed & 1500 & 12,000 & 1070 & 8.7 \\
Aged $100 \mathrm{hr}$ at $1300^{\circ} \mathrm{F}$ & 1500 & 13,500 & 170 & 16 \\
Solution annealed & 1500 & 13,500 & 670 & 5.7 \\
Aged $100 \mathrm{hr}$ at $1300^{\circ} \mathrm{F}$ & 1500 & 15,000 & 160 & 19 \\
Solution annealed & 1500 & 15,000 & 330 & 24 \\
Aged $100 \mathrm{hr}$ at $1300^{\circ} \mathrm{F}$ & 1650 & 10,000 & 270 & 14 \\
Solution annealed & 1650 & 10,000 & 92 & 12 \\
Aged $100 \mathrm{hr}$ at $1300^{\circ} \mathrm{F}$ & 1800 & 5,000 & 112 & 10 \\
Solution annealed & 1800 & 5,000 & 90 & 7.3 \\
Aged $100 \mathrm{hr}$ at $1300^{\circ} \mathrm{F}$ & 1800 & 3,500 & 310 & 5.9 \\
\hline
\end{tabular}




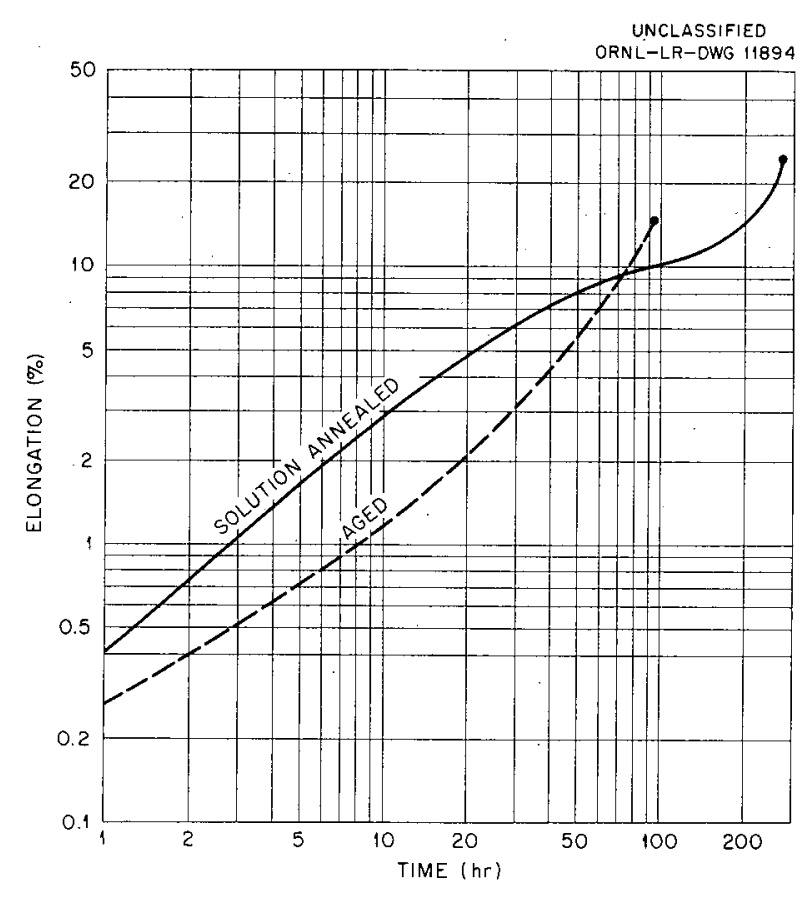

Fig. 32. Creep Curves for Hastelloy B Sheet Tested at 10,000 psi in Argon at $1650^{\circ} \mathrm{F}$.

is initiated in the aged specimen much earlier than in the annealed specimen. Thus, for the aged material, a somewhat shorter rupture life and a lower total elongation at failure result. At $1800^{\circ} \mathrm{F}$, which is well up in the alpha solidsolution range, the same pattern is repeated, as is shown in Fig. 33. This rather peculiar behavior can be explained by consideration of the rates of solution of the precipitate previously formed by aging.

Hardness tests and metallographic examination have shown that the molybdenum-rich precipitate is very slow to precipitate from a supersaturated lattice and is slow to redissolve into the matrix. It has also been shown that strain tends to accelerate these reactions. Thus, the aged specimens would be expected to exhibit lower initial strains and creep rates at $1650^{\circ}$ and $1800^{\circ} \mathrm{F}$ than the solution-annealed material since the precipitate would not have had time to go back into solution during the early portion of the test. As the test progresses, the precipitates in the grain-boundary regions tend to go into solution faster than those within the grains because of the greater strains at the boundary regions. This results in the

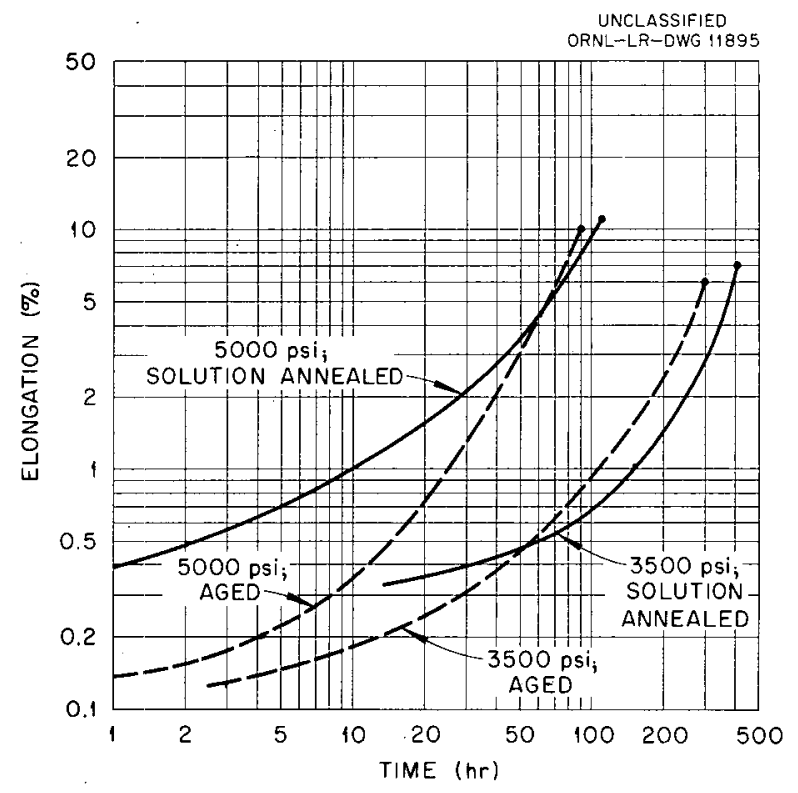

Fig. 33. Creep Curves for Hastelloy B Sheet Tested in Argon at $1800^{\circ} \mathrm{F}$.

grain boundaries weakening at a greater rate than the bulk of the grains. Grant and Chang' have observed that the initiation and the propagation of intergranular cracking are controlled by the ability of the grains to accommodate the deformation produced by grain-boundary sliding. In the case of solution-annealed material there are no precipitates to inhibit grain-boundary sliding, and the rate of deformation is more rapid. However, the grains can accommodate a considerable amount of deformation before intergranular cracking begins, and the rate of propagation of the cracks is relatively slow. In the aged material there is, likewise, considerable resistance to deformation until the precipitates in the grain boundaries begin to go into solution; and when this occurs, the strain rate increases. However, the grains themselves still contain precipitates, and the ir ability to accommodate deformation is considerably less than the grains in the solution-annealed material. Thus, once intergranular cracking is initiated in the aged material, propagation of these cracks is rather rapid and results in the accelerated thirdstage creep.

IH. C. Chang and N. J. Grant, "Mechanism of Intercrystalline Fracture" (unpublished manuscript). 


\section{TUBE-BURST TESTING OF INCONEL}

\section{J. W. Weir}

Stress-rupture testing of $3 / 4$-in. Inconel tubing in argon and in $\mathrm{NaF}_{-\mathrm{ZFF}_{4}}$ U. $_{4}$ (50-46-4 mole \%) at 1300,1500 , and $1650^{\circ} \mathrm{F}$ is now in progress. Although data at 1300 and $1650^{\circ} \mathrm{F}$ are as yet incomplete, the results of testing Inconel tubing with wall thicknesses of $0.010,0.020,0.040$, and 0.060 in. at $1500^{\circ} \mathrm{F}$ in argon and in the fusedfluoride mixture are sufficient to indicate important trends.

\section{The Biaxial Stress System}

In the biaxial stress system as applied to tubes such as those above, it is a matter of deciding whether failure is related to the effect of combined stresses, or whether the larger stress component (hoop stress $=2$ axial stress) singularly controls the time for failure. A comparison of the results of tensile creep-rupture tests and tube-burst tests is afforded by Figs. 34 and 35 . Time-to-rupture for various hoop stresses in tubing having 0.010-, $0.020-, 0.040-$, and 0.060 -in. walls are plotted against rupture times for $0.060-i n$. sheet specimens in similar environments. It is seen that there is good agreement between the rupture times of 0.060 -in.-wall tubing and of 0.060 -in. sheet in both environments. Thus, the presence of a small axial stress in the tubing does not appear to affect the action of the hoop stress in producing failure.

\section{Effect of Wall Thickness on Rupture Life}

It is noted that when those specimens which have the smaller wall thicknesses, 0.010 and 0.020 in., were tested much shorter rupture times resulted, on the basis of comparing hoop stresses

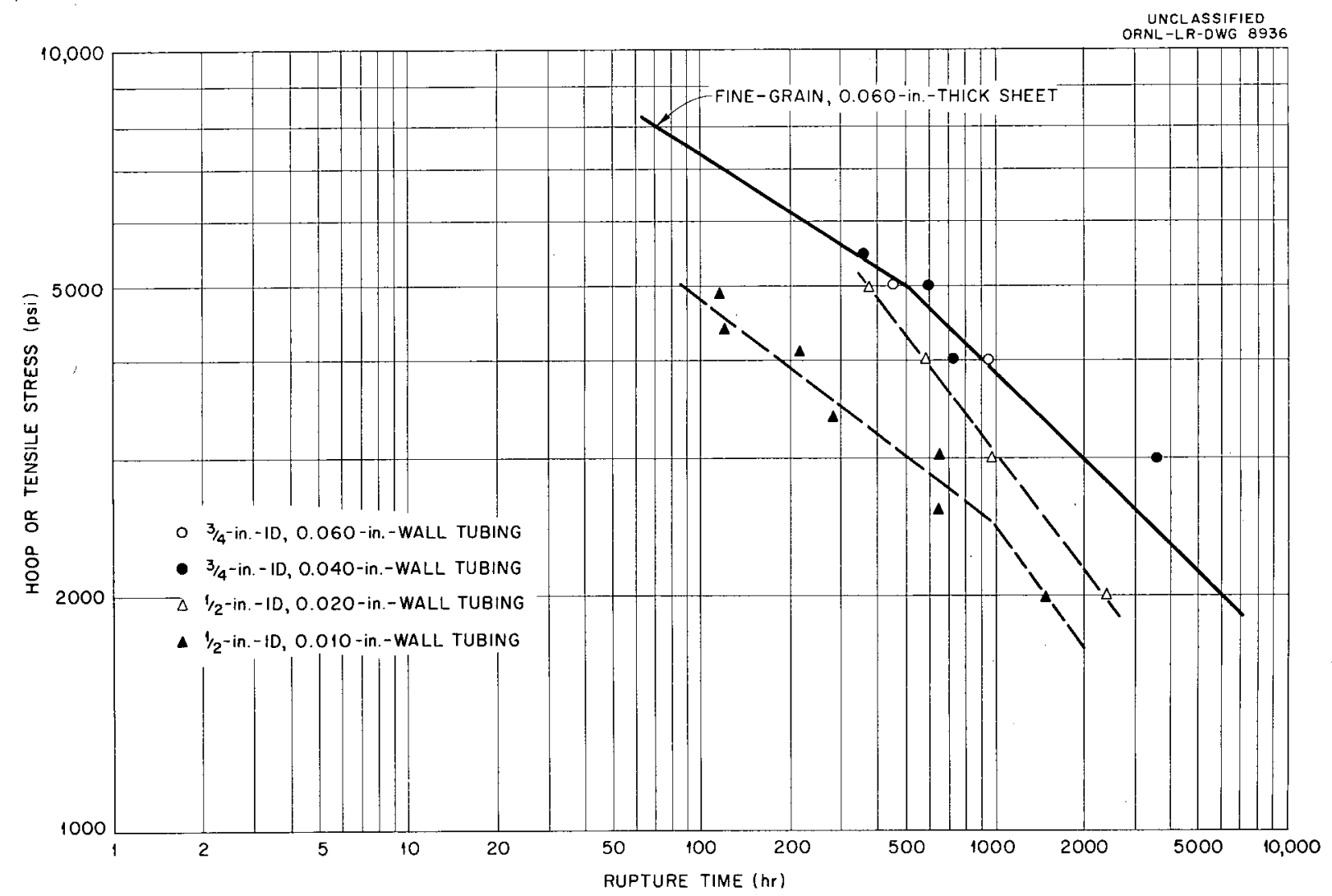

Fig. 34. Tube-Burst and Stress-Rupture Curves for Inconel Tested in Argon at $1500^{\circ}$ F. 
with stress-rupture data for 0.060 -in. sheet specimens. Though this was originally thought to be due to the effect of the biaxial stress system acting on the tube, it now appears, from the results of tests on 0.020 -in. sheet, that the poor rupture properties are associated with the smaller section thickness.

\section{Tests on Inconel Sheet}

Stress-rupture tests of 0.020 - and 0.060 -in. Inconel sheet in argon and hydrogen at 1500 and $1650^{\circ} \mathrm{F}$ are compared in Table 17. A substantial reduction in rupture life is seen to accompany the reduction in section size.

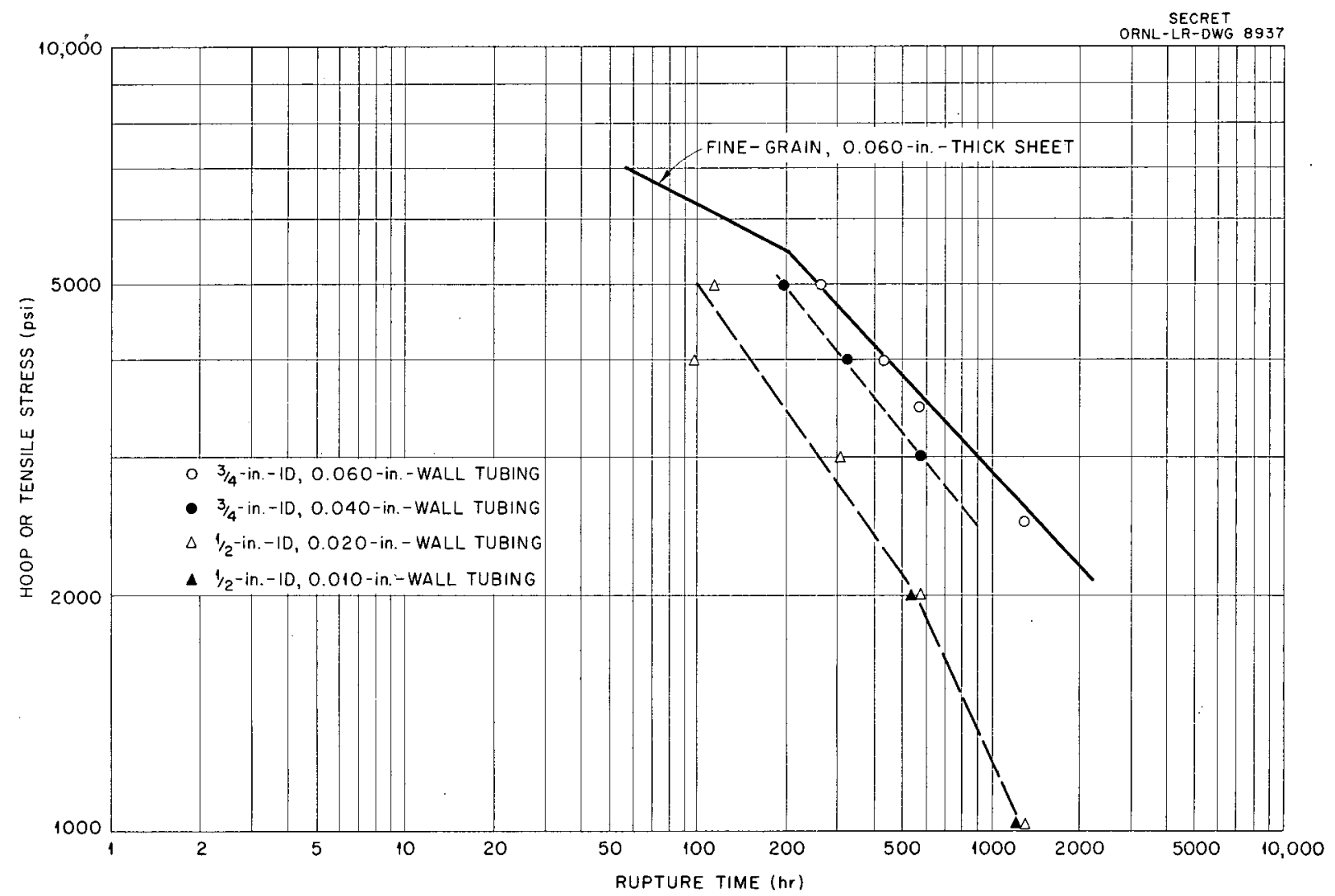

Fig. 35. Tube-Burst and Stress-Rupture Curves for Inconel Tested in NaF-ZrF $4-U F_{4}$ at $1500^{\circ} \mathrm{F}$.

TABLE 17. RESULTS OF STRESS-RUPTURE TESTS ON 0.020. AND 0.060-in. INCONEL SHEET

\begin{tabular}{|c|c|c|c|c|c|c|}
\hline \multirow{2}{*}{$\begin{array}{c}\text { Temperature } \\
\left({ }^{\circ} \mathrm{F}\right)\end{array}$} & \multirow{2}{*}{$\begin{array}{c}\text { Stress } \\
\text { (psi) }\end{array}$} & \multirow{2}{*}{ Atmosphere } & \multicolumn{2}{|c|}{ Time-to-Rupture (hr) } & \multicolumn{2}{|c|}{ Total Elongation (\%) } \\
\hline & & & 0.020 -in. Specimen & 0.060-in. Specimen & 0.020-in. Specimen & 0.060-in. Specimen \\
\hline 1500 & 3500 & Argon & 270 & 1467 & 8 & 13 \\
\hline 1500 & 3500 & Hydrogen & 350 & 618 & 11 & 8 \\
\hline 1650 & 2000 & Argon & 740 & 1125 & 14 & 30 \\
\hline 1650 & 2000 & Hydrogen & 200 & 385 & 12 & 11 \\
\hline
\end{tabular}




\title{
NONDESTRUCTIVE TESTING
}

\author{
R. B. Oliver \\ J. W. Allen K. Reber R. W. McClung
}

The Nondestructive Test Development Section was established in March 1955 for the purpose of developing, evaluating, and establishing methods for the nondestructive testing of materials and components for reactors. To accomplish this objective,radiographic, pulse-echo ultrasonic methods and impedance-analysis eddy-current techniques are being investigated.

\section{EDDY-CURRENT METHODS}

The recent successful use, at several $A E C$ installations, of the eddy-current method in the testing of aluminum shapes has suggested that the technique might be applied to flaw detection on tubing of low-conductivity alloys such as Inconel, Hastelloy, and stainless steel. As a result, a comprehensive literature and patent survey of eddy-current flaw detection was made, which showed that the method has been successfully applied to magnetic materials and to high-conductivity nonmagnetic materials, but that very little work has been done on low-conductivity nonmagnetic materials. Laboratory work with the experimental equipment has indicated, however, that eddy-current techniques are likely to be applicable to the inspection of Inconel and Hastelloy tubing.

In brief the method consists of inducing eddy currents into the tube wall by bringing it into the field of a coil supplied with a high-frequency alternating current. The eddy currents in the tube wall alter the original field and impedance of the coil. A flaw or any other variable in the tube that changes the magnitude or the distribution of the eddy currents is reflected as a change in the impedance of the coil and may be measured. Two coils that encircle the tube or very small probe coils that are placed on the surface of the tube may be utilized. Since it is easier to pass a tube through an encircling coil than it is to mechanically seam the surface of a tube with a probe coil, the use of encircling coils is presently being emphasized.

The magnitude of eddy currents in a material is directly proportional to the frequency. Accordingly, it has been found that the sensitivity of any eddycurrent instrument increases with the frequency. It has also been found that, for adequate sensi- tivity, tight coupling between the coil and the tubing must be maintained.

The "skin effect" of the eddy currents in the tube wall is a deterrent to the frequency being continually increased in order to improve the sensitivity. The relative magnitude of the eddy currents at any depth $x$ in a tube wall may be expressed by:

$$
\left|\frac{I_{x}}{I_{\text {surfoce }}}\right|=e^{-x \sqrt{\pi f \mu \gamma}},
$$

in which $f$ is the frequency, $\mu$ is the permeability, and $y$ is the conductivity and $x$ is depth in mils. For Inconel this reduces to

$$
\left|\frac{I_{x}}{I_{\text {surface }}}\right|=e^{-5.11 \times \sqrt{f} \times 10^{-5}} \text {. }
$$

This indicates that if the operating frequency is too high, the eddy currents will not penetrate and flaw detection at the inside tube wall will be ineffectual. The choice of frequency is, thus, the result of a compromise based on the size and material of each tube. In Table 18 are given some representative values for Inconel tubing.

TABLE 18. SOME REPRESENTATIVE DATA PERTAINING TO THE EDDY-CURRENT ANALYSIS OF INCONEL

\begin{tabular}{ccc}
$\begin{array}{c}\text { Tubing OD } \\
\text { (in.) }\end{array}$ & $\begin{array}{c}\text { Optimum Frequency } \\
(k \mathrm{c})\end{array}$ & $\begin{array}{c}\text { Maximum Inspection } \\
\text { Depth (in.) }\end{array}$ \\
\hline 0.200 & 500 & $0.030-0.040$ \\
0.250 & 320 & $0.035-0.050$ \\
0.375 & 140 & $0.055-0.075$ \\
0.500 & 80 & $0.070-0.100$ \\
1.00 & 20 & $0.150-0.200$
\end{tabular}

Figure 36 is a plot of the normalized impedance of a tightly coupled coil encircling 0.500-in. inconel. In the ratio $W L / W L_{0}$ the numerator is the inductive reactance of the coil with the Inconel inserted, and the denominator is the inductive 


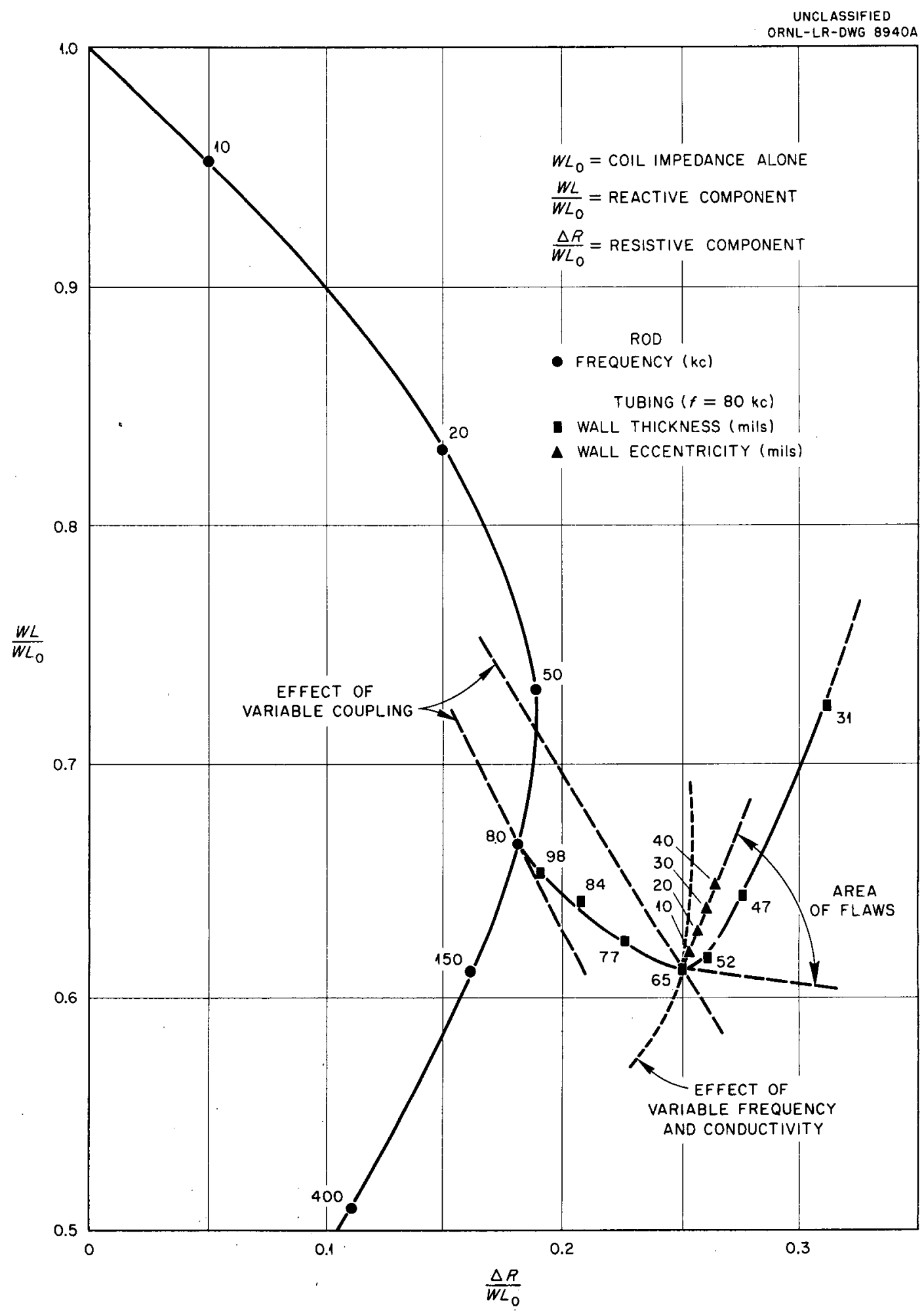

Fig. 36. Eddy-Current Analysis of Inconel. 
reactance of the coil with the Inconel removed; $\Delta R / W L_{0}$ is the ratio of the resistive impedance (Inconel present) of the coil to the inductive reactance (Inconel absent) of the coil. The ratio of the outside diameter of the Inconel to the effective diameter of the coil is called the "filling factor" and was held constant at 0.85 for this plot. The curve drawn through the circled points is a plot of the coil impedance for a 0.500-in. Inconel rod, the curve parameter being the frequency in kilocycles. The curve departing from the $80-k c$ point and passing through the square points is a plot of the coil impedance at $80 \mathrm{kc}$ for a 0.500-in. Inconel tube with its wall thickness (in mils) as the parameter. Departing from the $65-\mathrm{mil}$ point on the curve for the tube and plotted as triangular points is a curve of the coil impedance at $80 \mathrm{kc}$ for an eccentric $(0.500 \times 0.065$ in.) Inconel tube with eccentricity (in mils) as the parameter. The dashed lines drawn through the 80 -kc point on the curve for the rod and the 65-mil point on the curve for the tube (also at $80 \mathrm{kc}$ ) indicate the effect of variable coupling, that is, variable filling factor. Although the exact nature of the impedance changes caused by different types of flaws is not as yet known, they are almost certain to fall within the angle indicated on the impedance-plane plot as the "area of flaws."

When these curves were plotted, the conductivity was held constant at $1.02 \times 10^{6} \mathrm{mhos} / \mathrm{m}$ by restricting the considerations to Inconel. In the variable-frequency curve, a change in conductivity will produce the same effect as a proportional change in frequency. The effect of variation in frequency or conductivity on the $0.500 \times 0.065 \mathrm{in}$. tube is indicated by the dotted curve drawn through the 65-mil point.

Curves similar to these may be plotted by using the nondimensional parameter $f / f c$ instead of frequency, where

$$
f c=\frac{2}{\pi_{\mu y d^{2}}},
$$

and where the wall thickness or eccentricity is expressed as a fraction of the outside diameter of the tube or rod. In this expression, $\mu=$ permeability, $\gamma=$ conductivity, $d=$ outside diameter of tube or rod. Note that if rods or tubes of different outside diameters are to be tested and if the same operating point on the impedance plane is to be maintained, the frequency must be changed in- versely as the square of the ratio of the two diameters. Thus, in a plot of this type, when a tube with an outside diameter of 0.500 in. and tested at $80 \mathrm{kc}$ is to be correlated with a 0.250 -in.$O D$ tube, the frequency as sociated with this latter tube is $80 \mathrm{kc}(0.500 / 0.250)^{2}=320 \mathrm{kc}$. At this frequency the point for the $0.500 \times 0.065 \mathrm{in}$. tube becomes the point for a $0.250 \times 0.0325 \mathrm{in}$. Inconel tube. From Eq. 2, it is seen that an increase in the frequency from $80 \mathrm{kc}$ to $320 \mathrm{kc}$ and a reduction in the wall thickness from 0.065 to $0.0325 \mathrm{in}$. produce exactly the same relative eddy-current attenuation at the inside wall of the tube.

From the impedance-plane plot, it is apparent that if phase-sensitive detectors are employed to examine the changes in the coil impedance as the tube is moved through the coil, it is possible to interpret to some degree the types of signal variations being encountered. 1 An understanding of these signal variations is very important if irrelevant variations, such as those produced by slight changes in conductivity, are not to be responsible for tubing rejection. The eddy-current testing equipment being developed at ORNL is of the impedance-analysis type utilizing phase-sensitive detectors.

One of the objectionable features of most encircling-coil eddy-current testing instruments is that they operate at a single frequency and, thus, do not allow adequate inspection of tubes having a large variety of sizes and materials. The cyclograph is an exception in that its inspection coil determines the operating frequency, and as a result, the frequency may be changed by merely changing coils. Unfortunately, the cyclograph cannot be made definitive since it inherently measures only the resistive component of changes on the impedance plane. However, because of its versatility and because determinations can be made quickly, it is a very useful instrument for preliminary inspection or for sorting very bad tubing from good tubing. For instance, it has been successfully used to sort out, prior to detailed inspection, those pieces of Hastelloy $B$ welded tubing with the worst defects, thereby considerably reducing the time required for inspection.

Considerations regarding the building of a variablefrequency impedance-analysis instrument for use

\footnotetext{
This concept of flaw detection by impedance analysis was first introduced by F. Förster of the Institute Dr. Förster, Rulingen, Germany.
} 
with encircling coils have indicated that a considerable amount of development work would be required and that the proposed instrument would be very complex because of the variable-frequency requirement. As a result, emphasis is now on the development of eddy-current probe coils to be used with a single-frequency impedance-analysis instrument that is already in the final stages of development. Probe coils operating at a single frequency may be utilized to inspect tubing (of the same material) having a wide range of outside diameters without seriously affecting the flaw sensitivity. In addition it is believed that a probe coil, because of its small size, will be more sensitive to very small flaws than an encircling coil.

\section{ULTRASONIC METHODS}

Since in eddy-current methods many more unresolved problems are encountered than in ultrasonic methods, the latter method was chosen as the most readily available for the inspection of smalldiameter tubing. The ultrasonic equipment selected is manufactured by Electro Circuits, Inc., and operates with a shock-excited crystal and a wideband amplifier. The shock-excited crystal emits an ultrasonic pulse of very short duration which echoes as a very sharp signal from any interface. The wide-band-width amplifier permits the separation of closely spaced signals. The technique employed is to immerse both the crystal and the tubing and to introduce the ultrasonic wave circumferentially into the tube wall as a shear wave. This equipment and technique give signals that clearly indicate flaws and give a high resolution of signals from small, closely spaced flaws. Moreover, with these features a moderately high scanning speed should be possible, which is advantageous when large quantities of tubing are to be inspected.

It has been demonstrated that this equipment is capable of detecting flaws as small as pin holes which penetrate only $0.003 \mathrm{in}$. below the outside surface. All defects on the outer surface of the tubing that can be located by dye-penetrant inspection can, likewise, be located with ultrasonics. Also, subsurface defects as small in size as those mentioned above have been detected with ultrasonics, and metallographic examination has verified the results. On the basis of present experience, the ultrasonic method is expected to perform equally well in locating defects on the inner surface.
Ultrasonic data are conventionally presented on a cathode-ray tube as " $A$ " scan, the vertical sweep being the signal strength and the horizontal sweep being the distance (travel time) from the crystal. This type of presentation cannot be interpreted when the scanning speeds are high since the repetition rate (traveling indications) of flaw signals will be in excess of 100 times per minute. Gated alarm signals are also unsatisfactory because the response rate is not fast enough at high scanning speeds to give a flaw indication and because all spurious signals, as well as flaw indications, will pass through the gate. Another unsatisfactory property of gated alarm signals is that in certain instances the electronic gate may move with the flaw indication and give no alarm. The less conventional " $B$ " scan in which the defects are presented as a standing image of the tube cross section on a 17-in. cathode-ray tube holds promise of being a very powerful method for detecting and interpreting the defect signals. In this " $B$ " type of scan, the vertical sweep corresponds to an "A" type of prèsentation, and the horizontal sweep corresponds to the rotation of the impacted tubes. The long persistence of the image on the screen of the cathode-ray tube and the synchronization of the horizontal sweep with tube rotation result in a stroboscopic effect. Some indication as to the size of the defects may be obtained by observing (1) the number of degrees of tube rotation through which a flaw signal is obtained, (2) the relative brightness of the " $\mathrm{B}$ " scan flaw indication, and (3) whether or not that section of the vertical sweep below the flaw indication is blacked out by the signal strength.

Figure 37 shows a pattern for a " $B$ "' scan of a $3 / 8$ by $0.045 \mathrm{in}$. tube having only one defect in the particular cross section that is being scanned. The defect, which is indicated by the diagonal line, is a longitudinal crack extending along the entire 12-in. length of the outside surface and parallel to the axis. Dye-penetrant inspection and x-ray examination both indicated that the crack was discontinuous. When the tube was rotated through only $3 \frac{1}{2}$ deg and re-examined with $x$ rays, a portion of the crack was observed to disappear, which indicated that the crack was very tight and shallow in that particular portion. Figure 37 is the ultrasonic flaw indication for that section of the tube which gave no flaw indication when examined by dye- 


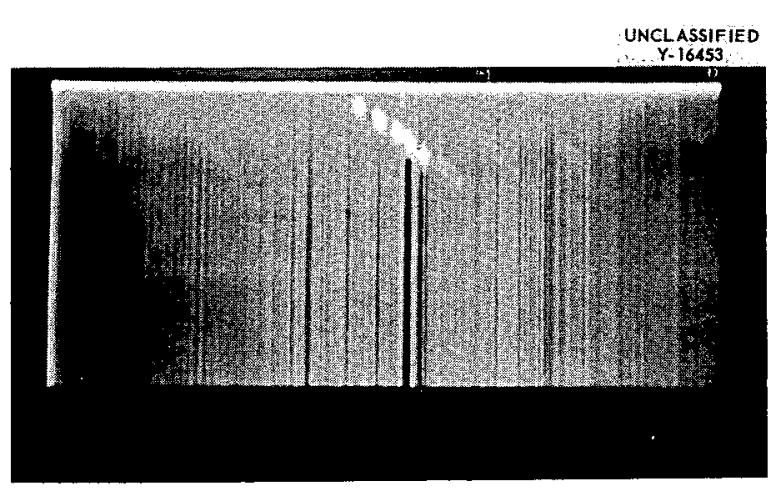

Fig. 37. "B" Scan on an Oscilloscope Screen. Diagonal line indicates a very tight, shallow crack. penetrant or $x$-ray methods. Further investigation on this test piece is necessary before it is metallographically examined in order to determine how the depth of the crack varies.

Mechanical equipment to rotate the tubing and to scan along the length of the tubing is being designed. The construction of this scanning equipment was handicapped by the neces sity of obtaining an accurate, synchronous, rotational signal for the horizontal sweep of the " $B$ " scan instrument. This scanner will permit the rapid inspection of tubing up to $27 \mathrm{ft}$ long; and if it is found to be desirable, a simultaneous scan can be made with both ultrasound and eddy currents. 


\title{
WELDING AND BRAZING
}

\author{
P. Patriarca G. M. Slaughter
}

R. E. Clausing

Metallurgy Division

R. L. Heestand

Pratt \& Whitney Aircraft

\section{FABRICATION OF TEST COMPONENTS}

\section{Twenty-Tube High-Velocity Heat Exchangers}

Three 20-tube Inconel fuel-to-NaK heat exchangers have been fabricated for a heat-exchanger test program at $Y=12$. The fabrication techniques used on these heat exchangers consisted essentially in the manual Heliarc welding and the subsequent back-brazing of the tube-to-header joints. All welding was performed by qualified operators' using qualified procedures, ${ }^{2}$ and complete penetration was utilized, except on the tube-to-header joints. Complete protection of the root of the welds by an inert gas was employed at all times to minimize scaling and oxidation. Back-brazing of the tube-to-header joints was employed for two reasons: to eliminate the "notch-effect" resulting from incomplete weld penetration, and to ensure against the development of leaks in the event of corrosion through an area of shallow weld penetration.

An evaluation of the corrosion resistance of brazing alloys, which was conducted by the General Corrosion Group of the Metallurgy Division, has shown that the brazing alloys Low-Melting Nicrobraz and Coast Metals 52 are compatible with both liquid media. Low-Melting Nicrobraz was used for back-brazing of the first unit, while Coast Metals 52 was used on the other two bundles because its flowability characteristics are better.

Two brazing operations were required for each heat exchanger, since the Globar pit furnace available in the Welding and Brazing Laboratory did not possess a heating zone of sufficient length to heat both ends of the unit to the brazing temperature. A "window" was removed from the pressure shell to permit preplacement of the brazing alloy on each end of the tube bundle, and a photograph illustrating this is presented in Fig. 38. The window was welded shut, and helium leak-testing indicated that

\footnotetext{
'T. R. Housley and P. Patriarca, Operator's Qualification Test, QTS-1.

${ }^{2}$ T. R. Housley and P. Patriarco, Procedure Specification, PS-1.
}

all welded and brazed joints were leak-tight. A photograph of a completed heat exchanger is shown in Fig. 39.

\section{Intermediate Heat Exchanger No. 2}

The semiautomatic Heliarc welding of the tubeto-header joints of the two tube bundles for the intermediate heat exchanger No. 2 test program was discussed in a previous report. ${ }^{3}$ These 400 welds

${ }^{3} \mathrm{P}$. Patriarca et al., ANP Quar. Prog. Rep. March 10, 1955, ORNL-1864, p 131.

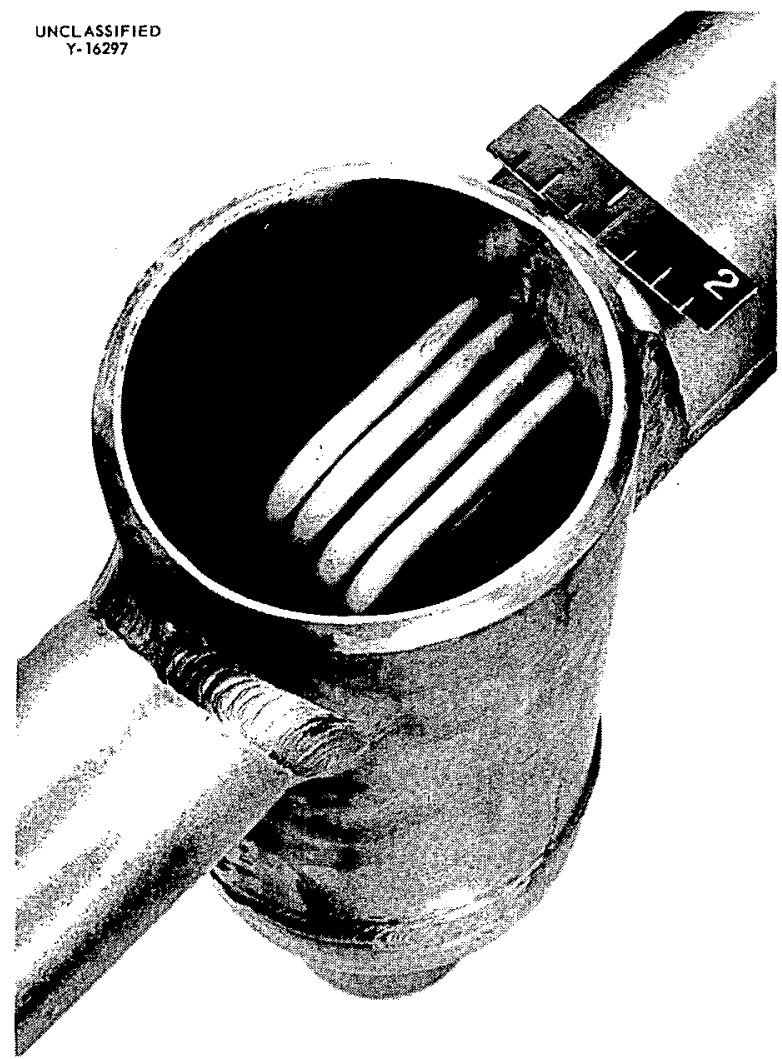

Fig. 38. One End of 20-Tube High-Velocity Heat Exchanger Showing "Window" Through Which Brazing Alloy Was Applied. 


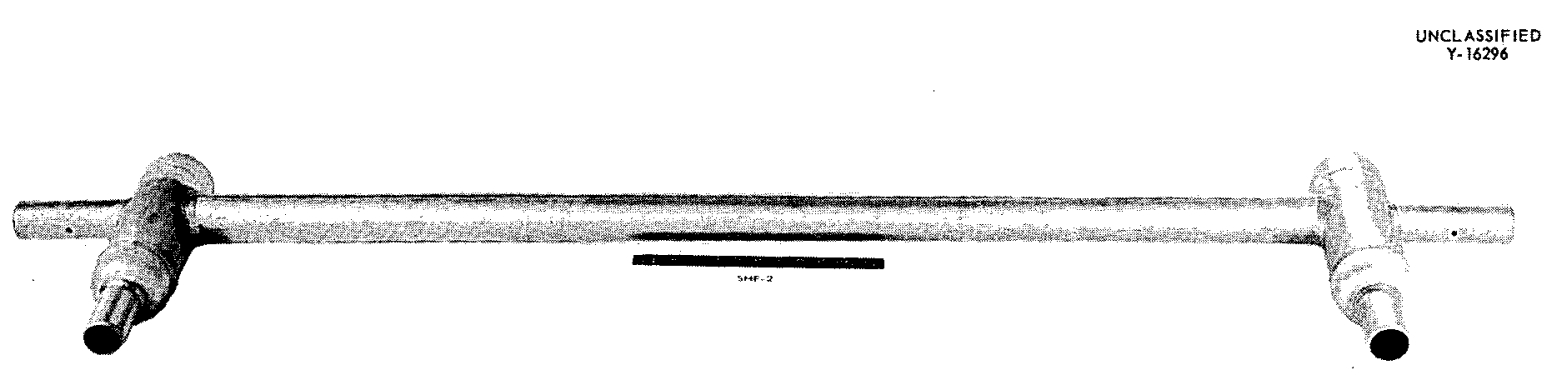

Fig. 39. Completed 20-Tube High-Velocity Heat Exchanger.

were helium leak-tight before initiation of the stages of fabrication discussed below.

Header Welding. - As a means for minimizing cracking of the brittle alloy used in back-brazing and for avoiding contamination of areas to be welded with the boron and silicon from this alloy, the header components were Heliarc-welded to each tube bundle before back-brazing of the tube-toheader joints. However, to permit accessibility to the joints, the components were not attached until after preplacement of the Low-Melting Nicrobraz had been completed.

The welding is shown at an early stage in Fig. 40 , and it can be seen that strongbacks were used to minimize distortion of the header and the consequent danger of tube-to-header weld fracture. Joint designs were used which permitted complete penetration, ${ }^{4}$ and qualified operators and procedures were used at all times. A photograph of a completed, leak-tight header section prior to backbrazing is shown in Fig. 41.

Back-brazing of Tube-to-Header Joints. - The Low-Melting Nicrobraz alloy was preplaced on the headers as a dry powder and was secured firmly in position with a methacrylate cement. Since the Globar-heated brazing furnace contained a heating zone of limited length, only one end of the tube bundle could be brazed at a time. As a result, the complete welding and brazing of one header of a tube bundle were necessitated before brazing-alloy preplacement and header welding of the second end were initiated. This was necessary because there was danger of spalling of preplaced brazing alloy

\footnotetext{
${ }^{4}$ T. R. Housley and P. Patriarca, Joint Design of Inert-Arc-Welded Pressure Vessels for High-Corrosion Applications (to be issued).
}

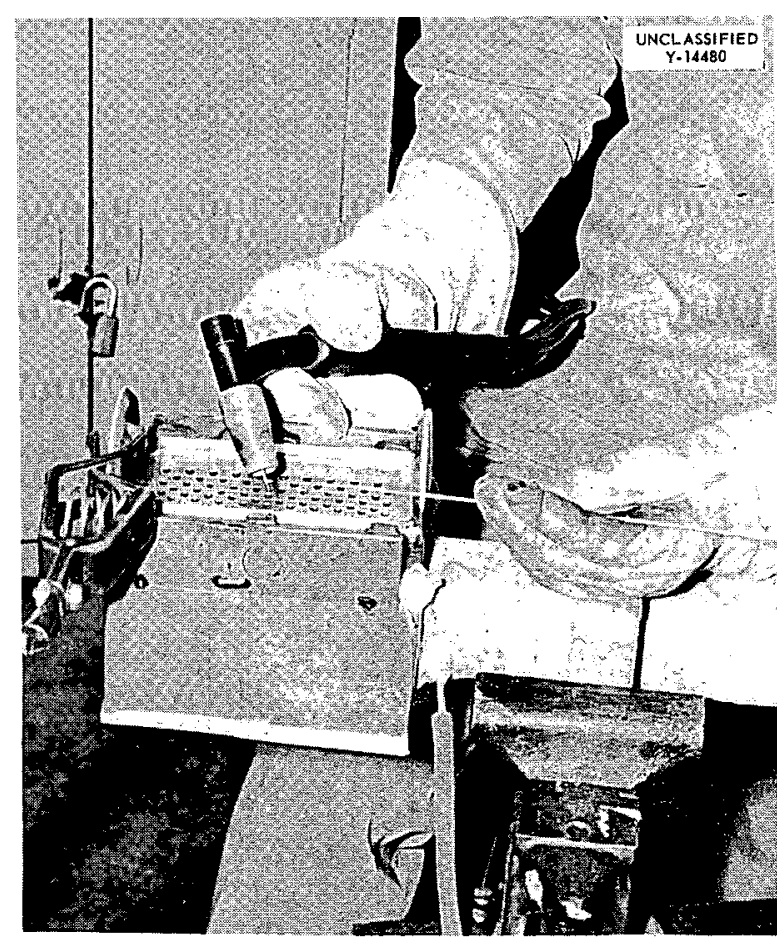

Fig. 40. Welding of Headers of Intermediate Heat Exchanger No. 2. Note that strongbacks were used to minimize distortion. (Secret with caption)

from the underside of the cold header during the brazing of the first header. It was thought that hot hydrogen gas might volatilize the binder on the cold header, leaving the brazing alloy insecurely positioned in its overhead locations. This important consideration increased the fabrication time to some degree, since the welding of both heads and 


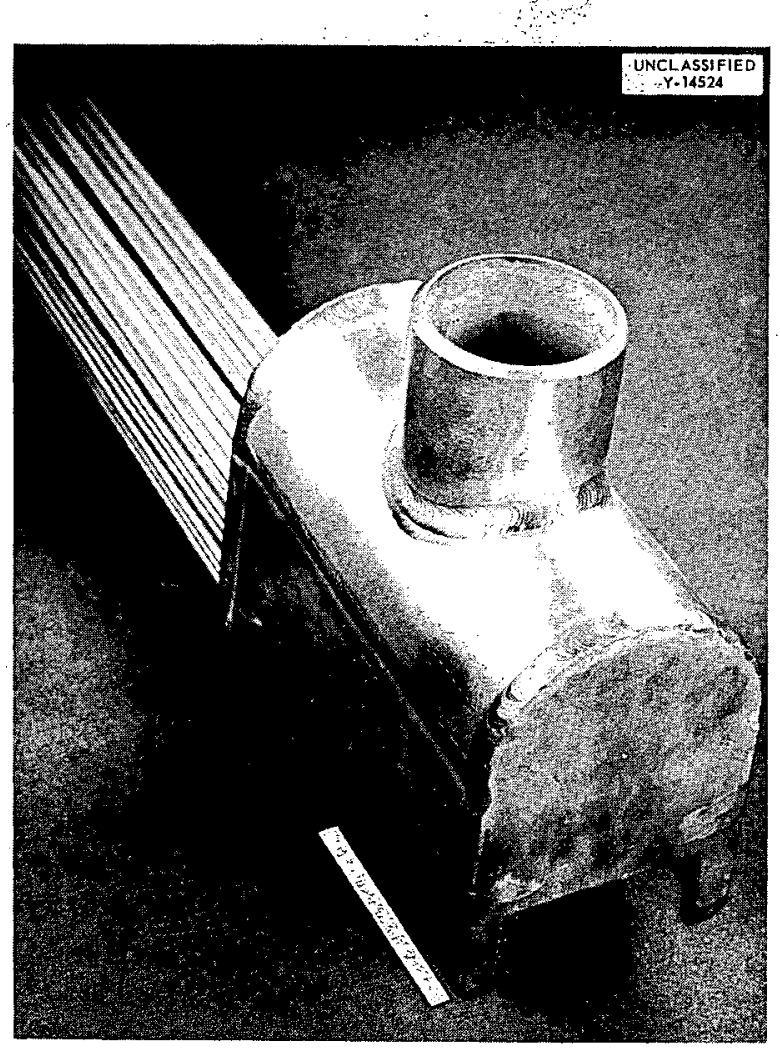

Fig. 41. Completed Header of Intermediate Heat Exchanger No. 2. (Secret with caption) the brazing of both heads could not be performed in a sequence.

The dry-hydrogen furnace brazing was performed in the Globar furnace, with the heat-exchanger tube bundle in a horizontal position and securely jigged in a long rectangular stainless steel retort; a dryhydrogen atmosphere was maintained in this retort during brazing. A time-temperature record of every brazing thermal cycle was measured by means of a Chromel-Alumel thermocouple firmly attached to the assembly.

Fabrication and Assembly of "Comb-Spacers." The use of wire "comb-spacers" was considered to be the most practical means for holding the tube bundle rigid over its free span length and for keeping the tubes separated in such a way as to permit the required mode of fluid flow between them. The combs were placed at 5-in. intervals along the bundle, with alternate spacers positioned 90 deg to each other. It was required, for a heattransfer evaluation, to have the spacers on one bundle placed perpendicular to the axis of the tubing, whereas they should have been placed in a plane at a $30-\mathrm{deg}$ angle to the tubing axis on the second bundle. The comb assemblies were fabricated and attached according to the se requirements, and $a$ photograph of both types of spacers on a sample tube bundle is shown in Fig. 42. It can be

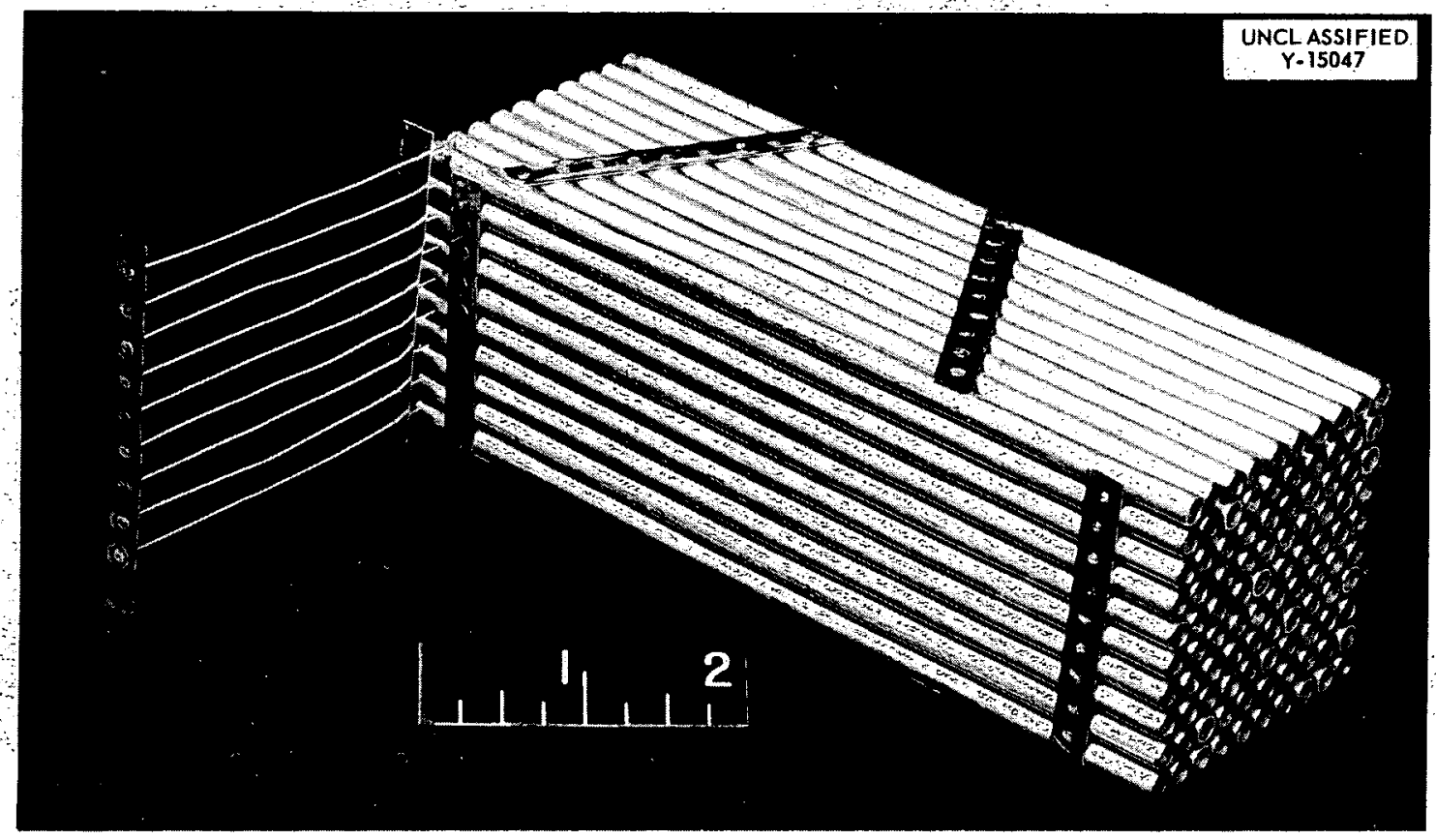

Fig. 42. "Comb Spacers" Used in Two Different Arrangements on Sample Tube Bundle. 
seen that the fabrication and assembly of these spacers required the use of precision jigging facilities and careful determination and control of the cone-arc plug-welding conditions. Meticulous care also was maintained when holes were punched in the strip headers since extremely close tolerances were specified.

Installation of Tube Bundle into Pressure Shell. The installation of the tube bundles into their pressure shells required a light machining of the shell to permit proper fitup. Each pressure shell had to be precision machined for its corresponding tube bundle to accommodate the very small variations in dimensions between them.

The heavy-walled pressure shell was beveled according to the recommended joint design, and the root pass was Heliarc-welded as prescribed for high-corrosion applications. The remainder of the welding was performed by using the metallic-arc process in order to minimize the heat input and consequent distortion of the unit. Figure 43 is a photograph showing the heat exchanger after completion of the root pass. The large l-beam was used as a strongback for the system in order to prevent severe distortion.

Joining of the Two Tube Bundles. - The two $500-\mathrm{kw}$ tube bundles were joined together after being welded into their respective pressure shells, and a photograph of the completed unit is presented in Fig. 44. It can be seen that this operation required several manual Heliarc welds to connect the sodium circuits and to attach the inlet and exit nozzles. Leak-testing with a helium leak detector indicated no flaws, and the heat exchanger was subsequently delivered to $Y-12$ for installation into the testing rig.

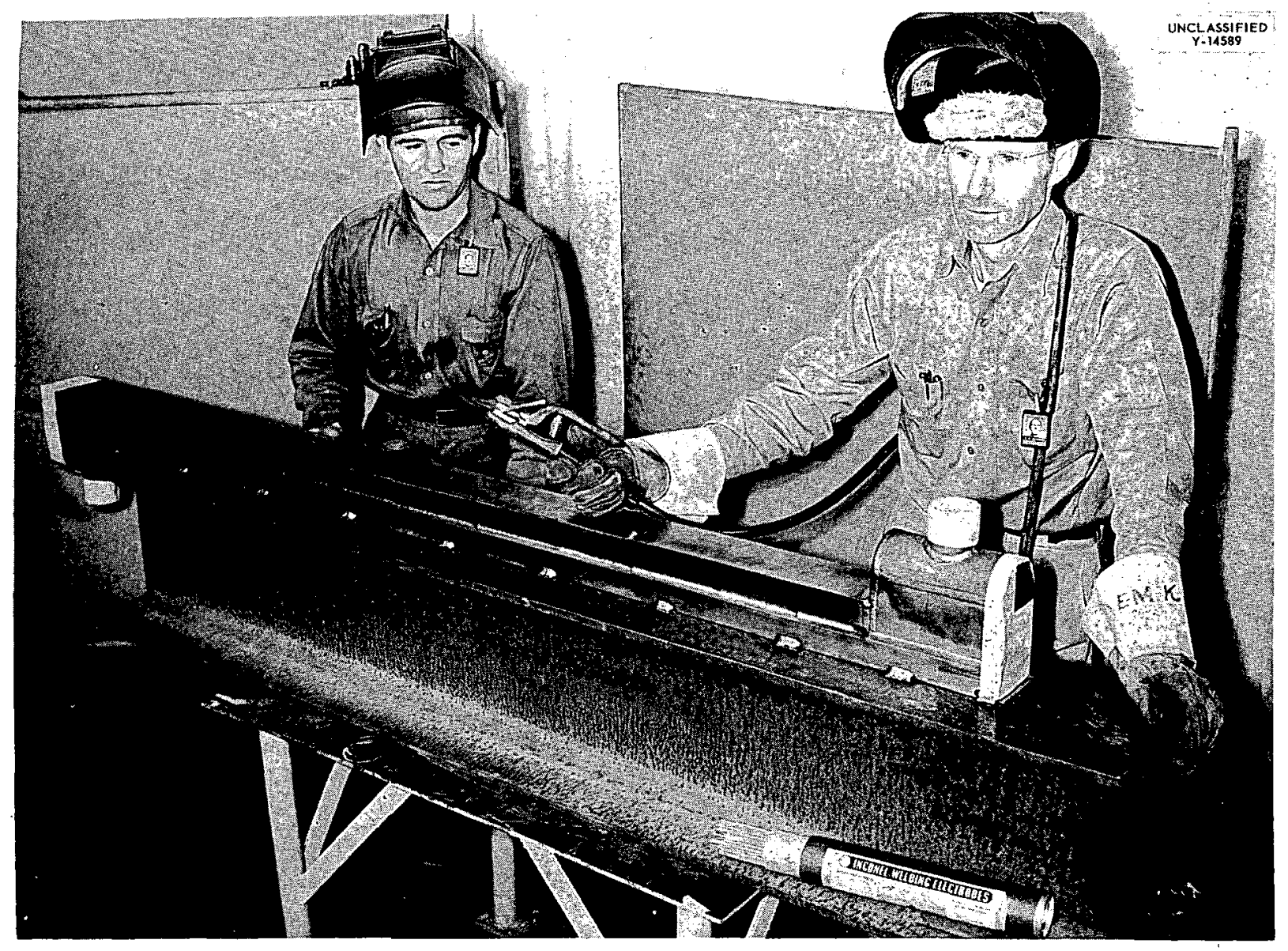

Fig. 43. Tube Bundle of Intermediate Heat Exchanger No. 2 After Completion of Root-Pass Weld on Pressure Shell. Note heavy strongback used to minimize distortion. (Secret with caption) 


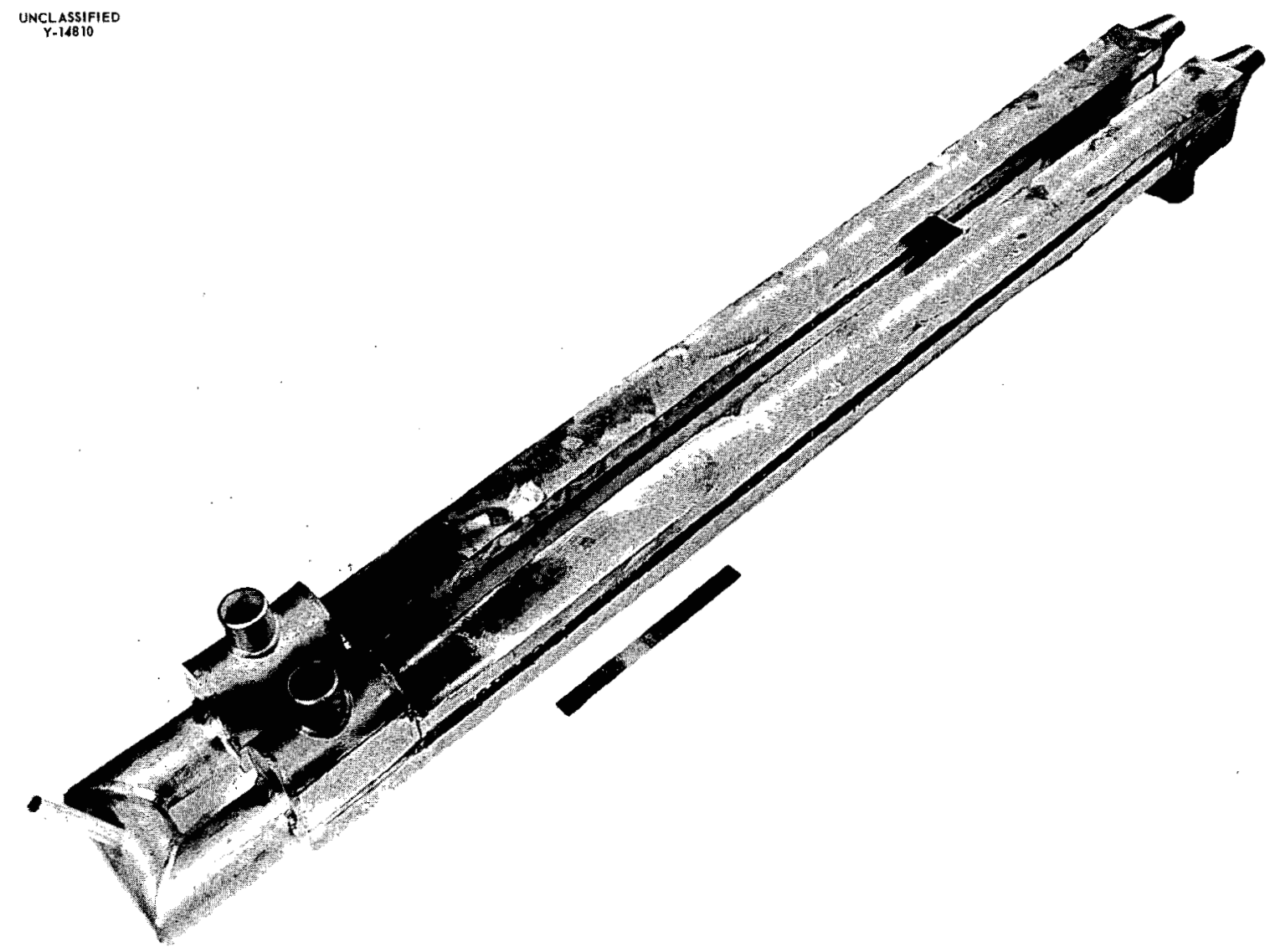

Fig. 44. Completed Intermediate Heat Exchanger No. 2. (Secret with caption)

\section{Intermediate Heat Exchanger No. 3}

The fuel-to-NaK intermediate heat exchanger No. 3 , similar, in general, to the intermediate heat exchanger No. 2, has al so been successfully fabricated. However, several design changes were made in order to promote better operating characteristics and to aid in their fabrication: A larger tubing diameter of 0.250 in. was used, and the right-angle corners of the header components of the previous heat exchanger were eliminated in order to provide a more favorable stress distribution. The new design is evidenced in Fig: 45, which shows the header with the strongbocks used tô minimize distortion during welding. A modification in pressure-shell design was also made so as to facilitate fabrication. A view of the unit in an advanced stage of fabrication is presented in Fig. 46.

Coast Metals 52 brazing alloy is being used in these tube bundles to back up the tube-to-header welds. Its use as a replacement for Low-Melting Nicrabraz is desirable since it possesses adequate corrosion resistance and better flowability characteristics. The alloy is applied as presintered rings that are manufactured by the techniques described in the section, "NoK-to-Air Radiators." Figure 47 shows these brazing-alloy rings in position on the underside of the heat-exchanger header. These rings can be secured to the header during ossembly of the tubes either by electric-resistance spot welding or by the use of a volatile organic binder. The photograph also exhibits the diagonal comb spacers installed on these units to ensure a uniform spacing between the tubes and to increase the rigidity of the bundles.

\section{NaK-to-Air Radiators}

The fabrication of two NaK-to-air radiators was required for use in the heat-exchanger test program. 


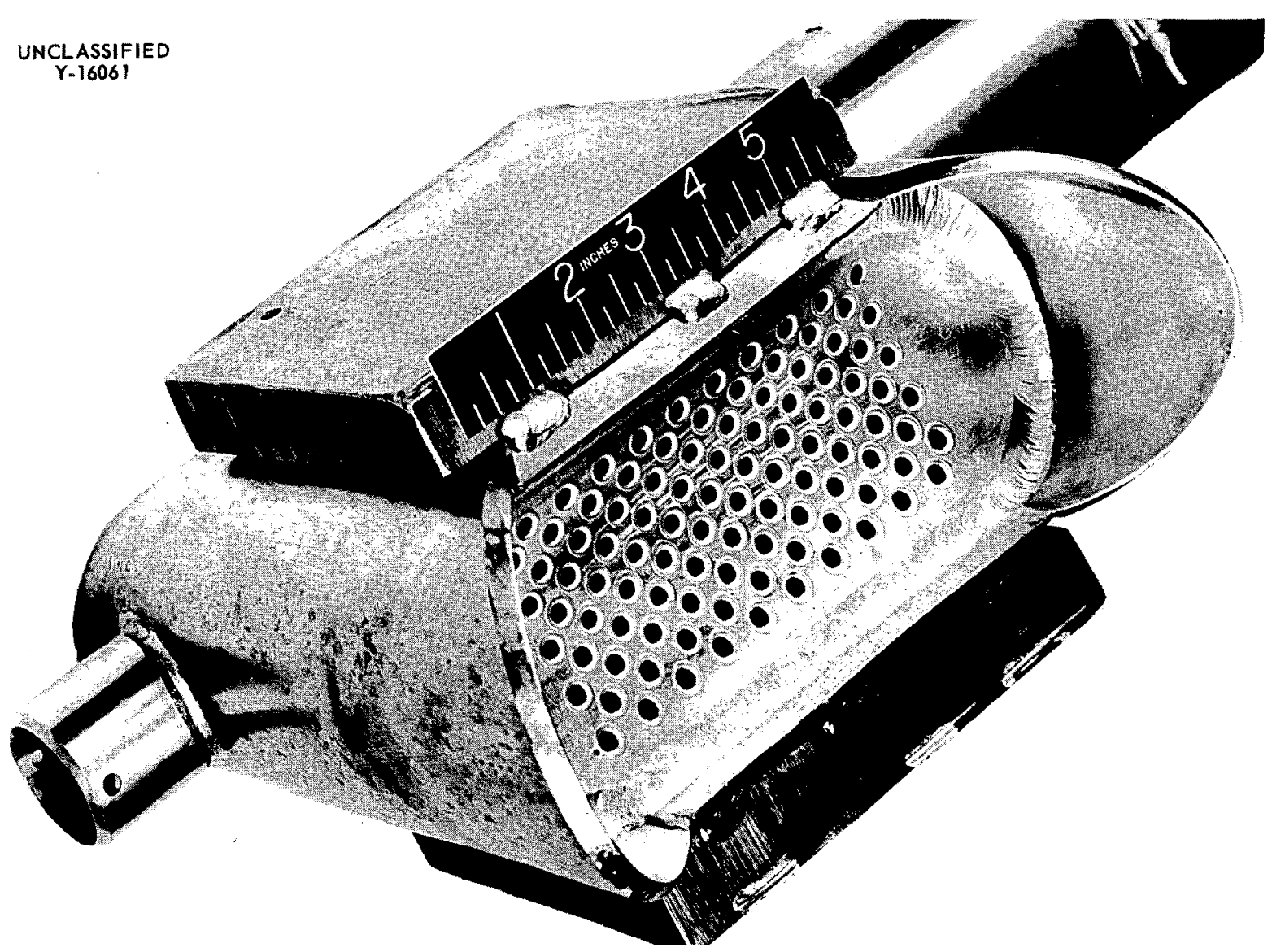

Fig. 45. Improved Header Design of Intermediate Heat Exchanger No. 3. Note strongbacks. (Secret with caption)

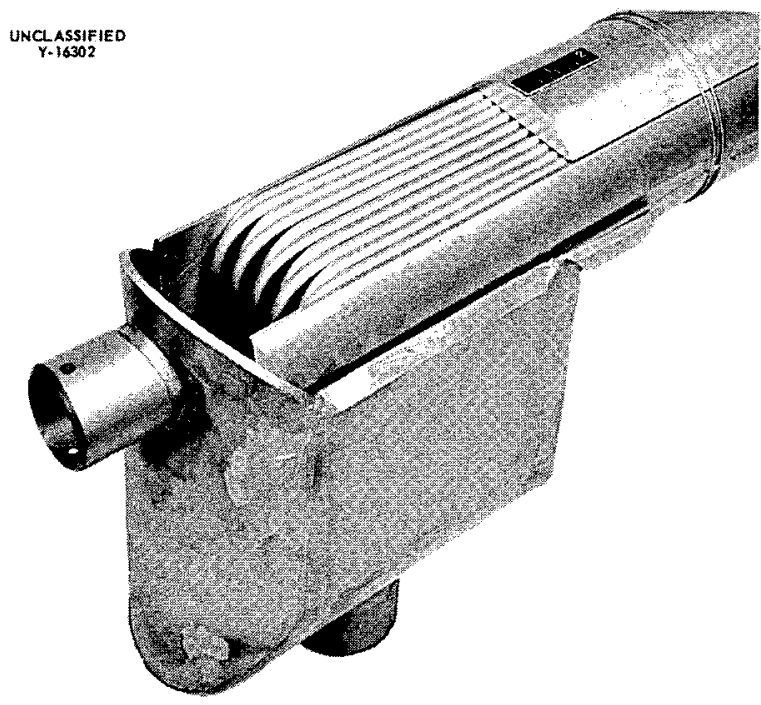

Fig. 46. Intermediate Heat Exchanger No. 3 After Attaching Header Components. (Secret with caption)
The previous semiannual report ${ }^{5}$ stated that type 310 stainless-steel-clad copper high-conductivity fins had been sheared, degreased, and edgeprotected with aluminum bronze. The construction of these units has now been completed, and a brief discussion of the intermediate steps is presented below:

Preplacement of Brazing Alloy. - Coast Metals 52 brazing alloy was designated for use on this radiator since it possesses good flowability at $1020^{\circ} \mathrm{C}$ and has good resistance to high-temperature oxidation. Its good compatibility with sodium was also of distinct advantage for two reasons: (1) the brazing alloy may actually come in contact with the liquid metal during service if it is used to seal pinhole leaks or if sufficient weld-metal corrosion occurs to expose a new braze surface, or (2) severe tube-wall dilution during brazing or solid-state

\footnotetext{
${ }^{5}$ P. Patriarca et al., Met. Semiann. Prog. Rep. April 10, 1955, ORNL-1911, p 68.
} 


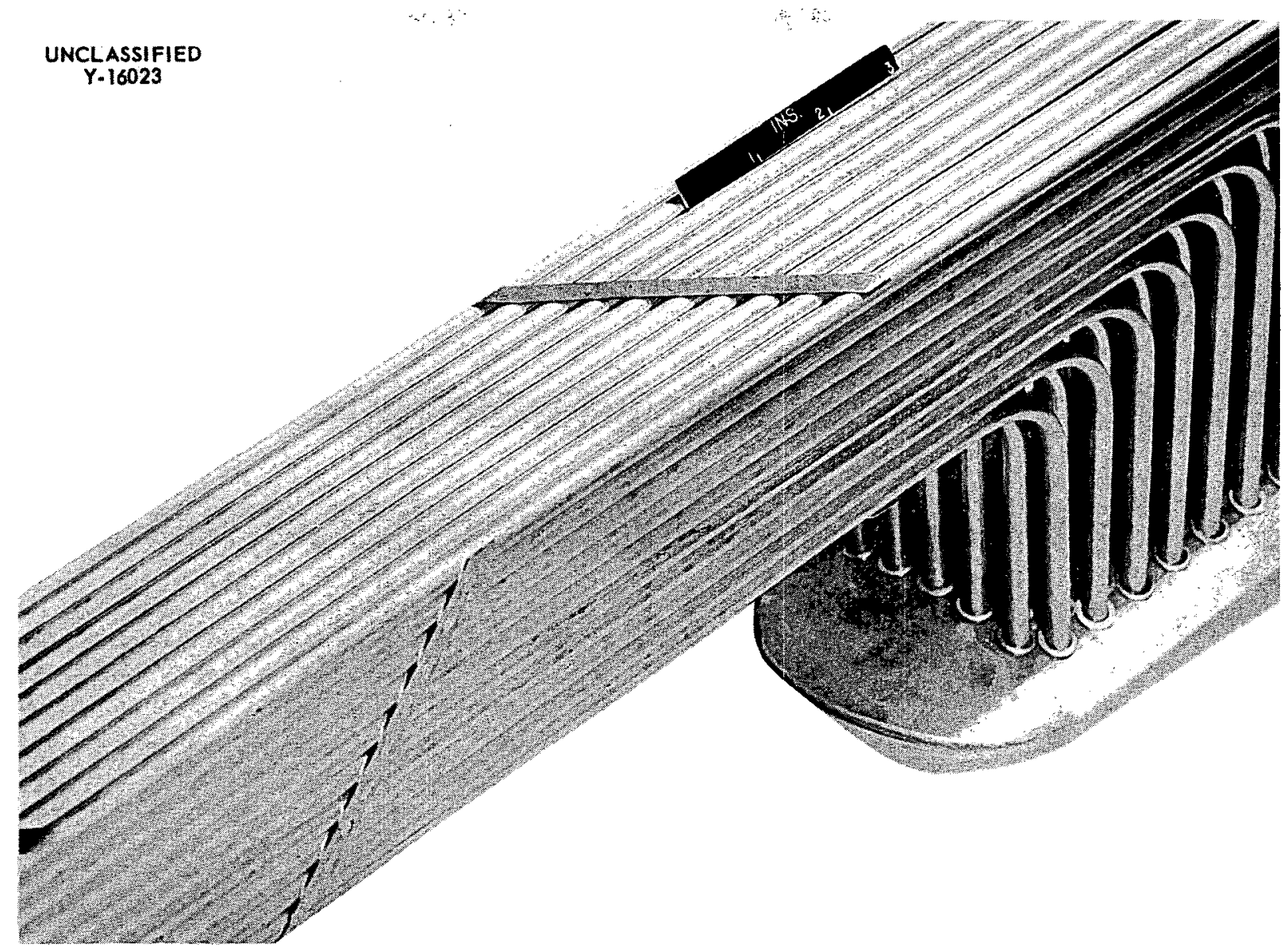

Fig. 47. Tube Bundle of Intermediate Heat Exchanger No. 3 Showing Presintered Rings of Coast Metals 52 Brazing Alloy Used for Back-Brazing Tube-to-Header Joints. Note diagonal comb spacers. (Secret with caption)

diffusion in service may produce a high concentration of brazing-alloy constituents near the circulating liquid.

The advantages of the dry-powder method of brazing-alloy preplacement were presented in a previous report, 5 and, consequently, this method was used in the fabrication of these radiators. This process, which provided-a means for placing controlled amounts of alloy on each tube-to-fin joint, utilized a stainless steel template containing holes that were precision-drilled. The template was placed over a sheared fin, leaving an annulus between each fin lip and the template-hole peripheries. After application of the brazing-alloy powder and subsequent removal of the excess, a ring of alloy of controlled quantity remained. Upon careful removal of the template, the powder was secured to the fin with Nicrobraz cement and allowed to dry. A $1 / 16^{- \text {in.-thick template containing holes }}$ $0.246 \mathrm{in}$. in diameter was found to provide the optimum quantity of brazing alloy per joint, and this was used to preplace alloy on the 2200 fins in preparation for assembly on the tubes.

Assembly of Fins. - The assembly of the fins on the radiator was conducted with the tube-bends down, as shown in Fig. 48, a photograph of the initial stages of fabrication of one radiator. The assembly of the first 4 in. of fins was extremely time-consuming since the tubes were not held rigidly in place. A heavy metal template was required to force each individual fin in place. Since some of this difficulty was also derived from the slight curvature of the straight lengths of tubing, it is thought that improvements in the bending techniques might substantially assist assembly in future units. 


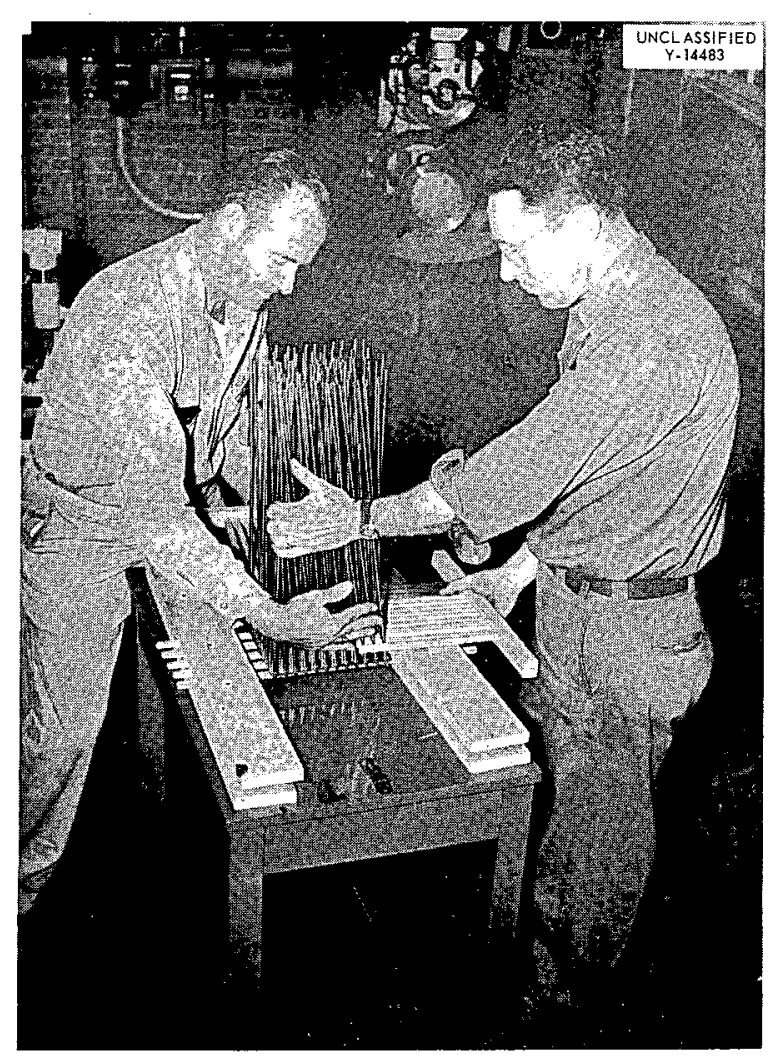

Fig. 48. Initial Phase of Fin Assembly for NaKto-Air Radiator. (Secret with caption)

A set of wooden "finger" $¡ i g s$ was designed and built, and this simplified the fin as sembly problem. These jigs, which can be seen in Fig. 48, enabled the tubes to be aligned in their desired positions so that they fit the punching geometry of the fin. Supporting sheet-metal channels were placed at 4-in. intervals to impart over-all structural stability to the radiator. These channels were Heliarcwelded together to form sheet-metal side plates. Two thin sheets of Inconel were also placed tightly together against the channels at these 4 -in. intervals. This modification was used to overcome the undesirable accumulation of excess alloy which might result from normal variations in the quantity deposited. The capillary joint between these two Inconel sheets acts as a sump to accommodate any excess brazing alloy.

Assembly of Headers. - The original design for these radiators required that all tubes enter the cylindrical headers normal to the curvature at the point of entrance. Sample specimens were prepared to determine the optimum tube-bending and fitting techniques, but no satisfactory means was developed. The complex tube design resulted in extreme difficulties in the placing of the headers upon the tubes.

In view of these complications, a new header design was proposed and accepted which utilized a 3-in. sched-40 pipe. All tubes except the two outside rows on each radiator half-section entered the headers without being bent. Several test samples were then prepared for the determination of proper bending techniques and for operator's qualification-test specimens.

Careful hand-polishing of each of the tubes was required to permit assembly of the split headers without the use of additional force from a handpress. The precision drilling and de-burring of the headers were also employed to prevent bending and distortion of the thin-walled Inconel tubes. After assembly of the headers, the tubes were meticulously hand-filed to conform to the exact curvature of the interior surfaces. Abrasive grinding or wet-milling was avoided since entrapped abrasive or lubricant would lead to inconsistencies during tube-to-header welding.

Welding. - The tube-to-header joints were manually Heliarc-welded by using conditions found satisfactory in the fabrication of test specimens. Helium backup on the underside of the joint was used throughout the welding procedure.

The manual Heliarc welding of the split headers, nozzles, and end-plates was accomplished by using qualified operators and procedures. Extreme care was taken to ensure complete penetration and good coverage by the backing-gas.

After the manifold welds were completed, the integrity of the system was determined by helium leak-testing. Although it was assumed that pinhole leaks could be sealed during the subsequent brazing operation, large leaks were to be avoided. It should be pointed out that headers containing questionable welds can be removed by simply cutting off the tubes at the underside of the header plates. New headers can then be attached by rebending the tubes and repolishing, as discussed above. This procedure was actually employed on these radiators in attempts to obtain leak-tight units before brazing.

Brazing. - The back-brazing of the tube-to-header welds and the brazing of the tube-to-fin joints were 
accomplished by using conventional canning techniques. The brazing alloy had already been preplaced on the fins, as described previously, and a medicine-dropper technique was used to place the braze slurry on the tube-to-header joints.

A special baffle design was used for the brazing of these radiators since it was very important to flush out the copious amounts of methacrylate binder present in the tube-to-fin matrix. A sheetmetal cover was attached to the front of the radiator, and the clean, dry inlet gas was forced between the fins before being exhausted to the outside of the can. The inside of the sheet-metal cover and inlet tube was designed to permit relatively even flow throughout the entire frontal area. A good circulation of hydrogen was also obtained around the tube-to-header joints.

The radiator was securely supported on a special heavy frame-work to prevent sagging or distortion during the high-temperature brazing cycle. The support bars were made from stainless steel which had been previously aluminized at $1500^{\circ} \mathrm{F}$. This aluminizing prevented the support bars from being brazed to the radiator since the aluminum oxide film prevents wetting by the Coast Metals 52 alloy.

The radiator was placed in the brazing can, with four thermocouples attached in various positions around the periphery. This temperature measurement around the radiator was desirable from a control standpoint even though previous experiments had indicated that all parts of a unit of this size could be held within $25^{\circ} \mathrm{C}$ at the brazing temperature. In the preliminary experiment, 12 thermocouples were attached at various points over the test specimen. This close control was necessary since the alloy possessed a $1020^{\circ} \mathrm{C}$ flow temperature and the copper in the fins melts at $1083^{\circ} \mathrm{C}$.

In order to minimize distortion during brazing, the unit was placed in the furnace at room temperature and was gradually raised to the brazing temperature. A photograph of the two completed radiators is shown in Fig. 49, and it can be seen that negligible distortion is present. No excess of brazing alloy was encountered, which indicates that the "sump" technique is practical for large assemblies. Good flowability of the brazing alloy was obtained. After leak-testing with a mass spectrometer helium leak detector had indicated that there were no flaws in the integrity of the closed sodium circuits, the two radiators were submitted to $Y .12$ for installation into the test rig.

A third NaK-to-air radiator with type 310 stainlesssteel-clad copper high-conductivity fins is now being fabricated. Although the design of this unit is essentially the same as that of the other two radiators, a few modifications in fabrication technique are being utilized. These modifications include:

1. the construction of a 36-hole punching die to ensure a more uniform fin-punching geometry,

2. the construction of new tube-bending dies to ensure close control of the tube-bending variables,

3. the development of techniques to permit the assembly of headers in such a manner that all tubes enter normal to the curvature of the header at the point of entrance,

4. the development of the presintered ring method of brazing-alloy preplacement,

5. the use of stearic acid as a lubricant during assembly of the fins.

Techniques for the preparation of presintered rings of Coast Metals 52 brazing alloy were developed by personnel of Pratt \& Whitney Aircraft. ${ }^{6}$ The alloy is sintered in suitable graphite molds in a dry-hydrogen atmosphere, where rings are formed possessing adequate strength and rigidity. Molds of the type shown in Fig. 50 were used to prepare approximately 45,000 rings possessing an inside diameter of $3 / 16$ in. Experiments conducted on 12-in. lengths of vertically brazed tube-to-fin joints have indicated that good flowability and edgeprotection of the copper on the punched fin lips can be obtained with the use of these brazing-alloy rings. This radiator is only partially completed, but it is shown, with the fins partially assembled, in Fig. 51. The wooden "finger" $j i g s$ and the felt-covered wooden stand are also shown in the illustration.

\section{Cornell Aeronautical Laboratory Radiators}

The assembly and partial fabrication of a fullscale liquid-metal-to-air radiator designed by the Cornell Aeronautical Laboratory has been described in a preceding progress report. ${ }^{7}$ Since the header plates on this heat exchanger were $5 / 8$ in. thick,

\footnotetext{
${ }^{6}$ Nuclear Propulsion Program Engineering Prog. Rep. No. 15, PWAC 551, p 71 (1955).

${ }^{7}$ P. Patriarca et al., ANP Quar. Prog. Rep. March 10, 1955, ORNL-1864, p 132.
} 


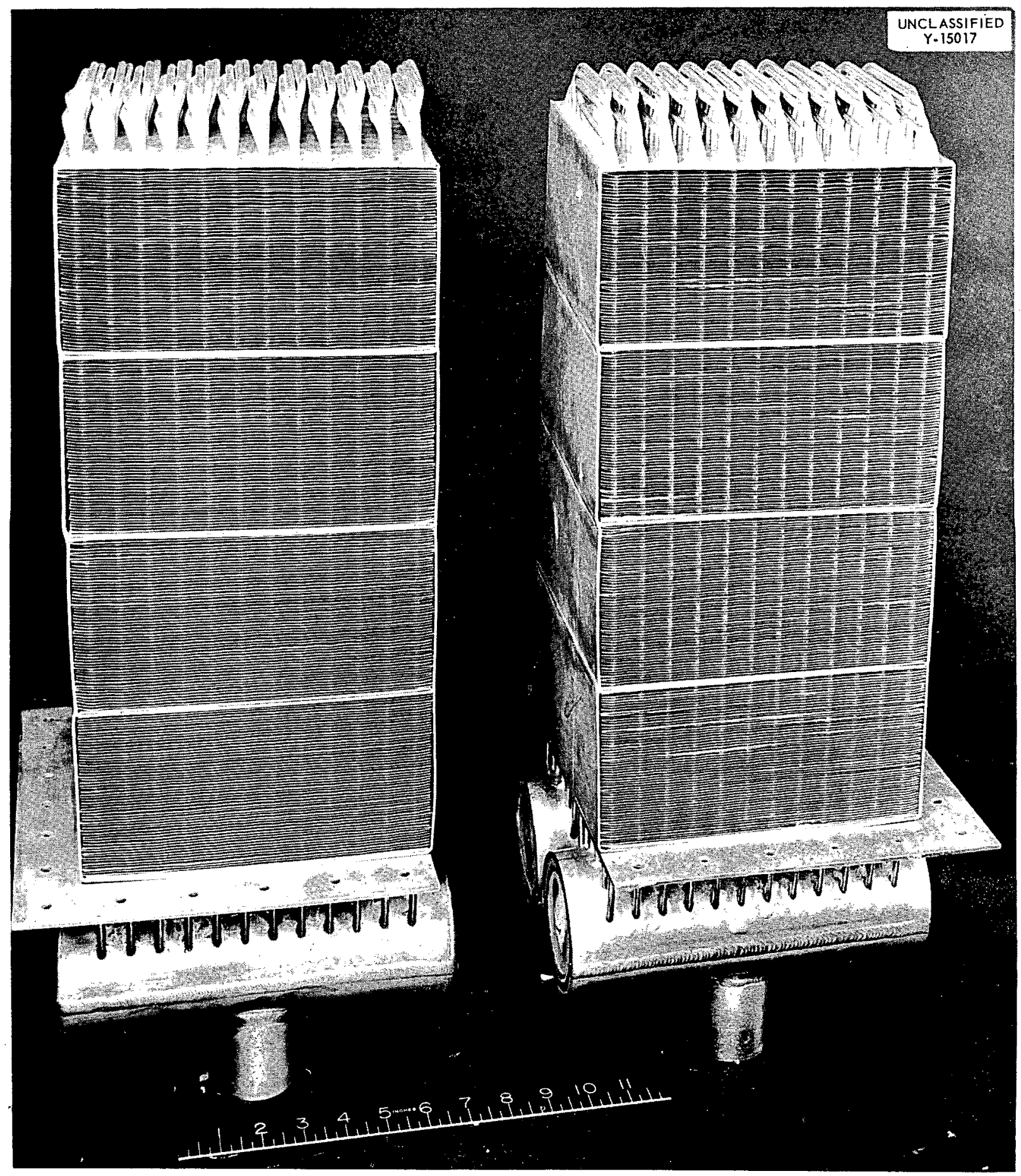

Fig. 49. Completed 500-kw NaK-to-Air Radiators. (Secret with caption) 


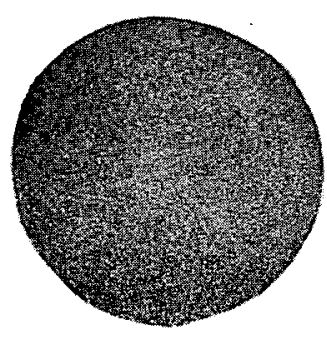

AS-RECEIVED ALLOY
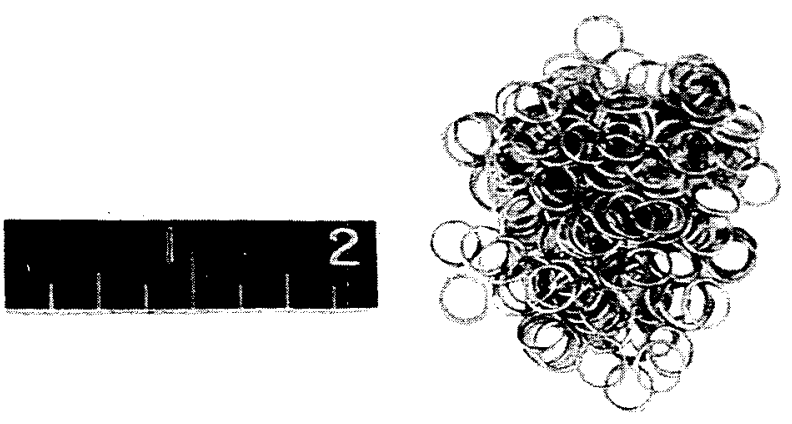

SINTERED RINGS
UNCLASSIFIED

$Y=16104$

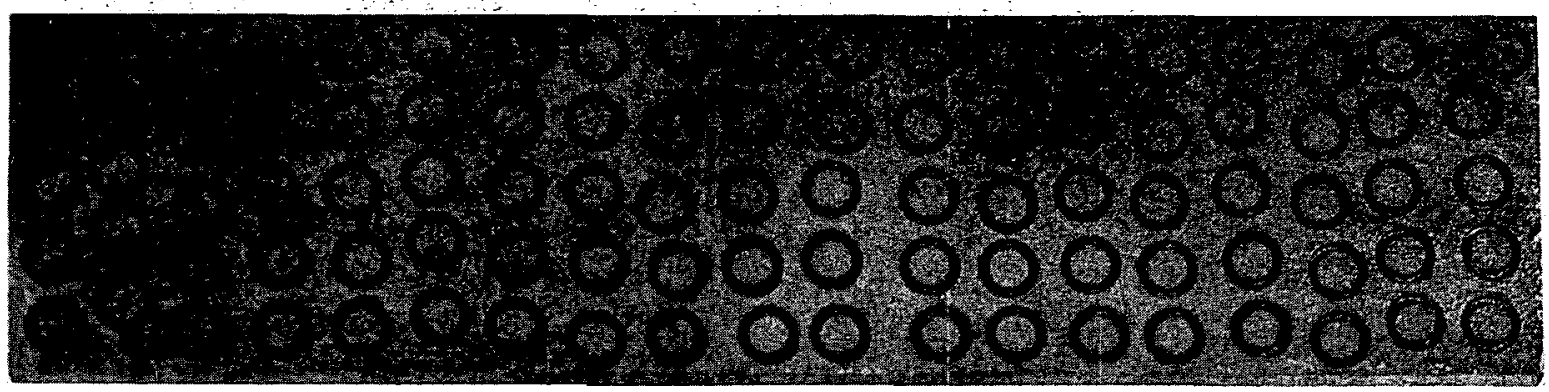

GRAPHITE MOLD

Fig. 50. As-received Coast Metals 52 Brazing Alloy and Graphite Mold Used to Produce the Presintered Rings Shown.

the brazed tube-to-header joints were extremely sensitive to cracking. Severe stresses result from the differences in thermal-expansion coefficients between the stainless steel base metal and the brazing alloy. However, an investigation of several high-temperature brazing alloys reveogled that Coast Metals 50 alloy possessed sufficient ductility to overcome the cracking of the joints when they: were furnace-cooled from the brazing temperature of $2050^{\circ} \mathrm{F}$ : Other brazing alloys such as Coast Metals 52 and General Electric 62 cracked to such an extent that they were not considered satisfoctory for this application.

Since brazing with this nickel-silicon boroniron alloy would necessarily result in the diffusion of boron into the type 316 stainless steel base metal, an investigation was conducted for the purpose of determining the extent of penetration and the effect of this penetration upon the mechanical properties of the base metal. Metallographic examination of typical brazed tube-to-header joints indicated that the extent of diffusion was minor (2-3 mils), even though long-time heating and cooling cycles were used. Samples which were subsequently heated for $24 \mathrm{hr}$ at $1650^{\circ} \mathrm{F}$ also exhibited diffusion to the same extent. After $100 \mathrm{hr}$ at $1650^{\circ} \mathrm{F}$, the diffusion had progressed to 4-5 mils. Several stainless steel tensile-test samples were coated with alloy and brazed at ORNL in order to study the effects of brazing upon the mechanical properties. Tests at room temperature and at $1600^{\circ} \mathrm{F}$ at Cornell indicated that no appreciable reduction in the tensile strength of the base metal resulted.

This alloy was therefore used to back-braze the welded tube-to-header joints on the radiator. The unit was placed in the furnace at room temperature and heated at a rate of $150^{\circ} \mathrm{C} / \mathrm{hr}$ until the brazing temperature was reached. It was held at $2050^{\circ} \mathrm{F}$ 


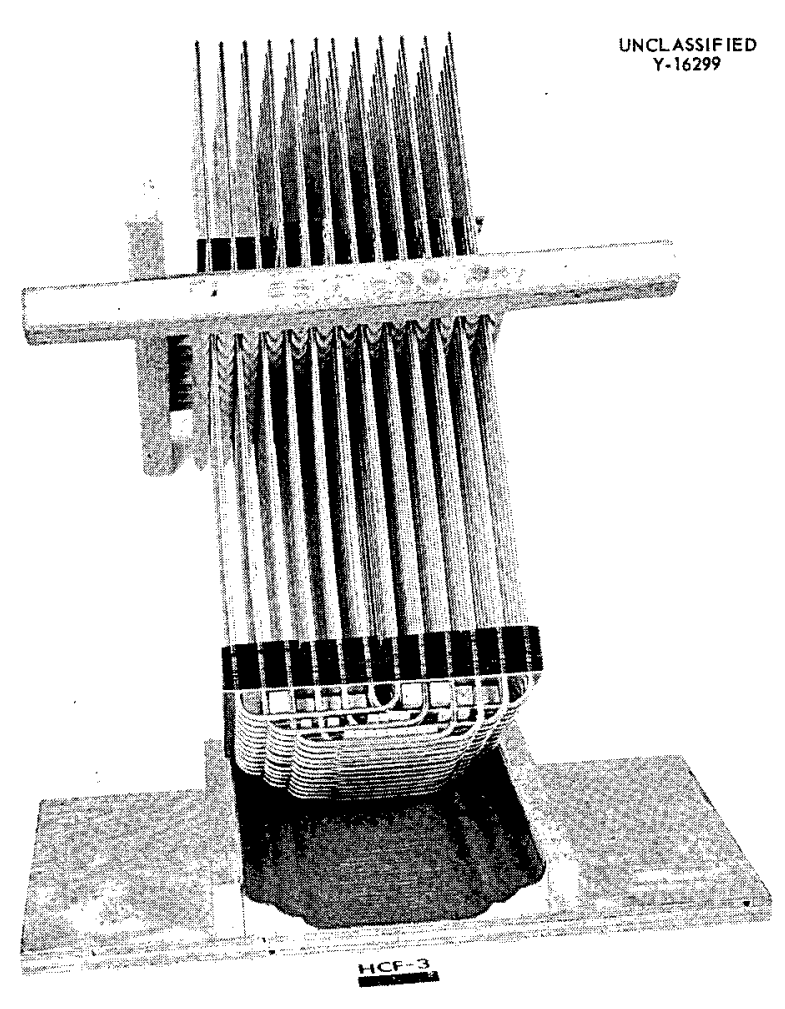

Fig. 51. High-Conductivity Fin Radiator After Partial Assembly of Fins. Note the felt-covered wooden stand and wooden "finger jigs."

for $1 / 2 \mathrm{hr}$ and then furnace-cooled at a maximum rate of $150^{\circ} \mathrm{C} / \mathrm{hr}$. A photograph of the heat exchanger after brazing is shown in Fig. 52.

Testing with a mass spectrometer type of helium leak detector indicated that all welded and brazed joints were leak-tight. The radiator was therefore submitted to the Cornell Aeronautical Laboratory.

In view of the success with this unit, a second liquid-metal-to-air radiator was fabricated. This construction problem was very similar to that described above, except that one header was not attached to the side plates, thereby making it free to "float" during thermal expansion and contraction of the assembly. A photograph of the radiator core, containing the "floating" header at the bottom, is shown in Fig. 53.

The side plates and remaining header sections were welded to the above-mentioned core, and the tube-to-header joints were back-brazed with Coast Metals 50 alloy. Leak-testing with a helium mass spectrometer indicated that all welded and brazed joints were leak-tight.

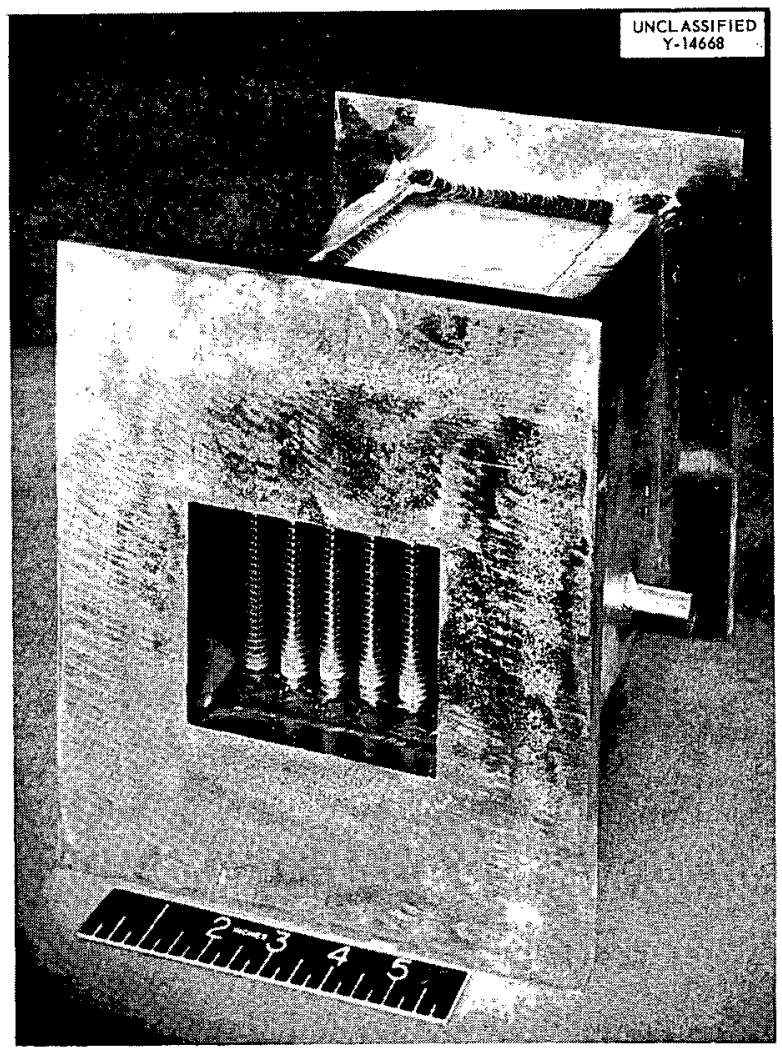

Fig. 52. Completed Cornell Aeronautical Laboratory Sodium-to-Air Radiator No. 1. (Secret with caption)

\section{Brazing of Cermet Valve Seats to Inconel Components}

Three assemblies incorporating Kentanium cermet valve parts have heen successfully brazed by using the technique described in a preceding progress report. ${ }^{8}$ Figure 54 shows an exploded view of an assembly for determining the self-welding characteristics of the se cermet valve parts. This assembly consists of: (1) an Inconel structural piece, (2) two copper-foil disks which supply brazing alloy for the Inconel-to-nickel joints, (3) a $1 / 4$-in.-thick nickel block to dissipate thermal stresses resulting from the different coefficients of thermal expansion of Inconel and Kentanium, (4) a copperfoil disk to supply supplementary brazing alloy to the nickel-Kentanium joint, (5) the Kentanium seat, which has previously been plated with a 0.0001 -in.

\footnotetext{
${ }^{8} \mathrm{P}$. Patriarca and R. E. Clausing, ANP Quar. Prog. Rep. June 10,1955, ORNL-1896, p 145.
} 


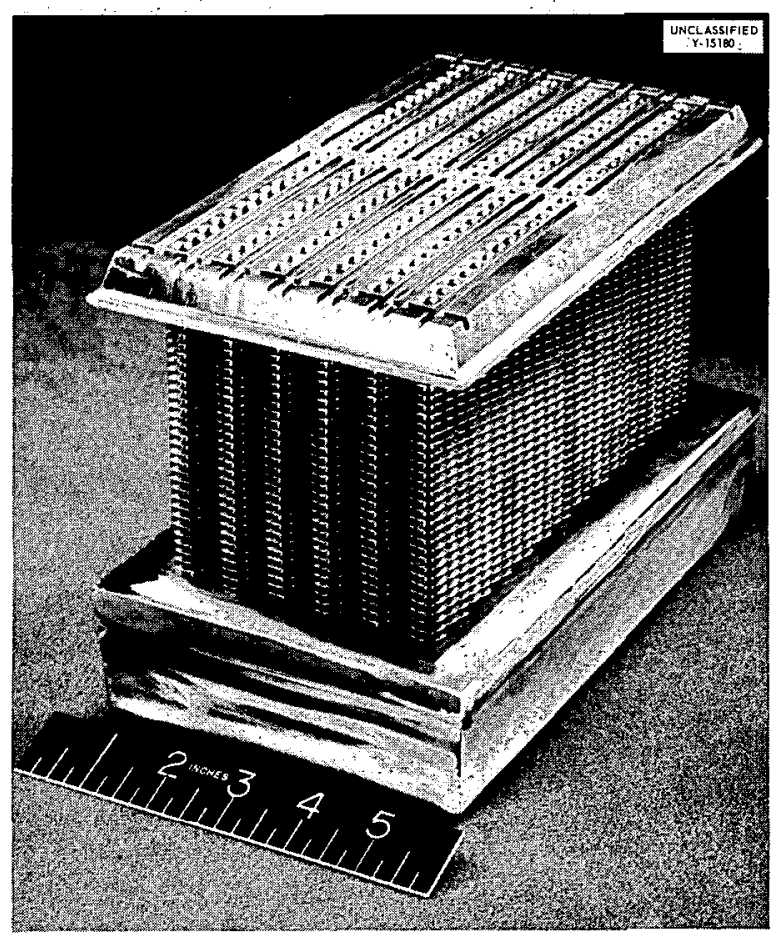

Fig. 53. Core of Cornell Aeronautical Laboratory Sodium-to-Air Radiator No. 2. "Floating header" can be seen at bottom of unit. (Secret with caption)

layer of nickel-phosphorus followed by a 0.003-in. layer of copper on the surface to be brazed.

Figure 55 shows on exploded view of an actual valve subassembly which is similar to the assembly for self-welding studies, except for the omission of several copper-foil disks. Copper powder was substituted for these disks. The powder was placed in recesses especially provided for this purpose. Figure 56 shows these components after having been brazed, prior to finish-machining and assembling into a test valve.

\section{BRAZING-ALLOY DEVEL OPMENT}

\section{High-Temperature Oxidation Tests}

An evaluation of the static oxidation resistance of several high-temperature brazing alloys has been conducted at both 1500 and $1700^{\circ} \mathrm{F}$. Cyclic oxidation tests on these alloys have now been initiated, and the results on some of the alloys at 1500 and $1700^{\circ} \mathrm{F}$ are presented in Tables 19 and 20.

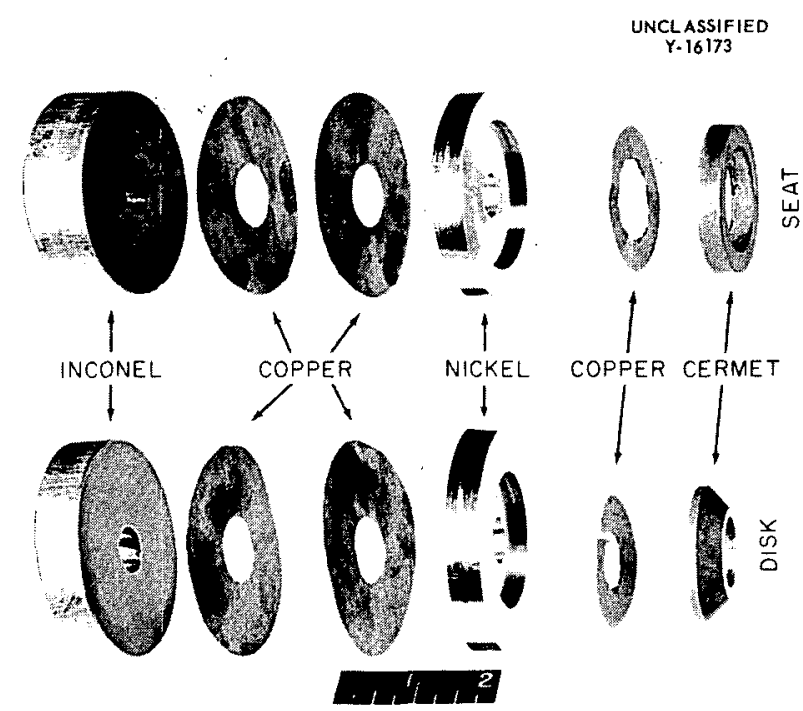

(a) ASSEMBLIES PRIOR TO BRAZING

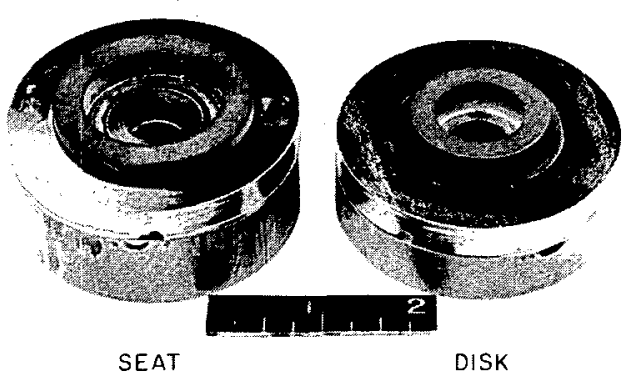

(b) BRAZED ASSEMBLIES

Fig. 54. Component Parts of TiC-Ni Valve Seat and Disk and Completed Experimental Units.

These 500-hr test samples were subjected to approximately 200 air cools from these temperatures, and the extent of attack is compared with that found in static tests. At $1500^{\circ} \mathrm{F}$, a major portion of the alloys have good resistance to attack under both conditions. However, it can be seen that the extent of oxidation on thermally cycled brazed joints at $1700^{\circ} \mathrm{F}$ is increased over that found on joints that were held at constant temperature. The Coost Metals 52 alloy, which is used extensively in brazing high-conductivity fin radiators, was attacked severely at $1700^{\circ} \mathrm{F}$, while the chromiumbearing Coast Metals 53 was not. This latter alloy should, therefore, be seriously considered for this fabrication application, even though a higherquality hydrogen atmosphere may be required to obtain flow with chromium-containing alloys. 


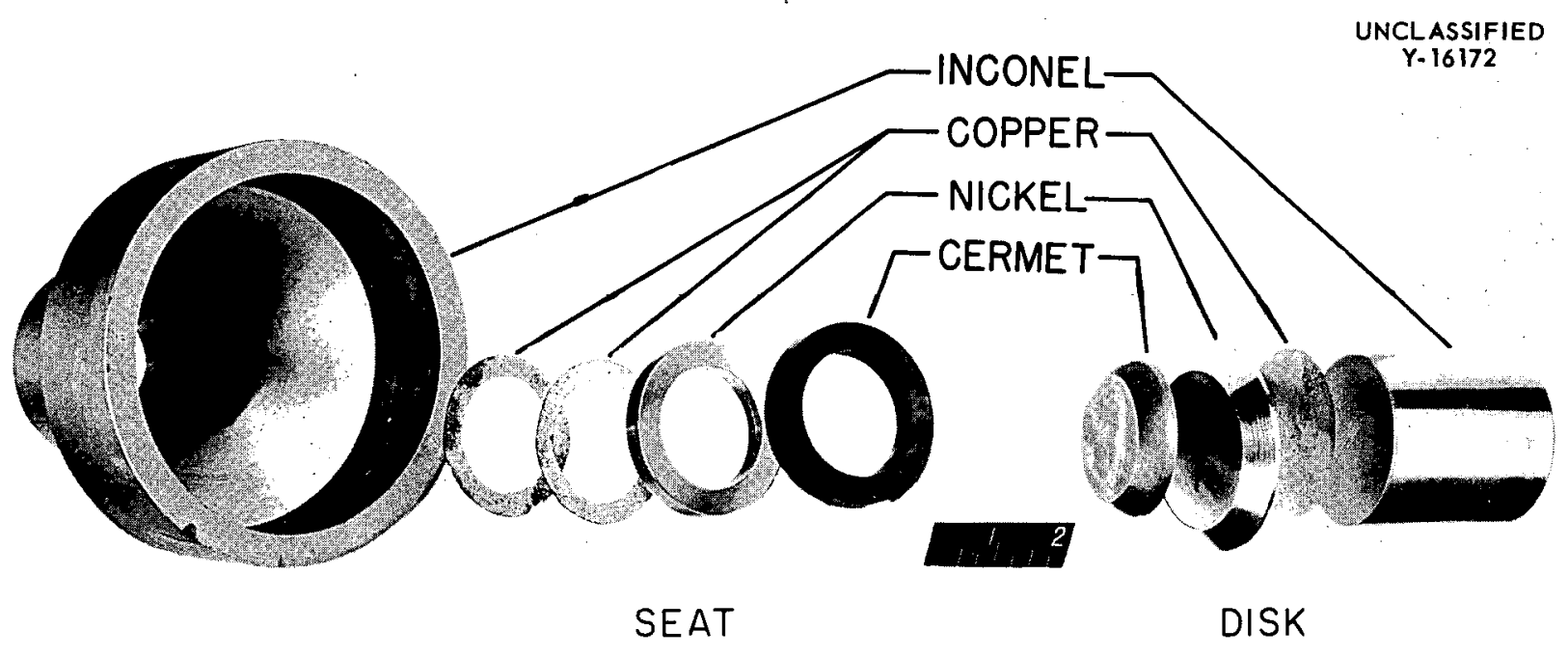

Fig. 55. Exploded View of Actual Cermet-Valve Subas sembly.

TABLE 19. OXIDATION RESISTANCE OF DRY-HYDROGEN-BRAZED INCONEL T.JOINTS AT $1500^{\circ} \mathrm{F}^{\star}$

\begin{tabular}{|c|c|c|}
\hline Brazing Alloy & $\begin{array}{l}\text { Oxidation for } 500 \mathrm{hr} \\
\text { in Static Air }{ }^{\star *}\end{array}$ & $\begin{array}{c}\text { Oxidation for } 500 \mathrm{hr} \text {, with } 190 \text { Air Cools } \\
\text { to Room Temperature** }\end{array}$ \\
\hline $82 \mathrm{Au}-18 \mathrm{Ni}$ & Very slight & Slight \\
\hline $90 \mathrm{Au}-10 \mathrm{Co}$ & Very slight & Slight \\
\hline Wall Colmonoy Nicrobraz & Slight & Slight \\
\hline Wall Colmonoy Low-Melting Nicrobraz & Slight & Slight \\
\hline Coast Metals 50 & Slight & Slight \\
\hline Coast Metals 53 & Slight & Slight \\
\hline Coast Metals NP & Slight & Slight \\
\hline General Electric 81 & Slight & Slight \\
\hline $75 \mathrm{Ni}-25 \mathrm{Ge}$ & Slight & Slight \\
\hline $65 \mathrm{Ni}-25 \mathrm{Ge}-10 \mathrm{Cr}$ & Slight & Slight \\
\hline $70 \mathrm{Ni}-13 \mathrm{Ge}-10 \mathrm{Cr}-6 \mathrm{Si}$ & Slight & Slight \\
\hline $50 \mathrm{Ni}-25 \mathrm{Mo}-25 \mathrm{Ge}$ & Slight & Slight \\
\hline $80 \mathrm{Ni}-10 \mathrm{P}-10 \mathrm{Cr}$ & Slight & Slight \\
\hline $60 \mathrm{Pd}-37 \mathrm{Ni}-3 \mathrm{Si}$ & Slight & Slight \\
\hline $92 \mathrm{Pd}-8 \mathrm{Al}$ & Very slight & Moderate \\
\hline Coast Metals 51 & Slight & Moderate \\
\hline Coast Metals 52 & Slight & Moderate \\
\hline $90 \mathrm{Ni}-10 \mathrm{P}$ & Slight & Moderate \\
\hline $90 \mathrm{Pd}-10 \mathrm{Ge}$ & Slight & Severe \\
\hline $68 \mathrm{Ni}-32 \mathrm{Sn}$ & Moderate & Severe \\
\hline $35 \mathrm{Ni}-55 \mathrm{Mn}-10 \mathrm{Cr}$ & Severe & Severe \\
\hline $64 \mathrm{Ag}-33 \mathrm{Pd}-3 \mathrm{Mn}$ & Severe & Severe \\
\hline Copper & Complete & Complete \\
\hline $40 \mathrm{Ni}-60 \mathrm{Mn}$ & Complete & Complete \\
\hline $80 \mathrm{Au}-20 \mathrm{Cu}$ & Complete & Complete \\
\hline
\end{tabular}

*Alloys are listed in order of decreasing oxidation resistance.

**Very slight, less than 1 mil penetration; slight, 1 to 2 mils of penetration; moderate, 2 to 5 mils of penetration; severe, greater than 5 mils of penetration; complete, fillet completely destroyed. 


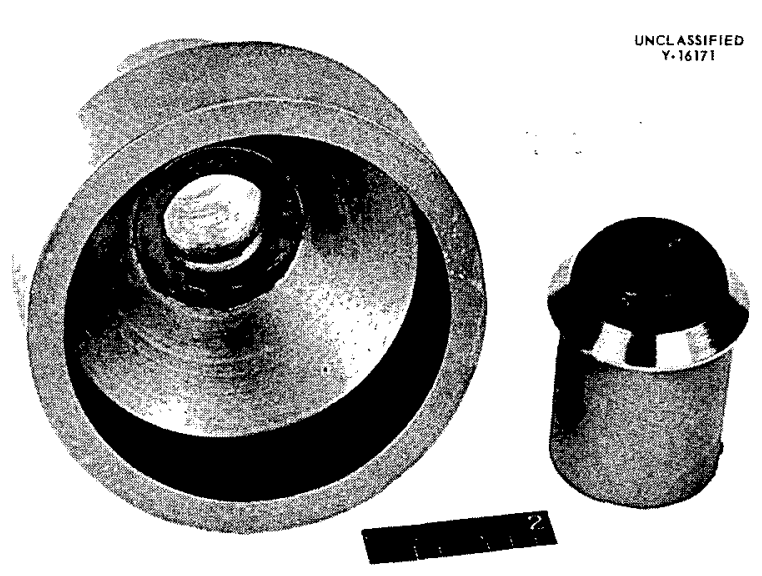

Fig. 56. Brazed Cermet-Valve Subassembly, Prior to Machining.

\section{Melting-Point Studies}

Melting-point studies on high-temperature brazing alloys are being made by the sintered conical sample method. These cones are sintered from fine powder in a Lavite mold and heated at various temperatures on a thin nickel sheet in a dry-hydrogen atmosphere. The results of studies on a typical brazing alloy, Coast Metals 52, are shown in Fig. 57.

\section{PHYSICAL PROPERTIES OF HASTELLOY B}

It has been shown that the physical properties of wrought Hostelloy $B$ alloy that has been solutionannealed at $2100^{\circ} \mathrm{F}$ for $2 \mathrm{hr}$ are directly influenced by the precipitation occurring at temperatures within the intended operational range of ANP reactors and heat exchangers. An extensive program is now

TABLE 20. OXIDATION RESISTANCE OF DRY-HYDROGEN-BRAZED INCONEL T-JOINTS AT $1700^{\circ} \mathrm{F}^{*}$

\begin{tabular}{|c|c|c|}
\hline Brazing Alloy & $\begin{array}{l}\text { Oxidation for } 500 \mathrm{hr} \\
\text { in Static Air }{ }^{\star \star}\end{array}$ & $\begin{array}{c}\text { Oxidation for } 500 \mathrm{hr} \text {, with } 220 \text { Air Cools } \\
\text { to Room Temperature }{ }^{\star}\end{array}$ \\
\hline Wall Colmonoy Nicrobraz & Slight & Slight \\
\hline Coast Metals 53 & Slight & Slight \\
\hline Wall Colmonoy Low-Melting Nierobraz & Slight & Moderate \\
\hline Coast Metals 50 & Slight & Moderate \\
\hline $60 \mathrm{Pd}-40 \mathrm{Ni}$ & Slight & Moderate \\
\hline $92 \mathrm{Pd}-8 \mathrm{Al}$ & Slight & Moderate \\
\hline Coast Metals 51 & Slight & Severe \\
\hline Coast Metals 52 & Slight & Severe \\
\hline Coast Metals NP & Moderate & Moderate \\
\hline General Electric 81 & Moderate & Moderate \\
\hline $75 \mathrm{Ni}-25 \mathrm{Ge}$ & Moderate & Moderate \\
\hline $65 \mathrm{Ni}-25 \mathrm{Ge}-10 \mathrm{Cr}$ & Moderate & Moderate \\
\hline $50 \mathrm{Ni}-25 \mathrm{Mo}-25 \mathrm{Ge}$ & Moderate & Moderate \\
\hline $82 \mathrm{Au}-18 \mathrm{Ni}$ & Moderate & Severe \\
\hline $90 \mathrm{Au}-10 \mathrm{Co}$ & Severe & Severe \\
\hline $90 \mathrm{Pd}-10 \mathrm{Ge}$ & Complete & Complete \\
\hline $68 \mathrm{Ni}-32 \mathrm{Sn}$ & Complete & Complete \\
\hline $64 \mathrm{Ag}-33 \mathrm{Pd}-3 \mathrm{Mn}$ & Complete & Complete \\
\hline $40 \mathrm{Ni}-60 \mathrm{Mn}$ & Complete & Complete \\
\hline $35 \mathrm{Ni}-55 \mathrm{Mn}-10 \mathrm{Cr}$ & Complete & Complete \\
\hline $80 \mathrm{Au}-20 \mathrm{Cu}$ & Complete & Complete \\
\hline $40 \mathrm{Ni}-60 \mathrm{Mn}$ & Complete & Complete \\
\hline Copper & Complete & Complete \\
\hline
\end{tabular}

*Alloys are listed in order of decreasing oxidation resistance.

** Very slight, less than 1 mil penetration; slight, 1 to 2 mils of penetration; moderate, 2 to 5 mils of penetration; severe, greater than 5 mils of penetration; complete, fillet completely destroyed. 


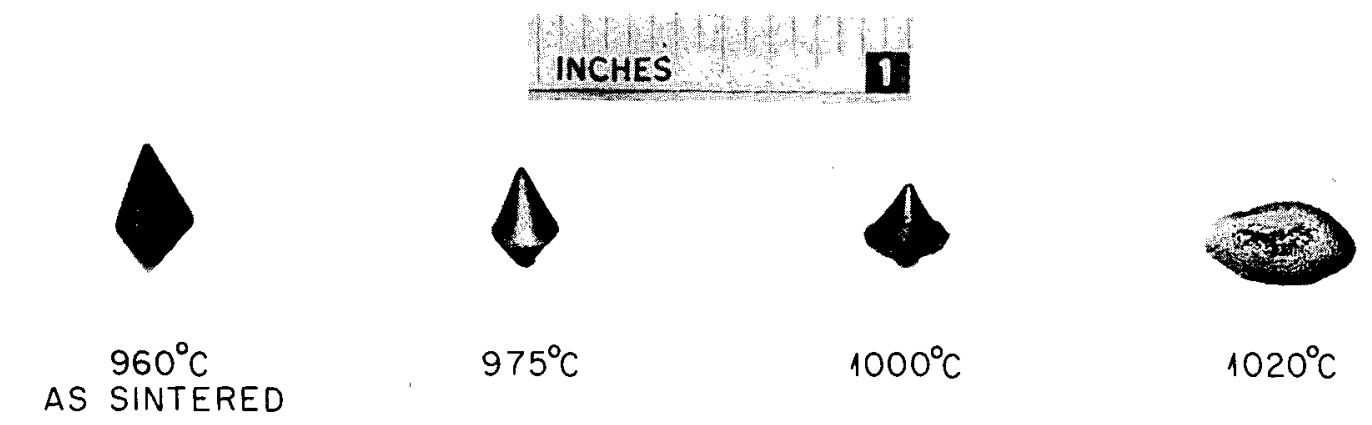

Fig. 57. Melting-Point Determination of High-Temperature Brazing Alloys as Applied to Coast Metals 52.

under way to obtain short-time tensile-strength data for this material after it is heated at temperatures from 1100 to $1600^{\circ} \mathrm{F}$ for periods of time ranging from 100 to $1000 \mathrm{hr}$. Since typical microstructures obtained from these heat treatments have been studied and photographed, a correlation is being made between the physical properties and the corresponding microstructures. As a result of this investigation, more comprehensive information on the high-temperature properties of this material is being obtained. The relative merits of various preaging heat treatments of Hastelloy $B$ are also being studied, and it is hoped that, as a result of this work, a procedure can be developed which will stabilize the microstructure sufficiently to reduce the sensitivity to high-temperature aging.

A summary of the short-time tensile data that have been obtained to date is presented in Figs. 58, 59, and 60, and in Table 21. It will be noted in Fig. 58, in which the variable of aging time was investigated, that the tensile-strength and yieldpoint curves for 500- and 1000-hr aging times reach a maximum at approximately $1300^{\circ} \mathrm{F}$, while the ductility curve reaches a minimum at this same temperature. The results of metallographic studies, discussed in the last semiannual report, 8 indicate that this is caused by the extensive precipitation of a second phase - beta or a combination of the two phases, beta and gamma - throughout the matrix. In Figs. 59 and 60, a comparison is made of the high-temperature tensile properties obtained by a special spheroidization heat treatment with those of solution-annealed material, both in the unaged and aged (1000 hr at testing temperature) conditions, while the room-temperature

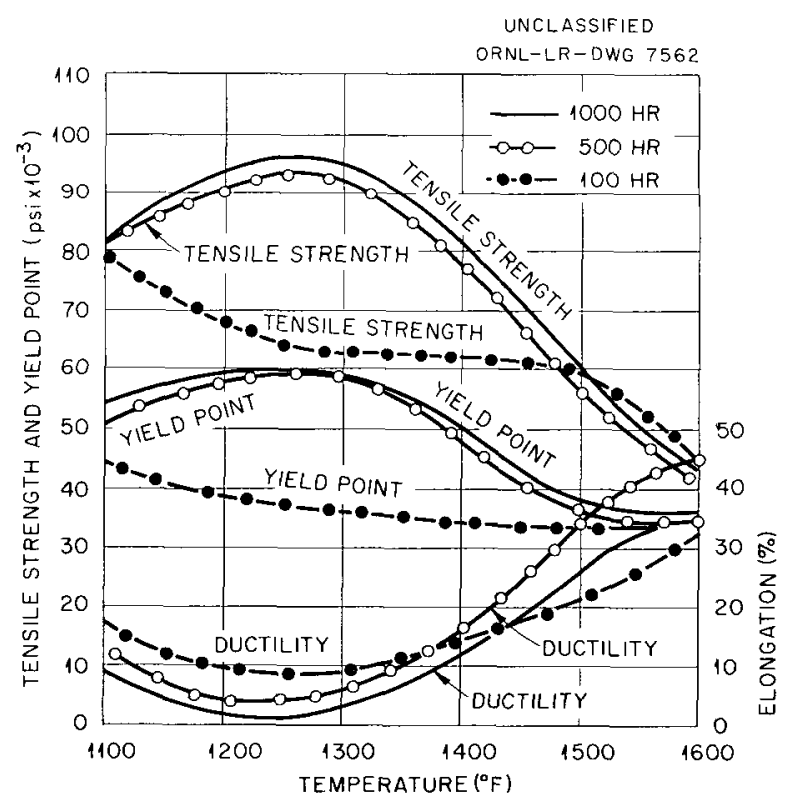

Fig. 58. High-Temperature Tensile Properties of Aged and Solution-Annealed Hastelloy B.

properties are presented in Table 21. Although this spheroidization treatment was intended to produce a stable microstructure between 1300 and $1600^{\circ} \mathrm{F}$, it can be noted that the ductility is lowered considerably in the 1100 to $1300^{\circ} \mathrm{F}$ temperature region. Even though very high tensile and yield strengths were obtained with this treatment, the low high-temperature ductility would probably prevent its useful application above $1000^{\circ} \mathrm{F}$.

Short-time tensile tests conducted after long-time aging of Hastelloy $B$ at elevated temperatures also 
TABLE 21. ROOM-TEMPERATURE TENSILE PROPERTIES OF HASTELLOY B

\begin{tabular}{lcc}
\hline & Spheroidized & Solution-annealed 2 hr at $2100^{\circ} \mathrm{F}$ \\
\hline Tensile strength, psi & $175,000-185,000$ & $125,000-130,000$ \\
Yield strength, psi & $100,000-115,000$ & $50,000-60,000$ \\
Elongation, \% & $15-20$ & $55-65$ \\
\hline
\end{tabular}

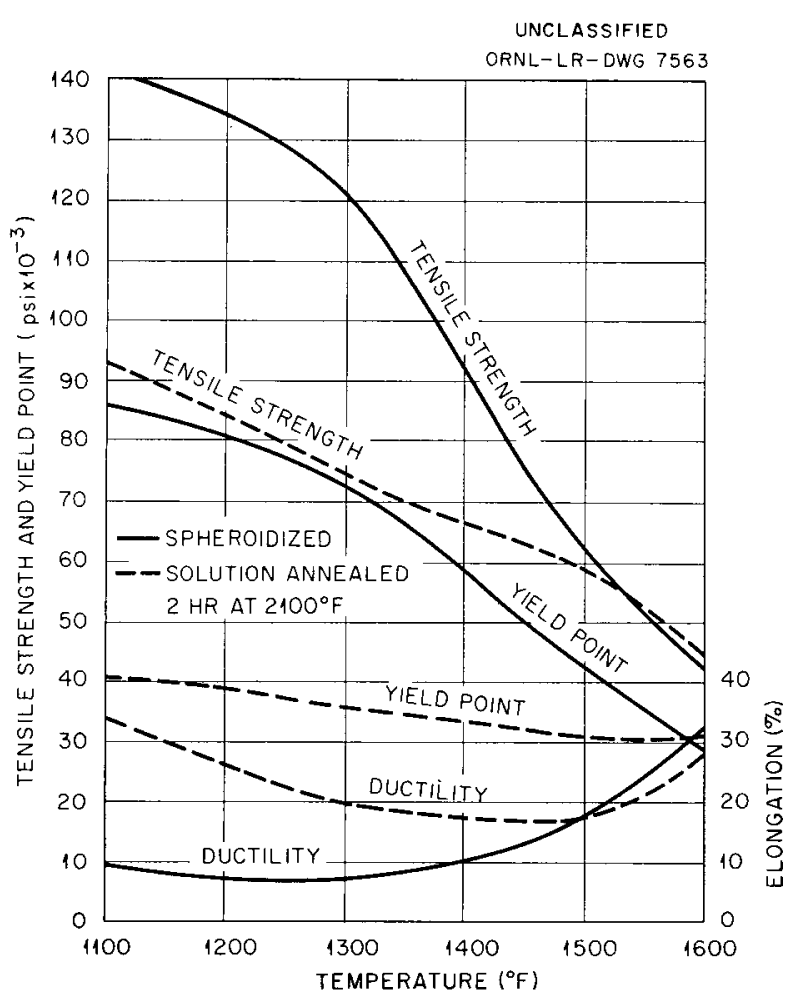

Fig. 59. High-Temperature Tensile Properties of Hastelloy $B$ in the Solution-Annealed and Spheroidized Conditions.

indicate that residual stresses not removed after a cold-working operation are quite detrimental to the ductility of this alloy. Tensile specimens, which had been cast from sheet that had been cold-reduced $20 \%$ in thickness, were aged at temperatures from 1100 to $1500^{\circ} \mathrm{F}$ in inert atmospheres and tested at both room and elevated temperatures. The data in Tables 22 and 23 show considerably lower ductility for these specimens than for specimens that were annealed before aging. Microstructural studies indicate that cold

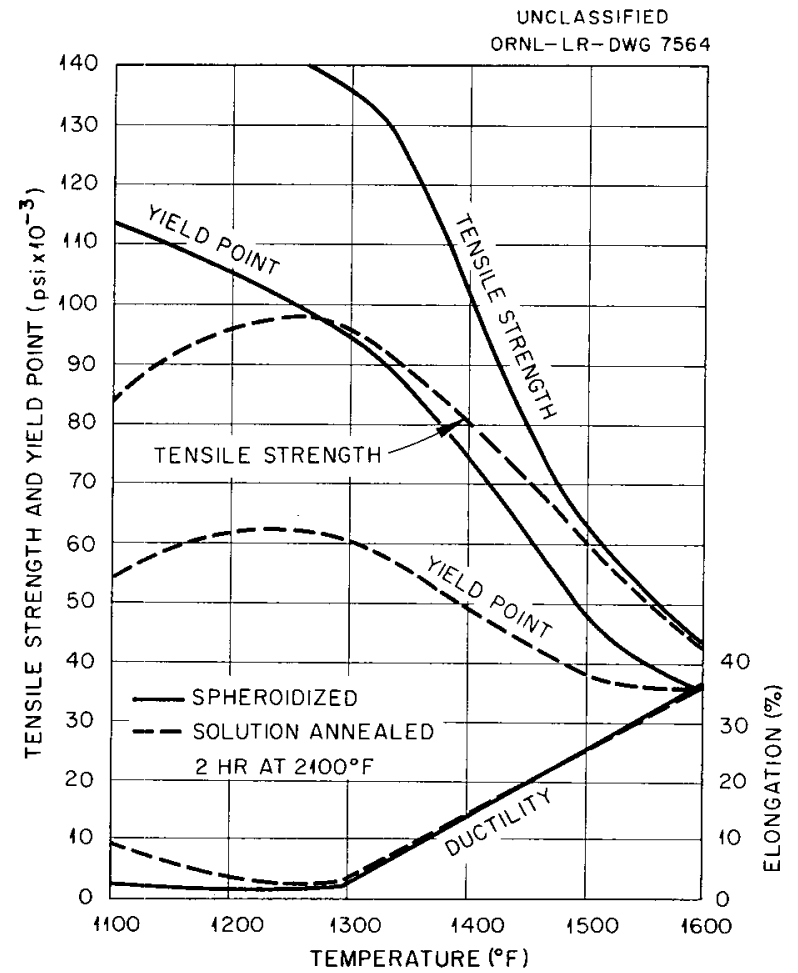

Fig. 60. High-Temperature Tensile Properties of Spheroidized Hastelloy B and Solution-Annealed and Aged Hastelloy B.

work induces precipitation to occur in larger quantities and perhaps in smaller particles than in annealed material. It is assumed that these particles effectively inhibit slip and cause the increased tensile strengths and radically reduced ductilities observed. It will be noted that the ductility of specimens aged at $1500^{\circ} \mathrm{F}$ is considerably greater than the ductility of those aged at $1400^{\circ} \mathrm{F}$. This may be due to the reduced amount of beta phase which may be stable at $1500^{\circ} \mathrm{F}$. (Gamma phase appears to be much more prevalent at this higher temperature than beta.) 
TABLE 22 PHYSICAL PROPERTIES OF AGED* HASTELLOY B AS DETERMINED BY SHORT-TIME TENSILE TESTS

\begin{tabular}{cllccc}
\hline $\begin{array}{c}\text { Aging } \\
\begin{array}{c}\text { Temperature } \\
\left({ }^{\circ} \mathrm{F}\right)\end{array}\end{array}$ & $\begin{array}{c}\text { Aging } \\
\text { Time } \\
(\mathrm{hr})\end{array}$ & $\begin{array}{c}\text { Test Temperature } \\
\left({ }^{\circ} \mathrm{F}\right)\end{array}$ & $\begin{array}{c}\text { Ductility } \\
(\%)\end{array}$ & $\begin{array}{c}\text { Tensile } \\
\text { Strength } \\
(\mathrm{psi})\end{array}$ & $\begin{array}{c}\text { Yield } \\
\text { Point } \\
(\mathrm{psi})\end{array}$ \\
\hline 1100 & 500 & Room temperature & 3.0 & 181,300 & 154,600 \\
1100 & 500 & 1100 & 2.5 & 130,500 & 115,500 \\
1100 & 500 & 1100 & 3.5 & 122,900 & 104,400 \\
1300 & 200 & Room temperature & 0.8 & 173,500 & 150,000 \\
1300 & 200 & Room temperature & 0.5 & 191,600 & 148,000 \\
1400 & 500 & Room temperature & 3.8 & 164,000 & 88,200 \\
1400 & 500 & 1400 & 6.3 & 84,500 & \\
1500 & 500 & Room temperature & 20.0 & 163,000 & 100,000 \\
1500 & 500 & 1500 & 30.0 & 64,600 & \\
\hline
\end{tabular}

*Aged from a condition of $20 \%$ residual cold work.

TABLE 23. TYPICAL PHYSICAL PROPERTIES OF AGED* HASTELLOY B AS DETERMINED BY SHORT-TIME TENSILE TESTS

\begin{tabular}{cllcrr}
\hline $\begin{array}{c}\text { Aging } \\
\text { Temperature } \\
\left({ }^{\circ} \mathrm{F}\right)\end{array}$ & $\begin{array}{c}\text { Aging } \\
\text { Time } \\
(\mathrm{hr})\end{array}$ & $\begin{array}{c}\text { Test Temperature } \\
\left({ }^{\circ} \mathrm{F}\right)\end{array}$ & $\begin{array}{c}\text { Ductility } \\
(\%)\end{array}$ & $\begin{array}{c}\text { Tensile } \\
\text { Strength } \\
(\mathrm{psi})\end{array}$ & $\begin{array}{c}\text { Yield } \\
\text { Point } \\
(\mathrm{psi})\end{array}$ \\
\hline 1100 & 500 & Room temperature & 14.0 & 126,000 & 78,000 \\
1100 & 500 & 1100 & 14.0 & 91,100 & 58,600 \\
1300 & 500 & Room temperature & 6.0 & 92,600 & 6,000 \\
1300 & 500 & 1300 & 12.5 & 140,600 & 90,000 \\
1400 & 500 & Room temperature & 20.0 & 128,000 & 73,500 \\
1400 & 500 & 1400 & 10.0 & 76,500 & 109,800 \\
1500 & 500 & Room temperature & 12.5 & 63,100 & 54,900 \\
1500 & 500 & 1500 & 37.5 & &
\end{tabular}

*Aged from a fully annealed condition.

Specimens are now being aged in air to determine if any embrittling effect can be noted due to oxidation or nitriding of this alloy. Alloys of compositions closely related to Hastelloy $B$ have been made and are now being examined to aid in the positive identification of the phases present in Hastelloy $B$. The identity of the phases present will aid considerably in the analysis of the effects of heat treatments.

\section{WELDING OF NIOBIUM (COLUMBIUM) THERMAL-CONVECTION LOOPS}

The fabrication of several type 310 stainlesssteel-clad niobium thermal-convection loops was required so as to obtain information on the resistance of this material to dynamic corrosion. In preparation for the fabrication of these loops, test specimens of 0.020 -in. niobium sheet were machine Heliarc-welded, with both argon and helium as the 
shielding gases. If excellent shielding is utilized, welds made with both gases are ductile. However, manual welds of the same material were found to be quite brittle, indicating that the thigh welding speed possible with machine welding is beneficial. This high rate of travel minimized the time interval over which the weld metal was molten, with a consequent decrease in the quantity of atmospheric contamination.

The dry-box manual welding of elad niobium loops was initiated, with a helium atmosphere being used in the chamber. A loop was fabricated which was pressure-tight to $35 \mathrm{psi}$ of helium. However, several extremely small pinholes were found when the loop was leak-tested with a helium mass spectrograph leak detector. Since these pinholes were attributed to the difficulty of torch manipulation that is inherent with the use of helium, argon was used in the dry box during the fabrication of four subsequent loops. These were all found to be leak-tight.

The welding of the stainless steel cladding was completed according to normal practice, and the loops were sent to the Corrosion Group for testing. 


\title{
FABRICATION
}

\author{
J. H. Coobs \\ H. Inouye \\ T. K. Roche \\ Metallurgy Division \\ J. P. Page \\ M. R. D'Amore \\ Pratt \& Whitney Aircraft
}

\section{DEVELOPMENT OF NICKEL-BASE ALLOYS}

\section{Hastelloy B}

Extrusion Experiments. - Two extruded tube blanks that had been shipped to the Superior Tube Co. for reduction to small-diameter tubing were processed. The tube blanks were made from wrought and cast material, respectively. The tube blank made from a vacuum-melted, cast billet fractured during the first reduction operation. On the other hand, the blank made from a wrought billet was successfully processed; namely, seamless tubing $1 \frac{1}{2}$ in. in outside diameter with a wall thickness of $0.025 \mathrm{in}$. was reduced to $0.187 \mathrm{in}$. in outside diameter by 0.017 in. in wall thickness. It was found that severe reduction schedules were permissible and that intermediate stress-relieving heat treatments were unnecessary.

Because of the successful extrusion of Hastelloy $B$ at this Laboratory, 12 extrusions were attempted by the Babcock and Wilcox Company in order to determine the commercial feasibility of making tube blanks for seamless tubing. This effort was supported by the Haynes Stellite Company.

Each of the 12 extrusion attempts was unsuccessful because of severe cracking of the tube blanks or of failure to extrude (stickers). The extrusion temperatures were between 2000 and $2250^{\circ} \mathrm{F}$. On the basis of experience at ORNL, it is concluded that soaking time, press capacity, and improper temperatures were the main causes for the unsuccessful extrusions.

Since this effort was the direct result of work performed at the Laboratory, additional experiments seemed advisable to (1) verify the recommended extrusion conditions for this alloy, (2) verify the superior redrawing properties of the extruded tube blanks by using a different heat of material, and (3) devise methods for reducing the pressure requirements during extrusion.

Two billets of Hastelloy B were successfully extruded into tube blanks at an extrusion ratio of $5 \frac{1}{2}$ to 1. The recommended conditions were verified, namely, temperature, $2000^{\circ} \mathrm{F}$; heating time,
45 min per inch of billet thickness; and pressure, 80 to $90 \mathrm{tsi}$. These tube blanks are scheduled for redrawing into small-diameter tubing.

A Hastelloy B billet canned with $1 / 16^{-i n}$. Inconel was extruded at $2100^{\circ} \mathrm{F}$ at an extrusion ratio of $5 \frac{1}{2}$ to 1. The pressure requirement for this extrusion was 55 tsi. A second canned extrusion was made at an extrusion ratio of 9 to 1 at $2100^{\circ} \mathrm{F}$ with fair success. Previously, at this temperature, uncanned billets cracked severely at the lower extrusion ratio and failed to extrude at the higher ratio.

The use of Inconel as a can material for Hastelloy serves a threefold purpose. Besides acting as a lubricant, the Inconel provides the thermally bonded oxidation-resistant layer desired for this alloy. In a high-temperature air stream, the formation of corrosive $\mathrm{MoO}_{3}$ vapor will be inhibited, thereby minimizing the possibility of catastrophic-type oxidation in the surrounding structural material. Moreover, this clad will probably enhance the tube-reducing properties of Hastelloy B since Inconel is not subject to "heat cracking," that is, surface cracking during anneal. ing of the cold-worked material, which is attributed to poor thermal conductivity and to a high workhardening rate.

Hot Forging. - Attempts to roll extruded rod at $2000^{\circ} \mathrm{F}$ have been unsuccessful because of severe cracking of the material after several $5 \%$ reduction passes. Smaller vacuum melts of Hastelloy B that contained $0.3 \% \mathrm{Ce}$ added as a Ce-Al master alloy also cracked during hot reduction. It was reported ${ }^{\prime}$ that cerium additions of $0.03 \%$ improved the hot-fabrication properties of Hastelloy $B$; the results of subsequent work indicate that cerium should not be added in excess of $0.1 \%$.

\section{Iron-Molybdenum-Nickel Alloy}

This alloy, $4 \% \mathrm{Fe}-28 \% \mathrm{Mo}-68 \% \mathrm{Ni}$, is the nominal composition of Hastelloy $B$ but without the

\footnotetext{
'H. Inouye, J. H. Coobs, and M. R. D'Amore, ANP Quar. Prog. Rep. March 10, 1955, ORNL-1864, p 97.
} 
"tramp" elements vanadium, silicon, manganese, cobalt, chromium, tungsten, and aluminum. Vacuummelted slab ingots weighing $3 \mathrm{lb}$ and $0.500 \mathrm{in}$. thick were prepared and were rolled at $2100^{\circ} \mathrm{F}$ into 0.150-in.-thick sheet. The material shows no tendency to crack during hot-rolling under moderate reduction schedules. The microstructure of the alloy in the as-cast condition shows a random distribution of a second phase, which appears to be an oxide. The source of this phase might be traced to the starting material or to the melting practice. It is becoming increasingly evident that the poor fabricability of Hastelloy $B$ at high temperatures is related to the impurity content. On the other hand, the superior strength of commercial Hastelloy B may be derived from these impurities. The room-temperature tensile data for $4 \% \mathrm{Fe}-28 \% \mathrm{Mo}-68 \% \mathrm{Ni}$ alloy are tabulated below:

$\begin{array}{ccc} & \text { Annealed } & \begin{array}{c}\text { Annealed and Aged } \\ \text { for } 500 \mathrm{hr} \\ \text { at } 1300^{\circ} \mathrm{F}\end{array} \\ \begin{array}{c}\text { Tensile strength, } \\ \text { psi }\end{array} & 130,000 & 137,000 \\ \text { Elongation, \% } & 60 & 2 \frac{1}{2}\end{array}$

The stress-rupture properties at $1500^{\circ} \mathrm{F}$ for specimens of this alloy that were annealed in hydrogen at $2100^{\circ} \mathrm{F}$ for $1 \mathrm{hr}$ are as follows:

$\begin{array}{lrl}\text { Stress, psi } & 8000 & 10,000 \\ \text { Time to rupture, hr } & 130 & 49 \\ \text { Elongation, \% } & 10 & 9\end{array}$

The strength and ductility of this alloy are comparable to the commercial alloy at room temperature but appear to be poor at $1500^{\circ} \mathrm{F}$.

\section{Molybdenum-Nickel Binary Alloys}

The physical property data for the alloys $20 \%$ $\mathrm{Mo}-80 \% \mathrm{Ni}, 24 \% \mathrm{Mo}-76 \% \mathrm{Ni}$, and $32 \% \mathrm{Mo}-68 \% \mathrm{Ni}$ have been reported. ${ }^{2}$ In addition a $15 \% \mathrm{Mo}-85 \% \mathrm{Ni}$ alloy has been included in the investigation in an effort to determine the effect of molybdenum concentration on the corrosion properties of these binary alloys. Tubing for thermal-convection loops has been made. Several rods of this latter composition were extruded so as to provide starting material for weld-rod fabrication. One oxidation

\footnotetext{
2lbid., p 103.
}

test of this alloy has been completed in static air at $1500^{\circ} \mathrm{F}$, and it indicates a lower rate of oxidation than was observed for a $20 \% \mathrm{Mo}-80 \% \mathrm{Ni}$ alloy. Additional tests are planned as a supplement to the present data. During the course of this investigation, it has become apparent that the rate of oxidation of binary $\mathrm{Mo}-\mathrm{Ni}$ alloys is not a function of the molybdenum content.

Both room- and elevated-temperature tensile tests of the Mo-Ni alloy have been completed. Erratic results were obtained in room-temperature tensile tests of aged specimens. The tensile strength of the alloy is low at all test temperatures, and low elongations are observed at test temperatures above $1300^{\circ} \mathrm{F}$. The results of these tests are listed in Table 24.

\section{Molybdenum-Nickel Ternary Alloys}

A screening program was initiated to observe the effects of additions of alloying elements to Mo-Ni base alloys. The alloy compositions investigated all have molybdenum, with the third element added at the expense of the nickel. The ternary systems that have been evaluated are:

2 to $10 \% \mathrm{Nb}(\mathrm{Cb})-20 \%$ Mo-balance $\mathrm{Ni}$

3 to $10 \% \mathrm{Nb}-20 \%$ Mo-balance $\mathrm{Ni}$

$2 \% \mathrm{Al}-20 \% \mathrm{Mo}-78 \% \mathrm{Ni}$

$2 \% \mathrm{~V}-20 \% \mathrm{Mo}-78 \% \mathrm{Ni}$

$1 \% \mathrm{Zr}-20 \% \mathrm{Mo}-79 \% \mathrm{Ni}$

$1 \% \mathrm{Ti}-20 \% \mathrm{Mo}-79 \% \mathrm{Ni}$

Physical property data for alloys containing 2 to $10 \%$ niobium (columbium) were reported previously. ${ }^{3}$ The Al-Mo-Ni alloys were investigated because exceptional creep properties were reported in the literature for this alloy system. Forgeability studies at high temperature were conducted on $100 \mathrm{~g}$ arc melts containing from 2 to $10 \%$ aluminum. The alloys containing less than $5 \%$ aluminum were found to be forgeable at $2100^{\circ} \mathrm{F}$. Further studies will be conducted on this alloy system.

Vanadium, zirconium, and titanium additions were investigated in an effort to improve the low ductility of the $20 \% \mathrm{Mo}-80 \% \mathrm{Ni}$ alloy at elevated temperatures. No difficulties were experienced in the hot-rolling of these alloys.

Preliminary room-temperature tensile-test data for the alloys containing aluminum, vanadium,

\footnotetext{
${ }^{3}$ Ibid., p 100.
} 
zirconium, and titanium in both the annealed and aged conditions are tabulated in Table 25. The specimens aged at $1650^{\circ} \mathrm{F}$ for long periods of time show lower strengths and ductilities than did the specimens given other treatments. The specimens aged at $1650^{\circ} \mathrm{F}$ were exposed to a hydrogen atmosphere; whereas treatments on the other specimens were conducted under a helium atmosphere or in evacuated quartz capsules.

Twenty Mo-Ni alloys containing between 3 and $10 \%$ chromium have been evaluated in stressrupture and tensile tests. The quantity of seamless tubing made for corrosion testing has been limited because the alloys shattered during ex- trusion. Although sound rod and tube blanks have been made at extrusion temperatures of $2200^{\circ} \mathrm{F}$, consistent results could not be obtained. The extrusion billets were inspected by $x$-ray and gamma-radiation techniques, prior to extrusion. No correlation between the soundness of the starting material and the results of extrusion was found. A further investigation of melting practice revealed that all the $\mathrm{Cr}-\mathrm{Mo}-\mathrm{Ni}$ alloys that were melted in a zirconia crucible had shown poor extrusion properties. Prior melts made in an $\mathrm{MgO}$ crucible were sound during subsequent extrusion. It is possible that a thin surface layer of the $\mathrm{MgO}$ crucible was reduced to magnesium under vacuum

TABLE 24. RESULTS OF TENSILE TESTS OF AN $85 \% \mathrm{Ni}-15 \%$ Mo ALLOY

\begin{tabular}{|c|c|c|c|c|}
\hline Condition of Test Specimen* & $\begin{array}{c}\text { Test Temperature } \\
\left({ }^{\circ} \mathrm{F}\right)\end{array}$ & $\begin{array}{l}\text { Yield Point, } \\
0.2 \% \text { Offset } \\
\text { (psi) }\end{array}$ & $\begin{array}{l}\text { Tensile } \\
\text { Strength } \\
\text { (psi) }\end{array}$ & $\begin{array}{c}\text { Elongation in 2-in. } \\
\text { Gage Lengths } \\
(\%)\end{array}$ \\
\hline Annealed $1 \mathrm{hr}$ at $2100^{\circ} \mathrm{F}$ & Room & 32,100 & 60,400 & 15 \\
\hline Annealed, aged $284 \mathrm{hr}$ at $1300^{\circ} \mathrm{F}$ & Room & 32,700 & 70,200 & 17.5 \\
\hline Annealed, aged $284 \mathrm{hr}$ at $1500^{\circ} \mathrm{F}$ & Room & 32,000 & 99,700 & 50 \\
\hline Annealed, aged $284 \mathrm{hr}$ at $1650^{\circ} \mathrm{F}$ & Room & 31,500 & 68,400 & 21 \\
\hline \multirow[t]{5}{*}{ Ar realed $1 \mathrm{hr}$ at $2100^{\circ} \mathrm{F}$} & 1100 & 18,700 & 39,900 & 16.5 \\
\hline & 1300 & 17,850 & 30,300 & 7.5 \\
\hline & 1500 & 17,000 & 26,000 & 5.0 \\
\hline & 1600 & 16,600 & 23,200 & 6.3 \\
\hline & 1650 & 16,000 & 20,700 & 9.0 \\
\hline
\end{tabular}

*Sheet, 0.065 in. thick.

TABLE 25. ROOM-TEMPERATURE TENSILE STRENGTHS OF SEVERAL MOLYBDENUM-NICKEL TERNARY ALLOYS

\begin{tabular}{|c|c|c|c|}
\hline $\begin{array}{l}\text { Alloy Composition } \\
\text { (wt \%) }\end{array}$ & Condition & $\begin{array}{c}\text { Tensile Strength } \\
\text { (psi) }\end{array}$ & $\begin{array}{c}\text { Elongation } \\
(\%)\end{array}$ \\
\hline \multirow[t]{3}{*}{$2 \mathrm{Al}-20 \mathrm{Mo}-78 \mathrm{Ni}$} & Annealed & 150,500 & 32 \\
\hline & Annealed, aged $500 \mathrm{hr}$ at $1500^{\circ} \mathrm{F}$ & 118,500 & 59 \\
\hline & Annealed, aged $284 \mathrm{hr}$ at $1650^{\circ} \mathrm{F}$ & 70,500 & 12 \\
\hline \multirow[t]{2}{*}{$2 \mathrm{~V}-20 \mathrm{Mo}-78 \mathrm{Ni}$} & Annealed & 117,000 & 32 \\
\hline & Annealed, aged $284 \mathrm{hr}$ at $1300^{\circ} \mathrm{F}$ & 127,000 & 30 \\
\hline \multirow[t]{2}{*}{$\mathrm{Zr}-20 \mathrm{Mo}-79 \mathrm{Ni}$} & Annealed & 101,000 & 33 \\
\hline & Annealed, aged $284 \mathrm{hr}$ at $1300^{\circ} \mathrm{F}$ & 115,000 & 58 \\
\hline \multirow[t]{2}{*}{$1 \mathrm{Ti}-20 \mathrm{Mo}-79 \mathrm{Ni}$} & Annealed & 115,000 & 60 \\
\hline & Annealed, aged $284 \mathrm{hr}$ at $1650^{\circ} \mathrm{F}$ & 73,700 & 15.5 \\
\hline
\end{tabular}


and that the magnesium which was formed aided in purifying the melts.

The hot-rolling of extruded rods of $\mathrm{Cr}-\mathrm{Mo}-\mathrm{Ni}$ alloys in the 1950 to $2200^{\circ} \mathrm{F}$ temperature range has been unsuccessful because of severe cracking. Subsequent studies showed that the hot shortness was probably caused by oxygen contamination of the electrolytic chromium used. It was found that the addition of $0.1 \%$ cerium per $3 \%$ chromium to the melt would render these alloys hot forgeable. Further experiments have been conducted on $100-\mathrm{g}$ arc melts that contain up to $2 \%$ titanium or aluminum as deoxidants. The aluminum additions were found to be ineffective. On the other hand, titanium additions reduced the hot shortness, and it was determined that approximately $2 \%$ titanium would render a $5 \% \mathrm{Cr}-20 \% \mathrm{Mo}-75 \% \mathrm{Ni}$ alloy completely hot forgeable. Extruded rods of the hotshort alloys can be rolled into sheet at room temperature. Work-hardening data for a $3 \% \mathrm{Cr}-$ $20 \% \mathrm{Mo}-77 \% \mathrm{Ni}$ alloy are presented below. The alloys containing between 3 and $10 \%$ chromium work harden at the same rate.

Thickness Reduction

(\%)

0

10.4

21.1

30.9

45.5

52.4

63.1

Room-temperature tensile data for Cr-Mo-Ni specimens subjected to various heat treatments are listed in Table 26. The data reported are the averages of two to three tests on each alloy.

The elevated-temperature tensile-test data for specimens of $\mathrm{Cr}-\mathrm{Mo}-\mathrm{Ni}$ alloys after various aging treatments are listed in Table 27. All materials were tested at the aging temperatures listed. These results are based on single tests. The results obtained from tests on alloys containing $0.5 \%$ niobium (columbium) or up to $0.25 \%$ cerium are also included. The tensile strength and ductility of these alloys appear to be slightly increased by minor additions of niobium, An average decrease of $5 \%$ in elongation and a slight increase in tensile strength were noted for ceriumcontaining alloys. The ductilities of these alloys at elevated temperatures are low, as compared with their ductilities at room temperature. Minor additions of cerium apparently aid in obtaining higher elevated-temperature strengths in these alloys, but more tests are needed to verify this conclusion. No relationship between the physical properties and the chromium content is readily apparent in either the room- or elevated-temperature tests.

In the temperature range above $1300^{\circ} \mathrm{F}$, the alloys containing up to $10 \%$ chromium appear to be single phase. Additional studies on the microstructures will be conducted on alloys made with high-purity starting material. Further evidence of the equilibrium structure is derived from the tests on the aged specimens. No significant changes in tensile strength or ductility are observed in specimens aged at 1300 and $1500^{\circ} \mathrm{F}$. The low strength and ductilities of specimens aged at $1650^{\circ} \mathrm{F}$ may be attributable to the hydrogen atmosphere used during the aging treatment. At temperatures other than $1650^{\circ} \mathrm{F}$, the specimens were aged either under a helium atmosphere or by enclosing them in evacuated quartz tubes.

The deleterious effect on strength and ductility after long heat treatments in hydrogen, noted in alloys containing titanium, aluminum, niobium, and chromium, was further investigated. Experiments were repeated in order to confirm that the effect was due to hydrogen and not to the aging heat treatment. The check tests were made on $5 \% \mathrm{Nb}-20 \% \mathrm{Mo}-75 \% \mathrm{Ni}$ alloy. The results of these tests are shown in Table 28 and verify that low strength and ductility result from long exposure in hydrogen at elevated temperatures. Moreover, the tests indicate that the effect of hydrogen can be removed by vacuum annealing, as evidenced by the return of strength and ductility. The formation of a hydride appears possible; but, if such is the case, embrittlement in alloys containing chromium and aluminum cannot be explained. This effect was not observed in Hastelloy B or the binary Ni-Mo alloys.

The $\mathrm{Cr}$-Mo-Ni alloys are being stress-rupture tested, and the results of these tests are being reported by the Mechanical Properties Group. The results from these tests showed that most of these alloys have low strengths and ductilities, which indicates that vacuum melting alone is not sufficient to obtain optimum properties. Increasing the strength and ductility through the addition of 
TABLE 26. ROOM-TEMPERATURE TENSILE STRENGTHS OF SHEET SPECIMENS OF Cr-MO-Ni ALLOYS Aging time: Minimum, $284 \mathrm{hr}$; maximum, $500 \mathrm{hr}$

\begin{tabular}{|c|c|c|c|}
\hline $\begin{array}{c}\text { Alloy Composition } \\
(w+\%)\end{array}$ & $\begin{array}{l}\text { Condition of } \\
\text { Test Specimen }\end{array}$ & $\begin{array}{c}\text { Tensile Strength } \\
\text { (psi) }\end{array}$ & $\begin{array}{c}\text { Elongation } \\
(\%)\end{array}$ \\
\hline \multirow[t]{4}{*}{$3 \mathrm{Cr}-20 \mathrm{Mo}-77 \mathrm{Ni}$} & Annealed & 107,000 & 61 \\
\hline & Aged at $1300^{\circ} \mathrm{F}$ & 109,500 & 60 \\
\hline & Aged at $1500^{\circ} \mathrm{F}$ & 111,100 & 64 \\
\hline & Aged at $1650^{\circ} \mathrm{F}$ & 67,500 & 19 \\
\hline \multirow[t]{3}{*}{ 5. $\mathrm{Cr}-20 \mathrm{Mo}-75 \mathrm{Ni}$} & Annealed & 120,000 & 58 \\
\hline & Aged at $1300^{\circ} \mathrm{F}$ & 119,000 & 59 \\
\hline & Aged at $1500^{\circ} \mathrm{F}$ & 115,000 & 62 \\
\hline . & Aged at $1650^{\circ} \mathrm{F}$ & 72,500 & 14 \\
\hline \multirow[t]{4}{*}{$7 \mathrm{Cr}-20 \mathrm{Mo}-73 \mathrm{Ni}$} & Annealed & 116,000 & 63 \\
\hline & Aged at $1300^{\circ} \mathrm{F}$ & 116,000 & 63 \\
\hline & Aged at $1500^{\circ} \mathrm{F}$ & 114,000 & 59 \\
\hline & Aged at $1650^{\circ} \mathrm{F}$ & 69,000 & 14 \\
\hline \multirow[t]{2}{*}{$10 \mathrm{Cr}-20 \mathrm{Mo}-70 \mathrm{Ni}$} & Annealed & 110,500 & 71 \\
\hline & Aged at $1300^{\circ} \mathrm{F}$ & 111,600 & 63 \\
\hline
\end{tabular}

TABLE 27. ELEVATED-TEMPERATURE TEST DATA FOR Cr-Mo-Ni ALLOYS

\begin{tabular}{|c|c|c|c|c|}
\hline \multirow{2}{*}{$\begin{array}{c}\text { Nominal Composition } \\
(w+\%)\end{array}$} & \multicolumn{2}{|c|}{ Aging Conditions } & \multirow{2}{*}{$\begin{array}{c}\text { Tensile Strength } \\
\text { (psi) }\end{array}$} & \multirow{2}{*}{$\begin{array}{c}\text { Elongation } \\
(\%)\end{array}$} \\
\hline & Time (hr) & Temperature $\left({ }^{\circ} \mathrm{F}\right)$ & & \\
\hline \multirow[t]{3}{*}{$3 \mathrm{Cr}-20 \mathrm{Mo}-77 \mathrm{Ni}$} & 500 & 1300 & 33,200 & 6.3 \\
\hline & 500 & 1500 & 27,300 & 5.0 \\
\hline & 284 & 1650 & 26,100 & 19.0 \\
\hline \multirow{2}{*}{$3 \mathrm{Cr}-0.5 \mathrm{Nb}-20 \mathrm{Mo}-76.5 \mathrm{Ni}$} & 362 & 1300 & 38,100 & 6.3 \\
\hline & 362 & 1500 & 30,000 & 5.0 \\
\hline \multirow[t]{2}{*}{$5 \mathrm{Cr}-0.5 \mathrm{Nb}-20 \mathrm{Mo}-74.5 \mathrm{Ni}$} & 500 & 1300 & 39,500 & 7.5 \\
\hline & 500 & 1500 & 29,400 & 5.0 \\
\hline \multirow[t]{2}{*}{$5 \mathrm{Cr}-0.25 \mathrm{Ce}-20 \mathrm{Mo}-74.75 \mathrm{Ni}$} & 362 & 1300 & 59,700 & 16.5 \\
\hline & 362 & 1500 & 43,100 & $11.0^{\star}$ \\
\hline \multirow[t]{2}{*}{$7 \mathrm{Cr}-20 \mathrm{Mo}-73 \mathrm{Ni}$} & 362 & 1300 & 40,800 & 9.0 \\
\hline & 362 & 1500 & 29,800 & $3.5^{\star}$ \\
\hline \multirow[t]{3}{*}{$7 \mathrm{Cr}-0.5 \mathrm{Nb}-20 \mathrm{Mo}-72.5 \mathrm{Ni}$} & 500 & 1300 & 48,800 & 12.5 \\
\hline & 500 & 1500 & 38,500 & 7.5 \\
\hline & 284 & 1650 & 29,800 & 3.8 \\
\hline \multirow[t]{2}{*}{$7 \mathrm{Cr}-0.1 \mathrm{Ce}-20 \mathrm{Mo}-72.9 \mathrm{Ni}$} & 362 & 1300 & 54,500 & 17.5 \\
\hline & 362 & 1500 & 40,500 & $8.8^{\star}$ \\
\hline \multirow[t]{3}{*}{$10 \mathrm{Cr}-0.5 \mathrm{Nb}-20 \mathrm{Mo}-69.5 \mathrm{Ni}$} & 500 & 1300 & 38,300 & 8.8 \\
\hline & 500 & 1500 & 43,600 & 9.0 \\
\hline & 284 & 1650 & 29,900 & 6.3 \\
\hline
\end{tabular}

* Specimen fractured outside 2-in.•gage length. 
cerium appears to be promising since such alloys with cerium have shown better physical properties during stress-rupture testing. It has become apparent that deoxidation practices are necessary when these alloys are melted, and efforts are being directed toward the production of sounder ingots.

A critical review of the progress made in developing Mo-Ni alloys is being made. A program is being outlined to determine the cause of poor fabricability, the reason for embrittlement after aging, and the effect of slight composition modifications on the mechanical properties of Hastelloy B. A research program paralleling that on Hastelloy $B$ is contemplated for Hastelloy W.

\section{Oxidation Studies}

The oxidation rate of an alloy of nominal composition 10\% Mo-10\% $\mathrm{Fe}-6 \% \mathrm{Cr}-74 \% \mathrm{Ni}$ was determined in air at $1500^{\circ} \mathrm{F}$. This alloy was previously corrosion-tested in fused fluorides, and the results were promising. It is considered to be heat resistant and forms a nonspalling oxide upon oxidation. Its rate of oxidation was found to be between that observed for the $7 \% \mathrm{Cr}-20 \%$
Mo-73\% $\mathrm{Ni}$ and the $10 \% \mathrm{Cr}-20 \% \mathrm{Mo}-70 \% \mathrm{Ni}$ alloys.

A vacuum melt of Hastelloy B supplied by the Haynes Stellite Company was tested in static air at $1500^{\circ} \mathrm{F}$. No significant difference in the oxidation rates of this heat and of commercial grades of Hastelloy B was noted.

The oxidation rates of two experimental alloys of nominal composition $2 \frac{1}{2} \% \mathrm{Be}-97 \frac{1}{2} \% \mathrm{Ni}$ and $2 \frac{1}{2} \% \mathrm{Be}-5 \% \mathrm{Nb}-92 \frac{\mathrm{l}}{2} \% \mathrm{Ni}$ were determined at $1500^{\circ} \mathrm{F}$. The former alloy forms a nonspalling oxide and is considered heat resistant. The addition of $5 \%$ niobium increases the oxidation rate to that observed for Hastelloy B. Experimental data for these alloys are given in Table 29.

\section{NIOBIUM (COLUMBIUM) RESEARCH}

$$
\text { H. Inouye J.P. Page }
$$

\section{Roll-Cladding Experiments}

A series of tests have been made of various combinations of heat-resistant alloys roll clad onto niobium. The experiments were designed so as to determine the lowest temperature at which

TABLE 28. ROOM-TEMPERATURE TENSILE TESTS OF A $5 \% \mathrm{Nb}-20 \% \mathrm{Mo}-75 \%$ Ni ALLOY*

\begin{tabular}{lcccc}
\hline \multicolumn{1}{c}{ Aging Conditions } & $\begin{array}{c}\text { Yield Point, } \\
0.2 \% \text { offset } \\
\text { (psi) }\end{array}$ & $\begin{array}{c}\text { Tensile } \\
\text { Strength } \\
\text { (psi) }\end{array}$ & $\begin{array}{c}\text { Elongation } \\
\text { (\% in 2 in.) }\end{array}$ & $\begin{array}{c}\text { Reduction } \\
\text { in Area } \\
\text { (\%) }\end{array}$ \\
\hline $285 \mathrm{hr}$ in vocuum & 78,500 & 153,700 & 35 & 30 \\
$285 \mathrm{hr}$ in $\mathrm{H}_{2}$ & 77,600 & 113,600 & 13 & 23 \\
$285 \mathrm{hr}$ in $\mathrm{H}_{2}$ followed by $2 \mathrm{hr}$ in vacuum & 78,300 & 151,000 & 30 & 26 \\
\hline
\end{tabular}

*Sheet, $0.065 \mathrm{in.;} 1 \mathrm{hr}$ at $2100^{\circ} \mathrm{F}$ in $\mathrm{H}_{2}$; aged $.1650^{\circ} \mathrm{F}$ as indicated.

TABLE 29. THE OXIDATION RATES OF NICKEL-BASE ALLOYS TESTED FOR $167 \mathrm{hr}$ IN STATIC AIR AT $1500^{\circ} \mathrm{F}$

\begin{tabular}{ccc}
\hline Alloy & Weight Gain $\left(\mathrm{g} / \mathrm{cm}^{2}\right)$ & Remarks \\
\hline $10 \% \mathrm{Mo}-10 \% \mathrm{Fe}-6 \% \mathrm{Cr}-74 \% \mathrm{Ni}$ & 0.0005 & Adherent oxide \\
Hastelloy B, vacuum melted & 0.0010 & Oxide spalls upon cooling \\
$2 \frac{1}{2} \% \mathrm{Be}-97 \frac{1}{2} \% \mathrm{Ni}$ & 0.0004 & Adherent oxide \\
$2 \frac{1}{2} \% \mathrm{Be}-5 \% \mathrm{Nb}-92 \frac{1}{2} \% \mathrm{Ni}$ & 0.0014 & Adherent oxide \\
\hline
\end{tabular}


bonding could be achieved with minimum intermetallic formation and contamination, since the reactivity of niobium with gases increases with temperature. Rolling temperatures of 1600, 1900, and $2200^{\circ} \mathrm{F}$ were investigated. Difficulties were expected in attaining the degree of metallurgical bonding necessary for efficient heat transfer because of the differences in the thermal-expansion properties of the heat-resistant cladding alloys and the niobium, as shown below:

\begin{tabular}{lc}
\multicolumn{1}{c}{ Alloy } & $\begin{array}{r}\text { Mean Coefficient of Thermal } \\
\text { Expansion }\left(\mu \mathrm{in.} /{ }^{\circ} \mathrm{C}\right) \\
\text { at } 0 \text { to } 815^{\circ} \mathrm{C}\end{array}$ \\
Niobium & 7.1 \\
$\begin{array}{l}\text { Type } 446 \text { stainless } \\
\text { steel }\end{array}$ & 11.2 \\
Type 310 stainless \\
steel \\
$\begin{array}{l}\text { Inconel } \\
\text { Hastelloy B }\end{array}$ \\
Nickel
\end{tabular}

Attempts to bond niobium to niobium were made for the purpose of developing a method for obtaining large sheets of the metal. For all the hotrolling temperatures investigated, the interface between the layers was not discernible; moreover, separation did not occur upon severe bending. Therefore, this appears to be feasible for obtaining large sheet sections of the composite.

Simulated service tests of niobium clad with heat-res istant alloys were made at 1500 and $1832^{\circ} \mathrm{F}$ for $500 \mathrm{hr}$. The tests showed that niobium is adequately protected and that its ductility is only slightly affected; however, interface reactions occurred in all the metal combinations after they had been service tested at the two temperatures, which caused separation at the interfaces for the reasons previously cited.

The problem in the development of clad niobium is not one of preventing the formation of intermetallic compounds but, rather, is one of selecting a suitable combination of metals that will remain thermally bonded in service. This is mandatory since this composite is intended as a heat-transfer surface.

\section{Diffusion-Barrier Studies}

Further studies of clad niobium were restricted to the use of diffusion barriers for the niobium. The barrier metals were selected somewhat arbitrarily since the phase relationships between niobium, the barrier metal, and Inconel have not been thoroughly determined, especially as to the nature of the compounds which form between them. Vanadium, titanium, molybdenum, tantalum, and copper were evaluated as barrier metals.

The composites were fabricated by hot-rolling capsules which had been previously evacuated at $1100^{\circ} \mathrm{F}$ to at least $1 \times 10^{-4} \mathrm{~mm} \mathrm{Hg}$. Rolling temperatures between 1800 and $2100^{\circ} \mathrm{F}$ were used at reduction schedules of 30 and $40 \%$ per pass. The total reduction in thickness was about 5 to $\mathrm{I}$. No particular effort was made to predetermine the thickness of the niobium core or the Inconel cladding. A thickness of 0.020 in. was determined for the final composite, and barrier thicknesses were calculated to be 0.001 in. The composite cross sections were examined microscopically after a strip had been bent to form an involute of a circle.

Inconel-Vanadium-Niobium. - A composite of these metals withstood several 90-deg bending reversals over a sharp radius. Microscopic examination of the Inconel-vanadium interface showed a reaction layer less than 0.0001 in. thick which was cracked perpendicular to a tangent to the curved surface. Because no separation occurred, this combination can probably be shaped into different forms by cold spinning.

After $100 \mathrm{hr}$ at $1650^{\circ} \mathrm{F}$, the composite separated at the Inconel-vanadium interface after having been subjected to bending. The reaction layer at this interface increased at the expense of the vanadium layer to a thickness of about $0.0005 \mathrm{in}$.

After $500 \mathrm{hr}$ at $1650^{\circ} \mathrm{F}$, the composite separated during sectioning. Microscopic examination of the composite showed that the vanadium layer had been completely transformed into an intermetallic.

Inconel-Copper-Niobium. - By means of the evacuated-capsule technique, a 0.001-in. layer of copper was roll-clad onto niobium at $1832^{\circ} \mathrm{F}$. Service tests at $1500^{\circ} \mathrm{F}$ for $150 \mathrm{hr}$ showed that a reaction occurred between the copper and the niobium; two reaction layers totaling about 0.0001 in. were evident. Separation at the bonded interface was slight or nonexistent. 
Inconel-Iron-Copper-Molybdenum-Niobium. - This combination was rolled at $1800^{\circ} \mathrm{F}$ without difficulty. Microscopic examination of the cross section of the composite indicated that the iron barrier was omitted during assembly. The above experiment will not be repeated identically but will be simplified to a combination of Inconelmolybdenum-niobium.

Inconel-Titanium-Niobium. - This combination was unsatisfactory because a low-melting compound formed at the rolling temperature of $2100^{\circ} \mathrm{F}$. The compound is brittle, and, consequently, separation of the composite results during cooling. Because the reaction rate for the solid is desired, the experiment will be repeated at a lower rolling temperature.

Inconel-Tantalum-Niobium. - Tantalum and niobium are isomorphous in several aspects; therefore, this combination was not expected to be successful. However, the combination was tested to observe how the difference in melting points of the metals affects their diffusion rate with Inconel ( $\mathrm{Nb}, \mathrm{mp} 4380^{\circ} \mathrm{F} ; \mathrm{Ta}, \mathrm{mp} 5425^{\circ} \mathrm{F}$ ) and to compare the properties of the resultant reaction products.

Examination of the composite after rolling at $2100^{\circ} \mathrm{F}$ showed a reaction layer which was 0.0001 in. thick at the Inconel-tantalum interface and was brittle at room temperature; however, separation did not occur even after numerous $90-$ deg bending reversals. The unbent portion of the composite showed no cracks in the reaction layer.

Service tests at $1650^{\circ} \mathrm{F}$ for 100 and $500 \mathrm{hr}$ were made. The reaction layer between tantalum and Inconel increased with time. About 0.0005 in. of tantalum was converted to the intermetallic in $500 \mathrm{hr}$. The tantalum-niobium interface showed no evidence of diffusion at these temperatures.

Bending reversals after these service tests resulted in no separation in the composite even though the reaction layer cracked perpendicular to a tangent at the curved surface. No cracks were observed in the unbent portion of the composite.

Future Work. - Future experiments and tests, listed below, are being designed and contemplated, which will decide the feasibility of using Inconelclad niobium.
1. Creep-strength tests of both clad and unclad niobium will be made in order to determine whether niobium can be substituted for a large portion of the Inconel and have a strength equal to or greater than that of Inconel alone.

2. Additional tests will be made in order to determine whether copper or tantalum is more suitable as a barrier in this composite. One objection to the use of tantalum is that it has a neutron cross section of 20 barns. Service tests of up to $500 \mathrm{hr}$ at $1650^{\circ} \mathrm{F}$ indicate that $0.0005 \mathrm{in}$. of tantalum is the minimum thickness that will prevent the Inconel-niobium reaction. In a composite of the proportions contemplated (0.024 in. Inconel-0.0001 in. tantalum-0.075 in. niobium$0.001 \mathrm{in}$. tantalum- $0.024 \mathrm{in.}$ Inconel), the presence of tantalum might not be objectionable. On the other hand, the use of a copper barrier requires an iron-base alloy to prevent interdiffusion between the copper and the Inconel. In addition, wider Inconel frames might be necessary for welding because of the low melting point of the copper. The choice of the proper barrier metal will depend on the room-temperature ductility, creep, and formability of the metal, and also, on the results of welding tests.

3. Finally, since the problem of welding sections of composite sheet appears to be formidable, experiments will be made for the purpose of determining the minimum frame width of Inconel that will permit a totally clad niobium core to be welded without serious heat effects.

\section{$\mathrm{Nb}-\mathrm{UO}_{2}$ Fuel Elements}

The compatibility of $\mathrm{UO}_{2}$ in niobium was determined by heating specimens at 1500 and $1832^{\circ} \mathrm{F}$ for $100 \mathrm{hr}$. The specimens were prepared by hotswaging 20 wt $\% \mathrm{UO}_{2}$ with niobium powder at $1742^{\circ} \mathrm{F}$. Both steam-treated and high-fired $\mathrm{UO}_{2}$ were used for the tests. Examinations were made on the as-swaged material and on the material which was exposed for $100 \mathrm{hr}$ to temperature. Under all conditions, a third phase, pinkish in color, appeared in the matrix as discrete particles or as a portion of a former $\mathrm{UO}_{2}$ particle. The amount of this phase increased with exposure time. $X$-ray patterns of the mixture after $100 \mathrm{hr}$ at temperature indicated a solid solution of $\mathrm{Nb}-\mathrm{U}$. This same phase was found as a network in an arc-melted button of a $5 \% \mathrm{Nb}-95 \%$ Ualloy. 


\section{SPECIAL ALLOYS}

\section{H. Inouye M. R. D'Amore \\ Composite-Tubing Fabrication}

Studies of flow patterns of duplex and three-ply materials during impact extrusion were continued. The flow-pattern studies of three-ply composites hove been directed toward accumulating information that will lead to the production of seamless, tubular stainless steel fuel elements. The experiments on duplex materials have been designed so that the fabrication problems involved in the cladding of tube materials can be studied. As previously reported, ${ }^{4}$ the layer compositions for these experiments were carbon steel and type 316 stainless steel. The two-ply extrusions were clad on the outside with the stainless steel, and the three-ply extrusions were clad on both sides with stainless steel.

It was found that, on starting with layers of equal thickness, layers of extruded metal resulted that departed widely from the calculated ratios. Equal metal ratios in the extruded tube were made possible through adjustments in the starting thickness; however, this procedure resulted in a low recovery of acceptable tubing.

The experiments described below were conducted in an effort to increase the recovery and to reduce the thickness variations between the layers. The major variable in these experiments was the billet design. Additional information regarding the deformation pattern was desirable in

4. H. Coobs, H. Inouye, and M. R. D'Amore, ANP Quar. Prog. Rep. June 10, 1955, ORNL-1896, p 140. order that the limits of the layer thickness could be established. Finally, the effect of built-in flaws and the effect of varying the extrusion ratio were of interest.

Built-in flaws consisted of molybdenum washers $0.010 \mathrm{in}$. thick that were spaced at $1 / 2$-in. intervals along the billet. These washers also served as markers to outline the deformation pattern.

Both flat and 45-deg tapered blocks were used on the front of the extrusion billets. In the two-ply extrusions, deviations in thickness were about 15\%. The inner layer in both extrusions was thinner than had been theoretically predicted. The shape of the block had only a slight effect on the results of the extrusions. The inner cladding was thinner and the outer cladding was thicker, by $15 \%$, in the three-ply extrusions than had been calculated. The core of the extrusion showed no deviation from the calculated thickness. The results obtained to date on extrusions of concentric layers of equal thicknesses are summarized in Table 30.

The extrusions which contained molybdenum markers were sectioned lengthwise and examined. The deformation across the tube-wall thickness is complex since both compression and tension are evident. Tensile forces prevail in the outer and inner tube-wall layers, whereas compression prevails in a zone in between. The original 0.010-in. molybdenum markers varied in thickness from about $0.003 \mathrm{in}$. near the tube walls to $0.050 \mathrm{in}$. at the middle of the tube wall. The displacement of the markers from their starting position was noted. After extrusion, the marker positions in the tube walls could be located as

TABLE 30. RESULTS OF ATTEMPTS TO EXTRUDE CONCENTRIC LAYERS OF EQUAL THICKNESSES

\begin{tabular}{|c|c|c|c|c|c|}
\hline \multirow[b]{2}{*}{ Tubing } & \multirow{2}{*}{$\begin{array}{c}\text { Type of Dummy Block } \\
\text { Used }\end{array}$} & \multicolumn{3}{|c|}{ Average Layer Thickness } & \multirow{2}{*}{$\begin{array}{c}\text { Length of Extrusion } \\
\text { Contoining Uniform Layers } \\
(\%)\end{array}$} \\
\hline & & $\begin{array}{l}\text { Inside Layer } \\
\text { (in.) }\end{array}$ & $\begin{array}{l}\text { Core } \\
\text { (in.) }\end{array}$ & $\begin{array}{c}\text { Outside Layer } \\
\text { (in.) }\end{array}$ & \\
\hline \multirow[t]{3}{*}{ Two-ply } & None & 0.087 & & 0.132 & 45 \\
\hline & Flat nosed & 0.109 & & 0.140 & 63 \\
\hline & 45-deg topered & 0.107 & & 0.118 & 66 \\
\hline \multirow[t]{3}{*}{ Three-ply } & None & 0.050 & 0.073 & 0.111 & 45 \\
\hline & Flat nosed & 0.070 & 0.074 & 0.103 & 55 \\
\hline & 45-deg tapered & 0.078 & 0.075 & 0.104 & 56 \\
\hline
\end{tabular}


coordinates of a parabola of revolution, with the center line of the tube as the axis. The shapes of the separate markers varied along the length of the extrusion.

Because of the tensile forces near the tube walls, flaws in the vicinity of the wall in the starting billet will result in flaws in the extrusion. This then restricts the location of a sectional core in the extrusion billet to those zones where compressive deformation will cause bonding.

A request has been placed with the Allegheny Ludlum Steel Corp. for the extrusion of six threeply composite tubes of $\mathrm{Al}_{2} \mathrm{O}_{3}$-stainless-steelpowder compacts clad on both sides with stainless steel.

\section{Special-Alloy Extrusions}

Three billets of vanadium were extruded at $2000^{\circ} \mathrm{F}$. The pressure requirement for an extrusion ratio of 9 to 1 is approximately $45 \mathrm{tsi}$. The billets were canned in mild steel so as to protect the vanadium from oxidation during extrusion. The canning material was removed from the extruded tube blanks by pickling in hot $\mathrm{HCl}$. The tube blanks have been shipped to the Superior Tube Co. for further reduction and for cladding of the outside diameter with stainless steel. The clad vanadium tubing will be used in corrosion studies.

Six high-purity billets of Mo- $0.7 \% \mathrm{Ti}$ alloy were extruded into rod for Battelle Memorial Institute. The extrusions are to be used for welding studies. The extrusions were made at $2600^{\circ} \mathrm{F}$, and demonstrated that the pressure requirement can be reduced by using a salt-type lubricant. These billets failed to extrude in the first two attempts when fiber glass and Necrolene were used as the lubricating materials. Since the salt cannot be used at $2600^{\circ} \mathrm{F}$ because of thermal decomposition, it was swabbed on the container walls. The use of salt in the container reduced the pressure requirement from 700 to 427 tons on a 3-in. ram for an extrusion ratio of $4 \frac{1}{2}$ to 1 . Similarly, at an extrusion ratio of $6 \frac{1}{4}$ to 1 ; the pressure required was reduced from 700 to 508 tons.

RADIATION SHIELDING AND CONTROL-ROD MATERIAL

$$
\text { J. H. Coobs H. Inouye }
$$

M. R. D'Amore

Lead-Calcium Alloys

The techniques for making creep-resistant $\mathrm{Pb}-\mathrm{Ca}$ alloys of specific chemical compositions have been evaluated. It was determined that chemical analyses are not indicative of the creep performance of these alloys because normal scatter in the analytical data frequently exceeds the desired composition of 0.03 to $0.06 \%$ calcium. More important, however, is the fact that the strengthening effect of calcium can be realized only if the calcium is in solid solution or if it exists as a compound with the lead. Thus, if a portion of the calcium is present as $\mathrm{CaO}$, the beneficial effects are lost, and, unless the $\mathrm{CaO}$ content of the alloy is known, calcium analyses serve only as a guide.

The results from three experimental alloys will be presented as an illustration of the difficulty mentioned above. The alloys were prepared from three master alloys which had been analyzed and shown to contain $2 \%$ calcium; thus, each of the prepared alloys, on the basis of calculations, should have contained $0.06 \%$ calcium. However, analyses indicated that their compositions were $0.043,0.030$, and $0.059 \%$ calcium, respectively. Moreover, in cantilever creep tests at room temperature and at a stress of $750 \mathrm{psi}$, the deflections at the end of a 2-in. beam were 0.87, 0.33, and $0.54 \mathrm{~cm}$, respectively.

Since the chemical analyses indicate the total calcium, the master alloy must be made under conditions whereby the oxidation of the calcium is held to a minimum. An alternate method for the determination of alloyed calcium, which has not been tried, is filtration of the master alloy at about $1475^{\circ} \mathrm{F}$ through a quartz filter prior to analysis.

About $150 \mathrm{lb}$ of a Pb-0.05\% Ca alloy has been supplied to WADC for elevated-temperature creep testing. Chemical analyses of the alloys indicate that calcium recovery is consistently high when the alloys are made from well-prepared master alloys. Cantilever creep tests in quadruplicate were made at room temperature on both the wrought and cast alloys supplied to WADC, and the results from each test were consistent. The wrought alloy was found to have the better creep properties.

\section{Neutron Shielding Material for the ART}

The fabrication of boron-containing shield material is being studied. The designers of the ART have expressed preference for a single-clad boron matrix in the Inconel annulus. The requirement is the fabrication of a boron-containing material which contains a minimum of $1 \mathrm{~g}$ of boron per cubic centimeter in a metallic matrix and which 
is bonded to a $\frac{1}{4}$-in.-thick Inconel hemisphere. The initial experiments consisted in attempts to obtain thermal bonds by flame spraying of mixtures of $\mathrm{Cu}-\mathrm{B}_{4} \mathrm{C}$ as wire. The results to date do not appear promising since a large proportion of the $\mathrm{B}_{4} \mathrm{C}$ is lost during spraying. Other experiments consisted in attempts to wet $B_{4} C$ with copper alloys and to cast the resultant slurry. The oxidation of the $\mathrm{B}_{4} \mathrm{C} \cdot$ to $\mathrm{B}_{2} \mathrm{O}_{3}$ appears to be a major problem in the melting of the slurries. The experiments are being continued, and an inert atmosphere is being used.

A layer equivalent to $0.008 \mathrm{in}$. of boron will reduce the neutron flux through it by about $90 \%$. Since this involves a relatively thin layer, experiments for depositing boron by electrophores is and by the electroplating of boron slurries are being contemplated. Provided that the thin layer, just mentioned, is thermally bonded to the Inconel, unbonded tiles or strips of boron compounds in a metallic matrix would be permissible as the filler material for the annular space of $3 / 8$ in. Tiles of $\mathrm{B}_{4} \mathrm{C}$ are being considered, and appropriate companies are being contacted for advice concerning their use.

\section{Boron Carbide-Copper Shield Material}

Two parts were fabricated from a mixture of boron carbide and copper. They will be used as neutron poisons in the hot critical experiment. The parts were a $6 \frac{3}{8}$-in.-dia by 0.500 -in.-thick disk and a ring $12 \frac{1}{4} \mathrm{in}$. in outside diameter with a $5 / 16 \times 1 / 2$ in. cross section.

The disk was formed by pressing a mixture of $B_{4} C$ and copper powders in a graphite mold at $900^{\circ} \mathrm{C}$. After pressing, the disk was $6 \frac{1}{2}$ in. in diameter, had an average thickness of $0.447 \mathrm{in.,}$ and had a boron content of $0.367 \mathrm{~g} / \mathrm{cc}$. A density $97.4 \%$ of theoretical was achieved by this technique. The disk was machined to a diameter of $63 / 8$ in. with diamond tools, and diffusion barriers of copper and of stainless steel were applied by flame spraying. The barrier layer thicknesses were 6 and 15 mils, respectively.
Attempts to fabricate the ring by extruding a billet of compacted $\mathrm{B}_{4} \mathrm{C} \cdot \mathrm{Cu}$ powders canned in copper were unsuccessful. Severe edge cracking of the material occurred during extrusion, which was probably due to either an extrusion temperature that was too high or to a copper can that was too thin. The ring was finally fabricated by drawing a round copper tube filled with $\mathrm{B}_{4} \mathrm{C}$ powders into a rectangular tube with the appropriate cross section. The tube was then roll-formed into a $12 \frac{1}{4}$-in. -OD ring and was split into two equal segments for ease of assembling. The open ends of the tube were closed with $\mathrm{B}_{4} \mathrm{C}-\mathrm{Cu}$ plugs. The ring contained approximately $2.25 \mathrm{~g}$ of boron per inch of length. A 7-mil layer of type 430 stainless steel was flame-sprayed onto the ring so as to act as a diffusion barrier.

\section{SPECIAL-MATERIALS FABRICATION}

$$
\text { J. H. Coobs }
$$

\section{Fuel Plates of Al-UO for Delayed-Neutron Shielding Experiment}

Endurance testing of the set of eighteen $24 \mathrm{~S}$ aluminum-clad fuel plates containing depleted SF material demonstrated that the plates were satisfactory. Two plates were bent severely when the lugs holding each to the endless chain failed; however, the plates remained intact, and there was no evidence of failure of the cladding or of the bond between the core and the cladding. A later endurance run made with heavier lugs was quite successful.

A full loading of 63 plates was fabricated; each plate contained about $92 \mathrm{~g}$ of enriched $\mathrm{UO}_{2}$ and was clad with $24 \mathrm{~S}$ alloy. The $24 \mathrm{~S}$ cover stock was welded to the $2 S$ frames; 435 filler rod was used, as was recommended by the Welding Laboratory. As a result, none of the billets failed during hot rolling, which is in marked contrast to the set of 22 depleted plates, of which 4 failed because of faulty welds. After machining to size, the plates were solution-annealed, bent to the specified 2 -in. radius, and precipitation-hardened. 


\title{
PHYSICAL CHEMISTRY OF CORROSION
}

\author{
G. P. Smith
}

\section{FILM FORMATION ON METALS}

$$
\text { J. V. Cathcart }
$$

\section{Oxidation of Sodium}

The investigation of the oxidation characteristics of sodium has been continued. Previous results ${ }^{1}$ have emphasized, contrary to generally accepted oxidation theory, ${ }^{2}$ the highly protective nature of sodium oxide films in dry hydrogen. This research has also supplemented and amplified the existing experimental oxidation data for alkali and alkalineearth metals. Finally, the results indicate a considerable similarity between the oxidation of sodium and that of other more extensively studied metals such as copper and aluminum. In this respect, added evidence has been obtained in support of the idea expressed by Cabrera and $\mathrm{Mott}^{3}$ that all metals have comparable oxidation mechanisms at relatively low temperatures.

Oxidation rate measurements for sodium were made manometrically. A film of sodium was evaporated onto the walls of a small glass bulb attached to one arm of a sensitive differential manometer. The rate of reaction could then be followed by measuring the decrease in pressure in the bulb as oxidation proceeded. The details of the experimental apparatus have already been de scribed. ${ }^{1}$

During the period covered by this report, most of the experimental work has been devoted to the measurement of oxidation rates at 25 and $48^{\circ} \mathrm{C}$. Experiments at these two temperatures (also at $35^{\circ} \mathrm{C}$ ) and lasting between 15,000 and $20,000 \mathrm{~min}$ have been completed.

Because there may be a gradual change in the reaction mechanism as oxidation proceeds and because of unavoidable errors in experimental measurements, a misleading impression of an oxidation curve can easily result if data for only the first portions of the rate curve are available. Thus, if a realistic determination is to be made of the analytical form of the curves, experiments

\footnotetext{
1J. V. Cathcart, Met. Semiann. Prog. Rep. April 10, 1955, ORNL-1911, p 98.

$2 \mathrm{U}$. R. Evans, Metallic Corrosion, Passivity, and Protection, pp 102, 134ff, Longman's, Green, New York, 1948.

${ }^{3}$ N. Cabrera and N. F. Matt, Repts. Progr. in Phys. 12,163 (1948-1949).
}

of long-time duration are considered necessary. A second reason for such extended-time tests lay in the fact that some metals, for example, niobium (see below), undergo abrupt changes in oxidation mechanism after a relatively thick oxide film has developed on them. It was important to determine whether or not sodium is subject to this phenomenon.

Seven rate determinations at $25^{\circ} \mathrm{C}$ and four at $48^{\circ} \mathrm{C}$, each lasting for from 17,000 to $20,000 \mathrm{~min}$, have been completed. Data from these, as well as measurements obtained at $-79,-20$, and $35^{\circ} \mathrm{C}$, are shown in Fig. 61. The change in pressure in the system, which is a function of the oxide. film thickness, is plotted against the time of oxidation on a log-log plot. Each unit of the vertical scale is equivalent to approximately $10 \AA$ of oxide; therefore, after $20,000 \mathrm{~min}$ at $48^{\circ} \mathrm{C}$, an oxide thickness of almost $1400 \AA$ was attained.

Each curve in Fig. 61 represents the composite of data from three or more experiments. Deviations of as much as $10 \%$ in the total pressure change were observed between readings at the same time and temperature in different experiments. An error of this magnitude was not considered serious. A basic assumption in comparing the results of different experiments was that the areas of the initial sodium films were the same. Since a new oxidation bulb was used for each experiment, it was impossible to avoid slight variations in the dimensions of these bulbs; therefore, the assumption that the apparent surface area of the sodium films was identical for all experiments was true only to a first approximation. Perhaps even more important was the possibility that the surface roughness (and, therefore, the true surface area) of the sodium films differed slightly from experiment to experiment. These two factors could easily account for the observed variations in the experimental results.

Mathematical analysis of the rate curves shows that none of the conventional oxidation rate laws were obeyed by sodium; that is, the data could not be fitted to rate equations of the form $x^{n}=k t$ (where $x$ is the oxide thickness after a time $t$, $k$ is the rate constant, and $n$ is 1,2 , or 3) nor to the logarithmic $(x=k \log t)$ or the inverse logarithmic $(1 / x=A-B \ln t)$ rate equations. The 


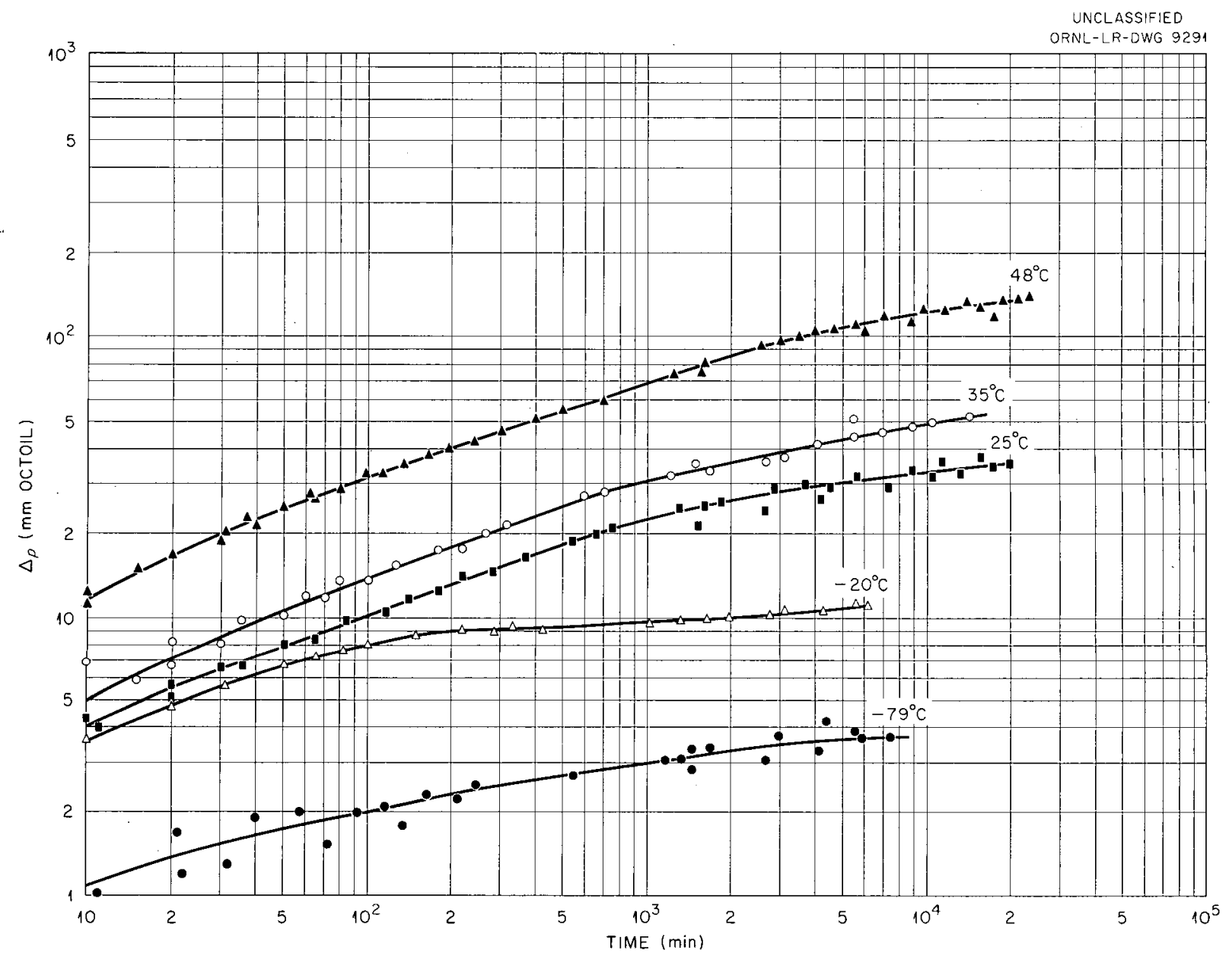

Fig. 61. Oxidation of Sodium at Various Temperatures.

absence of any abrupt changes in the curves indicates that there were no sudden changes in the oxidation mechanism.

One interesting feature of the results was that the rate of oxidation constantly decreased with time even at $48^{\circ} \mathrm{C}$. Thus, highly protective oxide films were observed under all the conditions investigated. There was no indication of any tendency toward crack formation in the oxide. For from obeying a linear rate law, as had been predicted theoretically, the oxidation characteristics of sodium in the temperature range -79 to $48^{\circ} \mathrm{C}$ appeared to be similar to those ${ }^{4}$ of copper between 100 and $150^{\circ} \mathrm{C}$.

${ }^{4}$ A. T. Gwathmey, F. W. Young, Jr., and J. V. Cathcart, Acta Metallurgia (in press).
Measurements of the over-all oxidation rate of a metal give only a macroscopic picture of the total oxidation process. Complete understanding of the oxidation mechanism requires a more detailed examination of the oxide. Accordingly, it is planned that the next phase of the research will involve an investigation of the surface topography and of the nucleation of the oxide films formed on sodium.

\section{Oxidation of Niobium (Columbium)}

The oxidation of niobium follows a linear rate equation above $400^{\circ} \mathrm{C}$. Below this temperature the rate curves are approximately parabolic. In a narrow temperature band centered around $400^{\circ} \mathrm{C}$, the rate curve is initially parabolic but becomes 
almost linear after a few hours of oxidation. ${ }^{5}$

The only theory of oxidation which predicts a linear rate equation is the "crack theory" of Pilling and Bedworth. ${ }^{2}$ However, the results ob. tained on the oxidation of sodium leave little doubt as to the inadequacy of this theory. An investigation of the oxidation of niobium at temperatures in the vicinity of $400^{\circ} \mathrm{C}$ was undertaken in the belief that a careful study of the structure, composition, and behavior of the oxide films during the transition from the parabolic to the linear rate will give some indication of the criteria for linear oxidation rates.

The first phase of the work consisted in a careful redetermination at $400^{\circ} \mathrm{C}$ of the oxidation rate curves for niobium. A manometric technique very similar to that used for the oxidation of sodium ${ }^{1}$ was found to be satisfactory for the measurements. The oxidation specimens consisted of $1 \times 2 \mathrm{~cm}$ strips cut from a 0.020-in.-thick sheet of niobium. The specimens were polished mechanically and were then electropolished in a $10 \% \mathrm{HF}-90 \% \mathrm{H}_{2} \mathrm{SO}_{4}$ bath. One such strip was placed in a 100-cc glass bulb attached to one arm of a differential manometer. Octoil-S diffusion pump oil was used as the manometric fluid in order to obtain the desired pressure sensitivity. The oxidation and reference bulbs of the manometer, having first been evacuated to a pressure of about $10^{-6} \mathrm{~mm} \mathrm{Hg}$, were immersed along with an oxygen reservoir in a molten-salt constant-temperature bath. The oxidation and reference bulbs were then filled simultaneously with oxygen to identical pressures. The absolute oxygen pressure was about $700 \mathrm{~mm} \mathrm{Hg}$. The rate of oxidation was then determined by measuring with the manometer the decrease in pressure in the oxidation bulb. The use of an accurately controlled constant-temperature bath was considered necessary so as to avoid spurious pressure changes arising from temperature differences in the oxidation and reference bulbs.

Four oxidation experiments have been completed at or near $400^{\circ} \mathrm{C}$. In each case the oxidation curve was approximately parabolic, becoming linear as the time of oxidation increased. The data from one of these experiments are shown. in Fig. 62. The decrease in oxygen pressure is plotted against the time of oxidation. For reasons as yet unknown, the time at which the transition from the parabolic

\footnotetext{
$5_{\mathrm{H}}$. Inouye, The Scaling of Columbium in Air, ORNL1565 (Sept. 24, 1953).
}

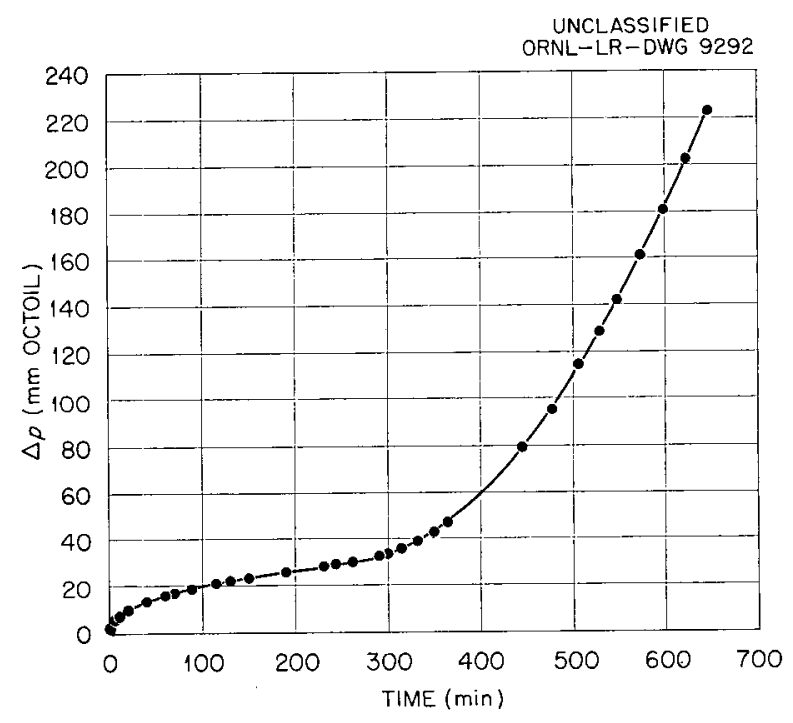

Fig. 62. Oxidation of Niobium at Approximately $400^{\circ} \mathrm{C}$.

to the linear portions of the rate curves occurred varied somewhat from experiment to experiment. However, the amount of oxygen which had been consumed by the time the transition region was reached was found to be relatively constant.

The oxide layers formed during the early stages of the reaction exhibited the interference tints typical of thin, transparent oxide films. However, as the reaction progressed, patches of a white, opaque material developed on the surface of the niobium specimens. These white areas appeared rough under an optical microscope, and it was assumed that these areas represented relatively porous regions in the oxide film. X-ray examination of the oxidized specimens indicated that both the white areas and the areas still showing interference colors consisted of niobium pentoxide $\left(\mathrm{Nb}_{2} \mathrm{O}_{5}\right)$. No other oxides of niobium were detected.

Although the evidence is still not complete, the occurrence of the regions of white oxide seemed to be associated with the deviation of the rate curves from their initial parabolic form. For this reason, it has been tentatively assumed that the white portions of the film represent the type of oxide film which produces a linear reaction rate.

In order to study the nucleation and growth of this white oxide, a hot-stage microscope has been constructed and is being tested. This apparatus should allow direct observation of the oxide films as they are formed. 
An attempt is being made to express the over-all oxidation rate equation for niobium as the sum of parabolic and linear terms approximately weighted in such a way as to take into account the fraction of the total surface area that is being oxidized according to each of the two mechanisms. Complete formulation and testing of this equation await further data concerning the growth characteristics of the areas of white oxide. It is hoped that this information can be obtained from observations of the oxidation under the hot-stage microscope.

\section{SELF-DECOMPOSITION OF FUSED HYDROXIDES}
M. E. Steidlitz
G. P. Smith

The importance of self-decomposition equilibria in determining the course of reactions in fused hydroxides of the group IB metals was stressed in preceding progress reports. No successful measurements of these equilibria have been reported, except for lithium hydroxide, whose chemical behavior is such that it is as closely akin to the group IIB hydroxides as to the group IB hydroxides. The writers have overcome the primary difficulties involved in these measurements by demonstrating that pure magnesium oxide is inert toward fused anhydrous sodium hydroxide and by fabricating reaction vessels from magnesium oxide single crystals.

\section{Experimental Results}

The reaction vessel and its attachments are illustrated in Fig. 63. The temperature of the fused hydroxide is measured by means of a thermocouple embedded in a well in the heated steel block. This arrangement was calibrated by use of another thermocouple contained in a small thinwalled nickel tube immersed in the hydroxide. Heat losses are sufficient to require a thermal correction of 40 to $50^{\circ} \mathrm{C}$.

In any one experiment, $1 / 2$ to $1 \mathrm{ml}$ of fused sodium hydroxide is used. This is dehydrated by attach. ing the ball joint to a vacuum pump and evacuating to a pressure of 1 to $10 \mu$ for $16 \mathrm{hr}$ at $325^{\circ} \mathrm{C}$ and for $1 \mathrm{hr}$ at $400^{\circ} \mathrm{C}$. In some of the earlier measurements, commercial cp grade hydroxide was used. This material contained traces of ammonia, the decomposition of which may have produced the hydrogen gas that was observed. Therefore, recent experiments have used sodium hydroxide made

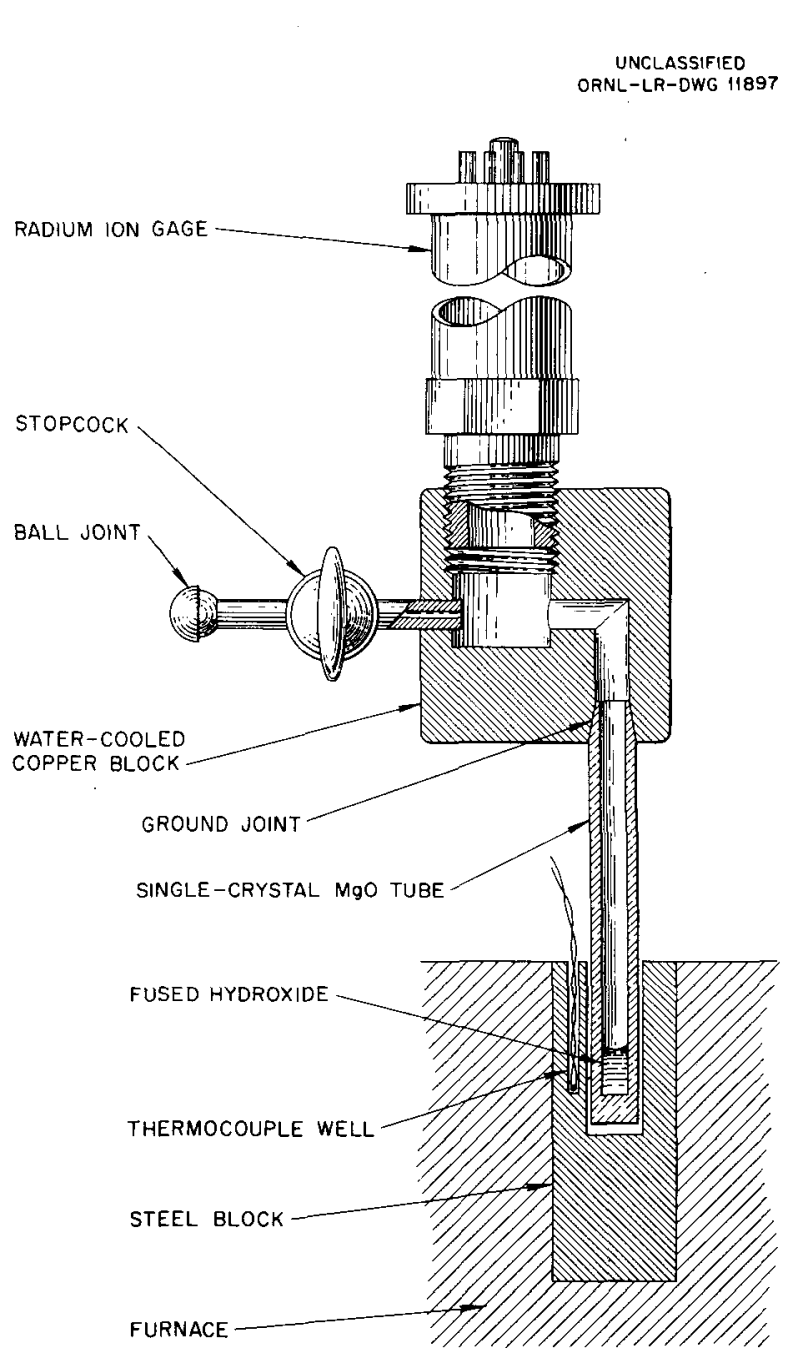

Fig. 63. Apparatus for Measuring Thermal SelfDecomposition of Fused Hydroxides.

under an argon atmosphere by the reaction of water with sodium metal.

In the most significant experiment made thus far, the apparatus containing dehydrated sodium hydroxide was attached to a 3-liter bulb and thence, through a calibrated leak, to a mass spectrometer. The writers are much indebted to $C$. E. Melton and C. R. Baldock for the mass-spectrometric part of this work. With this arrangement, it was possible to analyze the gas phase for all major components at any stage of the experiment. In this experiment, no special attempt was made to attain thermal equilibrium, but the temperature was raised at such a slow rate that rapid reactions may have attained equilibrium. 
The observed constituents of the gas phase were found to be water, hydrogen, and nitrogen. Quantitatively, water was the dominant gas by a large factor; hydrogen was present in moderate quantities, and nitrogen was present in trace amounts. Figure 64 is a plot of the logarithm of the partial pressure of water as a function of the reciprocal of the absolute temperature. The maximum pres. sure attained was almost $1 \mathrm{~mm} \mathrm{Hg}$.

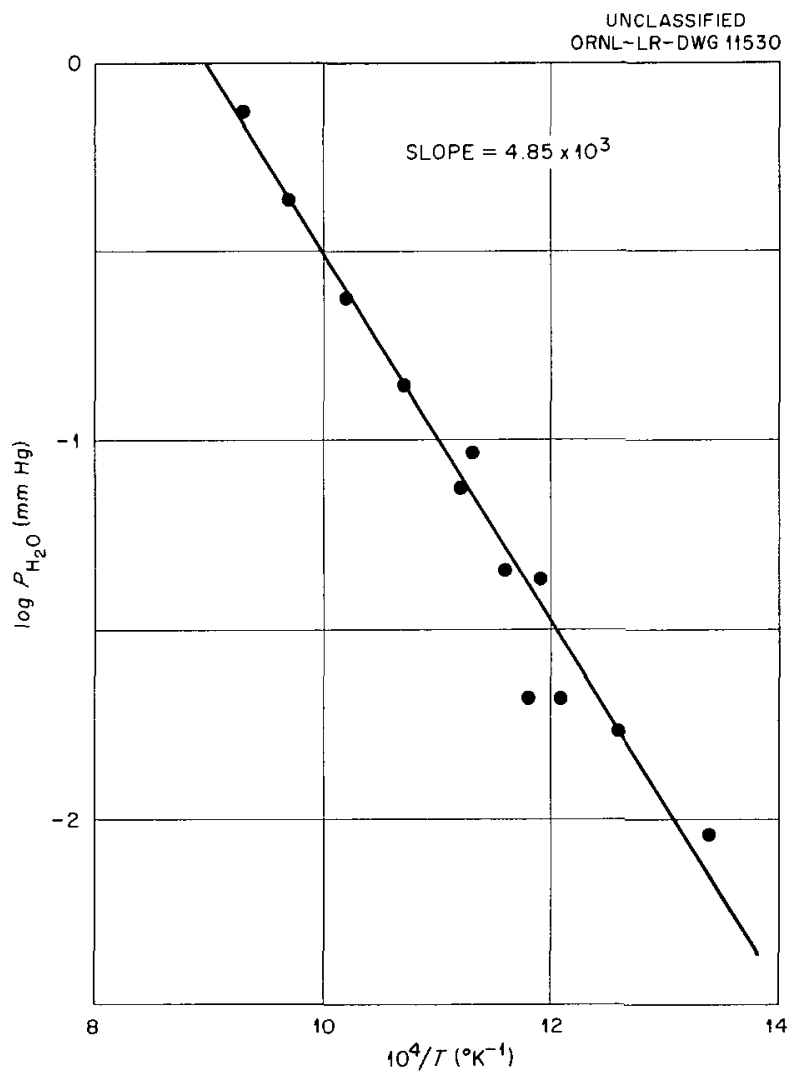

Fig. 64. Vapor Pressure of Water Over Fused Sodium Hydroxide vs Reciprocal Temperature.

The hydrogen pressure rose with temperature to $0.025 \mathrm{~mm} \mathrm{Hg}$ at about $600^{\circ} \mathrm{C}$ and remained at this level at higher temperatures. The explanation of this behavior is not obvious, but it may have been due in large part to some trivial cause, such as the removal of dissolved hydrogen. The nitrogen probably came, in part, from air contamination, but it may have come from the decomposition of traces of ammonia. Contamination by ammonia could have resulted from traces of organic matter containing proteins. The amount of hydrogen pro- duced from ammonia, as calculated from the amount of nitrogen, would have been quite small.

\section{MASS TRANSFER AND CORROSION IN FUSED SODIUM HYDROXIDE}
M. E. Steidlitz
G. P. Smith

The objectives of the present fused-hydroxide corrosion-testing program are:

1. the determination of the detailed empirical facts pertaining to hydroxide corrosion and mass transfer as measured metallographically;

2. the determination of the limiting service conditions for several metals immersed in fused hydroxides;

3. the development of an alloy with a corrosion resistance, to fused hydroxide, which approaches that of Inconel;

4. the ascertainment of corrosion and masstransfer inhibitors.

These objectives are listed in the order of current emphasis. The third and fourth objectives are of more importance but cannot be adequately accomplished until the first and second objectives are reasonably well resolved.

In order to obtain information pertinent to objectives 1 and 2, a systematic low-velocity testing was initiated on January 25, 1955, and 147 runs were made between this date and September 6, 1955. Of these, nine were operational failures. Metallographic preparation of the resultant specimens and evaluation of the results lag behind the testing program by two to four months. Work on objective 3 has begun in a very limited way with the cooperation of other members of the Metallurgy Division.

Since in the evaluation of a corrosion inhibitor it is presupposed that the extent of normal corrosion is known, objective 4 cannot be meaningfully undertaken until objectives 1 and 2 are more nearly attained. The development of inhibitors actually involves several problems, inasmuch as there is no a priori reason to suppose that a mass-transfer inhibitor will also be a corrosion inhibitor or that a mass-transfer inhibitor for one constituent of an alloy will serve for the other constituents.

\section{Apparatus}

The essential parts of the apparatus used to study mass transfer and corrosion under the influence of a thermal gradient are shown in Fig. 65. The sodium hydroxide is contained in a bucket 


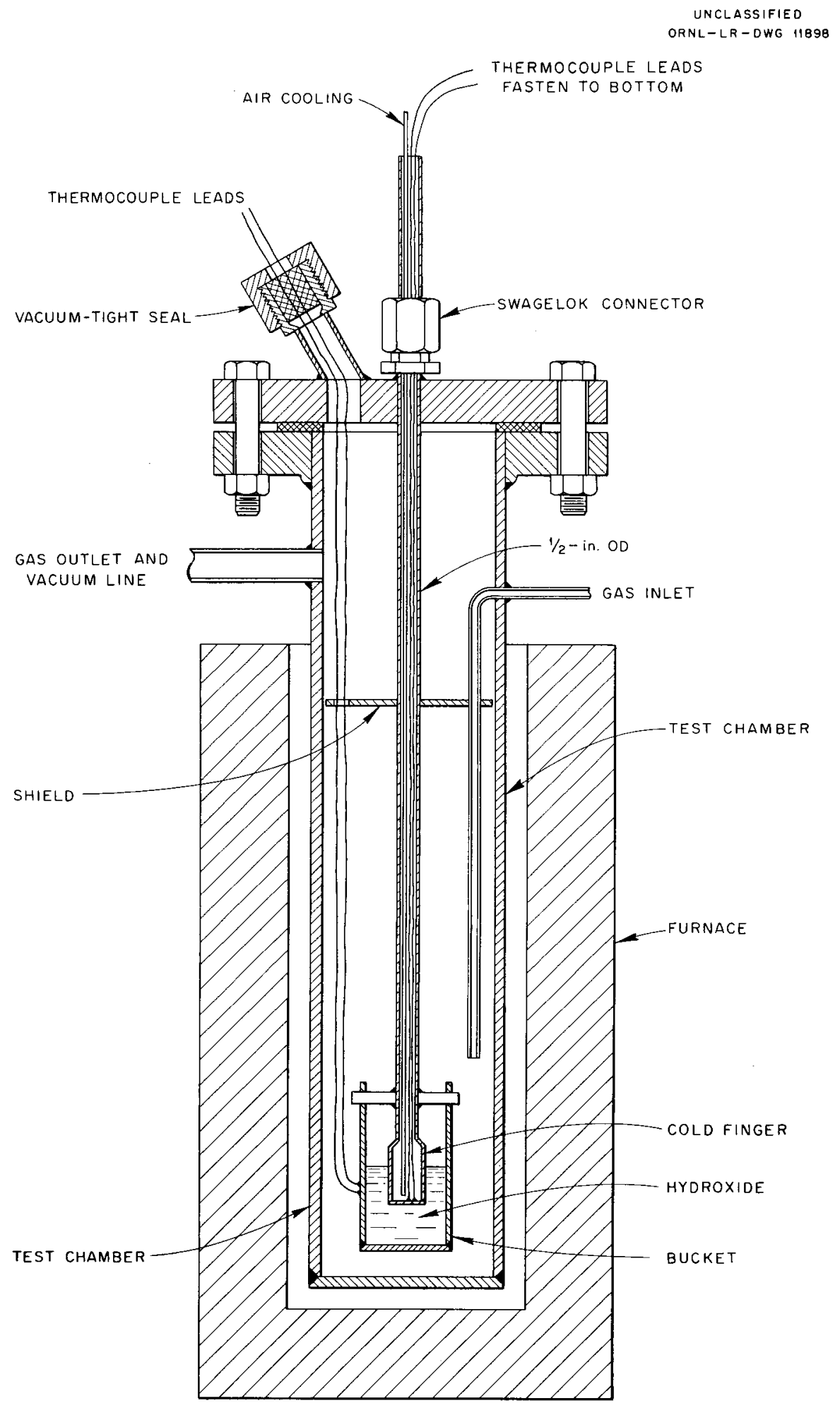

Fig. 65. Apparatus to Test Corrosive Properties of Fused Sodium Hydroxide. 
that is 2 in. in outside diameter, $3 \mathrm{in.} \mathrm{high} \mathrm{with}$ a wall $1 / 16$ in. thick, and is fabricated from the metal that is under test. The outside-wall temperature of the bucket is measured by a thermocouple spot-welded in place. Arranged axially within the bucket is a tube that has an outside diameter of $3 / 4$ in. and is closed off at the bottom. This tube will be referred to as a "cold finger." The cold finger is made of the metal under test. It passes out of the top of the test chamber through a Swagelok connector. The bottom of the cold finger is cooled by a stream of air introduced through a small metal tube, as shown in the diagram. The inside surface temperature of the cold finger is measured by means of a thermocouple spot-welded to the bottom.

Approximately $90 \mathrm{~g}$ of sodium hydroxide is used in each test, and this is sufficient, when molten, to fill the bucket to a depth of about $1.5 \mathrm{in}$. so that the cold finger can be immersed to a depth of about 0.75 in.

The temperature and temperature differences reported are measured by the thermocouples that are welded to the inside of the cold finger and to the outside of the bucket. The temperature of the metal-hydroxide interface is unquestionably different, but there is no simple way to measure it.

The gaseous atmospheres used in these tests are usually helium and hydrogen. The helium is purified by passing it over calcium turnings at $700^{\circ} \mathrm{C}$ and then over calcium turnings at $400^{\circ} \mathrm{C}$. The hydrogen is purified by passing it over copper turnings at $700^{\circ} \mathrm{C}$ and then over a calcium-calcium hydride mixture at $400^{\circ} \mathrm{C}$. For tests employing mixtures of these gases, the relative amounts are determined with calibrated flow meters placed in each line before mixing. For tests involving water vapor, the purified gases are bubbled through water at a specified temperature. The test chambers are vacuum-tight. The gases are introduced near the top of the bucket of hydroxide and a slow stream of gas is maintained throughout a run.

The apparatus used to study corrosion in the absence of a thermal gradient is like that described above except that the cold finger is replaced by a group of eight specimens of the metal under test. These specimens are generally 3 in. long, $\frac{1}{2}$ in. wide, and 0.035 in. thick, although special sizes are sometimes used. Each specimen is suspended from a separate wire which passes through a vacuum-tight seal in the top of the test chamber. Thus, each specimen may be separately removed from the fused hydroxide and brought into a cool region without disturbing the other specimens; hence, in a single run it is possible to corrode specimens for various times at a single temperature. As stated previously, the bucket and all of the specimens are of the same composition.

\section{Experimental Procedure}

In preparation for a run, the bucket and cold finger are washed with water and acetone and then annealed at $800^{\circ} \mathrm{C}$ in hydrogen for $2 \mathrm{hr}$. The apparatus is assembled, and $90 \mathrm{~g}$ of sodium hydroxide is added to the bucket immediately before the upper flange plate is bolted in place. The hydroxide is dehydrated under vacuum for $8 \mathrm{hr}$ at $300^{\circ} \mathrm{C}$ and then for $16 \mathrm{hr}$ at $400^{\circ} \mathrm{C}$. The blanketing atmosphere is then admitted, the temperature of the system is raised to the operating temperature, and, finally, the temperature differential is intro. duced by applying the cooling air stream.

At the completion of a run, the hydroxide is generally removed by dissolving it in water. Suitable sections of the bucket and cold finger are removed and mounted for metallographic examination.

\section{Static Corrosion of Inconel}

Thirty-two tests have been made on the corrosion of Inconel by fused sodium hydroxide in the absence of a thermal gradient. Tests were conducted under blanketing atmospheres of both helium and hydrogen. Metallography has been completed on the test specimens run under hydrogen.

Figure 66 shows semiquantitatively the extent of corrosion of Inconel when immersed in fused sodium hydroxide for various times at various temperatures under a blanketing atmosphere of hydrogen. The seven photomicrographs are of cross sections of the specimens in the region of the fused-hydroxide-metal interface. In each photograph, the pale-gray region at the bottom is the unattacked metal. The dark-gray region is the layer of corrosion product. The white area at the top corresponds to the area which was originally occupied by fused hydroxide.

The top row of pictures, Figs. $66 a$ to $66 c$, shows the rather severe attack found at $800^{\circ} \mathrm{C}$. The arrow to the right of Fig. $66 c$ gives the approximate position of the hydroxide-metal interface at the beginning of the test. A line extended horizontally from this arrow across Figs. $66 a$ and 


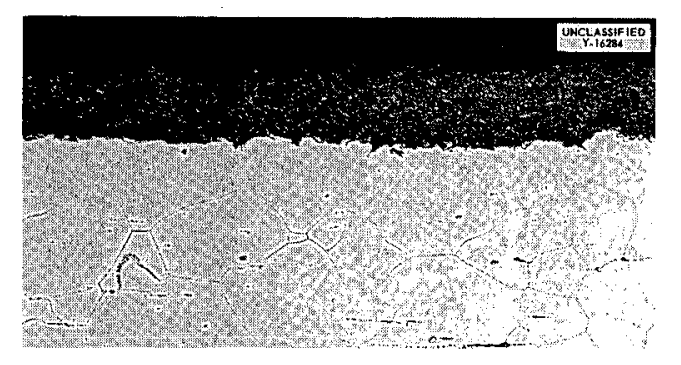

(a) EXPOSED AT $800^{\circ} \mathrm{C}$ FOR $28 \mathrm{hr}$.

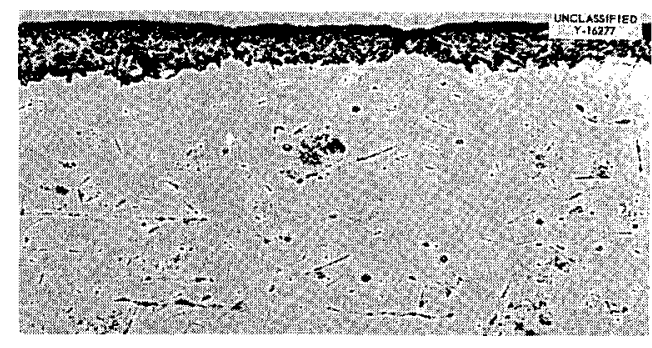

(d) EXPOSED AT 700'C FOR $23 \mathrm{hr}$

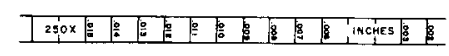

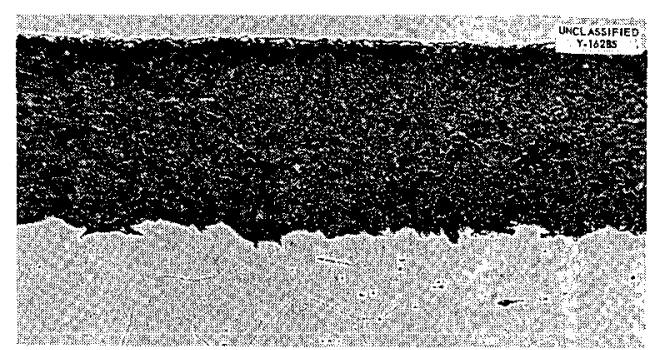

(b) EXPOSED AT $800^{\circ} \mathrm{C}$ FOR $54 \mathrm{hr}$.
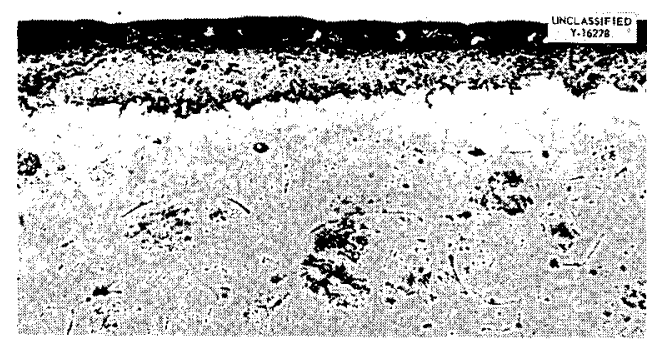

(e) EXPOSED AT $700^{\circ} \mathrm{C}$ FOR $50 \mathrm{hr}$.

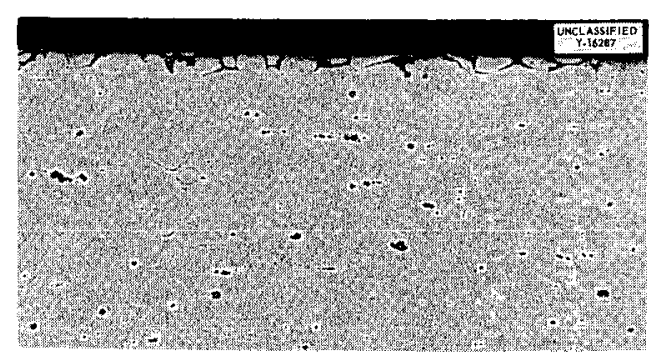

(8) EXPOSED AT 6000 C FOR $100 \mathrm{hr}$.

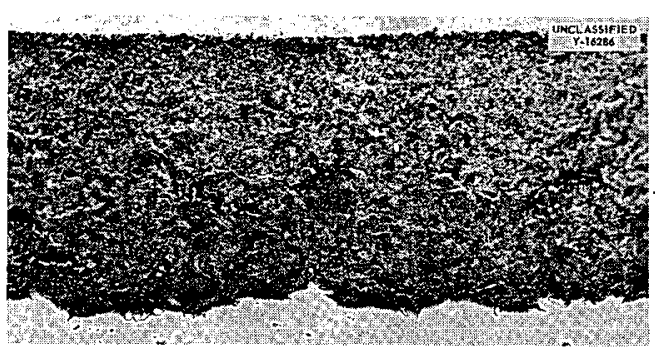

(c) EXPOSED AT $800^{\circ} \mathrm{C}$ FOR $100 \mathrm{hr}$.

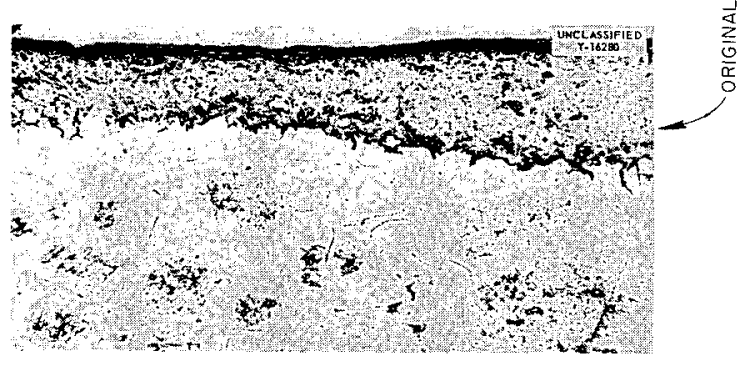

(i) EXPOSED AT 7000 COR $100 \mathrm{hr}$

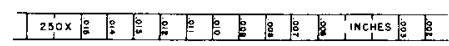

Fig. 66. Corrosion of Inconel by Fused Sodium Hydroxide Under a Blanketing Atmosphere of Hydrogen. 250X. Reduced $57 \%$. 
$66 b$ gives the initial hydroxide-metal interface for these tests also.

The second row shows the corrosion product formed at $700^{\circ} \mathrm{C}$. The arrow to the right of $\mathrm{Fig} .66 f$ has the same significance as the arrow described above. It will be noticed that the corrosionproduct thickness varies considerably. This is typical of all hydroxide corrosion that has been observed to date and has added to the difficulty of obtaining meaningful quantitative data on the extent of corrosion.

Only one picture, Fig. 66g, is shown for corrosion at $600^{\circ} \mathrm{C}$. For corrosion periods significantly shorter than $100 \mathrm{hr}$, very little to no attack is found at $600^{\circ} \mathrm{C}$. At $100 \mathrm{hr}$, it will be seen that there is no corrosion-product layer, only a slight intergranular penetration.

The metallographic details displayed in Fig. 66 may be taken as typical, except that in some tests run under the same conditions a narrow region of intergranular penetration separates the corrosionproduct layer from the unattacked metal.

Figure 67 gives quantitative data on the corrosion of Inconel by fused sodium hydroxide under a blanketing atmosphere of hydrogen. The circles are values of the average corrosion and have the

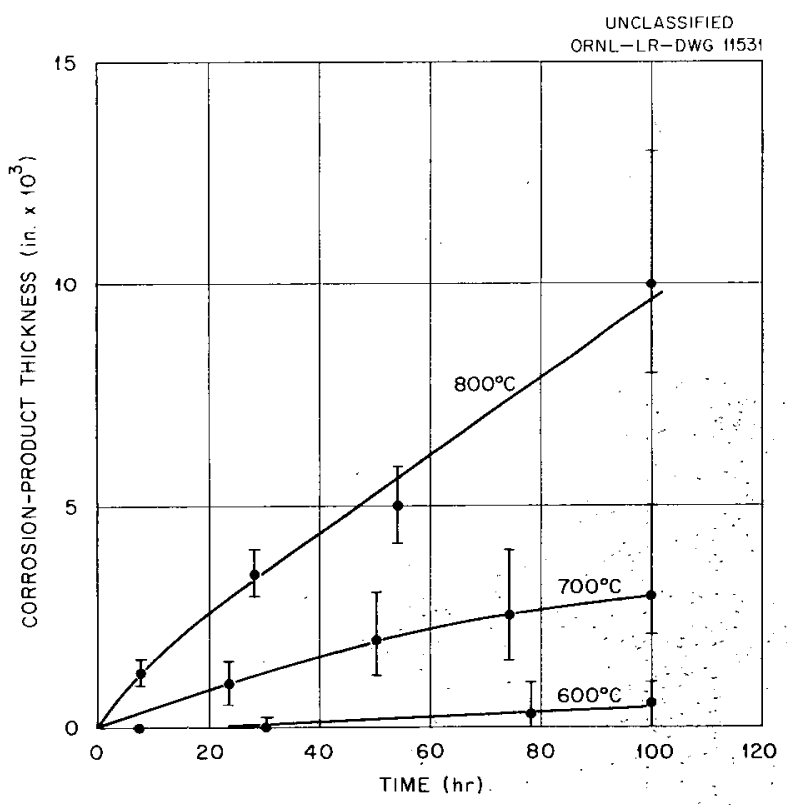

Fig. 67. Effect of Time and Temperature on Corrosion of Inconel by Fused Sodium Hydroxide Under a Blanketing Atmosphere of Hydrogen. following meaning. The numerical product of the average-corrosion volue times a given macroscopic area of external surface, assumed flat, results in an approximation to the actual volume of corrosion product contained beneath the given macroscopic surface. The vertical lines passing through a circle signify the values of maximum and minimum corrosion observed on a specimen.

Detailed studies were made of the microstructures of the corrosion product found on Inconel. Figure 68 is typical of the microstructures of the unetched corrosion products at high magnification. The region which is shown is in the neighborhood of the corrosion-product-unattacked-metal interface, but any other region would have appeared much the same. The most striking feature is that the corrosion product seems to consist of more or less acicular particles of a nonmetallic phase within a metallic matrix. The general impression given by such examinations at high magnification is that the nonmetallic phase may have precipitated from solid solution more or less preferentially along preferred crystal planes of the parent metal.

Examination of regions which had been attacked along the grain boundaries, such as occurs at the lower temperatures, showed that this attack was also complex. The grain-boundary region was occupied by a metallic phase, at the edges of which were exceedingly fine particles of a nonmetallic phase. Figure 69 is a photomicrograph of this intergranular attack. The nonmetallic particles are so small that they approach the resolving power of the microscope and appear in the photograph as diffuse gray areas along either side of elongated metallic areas.

Heavily corroded specimens were found to be strongly ferromagnetic. Microscopic studies were made of the migration of colloidal magnetite over a polished cross section of a specimen in a magnetic field. It was shown that the ferromagnetism is restricted to the corrosion-product layer.

Samples of ground corrosion product were leached with water for long periods, and it was found that appreciable sodium in the form of $\mathrm{Na}_{2} \mathrm{O}$ was removed. X-ray examination of the corrosion product gave an abundance of lines which could not be analyzed. Further efforts at determining the composition of the corrosion product are in progress. 


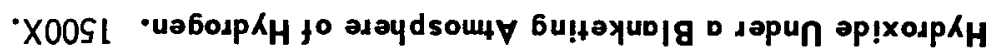

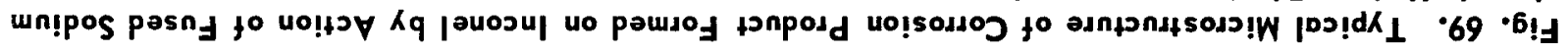

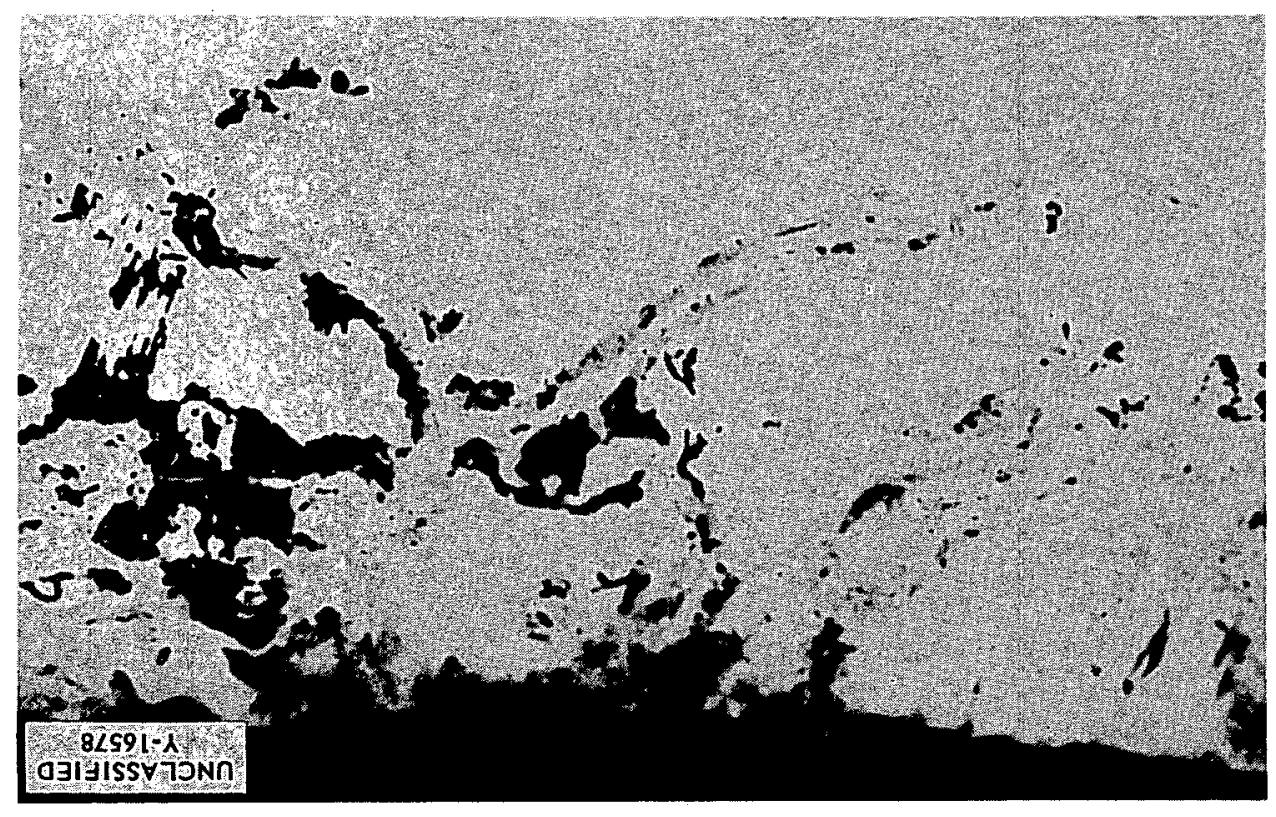

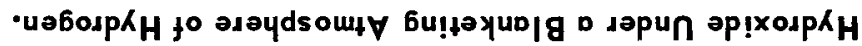

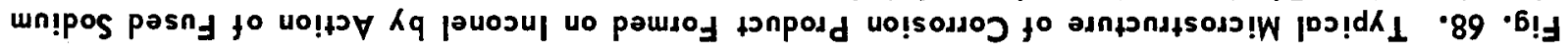

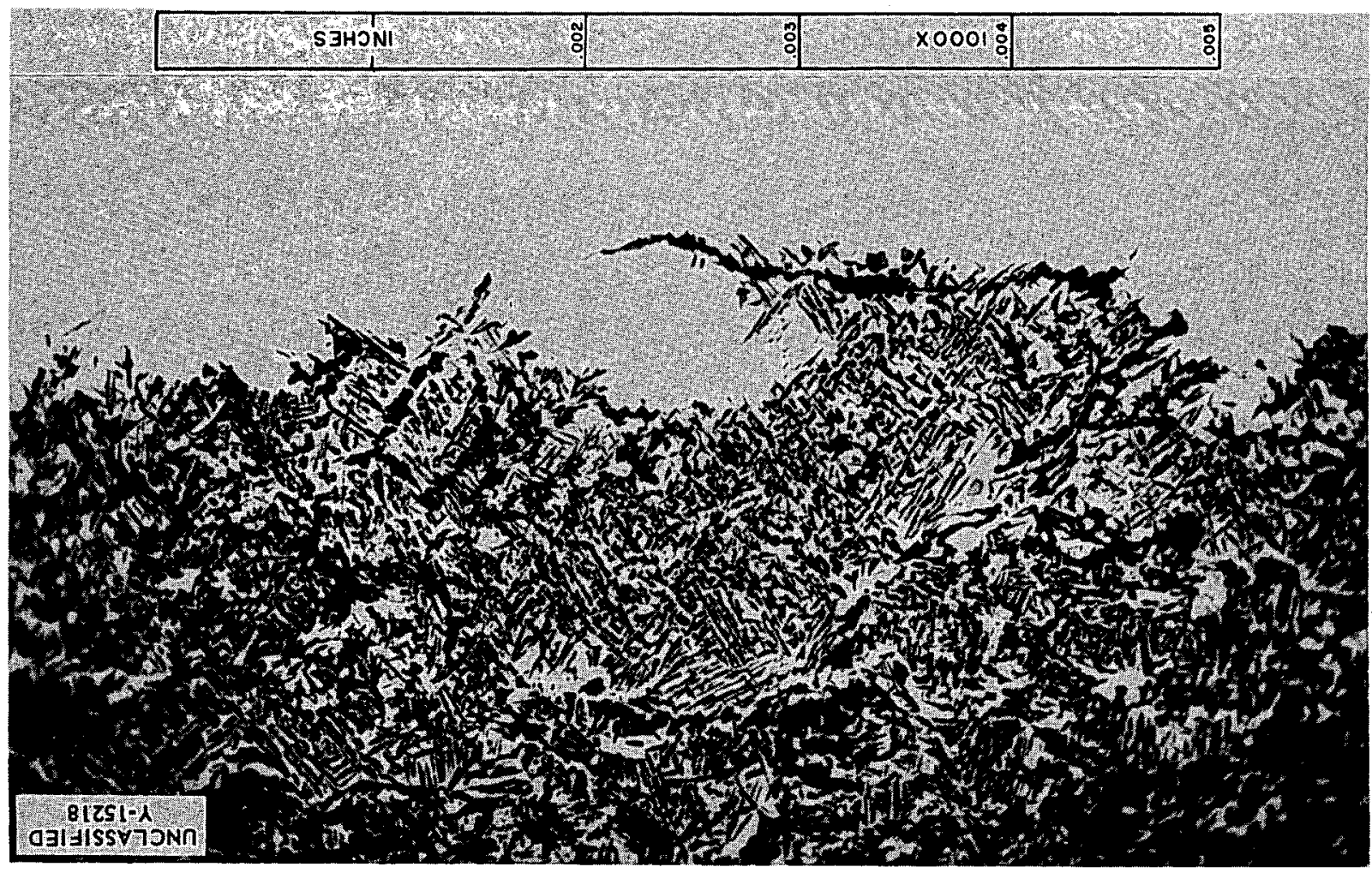




\section{Mass Transfer of Nickel}

Sixty-five runs have been made in an effort to study the mass transfer of nickel in fused sodium hydroxide. About half these runs have been evaluated by use of metallographic techniques. The only results complete enough to be presented in detail here are those in which a blanketing atmos. phere of hydrogen was used.

It is important to distinguish between the mass. transfer deposits at the gas-liquid interface and those that occurred on the immersed surface. Deposition occurs more readily at the interface than anywhere else in the system. On the other hand, such interfaces would occur only at a few special places in a heat-transfer system. Thus, this interface deposition should not be a source of trouble and will be ignored in this report.

Usually, the mass-transfer deposits of nickel under a blanketing atmosphere of hydrogen were less than 0.001 in. They were also, of course, of about the same composition as the base metal and frequently contained the same crystal orienta. tion as the base metal. Thus, it was necessary to use somewhat refined metallographic techniques to measure the thickness of the deposited films. In order to prevent rounding-off of the edges of the specimens during metallographic polishing, they were first copper-plated. Despite this, a very slight rounding-off was unavoidable. For this reason, $0.0001 \mathrm{in}$. is taken as the minimum thickness for which mass-transfer deposits can be positively identified. This corresponds to a uniform deposit of $2 \mathrm{mg} / \mathrm{cm}^{2}$. In order to determine the thickness of heavier deposits, it is necessary to establish the base-metal-deposited-metal boundary. It was found that very careful etching would, in some instances, yield a faint grainboundary-like groove along this base-metaldeposited-metal boundary. In other instances no such boundary could be found. However, it was discovered that the mass-transfer deposits oxidize at a slightly lower rate than the base metal, perhaps due to the greater purity of the former; there: fore, gentle oxidation of metallographically polished specimens was found to tarnish the base metal but not the deposit. Figure 70 shows a nickel mass-transfer deposit on a nickel cold finger. The maximum thickness of this film is 0.0007 in., and its average thickness is about $0.0002 \mathrm{in}$. The lower region of the photomicrograph is the base metal, the middle region is the copper plate, and the dark region at the top is the mounting plastic. The irregular mass-transfer deposit may be seen between the copper plate and the base metal. This specimen illustrates both the etching and the tarnishing tectiniques.

The mass-transfer depos its were very rough. They consisted of nickel crystals densely crowded together over the surface. The bases of these crystals had grown together so that in cross section the deposits appeared as a thin continuous deposit densely covered with elongated protuberances of irregular dimensions. Most of these protuberances were of approximately the same length (see Fig. 70). At temperatures of $750^{\circ} \mathrm{C}$ and above, an exceptional nickel crystal would grow as a dendrite several times the length of an average crystal. Usually less than six such dendrites were found on a given cross section of a cold finger. Most frequently, the cross section did not include either the base or tip of these exceptional dendrites, so that no reliable measure of their length can be given. Thus, it is useful to describe the depth of the mass-transfer deposits in terms of two parameters, (1) length of an average protuberance and (2) length of the longest protuberance of a given cross section, and merely to note the presence or absence of the rare dendrites. In some cases, even this description leaves something to be desired because an increase in deposition is sometimes manifested by a greater density of long protuberances rather than by an increase in the average protuberance length. For these reasons, representative photomicrographs might well provide a more adequate description of mass transfer than tables or graphs. Unfortunately, suitable photomicrographs are not available at the time of writing.

The data on the mass transfer of nickel in fused sodium hydroxide under a blanketing atmosphere of hydrogen are presented in Table 31.

The tremendous difference between a deposit of nickel at the gas-liquid interface and that on the immersed surface of a cold finger is illustrated by $\mathrm{Fig} .71$, which shows a cross section through the cold finger near the gas-liquid interface. The white region in the lower third of the picture is the base metal. The black area above was originally occupied by the melt. The irregular white patches in the black area are sections through which dendrites formed at the gas-liquid interface. 


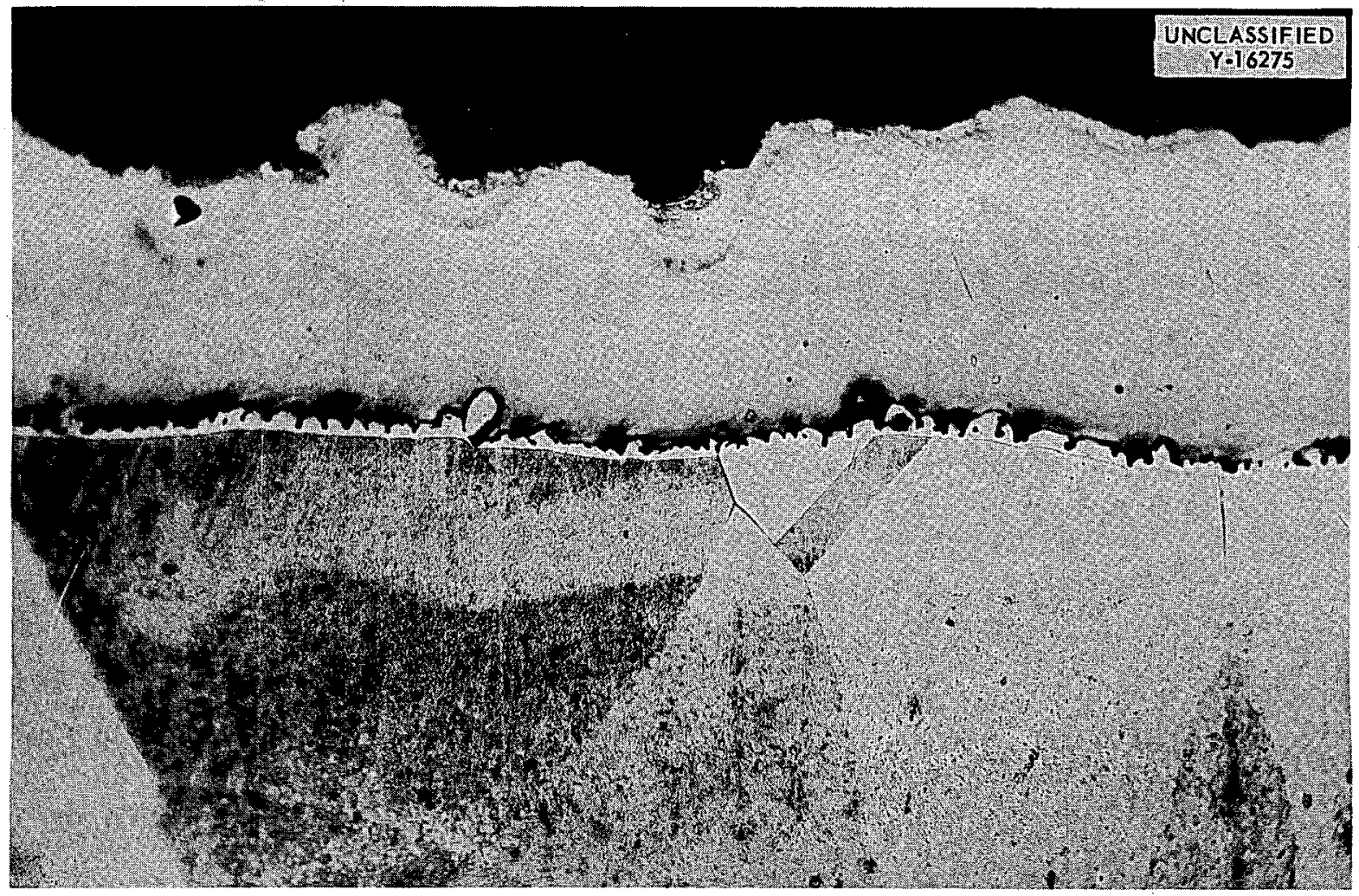

Fig. 70. A Mass-Transfer Deposit on Nickel. The metallographic technique used for measuring such deposits is illustrated. $330 \mathrm{X}$.

TABLE 31. MASS TRANSFER OF NICKEL IN FUSED SODIUM HYDROXIDE UNDER HYDROGEN

\begin{tabular}{ccccc}
\hline $\begin{array}{c}\text { Maximum } \\
\begin{array}{c}\text { Temperature } \\
\left({ }^{\circ} \mathrm{C}\right)\end{array}\end{array}$ & $\begin{array}{c}\text { Temperature } \\
\text { Differential } \\
\left({ }^{\circ} \mathrm{C}\right)\end{array}$ & $\begin{array}{c}\text { Time of } \\
\text { Test } \\
(\mathrm{hr})\end{array}$ & $\begin{array}{c}\text { Average } \\
\text { Thickness } \\
\left(\text { in. } \times 10^{3}\right)\end{array}$ & $\begin{array}{c}\text { Maximum } \\
\text { Thickness } \\
\left(\text { in. } \times 10^{3}\right)\end{array}$ \\
\hline 650 & 200 & 100 & 0 & 0 \\
675 & 50 & 100 & 0.1 & 0.1 \\
675 & 100 & 100 & 0.1 & 0.2 \\
700 & 50 & 100 & 0.2 & 0.4 \\
700 & 100 & 100 & 0.2 & 0.4 \\
700 & 125 & 100 & 0.3 & 0.5 \\
750 & 100 & 100 & 0.6 & 1.0 \\
800 & 100 & 1.0 & 3.0 \\
800 & 125 & 100 & 1.0 & 3.0 \\
\hline
\end{tabular}




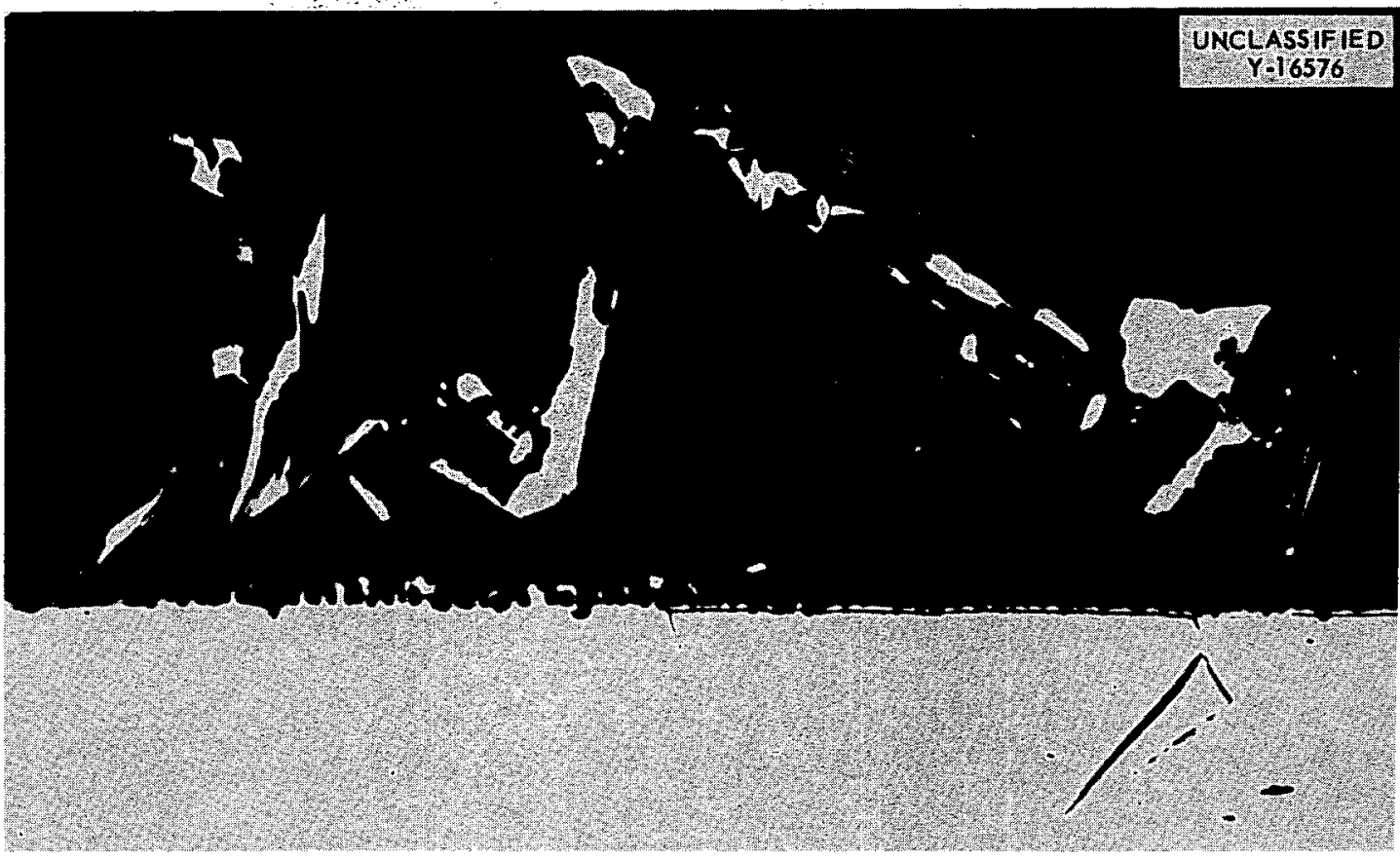

Fig. 71. Section of Nickel Cold Finger After Exposure to Fused Sodium Hydroxide Under a Blanketing Atmosphere of Hydrogen. The difference in magnitude of the mass-transfer deposits, on the surface at the gas-liquid interface and on the immersed surface, is illustrated. $100 \mathrm{X}$.

The row of white dots near the edge which separates the black and white areas is the deposit that formed on the immersed surface. The immersed deposit on the right-hand side of the photograph is representative of the deposit over the remainder of the cold finger. The interface deposit shown extends outward for about 0.009 in., whereas the immersed deposit is a barely detectable 0.0001 in., a factor-of-90 difference.

A number of runs have been made with nickel in which the hydrogen atmosphere was replaced by helium. The metallographic data are too incomplete to be described, but it is evident in general that the mass transfer was much worse with helium.

\section{Mass Transfer of Copper}

A number of runs have been made, and copper was found to mass-transfer readily; but no metallographic data are available.

\section{Mass Transfer of Iron}

Carbon steel (AISI No. C1015) was used in runs made under hydrogen. Each run lasted $100 \mathrm{hr}$, with a temperature differential of $100^{\circ} \mathrm{C}$. Figure 72 shows a series of cold fingers obtained from these tests. The heavy deposits of iron crystals on the lower ends, together with the even heavier skirts of crystals which formed at the liquid-gas interface, can be seen. In Fig. 72, specimen No. 127 was subjected to a maximum temperature of $550^{\circ} \mathrm{C}$, specimen No. 128 to $600^{\circ} \mathrm{C}$, specimen No. 129 to $650^{\circ} \mathrm{C}$, specimen No. 130 to $700^{\circ} \mathrm{C}$, and specimen No. 131 to $750^{\circ} \mathrm{C}$. It will be noted that, with other experimental parameters the same, the mass transfer was significantly worse for iron at $550^{\circ} \mathrm{C}$ than it was for nickel at $800^{\circ} \mathrm{C}$. However, the crystals deposited were roughly equiaxed for even the heaviest deposits; whereas similar heavy deposits of nickel; as formed under a helium blanketing atmosphere, were always dendritic.

\section{Mass Transfer and Corrosion of Inconel in Dynamic System}

Under the influence of a thermal gradient and at sufficiently high temperatures, Inconel undergoes both mass transfer and corrosive attack. The mass-transfer deposit apparently adheres quite well to the corrosion product. This is not too 


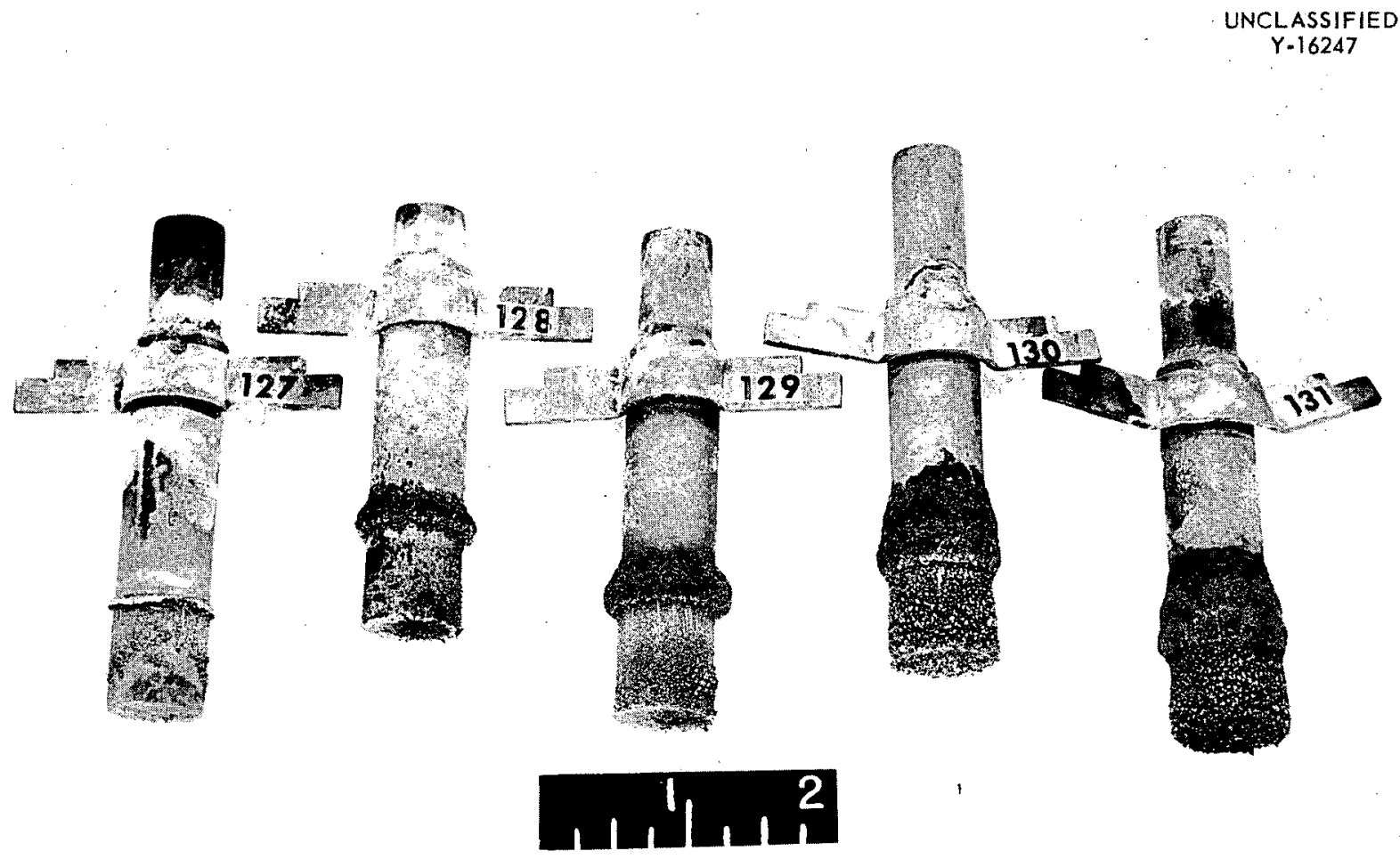

Fig. 72. Mass-Transfer Deposits on Carbon Steel (AISI No. C1015) Cold Fingers After Being Tested in Fused Sodium Hydroxide Over a Range of Increasing Temperatures and Under a Blanketing Atmosphere of Hydrogen.

surprising, however, in view of the metallic matrix which the corrosion product was found to contain, as described above. Figure 73 illustrates the formation of a mass-transfer deposit on Inconel. This figure shows a section of a cold finger from a 100-hr test under hydrogen in which the maximum temperature was $800^{\circ} \mathrm{C}$ and the temperature differential was $700^{\circ} \mathrm{C}$. The corrosion-product thickness is atypical for these experimental conditions and is attributed to the presence of a fissure in the original metal.

For Inconel under a blanketing atmosphere of hydrogen, the corrosion was slightly worse than would have been expected from the static tests reported in one of the previous sections, whereas the mass transfer was about the same as that found for pure nickel under the same conditions.

For Inconel under a blanketing atmosphere of helium, the available data are insufficient for quantitative evaluation. Qualitatively, however, both corrosion and mass transfer are much more severe than they are under similar experimental conditions when a blanketing atmosphere of hydrogen is used. The microstructure of the corrosion product that results in tests under helium is distinctively different from that found in tests under hydrogen, as shown in Fig. 74. This figure shows a cross section at the surface of a bucket corroded for $76 \mathrm{hr}$ in fused sodium hydroxide at $675^{\circ} \mathrm{C}$ with a temperature differential of $100^{\circ} \mathrm{C}$. The corrosion product consists of branched dendritic structures, many of which begin at the outer interface and penetrate deeply into the base metal. Along the axis of each dendrite is a relatively wide band of a metallic phase.

\section{Mass Transfer and Corrosion of Monel in Dynamic Systems}

A few tests have been run on monel, but the data are insufficient as yet for quantitative evaluation. Qualitatively, monel is found to mass- 




Fig. 73. A Mass-Transfer Deposit on a Substrate of Corroded Inconel Which Was Formed in a Dynamic Test with Fused Sodium Hydroxide and Under a Blanketing Atmosphere of Hydrogen. $250 X$.

transfer when tested at $700^{\circ} \mathrm{C}$ under hydrogen and with a temperature difference of $100^{\circ} \mathrm{C}$.

\section{Mass Transter and Corrosion of Hastelloy in Dynamic Systems}

The data on Hastelloy are confused to some extent by the poor quality of the metal available for test. This metal contained pits, cracks, and stringers, which are frequently of macroscopic size. It is known from other studies that fused sodium hydroxide has an extraordinary ability to penetrate deeply into minute voids. Hence, each flaw in Hastelloy which touched the surface provided a pathway along which the hydroxide moved, which carried localized corrosion deeply into the interior of the metal. Finally, the available metal sometimes consisted of two metallic phases in varying amounts.

All runs with Hastelloy were conducted for 100 hr under a blanketing atmosphere of hydrogen, and the temperature differential was $100^{\circ} \mathrm{C}$. The mass transfer found under these conditions was similar in magnitude to that found for nickel under similar conditions, with the exception that the mass transfer was detected at temperatures as low as $650^{\circ} \mathrm{C}$ for Hastelloy but not below $670^{\circ} \mathrm{C}$ for nickel.
This difference of $20^{\circ} \mathrm{C}$ is not especially significant, however, in terms of the over-all scatter in the experimental results. Corrosion was detected at $600^{\circ} \mathrm{C}$, the lowest temperature studied. The corrosion was, in general, 1.5 to 2 times that found for Inconel under similar conditions, but the scatter in results was quite bad. This scatter is associated with the poor and irreproducible quality of the metal available for test.

\section{Mass Transfer and Corrosion of Stainless Steels in Dynamic Systems}

A number of runs were made with types 310 and 405 stainless steel under hydrogen at temperatures from 550 to $750^{\circ} \mathrm{C}$ for $100 \mathrm{hr}$ and with a temperature differential of $100^{\circ} \mathrm{C}$. In all runs, scaling was so severe that the specimens were not subjected to metallographic study.

\section{Alloy Development Research ${ }^{6}$}

At present, activities intended for the development of a high-temperature alloy resistant to hydroxide corrosion are very limited. If the current studies prove to be unfruitful, this program will

\footnotetext{
${ }^{6}$ This work was done in collaboration with E. E. Hoffman.
} 


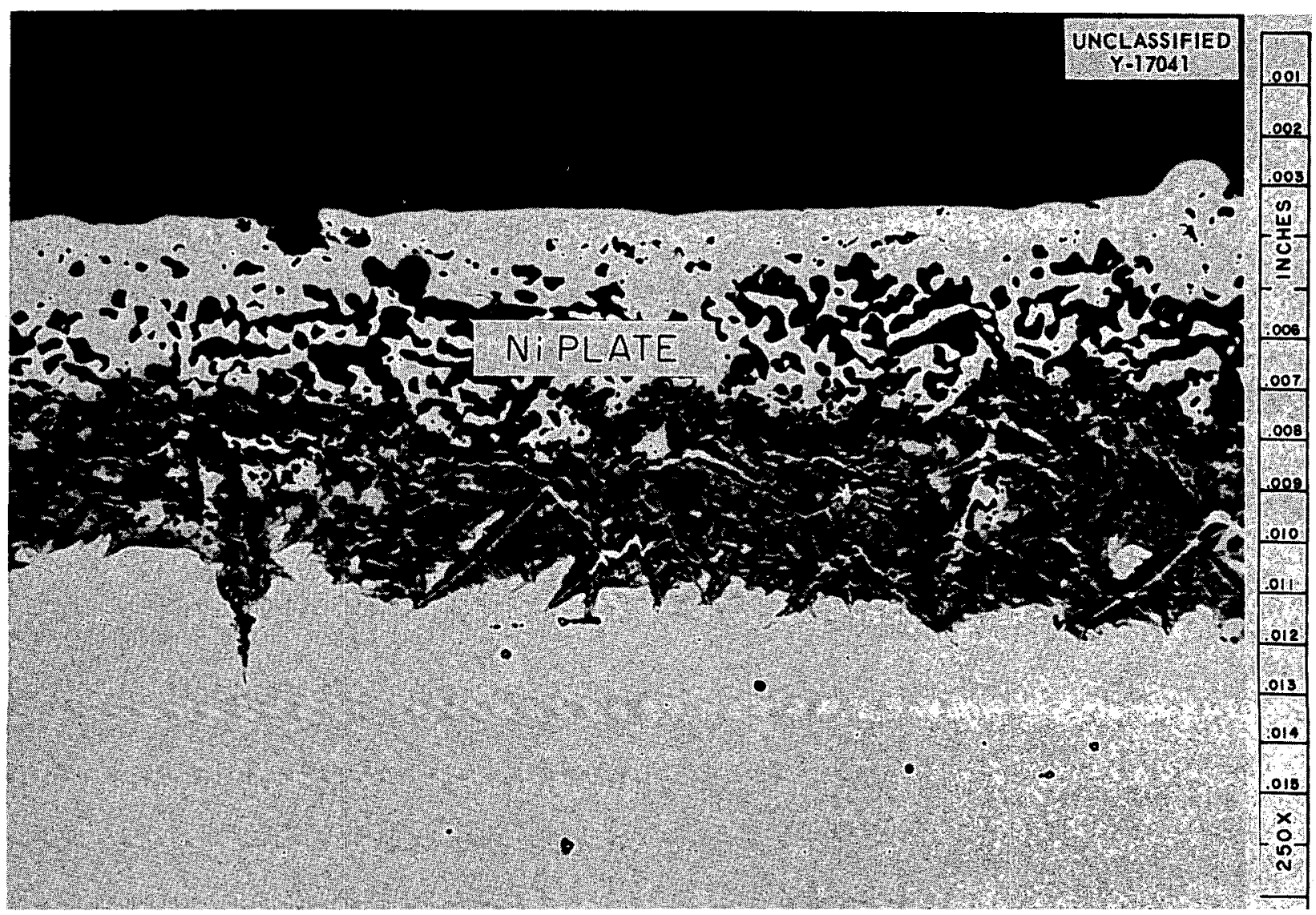

Fig. 74. Typical Microstructure of Corrosion-Product Layer Formed on Inconel by the Action of Fused Sodium Hydroxide in a Dynamic Test Under a Blanketing Atmosphere of Helium.

be dropped until such time as new information obtained on other programs offers hope of success.

All the hydroxide-corrosion static-screening tests previously carried out in the Metallurgy Division by Vreeland, Hoffman, et al. were recently reevaluated. These tests were carried out for $100 \mathrm{hr}$ in evacuated capsules at $815^{\circ} \mathrm{C}$. The results of interest may be briefly summarized as follows: Nickel did not measurably corrode. Iron corroded to the extent of 5 mils. Alloys of iron and nickel were attacked to a depth not exceeding 5 mils, except Carpenter Compensator 30 alloy, which was severely attacked. This corrosion rate is encouragingly low. However, pure nickel-iron alloys do not have significant high-temperature strength. The addition of chromium improves the strength of nickel-iron alloys, but a consequence of such an addition was that the corrosion rate was greatly accelerated. The alloys studied were commercial compositions which conventionally contain other metals in addition to the major constituents. However, more recent work by Steidlitz on a special heat of high-purity Inconel shows this material to corrode much like commercial Inconel. This suggests that in subsequent alloy-development work the addition of chromium should be avoided.

Molybdenum also improves the high-temperature strength of nickel and nickel-iron alloys. A corrosion test of a special heat of high-purity $80 \% \mathrm{Ni}-$ $20 \%$ Mo alloy showed only 1 to 2 mils of subsurface voids. This is exceptionally good corrosion resistance. However, a similar commercial alloy, Hastelloy $B$, has, on repeated testing (which is discussed above), proved to be quite susceptible to corrosion. Hastelloy $B$ is contaminated with significant amounts of foreign metals. Thus, it is possible either that the test on the high-purity 
nickel-molybdenum alloy was in error or that the impurities in Hastelloy B are a source of trouble. The present alloy-development program is embarked on an elucidation of this matter. If the favorable result on the high-purity alloy is verified, considerable effort will be devoted further to testing of this and similar compositions. Otherwise, the work will cease. 
0

0

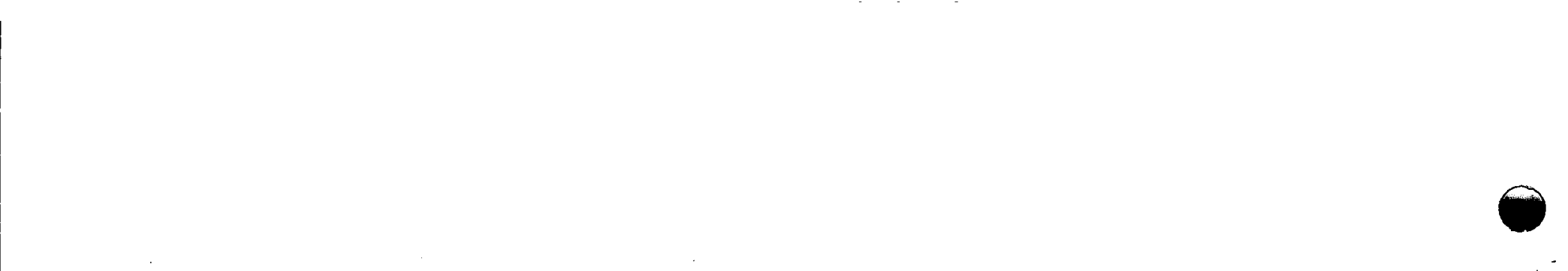




\title{
HRP METALLURGY
}

\author{
J. L. Gregg
}


•

•

1 


\section{HRP METALLURGY}

J. L. Gregg
G. E. Elder
W. O. Harms
J. I. Federer
W. J. Leonard
W. J. Fretague
G. B. Wadsworth

O. Zmeskal

PHYSICAL METALLURGY OF ZIRCONIUM ALLOYS

\section{W. J. Fretague}

Zircaloy-2 (Zirconium-Tin-Iron-Chromium-Nickel. Carbon)

Multiple-break impact specimens of Zircaloy-2 from HRP in-pile loop runs FF and GG were tested over temperatures ranging from -196 to approximately $300^{\circ} \mathrm{C}$. The data obtained with specimens from run GG are presented in Table 32. The results from run $G G$, together with those obtained previously ${ }^{\prime}$ for control specimens from the same lot of material, are plotted in Fig. 75. The results from run FF are plotted in Fig. 76 together with data obtained previously' from (1) samples irradiated in HRP environment (loop run DD), (2) samples exposed in HRP in-pile mock-up run $C C$, and (3) control samples tested in the vacuumannealed condition. 'W. J. Fretague, HRP Quar. Prog. Rep. April 30 ,
1955, ORNL-1895, P 167.

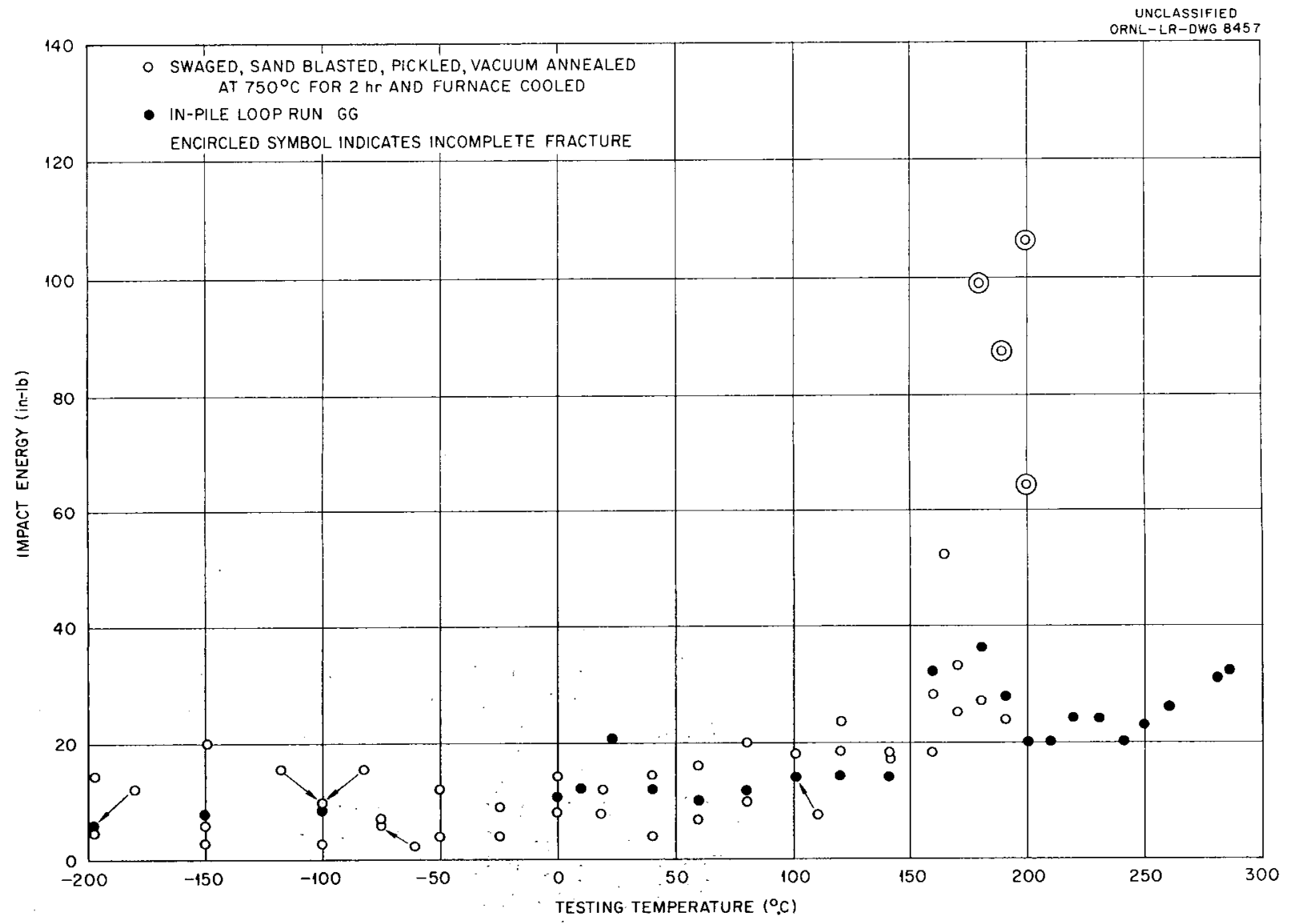

Fig. 75. Impact Energy vs Testing Temperature for Zircaloy-2. (Confidential with caption) 
TABLE 32. DATA ON IMPACT ENERGY VS TESTING TEMPERATURE FOR ZIRCALOY-2 SPECIMENS* EXPOSED IN IN-PILE LOOP GG

\begin{tabular}{|c|c|c|c|c|}
\hline $\begin{array}{l}\text { Specimen } \\
\text { No. }\end{array}$ & $\begin{array}{c}\text { Break } \\
\text { No. }\end{array}$ & $\begin{array}{l}\text { Scale Used } \\
\text { (in.-lb) }\end{array}$ & $\begin{array}{c}\text { Temperature } \\
\left({ }^{\circ} \mathrm{C}\right)\end{array}$ & $\begin{array}{c}\text { Impact Energy } \\
\text { (in.-lb) }\end{array}$ \\
\hline \multirow[t]{3}{*}{74} & 1 & $0-200$ & 40 & 12 \\
\hline & 2 & $0-200$ & 60 & 10 \\
\hline & 3 & $0-200$ & 80 & 12 \\
\hline \multirow[t]{3}{*}{76} & 1 & $0-200$ & 100 & 14 \\
\hline & 2 & $0-200$ & 120 & 14 \\
\hline & 3 & $0-200$ & 140 & 14 \\
\hline \multirow[t]{3}{*}{78} & 1 & $0-200$ & 160 & 32 \\
\hline & 2 & $0-200$ & 180 & 36 \\
\hline & 3 & $0-200$ & 190 & 28 \\
\hline \multirow[t]{3}{*}{80} & 1 & $0-200$ & 200 & 20 \\
\hline & 2 & $0-200$ & 210 & 22 \\
\hline & 3 & $0-200$ & 220 & 24 \\
\hline \multirow[t]{3}{*}{82} & 1 & $0-200$ & 230 & 24 \\
\hline & 2 & $0-200$ & 240 & 20 \\
\hline & 3 & $0-200$ & 250 & 23 \\
\hline \multirow[t]{3}{*}{84} & 1 & $0-200$ & 260 & 26 \\
\hline & 2 & $0-200$ & 280 & 31 \\
\hline & 3 & $0-200$ & 285 & 32 \\
\hline \multirow[t]{3}{*}{86} & 1 & $0-200$ & 24 & 21 \\
\hline & 2 & $0-200$ & 10 & 12 \\
\hline & 3 & $0-200$ & 0 & 11 \\
\hline \multirow[t]{3}{*}{88} & 1 & $0-200$ & -100 & 9 \\
\hline & 2 & $0-200$ & -150 & 8 \\
\hline & 3 & $0-200$ & -196 & 6 \\
\hline
\end{tabular}

*All specimens fractured completely.

It appears that the higher flux and the longer exposure time for specimens in run FF, as compared with run DD, and the higher acid content of the loop solution have not caused a change in the transition temperature of the material (energy ab. sorbed to break the specimens was used as a criterion). The energy level at the upper end (hightemperature or ductile region) of the curve for specimens from loop run FF is, however, generally lower than that obtained on previous samples.

It is noteworthy that all the specimens from in-pile loop run GG fractured completely on impact even at the highest testing temperature employed. In addition, the energy values recorded at the elevated testing temperatures were appreciably lower than those obtained on previous tests (in-pile loop runs DD and FF) of irradiated Zircaloy-2 specimens.

Specimens of Zircaloy-2 were irradiated at the MTR at temperatures less than $200^{\circ} \mathrm{C}$ (Facility HB-3, ORNL 10-2) by R. G. Berggren of the Solid State Division and were impact-tested by J. J. 


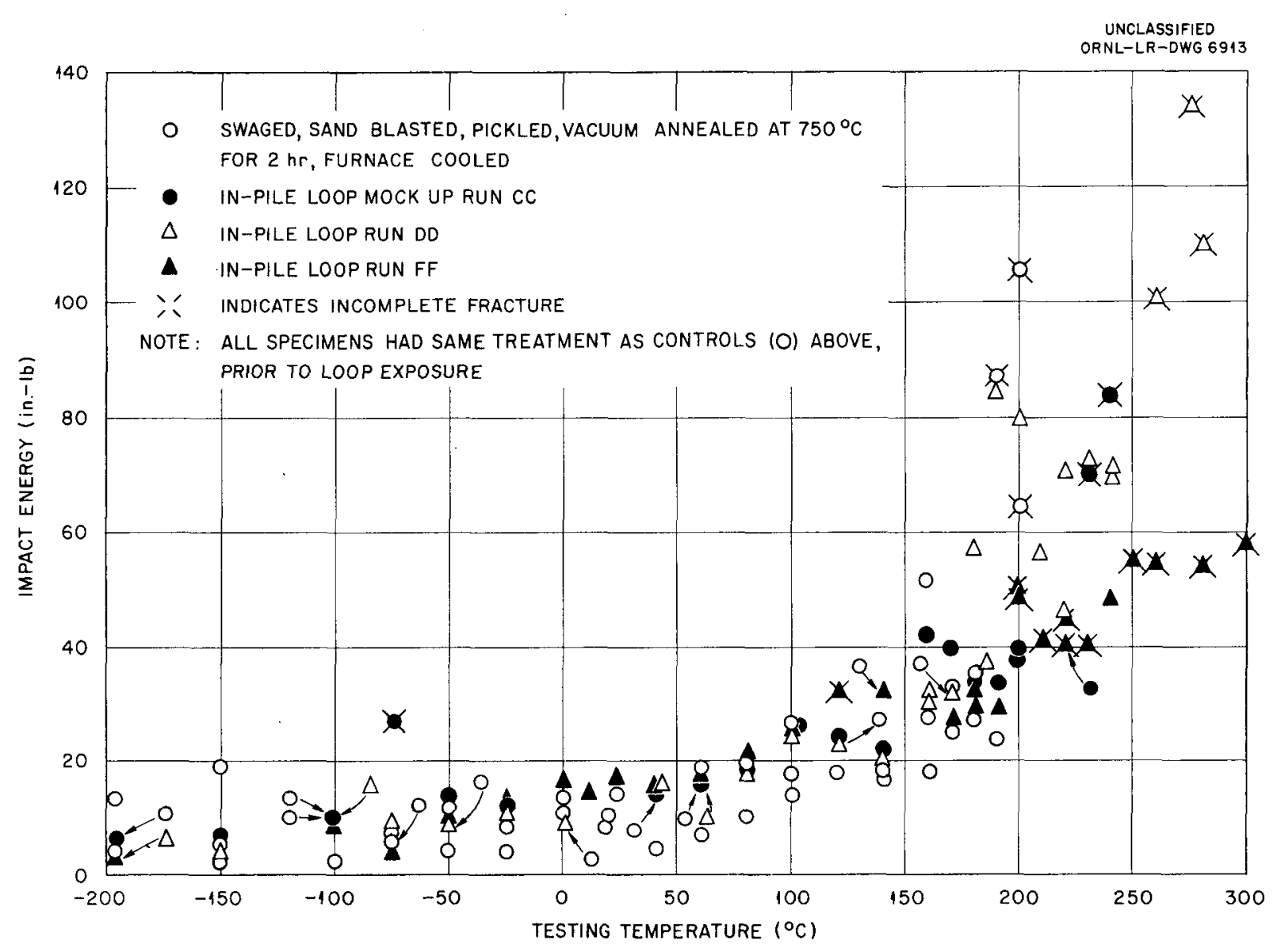

Fig. 76. Impact Energy vs Testing Temperature for Zircaloy-2. (Confidential with caption)

Woodhouse of the Metallurgy Division. The data obtained from the irradiated specimens are presented in Table 33, and the data from control specimens are presented in Table 34.

Vacuum-fusion analyses, in duplicate, of an irradiated impact specimen of Zircaloy-2 from inpile loop run GG gave results of 41 and $37 \mathrm{ppm}$ hydrogen. The control specimens had $35 \mathrm{ppm}$ hydrogen.

Microscopic examination of areas adjacent to that from which the vacuum-fusion sample was taken indicated that there was present in the alloy a second phase that seemed to be concentrated in the grain boundaries of the specimen from the in-pile loop run GG to a greater extent than in the control specimen.

Control specimens of Zircaloy-2 for impact and tensile testing are being aged at $250^{\circ} \mathrm{C}$ for $1000 \mathrm{hr}$ prior to testing. These controls are for a planned MTR irradiation of Zircaloy-2.

\section{SPECIAL ZIRCONIUM-BASE ALLOYS}
J. R. Johnson
O. Zmeskal
Ceramics Group

The oxidation of zirconium and its alloys is being studied in an effort to obtain some explanation for the fact that radiation induces more corrosion than normally occurs in unirradiated material. From observations of the results of neutron damage to monoclinic and cubic zirconium oxides, indications were that the cubic phase may be more stable under irradiation. It was found that a sample, originally consisting of a mixture of the monoclinic and cubic phases, when irradiated at Hanford with $2 \times 10^{20}$ nvt contained only the cubic phase. An irradiation of $1 \times 10^{20} n v t$ resulted in a definite decrease in the amount of monoclinic phase present. It is well known that when monoclinic $\mathrm{ZrO}_{2}$ is heated to about $1050^{\circ} \mathrm{C}$, the monoclinic structure is transformed into tetragonal (very 
TABLE 33. DATA ON IMPACT ENERGY VS TESTING TEMPERATURE FOR ZIRCALOY-2 IMPACT SPECIMENS IRRADIATED AT LESS THAN $200^{\circ} \mathrm{C}$ IN THE MTR

\begin{tabular}{|c|c|c|c|c|c|c|}
\hline $\begin{array}{l}\text { Specimen } \\
\text { No. }\end{array}$ & $\begin{array}{c}\text { Break } \\
\text { No. }\end{array}$ & $\begin{array}{l}\text { Scale Used } \\
\text { (in.-Ib) }\end{array}$ & $\begin{array}{c}\text { Temperature } \\
\left({ }^{\circ} \mathrm{C}\right)\end{array}$ & $\begin{array}{l}\text { Impact Energy } \\
\text { (in.-lb) }\end{array}$ & Fracture & $\begin{array}{c}\text { Flux } \text { caled, }>1 \mathrm{Mev} \\
\left(\text { nvt } f \times 10^{-20}\right)\end{array}$ \\
\hline \multirow[t]{4}{*}{545} & 1 & $0-200$ & 24 & 12 & Complete & 0.9 \\
\hline & 2 & $0-200$ & 70 & 12 & Complete & 1.1 \\
\hline & 3 & $0-200$ & 120 & $\sim 16$ & Complete & 1.5 \\
\hline & 4 & $0-200$ & 200 & 50 & $90 \%$ & 2 \\
\hline \multirow[t]{4}{*}{546} & 1 & $0-200$ & 160 & 22 & Complete & 1.7 to 1.8 \\
\hline & 2 & $0-200$ & 120 & 28 & Complete & 2.2 \\
\hline & 3 & $0-200$ & 70 & 14 & Complete & 3 \\
\hline & 4 & $0-200$ & 200 & $\sim 50$ & $90 \%$ & 3.8 \\
\hline \multirow[t]{4}{*}{547} & 1 & $0-200$ & 160 & 30 & $90 \%$ & 1.7 to 1.8 \\
\hline & 2 & $0-200$ & -25 & 10 & $99 \%$ & 2.2 \\
\hline & 3 & $0-200$ & 250 & $\sim 50$ & $80 \%$ & 3 \\
\hline & 4 & $0-200$ & 273 & $\sim 50$ & $80 \%$ & 3.8 \\
\hline
\end{tabular}

TABLE 34. DATA ON IMPACT ENERGY VS TESTING TEMPERATURE FOR ZIRCALOY-2 CONTROL SPECIMENS*

\begin{tabular}{|c|c|c|c|c|}
\hline $\begin{array}{c}\text { Specimen } \\
\text { No. }\end{array}$ & $\begin{array}{c}\text { Break } \\
\text { No. }\end{array}$ & $\begin{array}{l}\text { Scale Used } \\
\text { (in,-lb) }\end{array}$ & $\begin{array}{c}\text { Temperature } \\
\left({ }^{\circ} \mathrm{C}\right)\end{array}$ & $\begin{array}{l}\text { Impact Energy } \\
\quad(\text { in.-lb) }\end{array}$ \\
\hline \multirow[t]{4}{*}{30} & 1 & $0-200$ & 23 & 18 \\
\hline & 2 & $0-200$ & 60 & 20 \\
\hline & 3 & $0-200$ & 120 & 41 \\
\hline & 4 & $0-200$ & 200 & 39 \\
\hline 34 & 1 & $0-200$ & 23 & 10 \\
\hline
\end{tabular}

*For comparison with MTR irradiated specimens; all specimens fractured completely.

similar to the cubic). The transformation involves atomic rearrangement to such an extent that pieces of $\mathrm{ZrO}_{2}$ normally crack and crumble. This suggests that the effect of neutrons on monoclinic $\mathrm{ZrO}_{2}$ may be similar, that a protective monoclinic oxide film on the metal might be destroyed soon after its formation.

The protective film on zirconium alloys has been observed to be essentially monoclinic. Careful observations have been made at Battelle, and indications are that a very thin tetragonal layer may lie next to the metal. The Ceramics Section at ORNL investigated much thicker layers and observed only monoclinic oxide.

The practice of stabilizing cubic $\mathrm{ZrO}_{2}$ by adding minor amounts of other oxides to monoclinic $\mathrm{ZrO}_{2}$ has been utilized for some time. The oxide mixtures are sintered so as to obtain a solid solution and the cubic phase. It was believed that if those metals, the oxides of which stabilize $\mathrm{ZrO}_{2}$, were alloyed with zirconium, cubic $\mathrm{ZrO}_{2}$ might form rather than the monoclinic.

The investigation which followed included: (1) a study of numerous oxide additions to $\mathrm{ZrO}_{2}$ in order to determine their relative stabilizing effects, (2) the formation of several alloys of zirconium with the elements which appeared promising, (3) a study of the oxides formed on these alloys when oxidized in air, and (4) an investigation of the oxidation of those alloys in an autoclave. 
The tendency of various metal oxides to stabilize the cubic modification of zirconium oxide was investigated by grinding zirconium with relatively small amounts of these oxides and then firing the mixtures. Estimates of the relative amounts of monoclinic and cubic phases were made from $x$-ray

TABLE 35. STABILIZATION OF CUBIC ZIRCONIUM OXIDE BY OTHER OXIDES

\begin{tabular}{|c|c|c|}
\hline Oxides Added & $\begin{array}{c}\text { Concentration } \\
\text { (mole \%) }\end{array}$ & $\begin{array}{c}\text { Cubic Phase } \\
(\%)\end{array}$ \\
\hline $\mathrm{BaO}$ & 3 & 0 \\
\hline $\mathrm{BeO}$ & 3 & 0 \\
\hline $\mathrm{CaO}$ & 3 & 60 \\
\hline $\mathrm{CoO}$ & 5 & 90 \\
\hline $\mathrm{Nb}_{2} \mathrm{O}_{5}\left(\mathrm{Cb}_{2} \mathrm{O}_{5}\right)$ & 3 & 30 \\
\hline $\mathrm{Nb}_{2} \mathrm{O}_{5}$ & 5 & 70 \\
\hline $\mathrm{CeO}_{2}$ & 3 & 5 \\
\hline $\mathrm{CeO}_{2}$ & 5 & 10 \\
\hline $\mathrm{Cr}_{2} \mathrm{O}_{3}$ & 3 & 0 \\
\hline $\mathrm{Fe}_{2} \mathrm{O}_{3}$ & 3 & 0 \\
\hline $\mathrm{MgO}$ & 3 & 20 \\
\hline $\mathrm{MgO}$ & 5 & 35 \\
\hline $\mathrm{NiO}$ & 3 & 0 \\
\hline $\mathrm{PbO}$ & 3 & 0 \\
\hline $\mathrm{SnO}_{2}$ & 3 & 0 \\
\hline $\mathrm{TiO}_{2}$ & 3 & 0 \\
\hline $\mathrm{V}_{2} \mathrm{O}_{5}$ & 3 & 5 \\
\hline $\mathrm{Y}_{2} \mathrm{O}_{3}$ & 3 & 50 \\
\hline $\mathrm{Y}_{2} \mathrm{O}_{3}$ & 5 & 70 \\
\hline $\mathrm{ZnO}$ & 3 & 0 \\
\hline $\mathrm{CeO}_{2}, \mathrm{Nb}_{2} \mathrm{O}_{5}$ & 2,2 & 10 \\
\hline $\mathrm{SnO}_{2}, \mathrm{Nb}_{2} \mathrm{O}_{5}$ & 2,2 & 5 \\
\hline $\mathrm{Y}_{2} \mathrm{O}_{3}, \mathrm{Nb}_{2} \mathrm{O}_{5}$ & 2,2 & 0 \\
\hline $\mathrm{CeO}_{2}, \mathrm{Nb}_{2} \mathrm{O}_{5}$ & 2,8 & Questionable \\
\hline $\mathrm{SnO}_{2}, \mathrm{Nb}_{2} \mathrm{O}_{5}$ & 2,8 & 85 \\
\hline $\mathrm{Y}_{2} \mathrm{O}_{3}, \mathrm{Nb}_{2} \mathrm{O}_{5}$ & 2,8 & 75 \\
\hline $\mathrm{V}_{2} \mathrm{O}_{5}, \mathrm{Nb}_{2} \mathrm{O}_{5}$ & 2,8 & 90 \\
\hline $\mathrm{SnO}_{2}, \mathrm{Nb}_{2} \mathrm{O}_{5}$ & 2,15 & 95 \\
\hline
\end{tabular}

diffraction studies of the fired oxides. The approximate percentages of cubic phase in the various oxide mixtures are shown in Table 35.

Zirconium-base alloys of the compositions shown in Table 36 were made by using a crater-eroded copper hearth for melting. All surfaces of specimens of these alloys were oxidized by heating in air until relatively thick oxide coatings were formed. The approximate percentages of cubic zirconium in these coatings are indicated in Table 36. It can be observed that in no case is there complete stabilization of the oxide.

TABLE 36. CUBIC ZIRCONIUM OXIDE IN OXIDIZED SURFACES OF ZIRCONIUM ALLOYS

\begin{tabular}{lcc}
\hline Metal Added & $\begin{array}{c}\text { Amount } \\
(w+\%)\end{array}$ & $\begin{array}{c}\text { Cubic Phase } \\
(\%)\end{array}$ \\
\hline $\mathrm{Ag}$ & 6.7 & 5 \\
$\mathrm{Ce}$ & 3 & 5 \\
$\mathrm{Nb}(\mathrm{Cb})$ & 2 & 10 \\
$\mathrm{Nb}$ & 5 & 50 \\
$\mathrm{Nb}$ & 7.5 & 50 \\
$\mathrm{Nb}$ & 15 & 80 \\
$\mathrm{Cs}$ & 2.25 & 0 \\
$\mathrm{Sn}$ & 2 & 0 \\
$\mathrm{Y}$ & 5 & $20\left(+\mathrm{Y}_{2} \mathrm{O}_{3}\right)$ \\
\hline
\end{tabular}

The metal samples used were in the as-cast condition and were coarse grained. In general, the oxide film was shiny, having a glassy appearance. Some grains were quite dark, while others were very light; so oxidation had an etching effect, revealing the grains. Interpretations of $x$-ray diffraction line intensities indicated that there was a definite orientation of the oxide with respect to the metal; however, x-ray diffraction patterns of light and dark grains taken separately showed no differences. Some oxide stood in relief above or below the oxide on adjacent grains. There was some cracking of the oxide film along metal grain boundaries as well. When the alloy specimens were rapidly oxidized, a thick white oxide formed; it also formed at points where the surface may have been dirty (fingerprints, etc.).

With respect to the formation of the cubic oxide, when zirconium is oxidized, niobium (columbium) 
seems to be the most promising metal to be added. Alloys containing 2 and 15 wt $\%$ niobium were cold-rolled without difficulty; however, alloys containing 5 and $7 \frac{1}{2}$ wt $\%$ niobium cracked when an attempt was made to cold-roll them. The alloy containing 15 wt \% niobium could be cold-rolled because the metastable beta phase had been retained on cooling of the ingot. A zirconium-base



Fig. 77. As-deposited Type 347 Stainless Steel Weld Metal Containing Approximately 8\% Ferrite. Etchant: glyceria regia.



Fig. 78. As-deposited (8\% Ferrite) Type 347 Stainless Steel Weld Metal Heat-treated Until Only Approximately 2\% Ferrite Remains. Etchant: glyceria regia. 
alloy consisting of body-centered cubic beta phase might have much more desirable mechanical properties than Zircaloy-2, and work will be done to develop such an alloy. Wrought alloys containing 2 and 15 wt \% niobium will be exposed in an in-pile loop by the HRP Corrosion Group.

\section{WELDING OF STAINLESS STEELS}

W. J. Leonard

Effect of Heat Treatment on the Ductility and Corrosion Resistance of Type 347 Weld Metal

Plate- and pin-type corrosion specimens of welds on type 347 stainless steel plate were exposed for $200 \mathrm{hr}$ in a loop which contained $0.17 \mathrm{~m} \mathrm{UO}_{2} \mathrm{SO}_{4}$ and which was operated at $250^{\circ} \mathrm{C}$ with $200 \mathrm{psi}$ of oxygen. The plate-type specimens were tested in a low-velocity region, $11 \mathrm{fps}$, and the pin-type specimens were tested in a high-velocity region, $25 \mathrm{fps}$. The specimens, consisting of weld metal plus adjacent base metal, were electropolished prior to exposure.

The welds were deposited on a $1 / 4$-in. plate of type 347 base metal, and the composition of the filler was such that 7 to $9 \%$ ferrite was present in the weld metal. Half the specimens were heated at $1250^{\circ} \mathrm{F}$ for $48 \mathrm{hr}$ so as to convert most of the alpha to sigma phase. Photomicrographs of the weld metal, as-deposited and after heat treatment, are shown in Figs. 77 and 78, respectively.

At high velocities the corrosion rate was approximately 175 mpy for both types of specimens. At lower velocities the corrosion rates of the as. welded specimens were $8.5 \mathrm{mpy}$, as compared with 3 mpy for the heat-treated specimen.

Specimens were removed from the two plates and were prepared for guided-bend tests. The specimens from both the as-welded and the heat-treated plate passed the bend test. No difference in ductility, as evaluated by this method, could be observed between the specimen consisting of all ferrite and that containing the sigma phase. Figure 79 shows the as-welded and the heat-treated specimens after bending.

These data tend to indicate that neither the corrosion resistance nor the ductility of the weld metal is greatly influenced by the conversion of ferrite, in the amounts usually found in commercial weld metal, into sigma phase.

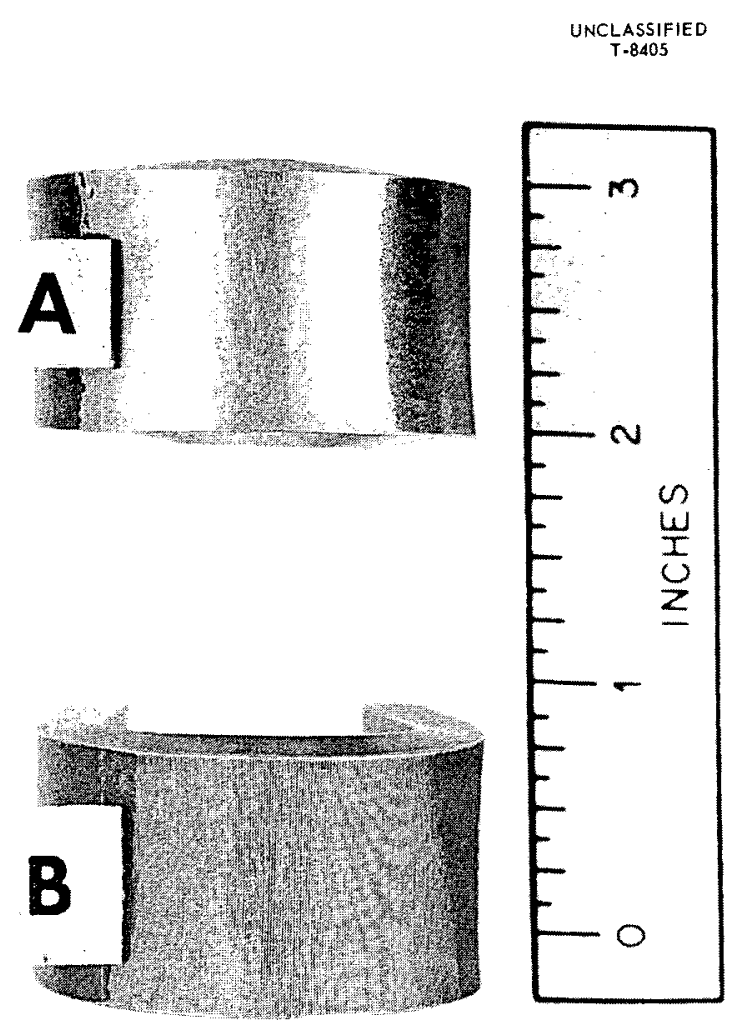

Fig. 79. Guided-Bend Tests of (A) As-welded Type 347 Stainless Steel Containing Approximately 8\% Ferrite and (B) As-welded (8\% Ferrite) Type 347 Stainless Steel Heat-treated So As to Contain Approximately $2 \%$ Ferrite.

\section{ME TALLURGY OF CORR OSION}

W. O. Harms J. I. Federer

G. B. Wadsworth

Stress-Corrosion Crocking of Austenitic Stainless Steels

The purpose of this experimental program, the hypothesis on which the experiments were based, and the testing procedures used have been previously described. ${ }^{2}$ Briefly, the purpose of these tests was the evaluation of the transgranular stress-corrosion-cracking susceptibility of austenitic stainless steels so as to furnish information

\footnotetext{
${ }^{2}$ W. O. Harms, J. I. Federer, and G. B. Wadsworth, Met. Semiann. Prog. Rep. April 10, 1955, ORNL-1911, p 49.
} 
which would be useful for HRP materials specifications. The tests were designed to indicate whether a correlation exists between the sus. ceptibility to stress-corrosion cracking and the martensite-forming tendencies of the steels. In the testing procedure, annealed and direct-loaded wire specimens ( $0.05 \mathrm{in.}$ in diameter) of six types of austenitic stainless steels were exposed to boiling 42 wt \% magnesium chloride solution, and stresses of from 20,000 to 40,000 psi were applied until failure occurred by stress-corrosion cracking or until the experiment was terminated after a sub. stantial period of time had elapsed. The materials to be tested, the $M_{d}$ temperatures, and the preliminary experiments which indicated the suitability of the testing method have also been described. ${ }^{2}$

In this work the tendency toward austenite stability, as indicated by the $M_{d}$ temperature, was considered of more practical value than the absolute value of the $M_{d}$ temperature itself. An austenite stability index $S$ can be calculated which assigns an arbitrary value of 100 to the steel having the lowest $M_{d}$ temperature, that is, greatest austenite stability, while the values for the indices of the other steels decrease as the $M_{d}$ temperatures of the steels increase. ${ }^{2}$ The austenite stability indices for the six steels and some room-temperature properties, as determined on 0.050 -in. specimens, are given in Table 37.

In Fig. 80 the time-to-failure is plotted against the austenite stability index $S$ for the four stress levels studied. The curves lead to the following conclusions as regards the susceptibility to stress. corrosion cracking: (1) the susceptibility is related to the chemical composition of the alloy, as shown by the low susceptibility to stress-corrosion failure of the more stable austenites; (2) for a given steel, the susceptibility is stress dependent over the range of stresses employed - for example, the type 310 steel broke readily at 40,000 psi, although it did not break when stressed as much as 36,000 psi for a reasonable length of time.

The se data may be considered as indirect support for the hypothesis that the propagation of transgranular stress cracks occurs along martensite plates as a result of local yielding under applied stress. The fact that careful metallographic examination failed to reveal any evidence of martensite plates near the fracture paths does not rule out the possibility that the plates had formed ahead of the cracks and had ultimately led to failure. The stresses at the root of a crack, once begun, are extremely high and could conceivably lead to localized transformation and subsequent corrosion attack on the local anodes thus created. To further investigate the martensite hypothesis, some electrode-potential measurements have been made on various martensites formed by subzero deformation and on undeformed austenite of similar composition. If it could be shown that austenite is more noble than freshly formed martensite, then the theory of crack propagation by selective corrosion of the minor microconstituent would be substantially supported. So far it has not been possible to determine the potential difference between martensite and austenite. Drifting potentials and polarization effects have prevented any reproducibility of measurements.

\section{TABLE 37. PROPERTIES OF AUSTENITIC STAINLESS STEELS USED IN STRESS-CORROSION STUDIES}

\begin{tabular}{lccc}
\hline & Room-Temperature Mechanical Properties & Yield Strength, \\
\cline { 2 - 4 } Alloy, AlSI Type & $\begin{array}{c}\text { Tensile Strength } \\
\text { (psi) }\end{array}$ & $\begin{array}{c}0.2 \% \text { Offset } \\
\text { (psi) }\end{array}$ & $\begin{array}{c}\text { Austenite Stability } \\
\text { Index, }\end{array}$ \\
\hline $304 \mathrm{~L}$ & 107,000 & 38,000 & 6 \\
347 & 104,000 & 43,500 & 17 \\
321 & 93,000 & 40,500 & 19 \\
$316 \mathrm{~L}$ & 96,000 & 37,500 & 28 \\
$309 \mathrm{SCb}$ & 111,000 & 51,500 & 53 \\
310 & 94,000 & 43,000 & 100
\end{tabular}






Fig. 80. Time-to-Failure vs Relative Austenite Stability for Six Austenitic Stainless Steels Tested in Boiling 42 wt \% Magnesium Chloride Solutions. Each datum represents the average of from two to five determinations.

When stress vs time-to-failure is plotted as in Fig. 81 , the possibility of adapting these data to engineering applications becomes apparent. Thus the designation of a threshold stress, below which it could be reasonably certain that a material would not fail because of stress corrosion, would be useful as a design criterion for such components as heat exchangers and associated equipment which are vulnerable to failure by stress-corrosion cracking. If it is assumed that boiling 42 wt \% magnesium chloride is the most severe transgranular stress corrodant for austenitic stainless steels and that some correlation can be established between the stress as applied in this test and the stresses encountered in a practical situation, it would appear that the threshold stress as indicated by data of the type in Fig. 81 could be used for design purposes. The severity of the environment should eliminate the necessity for any additional safety factors. The curves of Fig. 81 indicate the approximate threshold stresses for types $309 \mathrm{SCb}$ and 310 ; whereas it is evident that lower stress levels must be investigated in order to establish threshold stresses for materials such as types $304 \mathrm{~L}$ and 347.

In order to determine the threshold stress for type $304 \mathrm{~L}$, it has been tested at stresses from 10,000 to $40,000 \mathrm{psi}$. Since the surface of each specimen had many irregularities because of a poor swaging operation, the specimens were electropolished prior to testing in order to remove surface defects which would give rise to stress 


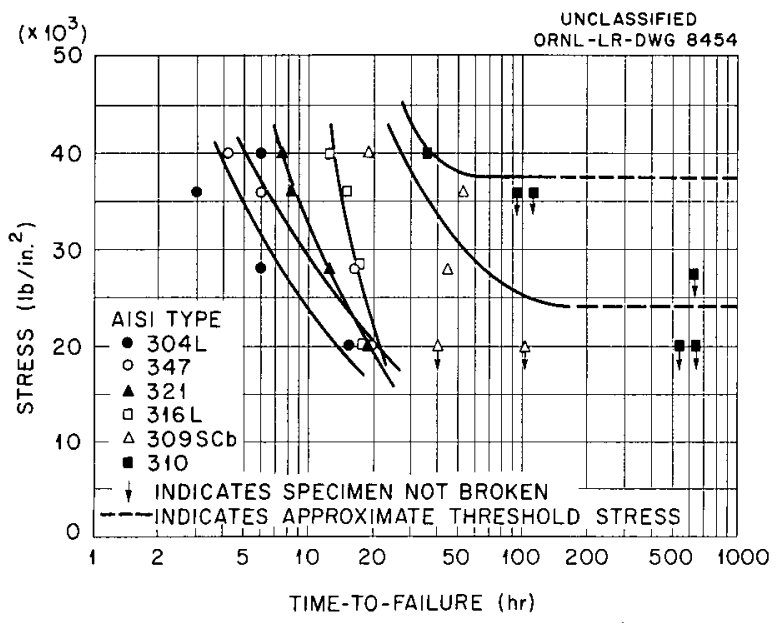

Fig. 81. Stress vs Time-to-Failure for Six Austenitic Stainless Steels Tested in Boiling 42 wt \% Magnesium Chloride Solutions. Each datum represents the average of from two to five determinations.

concentrations when the specimens were loaded in the stress-corrosion apparatus. It was observed that the failure time, for a given stress, of the electropolished specimens was about half that for specimens which had been bright-annealed in a reducing atmosphere. The data, thus far, indicate that the threshold stress for type $304 \mathrm{~L}$ is less than 10,000 psi. Threshold stresses are to be determined also for type 347 and for the precipitationhardening alloys 17.4 $\mathrm{PH}$ and $17.7 \mathrm{PH}$, which are of immediate interest to the HRP.

\section{Factors Associated with Grain Size and Sigma Phase in Wrought Austenitic Stainless Steel}

Specimens of types $304 \mathrm{~L}$ and 347 stainless steel in a range of ASTM grain sizes are being tested in uranyl sulfate solutions to determine the effect of grain size on the corrosion resistance of these metals. Pin-type corrosion specimens were machined from rods of types $304 \mathrm{~L}$ and 347 which had been cold-swaged approximately to size with reductions in area of 71 and $84 \%$, respectively.

For a given steel, four factors determine the grain size after recrystallization: (1) the amount of cold deformation, (2) the temperature to which the cold-worked metal is heated, (3) the time for which the metal is held at this temperature, and (4) the original grain size. It was decided to store a large amount of internal energy in each steel by means of cold deformation so that recrystalli- $z$ ation and subsequent grain growth could proceed as rapidly as possible. Since it was desired to test specimens in the annealed condition, an annealing temperature of $1950^{\circ} \mathrm{F}$ was chosen. The holding time, at the temperature that was necessary to cause the desired amount of grain growth, was determined by metallographic examination and grain-size determination. The initial grain size of the type 304L steel was ASTM 3-4, and the initial grain size of the type 347 was ASTM 7-8.

Initial grain-growth studies consisted in heating specimens to $1950^{\circ} \mathrm{F}$ for various periods of time, after which the grain sizes of the mounted and polished specimens were determined. It was observed that the grain size of the type 304L was ASTM 5 after only $5 \mathrm{~min}$ at $1950^{\circ} \mathrm{F}$. Small grains, that is, ASTM 7-8, were obtained by exposing the specimens to $1950^{\circ} \mathrm{F}$ for $2 \mathrm{~min}$, which includes the time required to come to temperature. However, type 347 had a grain size of only ASTM 3-4 after $308 \mathrm{hr}$ at temperature. A means of promoting grain growth in type 347 was derived from the observation that during welding of this steel considerable grain growth occurred in the heat-affected zone adjacent to the weld deposit where temperatures of $2500^{\circ} \mathrm{F}$ or higher are attained. It is thought that this rapid grain growth is due partly to the solution of niobium (columbium) carbides, which may somehow tend to anchor grain boundaries and restrict grain growth. Therefore, specimens of type 347 were heat-treated at temperatures up to $2450^{\circ} \mathrm{F}$ to promote grain growth. At temperatures above $2300^{\circ} \mathrm{F}$, grain growth was restricted by the formation of a magnetic phase, which precipitated as pools or islands in the microstructure. This phase amounted to 5 to $7 \%$ in a specimen which had been treated at $2450^{\circ} \mathrm{F}$ for $\mathrm{l} \mathrm{hr}$. Reference to the $\mathrm{Fe}-\mathrm{Cr}-\mathrm{Ni}$ ternary diagram and to the magnetic behavior of the precipitated phase suggests that delta ferrite was formed during the high-temperature heat treatment. Resorting to heat treatments at 2200 and $2300^{\circ} \mathrm{F}$ gave the desired grain growth with no delta ferrite formation. These specimens were furnace-cooled to $1950^{\circ} \mathrm{F}$ and held for $1 / 2 \mathrm{hr}$ to reprecipitate any niobium carbides which may have gone into solution.

Heat treatments, as determined by the preliminary work described above, were performed on machined corrosion pins. Table 38 lists the heat treatment which was given eight groups of 20 specimens each and the resulting grain size. The pins have been 
TABLE 38. HEAT TREATMENTS AND RESULTING GRAIN SIZES FOR TYPES 304L AND 347 STAINLESS STEEL*

\begin{tabular}{|c|c|c|c|}
\hline \multicolumn{3}{|c|}{ Heat-Treating Conditions * } & \multirow[b]{2}{*}{ ASTM Grain Size } \\
\hline $\begin{array}{c}\text { Temperature } \\
\left({ }^{\circ} \mathrm{F}\right)\end{array}$ & Time & Method of Cooling & \\
\hline \multicolumn{4}{|c|}{ Type 304L } \\
\hline 1950 & $3 \mathrm{~min}$ & Water quenched & 8 and smaller \\
\hline 1950 & $4 \mathrm{~min}$ & Woter quenched & 6 \\
\hline 1950 & $13 \mathrm{~min}$ & Water quenched & 4 \\
\hline 1950 & $98 \mathrm{hr}$ & Water quenched & 2 \\
\hline \multicolumn{4}{|c|}{ Type 347} \\
\hline 1950 & $10 \mathrm{hr}$ & Water quenched & 7 to 8 \\
\hline 1950 & $32 \mathrm{hr}$ & Water quenched & 6 to 7 \\
\hline 2200 & $2 \frac{l}{2} \mathrm{hr}$ & Furnace cooled at $1950^{\circ} \mathrm{F}$ for $1 / 2 \mathrm{hr}$; water quenched & 3 to 4 \\
\hline 2300 & $26 \mathrm{hr}$ & Furnace cooled at $1950^{\circ} \mathrm{F}$ for $1 / 2 \mathrm{hr}$; water quenched & 2 to 3 \\
\hline
\end{tabular}

*The types $304 \mathrm{~L}$ and 347 materials were coldreduced 71 and $84 \%$, respectively.

**All heat treating performed in dry-hydrogen atmosphere.

submitted to the HRP Corrosion Group for dynamic testing in uranyl sulfate solutions.

The preparation of dynamic corrosion pins from $56 \% \mathrm{Fe}-44 \% \mathrm{Cr}$ and $51 \% \mathrm{Fe}-44 \% \mathrm{Cr}-5 \% \mathrm{Ni}$ having compositions corresponding to sigma phase was described in the last semiannual report. ${ }^{3}$ It was reported that the transformation of metastable ferrite into sigma phase occurred readily for the $\mathrm{Fe}-\mathrm{Cr}-\mathrm{Ni}$ alloy. Magne-Gage measurements indicated that no ferrite remained in the microstructure after heat-treating at $800^{\circ} \mathrm{C}$ for $15 \mathrm{hr}$. The transformation of the $\mathrm{Fe}-\mathrm{Cr}$ alloy, however, appeared to be more sluggish, since Magne-Gage measurements indicated that 9.5 to $10.5 \%$ ferrite remained after heat-treating at $700^{\circ} \mathrm{C}$ for $32 \mathrm{hr}$. Subsequent heat treatment at $650^{\circ} \mathrm{C}$ for $92 \mathrm{hr}$ lowered the ferrite content to a value of less than $3 \%$, in which condition it was submitted for corrosion testing, along with the $\mathrm{Fe}-\mathrm{Cr}-\mathrm{Ni}$ alloy. For comparison, pins of each alloy were heat-treated at $1100^{\circ} \mathrm{C}$ so as to produce the ferritic condition, which is the equilibrium phase for both alloys at this temperature, and were then corrosion-tested.

${ }^{3}$ W. O. Harms, J. I. Federer, and G. B. Wadsworth, Met. Semiann. Prog. Rep. April 10, 1955, ORNL-1911, p 52.
The defilmed weight losses (in $\mathrm{mg}$ ) which occurred in HRP dynamic loop run $\mathrm{N}-3$ made with $0.04 \mathrm{~m}$ uranyl sulfate at $250^{\circ} \mathrm{C}$ and at $12 \mathrm{fps}$ for $200 \mathrm{hr}$ are as follows:

\begin{tabular}{cr} 
Sigma Phase & Ferrite \\
\multicolumn{2}{c}{ Fe-Cr Alloy } \\
11.7 & 9.1 \\
11.2 & 8.7 \\
\multicolumn{2}{c}{ Fe-Cr-Ni Alloy } \\
24.6 & \\
20.1 & 11.4
\end{tabular}

These data reveal that sigma specimens lost more weight than ferrite specimens of the same composition. However, all the brittle sigma specimens had broken into two pieces during testing, and the difference in weight loss may have been due to a loss of material as a result of the fracture. It is to be noted that under these test conditions sigma phase and ferrite of a similar composition are inferior to wrought type 347 , which had an average corrosion of $2.3 \mathrm{mg}$. 


\section{Dynamic Corrosion of Austenitic Stainless Steel Weld Specimens}

The results of dynamic-corrosion tests on welded coupon- and pin-type stainless steel corrosion specimens appear in Figs. 82 and 83 . The coupon specimens, represented by the data in Fig. 82, were machined from $1 / 4$-in. type 347 stainless steel plates that were welded with three different electrodes which had compositions that were balanced in such a way as to deposit ferrite in amounts of 3.9 to $5.1,5.2$ to 6.8 , and 7.0 to $9.0 \%$. Specimens were corrosion-tested for $200 \mathrm{hr}$ in $0.17 \mathrm{~m}$ uranyl sulfate at $250^{\circ} \mathrm{C}$ that was circulated at $25 \mathrm{fps}$ and were in the following heat-treated conditions: (1) as welded, (2) $6 \mathrm{hr}$ at $1000^{\circ} \mathrm{F}$ and air cooled, (3) $8 \mathrm{hr}$ at $1300^{\circ} \mathrm{F}$ and air cooled, (4) $2 \mathrm{hr}$ at $1650^{\circ} \mathrm{F}$ and water quenched, and (5) $\mathrm{l} / 2 \mathrm{hr}$ at $1900^{\circ} \mathrm{F}$ and water quenched. After run A-79 the specimens were refinished by light abrasion and tested in run A-81. For comparison, specimens of the type 347 base metal in the various heattreated conditions were tested also.

There are two significant features evident in the data: of the welded specimens, those given the $1000^{\circ} \mathrm{F}$ heat treatment had the smallest weight losses; and of the base-metal specimens (un-

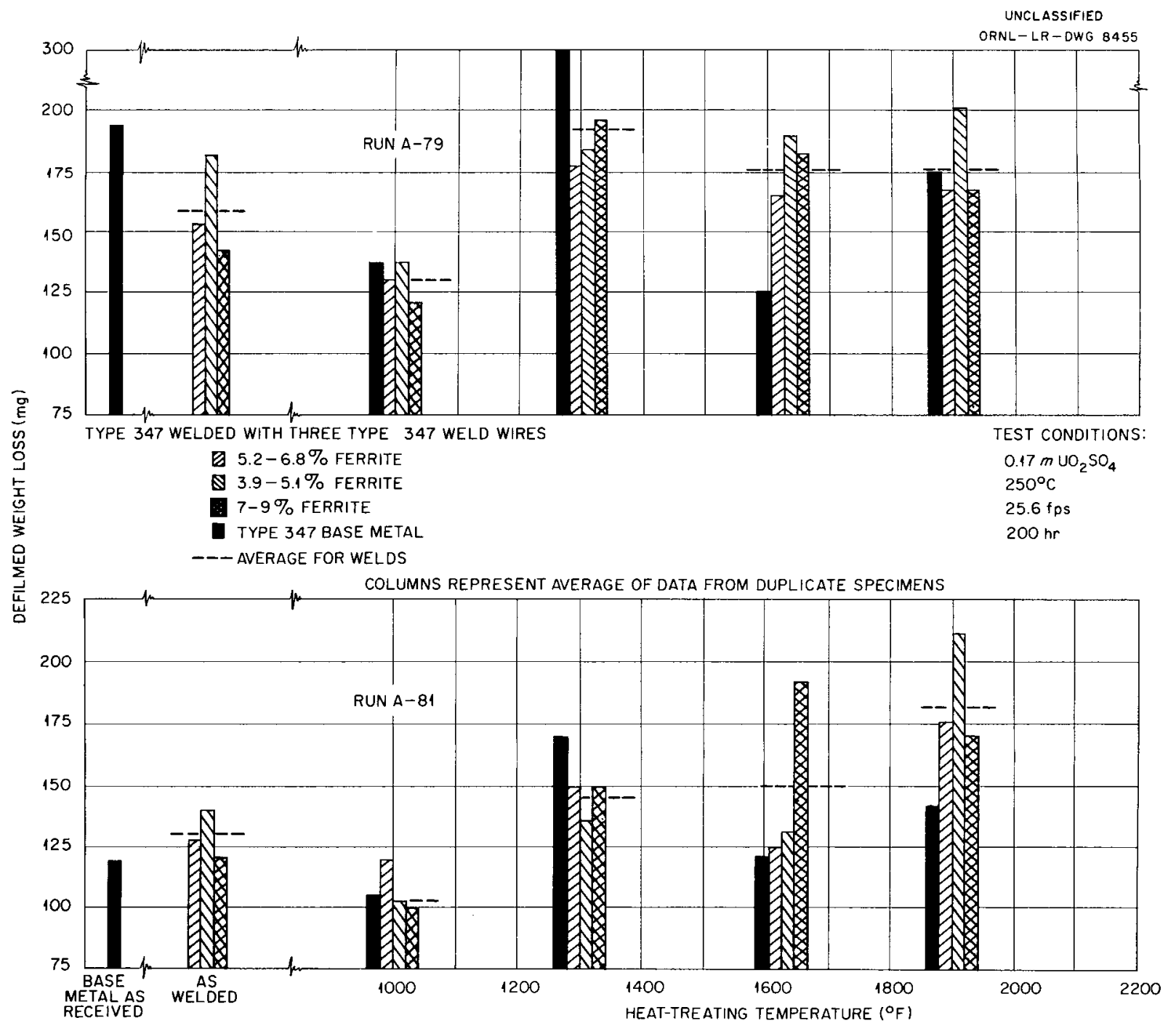

Fig. 82. Dynamic-Corrosion Tests on Coupon Specimens of Type 347 Stainless Steel Welds. 


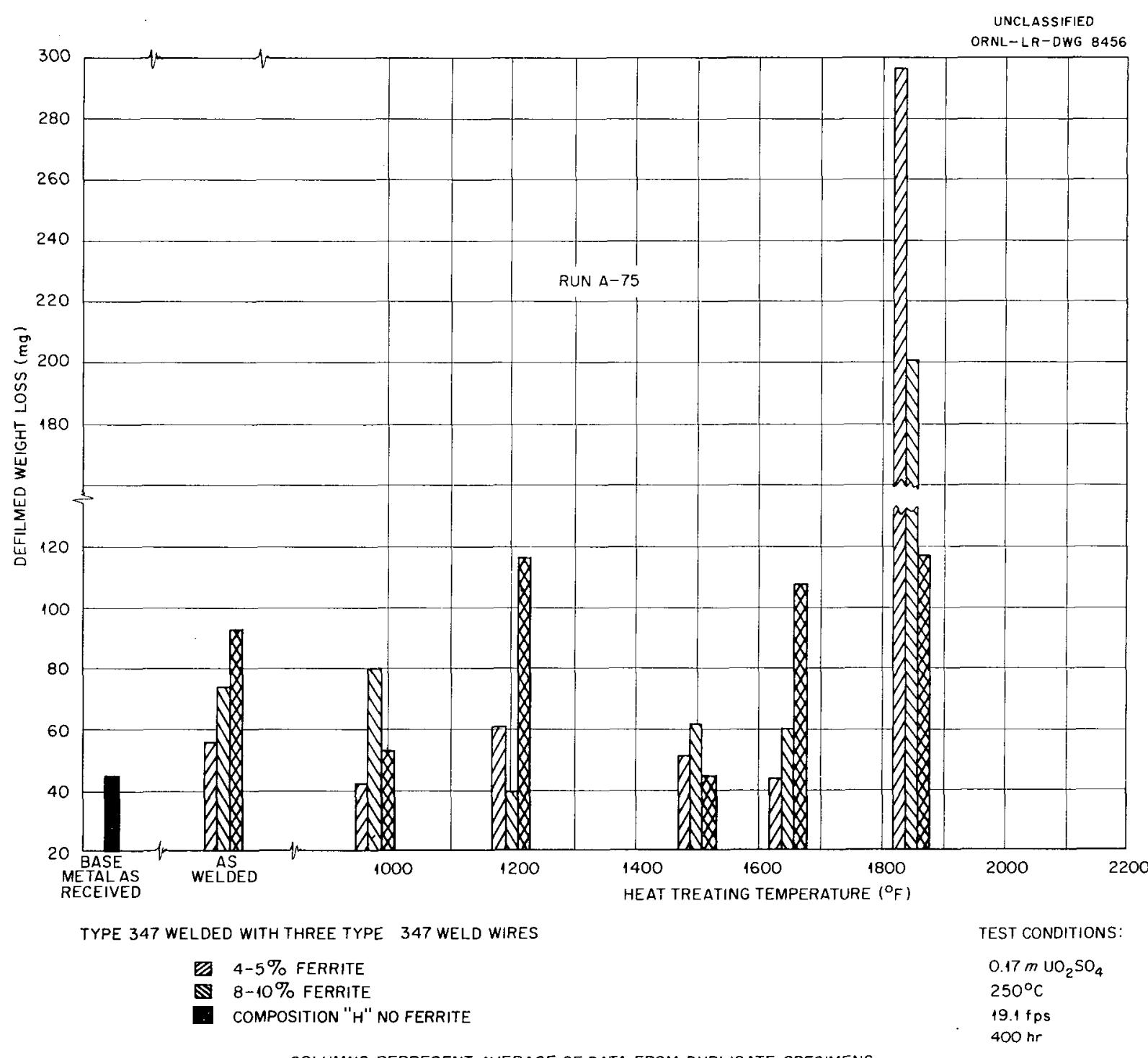

COLUMNS REPRESENT AVERAGE OF DATA FROM DUPLICATE SPECIMENS

Fig. 83. Dynamic-Corrosion Tests on Pin Specimens of Type 347 Stainless Steel Welds.

welded), the one heat-treated at $1300^{\circ} \mathrm{F}$ had a very high weight loss.

The first feature mentioned above has been demonstrated previously, and thus it appears that. the $1000^{\circ} \mathrm{F}$ heat treatment definitely has a beneficial effect on the corrosion resistance of welds of this type. An explanation of this behavior is not apparent from metallographic examination of heat-treated specimens. However, microstructural variations were observed in these specimens and are as follows.

\section{Weld Metal}

1. The interdendritic constituent present in all the welds appeared to agglomerate more with increasing heat-treating temperature.

2. A kind of subgrain formation occurred in the weld deposits with increasing heat-treating temperature. This effect was most evident in specimens heat-treated at $1900^{\circ} \mathrm{F}$, in which clearly outlined, darker etching areas were observed to have formed at random in the weld deposit. These areas often seemed to have been nucleated at the fusion line and appeared to grow inwardly. 


\section{Heat-Affected Zone}

1. Considerable grain growth had occurred. The grains were generally free of precipitated particles except in the specimens heat-treated at $1900^{\circ} \mathrm{F}$ in which niobium carbides had precipitated.

2. Around the grains of the specimens heattreated at $1300^{\circ} \mathrm{F}$, a grain-boundary precipitate, about 40 to $50 \%$ continuous, was present which probably consisted of chromium carbide particles. This situation could have resulted from the solution of niobium carbides near the fusion line during welding and from the subsequent precipitation of the dissolved carbon with chromium during the $1300^{\circ} \mathrm{F}$ treatment. Removal of chromium from solid solution is known to make the steel less corrosion resistant in the areas where precipitation has occurred and thus may account for the rela. tively high weight losses observed. Figure 84 illustrates the grain-boundary precipitate which occurred as the result of the $1300^{\circ} \mathrm{F}$ heat treatment.

\section{Base Metal}

1. The unaffected base metal appeared to be much like annealed type 347 except that fewer carbide particles were present than are usually observed. If this is taken as evidence of a low niobium content, then some degree of carbide precipitation at the grain boundaries, that is, sensitization, would have been expected in specimens heat-treated at $1300^{\circ} \mathrm{F}$; however, an excess of carbide particles at the grain boundaries was not observed. Therefore, the high weight loss of specimens of the base metal heat-treated at $1300^{\circ} \mathrm{F}$ remains unexplained.

The pin-type corrosion specimens represented by Fig. 83 were type 347 steel welded with three different electrodes which had compositions that were balanced in such a way as to deposit ferrite in the amounts of 0,4 to 5 , and 8 to $10 \%$. Specimens were corrosion-tested for $400 \mathrm{hr}$ in $0.17 \mathrm{~m}$ uranyl sulfate at $250^{\circ} \mathrm{C}$ that was circulated at

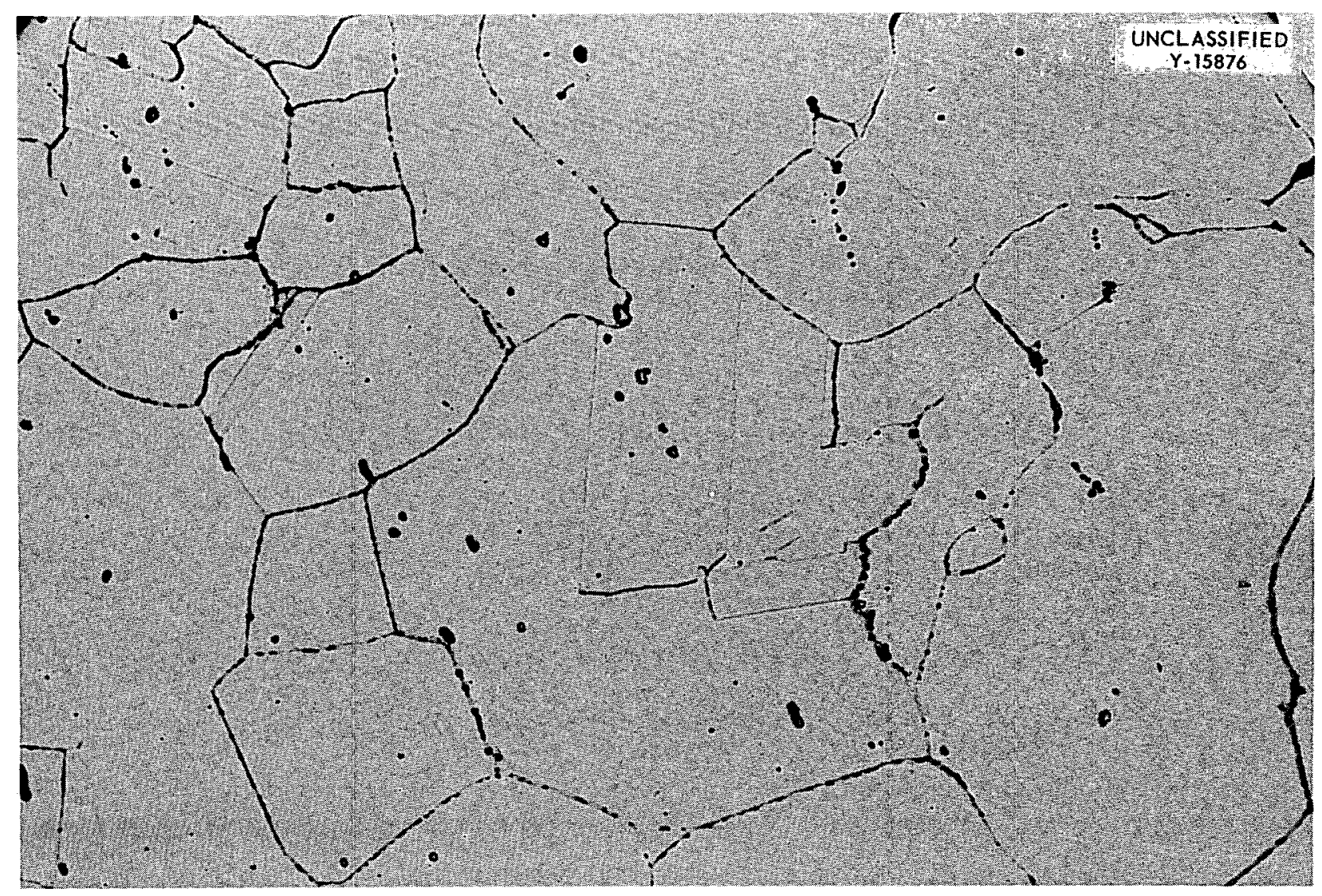

Fig. 84. Grain-Boundary Precipitate in Heat-affected Zone in Type 347 Stainless Steel, Adjacent to Weld Metal. Etchant: aqua regia. 500X. 
$19 \mathrm{fps}$ and were in the following heat-treated con. ditions: (1) as welded, (2) $4 \mathrm{hr}$ at $975^{\circ} \mathrm{F}$ and air cooled, (3) $1 \mathrm{hr}$ at $1200^{\circ} \mathrm{F}$ and air cooled, (4) $1 \mathrm{hr}$ at $1500^{\circ} \mathrm{F}$ and air cooled, (5) $1 \mathrm{hr}$ at $1650^{\circ} \mathrm{F}$ and air cooled, and (6) $1 \mathrm{hr}$ at $1850^{\circ} \mathrm{F}$ and air cooled. For comparison, specimens of the type 347 base metal were tested also, and all specimens were electropolished.

The data indicate that there is not a marked difference in the corrosion of as-welded specimens and specimens heat-treated at temperatures up to and including $1650^{\circ} \mathrm{F}$. The specimens which have welds with 4 to $5 \%$ ferrite generally appeared a little more corrosion-resistant than the other two, although there does not appear to be a definite trend in this direction. At $1850^{\circ} \mathrm{F}$, the high weight losses are consistent with previous data obtained from dynamic-corrosion tests. Thus, heat treatment to produce complete annealing appears to have a detrimental effect on these welds, and none of the heat treatments used seem to substantially improve the corrosion resistance over that of the as-welded condition.

\section{Effect of Hydrogen on Properties of Zirconium and Its Alloys}

A sketch of the apparatus, described in the previous report, ${ }^{4}$ for admitting known quantities of gases to metal specimens at a given temperature is shown in Fig. 85. Fumace 1, controlled at $700^{\circ} \mathrm{C}$, contains titanium sponge and zirconium powder as a "getter" for nitrogen and oxygen, which are the principal impurities present in most tank hydrogen. Furnace 2 contains titanium turnings which absorb hydrogen at $400^{\circ} \mathrm{C}$ and give off high-purity hydrogen when heated to $700^{\circ} \mathrm{C}$. Furnace 3, which is accurately controlled by a proportional controller, serves as the heating jacket for the specimen reaction tube. Not shown in Fig. 85 is a McLeod gage that is in the capillary line to the mercury manometer and is used to measure pressures of less than $5 \mathrm{~mm} \mathrm{Hg}$.

In order to obtain a specimen with a given hydrogen concentration, it is imperative that the hydrogen concentration be known before the actual hydrogenation. A method of doing this consists in removing all the hydrogen from the specimen before hydrogenation, since as-received material

\footnotetext{
${ }^{4}$ W. O. Harms, J. I. Federer, and G. B. Wadsworth, Met. Semiann. Prog. Rep. April 10, 1955, ORNL-1911. p 52.
}

contains hydrogen in varying concentrations. The results of an investigation into the effectiveness of removing hydrogen from Zircaloy- 2 by various treatments when a vacuum of $<10^{-5} \mathrm{~mm} \mathrm{Hg}$ is used are shown below:

$\begin{array}{ccc}\begin{array}{c}\text { Temperature } \\ \left({ }^{\circ} \mathrm{C}\right)\end{array} & \begin{array}{c}\text { Time } \\ (\mathrm{hr})\end{array} & \begin{array}{c}\text { Hydrogen Content } \\ (\mathrm{ppm})\end{array} \\ 750 & 2 & 97 \\ 750 & 2 & 54 \\ 800 & 24 & 35 \\ 800 & 48 & 3 \\ 850 & 24 & 5 \\ 850 & 48 & 8\end{array}$

Treatments at temperatures higher than $850^{\circ} \mathrm{C}$ were not attempted because contamination of the samples by the silica specimen tube is more likely at the higher temperatures. Vacuum annealing for $24 \mathrm{hr}$ at $850^{\circ} \mathrm{C}$ has been adopted as the standard treatment for this study.

Zircaloy-2 specimens for in-pile corrosion tests were the first to be hydrogenated in the apparatus. Eight specimens in each of four groups containing $500,1000,2000$, and $3000 \mathrm{ppm}$ hydrogen, respectively, were required for the tests. To prevent the samples from being in actual contact with the silica specimen tube during the hydrogenation process, they were inserted into a basket constructed of molybdenum wire. A blank run was made to establish the solubility of hydrogen in molybdenum at the operating temperature, $400^{\circ} \mathrm{C}$. Enough hydrogen was admitted into the tube containing the wire basket so that the basket would have a hydrogen concentration of $5000 \mathrm{ppm}$ if the hydrogen were completely adsorbed. Then the system was closed, and a temperature of $400^{\circ} \mathrm{C}$ was maintained throughout the test. After $18 \mathrm{hr}$ at temperature, no change in pressure was observed on the manometer. A decrease in pressure of $1 \mathrm{~mm}$ $\mathrm{Hg}$ would correspond to a hydrogen concentration of $50 \mathrm{ppm}$. Therefore, it was safe to assume that no appreciable amount of hydrogen was absorbed by the molybdenum basket.

The procedure for admitting hydrogen to specimens is as follows:

1. Barometric pressure and room temperature are recorded before and after each run.

2. The specimens are loaded into the quartz 


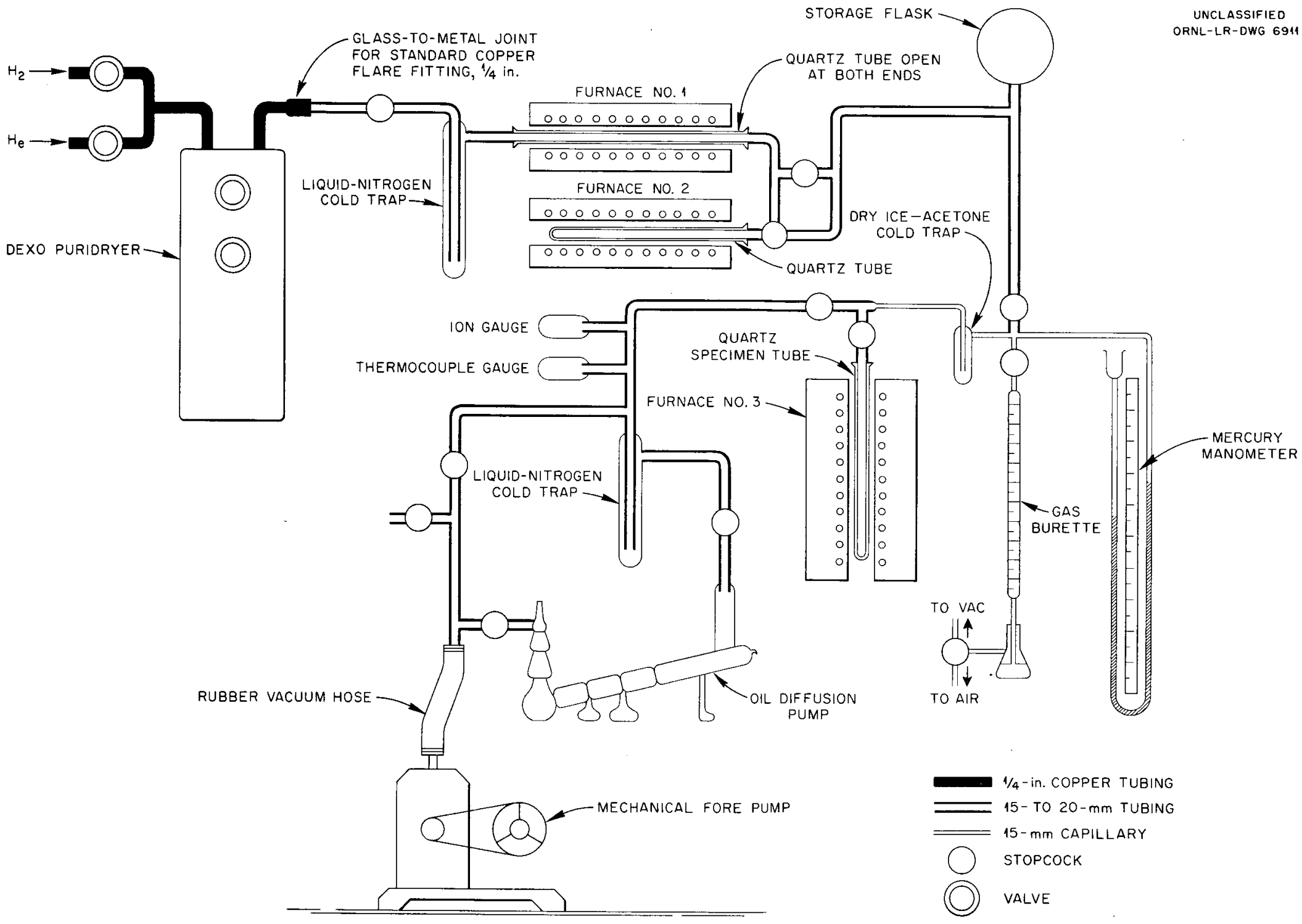

Fig. 85. Apparatus for Admitting Aliquoted Amounts of Gas to Metal Specimens at Specific Temperatures. 
reaction tube and sealed to the system with Apiezon W wax.

3. The system is outgassed at $850^{\circ} \mathrm{C}$ for $\frac{1}{2} \mathrm{hr}$.

4. The reaction-tube temperature is lowered to $400^{\circ} \mathrm{C}$.

5. By heating the hydride furnace, hydrogen is admitted into the system, excluding the reaction vessel, until the desired pressure is reached.

6. The calibrated storage flask and hydride furnace are isolated, and the remainder of the system is evacuated. The pressure is recorded.

7. The calibrated flask is opened to the system, including the reaction vessel, and the pressure is recorded at intervals until reaction is complete.

8. After absorption is complete, the temperature of the reaction-tube furnace is raised to $500^{\circ} \mathrm{C}$ for $24 \mathrm{hr}$ so as to get equilibration.

The pressure required to give the desired hydrogen concentration is calculated from the following equation:

$$
P_{\mathrm{H}_{2}}=\frac{760 \times\left[\mathrm{H}_{2}\right] \times w t \times 22,400(T+273)}{2.016 \times V_{F} \times 273} \times 10^{-6},
$$

where

$$
\begin{aligned}
w t & =\text { weight of specimens in run, } \mathrm{g}, \\
T & =\text { room temperature, }{ }^{\circ} \mathrm{C}, \\
{\left[\mathrm{H}_{2}\right] } & =\text { desired hydrogen concentration, ppm, } \\
V_{F} & =\text { volume of storage flask, } \mathrm{ml}, \\
P_{\mathrm{H}_{2}} & =\text { required hydrogen pressure, } \mathrm{mm} \mathrm{Hg} .
\end{aligned}
$$

Difficulty was experienced during the first runs because a hydride layer formed on the surface of the specimens, which prevented equilibration of the hydrogenation process under conditions given in the procedure. Due to the rather large volume increase associated with the formation of the hydride, the surfaces of the specimens cracked and broke. This situation was remedied by heating the specimens at $900^{\circ} \mathrm{C}$ for $24 \mathrm{hr}$. Microexamination of the hydrogenated material revealed that the hydride had precipitated in the grain boundaries instead of having precipitated randomly throughout. the specimen in the needlelike structure commonly. observed in high-purity zirconium.

\section{Role of Oxide. Films on Rate of Hydrogen Absorption by Zirconium and Its Alloys}

A brief description of experiments designed to evaluate the behavior of zirconium and its alloys under simulated exposure to radiolytic gas was given in the previous report. ${ }^{5}$ Several multiple. break subsize impact specimens of Zircaloy-2 and of high-purity zirconium were cathodically treated at $30^{\circ} \mathrm{C}$, and electrolysis runs of $250^{\circ} \mathrm{C}$ were made.

The electrolyte used in the cathodic treatments was $1 N$ sulfuric acid, and the concentration was checked periodically by titration with standard sodium hydroxide solution. The specimens were swaged, machined, cleaned with No. 360 grit alumina powder, chemically polished in waternitric acid-hydrofluoric acid (46-46-8) solution, and finally vacuum-annealed at $750^{\circ} \mathrm{C}$. Results of these experiments are described below.

The first run was performed with a gold anode at a current density of $10^{-8} \mathrm{amp} / \mathrm{cm}^{2}$ at $30^{\circ} \mathrm{C}$ in pyrex glassware. After $120 \mathrm{hr}$ of operation, the specimen was covered with a dark-gray film which by $x$-ray diffraction was found to contain gold with a trace of zirconium nitride. Gold, but not zirconium, was found on spectrographic analysis of this film. A second specimen, run at 10-6 amp $/ \mathrm{cm}^{2}$ at $30^{\circ} \mathrm{C}$ for $120 \mathrm{hr}$, was very heavily covered with what appeared to be the same film observed earlier. The presence of gold suggested that perhaps some ion such as chloride ion might be forming a complex with the gold, which ultimately deposited on the cathode. To test this possibility, the electrolyte for the next run was prepared with demineralized water which contained less than $0.5 \mathrm{ppm}$ of chloride; and after filtration through a fritted glass filter, the acid was electrolyzed with two gold electrodes at a current of 1 amp in order to remove impurities. A third electrolysis was performed at $30^{\circ} \mathrm{C}$ at a current density of $10 \mathrm{ma} / \mathrm{cm}^{2}$, which was just enough to produce a vigorous bubbling around the cathode. After $100 \mathrm{hr}$, the Zircaloy-2 surface was covered with a thick, smooth brown-yellow film, which was found to be almost pure gold by spectrographic and x-ray diffraction analyses. In a subsequent run, a porous alumina cup was used between the anode and cathode and resulted in the deposition and impregnation of a similar film on the cup, and the cathode remained bright. It was then certain that a different anode material would be required. Platinum was chosen and proved to be satisfactory.

Vacuum-extraction analysis of four specimens

\footnotetext{
${ }^{5}$ W. O. Harms, J. I. Federer, and G. B. Wadsworth, Met. Semiann. Prog. Rep. April 10, 1955, ORNL-1911, p 53.
} 
cathodically treated at $30^{\circ} \mathrm{C}$ for $100 \mathrm{hr}$ indicated that essentially no change in hydrogen content had occurred as a result of this treatment. These specimens had no visible film or scale on removal from the cell.

The autoclave 5 for the electrolysis at $250^{\circ} \mathrm{C}$ in $1 \mathrm{~N}$ sulfuric acid uses a platinum anode; the reactor vessel is a zirconium-lined type 347 stainless steel autoclave; a coil of platinum wire in the vapor phase is provided to catalyze the recombination of the electrolytic gas. During the first $100-\mathrm{hr}$ run at $250^{\circ} \mathrm{C}$, the coil was independently heated to $300^{\circ} \mathrm{C}$ to prevent condensation and possible poisoning of the catalyst. Upon removal of the current, no increase in cell pressure was noted, which indicated that the catalyst functioned satisfactorily without heating.

Considerable difficulty was encountered in the $250^{\circ} \mathrm{C}$ run. Four runs were terminated prematurely because of leakage in the pressure fittings and gaskets or because of corrosion of the stainless steel, which resulted from seepage of the acid through crevices in the zirconium protective lining. The difficulty was corrected by modification of the bomb design and included the use of a $1 / 8$-in. Teflon gasket, Teflon protective tubing for electrical leads, and a Teflon spacer that was inserted under the zirconium liner to force the liner against the zirconium cap.

Three specimens of Zircaloy-2 were successfully treated cathodically for $100 \mathrm{hr}$ in $1 \mathrm{~N}$ sulfuric acid at $250^{\circ} \mathrm{C}$ and with a current density of $10 \mathrm{ma} / \mathrm{cm}^{2}$, and the results are as follows:

\begin{tabular}{ccc} 
& \multicolumn{2}{c}{ Hydrogen Content (ppm) } \\
\cline { 2 - 3 } Specimen No. & Before & After \\
Z-2F2501 & 75 & 130 \\
Z-2F2502 & $<5$ & 140 \\
Z-2F2503 & $<5$ & 170
\end{tabular}

It appears that, whether previously outgassed or not, the specimens absorb hydrogen to a total concentration of 130 to $170 \mathrm{ppm}$ under the conditions of these runs. Metallographic examination revealed no hydride needles, neither near the surface nor in the bulk material. The specimens have not been impact-tested for determination of transition temperatures. 


\title{
APPLIED METALLURGY
}

\author{
J. E. Cunningham
}


•

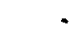

• 


\section{PROCESS METALLURGY}
R. J. Beaver
J. A. Milko
J. H. Erwin
W. C. Thurber

R. C. Waugh

\section{FABRICATION OF GENEVA CONFERENCE FUEL ELEMENTS}

\author{
J. H. Erwin \\ R. C. Waugh

\section{J. H. Coobs}

When the problem arose of designing a display reactor for the Geneva Conference, consideration of the various existing types of reactors resulted in the decision to construct a reactor similar to the Bulk Shielding Reactor (BSR). The 18-plate aluminum fuel elements for the display reactor were manufactured in accordance with specifications similar to those for BSR elements. Each fuel plate, however, contained 54 wt \% uranium dioxide. This high concentration was a direct result of the specification that the uranium be limited to $20 \%$ enrichment. Fifty-six fuel elements were constructed for the reactor. A typical fuel element is illustrated in Fig. 86, and a transverse section through the fuel element is shown in Fig. 87.

Each fuel element contained $170 \mathrm{~g}$ of $U^{235}$ in the form of $\mathrm{UO}_{2}$; thus a powder core compact containing $54 \mathrm{wt} \% \mathrm{UO}_{2}$ and $46 \mathrm{wt} \%$ aluminum was necessary. The fuel cores were prepared by powder-metallurgy techniques, which consisted in blending the aluminum and the $\mathrm{UO}_{2}$ powder for



Fig. 86. Geneva Reactor Fuel Element with End Adapters. 


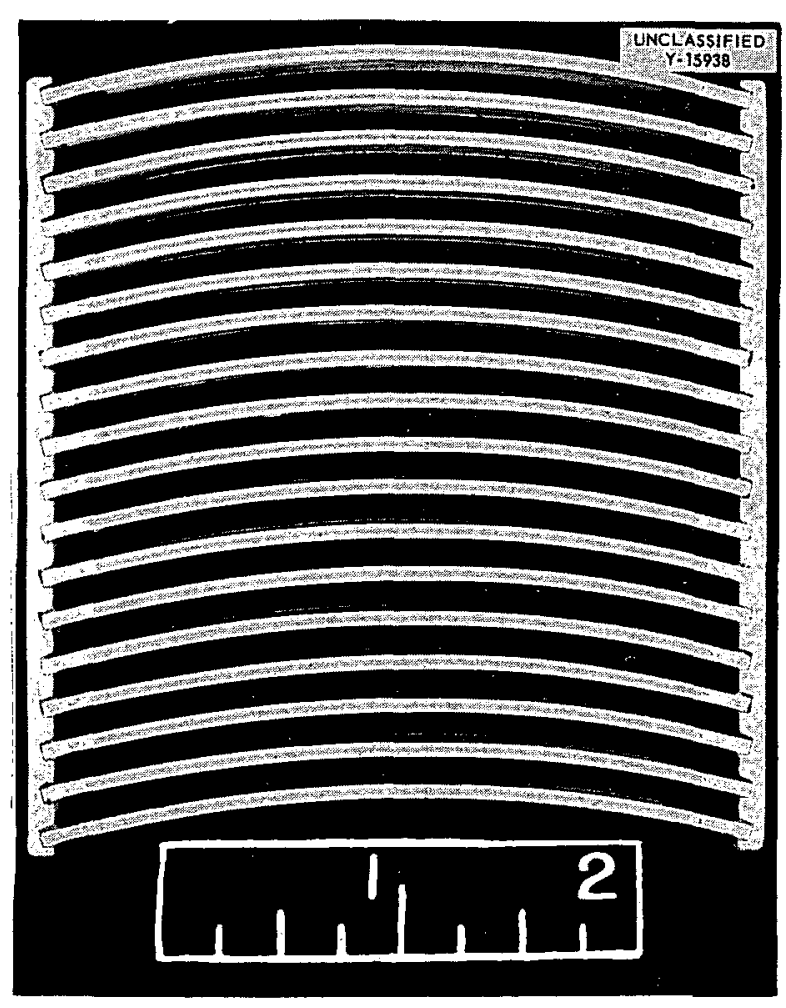

Fig. 87. Transverse Section of Geneva Reactor Fuel Element.

$1 \frac{1}{2} \mathrm{hr}$ and then cold-pressing the mixture between two 5 -mil aluminum foils in a $2 \times 2 \frac{1}{2} \mathrm{in}$. die to 33 tsi and to a density $95 \%$ of theoretical. The cores were pressed approximately 10 mils thicker than the frame to ensure exact fit between core and frame during initial fabrication. The materials utilized were vacuum-annealed aluminum, -100 mesh; and vacuum-annealed $\mathrm{UO}_{2},-100$ mesh, +25 mesh.

The billets. were prepared, and the plates were fabricated in a manner similar to that adopted for the MTR, except that the aluminum-cover plates were partially welded to the frame prior to rolling.

Considerable difficulty was experienced due to a reaction between the $\mathrm{UO}_{2}$ and the aluminum at the elevated temperatures encountered during the manufacturing sequences involved in the construction of the aluminum elements - hot-rolling at $590^{\circ} \mathrm{C}$, flux-annealing at $510^{\circ} \mathrm{C}$, and brazing at $610^{\circ} \mathrm{C}$. The reaction resulted in volume changes in the plate dimensions prior to brazing and in buckling of the fuel plates during brazing.
It was discovered that $\mathrm{UO}_{2}$ prepared by the hydrogen peroxide precipitation method was particularly reactive with aluminum at elevated temperatures. Microscopic examination of the as-received oxide and of the oxide in the fabricated plates revealed that the screened particle was an ag. glomerate that apparently disintegrated during hot rolling into fine particles, which readily reacted with the aluminum. Firing of the oxide in hydrogen at $2000^{\circ} \mathrm{C}$ prior to blending decreased the tendency of the oxide to fragment and react during fabrication. Firing to temperatures below $2000^{\circ} \mathrm{C}$, however, was not satisfactory with this type of oxide.

Because of equipment limitations and because of the erratic results obtained with the oxide precipitated with hydrogen peroxide, another type of oxide was developed in laboratory quantities by J. R. Johnson of the Ceramic Section and is described below. The oxide production was, subsequently, increased from $400-\mathrm{g}$ laboratory lots to $6-\mathrm{kg}$ production batches. This oxide was successfully utilized in Geneva Conference Reactor fuel plates. It is prepared from a $\mathrm{UO}_{4}$ cake which is in the presence of $10 \%$ uranyl nitrate and excess water and is heated for $10 \mathrm{hr}$ in an autoclave at $250^{\circ} \mathrm{C}$. Crystals of $\mathrm{UO}_{3}$ hydrate are produced; after a thorough rinsing to remove all traces of nitrate, the crystals are fired at $1700^{\circ} \mathrm{C}$ under a hydrogen atmosphere, which removes the water and reduces the material to $\mathrm{UO}_{2}$. Examination of the laboratory-prepared $\mathrm{UO}_{2}$ revealed that it consists of particles which are bipyramidal, very dense, and free of clinging agglomerates. However, production batches often contained oxide with platelets and clinging agglomerates, which indicated lack of control in the production process. Of the total quantity of oxide produced for the reactor, approximately one-third was rejected either before or during plate fabrication. The process, nevertheless, produces the densest and cleanest $\mathrm{UO}_{2}$ particles that have ever been observed at ORNL. With a modification in the production equipment and by rigid control of the process, it is believed that the yield of oxide will be improved.

An investigation is presently in progress to determine the fundamental cause of the volume increase caused by the $\mathrm{UO}_{2}-\mathrm{Al}$ reaction; however, there are not sufficient data at this time to yield any definite conclusions. It has been determined by $M$. L. Picklesimer that the primary reaction products are $\mathrm{UAI}_{3}, \mathrm{UAI}_{4}$ and $\mathrm{Al}_{2} \mathrm{O}_{3}$. 


\section{IRRADIATION TESTING OF GENEVA CONFERENCE REACTOR FUEL ELEMENTS}

\section{R. J. Beaver}

In view of the lack of radiation-damage information on aluminum fuel plates containing 54 wt \% $\mathrm{UO}_{2}$ in an aluminum matrix, it was decided to test two full-size fuel elements, like those for the Geneva Reactor, in the LITR and MTR. The fuel elements contained 18 plates and were constructed in accordance with a design similar to that for the Mark XI MTR unit. A typical fuel-plate core contained the following quantities of material:

$\begin{array}{lccc} & \begin{array}{c}\text { Weight } \\ (\mathrm{g})\end{array} & \begin{array}{c}\text { Weight } \\ (\%)\end{array} & \begin{array}{c}\text { Volume } \\ (\%)\end{array} \\ \text { Uranium dioxide } & 55.23 & 54.00 & 20.94 \\ \text { Uranium, total } & 48.59 & & \\ \text { Aluminum } & 47.03 & 46.00 & 71.78\end{array}$

The testing data are given in Table 39.

The LITR element was carefully examined in the hot cell at the Solid State Division. The element showed only a few slight pits, and there appeared to be no distortion. The MTR element was thoroughly inspected in the canal at the MTR. The element appeared to be free of any gross corrosion defects and of distortion from radiation damage. Several plate spacings were measured at random locations and compared with preirradiation measurements. The results are listed in Table 40. They strongly indicated that when a fuel element containing $\mathrm{UO}_{2}$ in a matrix of aluminum is inserted in a reactor and used until there is $23 \%$ burnup of the $U^{235}$, no gross damage to the fuel element is observed.

\section{DEVELOPMENT OF URANIUM-ALUMINUM ALLOYS WITH INCREASED AMOUNTS OF URANIUM FOR APPLICATION IN MTR-TYPE ALUMINUM FUEL ELEMENTS}

J. H. Erwin

The specification that the uranium for use in foreign research reactors be limited to $20 \%$ enrichment imposed restrictions in the design of aluminum fuel elements with the usual amounts

TABLE 39. TEST RESULTS FOR TWO GENEVA CONFERENCE REACTOR FUEL ELEMENTS

\begin{tabular}{lcccc}
\hline Reactor & $\begin{array}{c}\text { Time in Reactor } \\
\text { (days) }\end{array}$ & $\begin{array}{c}\text { Irradiation } \\
\text { (Mwd) }\end{array}$ & $\begin{array}{c}\text { Flux } \\
\left.\text { (neutrons } \mathrm{cm}^{-2} \cdot \mathrm{sec}^{-1}\right)\end{array}$ & $\begin{array}{c}\text { Estimated Burnup of U } \\
(\%)\end{array}$ \\
\hline LITR & 83 & 209 & $1.5 \times 10^{13}$ & 5 \\
MTR & 36 & 964 & $2.5 \times 10^{14}$ & 23 \\
\hline
\end{tabular}

TABLE 40. COMPARISON OF PLATE SPACINGS IN GENEVA CONFERENCE TEST ELEMENT IRRADIATED IN THE MTR

\begin{tabular}{cccc}
\hline Space No. & $\begin{array}{c}\text { Location of Measurement } \\
\text { (in.) }\end{array}$ & $\begin{array}{c}\text { Preirradiation Measurement } \\
\text { (mils) }\end{array}$ & $\begin{array}{c}\text { Postirradiation Measurement } \\
\text { (mils) }\end{array}$ \\
\hline 4 & 3 & 110 & 111 \\
4 & 12 & 112 & 111 \\
6 & 3 & 108 & 111 \\
6 & 12 & 105 & 111 \\
9 & 3 & 111 & 109 \\
9 & 12 & 107 & 113 \\
13 & 3 & 111 & 113 \\
13 & 12 & 112 & 112 \\
14 & 12 & 111 & 110 \\
\hline
\end{tabular}


of uranium currently utilized in the fuel elements of the MTR, BSF, and TSF. With regard to standard 18- or 19-plate elements, calculations reveal that a fuel-plate core requires a concentration of approximately 45 wt \% uranium in the uranium-aluminum alloy. If the design is modified from an 18-plate element with 60-mil-thick plates to a 14-plate element with 100-mil-thick plates, the concentration of uranium required decreases to 27 wt \%. Because of the lack of information on the homogeneity and the fabrication properties of uranium-aluminum alloys containing large concentrations of uranium, an investigation has been initiated to determine the limiting concentration which may be successfully utilized in aluminum fuel-plate manufacturing.

An alloy containing approximately 27 wt \% uranium has been cast and fabricated into fuel plates. Although complete information on the extent of homogeneity is not available at the present time, all indications suggest that this alloy can be successfully employed in the construction of aluminum fuel elements for research reactors.

As the concentration increases beyond 30 wt \% uranium, difficulties in melting practices and in fabrication of the alloy and the fuel plates increase accordingly. Castings containing 30 to 45 wt \% uranium exhibited a marked tendency toward porosity and segregation; and during breakdown of the costing into plate under ordinary rolling procedures, extensive edge cracking of the plate occurred. When the casting contained 45 wt \% uranium and was rolled at $600^{\circ} \mathrm{C}$ and subjected to merely one $10 \%$ reduction in thickness, it fragmented. Confining the edge of the casting by metal spraying with 100 mils of aluminum appeared to minimize the edge cracking of both 35 and 45 wt \% alloys. Breakdown of the alloy by extrusion showed promise, but the method appeared to require considerable development.

Cores were readily punched from the rolled alloy plates and were fabricated into composite fuel plates by using the standard procedures for MTR fuel plates. Radiographic examination of the fuel plate containing 45 wt \% uranium revealed considerable segregation of the uranium. Microscopic examination of the fuel plate indicated metallurgical bonding between core and clad as shown in Fig. 88. However, examination of a longitudinal section at the end of the plate revealed that the

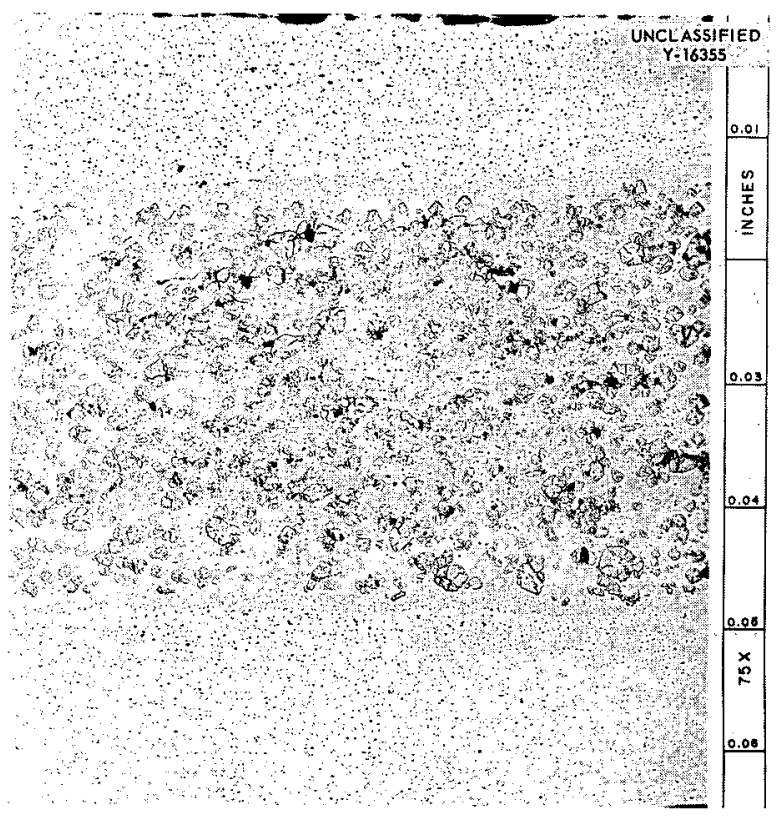

Fig. 88. Transverse Section of Aluminum-clad Fuel Plate Showing Metallurgically Bonded CoreClad Interface. 75X. Reduced 33.5\%.

alloy had not been plastically and uniformly deformed with the aluminum but had accumulated at the core-frame junction. The "dog-bone" shape of the core is illustrated in Fig. 89, and it is apparent that this phenomenon causes a drastic thinning of the aluminum cladding at this location.

\section{DEVELOPMENT OF ALUMINUM-URANIUM- BORON ALLOYS FOR APPLICATION IN MTR FUEL ELEMENTS}
J. A. Milko
W. C. Thurber

In order to obtain adequate fuel-element service life and to improve reactor performance in the 175-Mw Engineering Test Reactor, it is desirable that small quantities of boron be added to a uranium-aluminum alloy which contains approximately 17 wt \% uranium. The range of boron additions which may be necessary has been tentatively established as between 0.08 and 0.30 wt $\%$. Information on the aluminum-boron and aluminumuranium-boron systems is very limited. Consequently, efforts have been initiated to demonstrate the feasibility of casting and fabricating alloys containing low concentrations of boron. 


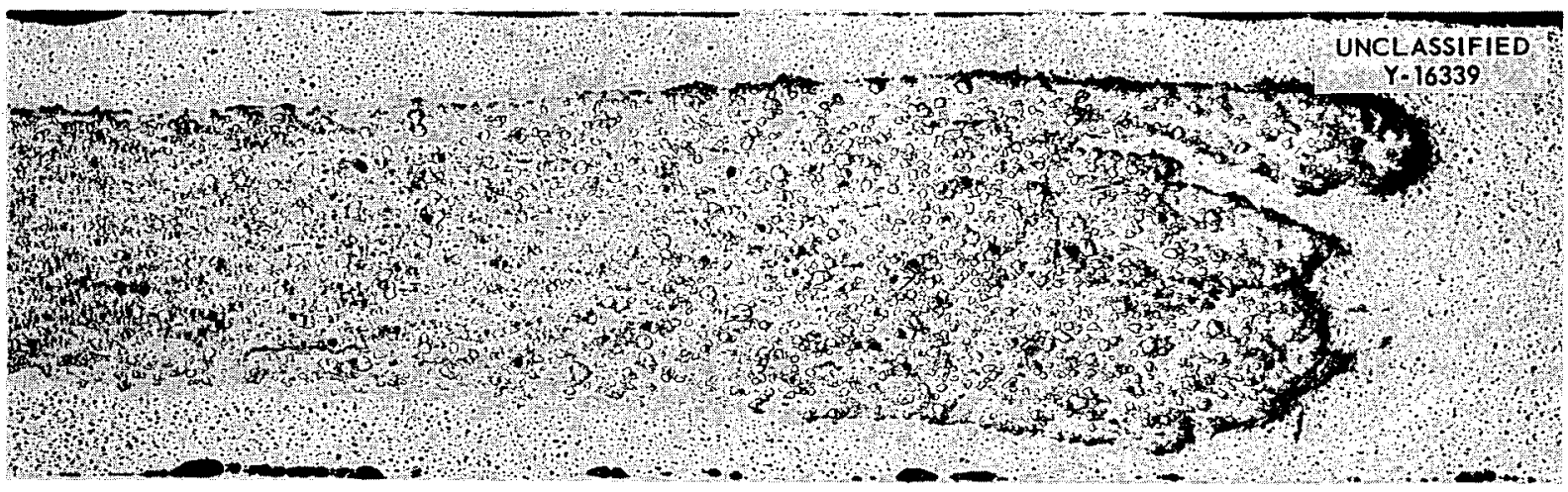

Fig. 89. Longitudinal Section of Aluminum-clad Fuel Plate Which Illustrates "Dog-Bone Effect" at the Core Ends. 25X.

The preliminary results of investigating aluminumboron binary alloys and the ternary system containing 17.00 wt \% U-0.22 wt \% B-82.78 wt \% Al indicated the following:

1. Binary alloys containing less than 1.0 wt $\%$ boron can be cold-reduced $90 \%$ with negligible edge cracking.

2. Induction-melted binary aluminum-boron alloys exhibit a marked tendency toward segregation.

3. No eutectic has been observed in binary alloys containing less than 18 wt \% boron.

4. Only one compound is present in alloys containing less than 18 wt \% boron.

5. Two compounds appear to be present in an alloy containing 44 wt $\%$ boron.

6. Aluminum boride is difficult to dissolve in an induction-mel ted uranium-aluminum al loy.

7. Induction-melted ternary alloys containing uranium exhibit a marked tendency for segregation of the boron.

\section{MANUFACTURE OF REACTOR COMPONENTS}

\section{J. H. Erwin}

\section{SPERT Fuel Elements}

Forty fuel elements were constructed for the Special Power Excursion Reactor Test being conducted by Phillips Petroleum Company. The test is a continuation of the ANL Borax experiments. The elements for the SPERT I program were a modification of the standard MTR elements. A completely brazed SPERT element is illustrated in Figs. 90 and 91 . The unit consists of 51 plates approximately 1 in. wide and similar in length and thickness to MTR elements. The change in design

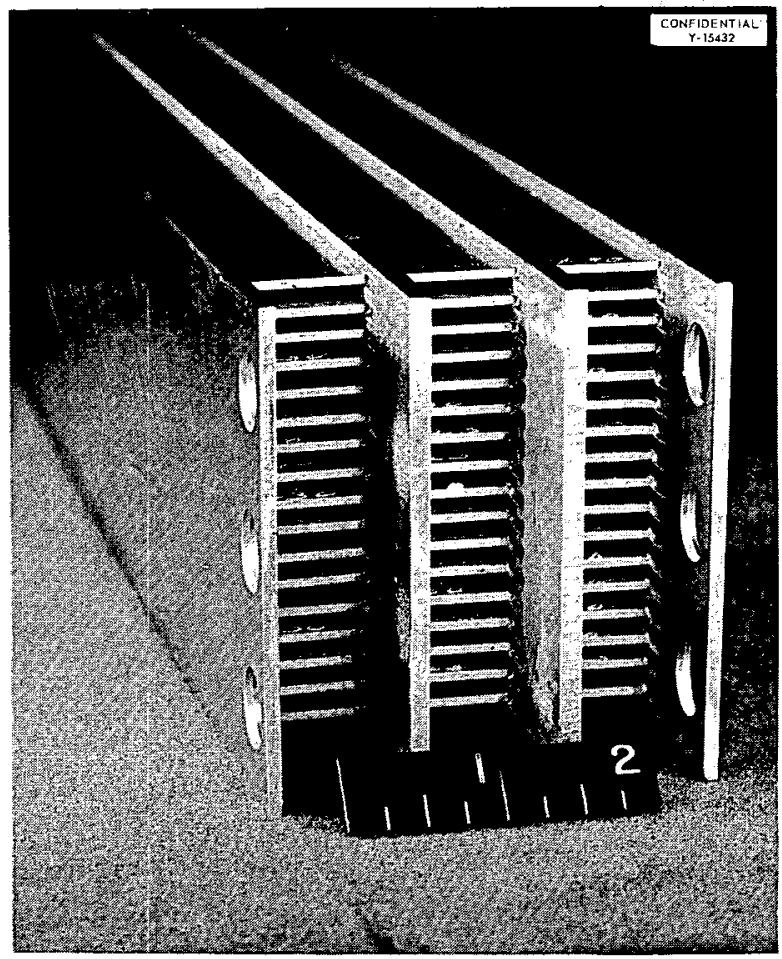

Fig. 90. Brazed SPERT Fuel Element.

increases the rigidity of the fuel element by a factor of 4 .

Fuel plates for the SPERT element were fabricated by applying the same procedures used for MTR plates with the exception that the plates were rolled in clusters of three, side by side, enclosed in a single frame. The brazing cycle 


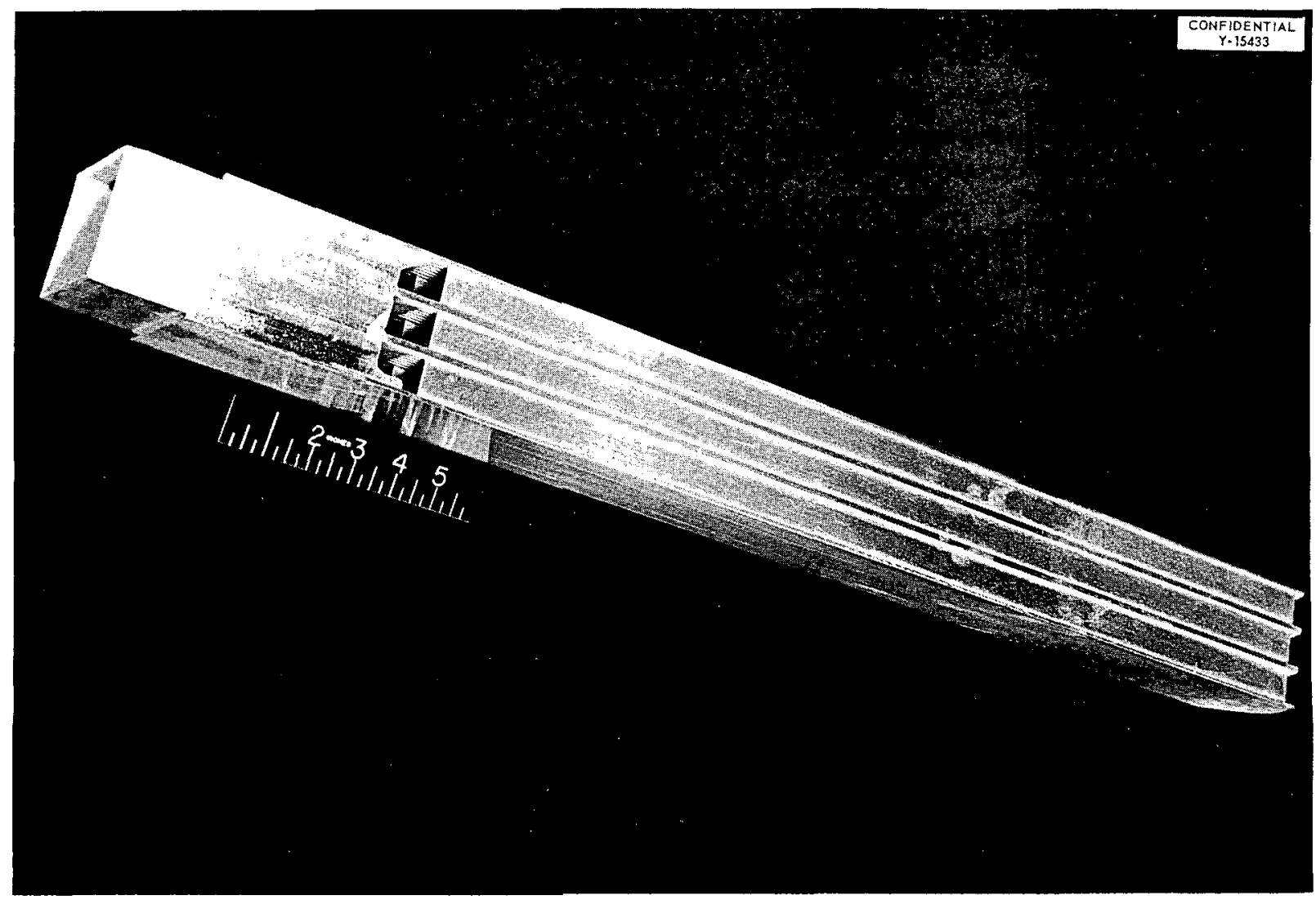

Fig. 91. Brazed SPERT Fuel Element with End Adapter.

was modified by preheating at $500^{\circ} \mathrm{C}$ for $1 \frac{1}{2}$ to $2 \mathrm{hr}$ in stead of the usual $1 \mathrm{hr}$.

\section{Plutonium-Aluminum Fuel Elements}

Los Alamos, ANL, and ORNL have jointly embarked on a program to obtain higher isotopes of plutonium by irradiating fuel elements containing a plutonium-aluminum alloy of 10 wt \% plutonium. Six elements are to be constructed during this program for irradiation in the active lattice of the MTR.

Since ORNL is not equipped to handle material of this activity, arrangements have been made for Los Alamos to prepare the billets. ORNL will manufacture the plates and construct the elements.

Preliminary development work at ORNL indicates that, since prerolling of the core in the frame does not appear to be feasible with plutonium-aluminum alloy, it will be necessary to seal billets under vacuum after vacuum degasification at $540^{\circ} \mathrm{C}$. The plates will be fabricated, and the units constructed in accordance with standard MTR schedules.

Billet parts have been shipped to Los Alamos where the casting of the alloy and the preparation of the billets are in progress.

\section{Initial Loading for Pennsylvania State College Research Reactor}

Twenty-two aluminum fuel elements were furnished to the Pennsylvania State College for its research reactor. The fuel elements were similar to BSF elements, with the exception that they were 10 -plate elements with 0.250 -in. plate spacings.

\section{Replacement Loading of CP-5 Fuel Elements}

Seventeen replacement CP-5 fuel elements were furnished to ANL.

\section{Initial Loading for BNL Medical Research Reactor}

Twenty-five BSF fuel elements were furnished to BNL for the Medical Research Reactor. 


\section{Control Rods for BSF}

Three replacement control-rod elements were furnished for the Bulk Shielding Facility.

\section{Replacement Fuel and Control-Rod Units for the MTR}

MTR fuel assemblies were modified; and the new design, Mark XI, consists of 17 inner plates, $50 \mathrm{mils}$ thick, and two outer plates, 65 mils thick. The side-plate thickness has been increased from $\frac{1}{8}$ to $3 / 16$ in. Phillips Petroleum Company has been provided with 118 of the new Mark XI fuel elements. The MTR has been furnished with 12 shim rods.

\section{Chalk River Compensating Rods}

Twenty compensating rods, each containing 19 "J" slugs, have been fabricated for the Canadian Chalk River Reactor.

\section{Cast and Extruded "J" Slugs for Phillips Petroleum Company}

Phillips Petroleum Company was furnished approximately $1360 \mathrm{~kg}$ of aluminum-uranium alloy, containing 7.5 wt \% depleted uranium, in the form of extruded and drawn " $J$ " slugs.

\section{Miscellaneous Fabrication Work}

Approximately 115 plates of Boral containing 35 wt \% boron carbide were fabricated for $Y-12$.

\section{Aluminum-clad Fuel Plates for Brookhaven National Laboratory}

Twenty-seven MTR-type aluminum fuel plates, with enriched-uranium-aluminum alloy cores containing approximately 17 wt \% uranium, were fabricated for BNL.

\section{Fuel Tubes and Control Slugs for Hanford Works}

Four hundred fuel tubes, $1.275 \mathrm{in}$. in $O D$ by $0.943 \mathrm{in.}$ in ID by $2 \mathrm{in.,}$ and 5400 fuel tubes, $1.275 \mathrm{in.} i \mathrm{in}$ OD by $0.943 \mathrm{in}$. in ID by $\frac{1}{2} \mathrm{in}$. were extruded for the Physical Constants Fuel Reactor at Hanford Works. The tubes contained 8.2 and $2.05 \mathrm{~g}$ of $\mathrm{U}^{235}$, respectively, in a uranium-aluminum alloy. An additional 40 clad slugs, $1.235 \mathrm{in}$. in diameter by $34.166 \mathrm{in}$. in length, were extruded for control rods. These latter slugs contained $55 \mathrm{~g}$ of $U^{235}$ in the uranium-aluminum alloy.

\section{MINIATURE APPR FUEL PLATES}

\section{J. H. Erwin}

Thirty miniature plates, containing APPR-type core material, were fabricated for fission-productactivity determinations. Core and clad thicknesses met APPR specifications. Six plates contained core sections that ranged in weight from 0.360 to $0.369 \mathrm{~g}$, and 24 contained core sections that ranged in weight from 0.370 to $0.379 \mathrm{~g}$. The average normal uranium content, as determined by chemical analysis, was $15.10 \%$. The core sections were oval in shape, having maximum dimensions of $5 / 7 \times 1 / 4$ in. The external dimensions of each plate were $1 / 2 \times 1$ in.

Thirty miniature plates containing APPR-type core material were fabricated for studying the effects of fission products on the stainless steel fuel-element recovery process. Core and clad thicknesses met APPR specifications. Six plates contained cores in the weight range of 0.860 to $0.879 \mathrm{~g}$, and 24 contained cores in the weight range of 0.880 to $0.899 \mathrm{~g}$. The average normal uranium content, as determined by chemical analysis, was $30.06 \%$. The maximum dimensions of the core are $2 \times \frac{1}{4} \mathrm{in}$. The external dimensions of each plate were $215 / 16 \times 11 / 16 \mathrm{in}$. 


\section{PACKAGE POWER REACTOR PROGRAM}

\section{R. J. Beaver}

Work is being continued on the development of a relatively cheap, reliable stainless steel fuel element for service in the Army Package Power Reactor. Two full-size irradiation-test elements have been tested in the STR and MTR, respectively. In addition, a number of miniature plates are presently being irradiated in the MTR to determine the effect of $\mathrm{UO}_{2}$ particle size on the degree of radiation damage. Other investigations were concerned with the development of coreblending procedures to improve homogeneity in the fabricated plate, the application of a stretcher straightener to plate-flattening operations, and the development of methods for the fabrication of boron-containing stainless-steel-clad plates for the APPR critical experiment. Experimental results and progress on each phase of the work are reported in detail below.

\section{IRRADIATION OF SIX-PLATE APPR ELEMENT IN THE STR}

\section{R. J. Beaver}

As described previously, ${ }^{1}$ an APPR-type element, constructed of composite stainless steel fuel plates containing $17.92 \mathrm{wt} \% \mathrm{UO}_{2}$ and 0.19 wt $\%$ $\mathrm{B}_{4} \mathrm{C}$, was manufactured and was inserted into the removable subassembly position in the Mark I core of the STR. The purpose of the test was to obtain operating performance and radiation-damage data after $8 \%$ burnup of $U^{235}$ atoms under thermal and hydraulic conditions similar to those selected for the APPR. The element operated satisfactorily for $190 \mathrm{hr}$ at full power. After the test, it was examined and appeared to be in excellent condition; there were no indications of corrosion or of any change in dimensions. The burnup of $U^{235}$ atoms is estimated to be $3 \%$. Efforts are being made to continue the test in the Mark III core.

\section{IRRADIATION OF 18-PLATE APPR ELEMENT IN THE MTR}

\section{R. J. Beaver}

An APPR 18-plate assembly, consisting of stainless steel plates bearing $\mathrm{UO}_{2}$ and $\mathrm{B}_{4} \mathrm{C}$, was designed and constructed for irradiation testing in

\footnotetext{
${ }^{\prime}$ R. J. Beaver, Met. Semiann. Prog. Rep. April 10, 1955, ORNL-191 i, p 105.
}

\author{
R. C. Waugh
}

the MTR. The purposes of this test were as follows:

1. to investigate, under conditions of high-fuel burnup, the behavior of composite fuel plates formed of a core mixture which consisted of $\cup_{2}, \mathrm{~B}_{4} \mathrm{C}$, and stainless steel powder and which was elad with wrought stainless steel;

2. to test the mechanical stability of a full-sized stainless steel element when subjected to the combined thermal, hydraulic, and irradiation conditions in the MTR;

3. to determine the general compatibility of selected structural materials when subjected simultaneously to radiation and high-velocity cooling water;

4. to ascertain whether any serious corrosion problems are apt to be encountered.

The assembly contained three sets of six plates which were designed for a lifetime of 15, 22.5, and 30 Mwy. Pertinent data for these plates are listed in Table 41. The particle-size range was maintained constant in this test; prior to fabrication it was 80 to $120 \mu$. The oxide selected was of the type prepared by the hydrogen peroxide precipitation method.

The cores were prepared and the plates were fabricated by methods which have been described previously for the manufacture of APPR plates. Prior to assembling, the plates were radiographically inspected for homogeneity. All plates were acceptable. In addition, samples were taken from extra plates and were analyzed to quantitatively determine homogeneity. The results, together with the average deviation associated with each type of plate, are tabulated below:

$$
\begin{array}{ll}
15 \mathrm{Mwy} & 16.50 \pm 0.53 \text { wt \% uranium } \\
22.5 \mathrm{Mwy} & 19.52 \pm 0.76 \text { wt \% uranium } \\
30 \mathrm{Mwy} & 23.66 \pm 0.54 \text { wt \% uranium }
\end{array}
$$

After careful inspection for surface defects, the plates were assembled into a unit consisting of 18 flat plates and were brazed with Coast Metals NP brazing alloy. Brazing procedures utilized were identical to those described previously. Measurement of plate spacings at various locations along the length of the element revealed that all but 2 of 68 measurements were within 10\% of the 
nominal 117-mil spacing, and those two were within 15\% of nominal. The completely brazed assembly is illustrated in Fig. 92. The stainless steel unit was housed in an aluminum-shell element, the outer dimensions of which matched the outer dimensions of the standard MTR fuel assembly. The stainless steel element was pinned to the aluminum housing as shown in Fig. 93, and standard end boxes were plug-welded to the aluminum-shell element.
The test element was inserted in the reactor on June 24, 1955, and was irradiated for $1431 \mathrm{Mwd}$. It was discharged on August 22, 1955. The estimated burnup of $U^{235}$ atoms, based on peak flux calculations, is $40 \%$. The stainless steel element was thoroughly examined in the MTR canal and showed no gross dimensional changes or failures due to corrosion. It appeared to be in excellent condition. Several random measurements were made of the plate spacings, which compared

TABLE 41. PERTINENT DATA FOR APPR FUEL PLATES TO BE TESTED IN THE MTR

\begin{tabular}{llll}
\hline & \multicolumn{3}{c}{ Designed Plate Lifetime } \\
\cline { 2 - 4 } & 15 Mwy & 22.5 Mwy & 30 Mwy \\
\hline Clad-core-clad thickness, mils & $9-12-9$ & $10-10-10$ & $11-8-11$ \\
Core mixture, wt \% & & & \\
$\mathrm{UO}_{2}$ & 18.75 & 22.18 & 26.89 \\
$\mathrm{~B}_{4} \mathrm{C}$ & 0.21 & 0.27 & 0.39 \\
$\quad$ Stainless steel & 81.04 & 77.55 & 72.72 \\
$\mathrm{U}^{235}$ enrichment level, \% & 93.14 & 93.14 & 93.14 \\
$\mathrm{U}^{235}$ distribution per plate, $\mathrm{g} / \mathrm{cm}^{2}$ & 0.031 & 0.031 & 0.031 \\
$\begin{array}{l}\text { Burnup of total atoms in core } \\
\text { mixture, \% }\end{array}$ & 1.63 & 1.92 & 2.39 \\
\hline
\end{tabular}

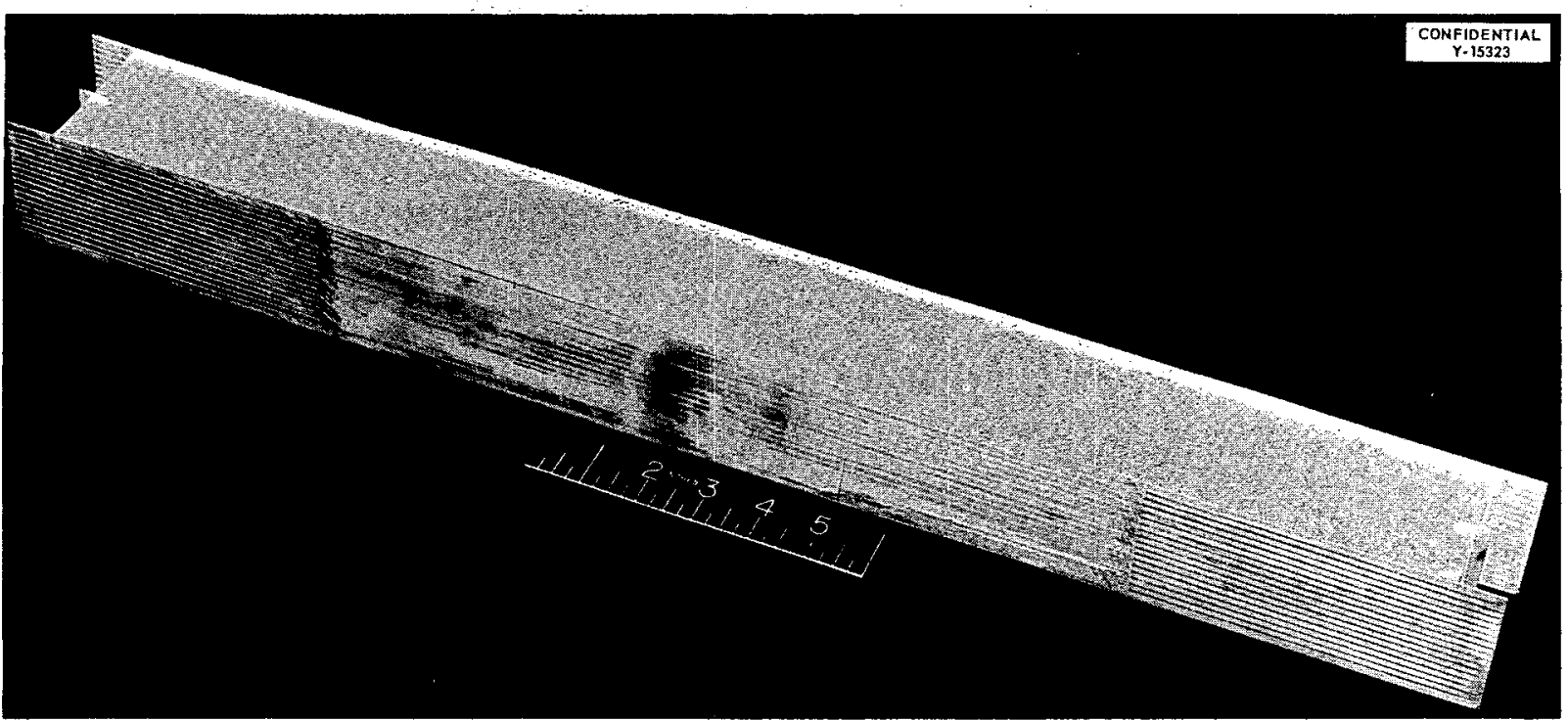

Fig. 92. APPR Assembly, Prior to Insertion in Aluminum Housing for Test Irradiation in MTR. 
favorably with preirradiation measurements. The results are shown in Table 42 . The element will remain in the MTR canal for a minimum of two months, after which time it will be sectioned for more thorough examination.

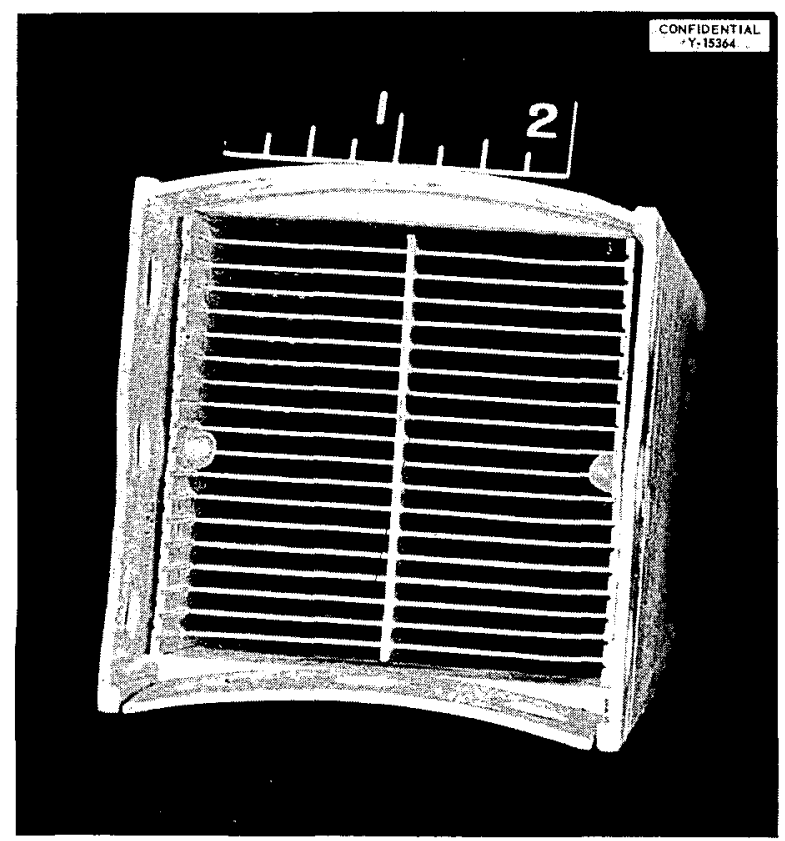

Fig. 93. Cross Section of APPR Assembly Enclosed in Aluminum Housing, Prior to Test Ir. radiation in MTR.

\section{IRRADIATION TESTING OF MINIATURE APPR PLATES IN THE MTR}

\author{
R. J. Beaver
}

Twenty-six specimens were sectioned from enriched APPR-type fuel plates that were designed for a lifetime of either $15 \mathrm{Mwy}$ or $30 \mathrm{Mwy}$. The specimens were enclosed in a sealed stainless steel jacket. The seal was made by first copper brazing and then Heliarc welding. The over-all size of the finished specimen was approximately $3 \times 1 \times 0.080 \mathrm{in}$. Two specimens were tack-welded together at their ends and inserted in an aluminum rabbit with circumferential holes for water passage. The fabricated parts for this test are illustrated in Fig. 94. The primary purpose of this test is to determine the effect of $\mathrm{UO}_{2}$ particle size on the radiation damage in the stainless steel matrix of the APPR fuel core. The particle sizes selected are listed in Table 43. The test is also designed to compare the radiation damage that occurs at $20 \%$ as well as at $42 \%$ burnup of the $U^{235}$.

\section{FABRICATION OF COMPOSITE STAINLESS STEEL-URANIUM DIOXIDE FUEL PLATES \\ R. C. Waugh}

An evaluation of the application of a stretcher straightener for flattening APPR fuel plates has revealed that permanent elongations of $1,1 \frac{1}{2}$, and $3 \%$ do not result in the required flatness. This

TABLE 42. COMPARISON OF PLATE SPACINGS IN APPR TEST ELEMENT BEFORE AND AFTER IRRADIATION FOR 1431 Mwd IN THE MTR

\begin{tabular}{|c|c|c|c|}
\hline Space No. & $\begin{array}{c}\text { Location Along } \\
\text { Length } \\
\text { (in.) }\end{array}$ & $\begin{array}{l}\text { Preirradiation } \\
\text { Measurement } \\
\text { (mils) }\end{array}$ & $\begin{array}{c}\text { Postirradiation } \\
\text { Measurement } \\
\text { (mils) }\end{array}$ \\
\hline 4 & 3 & 110 & 111 \\
\hline 4 & 12 & 112 & 111 \\
\hline 6 & 3 & 108 & 111 \\
\hline 6 & 12 & 105 & 111 \\
\hline 9 & 3 & 111 & 110 \\
\hline 9 & 12 & 107 & 109 \\
\hline 13 & 3 & 111 & 113 \\
\hline 13 & 12 & 112 & 113 \\
\hline 15 & 3 & 111 & 110 \\
\hline 15 & 12 & 111 & 112 \\
\hline
\end{tabular}



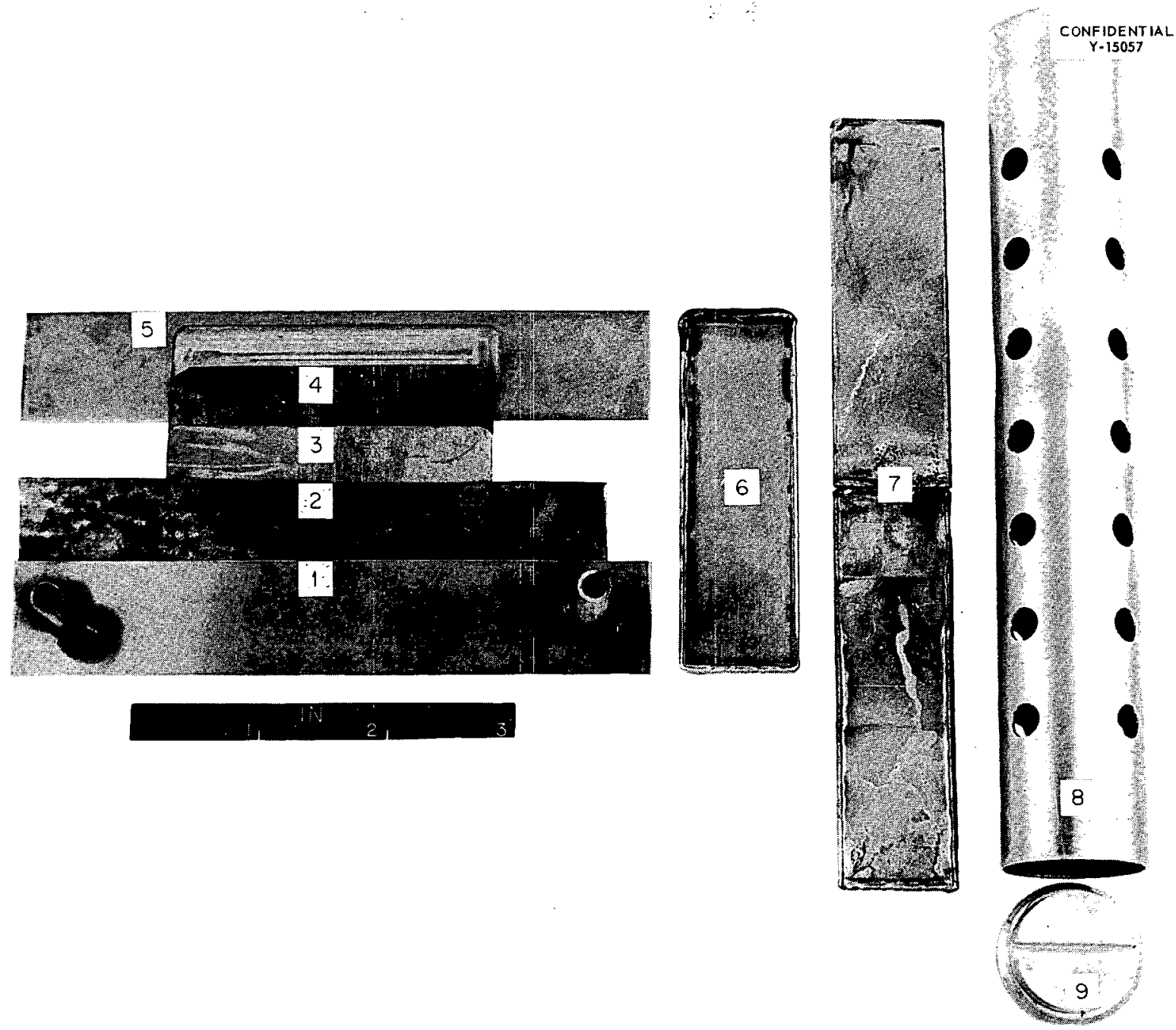

Fig. 94. Component Parts of Assembly for Irradiating Miniature APPR Fuel-Plate Specimens in the MTR. (1) Top stainless steel cover with copper-containing risers. (2) Copper foil. (3) APPR fuelplate specimen. (4) Copper foil. (5) Stainless steel frame. (6) Heliarc-welded specimen after copper brazing. (7) Two specimens tack-welded together, prior to enclosure in perforated aluminum rabbit. (8) Perforated aluminum rabbit. (9) Cap.

conclusion is based on observations of fuel plates which were fabricated in accordance with standard APPR plate fabrication procedures, except that during annealing at $1150^{\circ} \mathrm{C}$ for $20 \mathrm{~min}$ the plates were not restrained. Consequently, they buckled severely during this heat treatment. Metallographic examination of the clad-core bond indicated that there was no damage to the bond as a result of the permanent elongations during the straightening operation. Inasmuch as the degree of flatness did not improve with increasing permanent elongation, it appears that a stretcher straightener will not be of any value in flattening APPR fuel plates.

In order to improve homogeneity in the cores of APPR fuel plates, powder-metallurgy blending procedures were investigated. The techniques evaluated were dry mixing, the addition of lauryl alcohol in varying amounts and by different techniques, and the use of Teflon cubes. The total blend weight in each case ranged from 776.6 to $842.6 \mathrm{~g}$. The composition range and 
TABLE 43. MTR TEST NO. 3 OF DIFFERENT TYPES OF SPECIMENS OF APPR FUEL ELEMENTS

\begin{tabular}{|c|c|c|c|c|c|c|}
\hline \multirow{2}{*}{$\begin{array}{l}\text { Specimen } \\
\text { No. }\end{array}$} & \multirow{2}{*}{$\begin{array}{l}\text { Plate } \\
\text { No. }\end{array}$} & \multirow{2}{*}{$\begin{array}{c}\text { Type of } \\
\text { Plate }\end{array}$} & \multicolumn{2}{|c|}{ Stainless Steel in Core } & \multicolumn{2}{|c|}{$\mathrm{UO}_{2}$ in Core } \\
\hline & & & Type & Particle Size $(\mu)$ & Type & Particle Size $(\mu)$ \\
\hline 1 & 1 & $2^{\star}$ & Prealloyed 304 & 74 & Sintered & $44-74$ \\
\hline 2 & 2 & 2 & Prealloyed 304 & 74 & Sintered & $74-105$ \\
\hline 3 & 3 & 2 & Prealloyed 304 & $105-109$ & $\begin{array}{r}\text { Steam-treated } \\
\text { (run-of-mill) }\end{array}$ & 105 \\
\hline 4 & 4 & 2 & Prealloyed 304 & 44 & $\begin{array}{r}\text { Steam-treated } \\
\text { (run-of-mill) }\end{array}$ & 105 \\
\hline 5 & 5 & $1 * *$ & Prealloyed 304 & 74 & Sintered & $44-74$ \\
\hline 6 & 6 & 1 & Prealloyed 304 & 74 & Sintered & $74-105$ \\
\hline 7 & 7 & 1 & Prealloyed 304 & $105-149$ & $\begin{array}{r}\text { Steam-treated } \\
\text { (run-of-mill) }\end{array}$ & 105 \\
\hline 8 & 8 & 1 & Preolloyed 304 & 44 & $\begin{array}{r}\text { Steam-treated } \\
\text { (run-of-mill) }\end{array}$ & 105 \\
\hline 9 & 9 & 2 & Elemental 304 & 44 & Sintered & $31-44$ \\
\hline 10 & 19 & 2 & Prealloyed 304 & 44 & $\begin{array}{l}\text { Sintered } \\
\text { (run-of-mill) }\end{array}$ & 105 \\
\hline 11 & 10 & 2 & Prealloyed 304 & 44 & Sintered & $7-11$ \\
\hline 12 & 10 & 2 & Prealloyed 304 & 44 & Sintered & $7-11$ \\
\hline 13 & 12 & 2 & Prealloyed 304 & 44 & Sintered & $16-22$ \\
\hline 14 & 12 & 2 & Prealloyed 304 & 44 & Sintered & $16-22$ \\
\hline 15 & 13 & 2 & Prealloyed 304 & 44 & Sintered & $22-31$ \\
\hline 16 & 13 & 2 & Prealloyed 304 & 44 & Sintered & $22-31$ \\
\hline 17 & 14 & 2 & Prealloyed 304 & 44 & Sintered & $31-44$ \\
\hline 18 & 14 & 2 & Prealloyed 304 & 44 & Sintered & $31-44$ \\
\hline 19 & 15 & 2 & Prealloyed 304 & 44 & Sintered & $53-62$ \\
\hline 20 & 15 & 2 & Prealloyed 304 & 44 & Sintered & $53-62$ \\
\hline 21 & 16 & 2 & Prealloyed 304 & 44 & Sintered & $74-88$ \\
\hline 22 & 16 & 2 & Prealloyed 304 & 44 & Sintered & $74-88$ \\
\hline 23 & 17 & 2 & Prealloyed 304 & 44 & Sintered & $85-105$ \\
\hline 24 & 17 & 2 & Prealloyed 304 & 44 & Sintered & $85-105$ \\
\hline 25 & 18 & 2 & Prealloyed 304 & $105-149$ & $\begin{array}{l}\text { Sintered } \\
\text { (run-of-mill) }\end{array}$ & 105 \\
\hline 26 & 18 & 2 & Prealloyed 304 & $105-149$ & $\begin{array}{l}\text { Sintered } \\
\text { (run-of-mill) }\end{array}$ & 105 \\
\hline \multicolumn{4}{|l|}{ *Type 2} & \multicolumn{3}{|c|}{$\star *$ Type 1} \\
\hline \multicolumn{3}{|c|}{ Design life, Mwy } & 30 & \multicolumn{2}{|c|}{ Design life, Mwy } & 15 \\
\hline \multicolumn{3}{|c|}{$\begin{array}{l}\text { Thickness (clad-core-clad), } \\
\text { mils }\end{array}$} & $6.5-7-6.5$ & \multicolumn{2}{|c|}{$\begin{array}{l}\text { Thickness (clad-core-clad), } \\
\text { mils }\end{array}$} & $5-10-5$ \\
\hline \multicolumn{3}{|c|}{$\begin{array}{l}\text { Core composition }\left(\mathrm{UO}_{2}-\mathrm{B}_{4} \mathrm{C}_{-}\right. \\
\text {stainless steel), wt \% }\end{array}$} & $25.81-0.35-73.84$ & \multicolumn{2}{|c|}{$\begin{array}{l}\text { Core composition ( } \mathrm{UO}_{2}-\mathrm{B}_{4} \mathrm{C}- \\
\text { stainless steel), wt \% }\end{array}$} & $17.93-0.19-81.88$ \\
\hline \multicolumn{3}{|c|}{ Clad material } & $\begin{array}{l}304 \mathrm{~L} \text { stainless } \\
\text { steel }\end{array}$ & \multicolumn{2}{|c|}{ Clad material } & $\begin{array}{l}304 L \text { stainless } \\
\text { steel }\end{array}$ \\
\hline
\end{tabular}


particle size for each constituent were as follows:

$$
\begin{array}{ll}
\mathrm{UO}_{2} & 17.92 \text { to } 19.12 \text { wt } \%, 30-105 \mu \\
\mathrm{B}_{4} \mathrm{C} & 0.19 \text { wt } \%,<44 \mu \\
\begin{array}{l}
\text { Prealloyed stainless } \\
\text { steel }
\end{array} & 80.69 \text { to } 81.89 \text { wt } \%,<149 \mu
\end{array}
$$

All blending was done in an oblique-type blender. Alcohol was added by either an eyedropper or an atomizer. Teflon cubes ( $1 \frac{1}{2}$ in.) were utilized. All cores were pressed of $33 \mathrm{tsi}$, sintered at 1150 to $1175^{\circ} \mathrm{C}$, and coined to size. Radiography of the fabricated plates was employed to determine the homogeneity of the core.

The experimental results are summarized in Table 44 and indicate that (1) the volume of alcohol selected is an important factor, (2) best results are obtained when the atomizer is used for adding the alcohol, and (3) Teflon cubes reduce the blending time necessary to obtain satisfactory homogeneity in the cores of fabricated fuel plates.

\section{COMPONENT ASSEMBLING: BRAZING}

R. C. Waugh

Satisfactory brazed assemblies were constructed for the APPR irradiation tests in the STR and MTR. The braze metal selected was Coast Metals NP. Further experimentation has verified original observations that APPR fuel plates are sensitive to thermal shock, a condition which necessitated a brazing cycle that involves slow heating to brazing temperature followed by furnace cooling. Attempts to assemble APPR units with unannealed side plates revealed that the distortion of the side plate, caused by machining the grooves, must be removed prior to assembly of the plates.

\section{CORROSION STUDIES}

$$
\text { R. C. Waugh }
$$

The revised corrosion-testing program involves short-time testing (100 and $500 \mathrm{hr}$ ) of the core

\begin{tabular}{|c|c|c|c|c|c|c|}
\hline \multirow[b]{2}{*}{$\begin{array}{l}\text { Blend } \\
\text { No. }\end{array}$} & \multicolumn{2}{|l|}{ Blending Time } & \multicolumn{3}{|c|}{ Additional } & \multirow[b]{2}{*}{ Radiographic Evaluation } \\
\hline & $\begin{array}{c}\text { Prior to Alcohol } \\
\text { Addition } \\
\text { (hr) }\end{array}$ & $\begin{array}{l}\text { Alcohol } \\
\text { Applicotor }\end{array}$ & $\begin{array}{l}\text { Alcohol } \\
\text { (drops) }\end{array}$ & $\begin{array}{l}\text { Blending } \\
\text { Time } \\
\text { (hr) }\end{array}$ & $\begin{array}{l}\text { Teflon } \\
\text { Cubes }\end{array}$ & \\
\hline 1 & 16 & Eyedropper & None & None & None & General tendency to streak \\
\hline 2 & 16 & Eyedropper & 6 & 1 & None & Slight tendency to streak \\
\hline 3 & 16 & Eyedropper & 24 & 1 & None & $\begin{array}{l}\text { No streaking; several localized areas } \\
\text { of slight } \mathrm{UO}_{2} \text { segregation }\end{array}$ \\
\hline 4 & 16 & Atomizer & 6 & 1 & None & No streaking; good distribution \\
\hline 5 & 16 & Atomizer & 24 & 1 & None & Excellent distribution \\
\hline 6 & 4 & Eyedropper & 6 & 1 & 10 & $\begin{array}{l}\text { Slight tendency for streaking equivalent } \\
\text { to blend No. } 2\end{array}$ \\
\hline 7 & 4 & Eyedropper & 24 & 1 & 10 & $\begin{array}{l}\text { No streaking; good distribution equivalent } \\
\text { to blend No. } 4\end{array}$ \\
\hline 8 & 4 & Atomizer & 6 & 1 & 10 & $\begin{array}{l}\text { Slight tendency to streak; areas of local- } \\
\text { ized segregation }\end{array}$ \\
\hline 9 & 4 & Atomizer & 24 & 1 & 10 & $\begin{array}{l}\text { No streaking; good distribution equivalent } \\
\text { to blend No. } 4\end{array}$ \\
\hline
\end{tabular}
material and long-time testing ( 1 to 36 months) of brazed joints of eight alloys. In addition,

TABLE 44. EFFECT OF POWDER-METALLURGY BLENDING PROCEDURE ON HOMOGENEITY OF CORES FOR FABRICATED APPR FUEL PLATES 
long-time testing of a miniature clad plate and of brazed joints of Coast Metals NP will be conducted. The conditions of test are given below:

\begin{tabular}{|c|c|c|}
\hline Temperature & \\
\hline Pressure & \multicolumn{2}{|l|}{1200 psi } \\
\hline Water & \multicolumn{2}{|c|}{$\begin{array}{l}\text { Distilled and demineralized; } \mathrm{pH} \text {, } \\
\text { not less than } 6 \text {; total dissolved } \\
\text { solids, } 2-3 \mathrm{ppm} \text {; res istivity, } \\
\text { not less than } 0.3 \text { megohm } / \mathrm{cm}\end{array}$} \\
\hline & $\begin{array}{l}\text { Hydrogen } \\
\text { (cc/liter) }\end{array}$ & $\begin{array}{l}\text { Oxygen } \\
\text { (cc/liter) }\end{array}$ \\
\hline Environment No. 1 & None & 1 \\
\hline 2 & 50 & 1 \\
\hline 3 & 25 & 1 \\
\hline
\end{tabular}

Clad specimens with deliberate defects in the cladding and unclad specimens of as-rolled cores are presently being evaluated for corrosion by exposing them to test environment No. 2 for as long as $500 \mathrm{hr}$. The only result available at present is from an unclad specimen of as-rolled core ( $34 \mathrm{wt} \% \mathrm{UO}_{2}$ and $0.5 \mathrm{wt} \% \mathrm{~B}_{4} \mathrm{C}$ in a prealloyed type 304 stainless steel matrix) which was exposed for $25 \mathrm{hr}$. The calculated rate of attack on this specimen was $3 \mathrm{in}$./year.

\section{FABRICATION OF COMPONENTS FOR APPR CRITICAL EXPERIMENT}

\section{R. C. Waugh}

Initial specifications for the two types of stainless-steel-clad low-boron plates stipulated the incorporation of 0.994 and $1.889 \mathrm{~g}$ of boron (as $B_{4} C$ ), respectively, in a stainless steel matrix. Difficulty was experienced in maintaining the required flatness of plate during cold rolling.
Modifications of rolling temperature, hot-rolling schedule, total cold reduction, and cold-rolling schedule did not rectify the difficulty. All plates exhibited a longitudinal twist, which was attributed to differences in the cold-working characteristics of the core and edge stainless steel. Substitution of an electrolytic-iron matrix for the stainless steel matrix resulted in flat, cold-rolled plates of both boron concentrations. As anticipated from relative $x$-ray absorption calculations, it was impossible to differentiate fluoroscopically between the core and edge stainless steel of these plates for core centering measurements. Varying volume percentages of magnesium oxide and aluminum oxide were separately blended in with the stainless steel and boron carbide during core fabrication to decrease the effective core density. This expediency proved to be effective in permitting fluoroscopic marking but was discarded because a uniform sintering technique could not be developed with the available facilities. Wrapping the periphery of the core with tungsten or molybdenum foil before insertion into the pictureframe type of billet was investigated as another alternative. The molybdenum foil was ultimately selected because of its better forming characteristics.

Plates for the control-rod absorber section are designed to contain $75 \mathrm{~g}$ of boron in the form of boron carbide embedded in a copper matrix. The plates are clad with approximately 30 mils of stainless steel. Preliminary results have indicated that satisfactory plates can be fabricated for the critical experiment by nickel plating the pictureframe surfaces, applying APPR billet-assembling techniques, and rolling in a burning-hydrogen atmosphere at $1000^{\circ} \mathrm{C}$ with a $7 \frac{1}{2} \%$ reduction per pass and a total reduction of $45 \%$. 


\section{METALLURGICAL MATERIALS AND PROCESSING}

\section{E. S. Bomar \\ THORIUM - THE METALLEX PROCESS}

\section{E. S. Bomar}

Experimental work on the preparation of thorium by the Metallex process, described in the previous semiannual report, ${ }^{\prime}$ has been continued. Several pounds of metal were accumulated by repeated retorting operations, and several extrusions have been made in order to evaluate the consolidating of small pieces of thorium. A press has been purchased, and retorting equipment with an expected capacity of $10 \mathrm{lb}$ of thorium per day has been designed and built. A record of the events in a retorting cycle has been obtained on film by means of a movie camera and a timing device for making exposures at set time intervals.

\section{Consolidation by Extrusion}

The purpose of the present program is to obtain thorium in sufficient quantity and in a form suitable for evaluation tests. With the use of the present amalgam-pressing dies, the retorted product is in the form of small cylinders which are about $1 \frac{1}{8}$ in. in diameter and about $l \frac{1}{2}$ in. in length. The present work is directed toward developing a process for consolidating this product into a form, such as rod, suitable for metallurgical testing. Initial experiments have been conducted with Ames thorium so as to evaluate the possibility of consolidating small pieces of thorium by hot extrusion since the capacity of the equipment for processing the thorium amalgam is limited. The Ames thorium was obtained as $3 / 4-$ in. rod, which was cut into pieces about 1-in. long. Several charges of Ames thorium canned in: mild steel were extruded at temperatures ranging from 800 to $850^{\circ} \mathrm{C}$. The upper temperature is fixed by the presence of a eutectic at $860^{\circ} \mathrm{C}$ in the thorium-iron system.

The charges were degassed by heating at 200 to $400^{\circ} \mathrm{C}$ under a vacuum of about $10 \mu \mathrm{Hg}$, which was obtained with a mechanical pump. These conditions subsequently proved to be inadequate to prevent the thorium from oxidizing to such an extent that bonding was impeded. An inert atmosphere was introduced into the container in several

\footnotetext{
'E. S. Bomar, Met. Semiann. Prog. Rep. April 10, 1955, ORNL-1911, p 1.
}

\author{
R. E. Adams
}

runs so that, if a small hole were to develop in the preheating period prior to extrusion, possible contamination of the charge would be minimized. A range of container-wall thicknesses up to $\frac{1}{8} \mathrm{in}$. was used. When wall thicknesses were less than $\frac{1}{8}$ in., the container failed during the extrusion process. The $\frac{1}{8}$-in.-thick container wall formed a continuous but irregular cladding on the extruded thorium.

In order that the void volume would be at a minimum, one sample was consolidated cold, the canning material was machined off, and the resulting compact was recanned for extrusion. Some benefit was obtained; namely, the yield of good rod was somewhat greater than with material extruded without prior consolidation.

Meanwhile, sufficient thorium was accumulated by the Metallex process so that an extrusion of this special material could be made. The sequence for preparing the billet prior to extrusion was similar to that which was applied most satisfactorily in the above experiments and consisted in chemically cleaning the container can, evacuating, back-filling with helium, and consolidating the amalgam. However, in an effort to obtain preliminary bonding prior to extrusion, the amalgam was consolidated only after preheating at $750^{\circ} \mathrm{C}$. At least partial bonding would minimize the chance of the compacted billet breaking up during the machining operation for removal of the canning material. The Metallex billet was extruded at $800^{\circ} \mathrm{C}$ through a $3 / 4-$ in. shear die at a reduction ratio of 16:1. It was hoped that the use of a shear die would strip the canning material during the extrusion and thereby yield a rod with no residual cladding. The extruded rod had a very good surface appearance, but $x$-ray examination disclosed the presence of an extrusion defect one-third the length of the rod, which was due to enfoldment of the can. Therefore, it was concluded that a cone die must be used, the can being removed in a subsequent step, or that a process sequence must be found which will yield the thorium in a form suitable for bare extrusion. The presence of longitudinal seams or regions of poor bonding quality in the special thorium, as in the earlier experiments with Ames thorium, indicates that the thorium was inadequately protected during exposure to 
the elevated temperature. The tensile-strength values found for the various extrusions are listed in Table 45 and show that the ultimate tensile strengths of the materials are comparable to those for Ames thorium reported in project literature. ${ }^{2}$ The elongation values are appreciably below those values for the Ames stock which was consolidated by extrusion and for those of Ames material reported in the project handbook.

${ }^{2}$ The Reactor Handbook, 1st ed., vol 3, "Materials," p 349, USAEC (Secret).

TABLE 45. TENSILE TEST RESULTS ON THORIUM CONSOLIDATED BY EXTRUSION OR BY ARC MELTING

\begin{tabular}{|c|c|c|c|c|c|}
\hline Sample & $\begin{array}{l}\text { Tensile } \\
\text { Strength } \\
\text { (psi) }\end{array}$ & $\begin{array}{l}\text { Yield Point, } \\
2 \% \text { Offset } \\
\text { (psi) }\end{array}$ & $\begin{array}{l}\text { Elongation } \\
(\%)\end{array}$ & $\begin{array}{l}\text { Reduction } \\
\text { in Area } \\
(\%)\end{array}$ & Remarks \\
\hline 54-1 & 33,800 & 33,500 & 40 & 63 & 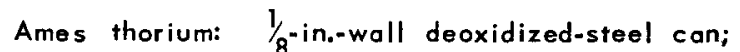 \\
\hline \multirow[t]{2}{*}{$54-2$} & 30,000 & 28,000 & 57 & 67 & evacuated at $200^{\circ} \mathrm{C}$ to $10 \mu \mathrm{Hg}$; extruded at $11: 1$ \\
\hline & 39,000 & 37,400 & 50 & 59 & at $850^{\circ} \mathrm{C}$ with 30 -deg cone die \\
\hline $65-1$ & 28,800 & 16,500 & 47 & 74 & Ames thorium: $1 / 32^{-i n .-w a l l ~ d e o x i d i z e d-s t e e l ~ c a n ; ~}$ \\
\hline $65-2$ & 33,800 & 23,800 & 34 & 68 & evacuated, and back-filled with helium to $10 \mathrm{in}$. \\
\hline $65-3$ & 27,400 & 15,400 & 50 & 75 & $\begin{array}{l}\mathrm{H}_{\mathrm{g}} \text {; extruded at } 11: 1 \text { at } 850^{\circ} \mathrm{C} \text { with } 30 \text {-deg cone } \\
\text { die }\end{array}$ \\
\hline $67-1$ & 27,000 & 18,000 & 44 & 74 & Ames thorium: $1 / 16^{-i n .-w a l l}$ deoxidized-steel can; \\
\hline $67-2$ & 27,500 & 17,500 & 45 & 76 & evacuated, and back-filled with helium to $10 \mathrm{in.}$ \\
\hline $67-3$ & 32,400 & & 42 & 73 & $\begin{array}{l}\mathrm{Hg}_{\mathrm{g}} \text { consolidated cold at } 75 \text { ts } \mathrm{i}_{\text {; }} \text { extruded at } 11: 1 \\
\text { at } 850^{\circ} \mathrm{C} \text { with } 30-\text { deg cone die }\end{array}$ \\
\hline 72 & 26,300 & 17,300 & 38 & 55 & $\begin{array}{l}\text { Metallex thorium: } 3 / 64^{-i n} \text {-wall deoxidized-steal } \\
\text { can; evacuated, and back-filled with helium to } \\
11 \mathrm{in.} \mathrm{Hg}-400^{\circ} \mathrm{C} \text {; consolidated at } 750^{\circ} \mathrm{C} \text { and at } \\
75 \mathrm{tsi} \text {; extruded at } 16: 1 \text { at } 800^{\circ} \mathrm{C} \text { with shear die; } \\
\text { extruded hardness, } 58 \text { av } \mathrm{BHN}_{i} \text { annealed }\left(\frac{1}{2} \mathrm{hr}\right. \\
\left.\text { at } 750^{\circ} \mathrm{C}\right) \text { hardness, } 56 \text { av } \mathrm{BHN} \text {; density, } 11.56 \\
\mathrm{~g} / \mathrm{cc}\end{array}$ \\
\hline 82 & 30,000 & 22,000 & 35 & & $\begin{array}{l}\text { Arc-melted single Metallex compact: hot-reduced, } \\
50 \% \text {; cold-rolled, } 72 \% \text {; annealed }\left(1 / 2 \mathrm{hr} \text { at } 750^{\circ} \mathrm{C}\right) \\
\text { hardness, } 65 \text { av BHN; density, } 11.65 \mathrm{~g} / \mathrm{cc}\end{array}$ \\
\hline Ames $-1^{\star}$ & 28,700 & 19,700 & 53 & 75 & Variations in physical properties appear to depend \\
\hline Ames-2* & 32,500 & 23,900 & 55 & 72 & on chemical composition; as extruded \\
\hline Ames $-3^{\star}$ & 27,500 & 17,200 & 46 & 76 & \\
\hline Ames $-1^{\star}$ & 27,700 & 19,300 & 54 & 76 & Physical property variation after annealing $1 / 2 \mathrm{hr}$ \\
\hline Ames-2* & 31,500 & 23,900 & 59 & 73 & at $750^{\circ} \mathrm{C}$ \\
\hline Ames-3* & 25,500 & 17,300 & 55 & 76 & \\
\hline $88-1$ & 38,200 & 25,000 & 28 & 37 & $\begin{array}{l}\text { Metallex thorium: as extruded; bare from salt bath; } \\
\text { hardness, } 74 \text { av BHN; density, } 11.66 \mathrm{~g} / \mathrm{cc}\end{array}$ \\
\hline 88-2 & 20,300 & 12,200 & 20 & 76 & $\begin{array}{l}\text { Metallex thorium: second extrusion; annealed }\left(\frac{1}{2}\right. \\
\left.\text { hr at } 750^{\circ} \mathrm{C}\right) \text { hardness, } 71 \text { av BHN; density, } 11.51 \\
\mathrm{~g} / \mathrm{cc}\end{array}$ \\
\hline
\end{tabular}

*Data obtained from Reactor Handbook. See reference 2. 


\section{Intermediate Process Facilities}

Because the chemical and metallurgical facilities differ in capacity, the amalgam had to be stored prior to pressing and the thorium compacts had to be stored following retorting; this resulted in deterioration of the amalgam and of the compacts. The size of the equipment presently available in the Metallurgy Division is such that several weeks are required before the amalgam resulting from a reduction run in the chemical facilities can be completely processed. An equal or longer delay occurs before sufficient retorted product can be collected for the preparation of an extrusion billet of reasonable size ( $3 \mathrm{in}$. in diameter by $4 \mathrm{in.}$ long, or about $10 \mathrm{lb}$ of metal).

In order that the above-mentioned difficulties may be circumvented and that sufficient material may be made available for evaluation of fabrication procedures, a press has been procured, and a larger retorting apparatus has been designed and built. The retort has a design capacity of $10 \mathrm{lb}$ per run, and it is expected that a run will be completed in an 8-hr shift.

\section{Time-Lapse Photography Study of the Retorting of an Amalgam Compact}

When cold-pressed compacts prepared from thorium amalgam are retorted, a variety of textures results. Efforts to relate these variations to chemical or metallurgical variables have been unsuccessful to date. There are at least three ways in which defects may originate during metallurgical treatment:

1. The compact may fail when ejected from the die.

2. An excessive mercury vapor pressure may be generated because of the evolution of "free" mercury or because of the rapid decomposition of a thorium-mercury intermetallic compound.

3. Cracks or voids may be formed because of a differential rate of sintering between the surface and the interior of the compact.

Reduction in compact failures may possibly be accomplished by varying the consolidation pressure or by supplying the proper amount of relief at the ejection end of the die. In order to directly observe a sample during the retorting cycle, so as to make a study of the last two possible causes for defects, a 16-mm camera was employed which exposed a frame every $6 \mathrm{sec}$. The film was viewed, and a plot of the volume of the sample as a function of time was examined; and the following events were indicated to have occurred: (1) the sample approached a temperature of $500^{\circ} \mathrm{C}$ in $33 \mathrm{~min}$ with no detectable change in volume - free mercury should be completely gone by this time; (2) accelerated rates of volume change occurred at $52 \mathrm{~min}\left(590^{\circ} \mathrm{C}\right)$ and at $90 \mathrm{~min}\left(700^{\circ} \mathrm{C}\right)$, which indicated that a critical temperature relative to the sintering characteristic of the material present was attained or that phase changes occurred with accompanying increases in the rate of sintering characteristics some surface cracking was observed at about $650^{\circ} \mathrm{C}$; (3) no change in volume was detected after a temperature of $1010^{\circ} \mathrm{C}$ was reached, even though the sample was subsequently held for $1 \mathrm{hr}$ at $1100^{\circ} \mathrm{C}$.

\section{Future Work}

Additional retorting runs are planned in which differential thermometry will be employed in an attempt to verity whether or not one or more phase changes occur.

The retorting behavior of large compacts will be observed. Plans are being made to fabricate a die with an inside diameter of 5 in. So as to obtain a feed material that is best suited for utilization in the nonconsumable electrode furnace, different methods of preparation will be investigated.

\section{CARBURIZATION OF STAINLESS STEEL FUEL ELEMENTS}

\section{R. E. Adams}

A study is in progress on the carburization of stainless steel, which is part of a process for recovering unburned uranium from spent stainless steel fuel elements from the Army Package Power Reactor. This process is based on the precipitation of the chromium as chromium-rich carbides. The matrix phase, depleted in chromium, is then chemically active and can be dissolved in chemical solutions which have little effect on ordinary stainless steel. The precipitated carbides are not dissolved but remain as a porous, friable powder from which the unburned uranium may be leached and recovered by solvent extraction.

The dissolution and recovery of uranium from carburized stainless steel fuel elements is being investigated by J. E. Savolainen of the Chemical Technology Division. Early work had shown that a neutral copper sulphate solution could be used to dissolve the matrix phase. Subsequent research has shown that better results can be obtained by 
using 3.0 M nitric acid which contains small amounts of urea. This solution also dissolves some of the uranium. Substantially all the remaining uranium may be dissolved by leaching the insoluble carbide residue with $10 \mathrm{M}$ nitric acid. The nitric acid solutions are both suitable as feed for the solvent-extraction columns conventionally used for recovery of uranium. Dissolution experiments have shown that the addition of about $2.5 \%$ carbon to stainless steel results in rapid dissolution and satisfactory recovery of uranium.

Previous research on carburization has shown that desired amounts of carbon can readily be added to the fuel-element material by gas carburization. ${ }^{3}$ The treatment of full-size fuel elements for the Army Package Power Reactor has also been investigated. These fuel assemblies are $27 \mathrm{in.} \mathrm{long}$ and contain 18 parallel fuel plates brazed into side plates. No carburization furnace is available at ORNL; therefore, the fuel assemblies have been carburized while enclosed in a gas-tight stainless steel box heated in a muffle furnace. The carburizing atmosphere was introduced at one end of the box, was passed through and around the fuel element, and was burned as it exhausted at the other end of the box. Methane-hydrogen mixtures have

${ }^{3}$ R. E. Adams, Met. Semiann. Prog. Rep. Oct. 10, 1954, ORNL-1875, p 21. been used for carburizing, and best results were obtained with a mixture containing $20 \%$ methane which was passed through the fuel element at about $17 \mathrm{fpm}$.

A fuel element containing depleted uranium was carburized at $950^{\circ} \mathrm{C}$ for $4 \mathrm{hr}$. The average carbon content, by weight-gain measurements, was $2.21 \%$. Based on uniform carbon absorption per unit area, the fuel plates contain about $2.45 \%$ carbon. The variation in carbon content along the length of the fuel element may be estimated from the weight gain of small stainless steel specimens hung at the inlet and exhaust ends of the element. Specimens at the inlet end absorbed $2.59 \%$ carbon, whereas those at the exhaust end absorbed $2.30 \%$ carbon. Variations in carbon content of this magnitude apparently have little effect on the dissolving rates of carburized stainless steel. However, with improved equipment and techniques, it is believed that more uniform carburization could be obtained, if necessary.

Thus, the feasibility of carburizing full-size Army Package Power Reactor fuel assemblies has been established. Future work will be directed toward determining what effect the radioactivity induced in the assemblies will have on the process, and what the optimum metallurgical and chemical treatments are, in terms of the total cost of the processing and of storing the waste products. 


\section{METALLOGRAPHY}

\section{R. J. Gray}
R. S. Crouse
E. L. Long, Jr.
T. M. Kegley, Jr.
J. H. Riddle

D. F. Stoneburner

\section{CATHODIC ETCHING}

$$
\text { R. J. Gray E. L. Long, Jr. }
$$

Equipment for cathodic, vacuum etching and sputtering has been obtained. The technique has been tried on numerous metallographic specimens. Etching with this equipment has been found to be very successful on multilayered metals, an accomplishment that would have been very difficult or impossible to achieve by chemical or electrolytic methods.

Cathodic etching consists in bombarding a metal specimen, which is made the cathode in a partial. vacuum glow discharge, with positively charged gaseous ions. A high potential is established between the two electrodes with argon gas, which is introduced into the vacuum chamber under a care. fully controlled leak rate.

The cathodic etching and sputtering unit is shown in Fig. 95. The vacuum chamber consists of a 12-in, bell jar resting on a stainless steel base plate. For cathodic etching, the specimen is clamped to a titanium cathode and suspended through an opening in the top of the bell jar, and an aluminum anode rests on the stainless steel base plate. The cathode is cooled during the etching operation by the circulation of ethylene glycol.

The etching operation consists in evacuating the bell jar to 0.1 or $0.2 \mu$ by means of an oil diffusion pump and a mechanical pump. The chamber is flushed several times with argon; then the argon is bled into the vacuum chamber and maintained at a pressure at $60 \mu$. The voltage is slowly adjusted to about $4200 \vee v$ and $35 \mathrm{ma}$. The etching period usually requires about 3 to 6 min.

To determine the effectiveness of tantalum as a diffusion barrier between. Inconel and niobium (columbium) at high temperatures, a specimen con- taining these metals in the desired order, with type 316 stainless steel as the base metal, was hot-rolled and heat-treated for $500 \mathrm{hr}$ at $1650^{\circ} \mathrm{F}$. The specimen was cathodically etched and photomicrographed (Fig. 96). Inspection of the photograph, with particular regard to the edge of the tantalum, reveals that the tantalum performed well as a barrier material between the niobium (columbium) and the Inconel.

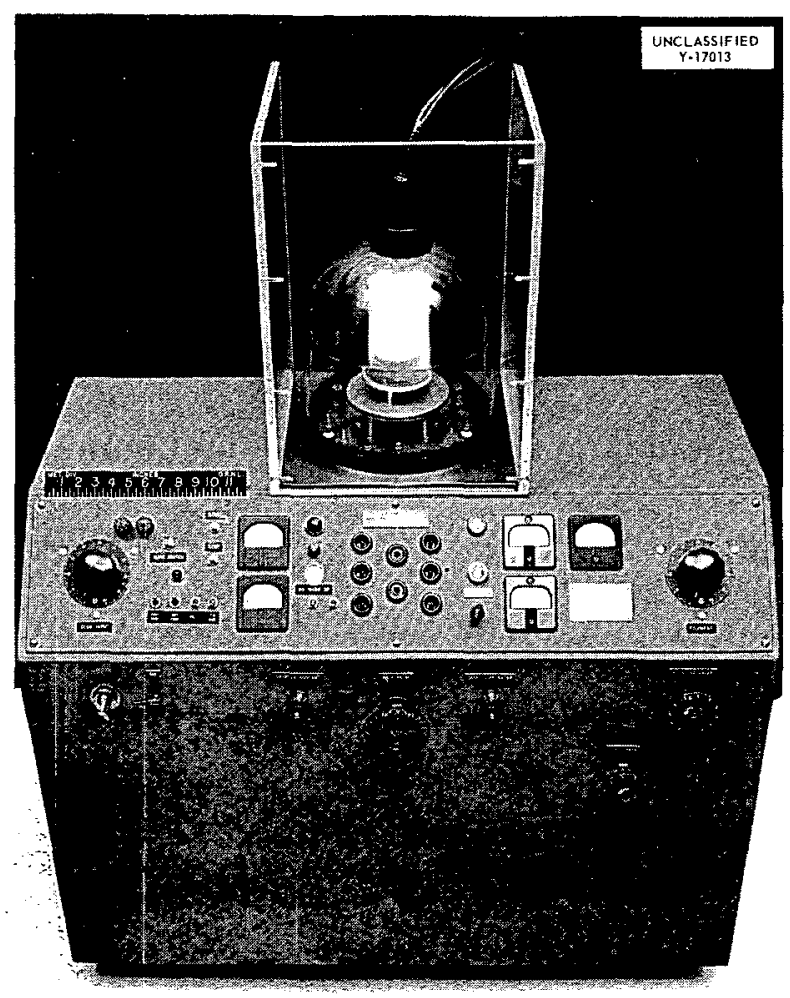

Fig. 95. Cathodic-Etching and Sputtering Unit. 


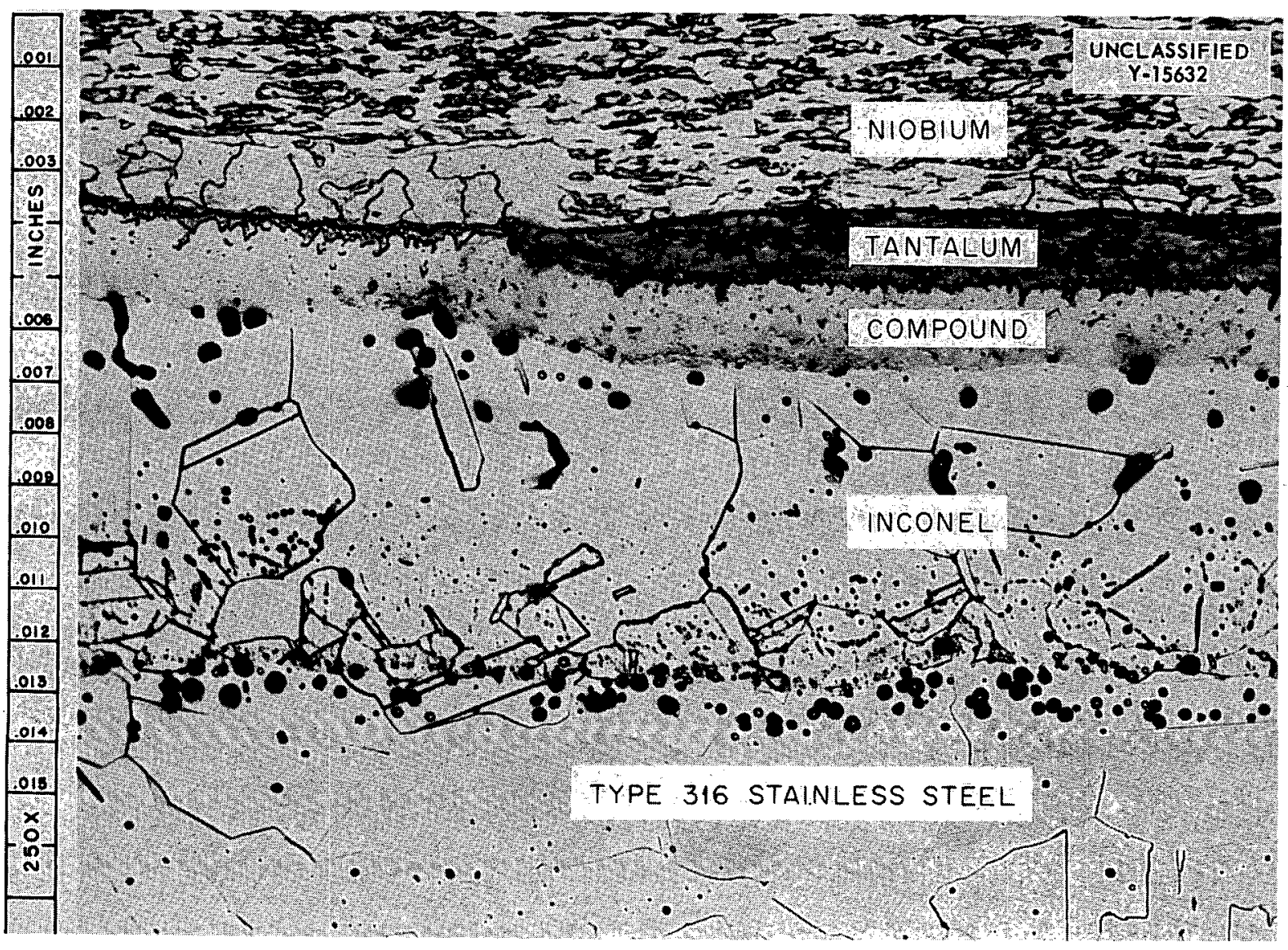

Fig. 96. Hot-rolled and Heat-treated Metal Sandwich in Which Compound Formation Between Inconel and Tantalum Occurred as a Result of Heat Treatment. 


\title{
CERAMICS RESEARCH
}

\author{
J. M. Warde
}




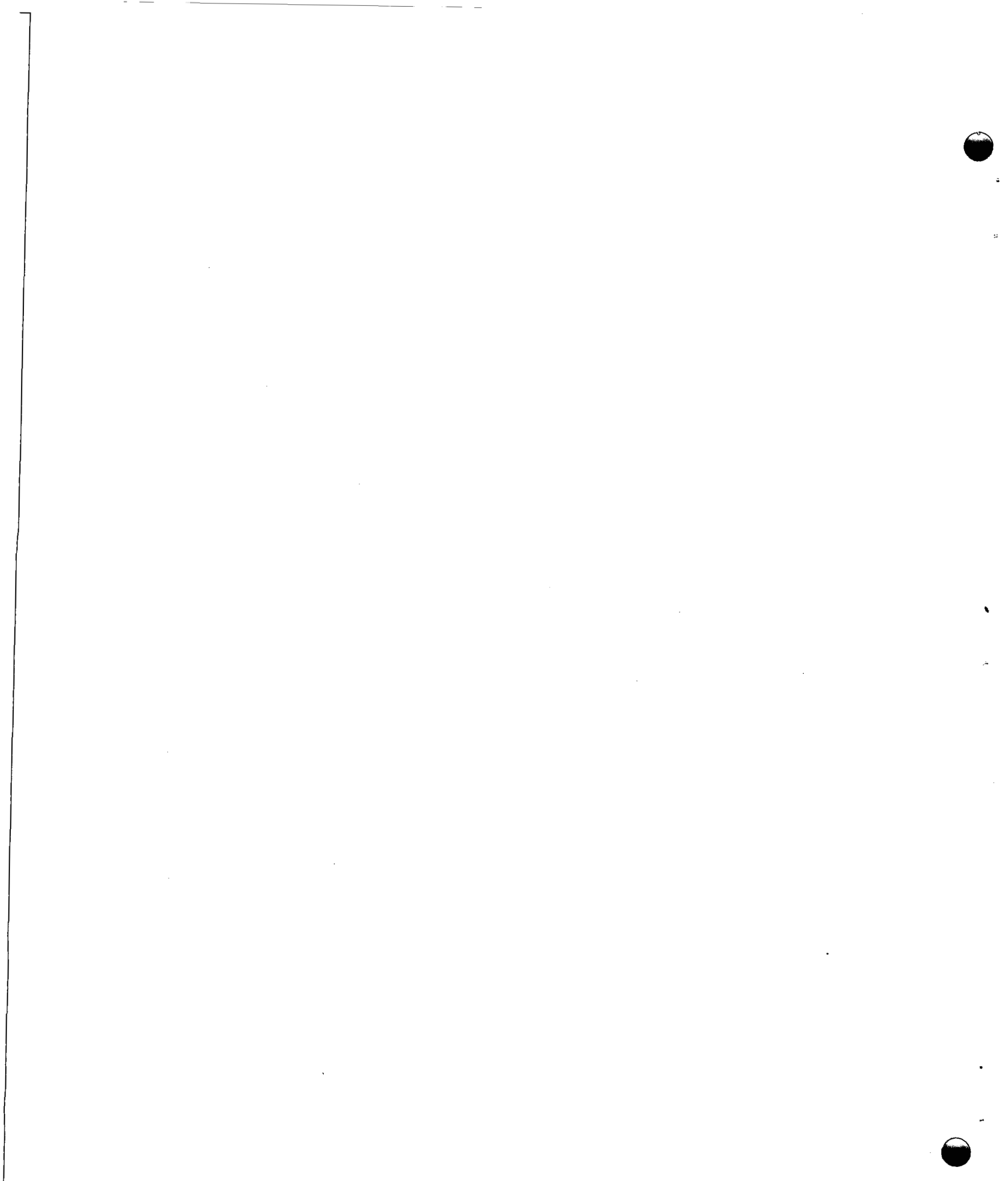




\section{CERAMICS RESEARCH}
J. M. Warde
C. E. Curtis
R. L. Homner
J. R. Johnson
L. M. Doney
M. P. Haydon
E. L. Alexander
J. A. Griffen
F. L. Carlson, Jr.
S. D. Fulkerson
A. J. Taylor
G. D. White

\section{$\mathrm{UO}_{2}$ DEVELOPMENT}

\section{J. R. Johnson A. J. Taylor \\ Oxidation of $\mathrm{UO}_{2}$}

$X$-ray diffraction patterns, differential thermal analyses, and petrographic and oxidation-weightchange studies of $\mathrm{UO}_{2}$ have been made in order to understand the nature of various uranium oxides used for fuel-element fabrication.

Figures 97, 98, and 99 show differential thermal analyses (DTA) and thermal gravimetric data for three kinds of $\mathrm{UO}_{2}$, from very fine grain to very coarse grain. The DTA peaks indicate exothermic reaction; in air the $\mathrm{UO}_{2}$ goes first to $\mathrm{U}_{3} \mathrm{O}_{7}$ and then to $\mathrm{U}_{3} \mathrm{O}_{8}$. $X$-ray diffraction patterns made for each oxidation level showed: first, cubic $\mathrm{UO}_{2}$; second, tetragonal $\mathrm{U}_{3} \mathrm{O}_{7}(a=5.37, c=5.55)$; and third, orthorhombic $\mathrm{U}_{3} \mathrm{O}_{8}$. In more than 50 such measurements, there have always been slight weight losses $(300-3000 \mathrm{ppm})$ at about $100^{\circ} \mathrm{C}$ which are assumed to be due to a loss of water.

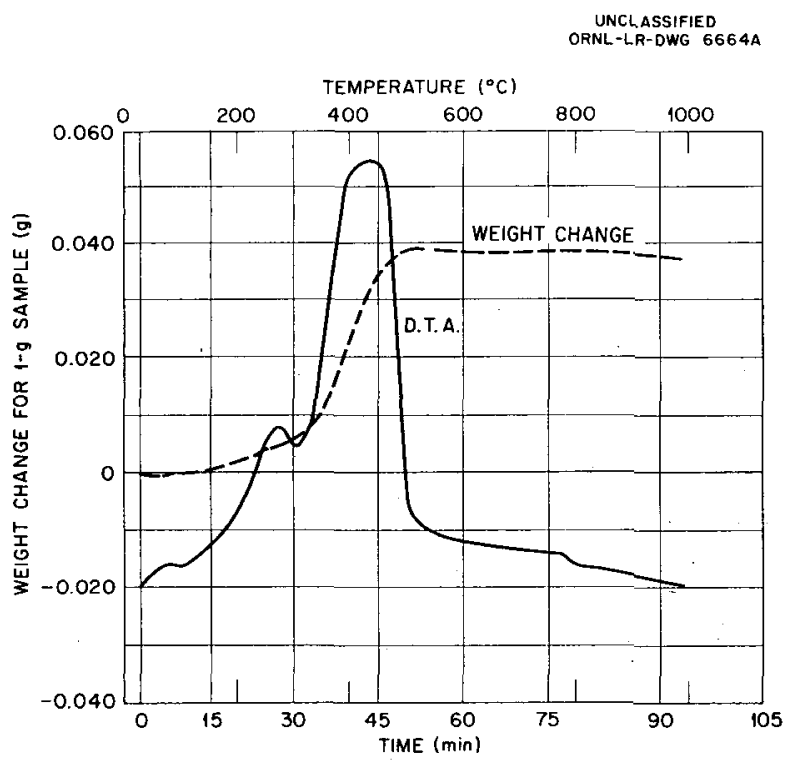

Fig. 97. Differential Thermal Analysis and Weight Change of Norton's Fused $\mathrm{UO}_{2}$.
Also, the maximum weight is always found to be at about 500 to $600^{\circ} \mathrm{C}$, which indicates a rather narrow stability range for $\mathrm{U}_{3} \mathrm{O}_{8}$ at ntp in air. Oxygen is gradually lost by the $\mathrm{U}_{3} \mathrm{O}_{8}$ until a temperature of about $1100^{\circ} \mathrm{C}$ is reached, whereupon reversion to $\mathrm{UO}_{2}$ becomes fairly rapid. The finer the grain size, the lower the temperature is at which the reactions $\mathrm{UO}_{2} \longrightarrow \mathrm{U}_{3} \mathrm{O}_{7} \longrightarrow \mathrm{U}_{3} \mathrm{O}_{8}$ occur, particularly the first reaction. In some very fine-grain $\mathrm{UO}_{2}$ batches precipitated from ammonium diuranate, due to the heat released in the reaction, the $\mathrm{UO}_{2}$ begins at room temperature to change spontane ously into $\mathrm{U}_{3} \mathrm{O}_{8}$.

Table 46 shows some uranium-oxygen compositions, calculated from DTA-weight-change data, for various kinds of $\mathrm{UO}_{2}$. It is of special interest to note that the lower the oxygen content is of the initial $\mathrm{UO}_{2}$, the lower is the oxygen content of the intermediate $\mathrm{U}_{3} \mathrm{O}_{7}$.

Petrographic analysis of the $\mathrm{UO}_{2}$ shows that

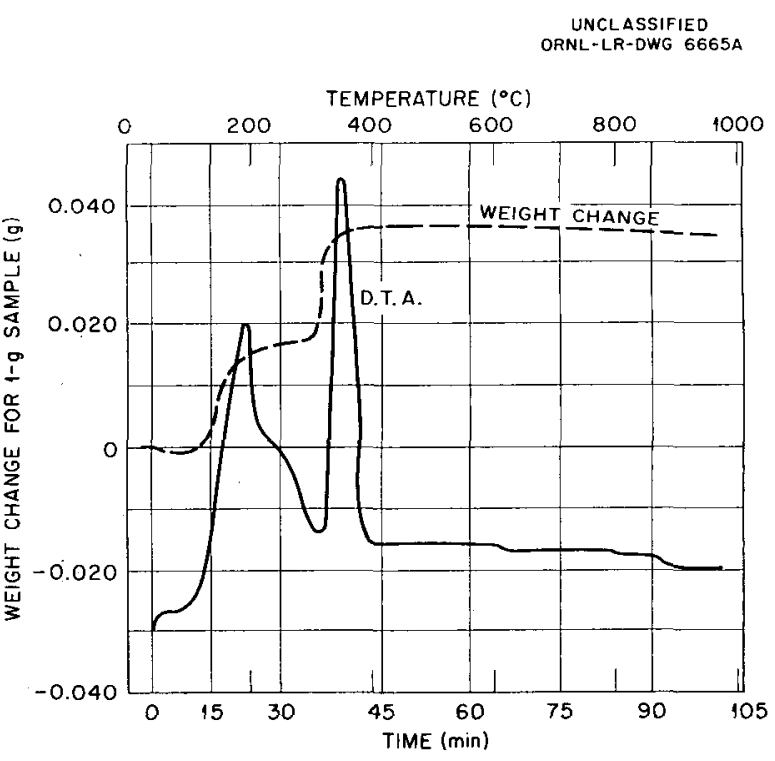

Fig. 98. Differential Thermal Analysis and Weight Change of Steam-oxidized Uranium Chips (Mallinckrodt). 
TABLE 46. OXYGEN CONTENTS OF $\mathrm{UO}_{2}$ AND $\mathrm{U}_{3} \mathrm{O}_{7}$

\begin{tabular}{|c|c|c|c|c|c|c|c|}
\hline & \multicolumn{7}{|c|}{ Types and Sources of Oxide } \\
\hline & Norton's & $\begin{array}{l}\text { Ammonium } \\
\text { Diuranate }\end{array}$ & Mallinckrodt & $\begin{array}{l}\text { Steam } \\
\text { Oxidized and } \\
\text { Hydrogenated }\end{array}$ & $\begin{array}{l}\text { Oxidized } \\
\text { Uranium } \\
\text { Chips }\end{array}$ & $\begin{array}{l}\text { Urani um } \\
\text { Peroxide }\end{array}$ & $\begin{array}{c}\mathrm{UO}_{3} \\
\text { Hydrate } \\
\text { Crystal }\end{array}$ \\
\hline \multicolumn{8}{|l|}{ Initial oxide, $\mathrm{UO}_{2}+x$} \\
\hline Chemical analysis & & $\mathrm{UO}_{2.091}$ & & $\mathrm{UO}_{2.021}$ & $\mathrm{UO}_{2.044}$ & $\mathrm{UO}_{2.083}$ & $\mathrm{UO}_{2.005}$ \\
\hline Calculated ${ }^{\star}$ & $\mathrm{UO}_{2.005}$ & $\mathrm{UO}_{2.129}$ & $\mathrm{UO}_{2.153}$ & $\mathrm{UO}_{2.02}$ & $\mathrm{UO}_{2.023}$ & $\mathrm{UO}_{2.056}$ & $\mathrm{UO}_{2.013}$ \\
\hline $\begin{array}{l}\text { Intermediate oxide, } \\
\mathrm{U}_{3} \mathrm{O}_{7}+x\end{array}$ & & $\mathrm{UO}_{2.383}$ & $\mathrm{UO}_{2.375}$ & $\mathrm{UO}_{2.336}$ & $\mathrm{UO}_{2.351}$ & $\mathrm{UO}_{2.369}$ & $\mathrm{UO}_{2.339}$ \\
\hline Water, wt \% & 0.003 & 0.0015 & 0.0020 & 0.0003 & 0.0003 & 0.0004 & 0.0003 \\
\hline
\end{tabular}

*From DTA-weight-change data.

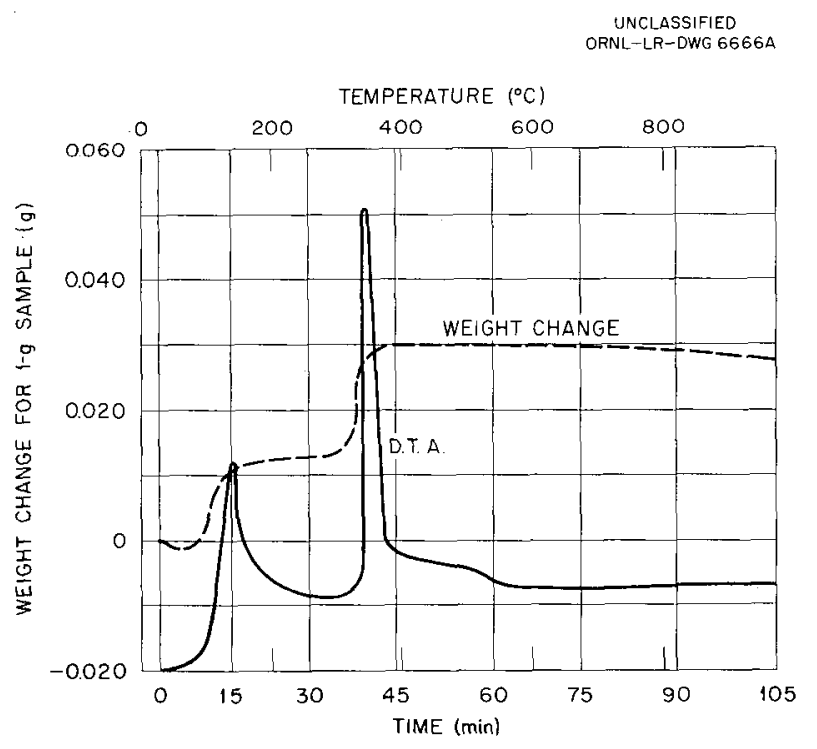

Fig. 99. Differential Thermal Analysis and Weight Change of $\mathrm{UO}_{2}$ Prepared from Ammonium Diuranate.

it is cubic, with an index of refraction of 2.35 . It is apparent that only by very precise measurements could the various $\mathrm{UO}_{2}$ materials in Table 46 be distinguished by differences in index of refraction.

The index is so high that sulfur-selenium mixes were used for the measurements, which made precision measurement difficult. On the other hand, petrographic examination has been very useful in showing grain forms, sizes, single crystals, grain inclusions, and other features of the $\mathrm{UO}_{2}$ that would not otherwise be observable.

\section{Production of Large Particles of $\mathrm{UO}_{2}$ from $\mathrm{UO}_{3}$ Hydrates}

As discussed in the last progress report, ${ }^{1} \mathrm{UO}_{2}$ is needed in a specific range of particle sizes for fuel elements in which the fuel is enclosed in a metal or ceramic sandwich. The oxide particle must be strong enough to withstand physical abuse, such as occurs during rolling in metalelement fabrication, and must have a minimum of surface area so as to have the least possible reactivity within its metal environment. It has been shown that particles ranging in size from 40 to $100 \mu$ are most desirable in such fuel elements in that fission-product damage to the surrounding metal is minimized.

In the process that has been developed, large crystals of $\mathrm{UO}_{3}$ hydrates are hydrothermally grown in an autoclave. The bulk of the crystals is heated and reduced with hydrogen to $\mathrm{UO}_{2}$; the final temperature is $1800^{\circ} \mathrm{C}$. The large crystals may be subsequently crushed and screened to obtain smaller sizes.

The starting material may be fines or large crystals of $\mathrm{UO}_{3}$ hydrate or fines of $\mathrm{UO}_{4}$ hydrate. To this material is added 10 to $20 \mathrm{wt} \%$ uranium as a uranyl salt, preferably uranyl nitrate crystals, although solutions may be used. Sufficient water is added to ensure that the material is bathed in the solution during autoclaving. The size of the crystals may be controlled by the rate

\footnotetext{
1J. M. Warde et al., Met. Semiann. Prog. Rep. April 10, 1955, ORNL-1911, p 108.
} 
at which the chemicals go into solution and by the concentration of the solution.

The mixture is heated in a stainless steel autoclave for several hours at $250^{\circ} \mathrm{C}$. Temperature control is important, inasmuch as different crystal forms may occur at higher temperatures and incomplete processing occurs at lower temperatures. Incomplete processing also results if the reaction time is less than $5 \mathrm{hr}$. Greater than $20 \mathrm{hr}$ of reaction time seems to have little effect in the growth of crystals in the size ranges investigated, 5 to $500 \mu$.

The supernatant liquid is decanted and the grown crystals of $\mathrm{UO}_{3}$ hydrate when cool are washed to remove uranyl salt from the crystal surfaces. An agglomeration of crystals occurs if this is not done thoroughly.

The $\mathrm{UO}_{3}$ hydrate is then heated and reduced with hydrogen to $\mathrm{UO}_{2}$. The reduction is accomplished at $1000^{\circ} \mathrm{C}$, but the product is not strong. A dense, hard $\mathrm{UO}_{2}$ results by further heating to $1800^{\circ} \mathrm{C}$.

Microscopic examination reveals the final product to be dense $\mathrm{UO}_{2}$ shapes which have the same external form as the parent $\mathrm{UO}_{3}$ hydrate but are about two-thirds as large. Needles, plates, rhombohedra, and bipyramids are observed, the latter two being generally desired. Although the $\mathrm{UO}_{2}$ particles are not single crystals, they appear to be made up of single-crystal domains about 5 to $20 \mu$ in size. Needles of $\mathrm{UO}_{2}, 5$ by $30 \mu$ in size, have been observed and appear to be single crystals.

Agglomerates, which may occur as described above, will break up into fines in the rolling process during fuel-element fabrication. Plates also may occur either from rough handling of the $\mathrm{UO}_{3}$ hydrates or from decrepitation caused by sudden heating of the $\mathrm{UO}_{3}$. Both forms defeat the intended purpose of the product.

Severe crushing or grinding of the $\mathrm{UO}_{2}$ to make smaller particles may produce sufficient fines to coat (by electrostatic attraction) the large $\mathrm{UO}_{2}$ grains, which apparently makes the ir surfaces more reactive. Crushing and screening should be carried out in small amounts and should be discontinued when coating becomes so bad that the remaining material becomes undesirable.

\footnotetext{
${ }^{2}$ ORSORT student, summer project.
}

\section{STUDY OF GAS.CERAMIC MIXTURES IN NUCLEAR POWER GENERATION}

\author{
D. C. Schluderberg ${ }^{2}$
}

Gases and vapors are of potential interest as heat-transfer fluids for high-temperature applications. However, compared with liquids, they possess lower heat capacity per unit volume and lower heat-transfer efficiency, both of which increase the difficulty of extracting heat from power reactors.

It is suggested that the heat capacity per unit volume and the heat-transfer rates associated with gaseous heat-transfer media in reactors may be improved by the addition of a finely divided refractory powder, such as graphite, suspended in the gas by flow turbulence.

Gas-ceramic mixtures are expected to be superior to gas alone because of (1) better cooling properties, (2) better thermodynamic properties, (3) better nuclear properties, and (4) better system decontamination. The purpose of this project, sponsored by ORSORT, was to carry out a preliminary investigation of these properties, with emphasis on the first, second, and fourth.

These properties appear to be best utilized in a nuclear-power plant of the type shown in Fig. 100, where the gas-ceramic mixture is not only used to extract heat from the reactor but also is the thermodynamic medium which does work in the turbine, and which is cooled in the regenerator and cooler, compressed in the compressor, and heated in the regenerator.

\section{Coolant Characteristics}

Since there was no information available on the cooling properties of such mixtures or on their behavior when flowing through pipes, heat exchangers, compressors, nozzles, etc.; it was necessary to construct the test loop shown in Fig. 101.

The loop has two six-stage blowers connected in tandem. The combined pressure rise in both blowers is used to force the mixture through a flow nozzle and then through a heat exchanger which removes heat put into the loop by the blowers. The heat exchanger was placed at a 45-deg angle to give good self-cleaning characteristics. The flow nozzle was made of $2 \mathrm{~S}$ aluminum so that any erosion by the suspended ceramic would be easily noticed. A container with a 


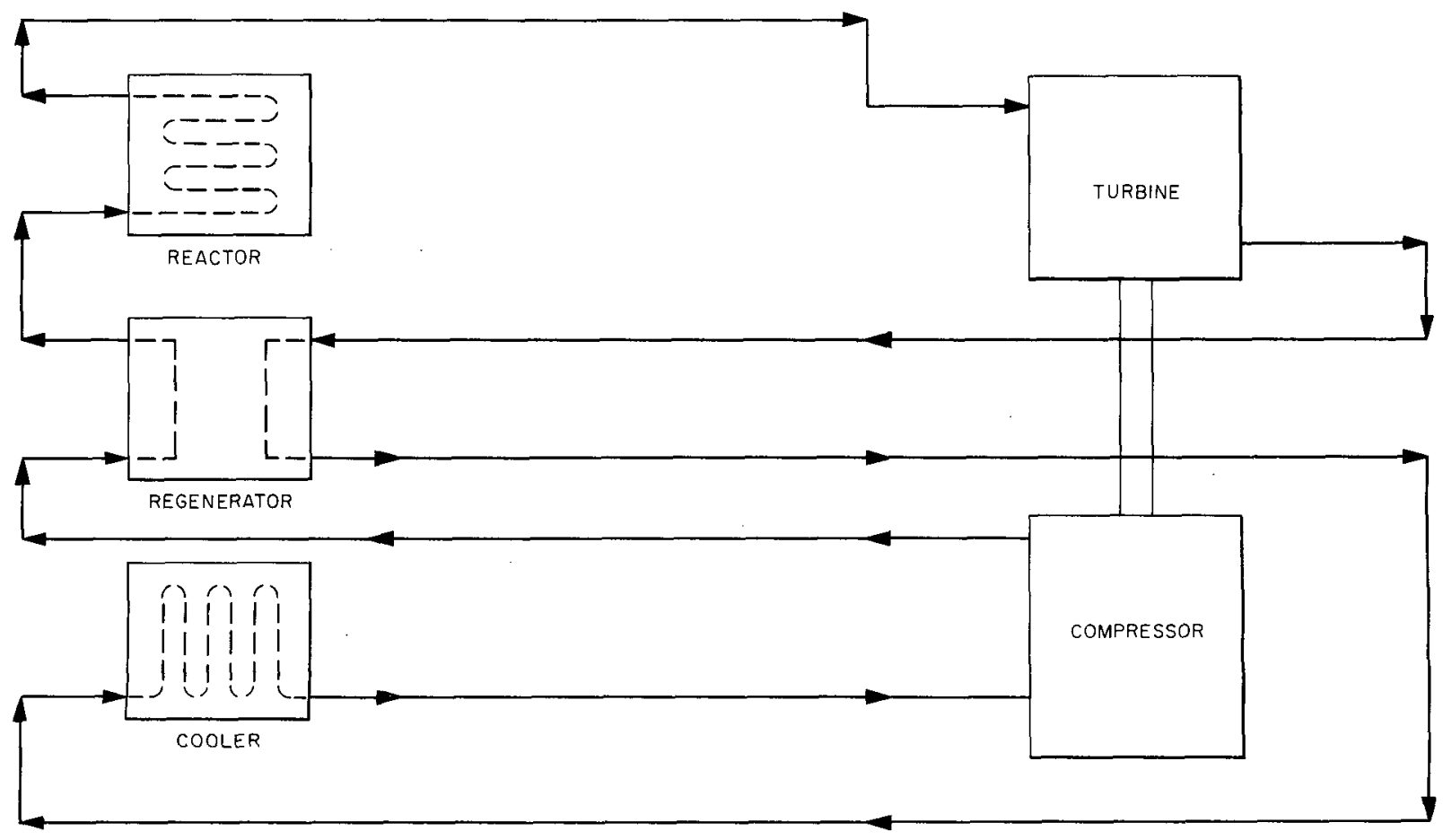

Fig. 100. Schematic Diagram of a Nuclear Power Plant Utilizing a Gas-Ceramic Mixture as HeatTransfer Medium.

filter bag inside was installed in a bypass so that the system could be cleared of ceramic powder when desired. Practically all the equipment was obtained from salvage. The test was limited to pressures below 25 psia and to temperatures not exceeding $250^{\circ} \mathrm{F}$. Within these limits, the test unit proved useful for obtaining data on heat transfer, pressure drop, and flow-nozzle erosion and for showing the feasibility of the general idea.

The curve in Fig. 102 shows how the addition of graphite increased heat-transfer rates in the heat exchanger. The ordinate is a ratio wherein the heat-transfer rate between the mixture and the heat-exchanger tube surface is related to the calculated heat-transfer rate between the pure gas $\left(\mathrm{N}_{2}\right.$ alone at the same velocity) and the tube surface.

Figure 103 shows how the heat-transfer rate and the velocity of the gaseous suspension in the heat-exchanger tubes vary with graphite loading for a constant pressure drop in the heat exchanger. A gradual increase in heat exchange occurs as graphite is added.

Figure 104 shows the relation of heat-transfer rate to heat capacity of the gaseous mixture which is defined as

$$
W_{g} C_{g}+W_{s} C_{s}
$$

where

$W_{g}=$ Flow rate of $N_{2}(\mathrm{lb} / \mathrm{hr})$,

$C_{g}=$ Specific heat of $N_{2}$ at constant pressure (Btu/lb. $\left.{ }^{\circ} \mathrm{F}\right)$,

$W_{s}=$ Flow rate of suspended solid (lb/hr),

$C_{s}=$ Specific heat of suspended solid (Btu/lb. ${ }^{\circ} \mathrm{F}$ ).

Additional heat-transfer data will be obtained for $\mathrm{N}_{2}$ and graphite loadings of up to about $3.0 \mathrm{lb}$ of graphite per pound of $\mathrm{N}_{2}$, for mixtures of $\mathrm{CO}_{2}$ and graphite, and for activated carbon in $\mathrm{N}_{2}$ and in $\mathrm{CO}_{2}$.

There was not enough power available to load the apparatus with more than $3.0 \mathrm{lb}$ of graphite 


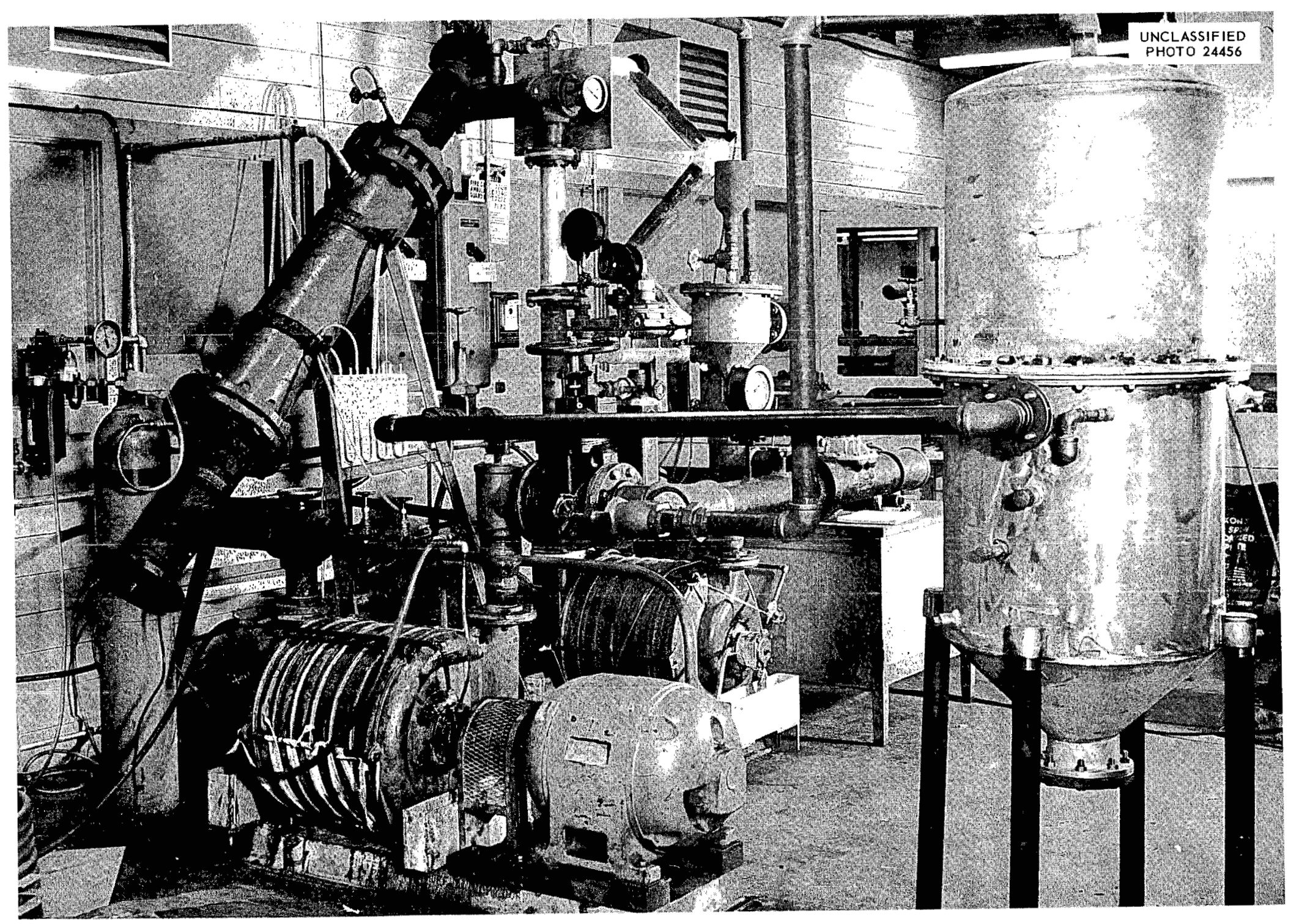




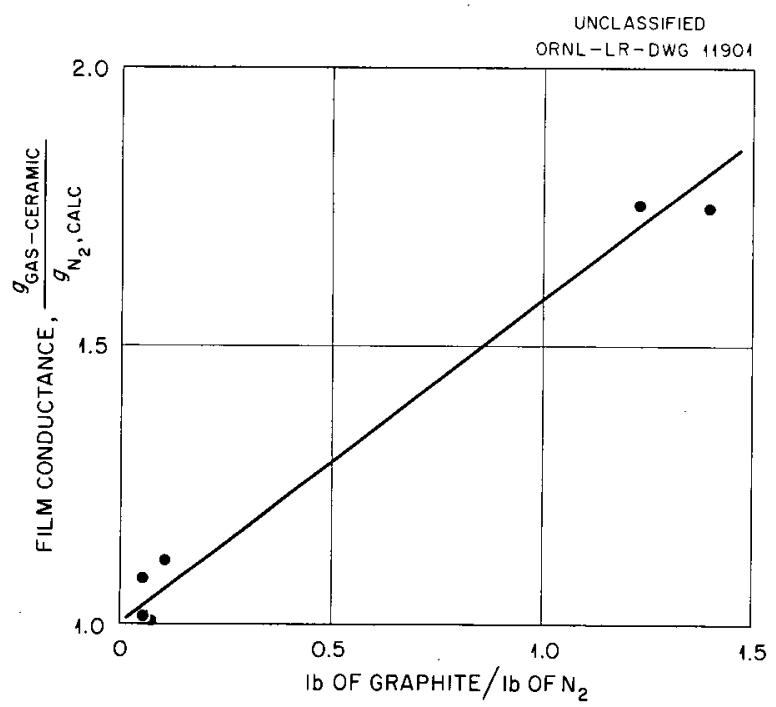

Fig. 102. Effect of Graphite Loading on Film Conductance.

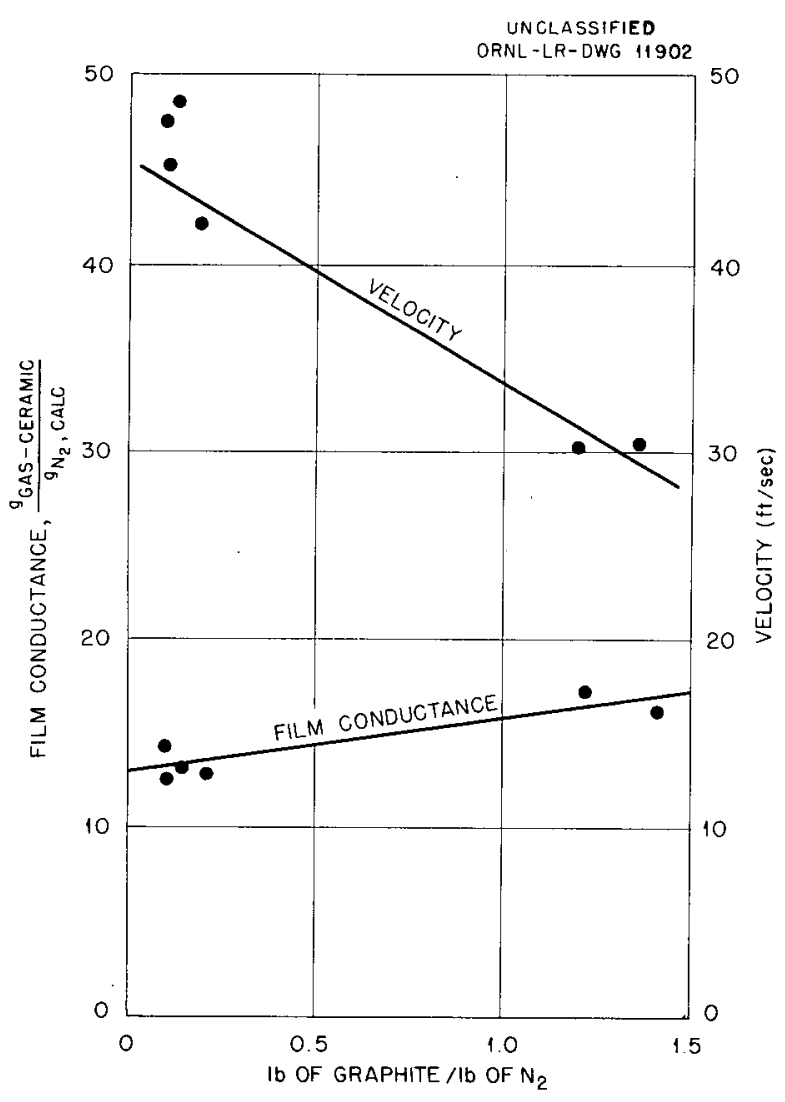

Fig. 103. Yariation of Film Conductance and Velocity with Graphite Loading - Pressure Drop in Heat Exchanger Held Constant.

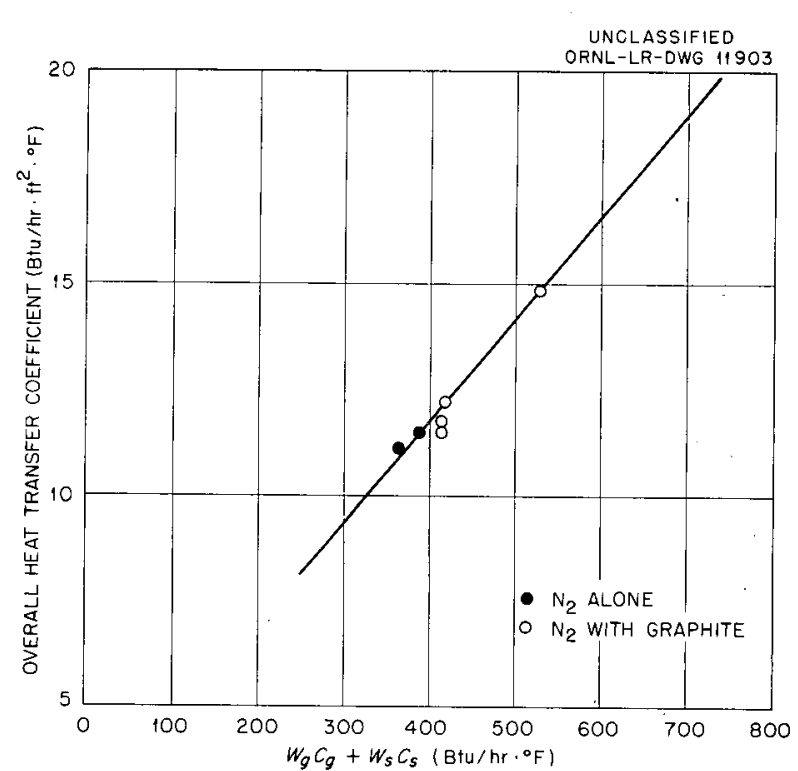

Fig. 104. Variation of Heat Transfer with Heat Capacity of Gaseous Fluid.

per pound of $\mathrm{N}_{2}$. Actually, much higher loadings seem possible since work by Gasterstadt shows that $14 \mathrm{lb}$ of wheat can be conveyed in horizontal pipes by $1 \mathrm{lb}$ of air at a velocity of $53 \mathrm{fps}$.

\section{Thermodynamic Properties}

The thermodynamic properties of a gas-suspension mixture are markedly different from those of a gas because a strong thermal bond exists between the fine particles and the suspending gas as a result of the large surface area of the particles and the high rate of heat transfer between gas and particles. For instance, $2-\mu$ graphite particles suspended in $\mathrm{CO}_{2}$ have about $15,000 \mathrm{ft}^{2}$ of surface per pound and transfer heat to the gas at a rate of about $12,000 \mathrm{Btu} / \mathrm{hr} \cdot{ }^{\circ} \mathrm{F} \cdot \mathrm{ft}^{2}$. Thus, if the difference in temperature between $1 \mathrm{lb}$ of graphite and $\mathrm{CO}_{2}$ is $1^{\circ} \mathrm{F}$, heat will flow between the two at a rate of $156 \times 10^{6} \mathrm{Btu} / \mathrm{hr}$. Hence, when a gas-suspension mixture is rapidly cooled as it flows through a nozzle, the gas and suspended particles will remain at nearly the same temperature. For example, in a mixture of air and graphite that is flowing at $1000 \mathrm{fps}$ and is being cooled at $100^{\circ} \mathrm{F}$ in $1 \frac{1}{2}$ in. of travel, the graphite will be only $7.0^{\circ} \mathrm{F}$ hotter than the air.

Figure 105 shows the effect of this property on an ideal power cycle. On this temperatureentropy diagram is represented the thermodynamic 


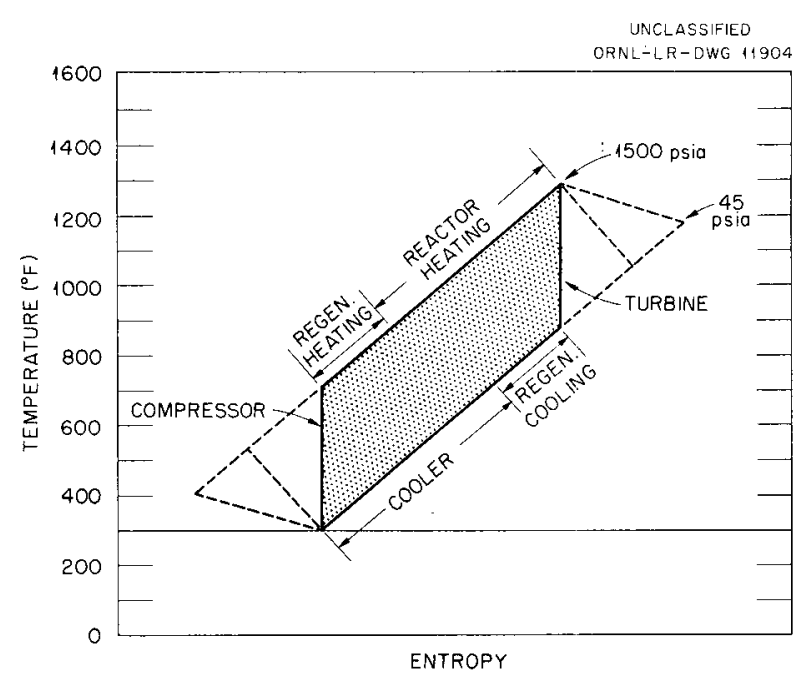

Fig. 105. Temperature-Entropy Diagram of Ideal Power Cycle With and Without Ceramic Powder Added to Gas.

states in all parts of a closed-cycle gas-turbine system. In the turbine, heat in the form of work is extracted from the gas by adiabatic expansion from a high pressure to a low pressure. Conversely, the compressor does work on the gas in compressing it adiabatically from a low pressure to a high pressure. If the plant has a regenerative heat exchanger, the turbine exhaust can theoretically be cooled to the compressor exhaust temperature by exchanging its heat to the compressor exit gas, which is thereby heated to the turbine exhaust temperature. Heating the regenerator exit gas to the turbine inlet temperature is accomplished in the reactor, and cooling the regenerator outlet gas to compressor inlet temperature is accomplished by the use of cooling water or air in another heat exchanger. The shaded area in Fig. 105 represents the net work output of the cycle as obtained with a gas containing no ceramic powder. Then, as ceramic powder is added to the gas, the paths through the turbine and compressor change as shown by the dotted lines. The area of the cycle increases, which indicates more work output than with the gas alone. Also, as turbine exhaust temperatures rise and compressor-outlet temperatures fall, it is possible to regenerate over a greater temperature difference. The result is an increase in thermal efficiency of the cycle.

To illustrate the magnitude of these effects, an experiment was carried out in which $\mathrm{CO}_{2}$ and graphite were used between the temperatures and pressures shown on Fig. 105, except that with graphite loadings of less than $5 \mathrm{lb}$ per pound of gas the lower pressure was 150 psia instead of 45 psia. Figure 106 shows how thermal efficiency is raised by the addition of graphite until it closely approaches the Carnot efficiency, the theoretical maximum efficiency, calculated for upper and lower cycle temperatures of 1300 and $300^{\circ} \mathrm{F}$, respectively.

Figure 107 shows the increase in work output as the graphite loading is increased. This would bring about a considerable reduction in the size of the power plant.

Figure 108 shows the effect of gas-suspension density on turbine operating speeds. With higher densities, the gas-suspension and blade velocities do not have to be so high for the same amount of power to be gotten out of a turbine stage;

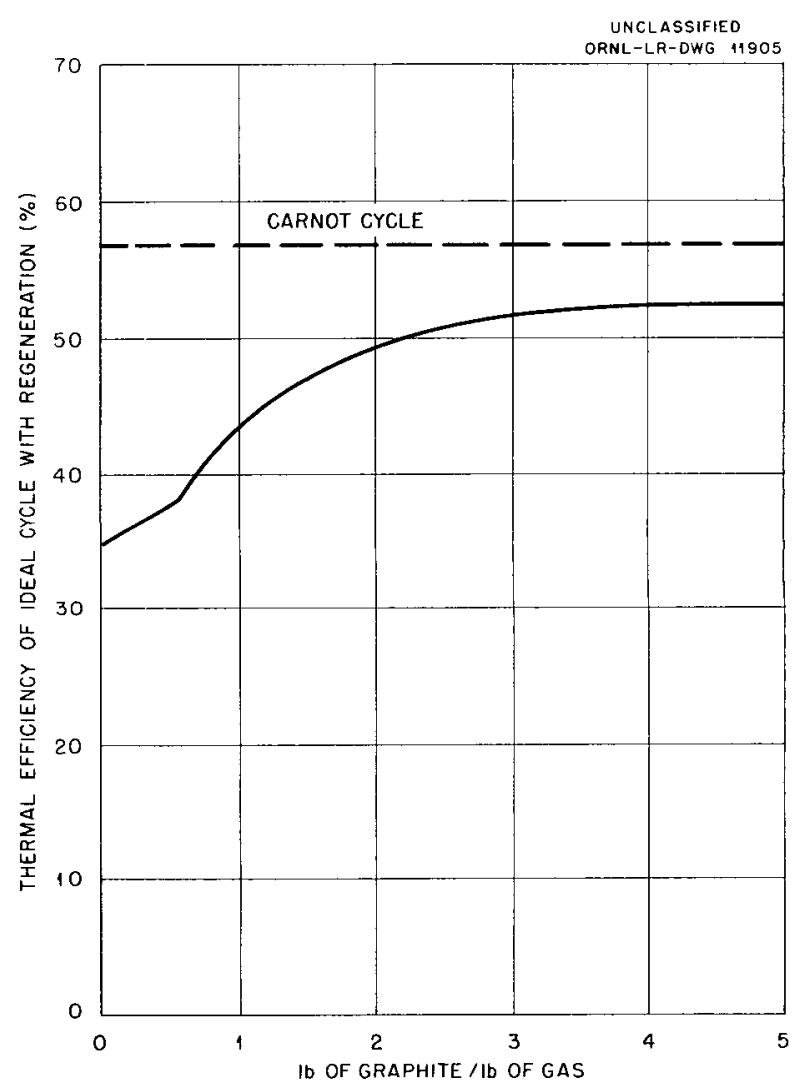

Fig. 106. Effect of Graphite on Thermal Efficiency. 


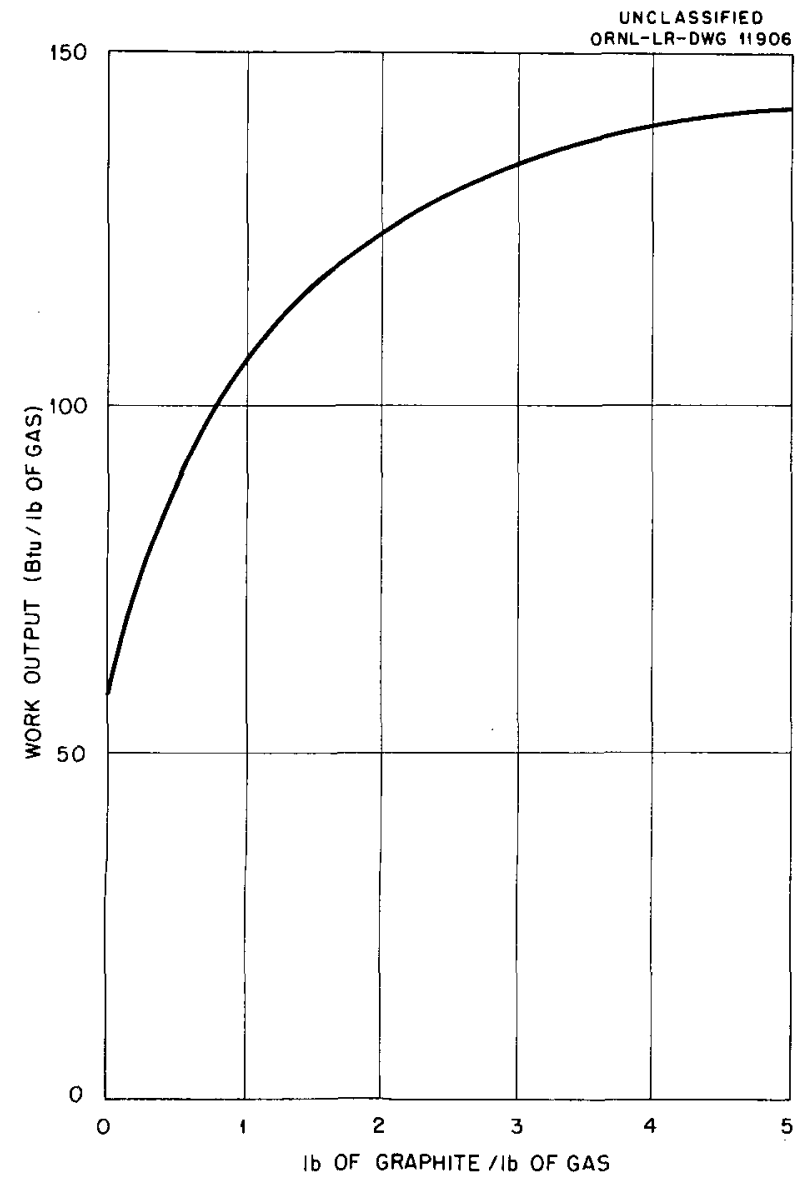

Fig. 107. Effect of Graphite on Work Output.

moreover, this reduction in $\mathrm{rpm}$ is desirable as it reduces blade stresses, bearing maintenance, and turbine-construction cost.

\section{Nuclear Properties}

If the gas-ceramic mixture is made up of good moderators, such as $\mathrm{CO}_{2}$ and graphite, it may have, at the densities attainable, sufficient moderating power to reduce the leakage of neutrons out of coolant openings in the reactor core and thereby make a small contribution toward a negative temperature coefficient. The magnitude of these effects has not been studied at this time. Any reactivity due to the moderating properties of the mixture can be increased or decreased by raising or lowering the mixture pressure in the reactor, which effectively changes the mixture density. This characteristic might

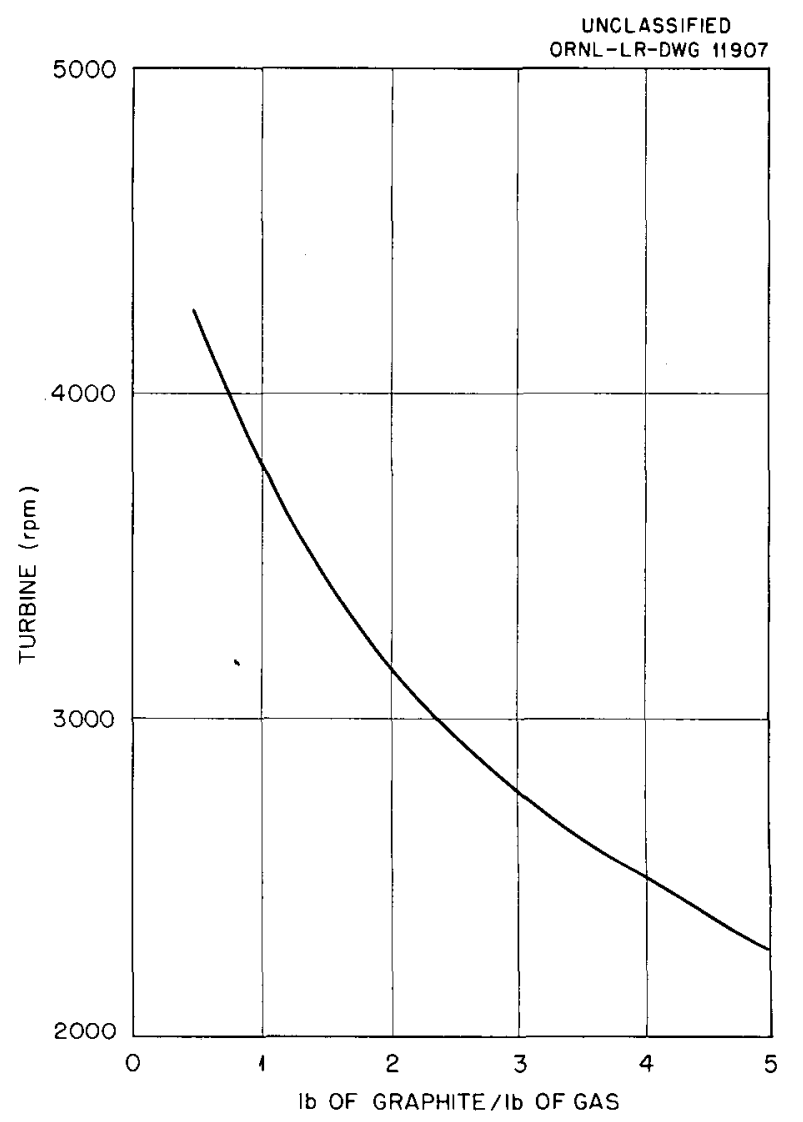

Fig. 108. Effect of Graphite on Required Turbine Speed.

be useful for control purposes and would tend to make the power plant self-regulating.

\section{System Decontamination Properties}

The high surface area of the suspended particles of a gas-ceramic mixture, as compared with the internal surfaces of the piping, the heat exchangers, the turbine, the reactor coolant passages, etc., of the plant, may provide an effective diffusion and adsorption trap for the gaseous fission products that have diffused through the solid fuel-element cladding. The rate at which the system components become radioactive might be substantially reduced by continuously changing the solid constituent of the circulated mixture. Graphite or activated carbon may be useful for this purpose. This expediency would serve to reduce plant-maintenance costs and would also 
provide an answer to the problem of contamination, which becomes very serious as fuelelement temperatures rise; in order to test its effectiveness, an experiment was performed to determine whether iodine and tellurium are preferentially picked up at $1300^{\circ} \mathrm{F}$ by activated charcoal in a stainless steel capsule. Results indicate that the stainless steel capsule containing carbon had about 700 times less activity on its surface than was on the surface of a similar empty capsule. Reheating the specimens to $300^{\circ} \mathrm{F}$ had little effect on reducing the activity, but acid washing $(\mathrm{HCl})$ reduced the activity by a factor of 10 .

\section{Erosion and Plugging}

Questions concerning the erosion and plugging of heat exchangers have often been raised in connection with the use of these mixtures. Limited experience, thus far, indicates that neither one would create any problem. The $2 S$ aluminum flow nozzle used in the test apparatus has shown no signs of wear after $15 \mathrm{hr}$ of operation with graphite and $\mathrm{N}_{2}$ passing through it at speeds of from 800 to $1150 \mathrm{fps}$.

Figure 109 shows a photograph of the lower tube sheet in the heat exchanger after $12 \mathrm{hr}$ of operation. Out of 150 tubes in the heat exchanger, all but two appear to be clean. Another indication of tube cleanliness was that the heatexchanger pressure drop remained constant even after graphite was added and was pumped through it.

It was noticed that the graphite tended to settle out in pockets where the system was not completely dry.

\section{FISSION-PRODUCT RETENTION}

\section{J. R. Johnson}

The diffusion of fission products through solids is of great importance in designing and constructing nuclear power reactors: A study of the diffusion of fission products through simulated fuel elements has been in progress at ORNL 3,4 since 1953. This study was continued at North

\footnotetext{
3J. M. Worde et al., Met. Semiann. Prog. Rep. Oct. 10, 1955, ORNL-1875, p. 41.

${ }^{4}$ W. E. Moody, A. J. Taylor, and J. R. Johnson, Preliminary Investigation of the Fission Product Retention Ability of Cermet Compacts, ORNL-1778 (June 23, 1955).
}

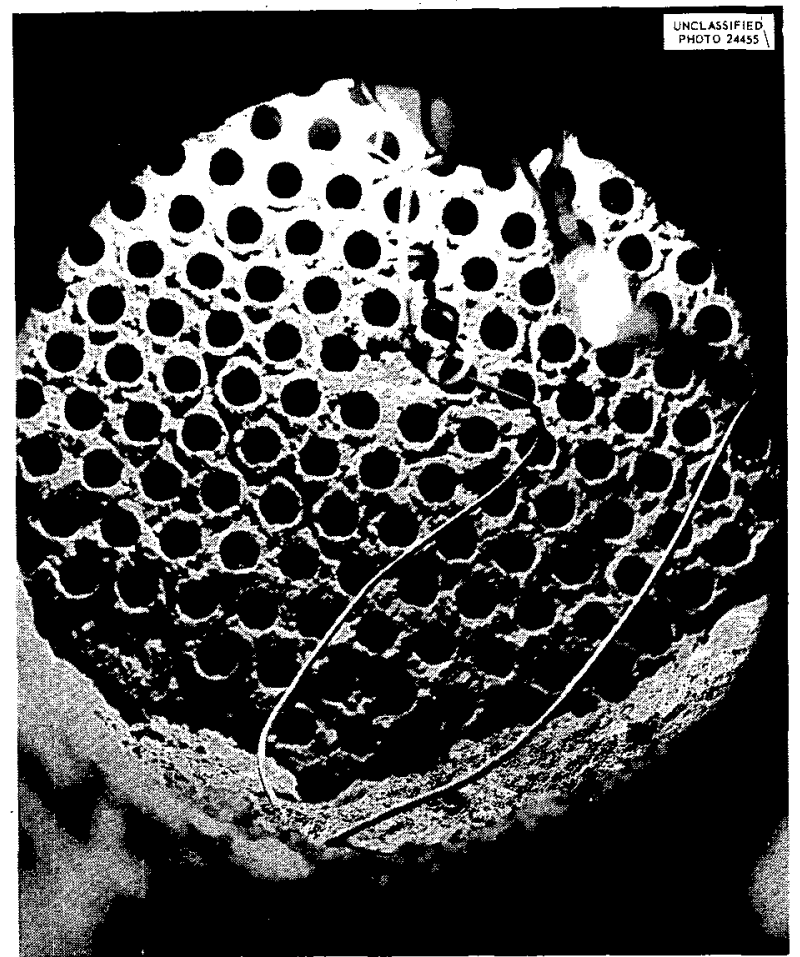

Fig. 109. Lower Tube Sheet from Heat Exchanger After Operation.

Carolina State College during the academic year 1954-55.

\section{Experimental Procedure}

The experimental procedure is described in detail in a previous report. ${ }^{4}$ In brief, the specimens were irradiated in the ORNL Graphite Reactor for seven days at a flux of $5 \times 10^{11}$ neutrons $\cdot \mathrm{cm}^{-2} \cdot \mathrm{sec}^{-1}$ and were shipped by air express to North Carolina State College. The specimens were enclosed in aluminum-silicate wool and sealed in a quartz process tube with a condenser projection. After the specimens were heated for $24 \mathrm{hr}$ at specific temperatures, the condenser projections were cooled for $4 \mathrm{hr}$ in liquid air, sealed off, and analyzed with a gamma spectrometer. The aluminum-silicate wool used to enclose the specimens was also examined for diffused fission products. Specimens were washed before and after heating, and the washings were examined for radioactive fission products. The fission-product retention factor was determined by comparing gamma-spectrometer peaks 
from the fission-product activities with the peaks from a standard $\mathrm{UO}_{2}$ powder, specimen G-33-3.

A quantity of $\mathrm{UO}_{2}$ powder in a quartz container provided with a friable stem was irradiated in the ORNL Graphite Reactor for seven days (specimen G-224-12). This container was sealed into a standard process tube with an aluminumsilicate wool filter between the condensing stem of the process tube and the container. The friable stem on the inner container was then broken, and the fission products were condensed in the normal manner without any heating period.

\section{Discussion of Results}

It is estimated that the specimens reached a temperature of 100 to $200^{\circ} \mathrm{C}$ during irradiation and that some of the gaseous fission products may have been lost during this time. In the case of the unheated specimen, G-224-12, of the $X_{e}{ }^{133}$ and $1^{133}$ calculated to have been generated, $22 \%$ of the former and $0.62 \%$ of the latter were collected in the liquid-air trap. From the standard specimen processed normally, $62 \%$ of the $\mathrm{Xe}^{133}$ was collected; this, together with the $22 \%$ accounted for as loss during irradiation, is $84 \%$ of the amount of $\mathrm{Xe}^{133}$ that was calculated to have been generated. This relatively high accountability value would indicate the adequacy of the experimental procedure. Fission-product losses during irradiation of the cermet and metal specimens have been assumed to be negligible, as the diffusion rate of isotopes such as xenon and iodine at the low irradiation temperatures have been calculated to be very low.

Specimens of $\mathrm{Cr}-\mathrm{Al}_{2} \mathrm{O}_{3}$, designated as the " $A$ " series, were fabricated so as to eliminate the tungsten impurity which was present in specimens reported previously. Tests on these specimens indicated that at $1000^{\circ} \mathrm{C}$ fission-product retention was improved by a factor of about 100 over previously tested specimens.

The " $H$ " series specimens, which were aluminum-clad uranium-aluminum alloy, were too large for the available quartz tubes, and it was necessary to roll the specimens into a coil. The rolling probably caused breaks in the aluminum cladding and resulted in greater diffusion of fission products. However, the relatively low temperatures used would account for the low diffusion rates. Some $L a^{140}$ was found on the specimens after heating.
The results for the $\mathrm{MgO}-\mathrm{Ni}$ specimens (D-33-14, D.33-15, and D.33-16) are probably in error because the gamma spectrometer was not functioning properly at the time of measurement.

The amount of activity found in all washings before and after heating was relatively small and in many cases could not be analyzed. Results ore given in Table 47.

\section{GRAPHITE-HYDROGEN CORROSION-EROSION INVESTIGATION}

$$
\text { J. R. Johnson A. J. Taylor }
$$

Graphite-hydrogen systems at temperatures of the order of $2400^{\circ} \mathrm{C}$ or higher are of interest for nuclear rocket applications. An investigation was carried out to determine whether the corrosion-erosion of hydrogen having a velocity of 0.15 Mach number was significant at approximately $2400^{\circ} \mathrm{C}$ on high-density graphite (Graphi-tite supplied by Graphite Specialties Corporation; density $\sim 1.8$ ) and commercial graphite (density 1.55).

A schematic drowing of the high-temperature graphite-hydrogen experiment is shown in Fig. 110. In this investigation the graphite specimen was heated electrically to $2400^{\circ} \mathrm{C}$. Helium was introduced until equilibrium conditions were attained. Hydrogen was applied for $10 \mathrm{~min}$, after which time helium was again introduced until the specimens were cooled. Data and results are given in Table 48.

The average corrosion-erosion for the tests on Graph-i-tite showed a loss of $0.0001 \mathrm{~g} / \mathrm{in.} 2 / \mathrm{sec}$. It was noted that the same corrosion-erosion loss occurred in helium as in hydrogen, and it is probable that the losses are due to water vapor present in the gases. The bulk hydrogen temperature of the test was believed to be about $1600^{\circ} \mathrm{C}$, with the velocity about $1900 \mathrm{fps}$ or approximately 0.18 Mach number. It was observed that with hydrogen and helium the corrosion-erosion loss on commercial-grade graphite was somewhat greater than that with Graph-i-tite.

\section{FABRICATION OF CERAMIC MATERIALS}
L. M. Doney
C. E. Curtis
J. A. Griffin
J. R. Johnson

\section{Rare-Earth-Oxide Control Rods}

Two control-rod assemblies were fabricated for critical experiments from a mixture of rare-earth oxides containing 63.8 wt \% $\mathrm{Sm}_{2} \mathrm{O}_{3}$ and 26.3 wt \% 
TABLE 47. DIFFUSION PRODUCTS OBTAINED FROM IRRADIATED COMPACTS

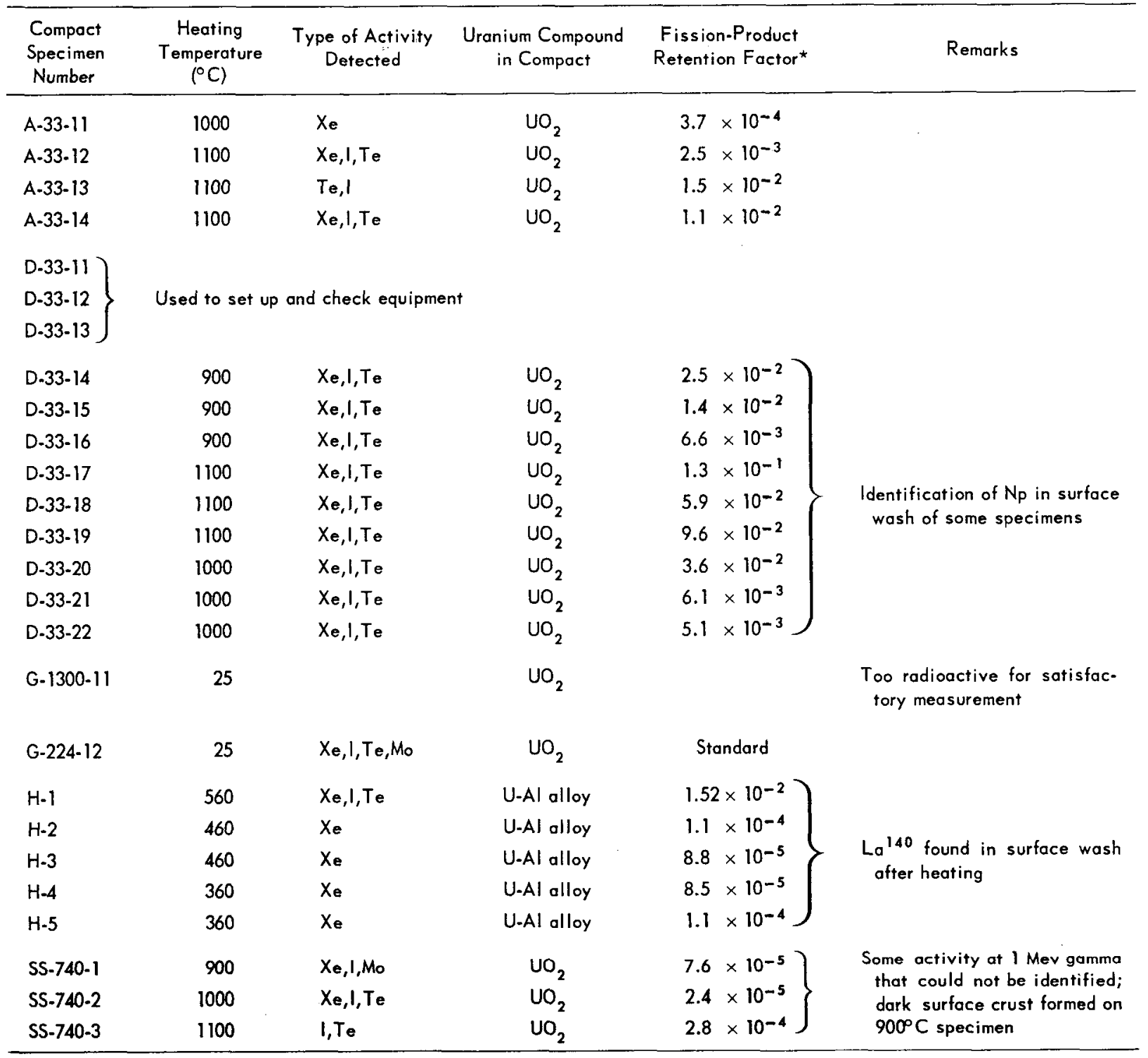

*Ratio of diffused activity to activity of G-33-3 standard specimen; calculated from activities under gammo spectrometer peaks.

$\mathrm{Gd}_{2} \mathrm{O}_{3}$. Material and fabrication techniques were similar to those previously reported. ${ }^{5}$ The firing temperature, $1550^{\circ} \mathrm{C}$, for these shapes was $50^{\circ} \mathrm{C}$ higher than was previously used. The specimens were machined to the following dimensions: $\frac{1}{8}$-in. wall, 1.275-in. $O D, 1.025$-in. ID; and $1 / 4$-in. wall, 1.275-in. OD, 0.775-in. ID. All pieces were l-in. long. Figure 111 shows samples of finished shapes.

5. M. Warde et al., Met. Semiann. Prog. Rep. April 10, 1955, ORNL-1911, p 118.

\section{Calcium Fluoride and Alumina Detector Spacers}

Detector spacers of calcium fluoride and alumina were produced for criticality experiments in the form of wafers $0.190 \mathrm{in}$. thick by $0.800 \mathrm{in}$. in diameter with an indentation 0.12 in. deep by 0.747 in. in diameter. Calcium fluoride, reagent grade, was precalcined at $1140^{\circ} \mathrm{C}$; it was ground to pass a 200 -mesh Tyler screen, and $2 \%$ Carbowax 4000 was added as a binder and lubricant. Wafers were pressed in a steel die at 50,000 psi and 
$A, B, C, D, E$ AND F REPRESENT

THERMOCOUPLE POSITIONS FOR

DIFFERENT RUNS (SEE TABLE 48)

ORNL - LR - DWG 894

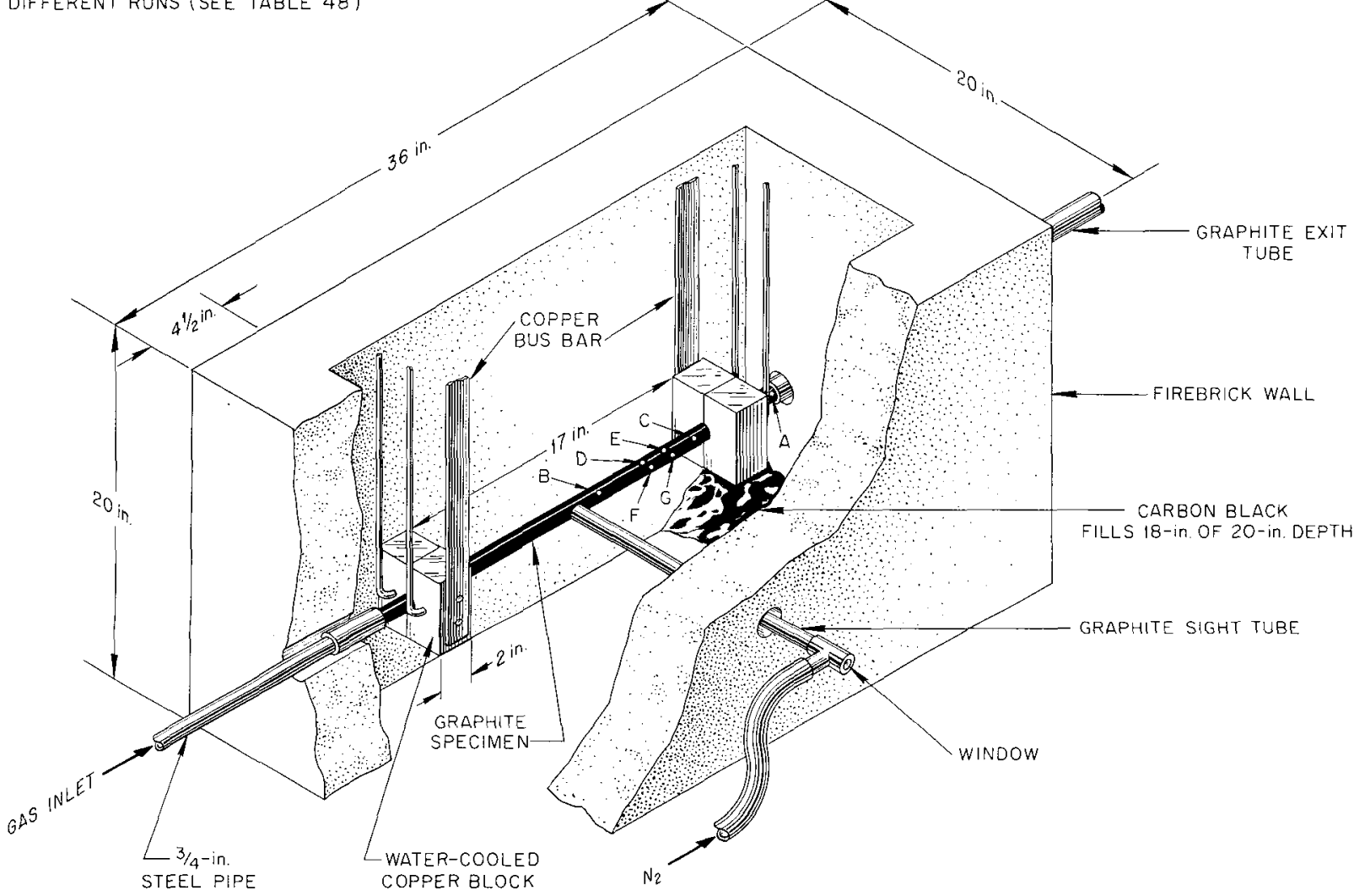

Fig. 110. Equipment for Investigating Corrosion-Erosion Characteristics of Hydrogen on Graphite.

were then heated at $700^{\circ} \mathrm{C}$ for $1 \mathrm{hr}$. The alumina wafers were pressed from fine-grained $\mathrm{Al}_{2} \mathrm{O}_{3}$ without calcination and were fired at $1350^{\circ} \mathrm{C}$ for $1 \mathrm{hr}$.

\section{Fluoride-Fuel Pellets}

An investigation is under way to determine the optimum pressing conditions for pelletizing fluoride fuels so as to produce convenient shapes for loading fuel into the reactor. It has been found that pellets of adequate strength could not be obtained from the fuel mixture $\mathrm{NaF} \cdot \mathrm{ZrF}_{4}$ UF $_{4}$ (50-46-4 mole \%) at a pressure of 4000 psi. Higher pressures are indicated as being necessary, and additional experiments are under way.

\section{Synthesis of Boron Compounds}

A program has been initiated to investigate the feasibility of synthesizing $\mathrm{Mo}_{2} \mathrm{~B}_{5}$ and $\mathrm{B}_{4} \mathrm{C}$, which are of interest for shielding purposes and for incorporating into other reactor components. No results are available at the present time for the $\mathrm{Mo}_{2} \mathrm{~B}_{5}$ and $\mathrm{B}_{4} \mathrm{C}$, but several samples have been submitted for analysis to check the efficiency of the synthesis conditions. The $B_{4} C$ was made from a stoichiometric mixture of boron and carbon heated to $1750^{\circ} \mathrm{C}$.

\section{Dysprosium Oxide Disks}

Dysprosium is of interest for use in measuring thermal flux in a reactor. Investigations by American Lava Corporation, consultants to ORNL, and under the supervision of the Ceramic Group were begun for the purpose of incorporating dysprosium oxide into thin disks for use in flux measurements. Disks 0.242 in. in diameter and 0.011 in. thick containing approximately $1 \mathrm{mg}$ of dysprosium oxide per square centimeter of area 
TABLE 48. RESULTS OF GRAPHITE-HYDROGEN CORROSION-EROSION EXPERIMENTS

\begin{tabular}{|c|c|c|c|c|c|c|c|c|c|c|}
\hline $\begin{array}{l}\operatorname{Run}^{a} \\
\text { No. }\end{array}$ & $\begin{array}{l}\text { Gos in } \\
\text { Graphite } \\
\text { Specimen }\end{array}$ & $\begin{array}{l}\text { Gas Flow } \\
\text { Rate } \\
\text { (efm, STP) }\end{array}$ & $\begin{array}{l}\text { Time Between } \\
\text { Temperature } \\
\text { Readings (min) }\end{array}$ & $\begin{array}{l}\text { Surface Temperature } \\
\text { of Graphite Specimen } \\
\text { at Beginning of Timed } \\
\text { Period } \\
{ }^{(\mathrm{C} C)^{b}}\end{array}$ & $\begin{array}{l}\text { Surface Temperature } \\
\text { of Graphite Specimen } \\
\text { at End of Timed } \\
\text { Poriod } \\
(\rho \mathrm{C})^{b}\end{array}$ & $\begin{array}{l}\text { Maximum } \\
\text { Temperature of Gas } \\
\left({ }^{\circ} \mathrm{C}\right)\end{array}$ & $\begin{array}{l}\text { Location of Thermocouple } \\
\text { from Which Maximum Gas } \\
\text { Temperature Was Obtained } \\
\text { (see Fig. 110) }\end{array}$ & 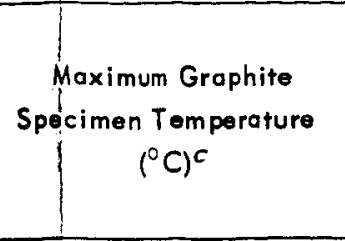 & $\begin{array}{l}\text { Power Input } \\
\text { to Specimon } \\
\text { (kw) }\end{array}$ & $\begin{array}{l}\text { Total Weight } \\
\text { Loss of } \\
\text { Specimen } \\
\text { (g) }\end{array}$ \\
\hline \multicolumn{11}{|c|}{ Specimen: Graphiolitite $\left(\varphi=1.8 \mathrm{~g} / \mathrm{cm}^{3}\right)$} \\
\hline \multirow[t]{3}{*}{3} & Nitrogen & & 41 & 20 & 2260 & & & 1 & ) & \\
\hline & Helium & 9.6 & 16 & 2255 & 2230 & & & & 10.7 & 3.3 \\
\hline & Hydrogen & 16.2 & 10 & 2230 & 1830 & & & & 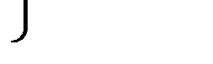 & \\
\hline \multirow[t]{2}{*}{4} & Helium & 10.8 & 33 & 20 & 2250 & & & & 10.9 & i.6 \\
\hline & Hydrogen & 12.2 & 10 & 2250 & 2220 & & & & 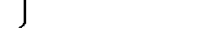 & \\
\hline 6 & Helium & 8.8 & 10 & 2205 & 2090 & & & & ... & 1.8 \\
\hline \multirow[t]{5}{*}{7} & Helium & 4.7 & 17 & 2240 & 2035 & & & & 11.2 & 1.4 \\
\hline & & & & 20 & 1500 & $\begin{array}{r}650 \\
1190\end{array}$ & $\begin{array}{l}\text { A } \\
\text { B }\end{array}$ & 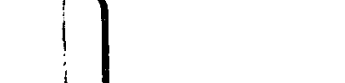 & & \\
\hline & Helium & 14.5 & 5 & 1500 & 1860 & $\begin{array}{l}590 \\
\text { Thermocouple melted }\end{array}$ & $\begin{array}{l}\text { A } \\
B\end{array}$ & 2450 & 12.1 & 1.1 \\
\hline & Helium & 9.4 & 23 & 1860 & 2250 & 840 & A & & & \\
\hline & & & & & & Thermocouple melted & B & & & \\
\hline \multirow[t]{5}{*}{8} & Helium & 4.6 & 19 & 20 & 2155 & 1540 & c & & & \\
\hline & Melium & 9.6 & 10 & 2155 & 2210 & 850 & c & & & \\
\hline & Hydrogen & 9.8 & 5 & 2210 & & 815 & c & 2400 & 8.8 & 1.7 \\
\hline & Hydrogen & 6.5 & 3 & & & 970 & c & & & \\
\hline & Hydrogen & 4.9 & 2 & & 2200 & 1120 & c & & & \\
\hline \multirow[t]{4}{*}{9} & Helium & 5.5 & 28 & 20 & 2160 & 1770 & D & ) & & \\
\hline & Helium & 10.1 & 12 & 2160 & 2220 & 1770 & $\mathrm{~F}$ & 2350 & 9.3 & 0.8 \\
\hline & Hydrogen & 13.3 & 9 & 2220 & & Thermocouple melted & & & & \\
\hline & Hydrogen & 9.8 & 1 & & 2270 & & & & & \\
\hline \multirow[t]{3}{*}{10} & Helium & 4.3 & 35 & 20 & $2020^{d}$ & & & 2450 & & \\
\hline & Helium & 9.4 & 6 & & $\vdots$ & & & 2380 & 9.3 & 4.1 \\
\hline & Hydrogen & 11.7 & 10 & & 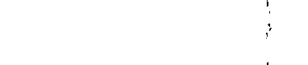 & & & & & \\
\hline \multicolumn{11}{|c|}{ Specimen: Commercial Graphite $\left(\rho=1.55 \mathrm{~g} / \mathrm{cm}^{3}\right)$} \\
\hline \multirow[t]{5}{*}{11} & Helium & 4.6 & 19 & 20 & 2210 & & & & & \\
\hline & Helium & 11.3 & 12 & 2210 & 2285 & & & 2380 & & \\
\hline & Helium & 12.2 & 4 & 2285 & : & & & & 9.3 & 3.3 \\
\hline & Hydrogen & 9.8 & 1 & & : & & & & & \\
\hline & Hydrogen & 9.8 & 9 & & 2025 & & & & ת & \\
\hline \multirow{3}{*}{12} & Helium & 5.6 & 15 & 20 & 2210 & & & 8 & 10.8 & \\
\hline & Helium & 9.2 & 15 & 2210 & 2305 & & & 2530 & 10.8 & 6.0 \\
\hline & Hydrogen & 8.6 & 10 & & 2260 & & & & $J$ & \\
\hline \multicolumn{11}{|c|}{$\begin{array}{l}a_{\text {Run } 1 \text { was for checking apparatus. }} \\
b_{\text {Reading obtained with optical pyrometer sighted down sight tube (see Fig. 110). }} \\
c_{\text {Reading obtained with optical pyrometer sighted down exit tube (see Fig. 110). }} \\
d_{\text {Sight tube clogged. }}\end{array}$} \\
\hline
\end{tabular}




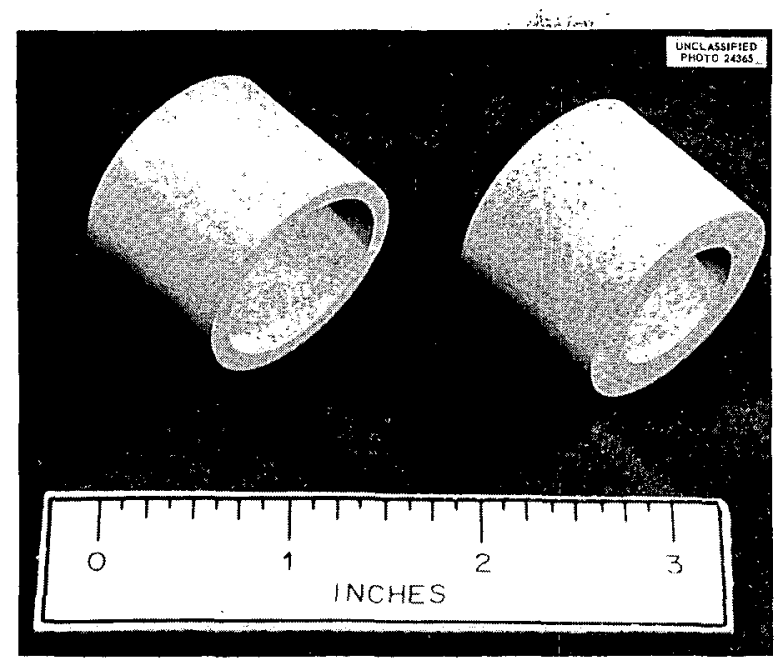

Fig. 111. Ceramic Specimens, Consisting of a Mixture of $\mathrm{Sm}_{2} \mathrm{O}_{3}$ and $\mathrm{Gd}_{2} \mathrm{O}_{3}$, for Use in Control. Rod Assemblies. (Secret with caption).

have been prepared. The disks contain an organic resin binder, the majority of the filler being electrically fused $\mathrm{Al}_{2} \mathrm{O}_{3}$ with a particle size of approximately 500 mesh and finer and with a purity of about $99.5 \%$. The principal contaminant is $\mathrm{SiO}_{2}$. The disks were submitted to the Critical Facility for evaluation.

\section{Europium Oxide Disks}

A preliminary investigation indicates that wafers of $\mathrm{Eu}_{2} \mathrm{O}_{3}, \frac{3}{4} \mathrm{in}$. in diameter and $0.030 \mathrm{in.}$ thick, prepared from the powdered oxide, precalcined of $1200^{\circ} \mathrm{C}$ for $1 \mathrm{hr}$, cold pressed at $20,000 \mathrm{psi}$, and sintered at $1500^{\circ} \mathrm{C}$ for $2 \mathrm{hr}$, disintegrate in boiling water. Specimens of similar size prepared from uncalcined material cold pressed as above and fired at $1200,1300,1400$, and $1500^{\circ} \mathrm{C}$ for $2 \mathrm{hr}$ showed no signs of breakdown in water. As soon as suitable specimens are prepared, they will be submitted to the MTR for exposure at about $10^{21}$ nut.

\section{FLUORIDE-F UEL INVESTIGATIONS}

$$
\text { G. D. White }
$$

\section{X-raying of Fluorides at High Temperature}

Samples of $3 \mathrm{LiF} \cdot \mathrm{ZrF}_{4}$ were $x$-rayed at elevated temperatures, obtained with the furnace attachment to the $x$-ray spectrometer. The determinations were made in order to confirm the de- composition temperature of $\mathrm{Li}_{3} \mathrm{ZrF}_{7}$, which has already been determined by quench methods and thermal data, and also to ascertain whether there is a high-temperature polymorph of $\mathrm{Li}_{3} \mathrm{ZrF}_{7}$ which could not be quenched.

At room temperature the samples contained three phases: $\mathrm{Li}_{2} \mathrm{ZrF}_{6}, \mathrm{Li}_{3} \mathrm{ZrF}_{7}$, and $\mathrm{LiF}$. The procedure consisted in heating the mounted sample to $550^{\circ} \mathrm{C}$ in the evacuated furnace attachment and allowing it to soak until the x-ray diffraction pattern contained none of the $\mathrm{Li}_{2} \mathrm{ZrF}_{6}$ or LiF peaks. The reacted sample was then cooled to successively lower temperatures until the $x$-ray pattern indicated the presence of $\mathrm{Li}_{2} \mathrm{ZrF}_{6}$ and $\mathrm{LiF}$. In this manner the decomposition temperature was determined to be $470^{\circ} \mathrm{C}$. Quench data showed that this temperature was about $475^{\circ} \mathrm{C}$. At no temperature above $470^{\circ} \mathrm{C}$ was the $x$-ray pattern for the low-temperature form of $\mathrm{Li}_{3} \mathrm{ZrF}_{7}$ obtained. The high-temperature $x$-ray pattern listed below is evidently that of a polymorph which inverts to the lower-temperature form of $\mathrm{Li}_{3} \mathrm{ZrF}_{7}$ iust slightly above the decomposition temperature.

$\begin{array}{lr}d(\mathbf{A}) & I / I_{0} \\ & \\ 4.58 & 100 \\ 3.65 & 12 \\ 3.24 & 28 \\ 3.15 & 57 \\ 2.84 & 41 \\ 2.64 & 22 \\ 2.36 & 21 \\ 2.05 & 59\end{array}$

\section{DEVELOPMENT OF SiC-Si FUEL PLATES}
A. J. Taylor
J. R. Johnson
R. L. Hamner
F. L. Carlson, Jr.

\section{E. L. Alexander}

Considerable progress has been made in the production of $\mathrm{SiC}-\mathrm{S}_{i}$ fuel plates containing up to $1 \frac{1}{2} \mathrm{~g}$ of $\mathrm{UO}_{2}$ per plate. More than 100 plates containing $1 / 2 \mathrm{~g}$ of $\mathrm{UO}_{2}$ have been made, and no disruption or cracking occurred. Several of them have been examined radiographically, and most of them hove been cut or broken in order to examine the fuel-bearing portion. Inasmuch as they were experimental plates and the fabrication pressures, fuel placement, and other factors had been varied, not all plates were alike. Many had 
$\mathrm{UO}_{2}$ remaining as the principal fuel material, whereas some had $\mathrm{USi}_{3}$, which formed by the reaction of the $\mathrm{UO}_{2}$ with the silicon during fabrication. A series of 20 plates that were made after optimum fabrication factors had been selected had principally $\mathrm{UO}_{2}$ as the remaining fuel. Most of the $\mathrm{UO}_{2}$ grains were surrounded by a thin shell of $\mathrm{USi}_{3}$, but radiography showed distinct grains and no diffusion of the oxide fuel or its silicide coating. Oxide grains were successfully used in the fabrication of five plates containing $1 \mathrm{~g}$ of $\mathrm{UO}_{2}$. Oxide rods were used in the preparation of ten plates containing $1 \frac{1}{2} g$ of $\mathrm{UO}_{2}$.

Two factors were responsible for the progress noted above: the SiC.Si body that has been developed was more suitable, and the unreactive $\mathrm{UO}_{2}$ made from $\mathrm{UO}_{3}$ crystals was improved.

An SiC-Si body made from Achesor or 2301 graphite and glucose was found to be stronger and more stable during fabrication than was a body made from micronized natural graphite and glucose. It was also found that placing the fuel in rows or in sections improved the stability and impregnation.

Reduction of hydrothermally grown $\mathrm{UO}_{3}$ hydrate resulted in $\mathrm{UO}_{2}$ that at 70 to 100 mesh was relatively unreactive with silicon at temperatures of approximately 1700 to $2000^{\circ} \mathrm{C}$. This oxide is placed in the core and is not previously mixed with the graphite body, as was done formerly. It is estimated that 1 to $1 \frac{1}{2} \mathrm{~g}$ of $\mathrm{UO}_{2}$ in this granular form is about as much fuel as can be used in a plate $3 \times 1 \times \frac{1}{8}$ in. It is estimated that up to $3 \mathrm{~g}$ may be added in the fabrication of such a plate when $\mathrm{UO}_{2}$ rods are used. These rods, suggested and produced by T. S. Shevlin, are about 0.020 in. in diameter and are placed in the graphite in short lengths of about $1 / 2$ in. Microscopic examination shows that in the case of dense $\mathrm{UO}_{2}$ a surface silicide coating is formed. Some improvement was noted when the rods were coated with $\mathrm{SiC}$ before placement.

Shown in Fig. 112 is a fuel plate which contains $1 / 3 \mathrm{~g}$ of $\mathrm{UO}_{2}$ per inch of length.

\section{CERAMIC ASPECTS OF WASTE DISPOSAL}

$$
\text { R. L. Hamner M. P. Haydon }
$$

Fixation of Radioisotopes in Ceramic Bodies

It was thought advisable to attempt to tie up in ceramic bodies the radioisotopes that are

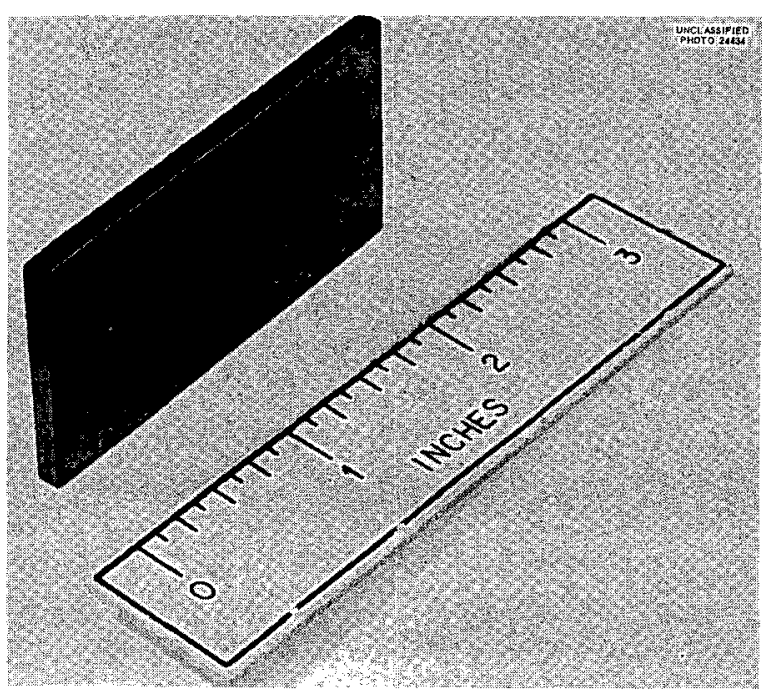

Fig. 112. An SiC.Si Fuel Plate.

present in atomic wastes so that in spite of leaching by ground water the water would not become radioactive. Thus the radioisotopes would be permanently fixed and stored. The work to date has been concerned largely with the fixation of radioisotopes present in Hope process solution. In preliminary experiments, it was found that when sodium carbonate or limestone or a combination of the two is mixed with Hope solution a stiff gel results, which is due to the formation of aluminum hydroxide. A very large number of combinations of limestone, dolomite, sodium carbonate, and clays were tested, and the compositions in Table 49 were selected for further study.

Initially it was assumed that fusing the ceramic masses would be necessary before any retention of radioactivity would be accomplished and that it would be necessary to add fluxes such as soda ash to aid in the fusion, particularly as it pertains to aluminum oxide, which forms when the compositions containing Hope solution are heated. It was later found that the radioactivity is fixed in a ceramic body by sintering at a temperature far below that at which any appreciable amount of glass is formed. Experiments show that a mixture of sodium carbonate and limestone with shale is more effective in retaining radioisotopes than is a mixture of limestone and shale alone. 
TABLE 49. COMPOSITIONS CHOSEN FOR EXPERIMENTS ON THE FIXATION OF RADIOISOTOPES

\begin{tabular}{ccccc}
\hline $\begin{array}{c}\text { Composition } \\
\text { No. }\end{array}$ & $\begin{array}{c}\text { Hope Solution } \\
(\mathrm{ml})\end{array}$ & $\begin{array}{c}\text { Limestone } \\
(\mathrm{g})\end{array}$ & $\begin{array}{c}\mathrm{Na}_{2} \mathrm{CO}_{3} \\
(\mathrm{~g})\end{array}$ & $\begin{array}{c}\text { Shale } \\
(\mathrm{g})\end{array}$ \\
\hline 5 & 250 & 30 & 30 & $200^{b}$ \\
9 & 250 & 30 & 30 & $200^{c}$ \\
15 & 250 & 30 & 30 & $100^{b}$ \\
16 & 250 & 30 & 30 & $150^{b}$ \\
\hline
\end{tabular}

${ }^{a}$ Chickamauga limestone from $X-10$ quarry, -80 mesh.

${ }^{b}$ Shale from the Volunteer Cement Co., -16 mesh.

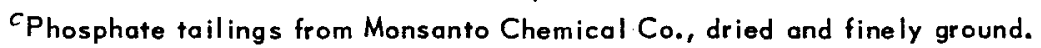

Procedure. - Two hundred and fifty milliliters of Hope solution was placed in a Hamilton Beach mixer, and the other ingredients were added slowly to avoid excessive frothing. After $\frac{1}{2}$ hr either a gel or a stiff slurry was formed. This mixture was dried and then fired for $2 \mathrm{hr}$ at various temperatures. After firing, weighed portions were placed in jars, and tap water was added. An attempt was made to keep constant the ratio of the final activity in the solid to the potential activity in the liquid by assuming that all the activity originally present in the Hope solution was present in the fired body. Consequently, the following body-to-water ratios were used:

Composition
No.
5
9
15
16

Fired Body
$(g)$
1
1
1
1

$\begin{gathered}\text { Tap Water } \\ (\mathrm{ml})\end{gathered}$
10
10
16.4
12.3

This procedure is not exactly correct because the amount of water markedly decreases as water is removed for activity counting. However, the results are comparative, and in the future larger amounts of solid and water will be used.

Experiment No. 1. - Composition 5 was used, and the Hope solution was tagged with $\mathrm{Sr}^{90}$ so as to contain 27,500 counts $/ \mathrm{min} / \mathrm{ml}$. No carrier was added. Portions of this batch were fired at $850,1050,1350,1450,1550,1650$, and $1750^{\circ} \mathrm{F}$. After the composition was leached for 90 days, the water surrounding the body that was fired at $850^{\circ} \mathrm{F}$ was slightly radioactive (15 counts) $\mathrm{min} / \mathrm{ml}$ ). The radioactivity in the water surrounding those portions that were fired at higher temperatures was less. As this composition had a fired weight of about $250 \mathrm{~g}$, the activity per gram should have been about the same as that for $1 \mathrm{ml}$ of Hope solution. However, the activity of the fired material was 85,000 counts $/ \mathrm{min} / \mathrm{g}$. Considerable difficulty has been encountered in measuring the activity of the fired material. However, the activity of the solid material in contact with the leach water was high, and this activity was not lost in drying and firing.

Another volume of the Hope solution was tagged with $\mathrm{Sr}^{90}$ so that it had an activity of 387,000 counts $/ \mathrm{min} / \mathrm{ml}$; the activity of the final material, which was fired at $1350^{\circ} \mathrm{F}$, was 342,000 counts $/ \mathrm{min} / \mathrm{g}$. After the body was leached for 34 days, the activity of the leach water was 26 counts $/ \mathrm{min} / \mathrm{ml}$. Higher firing temperatures should reduce the activity in the leach water, and an experiment to investigate this is in progress.

It was determined that the $\mathrm{Sr}^{90}$ could not be fixed by drying alone and that without subsequent firing the $\mathrm{Sr}^{90}$ would leach into the surrounding water.

Experiment No. 2. - Composition 9 was used, and the resultant body was fired of $1050^{\circ} \mathrm{F}$. The activity in the water surrounding the body was less than when shale was used. Indications are that phosphate tailings will give more satisfactory results than shale. However, this material is more difficult to handle and is more expensive than shale. 
Experiment No. 3. - Composition 15 was used, and the Hope solution was tagged with $\mathrm{Sr}^{90}$ so as to contain 37,500 counts $/ \mathrm{min} / \mathrm{ml}$. No carrier was added. The results were satisfactory except that the leach water from the composition fired at $850^{\circ} \mathrm{F}$ had an activity of 15 counts $/ \mathrm{min} / \mathrm{ml}$ after 103 days. There was very little activity in the leach waters surrounding the bodies which had been fired at higher temperatures.

Experiment No. 4. - Composition 16 was used, and in all other respects the conditions were the same as in experiment No. 3. The results were similar. A firing temperature of $850^{\circ} \mathrm{F}$ was not sufficiently high to fix the radioisotope.

\section{Summary of Experiments 1-4}

When compositions 5 and 9 were used, a firing temperature of $850^{\circ} \mathrm{F}$ was sufficient to fix $\mathrm{Sr}^{90}$ fairly well. With the others, a temperature of $1050^{\circ} \mathrm{F}$ was sufficient for ensuring little or no activity in the leach water. From a practical standpoint composition 15 is the most satisfactory because of the relatively small amount of clay needed to fix the $\mathrm{Sr}^{90}$ and because the body can be easily reduced to a volume that is practical for final disposal. Increasing the activity of the Hope solution tenfold did not cause any large increase in the activity of the leach water when composition 5 fired at $1350^{\circ} \mathrm{F}$ was used.

Experiment No. 5. - In order to determine whether it would be necessary to use aluminum nitrate solution, an amount of activated alumina was substituted that was equivalent to the amount of alumina which would result after the nitrogen oxides were driven off from $250 \mathrm{ml}$ of Hope solution. The new composition, No. 23, is described below.

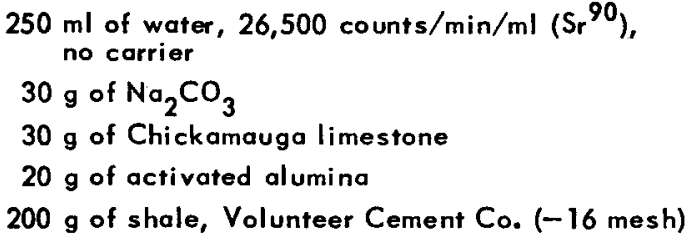

The composition was processed as before and was fired at 1050 and $1350^{\circ} \mathrm{F}$. The results of the leaching tests were similar to those obtained with experiment No. 1. Consequently, it is not necessary to have Hope solution in order to get satisfactory results.
Experiment No. 6. - In order to find out whether the limestone and the soda ash played an important part in the fixation of $\mathrm{Sr}^{90}$, the following composition, No. 24, was used:

$$
\begin{aligned}
& 250 \mathrm{ml} \text { of water, } 26,500 \text { counts } / \mathrm{min} / \mathrm{ml}\left(\mathrm{Sr}^{90}\right) \text {, } \\
& \text { no carrier } \\
& 20 \mathrm{~g} \text { of activated alumina } \\
& 260 \mathrm{~g} \text { of shale, Volunteer Cement } \mathrm{Co} .(-16 \mathrm{mesh})
\end{aligned}
$$

After processing, the body was fired at 1050 and $1350^{\circ} \mathrm{F}$. After the composition was leached for 53 days, there were indications of slight activity in the leach water, particularly with the body fired at $1350^{\circ} \mathrm{F}$. For some unaccountable reason, the leach water from the body fired at $1050^{\circ} \mathrm{F}$ was less active.

Experiment No. 7. - As there were indications that the alumina did not play an important part in the retention of $\mathrm{Sr}^{90}$, an experiment was designed to determine whether clay alone would be sufficient to render the $\mathrm{Sr}^{90}$ unaffected by leach solution. The following batch was made:

$$
\begin{aligned}
& 250 \mathrm{ml} \text { of water, } 26,500 \text { count } \mathrm{s} / \mathrm{min} / \mathrm{ml}\left(\mathrm{Sr}^{90}\right) \text {, } \\
& \text { no carrier } \\
& 260 \mathrm{~g} \text { of shale, Volunteer Cement Co. }(-16 \mathrm{mesh})
\end{aligned}
$$

Samples were fired at $450,650,850,1050$, and $1350^{\circ} \mathrm{F}$. After the composition was leached for 65 days, the leach water surrounding the bodies fired at 450 and $650^{\circ} \mathrm{F}$ was slightly radioactive, but a firing temperature of $850^{\circ} \mathrm{F}$ was sufficient to fix the $\mathrm{Sr}^{90}$ fairly well; the activity was 13 counts $/ \mathrm{min} / \mathrm{ml}$. There was no activity in the water surrounding the sample fired at $1350^{\circ} \mathrm{F}$. Thus, this experiment shows that even a coarsegrained shale is effective in preventing solubilization of the radioisotopes by leach water.

Another experiment consisted in using a simulated sea water for leaching, since this has been the experimental practice at Los Alamos. After 36 days, the water surrounding the composition fired at $1050^{\circ} \mathrm{F}$ had an activity of 258 counts/ $\mathrm{min} / \mathrm{ml}$; whereas firing at a temperature of $1350^{\circ} \mathrm{F}$ resulted in an activity for the leach water of 87 counts $/ \mathrm{min} / \mathrm{ml}$. It was quite evident that salt water is a more effective leaching agent than tap water.

Experiment No. 8. - In this experiment, compositions 5 and 15 were each tried with a Hope solution which contained carrier and Ru-Rh tracer and had an activity of 6160 counts $/ \mathrm{min} / \mathrm{ml}$. Por- 
tions of each were fired at $850,1050,1550$, and $1750^{\circ} \mathrm{F}$. After 90 days, no appreciable activity was found to be present in any of the leach waters. With composition 5 the activity of the fired body was 2600 counts $/ \mathrm{min} / \mathrm{g}$; whereas with composition 15, which contained less clay, the activity was about 5000 counts $/ \mathrm{min} / \mathrm{g}$, although the activity varied considerably at different firing temperatures. There was some error in counting the dry-fired material. Some of the activity was lost in drying and firing because the gases evolved were radioactive. It is estimated that about one-half the initial activity was fixed in the fired masses.

Experiment No. 9. - Compositions 5 and 15 were each tried with a mixture of Hope solution plus carrier and were tagged with $\mathrm{Cs}-\mathrm{Ba}$ so as to have an initial activity of 3630 counts $/ \mathrm{min} / \mathrm{ml}$. The bodies were fired at 1550 and $1750^{\circ} \mathrm{F}$. At the end of 90 days, the water surrounding composition 5 fired at $1550^{\circ} \mathrm{F}$ had an activity of 9 counts/ $\mathrm{min} / \mathrm{ml}$; whereas with the same body fired at $1750^{\circ} \mathrm{F}$, the count was about half that value. With composition 15 fired at $1550^{\circ} \mathrm{F}$, the leach water had an activity of 73 counts $/ \mathrm{min} / \mathrm{ml}$ and about half that value when fired at $1750^{\circ} \mathrm{F}$.

This experiment indicates that the radioactive $\mathrm{Cs}-\mathrm{Ba}$ is not fixed so completely as $\mathrm{Sr}^{90}$. Further experiments concerning the fixation of $\mathrm{C}_{s}-\mathrm{Ba}$ are in progress.

Experiment No. 10. - The same procedure and compositions were used in studying the fixation of radioactive cerium. The Hope solution contained radioactive cerium and carrier and had an activity of 3127 counts $/ \mathrm{min} / \mathrm{ml}$. The compositions were fired at 1550 and $1750^{\circ} \mathrm{F}$. After 90 days, the leach waters were only slightly radioactive. The highest activity was abtained from the leach water from composition 15 fired at $1550^{\circ} \mathrm{F}$; the activity was 14 counts $/ \mathrm{min} / \mathrm{ml}$.

Experiment No. 11. - As before, compositions 5 and 15 were tested, but in this experiment mixed fission products were used. The Hope solution with carrier was tagged with mixed fission products and had an activity of 38,000 counts $/ \mathrm{min} / \mathrm{ml}$. The compositions were fired at 1050 and $1350^{\circ} \mathrm{F}$. After the compositions were leached for 84 days, the water, in all cases, was very slightly above background. Composition 5 had higher retention than composition 15.

Experiment No. 12. - This experiment was performed in order to determine whether a mixture of limestone and shale fired at $1050^{\circ} \mathrm{F}$ would fix $\mathrm{Sr}^{90}$ or mixed fission products. The following compositions were used:

$\begin{array}{lrr}\text { Composition No. } & 26 & 27 \\ \text { Hope solution, ml } & 250 & 250 \\ \text { Chickamauga limestone, g } & 60 & 60 \\ \text { Volunteer shale, g } & 200 & 100\end{array}$

After being fired at $1050^{\circ} \mathrm{F}$, the bodies were leached for 12 days, and the activity of the solutions was excessive. Consequently, the use of these compositions will be discontinued, except when higher firing temperatures are employed.

Experiment No. 13. - The effect of hot water on leaching was studied with composition 5 made with Hope solution tagged with mixed fission products and fired at $1350^{\circ} \mathrm{F}$. An apparatus with a reflux condenser was so arranged that the fired body was in continuous contact with condensing steam for three days. At the end of this period, the leach water was nonradioactive.

\section{Summary}

Of all the isotopes tested, the radioactive $\mathrm{Cs}-\mathrm{Ba}$ mixture appears to be the most difficult to fix in a ceramic body. The degree of fixation required will depend to a large extent on the storage conditions. The amount of fixation is dependent upon the temperature used to fire bodies. More work will be done on this problem.

\section{SELF-FUSION EXPERIMENTS}

\section{J. R. Johnson \\ S. D. Fulkerson}

A system for disposing of high-level radioactive wastes into the ground must fulfill the requirement that the system retain the activity to within safe limits. Fixing such wastes in clays or clay-flux mixtures is a possible solution to the problem. The method, however, requires heating the clay mixes to high temperatures in order to ensure permanent fixation. The desirability of self-heating by using the heat in radioactive wastes is obvious. On the other hand, the amount of heat per unit volume of wastes is quite low, according to present estimates, which makes a self-heating process of rather uncertain feasibility. Although heat-loss calculations can be made for waste-disposal pits, the variability of the earth heat sink and the atmosphere, as well as the wide choice of insulation materials and other factors, makes a largescale pit experiment desirable. 
Several small-scale experiments have been devised in order to determine what temperature a clay will reach under well-insulated conditions and to observe the boiling, drying, fuming, and sintering characteristics of a mixture of clay, flux, and fission-product solution. These experiments indicate that about $0.01 \mathrm{w} / \mathrm{cc}$ will cause a clay-fission-product mixture to reach $900^{\circ} \mathrm{C}$ in a moderately well insulated pit $20 \mathrm{ft}$ in diameter in which the depth of the mixture when finally dry is about $6 \mathrm{ft}$. A heat generation of this order of magnitude would be available in one type of waste solution where the activity is about 1000 curies/gal.

The liquid clay-waste mixture attained equilibrium temperature in about 30 days when the power was about $0.005 \mathrm{w} / \mathrm{cc}$. The water had been driven off as steam in about ten days, and no "burping" was noted. The $\mathrm{NO}_{2}$ fumes from the nitrate waste came off between the sixth and nineteenth days. The level of the mix dropped from 24 to $7 \mathrm{in}$. When $\mathrm{NO}_{2}$ fumes were no longer evolved, insulation was placed on the top of the cake, which increased the temperature about $30 \%$.

Experiments Nos. 1, 2, and 4. - A schematic drawing of the experimental self-fusion apparatus was presented in the previous progress report. 6 In experiment No. 1, the inner container was 12 in. in diameter and 3 in. deep. In experiment No. 2, this container was 6 in. in diameter and 2 in. deep; in No. 4, it was 24 in. in diameter and $8 \mathrm{in.} \mathrm{deep.}$ In all three experiments there was 4 in. of carbonblack insulation around the inner container and then $8 \mathrm{in}$. of vermiculite. The inner container contained clay that was previously calcined at $600^{\circ} \mathrm{C}$. A Nichrome-wire heater wound on a sheet of pressed mica was mounted in the center. The wire was no closer than $1 \frac{1}{2}$ in. from the center and was approximately $2 \mathrm{in}$. from the outer surface of the container. Thermocouples were placed in the center of the inner. clay container, on its periphery, and on the periphery of the carbonblack container.

Figure 113 shows the temperature of the inner thermocouple as a function of the power and the time of heating in experiment No. 1. Similar data were obtained for experiments No. 2 and No. 4 and are given in Table 50. From these data the power input was calculated that would be required to

6. M. Warde et al., Met. Semiann. Prog. Rep. April 10. 1955, ORNL-1911, p 123.

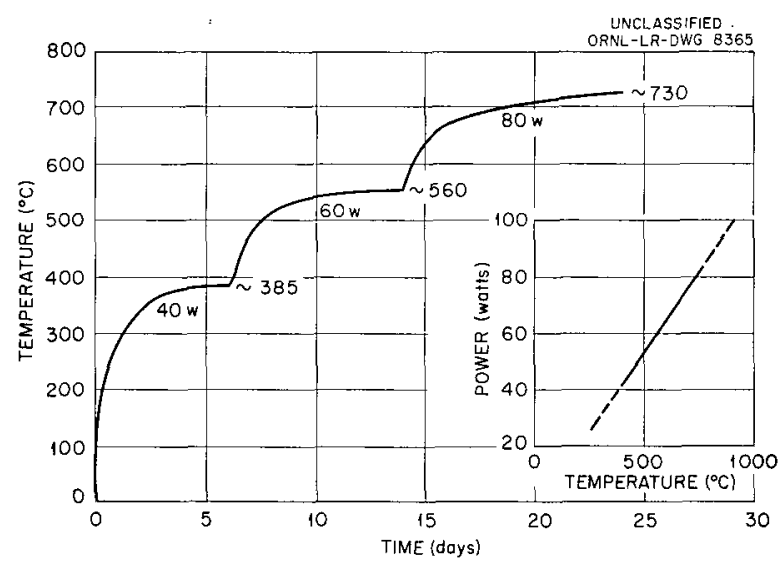

Fig. 113. Time-Temperature Plot for Self-Fusion Experiment No. 1.

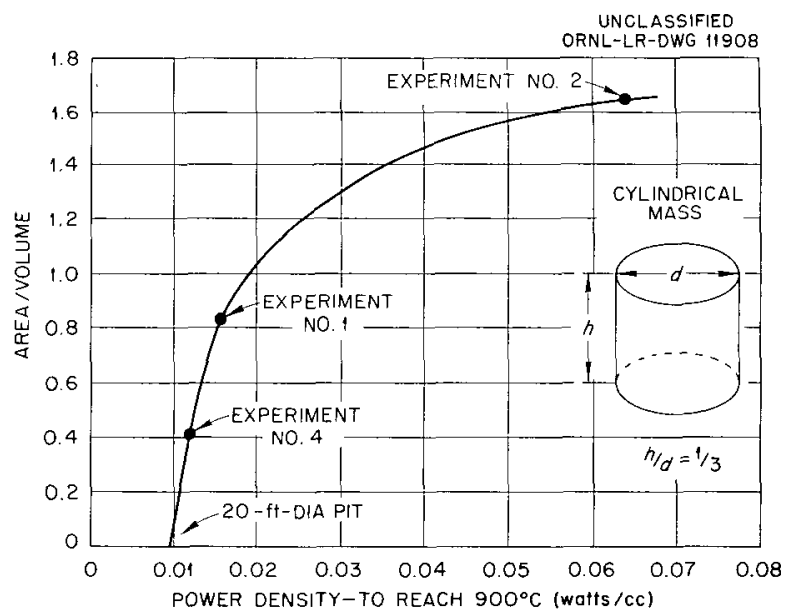

Fig. 114. Effect of Area-to-Volume Ratio on Energy Required to Heat an Insulated Clay Mass.

attain an average temperature of $900^{\circ} \mathrm{C}$ in the clay. Because of premature heater failure in experiment No. 4, the calculation is not very reliable; however, the value reported is believed to be a conservative one.

Figure 114 shows the power per unit volume that is required to attain $900^{\circ} \mathrm{C}$ as a function of the area-to-volume ratio of the clay container. The ratio for a 20 -ft-dia pit insulated in the same manner is indicated.

Experiment No. 3. - Figure 115 shows the results of heating a clay-flux-Hope-solution mixture. Of particular interest is the manner in which the water and $\mathrm{NO}_{2}$ fumes were lost under a static 
TABLE 50. DATA FROM SELF-FUSION EXPERIMENTS IN WHICH SIZE OF APPARATUS WAS VARIED

\begin{tabular}{|c|c|c|c|c|}
\hline $\begin{array}{c}\text { Time } \\
\text { (days) }\end{array}$ & $\begin{array}{c}\text { Power } \\
(w)\end{array}$ & $\begin{array}{c}\text { Center } \\
\text { Temperature } \\
\left({ }^{\circ} \mathrm{C}\right)\end{array}$ & $\begin{array}{c}\text { Exterior } \\
\text { Temperature } \\
\left({ }^{\circ} \mathrm{C}\right)\end{array}$ & $\begin{array}{c}\text { Carbon Insulation } \\
\text { Exterior Temperature } \\
\left({ }^{\circ} \mathrm{C}\right)\end{array}$ \\
\hline \multicolumn{5}{|c|}{ Experiment No. 1} \\
\hline 0 & 40 & 25 & 25 & 25 \\
\hline 1 & 40 & 280 & 157 & 46 \\
\hline 2 & 40 & 338 & 208 & 72 \\
\hline 7 & 60 & 383 & 254 & 98 \\
\hline 15 & 60 & 554 & 373 & 140 \\
\hline 17 & 80 & 636 & 414 & 144 \\
\hline 25 & 80 & 722 & 490 & 176 \\
\hline \multicolumn{5}{|c|}{ Experiment No. 2} \\
\hline 0 & 10 & 25 & 25 & 25 \\
\hline 2 & 10 & 226 & 176 & 54 \\
\hline 7 & 20 & 414 & 324 & 86 \\
\hline 9 & 40 & 764 & 616 & 143 \\
\hline 10 & 60 & 884 & & 152 \\
\hline \multicolumn{5}{|c|}{ Failed before equilibrium } \\
\hline \multicolumn{5}{|c|}{ Experiment No. 4} \\
\hline 0 & 400 & 25 & 25 & 25 \\
\hline 2 & 400 & 800 & 428 & 157 \\
\hline 3 & 400 & 876 & $(628)$ & 212 \\
\hline Heate & & & & \\
\hline
\end{tabular}

atmosphere. No violent bubbling, surging, or "burping" was observed; and as the mass shrank, it did not adhere to the container walls during the first two-thirds of its consolidation. Only. small amounts of the cake adhered thereafter. The mass appeared to be fairly uniformly heated. Although the temperature finally attained was insufficient to result in good sintering, the mass was hard and relatively small air bubbles were trapped within.

Inasmuch as the experiments indicate that selffusion of radioactive-waste-clay mixtures is feasible, it is suggested that a pilot pit be built, approximately $20 \mathrm{ft}$ in diameter by $20 \mathrm{ft}$ deep. This pit would be insulated with several feet of vermiculite or foam glass on its bottom and sides and a large electric heater placed so as to distribute the heat as uniformly as possible in the bottom $6 \mathrm{ft}$ of the pit. The pit would be filled with the liquid mixture and heated. When the mixture is nearly dry, foam-glass insulation would be placed on the surface. About $500 \mathrm{kw}$ and about 100 tons of clay-waste mix would be required.

A smaller pit, approximately $6 \mathrm{ft}$ in diameter by 6 . ft deep requiring a $20-\mathrm{kw}$ heater and 4 tons of clay-waste mix, might first be built to test the construction and operation of a ground pilot pit.

\section{General Considerations}

Self-fusion experiments (reported in the preceding section) show that an activity of about 1000 curies/gal of waste is necessary before selffusion in pits becomes an attractive proposition. As pointed out by F. L. Culler, waste solutions have varying activities and chemical compositions 


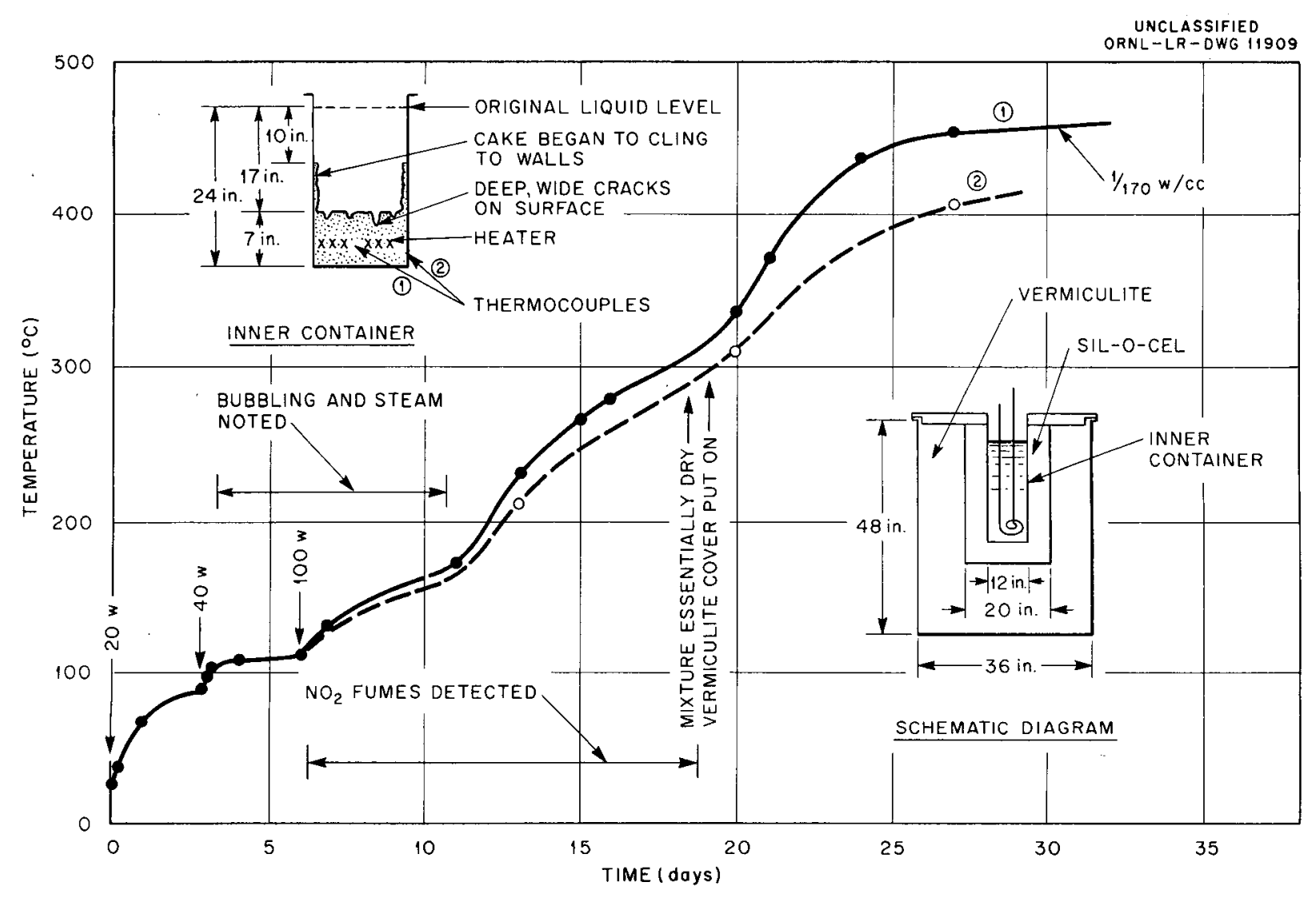

Fig. 115. Time-Temperature Plot for Self-Fusion Experiment No. 3.

and may have activities of 400 curies/gal and lower. This makes it mandatory that for fixation in a ceramic body external heat will have to be used for sintering. If external heating is used, the temperature limitations can be raised because the fuel requirements for reasonably high temperatures, say $1900^{\circ} \mathrm{F}$, are not markedly higher than for $1050^{\circ} \mathrm{F}$; moreover, a considerable amount of heat energy is necessary for drying, firing, and denitrating the Hope solution. Denitration, as shown by DTA, is an endothermic process and is complete at about $600^{\circ} \mathrm{C}$ when the firing rate is $10^{\circ} \mathrm{C} / \mathrm{min}$.

Some of the problems involved in the firing of these bodies are as follows:
1. forming a sinter which will fix radioisotopes the degree of fixation necessary depends on conditions of storage and nature of leach solutions,

2. forming a sinter that does not stick together, thereby facilitating its discharge from the furnace or kiln,

3. preventing radioactive dust and fission products from escaping into the atmosphere,

4. preventing vaporization of fission products at elevated temperatures,

5. handling of oxides of nitrogen evolved during heating of the nitrate solutions,

6. handling of ruthenium - there is evidence that it is volatile. 
FUNDAMENTAL METALLURGY 


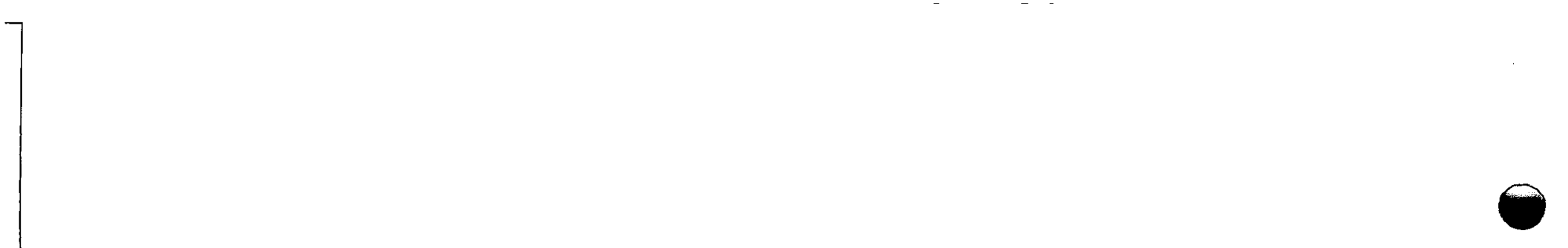

$\Delta$

• 


\title{
FUNDAMENTAL PHYSICO-METALLURGICAL RESEARCH
}

\author{
L. K. Jetter \\ C. J. McHargue \\ J. O. Betterton, Jr. \\ G. D. Kneip, Jr. \\ W. M. Spicer ${ }^{1}$
}

\section{PREFERRED ORIENTATION IN URANIUM ROD}
L. K. Jetter
C. J. Mchargue

Preferred orientation in uranium rod has been studied for a number of fabricating conditions. Rod formed by rolling at $300^{\circ} \mathrm{C}$ has been reported ${ }^{2}$ to develop a duplex texture in which the $\{010\}$ and $\{110\}$ poles were parallel to the rolling direction and had a $\{010\} /\{110\}$ ratio equal to 1.6. Recrystallization of this rod at $575^{\circ} \mathrm{C}$ gave a texture which had primarily $\{010\}$ and $\{140\}$ poles parallel to the rolling direction and had a trace of the $\{110\}$ com* ponent. [The convention has been adopted whereby the plane whose pole is parallel to the fiber axis is used to identify the component. Thus, the $\{110\}$ component has $\{110\}$ poles parallel to the fiber axis.] It has been reported ${ }^{3}$ that rod rolled at $600^{\circ} \mathrm{C}$ developed the $\{010\}-\{110\}$ duplex texture, but with a value of 0.36 for the $\{010\} /\{110\}$ ratio. Harris ${ }^{4}$ has reported that uranium rods produced by hot-rolling with light reductions exhibited a strong $\{010\}$ texture and a weak $\{110\}$ texture, whereas those made by hot-rolling with heavy reductions had a strong $\{110\}$ texture and a weak $\{010\}$ texture.

A method for the determination of preferred orientation has been developed in which the actual fiber-axis distribution is obtained from the experimentally observed pole distributions. The application of this technique has shown that the older methods often lead to inaccurate or incomplete results. 5,6 By means of this new method, a preliminary investigation of alpha-extruded and annealed alphomextruded uranium rod was carried

\footnotetext{
${ }^{I}$ Research participant.

${ }^{2}$ W. P. Chernock and P. A. Beck, Quarterly Report Jamuary, February, and March 1951; Metallurgy Division, ANL-4655, p 54-80.

${ }^{3}$ W. P. Chernock and P. A. Beck, Quantitative Determination of Rolling and Recrystallization Textures in $600^{\circ} \mathrm{C}$ - and $300^{\circ} \mathrm{C}$-rolled Uranium, ANL-4839 (Aug. 1951).

${ }^{4}$ G. B. Harris, Pbil. Mag. 43, 113 (1952).

${ }^{5} \mathrm{~L}$. K. Jetter and B. S. Borie, Jr., Proceedings of the Spring Metallurgy Conference, Marcb 24-26, 1952, vol 2, TID-5084, p $52 \%$.

${ }^{6}$ L. K. Jetter and C. J. MeHargue, Met. Semiann. Prog. Rep. April 10, 1954, ORNL-1727, p 97.
}

out, and the results indicated that the fiber axes were not poles of low-index planes, as was previously supposed. ${ }^{7}$

A thorough study was made of the textures in alpha-extruded and annealed alpha-extruded uranium rods, and complete fiber-axis determinations are presented.

Extrusions were made from $3 \frac{1}{8}$-in.-dia billets with a billet temperature of $500^{\circ} \mathrm{C}$. One rod of 1.5-in. diameter (extrusion ratio 4.3) and one of 0.9-in. diameter (extrusion ratio 12.1) were produced. The rods were water-quenched at the die in order to retain, insofar as possible, the asextruded structure. The 0.9 -in.-dia rod was subsequently vacuum-annealed for $1 \mathrm{hr}$ at $550^{\circ} \mathrm{C}$.

Pole-distribution data were obtained by the $x$-ray spectrometer method ${ }^{4}$ on 0.19-in. spherical diffraction specimens taken from the middle portion of each rod. These data were then used to construct the fiber-axis distribution charts.

\section{As-Extruded Rod}

The pole-distribution charts ( $R$ vs $\phi$ ) for the $\{002\},\{040\},\{110\}$, and $\{130\}$ planes of the specimen taken from the 1.5-in.-dia as-extruded rod are given in Fig. 116, and the fiber-axis distribution chart $(T$ vs $\phi, \beta)$ is shown in Fig. 117. The contours on the axis-distribution chart indicate locations of equal normalized-axis density $(T)$. The comparisons between the pole distribution calculated from the assumed axis distribution of Fig. $117[R(\phi)=\bar{T}(\phi)]$ and the experimentally observed pole distributions are indicated in Fig. 116.

It is apparent that the positions of maximum axis density do not coinçide with the poles of planes of low indices, as was assumed in previous investigations. The position of maximum intensity lies between the $\{041\}$ and the $\{010\}$ poles, $10 \mathrm{deg}$ from the latter. The center of this peak is 2 deg from the $\langle 041\rangle$ direction. A second region of high density is $10 \mathrm{deg}$ from the $\{110\}$ poles in the direction of the $\{001\}$ pole and is approximately at $\{331\}$. Thus, the actual positions of the fiber

\footnotetext{
7L. K. Jetter, Met. Semiann. Prog. Rep. April 10, 1953, ORNL-1551, p 6.
} 

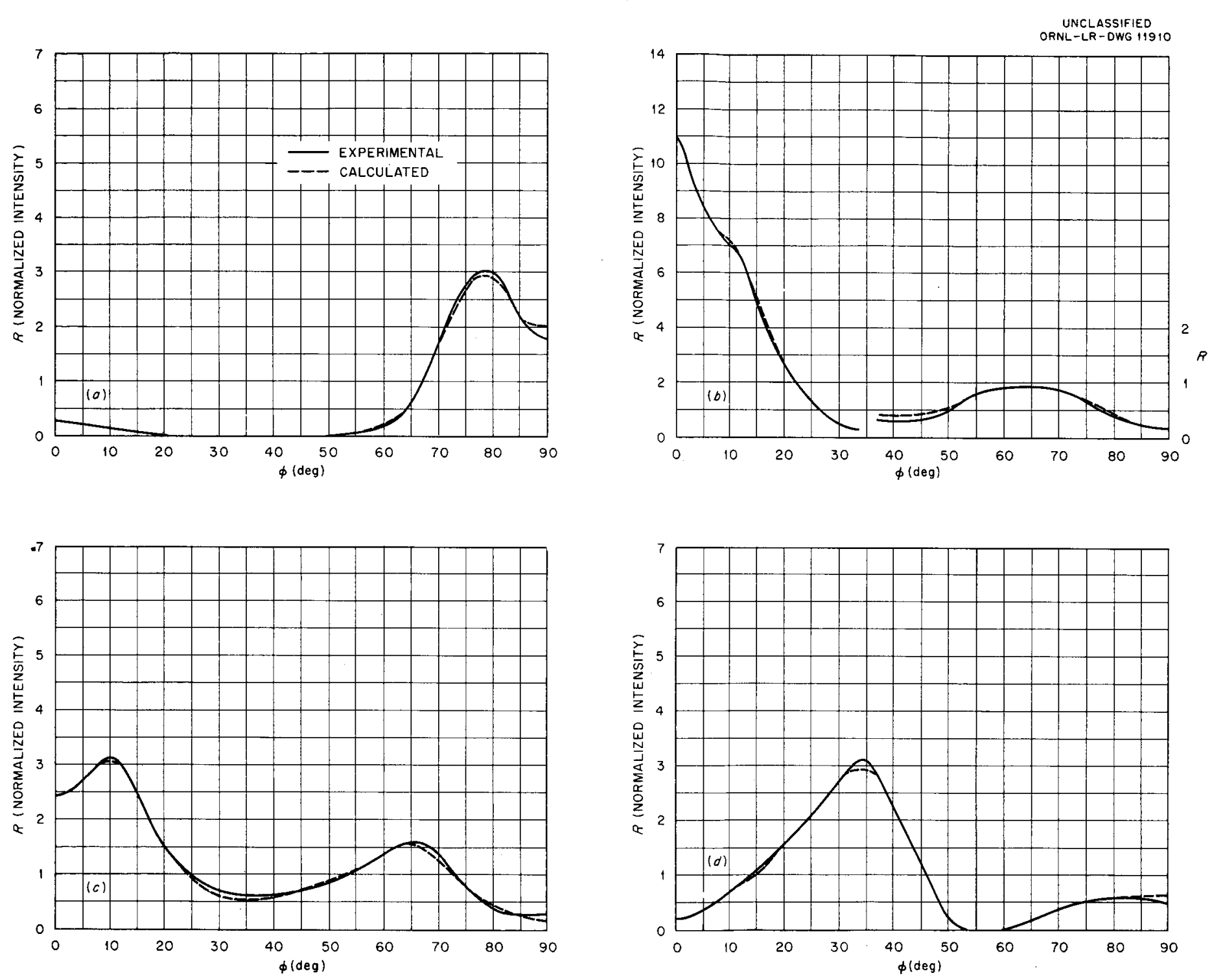

Fig. 116. Pole-Distribution Charts for Uranium Rod Extruded at $500^{\circ} \mathrm{C}$ with an Extrusion Ratio of 4.3. (a) $\{002\} .(b)\{040\} .(c)\{110\}$. (d) $\{130\}$.

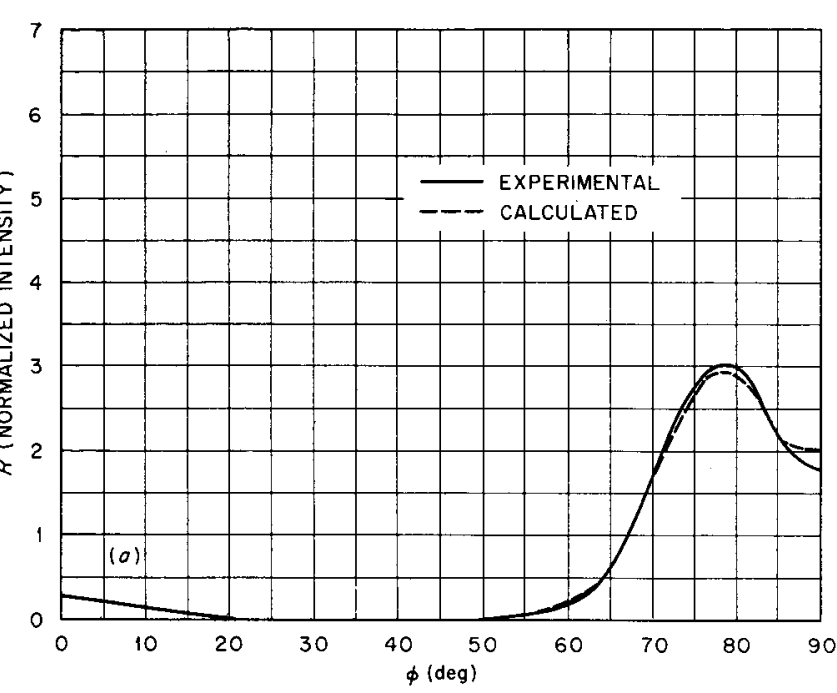




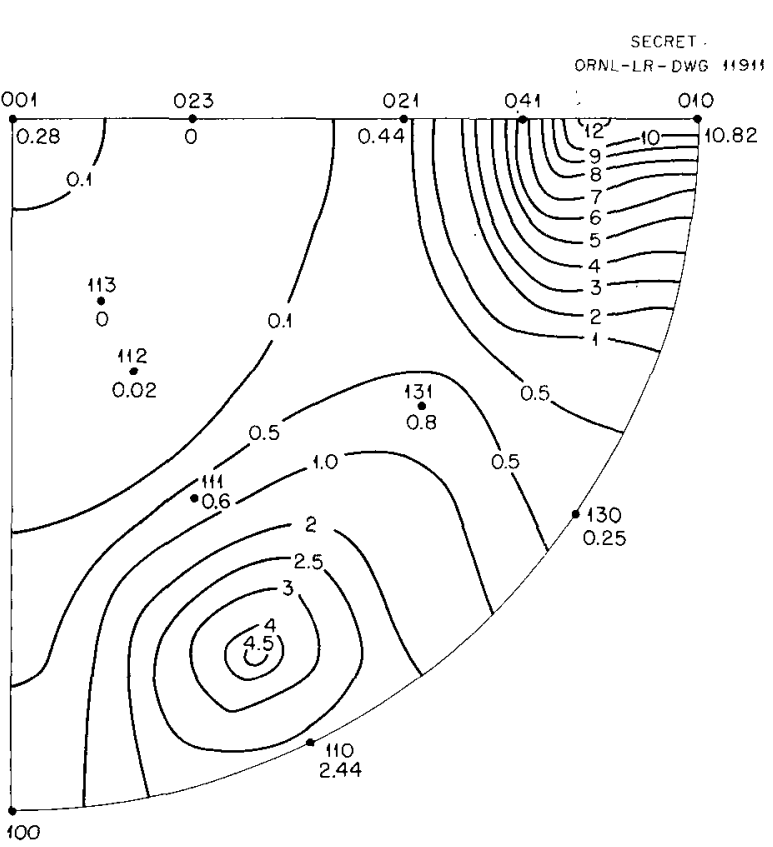

Fig. 117. Fiber-Axis Distribution Chart for Uranium Rod Extruded at $500^{\circ} \mathrm{C}$ with an Extrusion Ratio of 4.3.

axes are approximately $10 \mathrm{deg}$ from each of the commonly reported textures.

The volume of material with orientations within a radius of 20 deg of each peak was determined from $I$ sin $\phi$ vs $\phi$ plots. Approximately $40 \%$ of the volume was associated with the component near $\{010\}, 58 \%$ with the component near $\{110\}$, and the remaining $2 \%$ with other orientations. These volumes give the true ratio of the occurrence of the textures. In an earlier report, ${ }^{3}$ based on relative peak heights, the $\{010\}$ component was indicated as being only one-third as strong as the $\{110\}$ component in uranium rod rolled at $600^{\circ} \mathrm{C}$.

The microstructure of the 1.5-in.-dia as-extruded rod was that of a completely deformed material with no signs of recrystallized grains.

At least two attempts (in which current theories of texture formation were used) to predict or rationalize the deformation textures of uranium have been made. The treatment of Calnan and Clews $^{8}$ requires that the $\{110\}$ poles be parallel to the fiber axis in rods subjected to large amounts of deformation by rolling at temperatures greater than about $300^{\circ} \mathrm{C}$. For lower amounts of defor-

${ }^{8}$ E. A. Calnan and C. J. B. Clews, Pbil. Mag. 43, 93 (1952). mation, poles in the range of $\{010\}$ to $\{130\}$ should be aligned with the fiber axis. Another treatment ${ }^{9}$ indicates that on rolling at $600^{\circ} \mathrm{C}$ a $\{010\}$ component results from duplex slip on two $\{110\}<110\rangle$ type slip systems, and a $\{110\}$ component is the result of duplex slip on $\{110\}<110>$ and $\{010\}<100>$ slip systems. Depending on the relative critical sheer stresses for slip on the $\{110\}<110\rangle$ and $\{010\}<100>$ systems, this latter component may be shifted toward the $\{100\}$ pole.

There are no simple modifications of either of these treotments which will move the stable end orientations to the positions actually observed for the fiber axes.

\section{Recrystallized Extruded Rod}

An earlier investigation ${ }^{10}$ indicated that the fiber textures in the as-extruded 1.5-in.-dia and the 0.9-in.-dia rods were essentially the same, although a small amount of recrystallized material was observed in the latter rod.

The pole-distribution charts for the $\{002\},\{040\}$, $\{200\}$, and $\{110\}$ planes of the specimen taken from the portion of the 0.9-in.-dia rod which had been annealed for $1 \mathrm{hr}$ at $550^{\circ} \mathrm{C}$ are reproduced in $\mathrm{Fig}$. 118, and the axis-distribution chart is given in Fig. 119. The agreement of the assumed axis distribution and the observed pole distributions is also illustrated in Fig. 118.

Again the positions of maximum axis density do not correspond to poles of rational planes. The point of greatest density is approximately 4 deg from the pole of $\{131\}$. The other component lies $14 \mathrm{deg}$ from each of the $\{100\}$ and $\{110\}$ poles and 6 deg from the $\{311\}$ pole. In approximately $35 \%$ of the volume, the orientations are within $15 \mathrm{deg}$ of the peak of the component which is near the $\{100\}$ pole and the $\{110\}$ pole. Almost all the remaining $65 \%$ lies within $15 \mathrm{deg}$ of the $\{131\}$ component.

Some earlier reports indicated that no texture changes occurred upon recrystallization of rolled uranium rods; however, Chernock and Beck ${ }^{2}$ observed that in rod rolled at $300^{\circ} \mathrm{C}$, the $\{010\}-\{110\}$ texture changed to $\{010\}-\{140\}$ when this material was annealed for $1 \mathrm{hr}$ at $575^{\circ} \mathrm{C}$. These authors also reported texture changes in rod rolled at

\footnotetext{
${ }^{9}$ Knolls Atomic Power Laboratory, Reactor Materials, Progtess Report September, October, November 1951 . KAPL-655, P 22.

10 J. H. Frye, Jr., Met. Quar. Prog. Rep. Jan. 31, 1951. ORNL-987, p 17.
} 

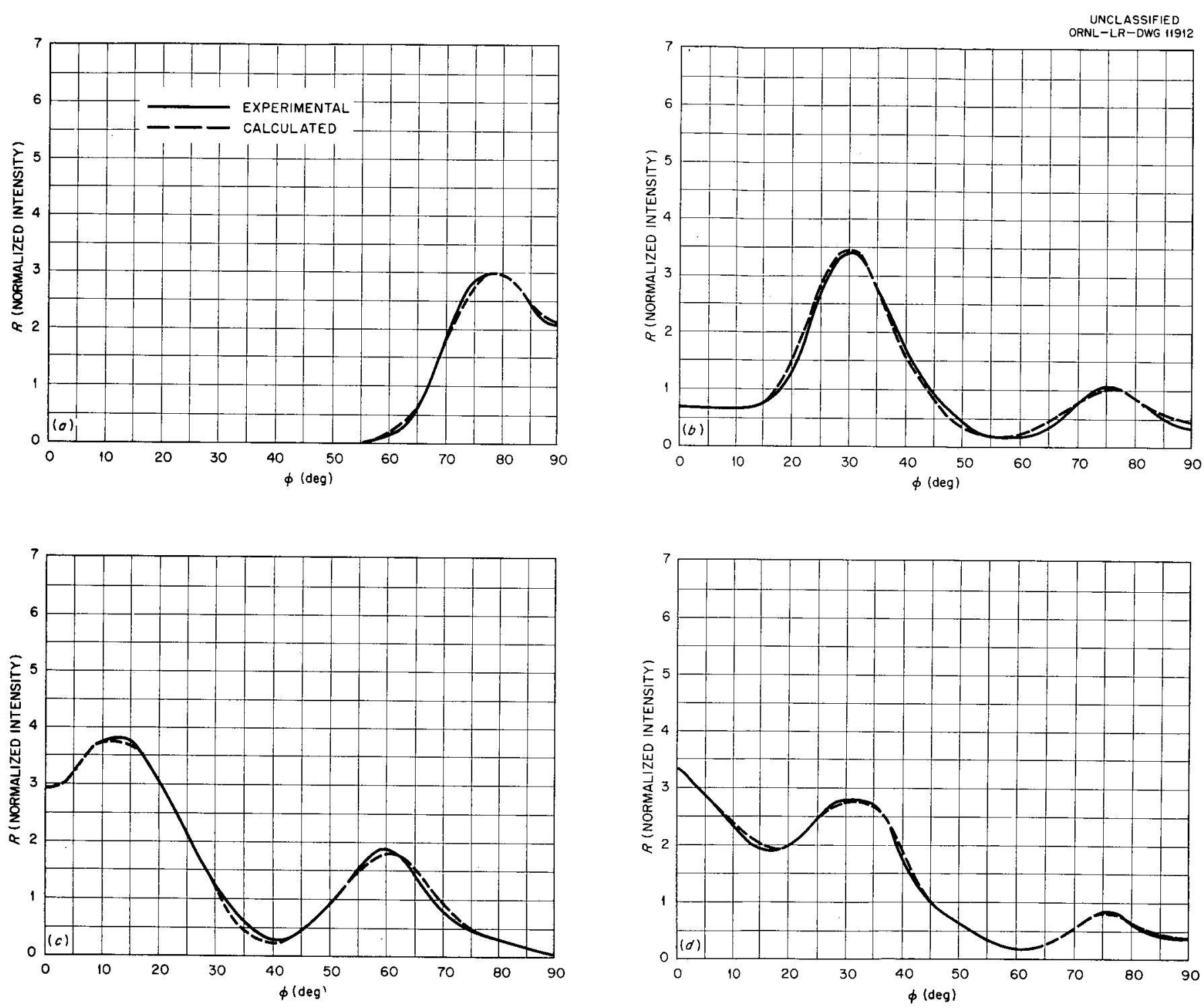

Fig. 118. Pole-Distribution Charts for Uranium Rod Extruded, at $500^{\circ} \mathrm{C}$ with an Extrusion Ratio of 12.1, and Annealed. (a) \{002\}. (b) \{040\}. (c) $\{200\}$. (d) $\{110\}$. 


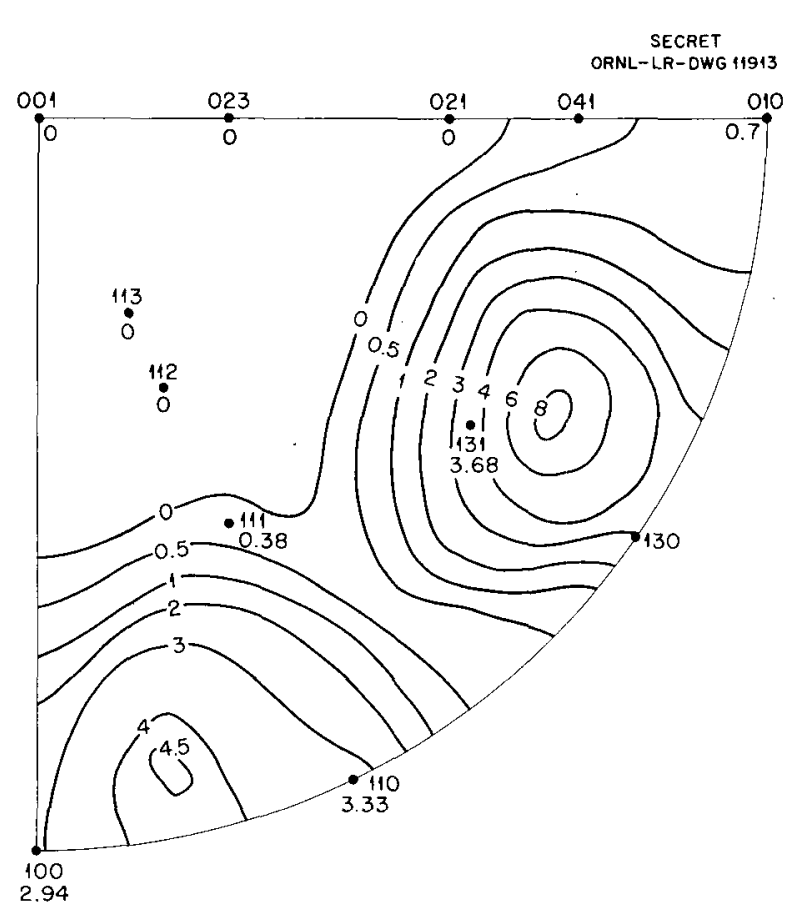

Fig. 119. Fiber-Axis Distribution Chart for Uranium Rod Extruded, at $500^{\circ} \mathrm{C}$ with an Extrusion Ratio of 12.1, and Annealed.

$600^{\circ} \mathrm{C}$ and annealed at $575^{\circ} \mathrm{C}$, although this annealed texture was not determined.

The components of both the rolled and the annealed rods, as deduced from pole-distribution data by Chernock and Beck and others, are orientations which lie in a range of 10 to 14 deg from components observed in the present investigations, and it is quite possible that complete axis distributions of the former would give results similar to those contained in this report.

A common method of indicating the relative orientation of deformation and annealing texture components is in terms of (1) an axis about which one component can be rotated so as to coincide with the other and (2) the angle of rotation. The deformation and annealing textures of the hexagonal closed-packed metals titanium and zirconium appear to be related by a 30-deg rotation about the (0001) pole. Those of many of the face-centered cubic metals are related by rotations about $\langle 111\rangle$ or $\langle 011\rangle$ axes. The amount of rotation usually reported is about one-half the angle corresponding to the twin orientation; however, the physical significance of this particular rotation is not now understood.
Some rotational relationships between the components of the as-extruded and the annealed specimens of uranium rod are shown in Fig. 120. The $\{131\}$ component of the recrystallization texture can be obtained by a clockwise rotation of $30 \mathrm{deg}$ about the pole of $\{001\}$ from the near $\{010\}$ component of the as-extruded texture or by a counterclockwise rotation of $35 \mathrm{deg}$ about the same axis from the near $\{1.10\}$ component. A clockwise rotation of 14 deg about the $\{001\}$ poles causes the components which ore near $\{110\}$ to coincide, or a clockwise rotation of $86 \mathrm{deg}$ about the $\{001\}$ poles brings the near $\{010\}$ component into the same orientation as the near $\{110\}$ component. However, it has been reported that similar and twin relationships are not very favorable for rapid growth in the case of face-centered cubic metals. The twin orientation for alpha-uranium is a 70-deg rotation about the $\{001\}$ pole. It would appear that the near $\{110\}$ component of the recrystallized texture has an orientation, relative to the deformed

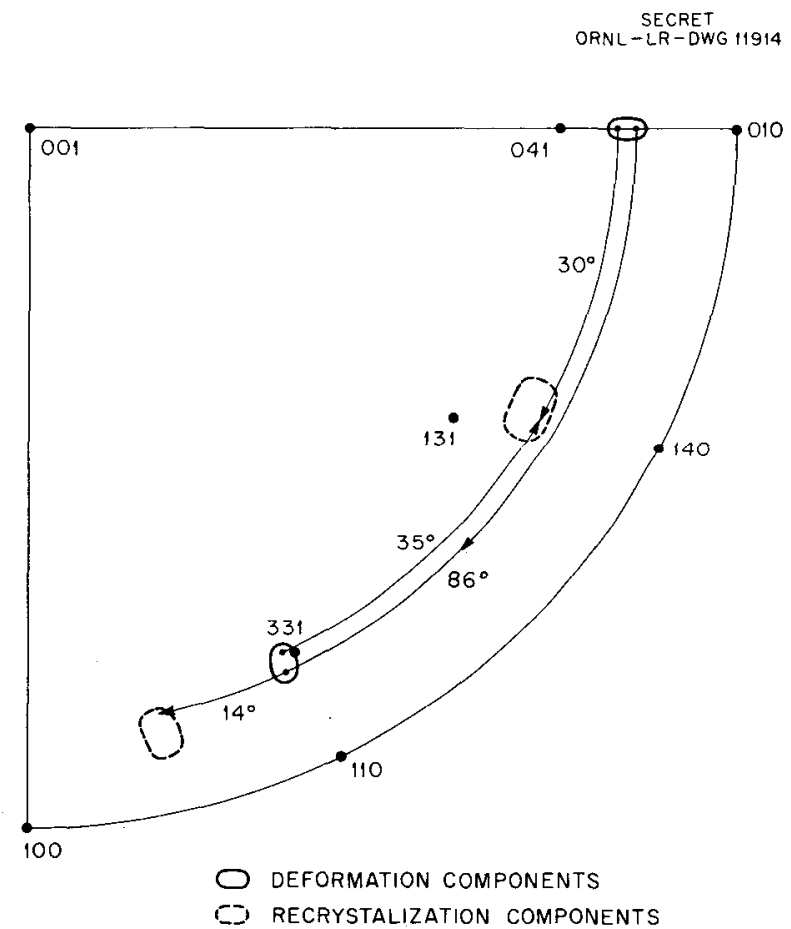

Fig. 120. Possible Orientation Relationships Between the Components of the Deformation and Recrystallization Fiber Textures of Uranium Rod. Axis of rotation is the $\{001\}$ pole. 
matrix, which may not be favorable for rapid grain growth.

The predominance of the $\{131\}$ component in the recrystallized state could be rationalized on the basis that it is favorably oriented with respect to both components of the deformation texture or that the near $\{110\}$ component is not in a suitable orientation relative to either component.

\section{Conclusions}

The fiber-axis distributions for $500^{\circ} \mathrm{C}$-extruded and for annealed $500^{\circ} \mathrm{C}$-extruded uranium rods show that the fiber axes are at locations that do not correspond to poles of planes with low indices. The two as-extruded components are $10 \mathrm{deg}$ from the $\{010\}$ poles and $10 \mathrm{deg}$ from the $\{110\}$ poles. The two components of the $550^{\circ} \mathrm{C}$-annealed specimen are at a position 4 deg from the $\{131\}$ poles and at a position $14 \mathrm{deg}$ from the $\{100\}$ and the $\{110\}$ poles.

There is a simple orientation relationship between the near $\{131\}$ recrystallized component and each of the deformation components - a rotation of 30 or $35 \mathrm{deg}$ about the $\{001\}$ pole. According to the "oriented growth" theory of annealing textures, this simple orientation relation ship probably favors rapid growth of the recrystallized grains. However, between the other recrystallized component and the deformation components, there does not appear to be any simple relationship which is favorable for rapid growth according to this theory.

THE ANTIMONY-ZIRCONIUM PHASE DIAGRAM

IN THE VICINITY OF THE ALLOTROPIC TRANSITION OF PURE ZIRCONIUM
W. M. Spicer
J. O. Betterton, Jr.

The constitution of the binary system, $\mathrm{Sb}-\mathrm{Z}_{\mathbf{r}}$, has been reported by Russi and Wilhelm, 11 who

${ }^{11}$ R. F. Russi, Jr., and H. A. Wilhelm, Constitution Diagram of the Antimony-Zirconium Alloy System, ISC-204 (Aug. 1951). have made a preliminary investigation of the zirconium-rich region by using sponge zirconium alloys. The phase diagram has a eutectic reaction at $1430^{\circ} \mathrm{C}$ where a liquid with 17.4 at. \% antimony decomposes and forms the solid beta phase with 10.9 at. \% antimony and the intermediate phase $\mathrm{Zr}_{2}$ Sb. Between 500 and $1450^{\circ} \mathrm{C}$, the terminal alpha and beta phases of zirconium are in equilibrium with $\mathrm{Zr}_{2} \mathrm{Sb}$. The alpha phase forms by a peritectic reaction $\beta+\mathrm{Zr}_{2} \mathrm{Sb} \rightleftharpoons \alpha$ at $980^{\circ} \mathrm{C}$. Later, at ORNL a more detailed investigation of the alpha- and beta-phase boundaries with iodidezirconium alloys ${ }^{12}$ confirmed the peritectoid reaction but showed that the alpha- and beta-solid solubilities were more restricted and that the temperature of the peritectoid reaction was about $870^{\circ} \mathrm{C}$.

Additional results have now been obtained which show the details of the dilute alloy region more clearly. The alloys were prepared from two batches of grade 1 iodide-zirconium with the analyses given in Table 51. The zirconium was degassed to a hydrogen content of approximately $10 \mathrm{ppm}$ and then cast in a purified-argon atmosphere on a watercooled copper hearth with a nonconsumable tungsten electrode. Two series of alloys were prepared. The first series was prepared in September 1954, and the alloys were made primarily from batch No. 3 . These alloys, on the basis of hardness measurements, apparently contain somewhat more impurities than a second series which was prepared in March 1955. These alloys were all made from batch No. 5. Figure 121 is a typical plot of hardness vs antimony content for both sets of alloys.

The cast alloys were homogenized by annealing from three to six days at $1100^{\circ} \mathrm{C}$ and were then heat-treated for five to twenty days at various temperatures near the peritectoid temperature. Figure 122 shows the phase constitution which

${ }^{12}$ W. M. Spicer and J. O. Betterton, Jr., Met. Semiann. Prog. Rep. April 10, 1954, ORNL-1727, p 135.

TABLE 51. ANALYSES OF IODIDE-ZIRCONIUM ALLOYS

\begin{tabular}{|c|c|c|c|c|c|c|c|c|c|c|c|c|c|c|}
\hline \multirow{2}{*}{ Batch No. } & \multicolumn{13}{|c|}{ Amount (ppm) } & \multirow{2}{*}{ VPN } \\
\hline & Al & $\mathrm{Cr}$ & $\mathrm{Cu}$ & $\mathrm{Fe}$ & $\mathrm{Hf}$ & Mo & $\mathrm{Ni}$ & Si & $w$ & $\mathrm{C}$ & 0 & $\mathbf{N}$ & $\mathrm{H}$ & \\
\hline 3 & $<1$ & 8.4 & 1.7 & 91 & 120 & 0.3 & 12 & 7 & 1.6 & 180 & 125 & 14 & 50 & 70 \\
\hline 5 & $<1$ & 7 & 0.6 & 45 & 115 & 0.8 & 5 & 7 & 0.2 & 150 & 125 & 9 & 40 & 60 \\
\hline
\end{tabular}




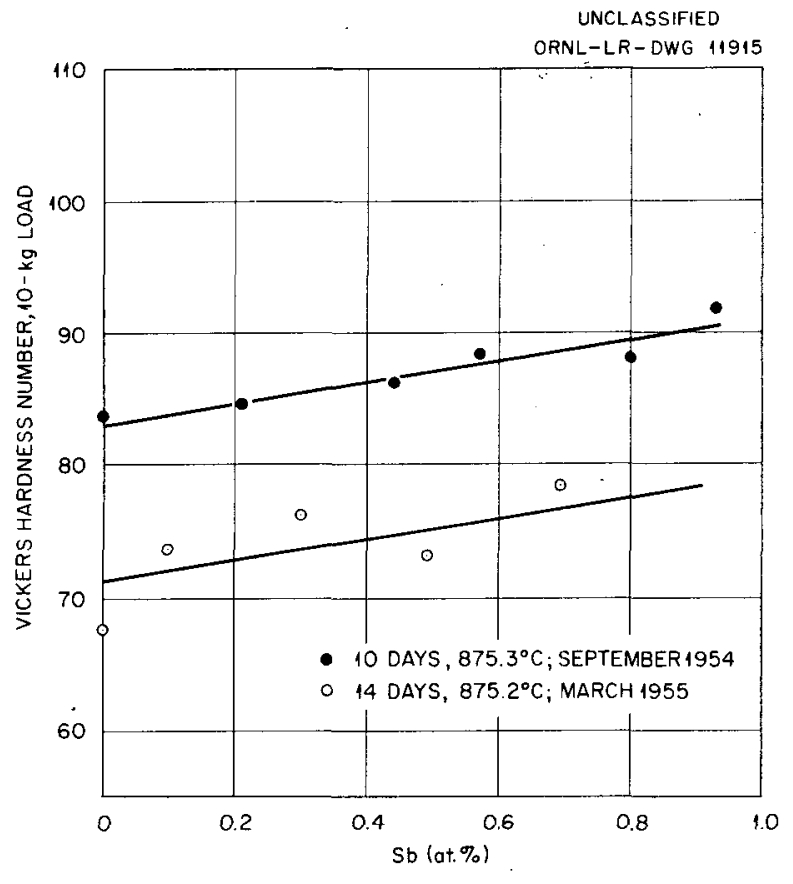

Fig. 121. Graph Illustrating the Lower Hardness of the 1955 Series of Antimony-Zirconium Alloys.

was observed in the various specimens after they were quenched in an ice and brine mixture. The minor impurities in both sets of alloys were great enough so that a three-phase region $(\alpha+\beta+\gamma)$ was found between 874 and $882^{\circ} \mathrm{C}$, and a two-phase region $(\alpha+\beta)$ with zero antimony content was found from 857 to $873^{\circ} \mathrm{C}$. From Fig. 122, the peritectoid reaction $\beta+\mathrm{Zr}_{2} \mathrm{Sb} \rightleftharpoons \alpha$ may be inferred in the pure binary diagram. The phase boundaries have been drawn to correspond to the purer. set of alloys indicated by the open symbols in Fig. 122. The somewhat less pure alloys, as indicated by the filled symbols, agree except for a discrepancy at $880^{\circ} \mathrm{C}$. At $880^{\circ} \mathrm{C}$, the latter alloys would indicate less solubility of antimony in the beta phase than is shown in Fig. 122:

All the compositions indicated above are based upon the original nominal additions and upon subsequent later weight changes in the alloys, which in every case were quite small. Experience in the earlier work indicates that these values should not be in error by greater than \pm 0.1 at. \% antimony, but the results of chemical analysis on these alloys are needed before it can be concluded finally that the $\beta /(\beta+\gamma)$ boundary is impuritydependent to the extent indicated above.

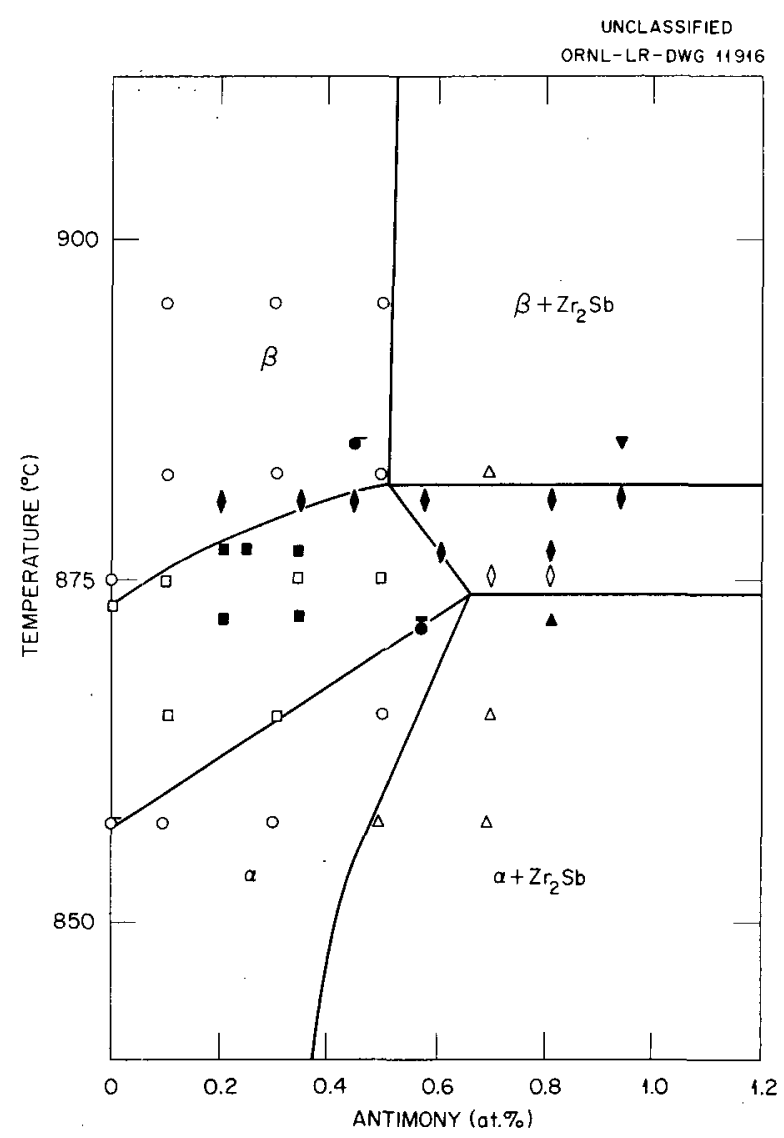

Fig. 122. Peritectoid Region of Antimony-Zirconium System. The filled symbols indicate the somewhat less pure 1954 set of alloys.

\section{FLOATING.ZONE PURIFICATION OF ZIRCONIUM}
G. D. Kneip, Jr.
J. O. Betterton, Jr.

The investigation of molten-zone refining as a method of producing zirconium with an impurity content lower than that of grade 1 crystal bar has been continued. This purer material is to be used in the study of the binary-alloy systems of zirconium.

Previous work had indicated that the floating molten zone was not particularly stable even for small-diameter rods of zirconium (5 $\mathrm{mm}$ in diameter) and that very careful control of the heating power was necessary. Thus, the original apparatus was modified so that it could be used with a Megatherm high-frequency generator (300 kc), which has a continuously variable power output. The apparatus was also modified to permit the use of an argon 
atmosphere during melting so as to reduce the amount of zirconium volatilized onto the quartz melting chamber. The change facilitated the observation of the molten zone while the purification process was in progress and also reduced the loss of power into the zirconium film, which had been found to build up fairly rapidly on the quartz when the melting was carried out under vacuum. Figure 123 shows the modified apparatus, and Fig. 124 shows the melting chamber, the single-turn high-frequency work coil, and the impedance-matching transformer. Neoprene O-rings are used for vacuum seals between the copper heads and the quartz tube. The support for the lower end of the zirconium bar is spring-loaded to permit thermal expansion of the zirconium to take place during the initial heating so that the bar does not bow and touch the quartz tube. During the refining process both the upper and lower copper heads are surrounded by ice water. As many as ten passes of the molten zone have been made successfully on 4.8-mm-dia zirconium rods. Figures 125, 126, and 127 show the typical shapes of the rods after 3,6 , and 10 passes, respectively.

The degree of purification obtained is being investigated by two methods: (1) isothermal annealing in the vicinity of the zirconium $\alpha / \beta$ transition temperature, which yields information on the final distribution of the impurities as a whole and (2) chemical analysis to establish the distribution of specific impurities. A typical phase diagram for an impurity which lowers the zirconium transition temperature is shown in Fig. 128 where the vertical line at $x=x_{0}$ represents the impurity content of the zirconium. If the impure zirconium specimens are brought to thermal equilibrium by annealing at $T_{0}$ and then rapidly quenched to retain the high-temperature structure, two phases, alpha of the composition $x_{a}$ and beta of composition $x_{\beta}$ will be found. The amount of beta phase present after annealing at a given temperature can be expressed in terms of the solubilities in the alpha and beta phases and of the impurity content of the zirconium as follows:

$$
\text { Beta phase, vol } \%=\frac{x_{0}-x_{a}}{x_{\beta}-x_{\alpha}} \cdot 100 \text {. }
$$

Thus, after isothermal annealing of the zirconium specimens a few degrees below the transition temperature, the amount of beta phase present is a measure of the amount of impurity in the speci- men. Even though the zirconium beta phase cannot be retained upon quenching, this method is still applicable, since the transformation product retains the isothermal beta grain shape and can be recognized as material that was beta phase at the annealing temperature.

Figure 129 shows the proportion of beta phase after an anneal of $100 \mathrm{hr}$ at $860^{\circ} \mathrm{C}$ as a function of the position on a bar which was subjected to three passes at $2.5 \mathrm{~mm} / \mathrm{min}$ of a molten zone, approximately $0.8 \mathrm{~mm}$ long. If iron is assumed to be the only impurity, then the iron contents of the various portions of the bar can be calculated from the zirconium-iron phase diagram (Fig. 128). For the region where no beta phase is present, the iron content would then be less than $30 \mu \mathrm{g} / \mathrm{g}$; and in the region of maximum beta phase, the iron would be $500 \mu \mathrm{g} / \mathrm{g}$ compared with the original level of $40 \mu \mathrm{g} / \mathrm{g}$. Figures 130, 131, 132, and 133 show the microstructures (after annealing for $100 \mathrm{hr}$ at $860^{\circ} \mathrm{C}$ ) of the unmelted bar, the purified region, the maximum beta-phase region, and the upper interface between the melted region and the original bar, respectively.

Figure 134 shows the proportion of beta phase as a function of displacement for the same bar after reannealing at $865^{\circ} \mathrm{C}$ for $100 \mathrm{hr}$. The minimum and maximum iron contents in this case are calculated to be less than 14 and $400 \mu \mathrm{g} / \mathrm{g}$, respectively. Figure 135 also shows the hardness as a function of position on the bar. The peak at the position of initial melting may be due to the oxygen concentration at this point, since the impurities which raise the melting point are moved opposite in direction to those which lower the melting point. This gain in hardness of about 7 Vickers numbers would correspond to an increase in oxygen content of approximately $100 \mu \mathrm{g} / \mathrm{g}$. The peak at the position of final solidification is much too large to be accounted for by 400 to $600 \mu \mathrm{g} / \mathrm{g}$ of iron and may indicate that carbon lowers the melting point of zirconium and, thus, is moved in the same direction as iron by the zone-melting process.

Figure 136 shows the nickel content as determined by neutron-activation analysis as a function of position on another bar which was melted three times under the same zone-refining conditions. The gradual decline from the initial level to about $1.5 \mu \mathrm{g}$ per gram of nickel at the starting end of the bar indicates that a considerable amount of diffusion has taken place from the end of the bar into 




Fig. 123. Zone-refining Apparatus. 


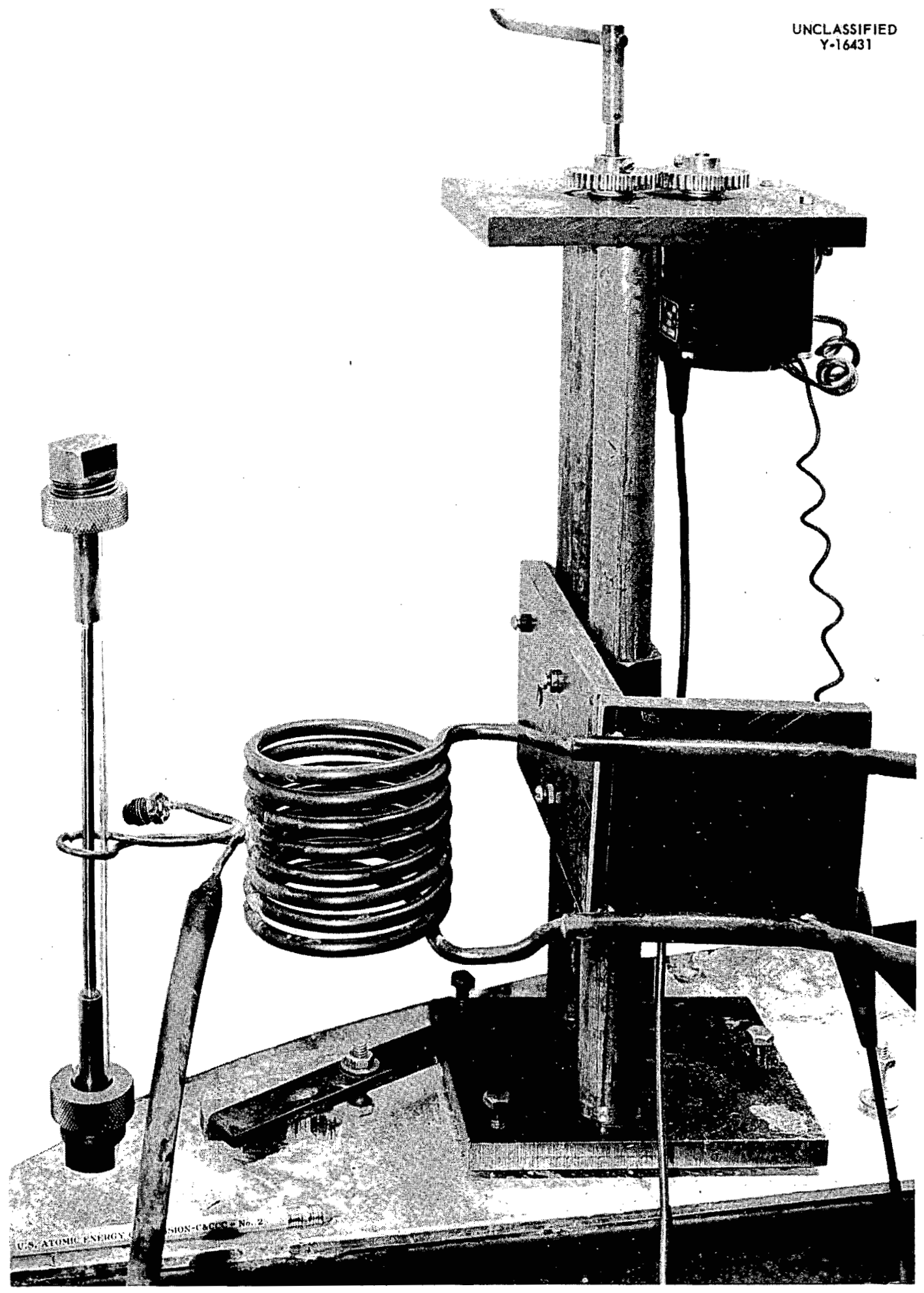

Fig. 124. Melting Chamber of Zone-refining Apparatus with Zirconium Rod in Position. 


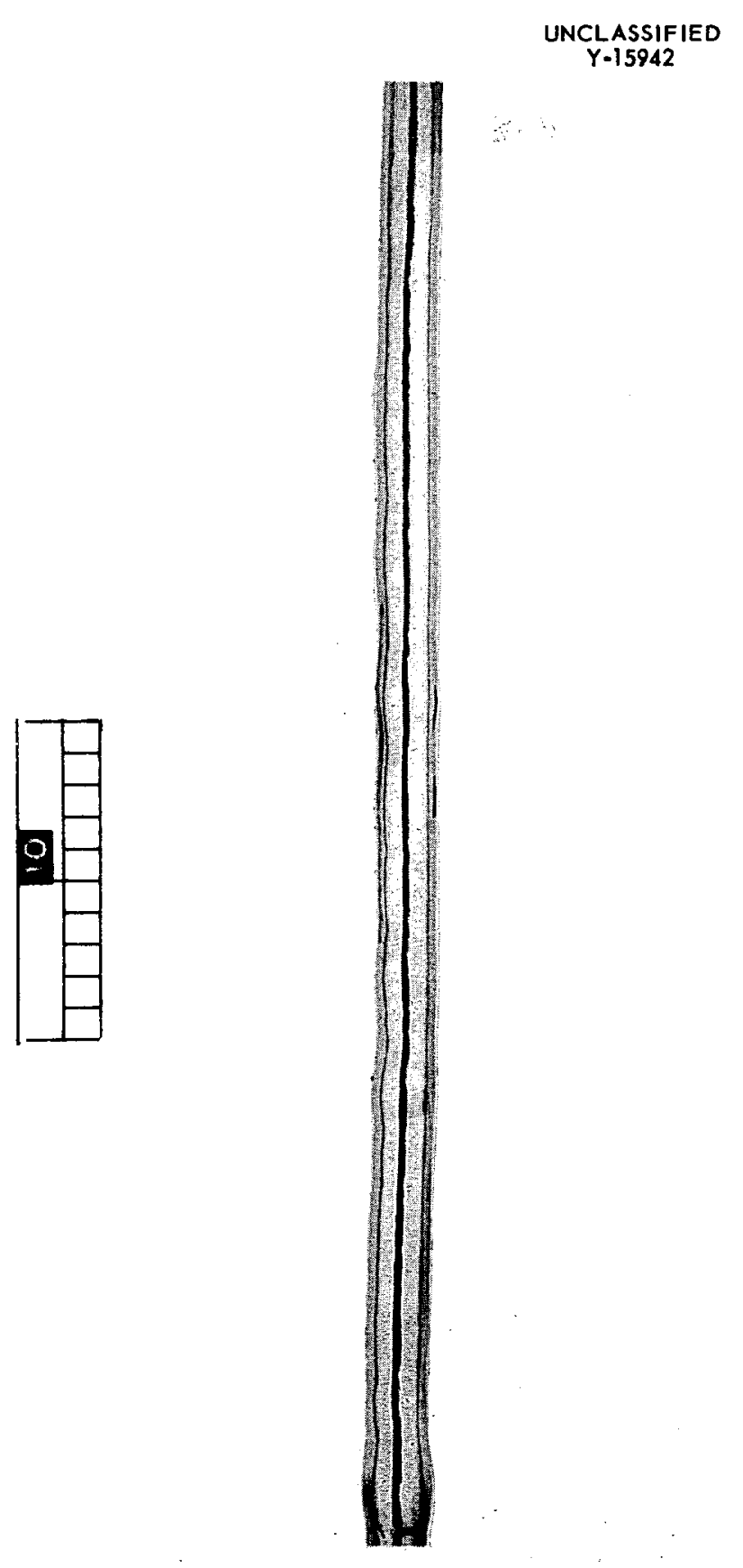

Fig. 125. Zone-refined Zirconium Rod After Three Passes of the Molten Zone.

the purified region and that a faster zone traverse speed is probably desirable if the best purification is to be obtained. The areas under the curve indicate that about $30 \%$ of the nickel involved in the process is lost if the base level shown is correct. In order to account for this amount of nickel, the
UNCLASSIFIED

Y-16018

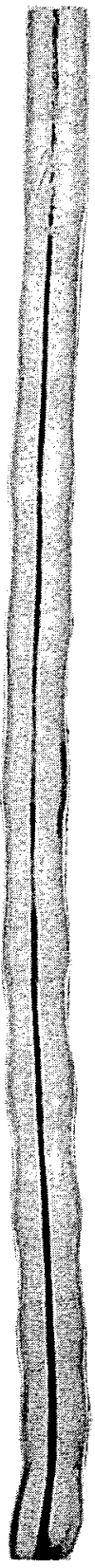

Fig. 126. Zone-refined Zirconium Rod After Six Passes of the Molten Zone.

base level would have to be about $4 \mu \mathrm{g} / \mathrm{g}$, which is not in very good agreement with the analytical data. It seems more likely that the nickel is lost by evaporation from the molten surface and that possibly greater purification could be obtained by performing the experiment in a vacuum so as to 


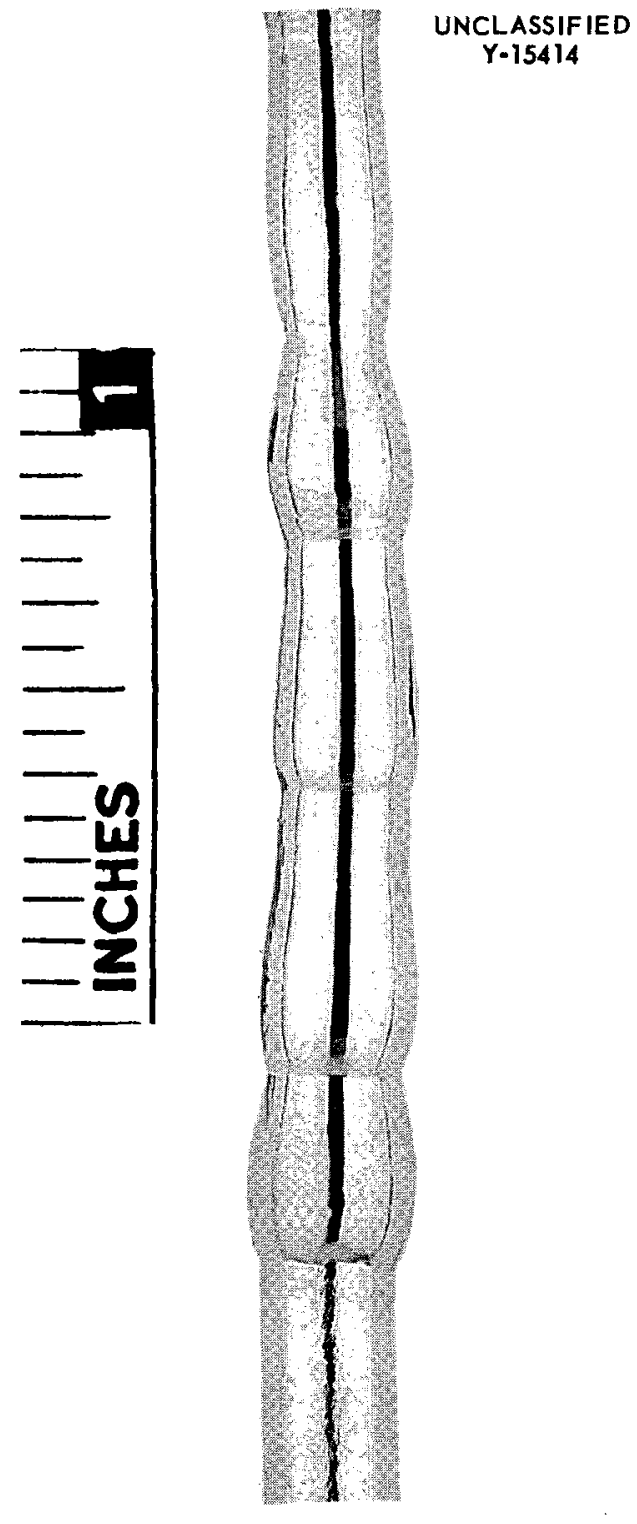

Fig. 127. Zone-refined Zirconium Rod After Ten Passes of the Molten Zone.

take full advantage of the volatilization of nickel as well as of the zone refining.

Analyses of zone-refined grade 1 zirconium crystal bar are being carried out to determine the distributions along the bar of some of the major impurities (oxygen, nitrogen, and iron) after various numbers of passes. The effect of the rate of movement of the molten zone will also be investigated.

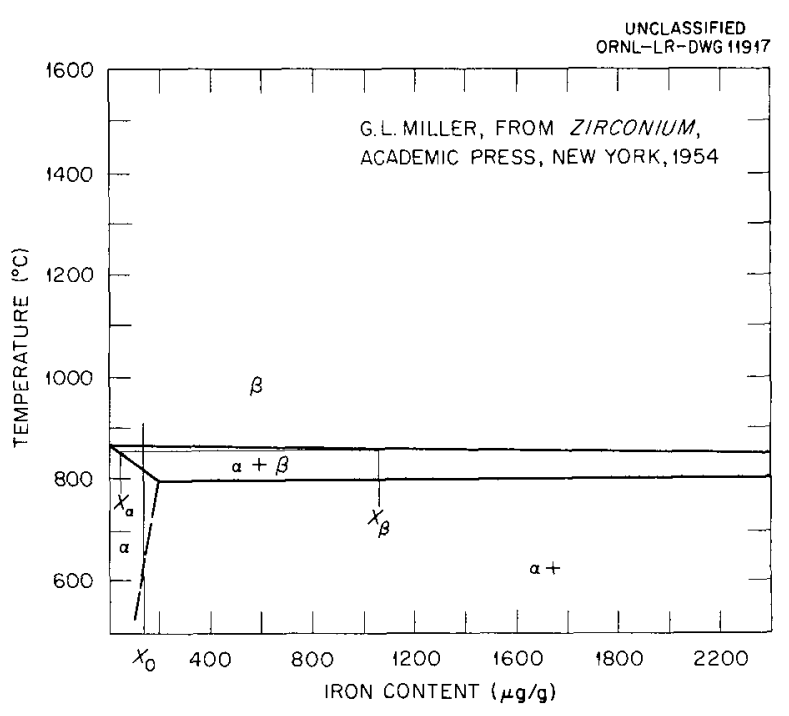

Fig. 128. Effect of Iron on Zirconium Alpha-Beta Transition.

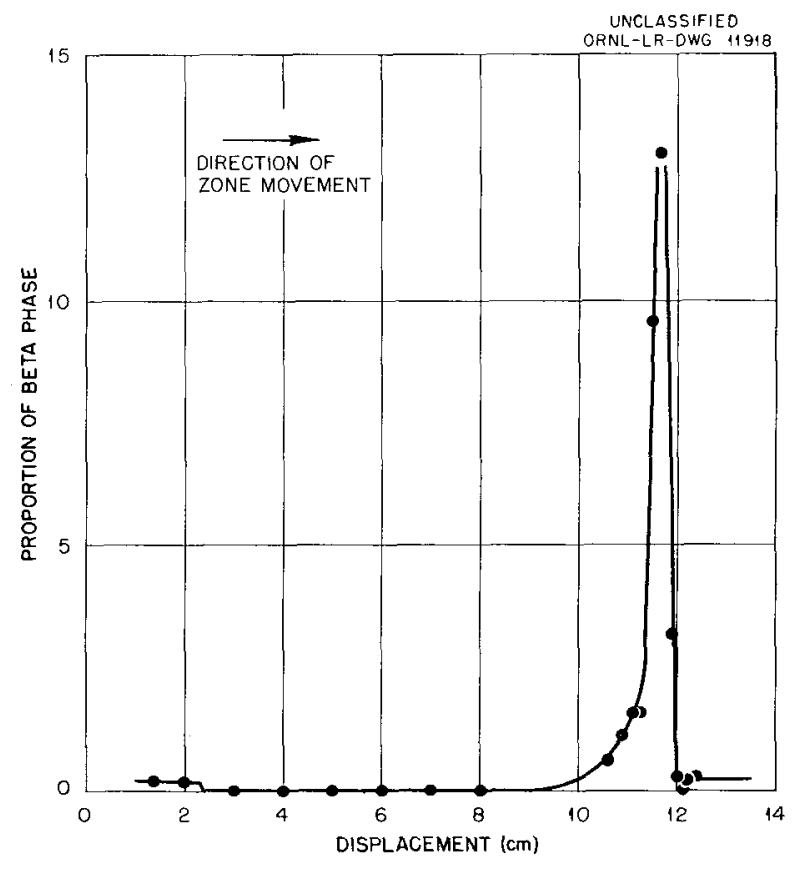

Fig. 129. Proportion of Beta Phase in Zonerefined Zirconium Bar as a Function of Displacement After Isothermal Annealing $\left(860^{\circ} \mathrm{C}\right)$ near the Zirconium Transition Temperature. 


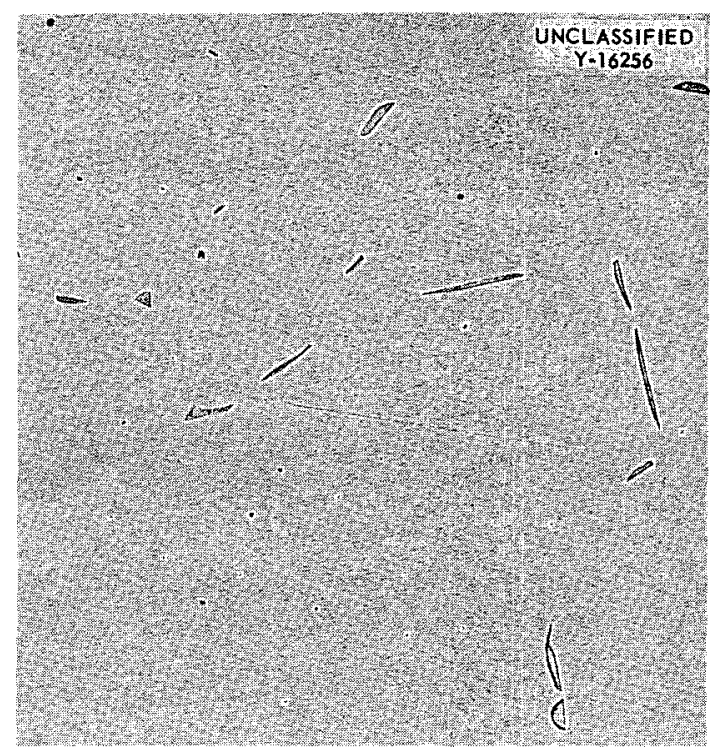

Fig. 130. Microstructure of Unpurified Portion of Zone-refined Zirconium Bar After Annealing at $860^{\circ} \mathrm{C}$. Alpha and beta phases are shown. Etchant: 60 parts lactic acid, 40 parts $\mathrm{HNO}_{3}$, and 4 parts HF. 50X. Reduced $17 \%$.

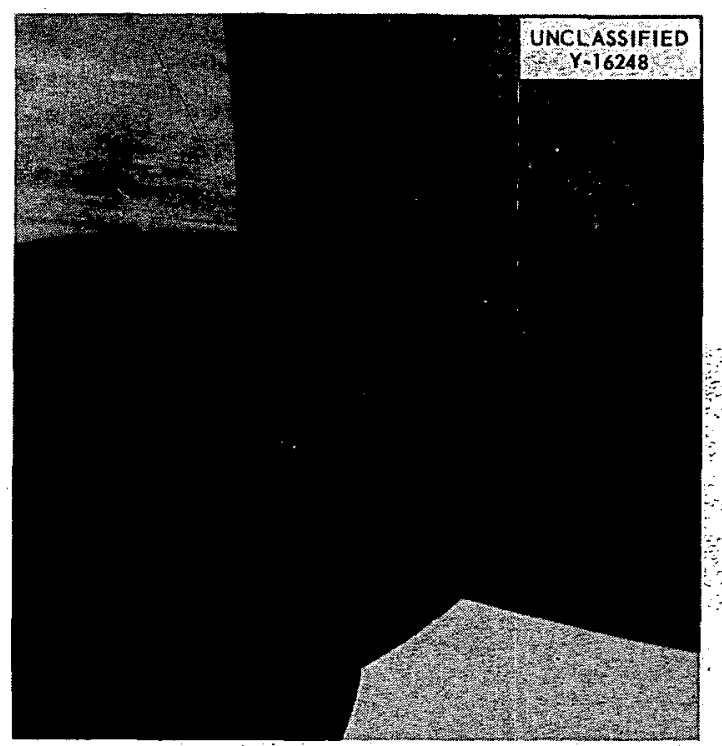

Fig. 131. Microstructure of Purified Region of Zone-refined Zirconium Bar After Annealing at $860^{\circ} \mathrm{C}$. The single-phiase alpha-zirconium structure is shown. Etchant: 60 parts lactic acid, 40 parts $\mathrm{HNO}_{3}$, and 4 parts HF. Polarized light. 50X. Reduced $17 \%$.

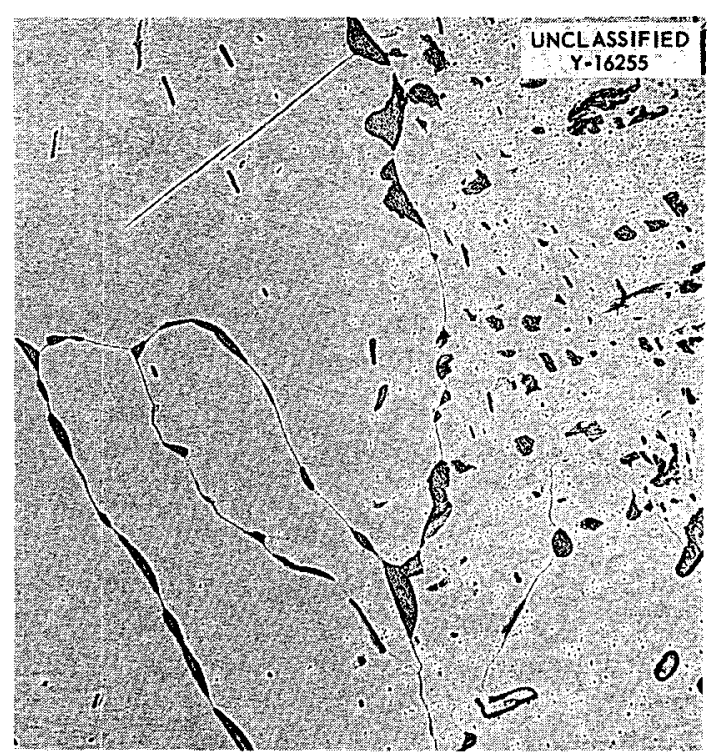

Fig. 132. Microstructure of the Region of Maximum Beta Phase in Zone-refined Zirconium Bar After Annealing at $860^{\circ} \mathrm{C}$. Etchant: 60 parts lactic acid, 40 parts $\mathrm{HNO}_{3}$, and 4 parts HF. 50X. Reduced $17 \%$.

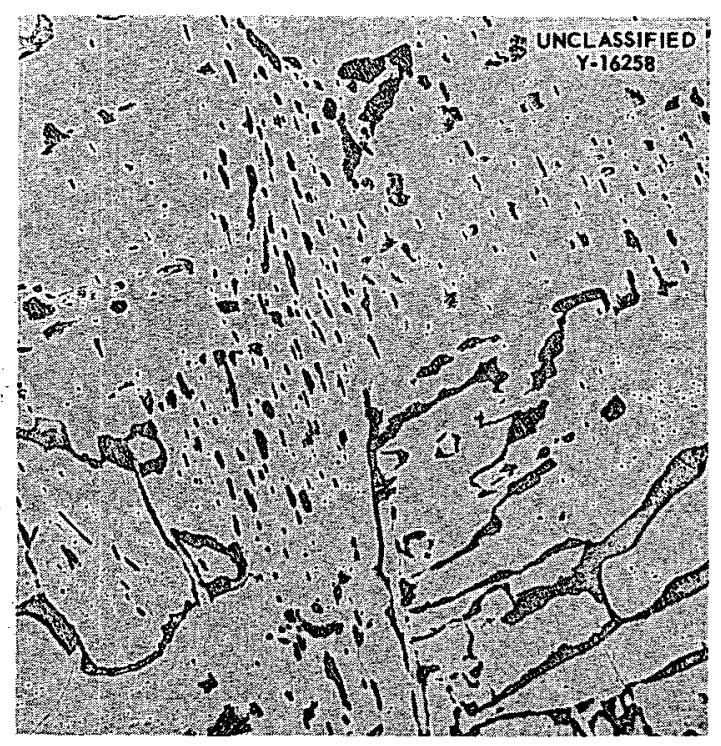

Fig. 133. Interface, Between Zone of Final Solidification and Unpurified Section, of Zonerefined Zirconium Bor After Annealing of $860^{\circ} \mathrm{C}$. Etchant: 40 parts lactic acid, 60 parts $\mathrm{HNO}_{3}$, and 4 parts HF. 50X. Reduced $17 \%$. 


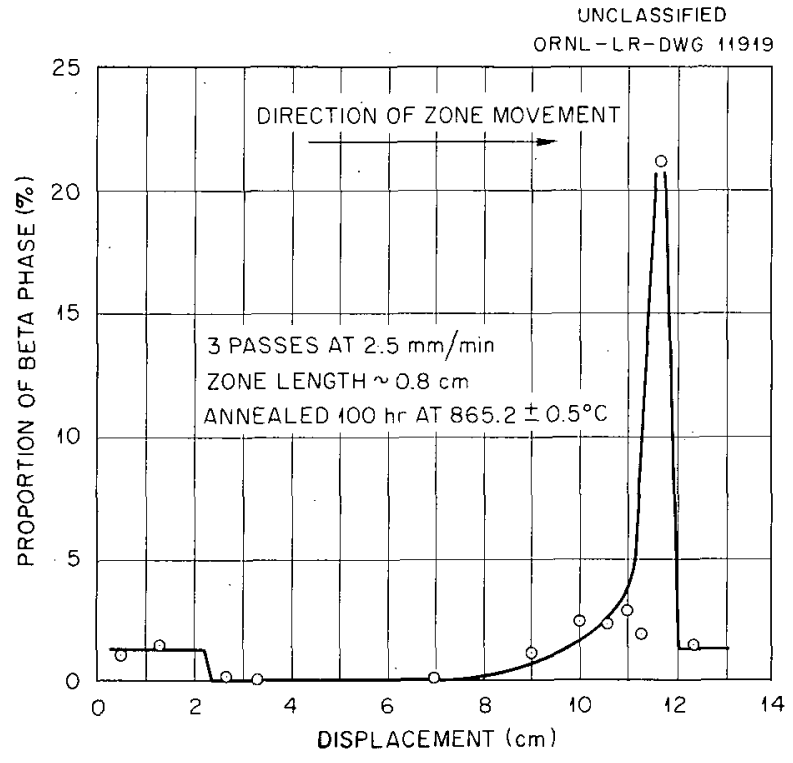

Fig. 134. Proportion of Beta Phase in Zonerefined Zirconium Bar as a Function of Displacement After Isothermal Annealing $\left(865^{\circ} \mathrm{C}\right)$ near the Zirconium Transition Temperature.

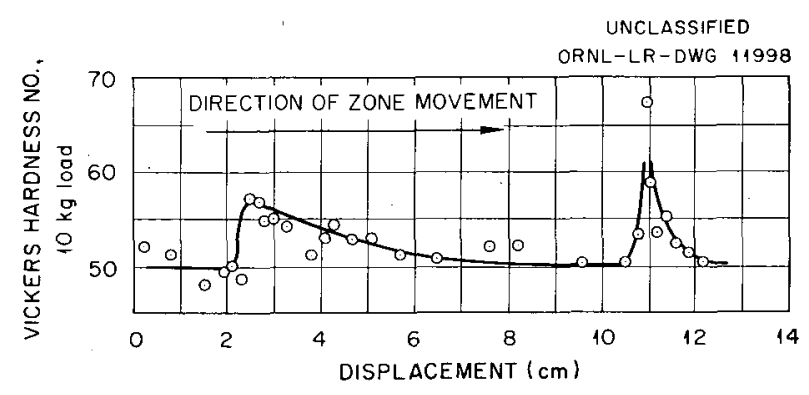

Fig. 135. Hardness of Alpha Matrix in Zonerefined Zirconium Bar as a Function of Displace. ment After Isothermal Annealing $\left(865^{\circ} \mathrm{C}\right)$ near the Zirconium Transition Temperature.

\section{THE SILVER-ZIRCONIUM ALPHA PHASE REGION}
D. S. Easton
J. O. Betterton, Jr.

The beta phase in the silver-zirconium system decomposes at $823^{\circ} \mathrm{C}$ by the eutectoid reaction ${ }^{13}$ $\beta(3.7$ at. $\% \mathrm{Ag}) \rightleftharpoons \alpha(0.8$ at. $\% \mathrm{Ag})+\mathrm{Zr}_{2} \mathrm{Ag}$. Earlier work ${ }^{13,14}$ has shown that the composition

\footnotetext{
${ }^{13}$ D. S. Easton, G.W. Cunningham, and J. O. Betterton, Jr., Met. Semiann. Prog. Rep. April 10, 1954, ORNL: 1727, p 125.
}

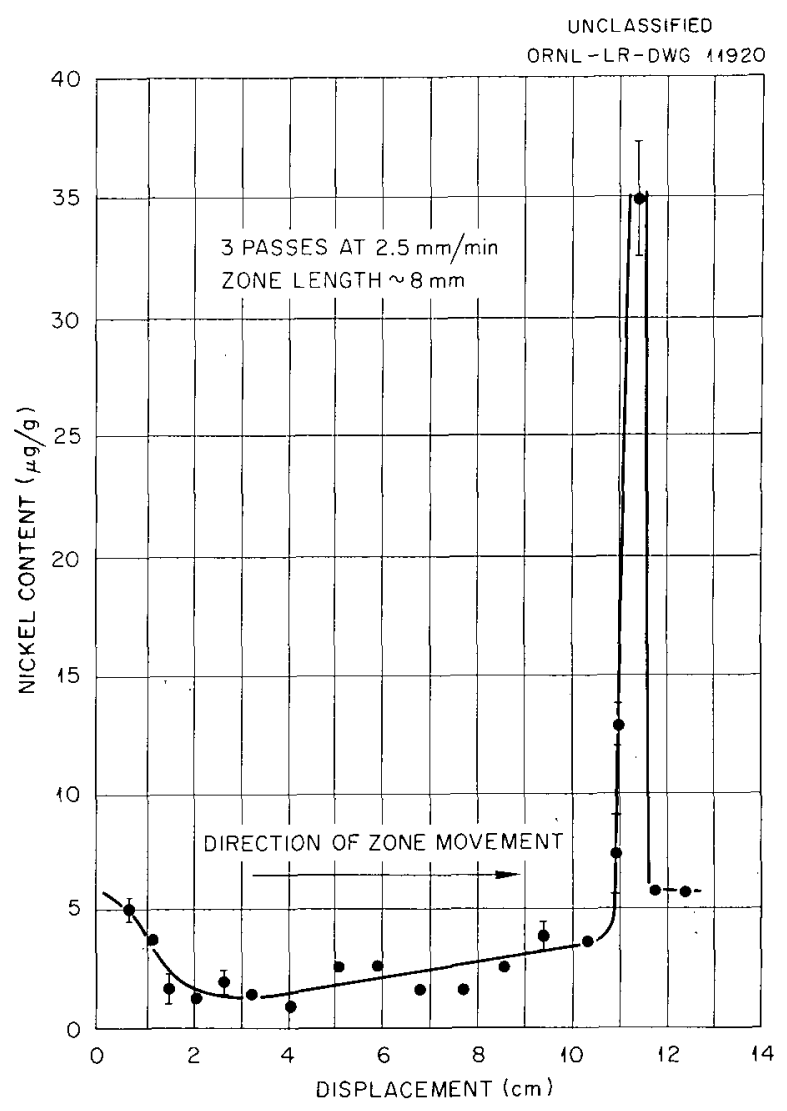

Fig. 136. Nickel Content in Zone-refined Zirconium as a Function of Displacement After Three Passes of the Molten Zone.

of the alpha phase at the eutectoid temperature is dependent upon the iron and nickel content of the iodide-zirconium used. The maximum solid solubility with 250 to $400 \mathrm{ppm}$ iron is of the order of 0.1 at. \% silver; whereas with 60 to $90 \mathrm{ppm}$ iron, the solid solubility is 0.8 at. $\%$ silver. Additional annealing experiments have been completed with zirconium alloys containing $45 \mathrm{ppm}$ iron, and the results are presented in Fig. 137. "The quality of the alloys can be judged from the $(\alpha+\beta)$ transition range and from the hardness of the pure zirconium specimen. The transition range was 857 to $872^{\circ} \mathrm{C}$, and the Vickers hardness (alphaannealed) was 54; both these data are equivalent to those for the original crystal-bar zirconium. The maximum alpha solid solubility in Fig. 137

\footnotetext{
${ }^{14}$ D. S. Easton and J. O. Betterton, Jr., Met. Semiann. Prog. Rep. April 10, 1954, ORNL-1911, p 16.
} 


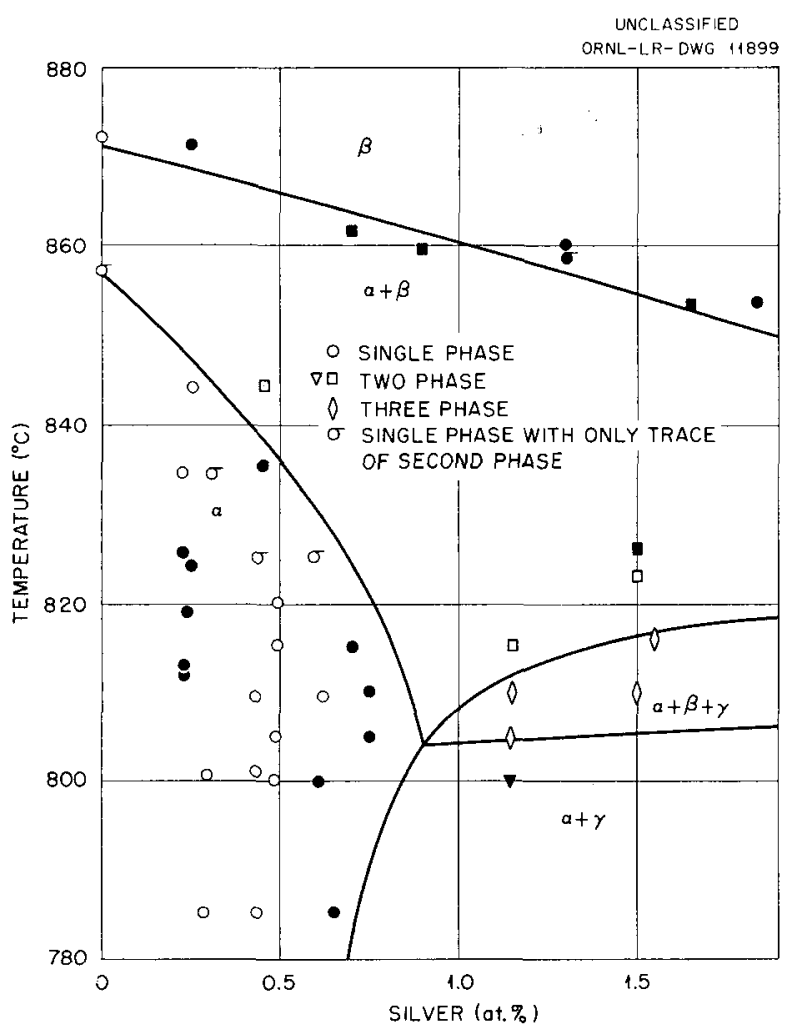

Fig. 137. The Alpha-Phase Region of the SilverZirconium System.

is 0.9 at. \% silver at $804^{\circ} \mathrm{C}$, which represents a more accurate value than the 0.8 at. \% reported earlier.

Further experiments are now in progress in which the effect of reducing the hydrogen content of the alloys from the present level of $10 \mathrm{ppm}$ to approximately $3 \mathrm{ppm}$ is being investigated further. The annealing results on pure zirconium with two different hydrogen contents (10 ppm and $1.5 \mathrm{ppm}$ ) indicate that the $\alpha /(\alpha+\beta)$ boundary may be raised by 2 to $4^{\circ} \mathrm{C}$ if the hydrogen content is reduced. It will be of interest to determine to what extent the existence of the $(\alpha+\beta+\gamma)$ region is dependent upon the hydrogen content.

The work of $H$. Jones on the epsilon and beta copper-zinc phases and of Hume-Rothery and Raynor on magnesium alloys has shown that Fermi energies, as affected by changes in electron concentration and as related to the details of the Brillowin structure of the alloy, may have pronounced effects on the variation of lattice spacings with composition in an alloy phase. Recently, Denny ${ }^{15}$ has explained, in terms of this theory, the effects of silver and gallium on titanium spacings. For this reason, an experimental determination of the $\alpha /(\alpha+\gamma)$ boundary in silver-zirconium by $x$-ray lattice spacings would serve a dual purpose, since not only would the limit of the solid solution be found by a method independent of the microscopical work, but interesting new data on the properties of the alpha solid solution would be obtained.

Certain preliminary experiments have now been made in order to determine the type specimen which should be used in an $x$-ray determination of the $\alpha /(\alpha+\gamma)$ phase boundary and of the effect of silver on the spacings and the $c / a$ ratio of zirconium. Equipment was first constructed so that a chemically cleaned lump of batch No. 5 iodidezirconium could be filed under a vacuum of $10^{-6}$ $\mathrm{mm}$. The filings were dropped past a strong magnet (which had previously been observed to collect all iron particles dropped in the same manner) into a zirconium chamber where the filings were annealed at $550^{\circ} \mathrm{C}$ for $30 \mathrm{~min}$. The material was then passed through a 100-mesh screen, without breaking the vacuum, and sealed in an $x$-ray capillary. Spacing measurements ${ }^{16}$ are given in Table 52, together with the measurements of material from the same lump but filed in air and then vacuumannealed at $550^{\circ} \mathrm{C}$ in a zirconium can. A third experiment with the same material filed in air and likewise placed in a zirconium can was vacuumannealed at $800^{\circ} \mathrm{C}$. Finally, a zirconium wire was prepared from the same lump and was vacuumannealed at $800^{\circ} \mathrm{C}$ in a zirconium-foil envelope. After the annealing, it was etched to a small diameter. The data in the last line in Table 52 pertains to a wire prepared from an alpha-phase zirconium-silver alloy with $0.46 \mathrm{at} \% \mathrm{Ag}$ that was annealed at $800^{\circ} \mathrm{C}$.

The lattice spacings, with the exception of specimen DSE $/ 5 X$, corroborate the hypothesis that the surface film formed on zirconium filed in air is not dissolved sufficiently at $550^{\circ} \mathrm{C}$ to affect the lattice spacings appreciably; whereas at $800^{\circ} \mathrm{C}$ the surface film dissolved and expanded the $a$ and $c$ spacings in accordance with the observations of Treco 17

\footnotetext{
$15 \mathrm{~J}$. M. Denny, A Study of Electron Effects in Solid Solution Alloys of Titanium, 6th Tecbnical Report to Office of Naval Research, California Institute of Technology Physical Metallurgy Laboratory (Jan. 1955).

${ }^{16}$ The fottice spacings were determined by $H$. L. Yakel of the Metallurgy Division.

${ }^{17}$ R. M. Treco, Trans. Am. Inst. Mining Met. Engrs. 197,344 (1953).
} 


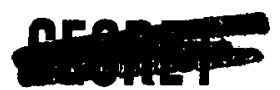

TABLE 52. DETERMINATION* OF LATTICE SPACINGS OF ZIRCONIUM AT 22 TO $26^{\circ} \mathrm{C}$ AFTER ANNEALING

\begin{tabular}{|c|c|c|c|c|}
\hline Specimen & $\begin{array}{l}\text { Time } \\
(\min )\end{array}$ & $\begin{array}{c}\text { Temperature } \\
\left({ }^{\circ} \mathrm{C}\right)\end{array}$ & $a_{0}$ & $c_{0}$ \\
\hline DSE $/ 2 X$ powder, filed in vacuum & 30 & 550 & 3.2323 & 5.1482 \\
\hline DSE $/ 3 X$ powder, filed in oir & 30 & 550 & 3.2323 & 5.1479 \\
\hline DSE $/ 4 X$ powder, filed in air & 30 & 800 & 3.2338 & 5.1498 \\
\hline DSE $/ 5 X$ wire & 15 & 800 & 3.2328 & 5.1473 \\
\hline $\mathrm{DSE} / 7 \mathrm{X}$ wire $(+0.46$ at. $\% \mathrm{Ag})$ & 30 & 800 & 3.2308 & 5.1455 \\
\hline
\end{tabular}

^Debye Scherrer camera, $5.6 \mathrm{~cm}$ radius;

Copper radiation: $K_{a^{\prime}} 1.54050 \AA \mathrm{A}_{;} K_{\alpha_{2}}, 1.54434 \stackrel{\circ}{\mathrm{A} ;} K_{\beta_{1}}, 1.39217 \AA$

Annealing temperature on lump alloy: $810^{\circ} \mathrm{C}$ before cold working into wire form.

and Fast, ${ }^{18}$ who investigated the effect of oxygen and nitrogen on zirconium. On the other hand the wire specimen DSE $/ 5 X$, which has a surface-tovolume ratio significantly less than that for the filings, gave results which were 1 part in 6000 higher in $a$ and 1 part in 6000 lower in $c$ than was observed with powder filed in vacuum. This fact suggests that either the specimens filed in air or in vacuum and annealed at $550^{\circ} \mathrm{C}$ have been contaminated or that the wire has been contaminated with some element such as hydrogen. Resolution

\footnotetext{
18 J. D. Faste, Foote Prints 13, 22 (1940).
}

of this discrepancy will be attempted by means of further experiments performed under improved vacuum conditions; the iron content of the fillings will be investigated, and the hydrogen content will be more carefully controlled.

In spite of the above uncertainty for pure zirconium, the effect of silver is large enough to be observed. The effect is to contract both the $a$ and $c$ spacings. The effect of silver on the $c / a$ ratio of zirconium is less definite since the ratio is within the range of values observed for pure zirconium. 


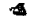

\section{RESTRLCTED UATA}

This document contains Restotedos defined in the Atomic Energy Act of 1954. in any manner to an una uthorized person is prohibited. 